\title{
A new model of competitor accounting for the German Mechanical Engineering Sector
}

\author{
Stephan Schulte
}

\author{
A thesis submitted to \\ The University of Gloucestershire \\ In accordance with the requirements of the degree of \\ Doctor of Business Administration \\ School of Business and Technology
}

August 2019 


\section{Abstract}

The trend of increasing internationalization of business and competition in general and particularly within the German mechanical engineering sector, as one of Germany's most important industrial sectors, forms the economic background of this project concerning competitor accounting/analysis. This has implications regarding the interface between the corporate functions of marketing and control.

In this context, literature confirms that resilient contributions regarding competitor accounting/analysis from strategic management accounting (SMA) are needed and that management accounting knowledge would support in developing this, which contributes to closing the gap in literature and practice.

Regarding theory, performance-orientated elements, particularly from the area of consolidated margin accounting, have been transferred into the context of SMA/competitor accounting/-analysis and have been applied in the conceptual framework/model. Theoretical generalization has been conducted through applying an existing theory (cost accounting on the group level) in a new context (SMA/competitor accounting) and through extending the applicability of the conceptual framework/model to other industries within the mechanical engineering sector.

Concerning practice, the implication in this context would be to execute this step of transferring knowledge from the area of group cost accounting/management accounting into competitor accounting/-analysis in practice as well. The conceptual framework/model contributes to closing the gap in competitor accounting/-analysis through providing both the theoretical foundation and the application in practice.

The data considered in the case study covers a five-year period. Both numerical data and the textual information contained in almost 2000 documents has been structured according to the dimensions information category and consolidation hierarchy. Textual information has been evaluated and related to numerical data which enabled a model to be built of competitions' margin accounting, P\&L statement, balance sheet and cash flow statement on both the level of single entity and the group. Furthermore, the processes established allow contrasting of the competition's actual performance with the model and, in addition, identifying the competition's critical success factors. This in turn sheds light on the competition's next strategic move and thus aids in the creation of competitive advantage. 


\section{Declaration of Original Content}

I declare that the work in this thesis was carried out in accordance with the regulations of the University of Gloucestershire and is original except where indicated by specific reference in the text. No part of the thesis has been submitted as part of any other academic award. The thesis has not been presented to any other education institution in the United Kingdom or overseas. Any views expressed in the thesis are those of the author and in no way represent those of the University.

Signed Date 


\section{Table of Contents}

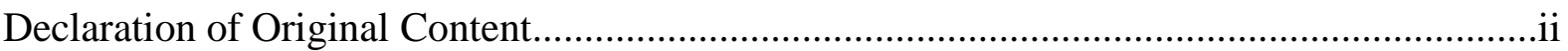

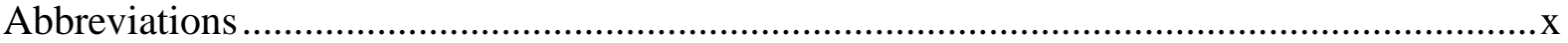

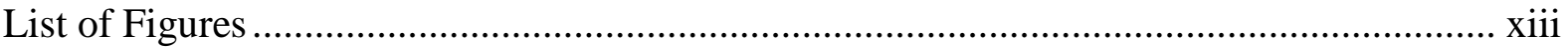

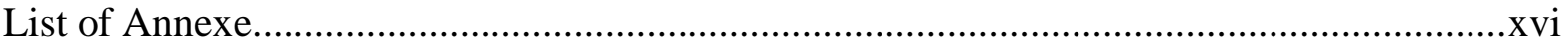

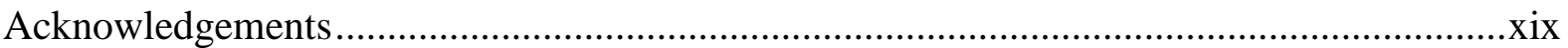

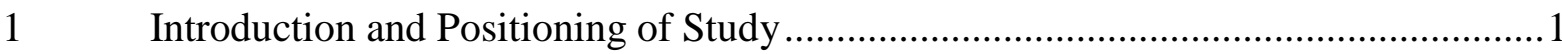

1.1 Germany's mechanical engineering industry and its international orientation ...........1

1.2 Organizational role and foci of the corporate functions of control and marketing ......3

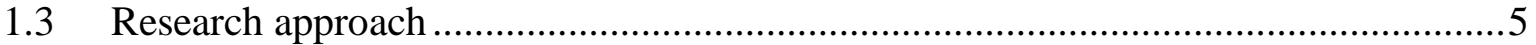

1.3.1 Research questions, objectives and aim .....................................................

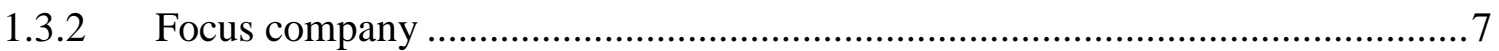

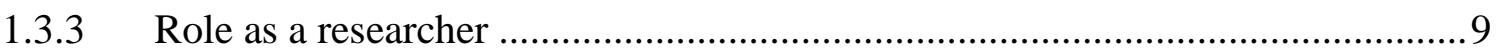

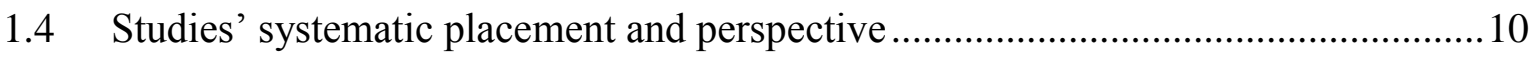

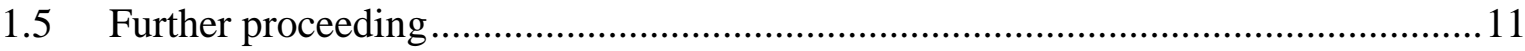

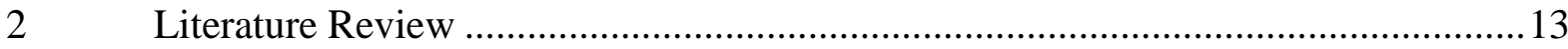

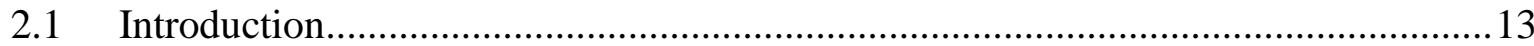

2.2 Impact of globalization on international business literature ..................................... 14

2.3 German cost accounting and Anglo-Saxon management accounting ......................16

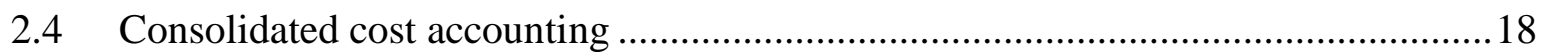

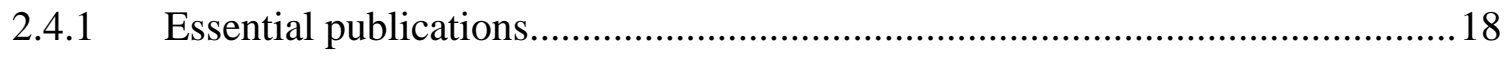

2.4.2 Development from evaluation of inventory to management accounting ........... 19

2.4.3 Contributions from practice to Consolidated Cost Accounting .........................22

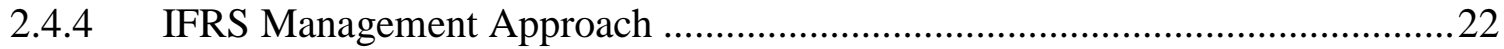

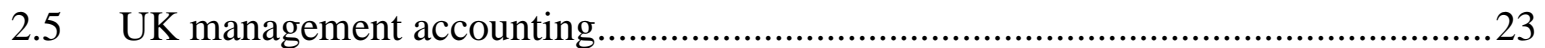

2.5.1 UK management accounting and consolidated cost accounting ......................23

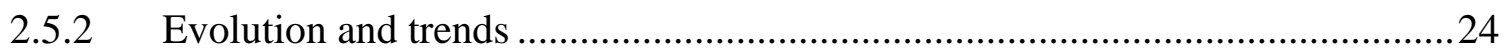

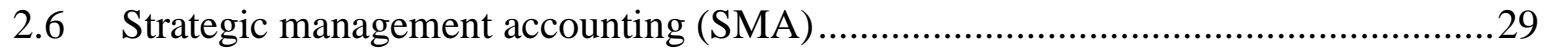

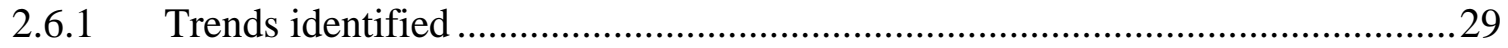

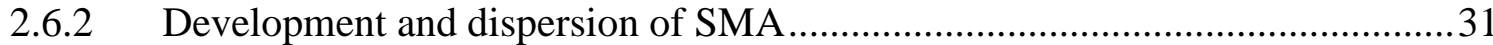

2.6.3 Focal points in SMA - Literature in relation to the research to be conducted ..36 
2.6.4 Performance orientation and competitive advantage ...................................42

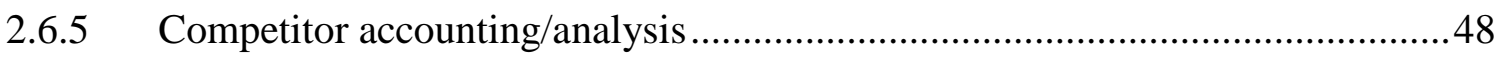

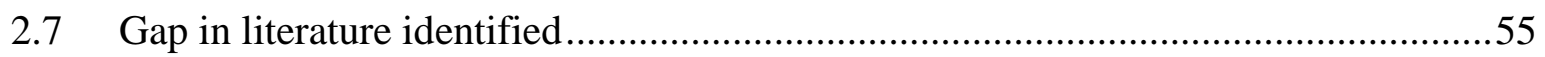

2.8 Connecting the gap in literature with requirements of a conceptual framework.......57

3 Research methodology: identifying philosophical tradition adopted .......................59

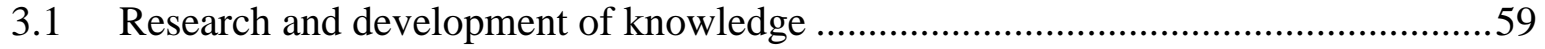

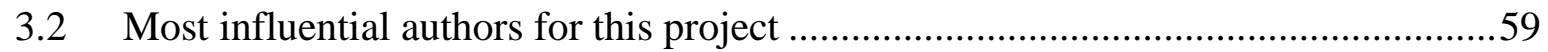

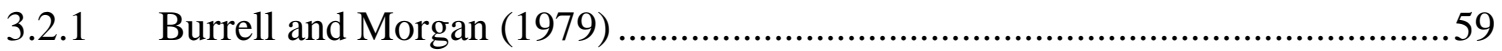

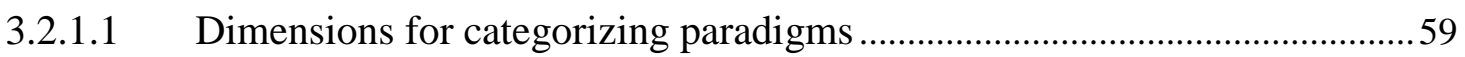

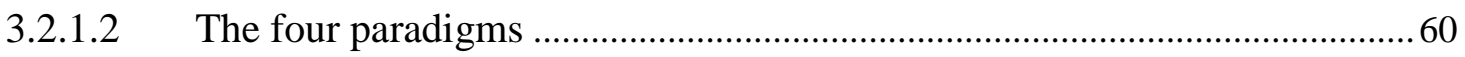

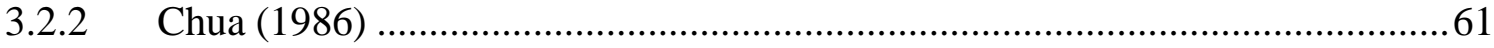

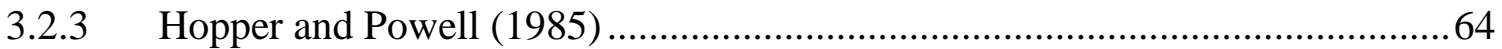

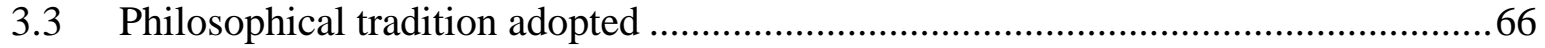

$4 \quad$ Research Method: case study as the Best Fitting Approach .....................................68

4.1 Connecting gap in literature and task to resolve ...................................................68

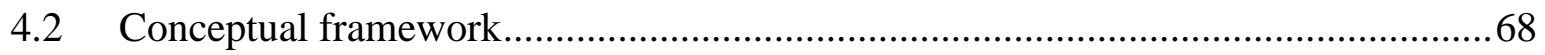

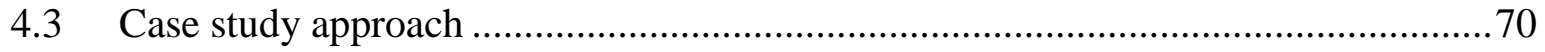

4.3.1 Rationale for case study approach and course of action ................................. 70

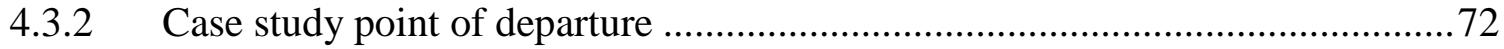

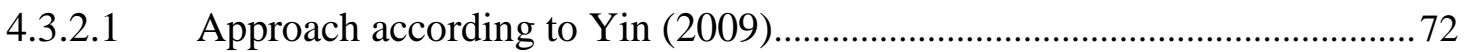

4.3.2.2 Connecting case study approach and research objectives ..............................72

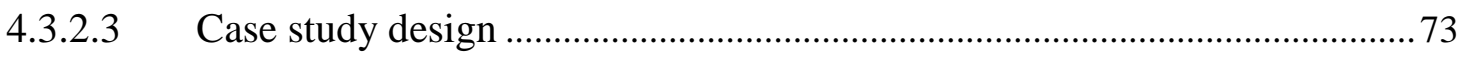

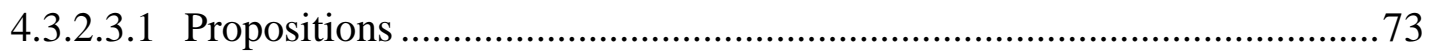

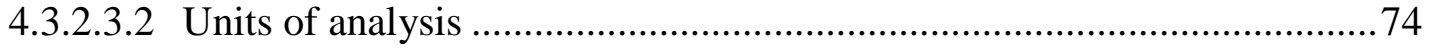

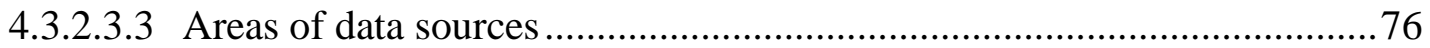

4.3.2.3.4 Linking textual information and figures ............................................. 76

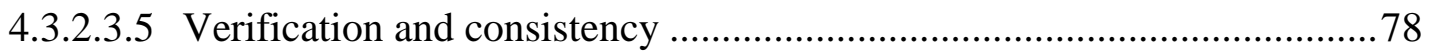

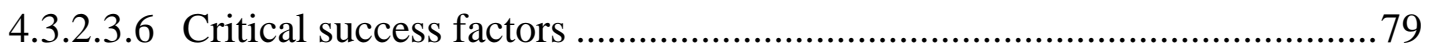

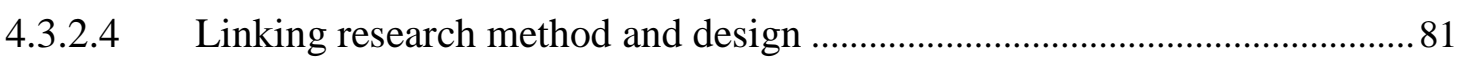

4.3.2.5 Alignment of research method with research questions and objectives...... 81

4.4 The entrepreneurial unit and its corresponding element in accounting ....................83 
4.5 Aligning concept of decision usefulness with design of the model of the major competitor.....

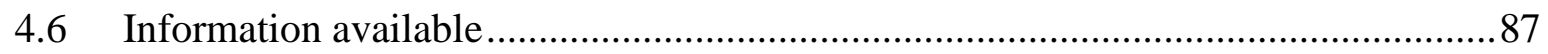

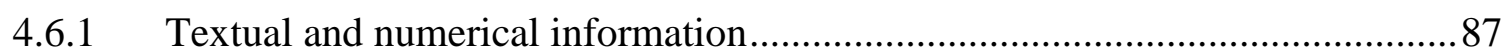

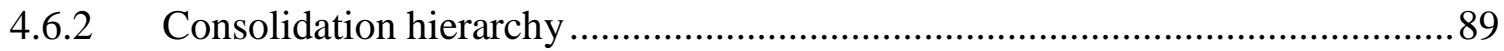

4.6.3 Perspectives of focused company, major competitor and financial analysts .....90

4.6.4 Software used for handling of textual information: NVivo .............................91

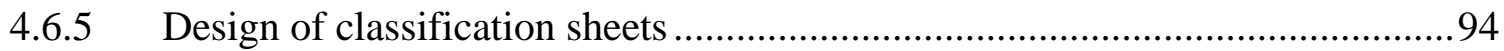

4.6.5.1 Role and tasks of NVivo classification sheets in the project ........................94

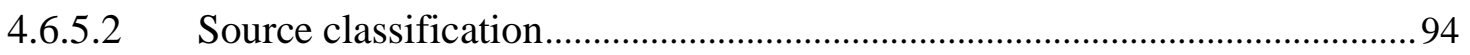

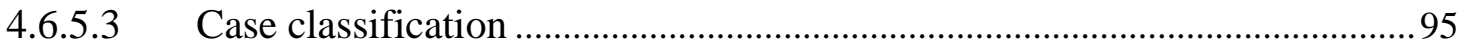

4.6.6 Software used for handling of numerical information: MS Excel .....................97

4.6.7 Organizational structure and processes to be considered in context of numerical

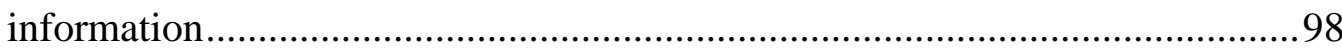

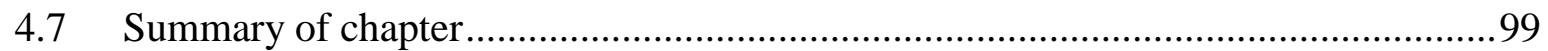

$5 \quad$ Case Study Findings: Developing a Model of the Major Competitor ...................... 101

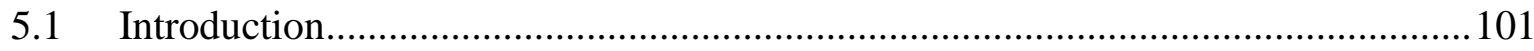

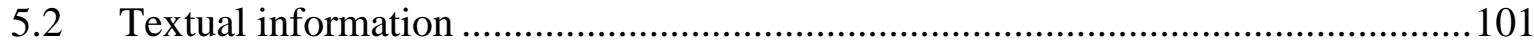

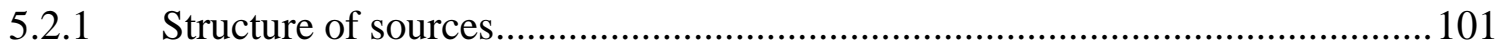

5.2.2 Phase 1: Categories of conceptual framework .............................................. 108

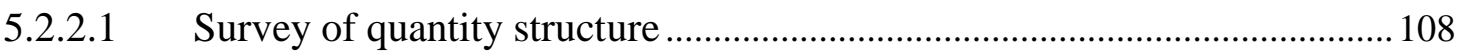

5.2.2.2 Aligning the NVivo node structure with the conceptual framework.......... 110

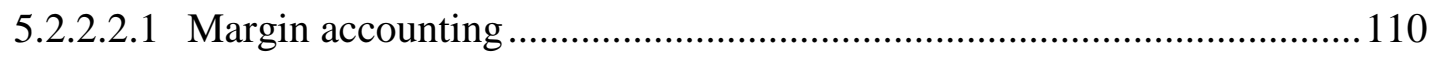

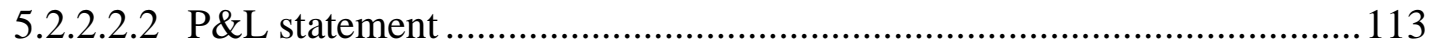

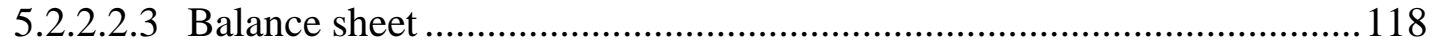

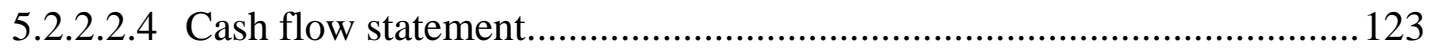

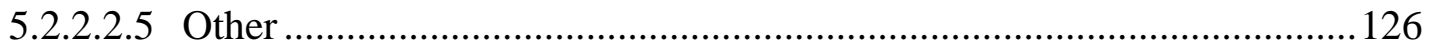

5.2.3 Phase 2: Differentiation by periods and alignment with numerical Information...

5.2.4 Phase 3: identifying trends and themes with strategic context ....................... 135

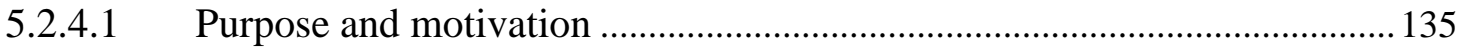

5.2.4.2 Comparisons versus the major competitor and financial analysts .............. 137

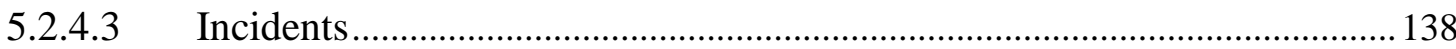


5.2.5 Developing a notion of a reasonable Sales Figure ......................................... 140

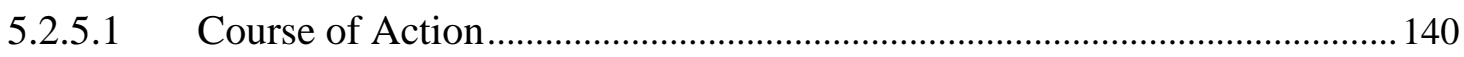

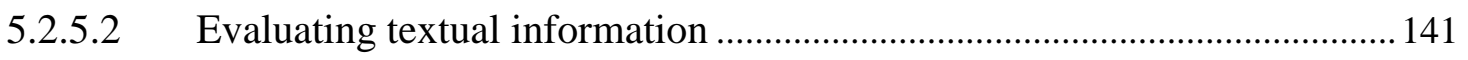

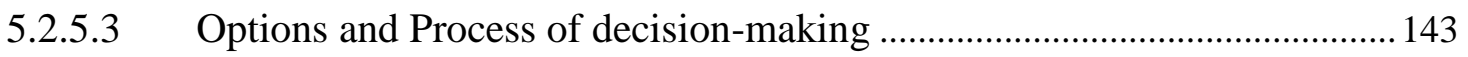

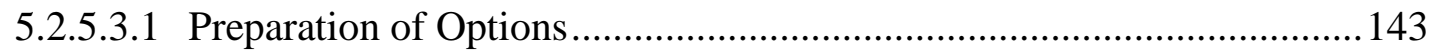

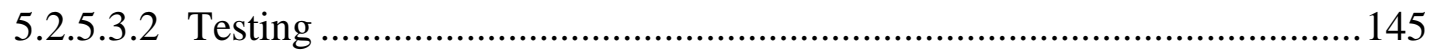

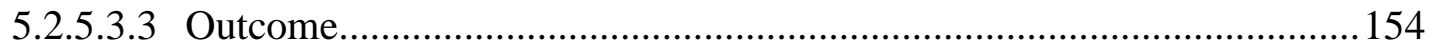

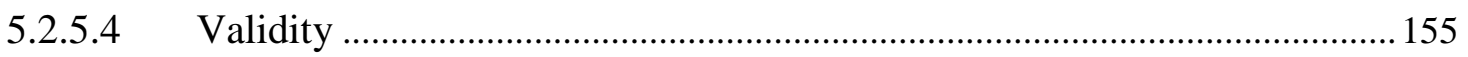

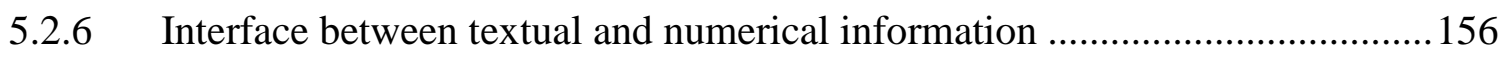

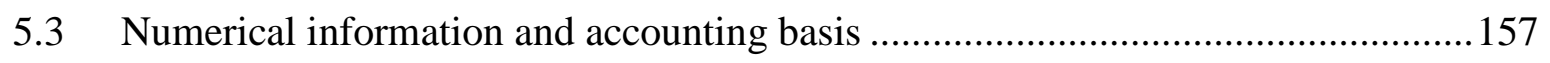

5.3.1 Utilizing Value from Test for deriving additional competitor information ...... 157

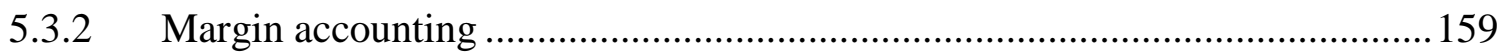

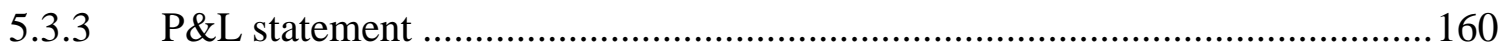

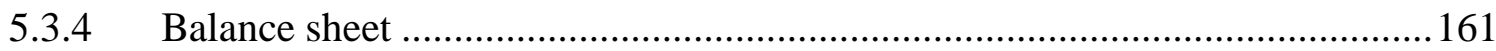

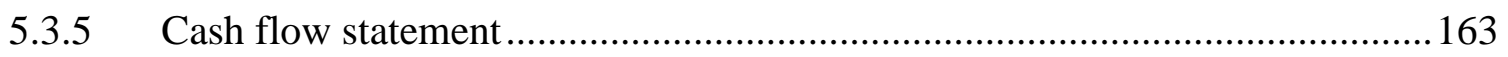

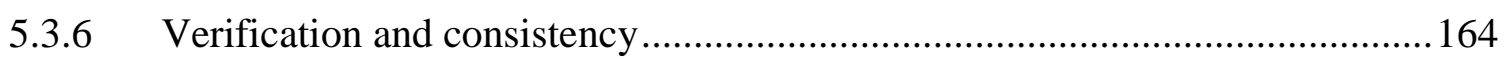

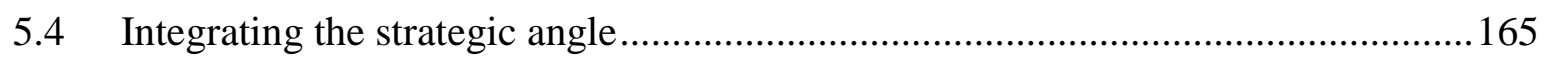

5.4.1 Major competitor's communicated story and goals ..................................... 165

5.4.2 Contrasting competitors' strategic view with the model ................................165

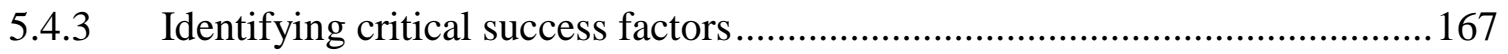

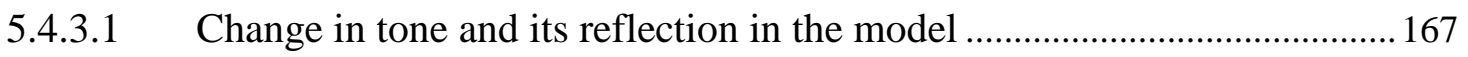

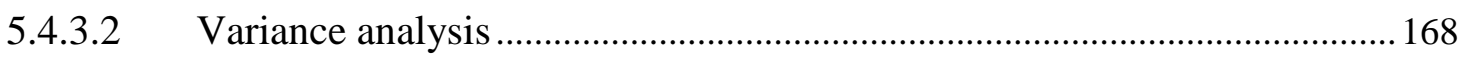

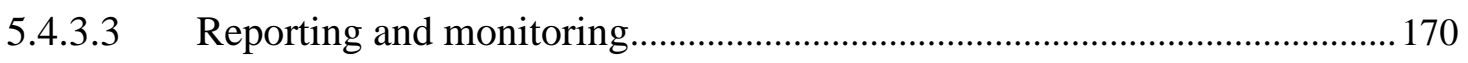

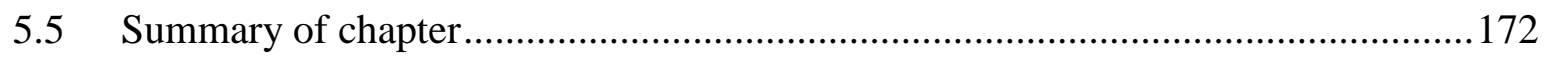

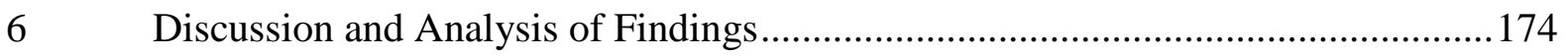

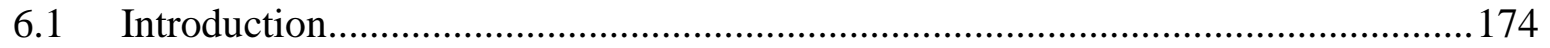

6.2 Connecting the conceptual framework/model with SMA literature ........................ 174

6.3 Discussion of core elements of the conceptual framework/model .........................177

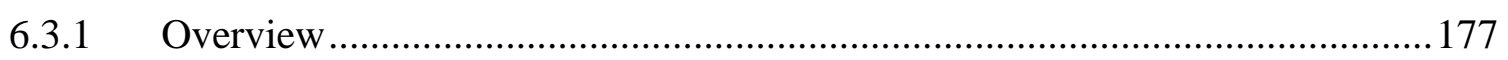

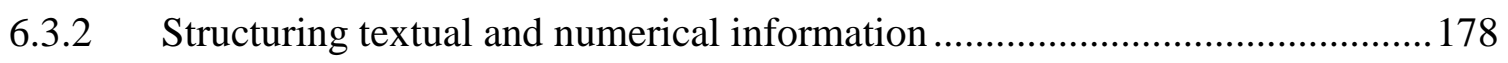

6.3.3 Performance-orientated approach in management accounting literature and its integration in the conceptual framework/model 


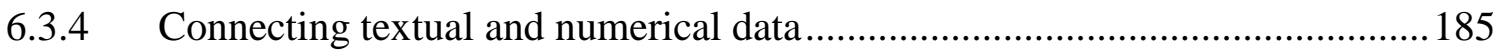

6.3.5 Discussion by performance-relevant variable.............................................. 191

6.4 Identifying competitive advantage provided through the application of the

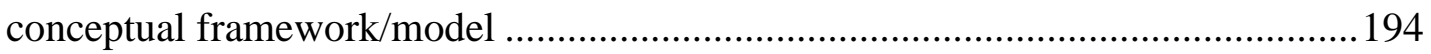

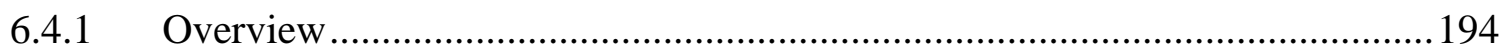

6.4.2 The major competitor's critical success factors ............................................ 195

6.4.3 The holistic view: comparing the model with the major competitor's

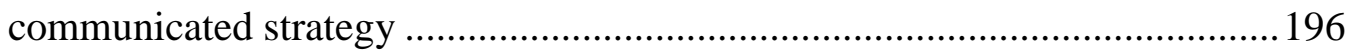

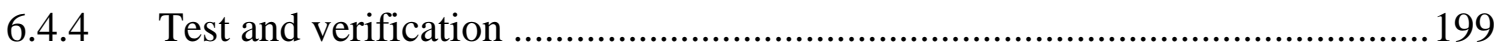

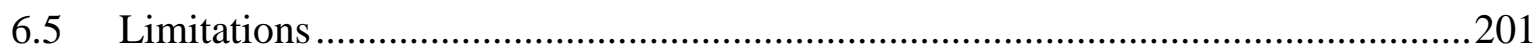

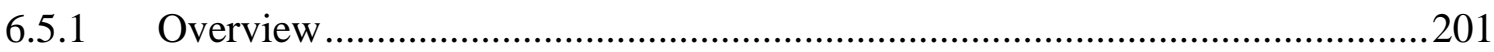

6.5.2 Limitations and relating potential enhancements of the conceptual

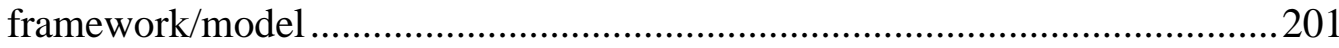

6.5.2.1 Evaluation of textual information and availability of data...........................201

6.5.2.2 Development of "Value from Test" ................................................................... 203

6.5.2.3 Interfaces with other functions of the organization of the focus company.....

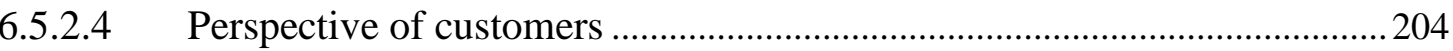

6.5.2.5 Role of management accountants and a holistic view on business .............205

6.5.2.6 Behavioural aspects in the domain of focus company.................................206

6.5.2.7 Potential approaches of enhancements of the conceptual framework/model.

6.5.2.8 Cornerstones of a revised version of the conceptual framework/model ...209

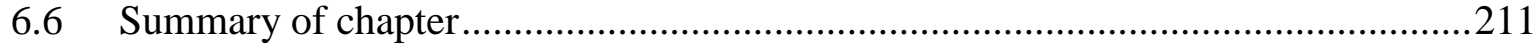

7 Conclusions.

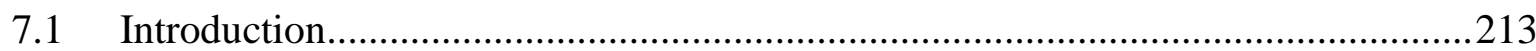

7.2 Critical evaluation of the conceptual framework/model by Research Question .....213

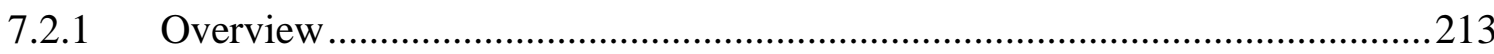

7.2.2 Research Question 1: What information would be needed to use competitor accounting to build a strategic model of competition?

7.2.3 Research Question 2: How can management accounting data/techniques be utilized to develop informed assumptions regarding competitor performance?.... 
7.2.4 Research Question 3: How could a strategic model of competitor accounting aid in the creation of competitive advantage?

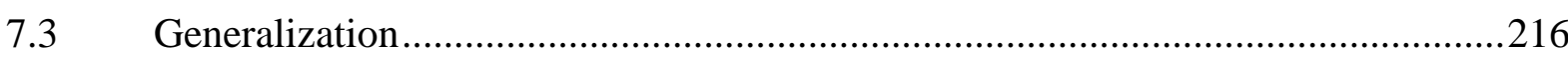

7.3.1 Case study method and theoretical generalization.......................................216

7.3.2 Extending applicability of case study findings to other contexts ...................217

7.3.3 Applicability of the conceptual framework/model in the mechanical engineering Sector and subsequent Sectors

7.3.4 Requirements regarding the applicability of the conceptual framework/model outlying the mechanical engineering sector and subsequent sectors .221

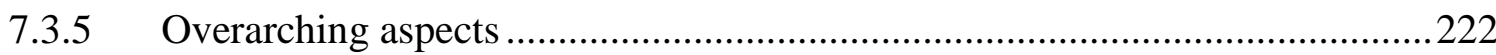

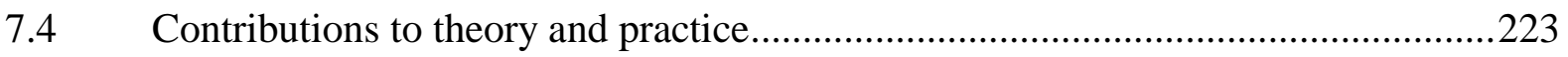

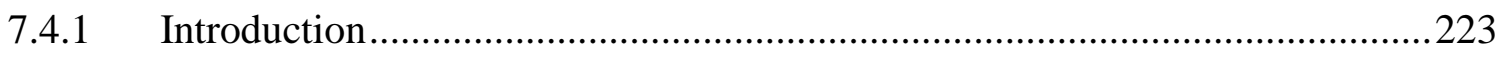

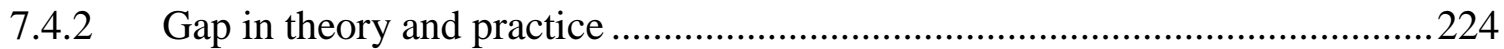

7.4.3 The conceptual framework/model and its performance-orientation ................225

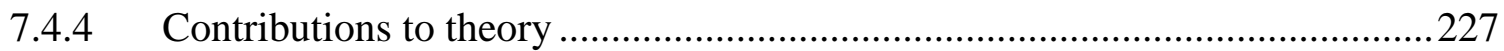

7.4.4.1 Contribution to closing the gap in literature identified ...............................227

7.4.4.2 Contribution to support decision-making in the area of SMA/competitor

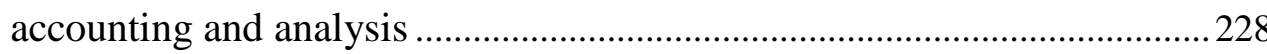

7.4.4.3 Providing an approach for test and verification in competitor accounting/analysis

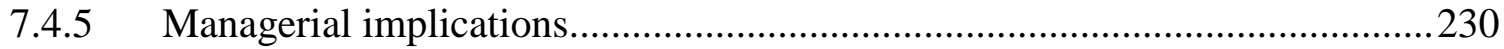

7.4.5.1 Utilizing knowledge of the international organization ................................2. 230

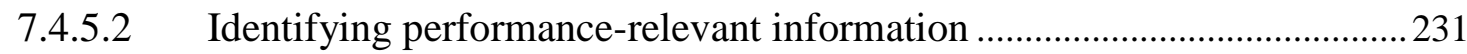

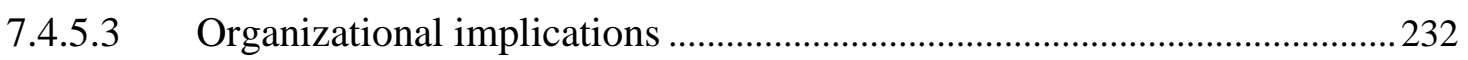

7.4.5.4 Closing the gap in competitor accounting/analysis....................................22

7.4.5.5 Competitive advantage and potential future growth ....................................233

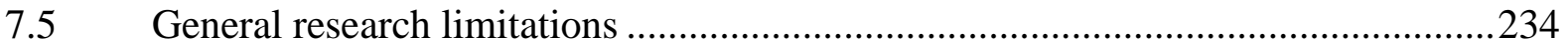

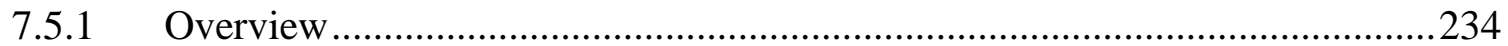

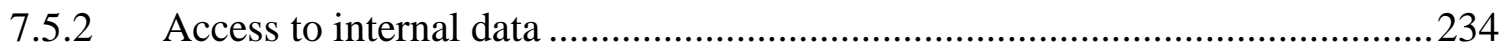

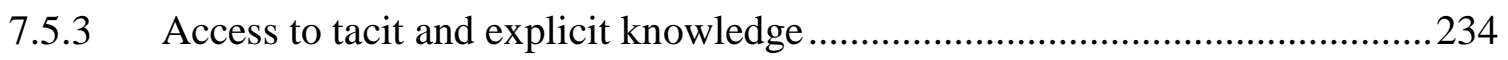

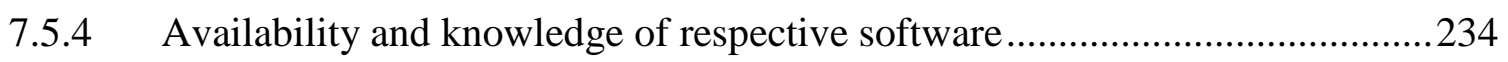

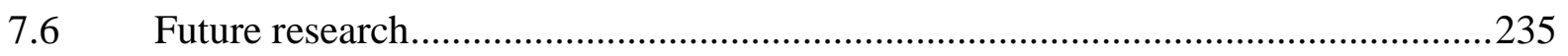

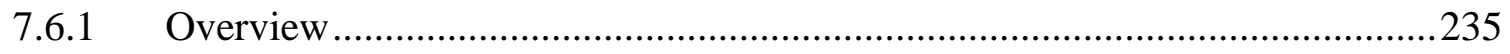

7.6.2 Connecting performance-relevant textual and numerical information ............235 
7.6.3 Integrating other functions of the organization into the conceptual

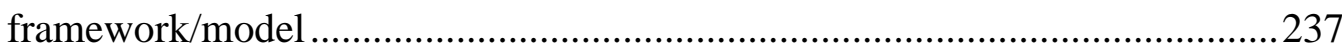

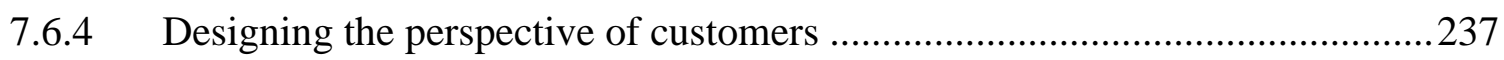

7.6.5 Defining management accountants' role in the context of competitor

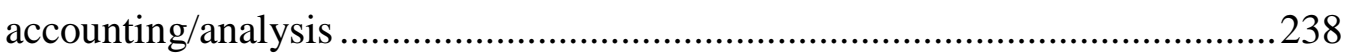

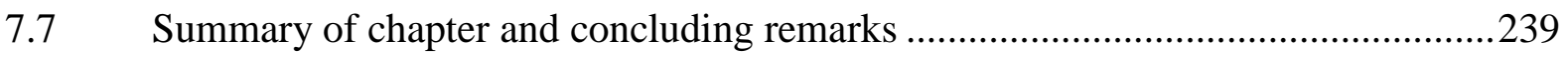

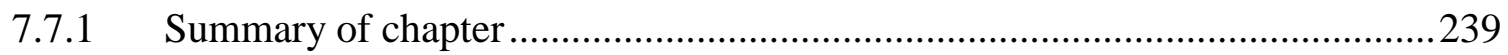

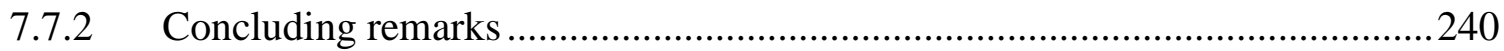

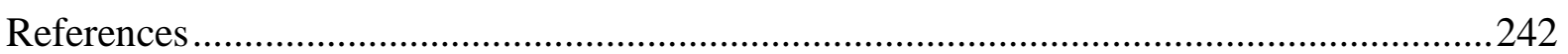

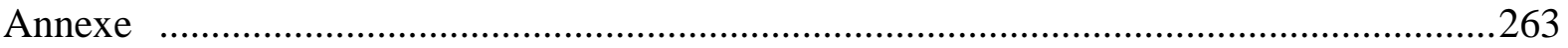




\section{Abbreviations}

$\mathrm{ABC}$

AIS

AICPA

AR

AP

ASB

BL

BRIC

BRM

bsp

CA

Ca.

CAGR

CAPEX

CEO

$\mathrm{CFO}$

CI

CIMA

CGMA

CS

$\mathrm{CSF}$

DIHK

DOS

DTA

ERP

est.

et al

et seq.

et sqq.

etc.

e.g.
Activity Based Costing

Accounting Information System

American Institute of Certified Public Accountants

Accounts Receivable

Accounts Payable

Accounting Standards Board

Business Line

Brazil, Russia, India and China

Budget Review Meeting

basic points

Competitor Accounting

Circa

Compounded Annual Growth

Capital Expenditure

Chief Executive Officer

Chief Financial Officer

Competitive Intelligence

Chartered Institute of Management Accountants

Chartered Global Management Accountant

Case Study

Critical Success Factors

Deutsche Industrie- und Handelskammer (German Chamber of

Industry and Commerce)

Days outstanding trade receivables

Deferred Tax Assets

Enterprise Resource Planning

estimation

et alii

Page following

Pages following

et cetera

For example (exempli gratia) 


\begin{tabular}{|c|c|}
\hline EPU & Entrepreneurial Unit \\
\hline EVA & Economic Value Added \\
\hline FA & Financial Analysts \\
\hline $\mathrm{FC}$ & Focused Company \\
\hline FDI & Foreign Direct Investment \\
\hline GE & General Electric \\
\hline GM & Gross Margin \\
\hline GM-\% & Gross Margin Percentage \\
\hline GP & Gross Profit \\
\hline GP-\% & Gross Profit Percentage \\
\hline IAS & International Accounting Standards \\
\hline IB & International Business \\
\hline $\mathrm{IM}$ & International Management \\
\hline IMA & Institute of Management Accountants \\
\hline IPA & Importance Performance Method \\
\hline IT & Intelligence \\
\hline JIT & Just in time \\
\hline KPI & Key Performance Indicator \\
\hline MARG & Management Accounting Research Group \\
\hline Max. & Maximum \\
\hline $\mathrm{MC}$ & Major Competitor \\
\hline MD\&A & Management Discussion and Analysis \\
\hline MEUR & Million Euros \\
\hline Min. & Minimum \\
\hline $\mathrm{MNC}$ & Multinational Company \\
\hline MS & Microsoft \\
\hline $\mathrm{O} / \mathrm{H}$ & Overhead \\
\hline P\&L & Profit and Loss \\
\hline $\mathrm{p}$ & Page \\
\hline pdf & portable document format \\
\hline $\mathrm{PoC}$ & Percentage of Completion \\
\hline $\mathrm{pp}$ & Pages \\
\hline P\&L & Profit and Loss \\
\hline PY & Prior Year \\
\hline
\end{tabular}


QDAS

R\&D

RO

ROCE

ROI

RQ

SAP

SEC

SM

SMA

SWOT

TGC

TLC

TQM

U. K.

U.S. A.

VBM

VDMA

vs.

WTO

YoY
Qualitative Data Analysis Software

Research and Development

Research Objective

Return on Capital employed

Return on Investment

Research Question

Systeme, Anwendungen, Produkte (= Systems, Applications, Products)

United States Securities and Exchange Commission

Strategic Management

Strategic Management Accounting

Analysis of Strength, Weakness, Opportunities and Threats

Thousand Group Currency

Thousand Local Currency

Total Quality Management

United Kingdom

United States of America

Value-based Management

Verband Deutscher Maschinen- und Anlagenbauer (= German

Association of Mechanical Engineering Companies)

versus

World Trade Organization

Year on Year 


\section{List of Figures}

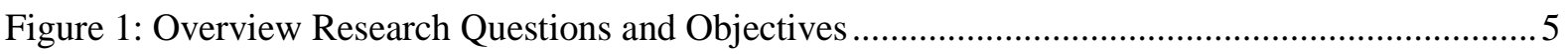

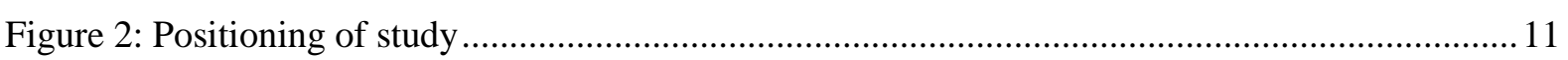

Figure 3: Comparison of the foci of the function of Control in German and US firms according to

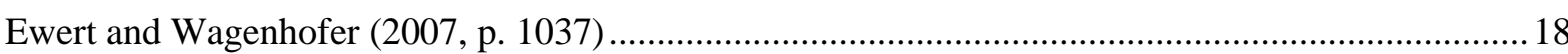

Figure 4: Management Accounting Research Topics adopted from Hesford et al. (2006, p. 8) and extended 25

Figure 5: The development of SMA according to Grant (2002, p. 22) adopted from Günther and

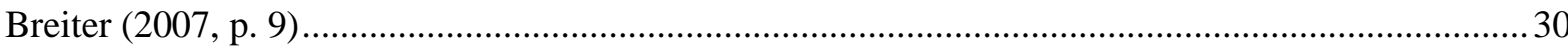

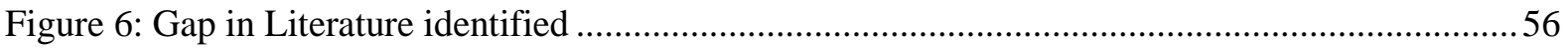

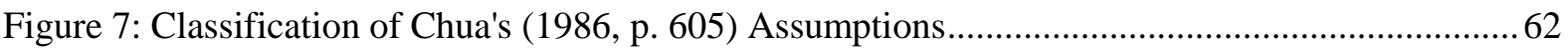

Figure 8: Dominant Assumptions of Mainstream Accounting according to Chua (1986, p. 611) .......63

Figure 9: Dominant Assumptions of the Interpretative Perspective according to Chua (1986, p. 615)64

Figure 10: Hopper and Powell (1985) Taxonomy of Accounting Research (adopted from Ryan et al., 2002 , p. 40)

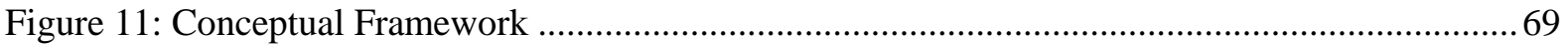

Figure 12: Basic Types of Designs for Case Studies, adopted from Yin (2009, p. 46) ........................ 74

Figure 13: Embedded (multiple units of analysis) case study Design for this Project.......................... 75

Figure 14: Preparing textual information and figures for interpretation and designing....................... 77

Figure 15: Entrepreneurial Unit and Cost Accounting - adopted from Lorson, Melcher, and Zündorf

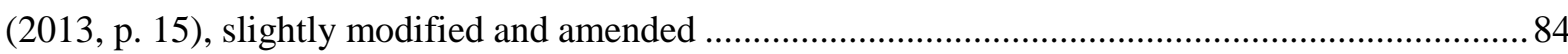

Figure 16: Differentiation of Cost Accounting Systems - adopted from Ossadnik (2008, p. 46) and Vormbaum and Rautenberg (1985, p. 22), slightly modified and amended ........................................... 86

Figure 17: Organizational Basis for Designing Cost Accounting Structures........................................ 86

Figure 18: Structure of Source Classifications .............................................................................. 94

Figure 19: Structure of Case Classification of Entrepreneurial Units..................................................96

Figure 20: Structure of Case Classification of Major Competitor's Product Lines ..............................97

Figure 21: Structure of Classification of Regions............................................................................... 97

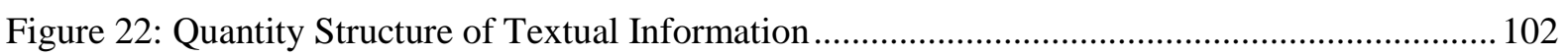

Figure 23: Total Perspectives: Distribution of Sources by A-B-C Classification by Year.................. 104

Figure 24: Perspective Focus Company: Distribution of Sources by A-B-C Classification by Year. 105

Figure 25: Perspective of Major Competitor: Distribution of Sources by A-B-C Classification by Year

Figure 26: Perspective Financial Analysts: Distribution of Sources by A-B-C Classification by Year

Figure 27: References by Information Category 2008-2012 …..................................................... 109 
Figure 28: References by Perspectives 2008-2012 . 109

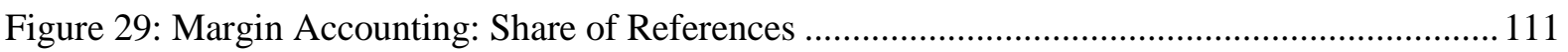

Figure 30: Margin Accounting: References by Product Line 2008-2012 …..................................... 112

Figure 31: Margin Accounting: References by Perspectives 2008-2012 …..................................... 113

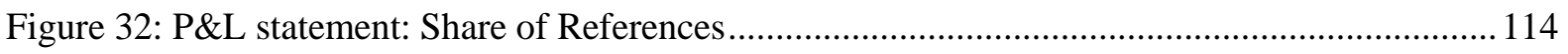

Figure 33: P\&L statement (Total Cost Format): References by Accounts 2008-2012 ...................... 115

Figure 34: P\&L statement (Total Cost Format): References by Perspectives 2008-2012 .................. 116

Figure 35: P\&L statement (Cost of Sales Format): References by Accounts 2008-2012................... 117

Figure 36: P\&L statement (Cost of Sales Format): References by Perspectives 2008-2012 .............. 118

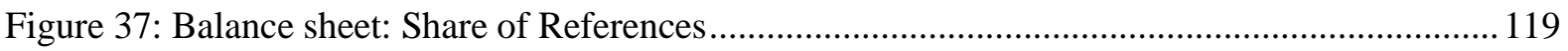

Figure 38: Balance sheet Assets: References by Accounts 2008-2012 …....................................... 120

Figure 39: Balance sheet Assets: References by Perspectives 2008-2012 ....................................... 121

Figure 40: Balance sheet Equity and Liabilities: References by Account 2008-2012 ...................... 121

Figure 41: Balance sheet - Equity and Liabilities: References by Perspectives 2008-2012 ............... 122

Figure 42: Balance sheet Working Capital: References by Perspectives 2008-2012 ......................... 123

Figure 43: Cash Flow Statement: Share of References..................................................................... 124

Figure 44: Cash Flow Statement: References 2008-2012 ............................................................. 125

Figure 45: Cash Flow Statement: References by Perspectives 2008-2012 ….................................. 126

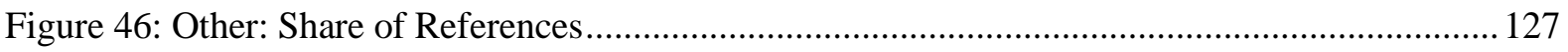

Figure 47: Statistics \& Other: References by KPIs/Themes 2008-2012 ......................................... 128

Figure 48: Statistics \& Other: References by Perspectives 2008-2012 …....................................... 129

Figure 49: Other Consolidation Hierarchy: References by Level of Consolidation 2008-2012 ......... 129

Figure 50: Other/Consolidation Hierarchy: References by Perspectives 2008-2012 ......................... 130

Figure 51: Other Regions: References by Perspectives 2008 - 2012 ................................................. 131

Figure 52: Other Regions: References by Perspectives 2008 - 2012 …............................................. 132

Figure 53: Strategic Planning and Competitor's Highlights: References by Topics 2008-2012 ........ 133

Figure 54: Strategic Planning and Competitor's Highlights: References by Perspectives 2008 - 2012

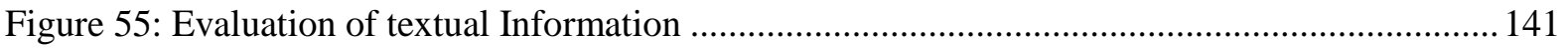

Figure 56: Process of Testing Options of Estimations of Competitor's Sales .................................... 144

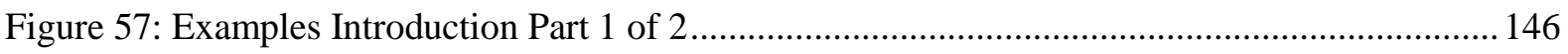

Figure 58: Examples Introduction Part 2 of 2 - developing 2009 Value from Test ........................... 147

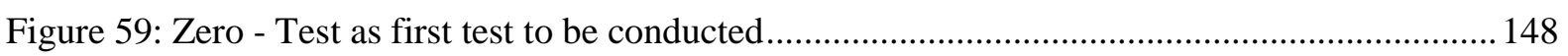

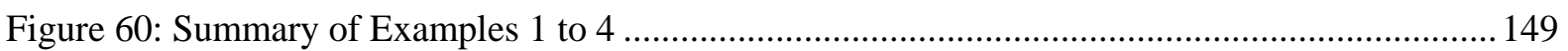

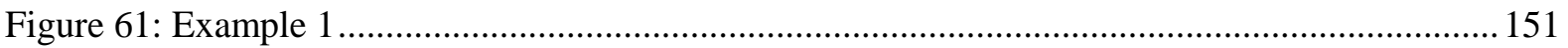

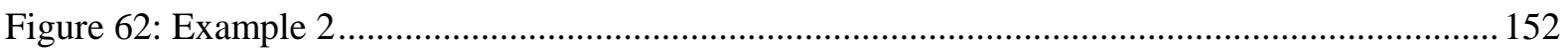

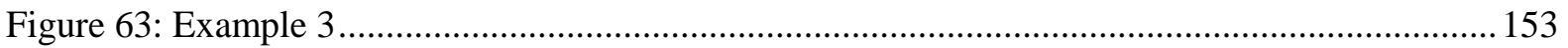


Figure 64: Example 4. 154

Figure 65: Deviation between Total Values from Test and the major competitor Actual Sales by Year 166

Figure 66: Schematic representation of Variance Analysis by product line 169

Figure 67: Development of Sales and Related Textual Information............................................... 170

Figure 68: 2013 Sales and Gross Margin - Comparisons ACT vs. EST by Product Line ................... 171

Figure 69: Development of the Major Competitor's Working Capital and Operational Cash Flow .. 172 


\section{List of Annexe}

Annex 1: Search on EBSCO database on March 11th, 2018, using "strategic\&management\&accounting" as search terms page 1 of 21

Annex 2: Search on EBSCO database on March 11th, 2018, using "strategic\&management\&accounting" as search terms page 2 of 21

Annex 3: Search on EBSCO database on March 11th, 2018, using "strategic\&management\&accounting" as search terms page 3 of 21

Annex 4: Search on EBSCO database on March 11th, 2018, using "strategic\&management\&accounting" as search terms page 4 of 21

Annex 5: Search on EBSCO database on March 11th, 2018, using "strategic\&management\&accounting" as search terms page 5 of 21

Annex 6: Search on EBSCO database on March 11th, 2018, using "strategic\&management\&accounting" as search terms page 6 of 21

Annex 7: Search on EBSCO database on March 11th, 2018, using

"strategic\&management\&accounting" as search terms page 7 of 21

Annex 8: Search on EBSCO database on March 11th, 2018, using

"strategic\&management\&accounting" as search terms page 8 of 21 270

Annex 9: Search on EBSCO database on March 11th, 2018, using "strategic\&management\&accounting" as search terms page 9 of 21 271

Annex 10: Search on EBSCO database on March 11th, 2018, using "strategic\&management\&accounting" as search terms page 10 of 21 272

Annex 11: Search on EBSCO database on March 11th, 2018, using "strategic\&management\&accounting" as search terms page 11 of 21

Annex 12: Search on EBSCO database on March 11th, 2018, using "strategic\&management\&accounting" as search terms page 12 of 21

Annex 13: Search on EBSCO database on March 11th, 2018, using "strategic\&management\&accounting" as search terms page 13 of 21

Annex 14: Search on EBSCO database on March 11th, 2018, using "strategic\&management\&accounting" as search terms page 14 of 21

Annex 15: Search on EBSCO database on March 11th, 2018, using "strategic\&management\&accounting" as search terms page 15 of 21

Annex 16: Search on EBSCO database on March 11th, 2018, using "strategic\&management\&accounting" as search terms page 16 of 21

Annex 17: Search on EBSCO database on March 11th, 2018, using "strategic\&management\&accounting" as search terms page 17 of 21 
Annex 18: Search on EBSCO database on March 11th, 2018, using

"strategic\&management\&accounting" as search terms page 18 of 21

Annex 19: Search on EBSCO database on March 11th, 2018, using

"strategic\&management\&accounting" as search terms page 19 of 21

Annex 20: Search on EBSCO database on March 11th, 2018, using

"strategic\&management\&accounting" as search terms page 20 of 21

Annex 21: Search on EBSCO database on March 11th, 2018, using

"strategic\&management\&accounting" as search terms page 21 of 21

Annex 22: Conceptual Framework: References grouped according to Information Categories and

Perspectives by year / Top level

Annex 23: Conceptual Framework: References group according to Information Categories and

Perspectives by year / Margin Accounting ...

Annex 24: Conceptual Framework: References grouped according to Information Categories and

Perspectives by year / P\&L - Statement - Total Cost Format

Annex 25: Conceptual Framework: References grouped according to Information Categories and

Perspectives by year / P\&L - Statement - Cost of Sales Format.

Annex 26: Conceptual Framework: References grouped according to Information Categories and

Perspectives by year / Balance Sheet - Assets

Annex 27: Conceptual Framework: References grouped according to Information Categories and Perspectives by year / Balance Sheet - Equity and Liabilities .

Annex 28: Conceptual Framework: References grouped according to Information Categories and Perspectives by year / Balance Sheet - Working Capital / ROCE

Annex 29: Conceptual Framework: References grouped according to Information Categories and Perspectives by year / Cash Flow Statement

Annex 30: Conceptual Framework: References grouped according to Information Categories and Perspectives by year / Statistics \& Other

Annex 31: Conceptual Framework: References grouped according to Information Categories and Perspectives by year / Other - Consolidation Hierarchy.

Annex 32: Conceptual Framework: References grouped according to Information Categories and Perspectives by year / Other - Region.

Annex 33: Conceptual Framework: References grouped according to Information Categories and Perspectives by year / Strategic Planning \& Competitor's Highlights . 295

Annex 34: Structure of Case Classification of Entrepreneurial Units Part 1 of 5................................296

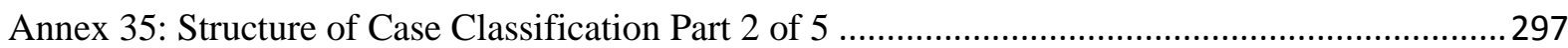

Annex 36: Structure of Case Classification of Entrepreneurial Units Part 3 of 5. 298 
Annex 37: Structure of Case Classification of Entrepreneurial Units Part 4 of 5 ..............................299

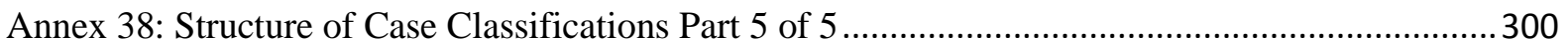

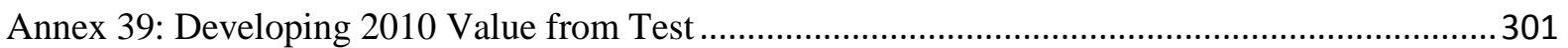

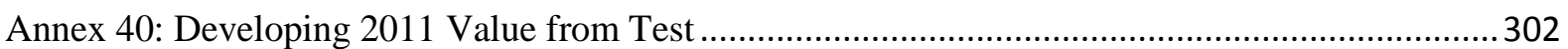

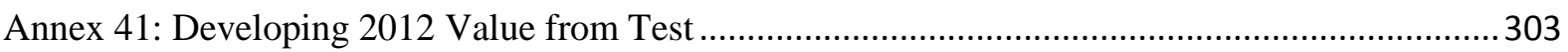

Annex 42: Schematic representation of Variance Analysis of basic Scenarios by Product Line ........304 


\section{Acknowledgements}

I would like to thank my wife Dagmar and my daughters Rebecca and Ricarda for their sympathy, encouragement and never-ending support over the time it has taken to finalize this work, in addition to an already busy professional life.

My thanks also to my supervisors Tracy Jones and Angela Lorenz who have given me help and advice in not losing sight of the important elements of this project.

Finally, I am grateful for the in-depth discussions with friends and colleagues who have consistently encouraged me over the duration of this project. 


\section{$1 \quad$ Introduction and Positioning of Study}

\subsection{Germany's mechanical engineering industry and its international orientation}

This introductory section, firstly, seeks to associate the German mechanical engineering Industry as Germany's largest industrial sector (VDMA, 2013) within the international context. Therefore, in an initial step, the development of globalization will be illustrated, and Germany's role identified. Thereafter, the resulting organizational implications of increasing globalization will be illuminated. Emphasis will be put on the corporate functions of control and marketing because of their importance for providing information to top management at the global (group) level. This also applies to information regarding competition at the global level and forms the basis of this works' research approach, which then flows into a description of the line of action this project attempts to follow.

"Globalization is leading to rapid changes in the economic and social environment..." - this statement made by Hubert Escaith, WTO Chief Statistician (WTO, 2013, p. 4) places emphasis on the effect that increasing international trade is expected to have. Escaith (2013, p. 5) highlights the role of "...global value chains..." and the dominance of only ten nations incorporating $60 \%$ of world trade. According to Escaith (2013, p. 5), these "...global value or production chains..." have mainly been established and operated by international firms.

WTO statistics (WTO, 2013, p. 22) show a constantly strong growth for "...world merchandise exports..." from 1948 to 2012 (the last year of the current statistics). According to the World Trade Organization (WTO, 2013) world merchandise exports accounted in 2012, for 17930 Billion USD out of which 1399 Billion USD (7.8\%) are contributed from Germany. In the decade from 1993 to 2003, world trade doubled and from 2003 to 2012 increased by another 143.0\% (WTO, 2013). From 1993 to 2003, Germany shows a similar development, however, the growth from 2003 to 2012 was 85.8\% (WTO, 2013). Consequently, Germany's part on world trade went down from above 10.0\% (1993 and 2003) to $7.8 \%$ in 2012 (WTO, 2013). This coincides with the fact that other nations' share became bigger within an overall growing world-market. In particular China increased its portion from $2.5 \%$ (1993) to $5.9 \%$ (2003) and $11.4 \%$ in 2012 which made China the leading trading nation (WTO, 2013, p. 24) and indicates a growing competition with these fast expanding nations.

Looking at the development of world trade from the point of view of manufacturers, the respective 2012 share of world merchandise exports was $64.1 \%$ (11490 Billion USD) with 4734 Billion USD generated in Europe (WTO, 2013, p. 60). With regard to Germany, it has been observed (Brutscher, Raschen, Schwartz, \& Zimmermann, 2012) that increasing export 
activities were followed by increasing FDIs (Foreign Direct Investments) especially in production capacities abroad, resulting in more internationalized value chains. A study of the German chamber of industry and commerce (DIHK Bereich Wirtschaftspolitik, 2011) illustrates that this investment behaviour is primarily related to companies' aim to be closer to attractive markets abroad and in addition to that to benefit from cost advantages (DIHK Bereich Wirtschaftspolitik, 2011). Along with that, Maisch (1996) identified a certain level of coercion amongst German industrials to go global in order to meet the challenges of international competitors.

According to DIHK - statistics (DIHK Bereich Wirtschaftspolitik, 2011), FDIs of German Investors have focused on the BRIC countries (Brazil, Russia, India and China) and are especially related to chemicals - and consumer goods industry. An important factor in this development is represented by the BRIC countries and their increasingly western orientated consuming behaviour (Wong \& Ahuvia, 1998) which has offered manifold business opportunities for German Industries (DIHK Bereich Wirtschaftspolitik, 2011). Looking at the evolution of the BRIC countries' growth of population, it can be observed that this shows a similar trend to that of the FDIs of German investors in these countries. The development of population in the BRIC countries shows a significant increase from 1.3 billion (1960) to 2.9 billion (2012) and represents $40.4 \%$ of the growth of world population, whereas the respective figures for western regions like Europe and North America show a markedly lower increase The World Bank (2014).

The above described process of internationalization applies significantly to Germany's mechanical engineering industry. According to the Association of German mechanical engineering companies (VDMA) exports of goods increased from 2000 to 2011 by $80 \%$ and FDIs almost doubled (VDMA, 2013). Mechanical engineering is one of the most important industrial sectors of Germany's economy. In 2011 and 2012, this branch of industry represented more than one-third of the companies operating in the industrial sector with c.970,000 employees and generating a turnover of more than 207 billion Euro (VDMA, 2013). Gertler (1996) views the quality of its products and the high degree of innovation as a major reason for the positive development of the German mechanical engineering industry after World War II. However, this sector went through a crisis which Gertler (1996) partly explains with cost arguments such as the cost of the reunification of the two German countries but also with the high level of wages and salaries. In addition, the author considers the negative developments on the markets in Germany and Europe as an explanation. More 
recent publications (Brutscher et al., 2012) attest the industry to have successfully emerged as 'Global Players' since then.

In the next section the implications of this increasing internationalization of business in general on industrial organizations will be illuminated. The focus will be on the corporate functions because multinational organizations need to control their international business. In particular the functions of control and marketing are in charge of providing worldwide consolidated information for top management at the group level.

\subsection{Organizational role and foci of the corporate functions of control and marketing}

According to Blödorn (1998a) the organizational form of MNCs can be characterized using the dimensions region, product and function; and the attributes overlapping responsibility, managers reporting to a line supervisor- and functional superior and different nationalities within the management board. Based on this systemization the author differentiates organizational models which follow either a more centralized or more decentralized concept of integration of activities abroad. In addition, Blödorn (1998a) distinguishes between a functional and object-related organization. The concept of a functional orientated organization allots departments for the main operational functions (for example, sourcing, production, sales or accounting) below top management whereas the object-related organization focuses on categories such as divisions or regions (Blödorn, 1998a). The author states that these ideal types of organizational concepts can hardly be observed in practice and that MNCs prefer hybrid organizational forms to control their organization.

Within German MNCs an essential organizational aspect with regard to the corporate functions of control and marketing is the extent to which certain tasks and responsibilities should be assigned to central departments or be decentralized (Blödorn, 1998b; Littkemann, 2009; Littkemann, Derfuß, \& Holtrup, 2018; Mahefa, 1998).

As to the function of control Blödorn (1998b) links this to management tasks and states that strategy is based on worldwide concepts and that therefore in practice it is assigned to the corporate level whereas management of single entities abroad is appointed to local staff. The author recognizes as a core element of the tasks of the function of control at the corporate level the support of a performance/result-orientated management of the organization. In particular, the author sees, as a precondition for a performance orientated management at the corporate level, a sophisticated cost/result accounting at the group level reflecting the operational performance of worldwide areas of responsibility for example, for product lines. 
Despite the fact that the author emphasizes the necessity of having such information available he admits that this maybe accompanied with challenges relating to consolidation (Blödorn, 1998b). Littkemann (2004) emphasizes that the key task of the function of control at the group level is to provide top management with decision relevant information. With regard to the internal organisation of the function of control the author also stresses the elements of coordinating activities (such as for example, budgeting) between headquarters and subsidiaries as well as managing the flow of information between corporate- and local departments.

Since this project has the perspective of a German organization it is important to note that the German definition of 'controlling' coincides to a high degree with the Anglo-Saxon 'management accounting'. However, the development of the contents of these concepts is different (Ahrens \& Chapman, 1999, 2000; Luther, Jones, \& Saxl, 2009). Luther, Jones, and Saxl (2010) identify as a major difference that the German concept strongly differentiates between cost accounting and financial accounting and looks at the stronger manufacturing background of Germany as an explanation. A major achievement of cost accounting is the development of methods to calculate the contribution margin, which can roughly be related to the UK-marginal costing concept (Luther et al., 2010). The connecting element between these two concepts is the aim to produce decision-relevant information for management (Luther et al., 2010).

Management accounting is closely related to strategic management accounting (SMA) as it is an essential part of strategic decision-making processes (Keith Ward, 1992). Due to the increasing importance of international competition, it has to be assured that decision-relevant information regarding competition is integrated into strategic decision making. The means to accomplish this is competitor accounting/analysis as a sub-discipline of SMA which is the point of view of UK and German authors (Hoffjan \& Wömpener, 2006; Keith Ward, 1992).

With regard to the function of marketing, Mahefa (1998) states, that marketing at the international (group) level does not constitute a basically different marketing problem in comparison to marketing at the level of a single entity (national). Both marketing at the group level as well as marketing within a single entity is based on the attitude that the way the organization is managed is determined by aspects coming from the markets. The author emphasizes the need for a consistent world-wide marketing concept which has to be elaborated by the function of marketing at the corporate level. Competition-related aspects are reflected, for example, in the context of price strategy (Mahefa, 1998). 
In the previous part, I have elaborated that the strong growth of world trade in recent decades has led to international value chains within industrial organizations and that this development has also entailed additional requirements regarding competitor-related information for strategic decision making at the international (group) level. Emphasis has been put on German mechanical engineering as Germany's largest industrial sector. Concerning the function of control at the group level the importance of providing top management with decision-relevant information along with performance/result orientated focus of information has been accentuated. This has been linked to SMA underlining competitor accounting/analysis at a global level.

Based on these grass roots, I will attempt to formulate my research approach in the next section. Firstly, I will develop the research question and objectives and connect them with the aim of this research. This will be followed by a portrayal of the focused company relating to the organizational implications of increasing internationality of business. Thereafter, I will describe my role as a researcher in this project.

\subsection{Research approach}

\subsubsection{Research questions, objectives and aim}

Figure 1 illustrates the systematic research questions and the objectives of this project. I will use this overview to explain this project research questions and objectives and, based on this, derive the research aim.

Figure 1: Overview Research Questions and Objectives

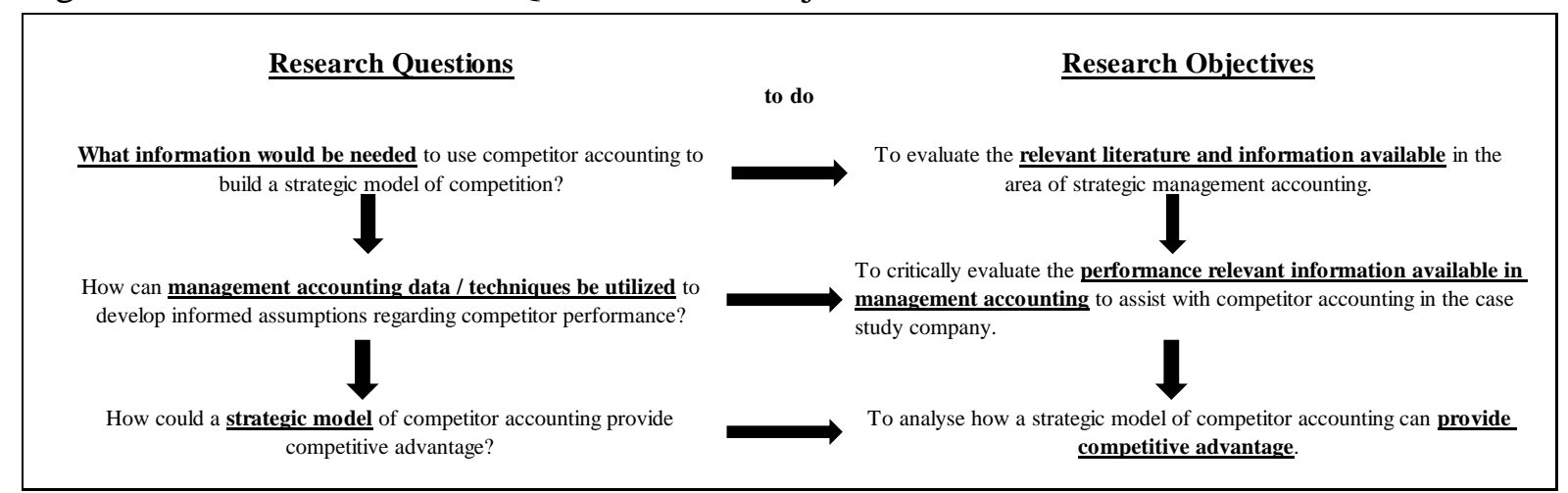

In Figure 1 research questions are itemized on the left and research objectives on the right of the illustration. The arrows show that this picture needs to be read in both horizontal and vertical directions. The arrows in the middle (horizontal direction) indicate that the research objective implies the necessary activities/measures to answer the research question, whereas the arrows in a vertical direction illustrate the systematic order in which research questions and objectives are going to be dealt with. This assures a consistent composition of research 
questions and objectives. In the following, I will elaborate the research questions and objectives in more detail and illuminate the context in which they are embedded.

In the light of the increasing world trade and the emergence of international value chains within German industrial organizations, there is the need to integrate information regarding competition into strategic decision making at a global (group) level. A platform for doing this could be competitor accounting/analysis as a sub-discipline of SMA (Hoffjan \& Wömpener, 2006; Keith Ward, 1992). This forms the basis for the first research question:

Research Question 1: What information would be needed to use competitor accounting to build a strategic model of competition?

The activity resulting from this research question is now to scrutinize the literature in the fields of management accounting, SMA and competitor accounting/analysis. In addition, the respective information/techniques in the focus company have to be considered. This leads to the first research objective:

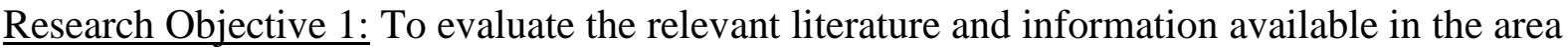
of strategic management accounting (SMA).

Due to the performance/result orientated focus of information to be provided to management at the group level, it is now reasonable to examine how the information identified can be connected with competitors' performance. Therefore, based on research question 1 and research objective 1 , the next step would be to target competitors' performance, which guides us to research question 2 .

Research Question 2: How can management accounting data and techniques be utilized to develop informed assumptions regarding competitors' performance?

The work to answer research question 2 is to determine what information scrutinized in research objective 1 relates to performance in order to support competitor accounting in the focus company. This constitutes the subsequent research objective 2 . 
Research Objective 2: To critically evaluate the performance relevant information available in management accounting to assist with competitor accounting in the case study company.

The criterion for evaluating information as a contribution to competitor accounting is whether it can be incorporated in the competitor accounting system of the case study company.

The first two research questions/objectives route now to the aspect of competitive advantage:

Research Question 3: How could a strategic model of competitor accounting provide competitive advantage?

Therefore, the resulting research objective has to center on a strategic model of competitor and achieving competitive advantage:

Research Objective 3: To analyse how a strategic model of competitor accounting can provide information to aid in the creation of a competitive advantage.

The criterion for being evaluated as a contribution to generating competitive advantage would be if corporate level management could be provided with information about competitors' performance for the objective to provide information to aid in the creation of a competitive advantage. Furthermore, it can be argued that informed assumptions about the competitive performance position improves one's own performance (Heinen \& Hoffjan, 2005).

Research questions and objectives are in line with the research aim, which is to improve competitor accounting through the comprehensive use of management accounting information in order to produce competitive advantage. A case study approach that focuses on a German mechanical engineering organization operating internationally will be applied in order to achieve this aim.

\subsubsection{Focus company}

The focus company is an internationally operating German machine building company with production sites in Germany and abroad. It consists of consolidated and non-consolidated subsidiaries with a worldwide headcount of several thousand. The business model is reflected through a matrix organization with eight business lines. Total market share is estimated to be one-third and to be at the same level as the major competitor, which is confirmed on their 
Internet site. This estimated total market share can be considered as significant and therefore justifies conducting this project with just one case.

The company was founded more than 100 years ago and has been managed by members of the founding family up to the mid-nineties when it was acquired by a larger group. Regarding its innovative capacity as well as the quality of its products it matches Gertler's (1996) description of German mechanical engineering companies. This coincides with the large share of highly qualified engineers among its staff along with their length of service in the company.

Regarding the organizational structure, two major aspects characterize the company. Firstly, the strong parent-company part of the organization ensures that common policies (for example, strategies, procedures etc.) are rolled out in the entire international organization in a consistent way. This enables the organization to react to changes in its environment very quickly. Secondly, the companies' international sales and service organization secures independent direct access to international markets. This favours that customers relate the companies' strong technical performance to the company directly and additionally to establish long lasting strategic relationships with customers.

With respect to markets, the company seeks to meet the demands of an increasing world population and is in this respect in line with the trend of German industrials (DIHK Bereich Wirtschaftspolitik, 2011). Important applications are, for example, in the fields of energy and food.

Using Blödorn's (1998a) terminology the case study companies organizational form can be characterized as hybrid because it uses the advantages of functional and object-related organizational concepts through combining them efficiently. With regard to the function of control, single entities abroad have full responsibility for their P\&L-statement and balance sheet according to local GAAP and for their entries according to IFRS in groups' consolidation systems as well as for all other reporting (for example, additional statistics, monthly comments etc.) regarding their entity. The budget process follows the bottom-uptop-down principle and covers a forecast for the current year, the budget for the following year plus two mid-term planning periods and is coordinated through the corporate function of control. All subsidiaries have to discuss their planning with group management using a standard presentation template which also contains assumptions regarding competitors' volume by business line in planning periods. 
Aspects of strategic planning are also dealt with in the course of the planning process. Strategic planning does not relate to the planning of single entities, is reflected on a more abstract level and is conducted by the corporate functions of control and marketing.

Case study company's management accounting systems are performance/result orientated. The precondition (Blödorn, 1998b) of a sophisticated cost/result accounting system reflecting product (business) lines as areas of responsibility at the group level allowing a performance/result orientated management at the group level have been fulfilled for almost 10 years now.

After having described briefly the case study company and its internal and external environment, I will now emphasise my role as a researcher in this project and how this relates to my position in the case study company.

\subsubsection{Role as a researcher}

In order to determine my role as a researcher in this project I will, firstly, describe briefly my position in the company in the years from 2003 to 2017 and relate that to the case studies' internal environment described in the previous section. This will then pass into an explanation of how my position in the organization and professional experience support my role as a researcher.

Within the focus company I head the corporate function of control. I have held this position for almost 14 years with a total professional experience of almost 30 years in the management accounting/finance area of internationally operating German producing organizations. My direct superior during these years was the Chief Financial Officer (CFO) and Vice President Finance. The corporate function of marketing was assigned to the same hierarchy level that allocated to the corporate function of control. However, the corporate function of marketing is reporting to the Chief Executive Officer (CEO) and the CFO.

During my first years in the company I built up a highly developed cost/result orientated management accounting system at the group level as required by Blödorn (1998b) and described as state-of-the-art in the expert literature (Franz \& Hieronimus, 2003). This system was used from that point onwards by management at the group level for controlling the organization. Regarding the organizational dimension, my position is a corporate function and therefore closely related to the tasks of coordinating, for example, processes and information between centralized and decentralized departments/international subsidiaries.

Due to my function in the organization, I have access to all internal data needed for this project, which is an important concern for projects in management research (Gummesson, 
2000, 2017). In addition, a high degree of pre-understanding as elucidated by Gummesson (2000, 2017) can be assumed due to my professional experience and length of service in the company.

In the section '1.3 Research approach', I have formulated my research questions and derived the aim of this project, which is to produce competitive advantage. Thereafter, the focussed company and its internal and external environment has been described briefly. This section has been completed by illuminating my role as a researcher in this project and how this relates to my position in the focussed organization. The next section will emanate from this basis and endeavour to find the most appropriate systematic placement of this project in the context elaborated so far.

\subsection{Studies' systematic placement and perspective}

In order to accomplish a contemporary suitable assignment of the study, its international context along with its German mechanical engineering background needs to be irradiated in this section in a few words. Along with this the management accounting/SMA background will be outlined.

The global perspective of this study is determined by the focus company's worldwide organized activities. The case study companies' development of business is in line with the overall evolution of German mechanical engineering as portrayed by DIHK Bereich Wirtschaftspolitik (2011) and coined by increasingly international competition as identified by Maisch (1996). Therefore, this study has a clear international core emphasizing the management accounting point of view from the consolidated group perspective in order to produce worldwide consolidated information. In this context, the performance/result orientation has to be emphasized as well as its striving to align with German cost accounting principles.

Closely linked to the management accounting perspective in an international context is the studys' strategic orientation. It seeks to support competitor accounting/analysis which are sub-disciplines of SMA (Hoffjan \& Wömpener, 2006; Keith Ward, 1992) and is therefore connected with SMA. This has to be distinguished from the perspective of the function of corporate marketing. The relationship between SMA and the function of marketing needs to be touched due to an intersecting set in the area of competitor accounting/analysis, but the perspective of the function of marketing does not belong to the scope of my research. However, due to case study companies' organizational specifics, the boundaries between SMA and the function of marketing are not always explicit in practice. 
Figure 2 illustrates the study's classification and perspective using the dimensions 'organization' and 'subject-area'. The shaded area indicates the importance of the subject area and organizational orientation for the study. In addition, the arrow underlines the direction of the study coming from management accounting and develops this further to assist SMA in establishing informed assumption in the sub-disciplines competitor accounting/analysis in order to produce competitive advantage.

Figure 2: Positioning of study

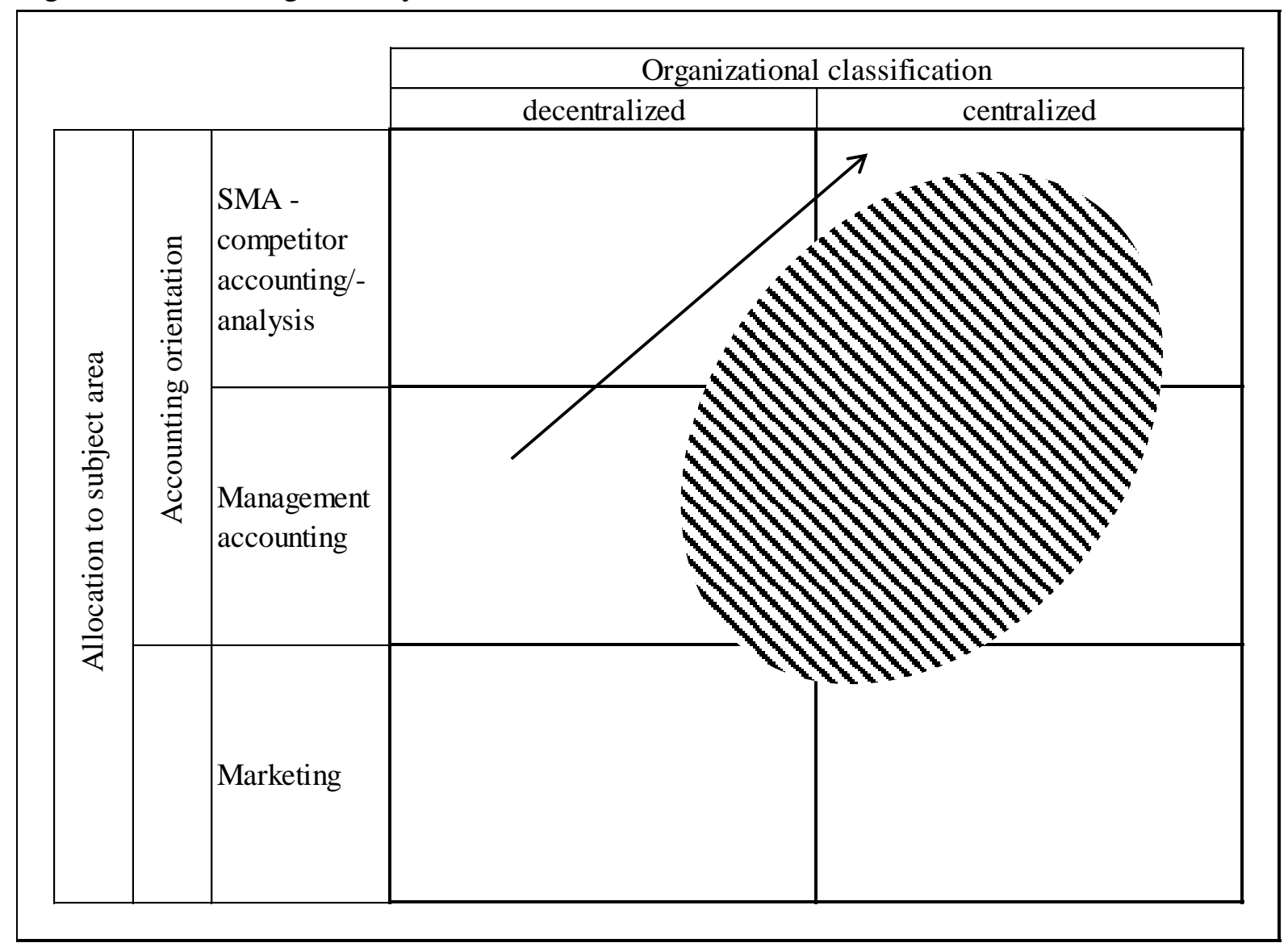

After having outlined the emphasis of the studies' systematically position based on the research approach, I will now seek to specify the build-up of the thesis.

\subsection{Further proceeding}

In particular, the previous section reveals that the literature review needs to span more than one subject area. Therefore, in the next section I will scrutinize the literature in the relevant academic disciplines based on a rationale for the philosophical tradition adopted. The section will conclude with the gap identified in literature. In this context, it is essential that the research questions and objectives are designed to support both, making a contribution to closing the gap in literature identified and providing the means for the focus company to have 
access to the right information to achieve a competitive advantage and potentially improve its position in the market based on a model which is new for the organization.

Thereafter I will attempt to demonstrate the research methodology (chapter 3) and the research method (chapter 4) applied in this project. The case study method is based on my conceptual framework which I will connect first with the research questions and objectives.

The findings of the Case Study will be outlined in chapter 5 and the respective discussion conducted in chapter 6 . This work will then end with the conclusions in chapter 7. 


\section{$2 \quad$ Literature Review}

\subsection{Introduction}

As a first step, I will attempt to derive the aim of my literature review from the study's systematic placement and perspective.

In the introductory section, I have outlined that the extent of world trade grew significantly after World War II. This development also applies to the manufacturing area, in particular to German manufacturers whose largest sector is mechanical engineering (VDMA, 2013). Regarding the organizational implications of the corporate functions of control and marketing within German MNCs resulting from the increased internationality of business, the question of centralization versus decentralization of tasks has been illuminated (Blödorn, 1998a, 1998b; Mahefa, 1998). As shown in Figure 2 on page 11 the research has subsequently been positioned from the organizational perspective and area of subject. Emphasis has been put on the subjects management accounting/cost accounting and strategic management accounting (including the field of competitor accounting/analysis) at a consolidated level. Therefore, the aim of my literature review is to scrutinize the areas of management accounting/SMA with emphasis on literature dealing with these subjects at a consolidated level. This constitutes the core areas of my literature review.

Upon connecting the study's background with the aim of the literature review, I will now strive to conjoin this with the research questions and objectives.

Research Question 1 relates to the information needed in order to use competitor accounting for building a strategic model of competition. The resulting research objective zooms in on evaluating the relevant literature and information available in the area of SMA. This confirms the conclusion derived from the studies placement that the literature in the area of SMA/competitor accounting/analysis has to be a central point of my literature review.

My second research question concentrates on the possibility of using management accounting data and techniques for developing informed assumptions regarding competitors' performance. This leads to the research objective of critically evaluating the performance relevant information available in management accounting to assist with competitor accounting in the focus company. In order to achieve this research objective, the management accounting literature has to be scrutinized specially to identify contributions relating to performance-relevance which is also in line with the implication made in the study's placement. This also relates to the literature in the fields of SMA/competitor accounting/analysis. 
The last research question refers to producing competitive advantage through using the strategic model which is going to be elaborated in this project. Consequently, the literature in the area of competitive advantage has to be scrutinized, which I will treat as an additional aspect within the literature review in the area of competitor accounting/advantage.

Given the study's perspective along with its research questions and objectives the resulting core areas for my literature review are management accounting/consolidated cost accounting and SMA including competitor accounting/analysis.

In this section, I attempted to derive the core areas for my Literature Review from the placement of my project and the direction of research questions and objectives as well as with the research aim.

In order to ensure that the application area of globalization is of interest for international business literature I will focus on this in the following section.

\subsection{Impact of globalization on international business literature}

The dominant role of MNCs in the context of globalization has been described in the introductory section. The importance of globally acting industrial organizations in the context of globalization has already been emphasized (WTO, 2013). In addition, the organizational aspect has been underlined, for example, by Blödorn (1998a).

Fetscherin, Voss, and Gugler (2010) did an interdisciplinary literature review relating to three decades of FDIs in China. The authors (2010) identified that the domains of 'Economics', 'Business and Management', 'Planning and Development' and 'International Relations' account for $95 \%$ of the publications scrutinized. In addition, Fetscherin et al. (2010) state that major research streams relate to MNCs, for example, the internal perspective of MNCs doing FDIs in China.

Pillania and Fetscherin (2009) focused their literature on the BRIC countries covering the decades from 1968 to 2008 and identified 'management', 'business' and 'economics' as the dominant themes representing $70 \%$ of the articles examined. The authors ascertain a marked increase of publications in this area in general and conclude that the theme 'Emerging Markets' in conjunction with 'MNCs' has acquired increasing consideration in literature, especially since 2000 (Pillania \& Fetscherin, 2009).

In the light of increasing internationalization, new academic approaches, namely International Management (IM) and International Business (IB), have been initiated involving collaboration with practitioners (Oesterle \& Wolf, 2011). Regarding the basic orientation of 
IM/IB Oesterle and Wolf (2011) see 'Business Administration' as the fundament of IM/IB and emphasize that qualitative research methods are granted to have a prominent meaning in this academic discipline (Oesterle \& Wolf, 2011). However, the authors admit that an interdisciplinary collaboration between the subfields of business administration, like for example, marketing or the finance area and IM/IB is problematic.

Another area that appears to be relevant in international business literature is the field of research methods and in particular the application of case studies (Bon \& Kee, 2015; Frost, Vogel, \& Bagban, 2016; Jell-Ojobor \& Windsperger, 2017; Pawel, 2017; Poulis, Poulis, \& Plakoyiannaki, 2013; Spigarelli, Alon, \& Mucelli, 2015).

Babińska (2013), in her literature review, concentrates on the function of knowledge in the context of a company's development in the course of the process of internationalization.

Contributions in international Business Literature which are not directly related to my research aim are those concerning the social responsibility of MNCs in the countries where their subsidiaries are located (Mella \& Gazzola, 2018), research referring to expatriates (Bader, Berg, \& Holtbrügge, 2015; Haile \& Williams, 2011; Kupka, Everett, \& Cathro, 2008; Lee, Chua, Miska, \& Stahl, 2017) and the area of R\&D activities (Davis \& Meyer, 2004; Gorecki, 1976; Luostarinen \& Gabrielsson, 2006; Y. Yang, 2015).

In this section, I have illuminated the impact of globalization on the international business literature. It can be concluded that there is brisk interest on the theme of globalization in international business literature which is also documented in the generally increasing number of publications, especially since the mid-1990s (Fetscherin et al., 2010; Pillania \& Fetscherin, 2009). It became obvious that a significant share of the publications scrutinized deal with the themes 'economics' and 'business and management'. In addition, emerging markets especially in the BRIC countries along with contributions to the field of MNCs have been key aspects in international business literature. Besides the role that quantitative research methods play in particular (Poulis et al., 2013), it can also be observed that the development of knowledge in organizations in the course of the internationalization process is an important element in international business literature (Babińska, 2013).

The alignment of the study's literature review with its constitutional avenue leads to its systematic approach.

Based on the research objectives and the aim of this project the literature to be reviewed has to span more than one subject area. Key literature is in the areas of consolidated cost 
accounting, management accounting and strategic management accounting (SMA/competitor accounting/analysis).

Given the evolution of globalization in relation to consolidated cost accounting and management accounting it appears reasonable to analyse the development of the requirements towards group accounting after World War II because of the recommencement of world economy since then. Regarding the aspect of competition in relation to the development of group accounting, the benefit for studying rivals in the market needs to be illuminated. In particular the evolved management accounting tools and techniques form a core area of interest for the literature review.

This work mainly uses the resources provided by the University of Gloucestershire and provided links to databases, for example, 'German thesis' which directs to the database of 'Deutsche Nationalbibliothek' (German National Library).

The following sections are structured according to the subject areas identified as relevant for this research.

\subsection{German cost accounting and Anglo-Saxon management accounting}

Prior to elaborating on the literature review in the fields of German Cost Accounting and Anglo-Saxon management accounting, the different historical background of German and Anglo-Saxon (in particular the U. K.) accounting systems needs to be illuminated in order to understand the differences.

According to Luther et al. (2010), European management accounting comparative studies primarily focus on observing similarities or differences between the management accounting literature and practice between two countries. According to the authors, existing studies which attempted to conduct comparisons on a larger European-wide scale lacked, for example, an empirical basis. Comparing Germany and the UK, Ahrens and Chapman (1999, 2000) emphasize the dominant role of German academics for evolving the current state of research in Germany juxtaposed with the UK.

The traditionally strong German industrial sector forms the background of the differentiation between cost accounting and financial accounting (Luther et al., 2010). German authors (for example, Ossadnik, 2008; Varnholt, Lebefromm, \& Hoberg, 2009) define as a primary aim of cost accounting the documentation of the costs of the internal business process along with reporting the information in a structured way to internal addressees. The authors see as addressees of information provided by Financial Accounting primarily the relationships between the organization and its external environment, especially customers and vendors. 
Looking onto this phenomenon from the UK perspective, Luther et al. (2010, p. 17) put it like this:

"The heritage of this is a German approach that insists that cost accounting and financial accounting should be separate: one dealing with costs and benefits, the other with transactionbased payments and receipts. The distinctive feature of German financial accounting is its shaping by capital maintenance and tax requirements (Haller \& Eierle, 2004; Leuz \& Verrecha, 2000); that of German management accounting by its deployment of 'contribution costing' and 'flexible standard costing' (Kilger, 1990; Schildbach, 1997)".

German authors (for example, Varnholt et al., 2009) as well as UK authors (for example, Luther et al., 2010) see as the connecting element between these two concepts (German 'Cost Accounting' and UK 'Management Accounting') the aim to produce decision relevant information for management. However, Kajüter and Schröder (2014) confirm that subsidiaries in Anglophone groups plan and monitor their consumption of resources more approximately compared to German companies.

Ewert and Wagenhofer (2007) analysed the differences between 'German controlling' and 'Anglo-Saxon management accounting' by comparing the different foci of German and US firms at the level of function (Figure 3 on page 18). Where management accountants in the US have financial accounting as their core area, their German colleagues center on budgeting. However, 'management reporting' represents a common centre of gravity. This positions management accountants as 'business partners' (Coad, 1999) of management. 
Figure 3: Comparison of the foci of the function of Control in German and US firms according to Ewert and Wagenhofer (2007, p. 1037)

\begin{tabular}{|l|r|r|}
\hline \multicolumn{1}{|c|}{ Function } & German firms (\%) & US firms (\%) \\
\hline Budgeting & $97 \%$ & $89 \%$ \\
\hline Operative planning & $80 \%$ & $34 \%$ \\
\hline Strategic planning & $36 \%$ & $23 \%$ \\
\hline Management reporting & $90 \%$ & $86 \%$ \\
\hline Capital budgeting & $70 \%$ & $34 \%$ \\
\hline Cost accounting & $65 \%$ & $91 \%$ \\
\hline Financial accounting & $21 \%$ & $97 \%$ \\
\hline Financial planning & $25 \%$ & $57 \%$ \\
\hline Financial reporting & $30 \%$ & $63 \%$ \\
\hline Tax planning & $12 \%$ & $57 \%$ \\
\hline
\end{tabular}

Despite the different background of German 'controlling' and UK 'management accounting', the terms are used identically, especially by practitioners (Luther et al., 2010). German 'controlling' is closely related to cost accounting. Due to the internationality of this project, the literature to be reviewed has to consider the consolidated (group) level. Therefore, the Literature Review will focus on the fields of consolidated cost accounting (German perspective) and management accounting (UK view) in order to cover the field of accounting.

\subsection{Consolidated cost accounting}

\subsubsection{Essential publications}

The subject area of 'Konzernkostenrechnung' (= consolidated cost accounting) is coined by the publications of Franz and Hieronimus (2003) and Dusemond (1994) who relate in their work to Rein (1993).

The work by Franz and Hieronimus (2003, "Kostenrechnung im international vernetzten Konzern", Translaton: "Cost accounting in internationally networked groups") contains six articles which are all relevant for this review. These articles contain further references which help to understand the development of group cost accounting. 
The doctoral dissertation of Dusemond (1994) takes an essential role in that area in German literature and will be discussed later on in more detail.

In the following I will attempt to portray the most notable contributions focusing on major steps of the development of the subject over the decades after World War II.

\subsubsection{Development from evaluation of inventory to management accounting}

The special edition of Schmalenbach Society (Franz \& Hieronimus, 2003) contains one contribution dealing with the status of the research in the field of group cost accounting (Kajüter, 2003; “Theoretische Grundlagen der Kostenrechnung im Konzern” which can be translated into English as "Theoretical Foundations of Cost Accounting on Group level"). I will use this article as a basis to scrutinize the different evolutional milestones of this field and go into the literature cited in order to touch the ground of the leading literature published in this field.

Before starting to review the literature in this area, the term 'Kostenrechnung' (= cost accounting) needs to be described. As already explained by Luther et al. (2010) German accounting differentiates between internal (cost) and external (financial) accounting. According to Franz (2003), internal accounting consists of 'Erlösrechnung' (no official translation available, a reasonable translation in this context would be 'revenue accounting/calculation') and 'Erfolgsrechnung' (reasonable translation would come close to 'earnings statement'). The terms 'Erfolgsrechnung' and 'Ergebnisrechnung' are used identically, especially by practitioners used (Franz, 2003). This vocabulary appears to be close to the respective UK management accounting terminology and is the result of the development in recent decades (Luther et al., 2010, p. 96 “...times are changing and the Controllers...were keenly aware of this").

According to Kajüter (2003), the number of publications for group cost accounting is low compared to what has been published for the Cost Accounting of single entities.

Kajüter (2003) identifies Marchand (1949) as the first author in the field of group cost accounting. Status at that time was that a consolidated balance sheet and P\&L statement could be prepared (Marchand, 1949). He (Marchand, 1949) sees the tasks of group cost accounting as follows:

- Supervision of cost-effectiveness by means of comparison actual versus budgeted cost

- Reporting of the operating result by product lines on Group level in order to make the sources of the operating result transparent. 
Marchand (1949) does not see the necessity to do preliminary or actual calculation at a group level for the purpose of pricing because from his point of view the calculation of the single business operation is sufficient for that.

Furthermore, the author differentiates between horizontal and vertical flow of production within the group in order to demonstrate the complexity of consolidation requirements in this context. In addition, the author also shows how to handle intercompany sales and, along with that, the problem of missing computation of primary cost. Marchand (1949) provides a complete numerical example of the cost distribution sheet of three single entities and the respective consolidated cost distribution sheet.

Koberstein (1949) describes in the group cost accounting section the questions that are related to transfer prices between group entities. The author does not present a precise form of how the group cost accounting could be organized.

According to Kajüter (2003) the literature published after Marchand (1949) and Koberstein (1949) can be differentiated from those coming from the external (financial) accounting demanding a group cost accounting merely for the purpose of evaluating inventory and those coming from the management accounting perspective focusing on information necessary to control the organization.

According to Kajüter (2003) the articles focusing on evaluating inventory were motivated by German legislation which defined respective rules and regulations for the first time in 1965 . The author states that due to the implementation of European Community Directives into German legislation the question of evaluation of inventories became relevant again in 1990 . Kajüter (2003) sees the identification of an appropriate approach to evaluating inventory as the subject of the thesis of Dusemond (1994) who states that the management of a single legal entity has all the information that a cost accounting system can provide available but the management at a group level does not have consolidated cost accounting information available. Dusemond (1994) recognizes the following key aspects as the tasks of an independent group cost accounting:

- Cost Control within the entire Group,

- Perception of planning and decisive (dispositive) tasks within the Group,

- Documentation with focus evaluation of inventory.

Dusemond (1994) suggests to capture the transactions between the entities of a group and reporting them to one consolidation department. He proposes a concrete form which should 
be filled out and signed by both the entity delivering performance and the entity consuming the delivered performance. By defining the above mentioned tasks, Dusemond (1994) is clearly going beyond the approach of Marchand (1949), of just doing supervision of cost at the group level. Even though Dusemond's (1994) work is basically assigned to the area of literature primarily focusing on the question of evaluation inventories, it also has a close relation to group cost accounting/management accounting. In the section of his dissertation regarding 'Basic thoughts for an independent group cost accounting' (Dusemond, 1994, p. 477 et seq.) he is referencing in footnote 65 on page 487 to Rein (1993) who has clear preference for the area of management accounting. The work of Rein (1993) will be reviewed later.

The literature published from the mid-seventies is mainly coming from the management accounting perspective. These articles are based on simplifying assumptions (for example, disregarding the change of finished- and semi-finished goods when eliminating intercompany profits \& losses) and by deriving group cost accounting from the single entities cost accounting systems in order to reduce the complexity of consolidation and hence come to a lean solution (Kajüter, 2003).

Rein (1993) develops in his thesis the build-up of an independent group cost accounting system. The core of Reins' (1993) work is focusing on the consolidation of cost accounting of the single entities. The author develops five models taking the perspectives of the single entities and group. Rein (1993) starts with model 1 which shows how to handle costs which are from the perspective of the single entity direct cost and from the point of view of the group overhead cost. In model 2 the author describes the case of direct costs from the single entity's perspective that remain also direct cost on group level. Model 3 amplifies the approach by considering the case that the delivering single entity has external (third party) sales as well. Model 4 considers the case of having intercompany transaction between consolidated entities in both directions. Eventually model 5 expands the system on more than two consolidated entities. Based on this Rein (1993), then demonstrates the application of the data of the consolidated marginal accounting in the context of production planning.

The realization of a Consolidated Marginal Accounting system as developed by Rein (1993) necessitates the standardization of single entity cost accounting systems. Wullenkord (1995) makes precise suggestions, for example, regarding standard cost account lists, cost Centres and calculation procedures. Concerning the intercompany relationships to be reflected within a Group Accounting system, Wullenkord (1995) sees three different alternatives (additive 
method, primary cost accounting, consolidation). Assessing these options, the author concludes that the additive method is too restrictive and primary cost accounting too work intensive and time consuming. Hence a Group Accounting System should be established as an integrated system. In this context, Wullenkord (1995) references on page 229 in footnote 74 to Rein (1993) and his demonstration of a consolidated group cost accounting system. Müller (2000) describes the requirements of a consolidated cost accounting system without adding anything new to Rein (1993).

\subsubsection{Contributions from practice to Consolidated Cost Accounting}

In particular, practitioners are stating that there is a gap between the importance in business and needed, but not yet available solutions (Franz \& Hieronimus, 2003). Kajüter (2003) mentions reports coming from practitioners (for example, Bierich, 1990; Kleber, 1993; Nuppeney, 2002; Schnell, 1989) and ascertains, that these systems are derived from the Cost Accounting Systems of the single entities of the Group. This literature review identified no new system (only systems that apply the existing system, for example, Veil \& Hess, 2000).

\subsubsection{IFRS Management Approach}

The literature for this academic field is partly contained in the academic fields for cost or financial accounting as well as in typical IFRS literature, mainly due to the IFRS segmentreporting. Only a few sources could be identified with no relevance for this project.

Looking into the German literature, it becomes obvious that in the light of the development of implementation of IFRS regulations a process of convergence of cost accounting and financial accounting could be observed to a certain extent (Schaier, 2007). Beißel and Steinke (2004) published an article about an integrated reporting under IFRS at Lufthansa which attracted lot of attention from experts. In their article the authors demonstrate by example how to build up a common database of the internal (management accounting) and external (financial accounting) accounting at the Group level following the target of increasing the transparency and acceptance of the financial statement and reports within the organization. According to Beißel and Steinke (2004) the internally reported operating result (management accounting) is identical to what has been reported to the external capital market beginning with the fiscal year 2004. In addition, the authors state that the operating result is published by segment.

Schöb (2008a, 2008b, 2009) states in his works that the requirements that internal reporting (management accounting) has to meet increased due to the International Financial Reporting System (IFRS) reporting by segment. According to his point of view, a reporting of a single 
segment's result would not be possible without the support of the internal reporting. Schöb (2008a) points out the necessity of having standardized structures (for example, cost Centres) in the group's single entities. Based on that, Schöb (2008a) demonstrates a practical example of how the data for segment reporting can be generated by using the standardized structures within the group. Schöb (2009) then develops his work to a Segment Reporting by defining a reporting matrix. In another article the author (Schöb, 2008b) specifies this in the environment of SAP - Business and Consolidation System (BCS).

The increased transparency caused by the IFRS segment reporting is encompassed on purpose in order to ensure neutrality in terms of the effect on competition (Coenenberg, 2005). Practitioners look at this very critically. Pötsch (2008) alerts us to the fact that, the convergence of both internal and external accounting reporting systems are touching boundaries as regards competition sensitive data and hence the company should not publish this data in its own interest. From that restrained argumentation regarding publishing competition sensitive data due to IFRS segment reporting requirements, it can be concluded conversely that the IFRS segment reporting can deliver very good information for competition analysis.

\subsection{UK management accounting}

\subsubsection{UK management accounting and consolidated cost accounting}

The literature discussed so far had a German perspective. In the following I will attempt to take the UK perspective in order to identify the management accounting - Literature that would be the equivalent to the German consolidated Cost Accounting literature.

All sources recognized are articles; a doctoral thesis could not be identified. The management accounting literature in this area draws a heterogenous picture. In order to get an overview of the core areas, I will briefly summarize their contents in the following.

Soo Young and Chang Joon (1996) discuss controversies regarding accounting standards. Three articles (Abad et al., 2000; Kaye, 2004; H. Ward \& Callaway, 2004) also deal with specific questions in the area of consolidation. The works of Dominica Suk-yee (2005) and Meyssonnier and Pourtier (2013) focus on questions of consolidation in the context of acquisitions. Busco, Frigo, Giovannoni, Riccaboni, and Scapens (2006) focus on the examples of General Electric and Nestle Waters to analyse how concepts of performance measurement can be useful in harmonizing different cultures within their international organizations. The newest source that I was able to identify (Gardini \& Grossi, 2014) 
describes the application of consolidated financial statements in governmental organizations in Italy.

Scrutinizing which of the articles described briefly above can be aligned with my research objectives leads me to the conclusion that only the contribution of Busco et al. (2006) is close to my area of research. Busco et al. (2006) describe how GE and Nestlé integrated acquisitions in their international organizations. In the case of GE, the integration of a newly acquired Italian manufacturing company is described. In essence Busco et al. (2006, p. 33) emphasize the importance of a consistent performance measurement "... alignment within the company as the entire managerial structure...". In the case of Nestlé, the value of stable and compatible budgeting processes for the entire global organization is stressed. My second research objective (critical evaluation of the performance relevant information available in management accounting to assist with competitor accounting in the focus company) emphasizes the element 'performance relevant information'. In addition, my research has an international alignment. Both, the performance orientation of my second research objective and the international arrangement of my project correspond to the direction of the article of Busco et al. (2006).

Although Anglophone literature regarding management accounting at the group level is very rare in the given context, it is fruitful to look into the development of this subject because of my research objectives. Management accounting is of fundamental importance for SMA. This relates to research objectives one (evaluation of the relevant literature and information available in the area of SMA) and three (analysis of how a strategic model of competitor accounting can provide competitive advantage). In addition, the increasing performance orientation of management accounting literature (Chapman, Hopwood, \& Shields, 2007) is in line with research objective 2. Therefore, I will seek to elaborate on the English language management accounting literature in view of my research objectives in the following.

\subsubsection{Evolution and trends}

This section will start with a portrayal of the general development of the subject along with a description of specific techniques developed over recent decades.

According to Chapman, Hopwood, and Michael (2006) the term "management accounting" appeared in the 1930s in the USA emerging from existing practices. The authors identify research-orientated contributions in management accounting in Central Europe in 1960s and see the comprehension of the build-up of cost accounting systems and their operation in different frameworks and settings as a core area. 
Hesford, Lee, Van der Stede, and Young (2006) analysed the thematic emphases of 10 leading English-language journals in the field of accounting in the period from 1981 to 2000. In order to recognize changes of the thematic emphases over time, the authors split the period into two decades (Figure 4).

Figure 4: Management Accounting Research Topics adopted from Hesford et al. (2006, p. 8) and extended

\begin{tabular}{|c|c|c|c|c|c|c|c|c|}
\hline \multirow[t]{2}{*}{ Research topic } & \multicolumn{2}{|c|}{$\begin{array}{r}\text { Total Period } \\
1981-2000\end{array}$} & \multicolumn{2}{|c|}{$\begin{array}{c}\text { 1st Decade } \\
1981-1990\end{array}$} & \multicolumn{2}{|c|}{$\begin{array}{l}\text { 2nd Decade } \\
1991-2000\end{array}$} & \multicolumn{2}{|c|}{$\begin{array}{c}\text { Change } \\
\text { 2nd versus 1st Decade }\end{array}$} \\
\hline & Articles & $\%$ - Share & Articles & $\%$ - Share & Articles & $\%$ - Share & Articles & $\%$ \\
\hline \multicolumn{9}{|l|}{ Cost } \\
\hline Cost allocation & 140 & $15.3 \%$ & 36 & $11.3 \%$ & 104 & $17.4 \%$ & 68 & $188.9 \%$ \\
\hline Other cost accounting topics & 21 & $2.3 \%$ & 14 & $4.4 \%$ & 7 & $1.2 \%$ & -7 & $50.0 \%$ \\
\hline Cost practices & 15 & $1.6 \%$ & 4 & $1.3 \%$ & 11 & $1.8 \%$ & 7 & $175.0 \%$ \\
\hline Multiple & 1 & $0.1 \%$ & 0 & $0,0 \%$ & 1 & $0.2 \%$ & & alculated \\
\hline Sub-total Cost & 177 & $19.3 \%$ & 54 & $16.9 \%$ & 123 & $20.6 \%$ & 69 & $127.8 \%$ \\
\hline \multicolumn{9}{|l|}{ Control } \\
\hline Budgeting & 134 & $14.6 \%$ & 64 & $20 \%$ & 70 & $11.7 \%$ & 6 & $9.4 \%$ \\
\hline Capital budgeting & 47 & $5.1 \%$ & 14 & $4.4 \%$ & 33 & $5.5 \%$ & 19 & $135.7 \%$ \\
\hline Performance measurement and evaluation & 148 & $16.2 \%$ & 35 & $10.9 \%$ & 113 & $19 \%$ & 78 & $222.9 \%$ \\
\hline Organizational control & 296 & $32.3 \%$ & 119 & $37.2 \%$ & 177 & $29.7 \%$ & 58 & $48.7 \%$ \\
\hline International control & 16 & $1.7 \%$ & 4 & $1.3 \%$ & 12 & $2.0 \%$ & 8 & $2.0 \%$ \\
\hline Multiple & 3 & $0.3 \%$ & 1 & $0.3 \%$ & 2 & $0.3 \%$ & 1 & $100.0 \%$ \\
\hline Sub-total Control & 644 & $70.3 \%$ & 237 & $74.1 \%$ & 407 & $68.3 \%$ & 170 & $71.7 \%$ \\
\hline \multicolumn{9}{|l|}{ Other } \\
\hline AIS & 7 & $0.8 \%$ & 4 & $1.3 \%$ & 3 & $0.5 \%$ & -1 & $-25 \%$ \\
\hline Benchmarking & 2 & $0.2 \%$ & 0 & $0 \%$ & 2 & $0.3 \%$ & & alculated \\
\hline Quality (TQM) & 9 & $1 \%$ & 0 & $0 \%$ & 9 & $1.5 \%$ & & alculated \\
\hline Just-in-time (JIT) & 7 & $0.8 \%$ & 0 & $0 \%$ & 7 & $1.2 \%$ & & alculated \\
\hline Research methods & 20 & $2.2 \%$ & 6 & $1.9 \%$ & 14 & $2.3 \%$ & 8 & $133.3 \%$ \\
\hline Strategic management & 15 & $1.6 \%$ & 7 & $2.2 \%$ & 8 & $1.3 \%$ & 1 & $14.3 \%$ \\
\hline Transfer pricing & 31 & $3.4 \%$ & 9 & $2.8 \%$ & 22 & $3.7 \%$ & 13 & $144.4 \%$ \\
\hline Multiple & 4 & $0.4 \%$ & 3 & $0.9 \%$ & 1 & $0.2 \%$ & -2 & $-66.7 \%$ \\
\hline Sub-total Other & 95 & $10.4 \%$ & 29 & $9.1 \%$ & 66 & $11.1 \%$ & 37 & $127.6 \%$ \\
\hline Total & 916 & $100.0 \%$ & 320 & $100.0 \%$ & 596 & $100.0 \%$ & 276 & $86.3 \%$ \\
\hline
\end{tabular}

The authors differentiate between the themes/research topics 'Cost', 'Control' and 'Other'. These themes are differentiated in further sub-categories.

Figure 4 stresses the following focal points:

- The total number of articles in the areas observed increased by $276(+86.3 \%)$. This increase was dominated by the field of 'Control' accounting for more than sixty percent of this increase.

- The biggest area in this illustration (Figure 4) is 'Control' representing a share of more than two-third in both decades.

- Within 'Control' the sub-categories 'Performance measurement and evaluation' (+78 articles and $+222.9 \%)$ and 'Organizational control' (+58 articles and $+48.7 \%)$ are the areas of major interest. 
- The themes 'International control' (sub-category of 'Control', increasing from 4 to 12 articles) and 'Transfer pricing' (sub-category 'Other', increasing from 9 to 22 articles) coincide with the increasing globalization of business in general as described in the introductory section.

- The development of the research topic 'Cost' is in essence represented by its subcategory 'Cost allocation'.

Lorenz (2015) refers to Johnson and Kaplan (1987) when describing that since the end of the 1980s management accounting has been confronted with the criticism that the information provided by management accounting does not support management sufficiently in decisionmaking. In addition, Lorenz (2015) relates to Kaplan (1983, 1984a, 1984b, 1986, 1990) when identifying the following central reasons for this development:

- Decision-making

Due to its financial accounting orientation, the aspect of providing information for decision-making for management had been neglected.

- Advances in manufacturing technology

Management accounting did not align with the progress made in manufacturing technology and had been outdistanced from the respective progress made in that area.

- Including study of practice

“...accounting research being conducted did not include study of practice and accounting academics had lost sight of what was happening in real organisations." (Lorenz, 2015, p. 1)

- Development beyond effective cost management

No further development of management accounting beyond its traditional emphasis on cost management.

According to Nixon and Burns (2005), the 1990s saw a change of the role of management accountants in their organizations due to the pressure caused by increasing competition, especially due to increasing globalization. Burns and Vaivio (2001) relate to Coad (1999) when observing a change of the role of management accountants from a mere focus on reporting numbers/figures to a more business-orientated specialist and partner of management. The authors (Burns \& Vaivio, 2001) underline the trend of involving management accountants in questions that relate to other domains and highlight in this context information technology and strategy. 
Clinton and White (2012) analysed in their work the status of the appreciation of the role of management accountants during the period 2003 to 2012. In view of my research objectives, the authors identify the following incidents as formative for the development of management accounting practice:

- Globalization

Clinton and White (2012) describe the evolution of the perspective of International Financial Reporting Standards (IFRS) as more globally orientated.

The professional accounting bodies of the Chartered Institute of Management Accountants (CIMA) and the American Institute of Certified Public Accountants (AICPA) established a common organization (Chartered Global Management Accountants, CGMA) in order to accommodate the development of increasing internationalization of business.

- Economic development

Continuing emphasis on cost control due to the aftermath of the subprime mortgage crisis in the USA and increased international competition due to the fact that emerging nations like China and India now have leading positions in the world economy (Clinton \& White, 2012).

Regarding thematic core areas in this period in management accounting practice, the authors (Clinton \& White, 2012, p. 42) identify consequently “...cost reduction and efficiency improvements..." in the area of accounting/finance. With respect to IT tools (for example, Business Intelligence) improvements in view of applicability have been of major concern (Clinton \& White, 2012).

In the following, I seek to align the central aspect of 'Performance measurement and evaluation' with my project. Research question 2 relates to the use 'management accounting data/techniques' in order to generate informed assumptions regarding competitor performance'. Therefore, I will now describe the techniques explained in the management accounting literature in relation to the model of the major competitor of the focus company.

Due to the focus of this project on producing information regarding the major competitor's performance in the markets by product line, the attention of the literature review is on margin accounting primarily. Therefore, the contributions concentrating on activity-based costing $(\mathrm{ABC})$ are not going to be reviewed in more detail (for example, Abdel-Kader, 2011; Innes \& Kouhy, 2011). Furthermore, sources which are too specialized are not close enough to the 
approach of my project will not be reviewed, for example, the contribution of Tollington and Pilla (2011) regarding throughput accounting which focuses on optimizing the speed of the flow of an order through production.

According to Kim and Berry (2011) there are numerous definitions of target costing which do not contradict each other. Major elements of these definitions are that the complete value chain is subject to analysis, the involvement of all departments who can contribute with their knowledge and the aim, to achieve a competitive cost level (this brief outline of target costing is based on: Kim \& Berry, 2011). With regard to my project (in particular Research Question 2) the element of considering value chains can be linked to the model of the major competitor. In particular, when considering the differentiation of the functions of production, international sales/service steering and international sales/service at a group level (see Figure 17) considering value chains is beneficial for this project.

Laitinen (2011) relates Pricing decisions to the level of demand in that a low product price is assumed to lead to a high demand and conversely a high price to a low demand. This has to be seen in the context of the firm's cost structure and -level because of the resulting cost coverage. Regarding the time horizon of a pricing decision the author differentiates the cases of long-term, intermediate-term and short-term pricing decisions. Long-term pricing decisions involve strategic aspects of the organization. In this case a low price can be justified if this decision, for example, helps in 'buying' the entry into a market of strategic relevance. The second category (intermediate-term) follows “...tactical decision making...” whereas short-term pricing decisions fall into the category of "...operational decision making..." (Laitinen, 2011, pp. 311-312). It is common practice that the level of pricing decisions is related to the organizational hierarchy level, for example, top management makes strategic pricing decisions (explanations are based on: Laitinen, 2011). With reference to my project the component of pricing is mentioned very often in the textual data used in this project. Due to its close relation to the major competitor's sales, this aspect is performance relevant (RO2). Figure 55 and Figure 56 illustrate how textual data is integrated in the process of developing reasonable sales figures for the major competitor at the product line level.

Nixon and Burns (2005, p. 262) stress the increasingly close connection in literature between “...management control and performance management and measurement". In this context, the authors link this field of activity to the term strategy. In particular, Nixon and Burns (2005) see in this relation tools like, for example, balanced scorecard which assists managers 
to monitor crucial strategic topics. The element of emphasizing the strategic view builds a bridge to strategic management accounting (SMA).

In the following I seek to elaborate on the topics which appear to be reasonable to use to scrutinize the literature in SMA.

\subsection{Strategic management accounting (SMA)}

\subsubsection{Trends identified}

The overview of the SMA-literature published in a special edition of the Journal of Controlling \& Management (Günther \& Breiter, 2007: Strategisches Controlling State of the Art und Entwicklungstrends; translation: strategic management accounting state of the art and trends in development).

Günther and Breiter (2007) relate to Grant (2002) when systemizing the development of the SMA-literature (Figure 5). This overview illustrates the foci of SMA literature over time, differentiating between the categories 'Dominant Theme', 'Main Issues', 'Principal Concepts and Techniques' and 'Organizational Implications'. Looking into this overview (Figure 5 on page 30) in relation to my research objectives, the terms 'competitive advantage' (Research Objective 3) and 'strategic innovation' (Research Objective 1) are of major importance. It becomes obvious that these issues appeared in the literature as 'Dominant Theme' or 'Main Issue' for the first time at the end of the eighties and the beginning of the nineties. Comparing that to the strand 'group cost accounting' of this literature review it can be observed, that according to Kajüter (2003) literature in that area started some thirty years earlier (with Koberstein, 1949; Marchand, 1949) and has developed since then. 
Figure 5: The development of SMA according to Grant (2002, p. 22) adopted from Günther and Breiter $(2007$, p. 9)

\begin{tabular}{|c|c|c|c|c|c|c|}
\hline PERIOD & $1950 \mathrm{~s}$ & $1960 \mathrm{~s}$ & $\begin{array}{c}\text { EARLY-MID } \\
\text { 1970s }\end{array}$ & \begin{tabular}{|c|} 
LATE 1970s \\
AND \\
EARLY \\
1980s \\
\end{tabular} & \begin{tabular}{|c} 
LATE 1980s \\
AND \\
EARLY \\
1990s \\
\end{tabular} & $\begin{array}{c}\text { LATE 1990s } \\
\text { AND EARLY } \\
2000 \mathrm{~s}\end{array}$ \\
\hline $\begin{array}{l}\text { Dominant } \\
\text { Theme }\end{array}$ & $\begin{array}{l}\text { Budgetary } \\
\text { planning and } \\
\text { control }\end{array}$ & $\begin{array}{l}\text { Corporate } \\
\text { planning }\end{array}$ & $\begin{array}{l}\text { Corporate } \\
\text { strategy }\end{array}$ & $\begin{array}{l}\text { Analysis of } \\
\text { industry and } \\
\text { competition }\end{array}$ & $\begin{array}{l}\text { The quest for } \\
\text { competitive } \\
\text { advantage }\end{array}$ & $\begin{array}{l}\text { Strategice inno- } \\
\text { vation and the } \\
\text { new economy }\end{array}$ \\
\hline \multirow{3}{*}{ Main Issues } & \multirow[t]{3}{*}{$\begin{array}{l}\text { Financial } \\
\text { control through } \\
\text { operational } \\
\text { and capital } \\
\text { budgeting }\end{array}$} & \multirow[t]{3}{*}{$\begin{array}{l}\text { Planning } \\
\text { growth }\end{array}$} & \multirow[t]{3}{*}{$\begin{array}{l}\text { Diversification } \\
\text { and portfolio } \\
\text { planning }\end{array}$} & \multirow[t]{3}{*}{$\begin{array}{l}\text { Choice of } \\
\text { industries, } \\
\text { markets, and } \\
\text { segments, and } \\
\text { positioning } \\
\text { within them }\end{array}$} & \multirow[t]{3}{*}{$\begin{array}{l}\text { Sources of } \\
\text { competitive } \\
\text { advantage } \\
\text { within the firm }\end{array}$} & $\begin{array}{l}\text { Competitive } \\
\text { advantage } \\
\text { through } \\
\text { innovation }\end{array}$ \\
\hline & & & & & & $\begin{array}{l}\text { Competing on } \\
\text { knowledge }\end{array}$ \\
\hline & & & & & & $\begin{array}{l}\text { Adapting to the } \\
\text { new, digital, net- } \\
\text { worked } \\
\text { economy }\end{array}$ \\
\hline \multirow{4}{*}{$\begin{array}{l}\text { Principal } \\
\text { Concepts } \\
\text { and Tech- } \\
\text { niques }\end{array}$} & $\begin{array}{l}\text { Financial } \\
\text { budgeting }\end{array}$ & \begin{tabular}{|l} 
Business \\
forecasting
\end{tabular} & Synergy & \begin{tabular}{|l} 
Experience \\
curve and \\
returns to the \\
market share \\
\end{tabular} & $\begin{array}{l}\text { Resource } \\
\text { analysis }\end{array}$ & $\begin{array}{l}\text { Organizational } \\
\text { flexibility and } \\
\text { speed of } \\
\text { response } \\
\end{array}$ \\
\hline & $\begin{array}{l}\text { Investment } \\
\text { planning }\end{array}$ & \multirow{3}{*}{$\begin{array}{l}\text { Investment } \\
\text { planning } \\
\text { models }\end{array}$} & $\begin{array}{l}\text { Strategic } \\
\text { business units }\end{array}$ & $\begin{array}{l}\text { Analysis of } \\
\text { industry } \\
\text { structure }\end{array}$ & \multirow{3}{*}{$\begin{array}{l}\text { Analysis of } \\
\text { core compe- } \\
\text { tencies }\end{array}$} & $\begin{array}{l}\text { Knowledge } \\
\text { management } \\
\text { and } \\
\text { organizational } \\
\text { learning } \\
\end{array}$ \\
\hline & \multirow{2}{*}{$\begin{array}{l}\text { Project } \\
\text { appraisal }\end{array}$} & & \multirow{2}{*}{$\begin{array}{l}\text { Portfolio plan- } \\
\text { matrices }\end{array}$} & $\begin{array}{l}\text { Competitor } \\
\text { analysis }\end{array}$ & & \begin{tabular}{|l} 
Competing for \\
standards
\end{tabular} \\
\hline & & & & $\begin{array}{l}\text { PIMPS } \\
\text { analysis }\end{array}$ & & $\begin{array}{l}\text { Early-mover } \\
\text { advantage }\end{array}$ \\
\hline \multirow{4}{*}{$\begin{array}{l}\text { Organiza- } \\
\text { tional } \\
\text { Implications }\end{array}$} & \multirow[t]{4}{*}{$\begin{array}{l}\text { Financial ma- } \\
\text { nagement the } \\
\text { key }\end{array}$} & \multirow[t]{4}{*}{$\begin{array}{l}\text { Rise of corpo- } \\
\text { rate planning } \\
\text { departments } \\
\text { and medium- } \\
\text { term planning }\end{array}$} & $\begin{array}{l}\text { Diversification } \\
\text { Multidivisional } \\
\text { structures }\end{array}$ & $\begin{array}{l}\text { Greater } \\
\text { industry and } \\
\text { market } \\
\text { selectivity }\end{array}$ & $\begin{array}{l}\text { Corporate } \\
\text { restructuring } \\
\text { and business } \\
\text { process }\end{array}$ & $\begin{array}{l}\text { The virtual } \\
\text { organization }\end{array}$ \\
\hline & & & \multirow{3}{*}{$\begin{array}{l}\text { Quest for global } \\
\text { market share }\end{array}$} & $\begin{array}{l}\text { Industry } \\
\text { restructuring }\end{array}$ & \multirow{3}{*}{$\begin{array}{l}\text { Refocusing } \\
\text { and } \\
\text { outsourcing }\end{array}$} & $\begin{array}{l}\text { The knowledge- } \\
\text { based firm }\end{array}$ \\
\hline & & & & Active asset & & $\begin{array}{l}\text { Alliances and } \\
\text { networks }\end{array}$ \\
\hline & & & & management & & $\begin{array}{l}\text { The quest for } \\
\text { critical mass }\end{array}$ \\
\hline
\end{tabular}


In order to identify sources after the publishing date of the overview given by Günther and Breiter (2007) and to ensure alignment with my research objectives I conducted additional searches. The outcome of this procedure is contained in Annex 1 to Annex 21. For this project relevant sources will be discussed in three different areas:

- Development and dispersion of SMA

In this area I aim to elaborate on sources which describe the further development of management accounting techniques for use as SMA tools. This part illuminates the emergence of SMA as a separate discipline on the basis of management accounting.

- Focal points in SMA literature in relation to Research Question 2 and Research Objective 2

In this part I seek to identify those areas which are particularly relevant for achieving RO2 in current literature and practice. In particular publications of CIMA reflect an official viewpoint on the subject as CIMA is the professional body of management accountants.

- Performance orientation and competitive advantage

This area focuses on sources which come very close to achieving my research objectives as they meet my research objective three ('Analyze how a strategic model of competitor accounting can provide competitive advantage').

In the next sections I seek to elaborate on these areas and to point out the relationship of the sources identified to my research objectives.

\subsubsection{Development and dispersion of SMA}

In the following I strive first to elaborate on 'Development and dispersion of SMA'.

It can be observed that a part of this literature is based on management accounting. These contributions elaborate on approaches like economic value added in context with target costing ("EVA": Taylor, Woods, \& Cheng Ge Fang, 2014; Woods, Taylor, \& Fang, 2012), Activity-Based-Costing ("ABC": Wegmann, 2009) and target costing in connection with strategic cost management (Clarke, 1995; Ewert \& Ernst, 1999; Innes, 1999). The issue of considering costs in a strategic context has also been a central point for Bromwich (1990) who advocates involving management accountants when it comes to making estimations regarding competitors' costs. Erben (2002) points out the importance of contemporary electronic communication methods in the context of management accounting and their usefulness for the productivity of processes in this area, whereas Tillmann and Goddard 
(2008) take the viewpoint of the organizational actors in a German multinational industrial organisation. Noordin, Zainuddin, and Tayles (2009) scrutinize how traditional management accounting has been developed further in practice in Malaysian manufacturing companies. The authors (Noordin et al., 2009) stress that the focus has become more externally and strategically orientated.

McLellan (2014) scrutinized the dissemination and perceived effectiveness of SMA tools in the USA by management accountants and identified a low degree of dispersion of SMA techniques in practice. Nixon and Burns (2012a) observe a contradiction between the missing adoption of SMA tools in practice and the continuing high number of new approaches (for example, models) in that domain. In this context, Nixon and Burns (2012b) and Nixon and Burns (2005) emphasize the need for a comprehensive conceptual framework which builds the basis for literature and practice in the field as well as aligning with strategic management (SM) and in addition is capable of adjusting to changing trends in the environment.

Langfield-Smith (2008) and others (for example, Hoffjan \& Wömpener, 2006) elaborate on the development of SMA since its emergence in the 1980s. The authors see Simmonds (1981) as the writer who coined the phrase SMA and together with Bromwich (1989) and Bromwich and Bhimani (1994) are the key authors in this area. According to the authors, an integral element of SMA is to enhance management accounting from a mere reporting of figures towards a strategic level in order to meet the strategic information needs of top management. In this context, the authors also see, for example, the integration of non-financial information into SMA tools as an essential requirement.

The debate in the 1990s was about the benefit that practice could obtain from SMA (Roslender, Hart, \& Gosh, 1998; Roslender \& Hart, 2003) with critics like Johnson and Kaplan (1991), Clarke (1995), Lord (1996), Dixon (1998) and Clarke and Tagoe (2002) and studies from Coopers and Lybrand (1994) and McKinsey and Co. (1994). Roslender and Hart (2003) focus on the integration of the function of marketing into strategic management accounting. The authors (Roslender \& Hart, 2003, p. 258) identify as one reason for the loss of acceptance of strategic management accounting the fact that existing practices "...were largely the province of marketing, and did not involve management accountants or much financial quantification work".

In order to refine the strategic management accounting concept, Roslender and Hart (2003) emphasize the necessity of having a common solid platform on which management accountants and their respective colleagues in the marketing area collaborate. They prove, by 
citing Bromwich and Bhimani (1994, p. 130), that this has also been a fundamental requirement in their work.

In essence Roslender and Hart (2003, p. 260) formulate their view on strategic management accounting " $\ldots$ as an attempt to integrate insights from management accounting and marketing management within a strategic management framework". This position emphasizes the need of resilient contributions from SMA and that the use of management accounting knowledge would help to develop this.

In the process of this literature review the works of Michael E. Porter have been referred to by several authors (for example, Roslender \& Hart, 2010a; Keith Ward, 1992). Therefore, it is reasonable to elaborate on those contributions of this author which relate to my research objectives.

In 'Competition in Global Industries: A Conceptual Framework' Porter (1986, p. 7) states that the "...focus is on the problems of international competition in industries and on the ways a firm can configure and coordinate its internal activities in order to gain a competitive advantage over domestic and foreign rivals". The author analyzes the consequences of international competition on the major activities of the organization (manufacturing and technology, marketing/strategy and finance). In chapters 5 and 6 of this book, Porter (1986) describes the role of the finance function in the organization's configuration mainly in the context of handling volatile exchange rates between the involved currencies and optimizing the cost of capital in an international environment as well as optimizing the overall worldwide tax burden.

Porter (1999, 5th Edition of 'Competitive Advantage') describes his book 'Competitive Advantage' as the starting point of competitor accounting in the area of strategic management accounting as it has no clear predecessor. The author emphasizes the importance of activities as part of the organization's value chain and contrasts it to the functional approach, for example, function of marketing or function of research \& development. Porter (1999) looks at this activity-based costing as the new standard of accounting but at the same time admits that it still has to unfold its full potential as a strategic device. Kilger, Pampel, and Vikas (2007) answer the question that one may ask at this point about which cost accounting system (marginal cost accounting or activity-based costing) is the more adequate by arguing that the appropriate way to look at this is that marginal cost accounting and activity-based costing are models that basically can complement each other. The results of the respective analysis of processes within the organization unfolds processes and cost drivers which then can improve 
the planning, allocation and control capacity-dependent proportional costs that have not yet been mapped accordingly in terms of cost accounting. In addition, the authors see the relations between cost centres identified in the course of the process analysis as a backup to the explanation of variances and especially their comprehensive context. Friedl, Küpper, and Pedell (2005) are combining activity based costing and German cost accounting. Even though Porter (1999) explicitly writes about the necessity of a group strategy, he does not discuss requirements that a group cost accounting system has to meet. Regarding the defining of competitors cost position, Porter (1999) recommends estimating competitors cost position based on one's own knowledge about behaviour of cost.

'Competing Across Locations' (Porter, 2008, published in : On Competition) discusses three case studies of international operating companies. Based on analysis of the processes within these organizations, the value chain is going to be defined by differentiating between 'support activities' (firm infrastructure, human resource management, technology development and procurement) and 'primary activities' (inbound logistics, operations, outbound logistics, marketing and sales, after-sales service). In a second step, it is checked where in the international organization these activities can be established. For doing that, the author uses the categories 'concentrated', 'dispersed', 'coordinated' and 'decentralized'. Subsequently, the author discusses aspects that might be relevant for evaluating locations in order to gain competitive advantage and transfers that framework in a concluding step from the local to the international level and derives essential options available now.

In the course of the Literature Review it became obvious that Andreas Hoffjan has published several contributions in the field of SMA which have a connection to my research objectives. Therefore, I will attempt to refer to these sources in relation to my research aim.

Hoffjan and Wömpener (2006) conducted a comparison of the prevalence of SMA in English and German speaking countries through scrutinizing 20 general management accounting textbooks. The authors (Hoffjan \& Wömpener, 2006) ascertain that the term SMA is rarely used and in addition phrases like 'competitor costing' and 'competitor appraisal based on published financial statements' could not be identified. Comparing the foci of German 'controlling' and US/UK 'management accounting' the authors see a more strategic orientation in German controlling. Hoffjan and Wömpener (2006, p. 237) define SMA as a “...generic approach to management accounting for strategic positioning..." which “...includes gathering, refining, analysing, and presenting data that originates in the 
competitive environment and thus encompasses both customers and competitors". This definition categorizes competitor accounting as a subdiscipline of SMA.

Kaland and Wömpener (2007) are referring to Hoffjan and Wömpener (2006) in their work about strategic controlling and its relation to the function of marketing when stressing the strategic element in German controlling.

With respect to Competitor Accounting Heinen and Hoffjan (2005) scrutinized the strategic importance through conducting an empirical study. In a laboratory experiment, the authors compared the decision-making process and the success of a group of test persons considering competitor-related information with a group of test persons who in contrast did not consider such information. As a result, the authors observed that the group that considered competitorrelated information acted more efficiently and were more focused than the other group and eventually was more successful. Even though increasing internationality of business is emphasized by Hoffjan and his co-authors they do not discuss questions of structuring information due to necessary consolidation hierarchies.

Regarding the development of SMA and its dispersion following central points can be recognized in relation to my research objectives:

- Advent of SMA and key authors

The emergence of SMA can be observed in the 1980s with Simmonds (1981), Bromwich (1989), Bromwich and Bhimani (1994) and Alnoor Bhimani and Bromwich (2010) as key authors. SMA attempts to enhance management accounting - Techniques on a strategic level in order to meet the strategic information needs of top management.

- Dispersion of SMA

Low degree of dissemination of SMA due to lack of an accepted comprehensive conceptual framework which would be the basis for literature and assure alignment with Strategic Management.

- Involvement of management accountants

Management accountants are involved in SMA topics only to a low extent. The function of marketing dominates SMA and as a consequence management accounting knowledge is needed but, in the organization, existing respective competence is not integrated. A constructive way to approach this dilemma would be the integration of 
insights from both, management accounting and marketing within an SMA framework (Roslender \& Hart, 2003).

- Internationalization

Despite the accepted phenomenon of increasing internationality in business and the resulting international build-up of the organization questions of consolidating information are not discussed in the SMA literature.

After having discussed the evolution of SMA in relation to my research objectives I will now continue my Literature review by zooming in on the aspects in the SMA literature which appear to be most relevant.

\subsubsection{Focal points in SMA - Literature in relation to the research to be conducted}

In order to cover a broad base of SMA literature, I have based this part of the literature review primarily on contributions of well-known authors (Alnoor Bhimani \& Bromwich, 2010; Broadbent \& Cullen, 2003; Hoque, 2006; Hossain, Akter, \& Hoque, 2011; Smith, 1997; Keith Ward, 1992). I seek to relate these contributions to my research in the course of the review of the respective source and in addition at the end of this section summarize the implications of what literature says.

Alnoor Bhimani and Bromwich (2010) wrote their work as part of CIMAs 90th anniversary celebrations in 2009. Due to the fact that this is an official CIMA publication, it has the importance of the viewpoint of the professional body of UK management accountants. According to the authors this book is based on their fundamental works in the 1990s (Bromwich, 1989; Bromwich \& Bhimani, 1994) which distinguish them together with Simmonds (1981) as key authors in this field. The authors emphasize that SMA explicitly permits to deal with competitors' cost structures and anchor this in their definition of SMA which is based on Bromwich (1990):

SMA is "...the provision and analysis of financial and now non-financial information on the firm's products, markets and competitors' costs, and the monitoring of the enterprise's strategies and those of its competitors in these markets over a period of time”. (Alnoor Bhimani \& Bromwich, 2010, p. 49)

The implication of this definition for this project lies in the intertwining of strategy and competitor accounting which is, in accordance with the assignment of competitor accounting to SMA, a subcategory according to Hoffjan and Wömpener (2006). Furthermore, the authors (2010, p. 49) limit the information-need to "competitors cost" which appears in relation to my 
research to be too tight. Even though Alnoor Bhimani and Bromwich (2010) outline organizational requirements due to globalization, conclusions relating to consolidation hierarchies or interdependencies between organizational resources (for example, financial resources or production capacities) are not emphasized.

Broadbent and Cullen (2003) published "Managing Financial Resources", which contains teaching material for courses in the area of finance and management accounting. Since this book also aims to address non-financial readers, its approach is broader in that it also deals with other subject areas, such as marketing. Regarding the strategic perspective, the authors refer to Porter (1985) and stress in an accounting context the concept of cost leadership. Another focus is put on issues to be considered in the field of pricing. Regarding my research, the implications made particularly refer to competitors' costs and pricing which have been considered in the conceptual framework/the model through its performance-orientation.

Hoque (2006) devotes an entire chapter to 'Competitor analysis/competitor accounting' which relates especially to my Research Objective 3 (analyzing how a strategic model of competitor accounting can provide competitive advantage). The author assigns competitor accounting to the field of SMA and emphasizes that the way an organization deals with a competitive situation can be essential for its position in the market. Concerning my project, the emphasis is on Hoque's (2006) broad approach in relation to competitor accounting/analysis which I seek to portray in more detail.

Regarding the key components of competitor accounting Hoque (2006, pp. 134-136) alludes especially to Guilding (1999); Guilding, Cravens, and Tayles (2000); Porter (1985); Simmonds (1981); K. Ward, Wendy, and Sri (1992) when identifying the following focal points:

- Competitor cost analysis

Based on the distinction between 'low-cost' and 'differentiation' strategy (Porter, 1985) a low-cost strategy requires assumptions regarding competitors cost structures. In a second step, the analysed market participants can be ranked using the results of this cost structure-analysis and measures can be defined to improve one's own cost position.

- Competitor quality and price analysis

In particular, in mature markets price increases will only be accepted to a very limited extent. In this environment the basis of competition is the selling price. Respective 
parameters to observe versus competition in these case are the quality in relation to the price of the products (Digman, 1999) and according to Ward (1992), the costs.

- Best practice benchmarking

Hereunder, Hoque (2006) relates to Digman (1999) and comprehends a comparison of the organizations, for example, processes versus another firms (not necessarily being a competitor) approach. According to the author this may unfold potentials of improvement and therefore contribute to improve the organizations performance.

- Value-chain analysis

Hoque (2006) embraces the comparison of the activities in one's value-chain versus the respective parts in competitors' value-chains.

- Competitive profiling/position monitoring

This means encompassing the observation of one's own position versus competitors regarding parameters such as, for example, sales and market share (Guilding, 1999). The outcome of such a study can be a better understanding of sustainable trends in this field and a verification of ones' own strategies (Guilding et al., 2000; Simmonds, 1981; K. Ward et al., 1992).

- Industry profitability analysis

This point relates to Porter (1980a) and his five forces influencing the competitive environment of an industry (entry barriers, competitive rivalry, substitute products, power of buyers, power of suppliers). According to Hoque (2006) this framework enables an organization to identify its position in the market compared to others in a structured way.

Hoque (2006) sees the lack of information available as a major problem of competitor accounting and the high degree of effort it takes to build up a respective meaningful information system. According to the author this could limit the application of competitor accounting systems to larger organizations. Regarding the part that accorded to management accountants in this field, Hoque (2006, p. 137) sees especially the task of collecting and verifying cost information and summarizes that "...the whole idea is to bring together many ideas into one whole - strategic management accounting..." in order to "...manage costs for improved financial performance in the long term".

In their publication 'Contemporary Issues in Strategic Management Accounting', Hossain et al. (2011) cover the areas of concurrent engineering, quality issues, supply chain 
management, Just-in-Time, lean manufacturing, target costing, performance measurement and knowledge management. Referring to my Research Objective 2 (critical evaluation of the performant relevant information available in management accounting to assist with competitor accounting in the focus company) the section regarding performance measurement supports the approach of my project. The authors emphasize that an accounting and control system must have precisely defined objectives, measurable outputs which are aligned with the objectives. In addition, a model is required which allows to forecast outputs and to adjust objectives appropriately. Furthermore, the authors complement the element of taking actions in case measured output and objectives diverge (the authors relate to Otley \& Berry, 1980). Hossain et al. (2011) base their observation of a further development regarding the design of performance measurement due to an advancement of business from the industrial to the information era (the authors refer to Kaplan \& Atkinson, 1998). In the course of this development the importance of non-financial indicators for measuring performance has increased (Eccles, 1991; Vaivio, 1999). In this context the authors see strategic performance as a firm's ability of adaption to a changing environment (the authors allude to Chakravarty, 1981) and therefore as a major task of a performance measuring system to support top management in observing organizations' strategic position (Hoque, 2003). The aspect of being capable to adapt to a changing environment represents an important implication for my research. The conceptual framework/the model going to be developed needs to provide the possibility to consider flexible ways to detect and to handle information regarding major competitor's performance.

Smith (1997) published his textbook based on his professional experiences and case studies which are embedded in a strategic context. The author emphasizes the importance of considering both non-financial performance measures and traditional financial performance measures. According to the author this allows to verify the outcome of financial performance measures and complementally to explain them using the results of the non-financial performance measures. In addition, Smith (1997) underlines the importance of intersecting sets of SMA with other areas within the organization for strategic decision making and explicitly refers to the function of marketing. In the chapter on SMA, the author allots a section to performance benchmarking. Regarding the sources of benchmark measures, the author differentiates between internally and externally derived values. Focusing on external sources, Smith (1997) alludes to, for example, publications of professional organizations who most likely can provide benchmark measures of, for example, production companies who 
have similar frameworks but are not active in the same market. In the opinion of the author this procedure of collecting data for benchmarking helps to avoid competition receiving sensitive data. As Smith (1997) believed, a collaboration with companies which have similar processes in place but are not active in the same markets as well as not touching areas like financial results or R\&D-topics appears to be fruitful for generating meaningful benchmarking measures. However, the author does not elaborate on the possibility of combining external and internal information in order to generate benchmarks. The author rather recommends excluding competition sensitive areas of benchmarking and does not elaborate on how information gaps can be closed to the largest extent based on knowledge existing in one's own organization. In relation to my research, the aspect of considering interfaces with other functions of the organization in the context of competitor accounting/analysis appears to be in line with my approach. However, Smith (1997) concentrates on how to receive information regarding competitors' financial performance from outside the own organisation, which is not the emphasis of my research.

Keith Ward (1992, reprinted edition 1999) prepared an official CIMA publication and therefore this can be considered as the position of the official professional body of UK management accountants. The author sees the role of management accounting in: (1) recording the financial transaction and respective external reporting, (2) raising funds required by the business and (3) supporting managers in their financial decision-making process. After describing the management accounting process (differentiated in financial planning and control) the author also gives attention to the area of competitor accounting by integrating it in the context of suppliers and customers. Ward (1992) is describing a position which is very close to the activity-based costing approach of Porter (1980a). In the chapter dealing with "Multinational and global companies" the author is focusing on sourcing decisions, exchange-rate problems and the importance of transfer prices between the divisions of an international organization. Notably the author is not elaborating on competitor accounting activities at the group level. Eventually, Ward (1992) describes the information requirements for a SMA system and goes into questions of organization of data and respective data collection. In relation to my research, the author's position regarding the support of managers in decision-making processes comes close to the view of management accountants as business partners of management in respective processes which is also the view of Coad (1999) and Wolf, Weißenberger, Wehner, and Kabst (2015). 
Summarizing the contributions of well-known authors in relation to my research objectives following focal points appears to be essential:

- Competitor's cost structure

Analysing the competitor's cost structure unfolds both the competitor's strength/weaknesses regarding his cost position and to consider this information when defining one's own strategy. In relation to my research, the focus on the competitor's costs is essential in the context of performance-orientation which is due to the nature of the markets the focused company and the major competitor are acting in. However, the restriction of competitor accounting/analysis on the aspect of the competitor's costs would be too narrow for my research in that it does not consider variables which are also related to the competitor's performance.

- Performance orientation

Performance measurement and -management requires a model which allows to monitor the organizations financial performance and to forecast outputs in order to recognize a possible need for action or a demand to modify objectives. Relating this point to my research leads to the requirement of transferring performance-orientation into the area of competitor accounting/analysis and the need to provide a respective conceptual framework/model in order to produce resilient assumptions regarding the major competitor's performance.

- Technological progress

In the light of the fast-developing IT-technology, information is easy to access and uncomplicated to process it in the organizations own data processing systems. New techniques also allow to scrutinize, for example, textual information and to align this with the organization's strategic radar. In this context, performance measurement systems help to monitor the organization's strategic position and to adapt early to the changing business environment. The aspect of scrutinizing textual information regarding performance-relevant information and the possibility to connect this with numerical data is, due to the nature of this project, of particular importance.

- Management accountant as 'information broker' and business partner

In view of today's fast changing surrounding conditions, management accountant's role in the organization is centered on the function of coordinating information from inside and outside the organization and therefore based on a profound knowledge of 
the business which builds the basis for their role as business partners of management in decision-making processes. Furthermore, this understanding of the role of management accountants underlines the importance of taking a holistic view which considers also the perspectives of other functions of the organization in the context of SMA/competitor accounting/analysis.

- International perspective

Globalization has increased the internationalization of business in general. As such, firms follow this trend and align their organization accordingly. In relation to my research, the consideration of increased internationalization is indispensable due to the nature of the business in which the focus company and major competitor are acting.

The aspects of performance orientation and competitor accounting/analysis are relating to my research objectives in particular. Therefore, the review of the Literature referring in particular to performance and competitive advantage will be conducted in the next section.

\subsubsection{Performance orientation and competitive advantage}

With reference to the area of performance orientation/competitive advantage, I will attempt to trace the literature in this section in relation to my research objectives.

The first published articles deal with specific key aspects. Simmonds (1982) distinguishes between traditional management accounting and the SMA approach regarding pricing decisions. The author emphasizes that formation of prices is independent from emergence of costs in the organization. In fact, the author sees the development of market prices as an implication of demand in the market and the competitor's behaviour and underlines that the traditional management accounting approach of contribution margin does not reflect marketrelated inferences appropriately. Simmonds (1982) believes that SMA would offer respective approaches. With reference to my research the aspect of considering the impact of pricing needs to be distinguished between the different markets/product lines. Also, these aspects need to be observed by year as the respective environment may have changed. This view on SMA/competitor accounting/analysis supports the application of a conceptual framework/model which is in a position to consider respective information concerning the performance-relevant variables regardless of whether they are of textual or numerical nature.

Partridge and Perren (1994) refer to Porter (1985), Govindarajan and Shank (1989) and Shank and Govindarajan (1992) when elaborating on the potential competitive advantage that 
a comparison of the organizations processes and their related costs with estimations regarding the competitor's processes may unfold.

Following articles published in the 1990s focused on particular aspects of SMA:

- Rangone (1997) suggests a conceptual framework which allows to assign indefinite values to variables, for example, critical success factors. With regard to my research, this concept can basically be linked with the concept of connecting textual with numerical information.

- Harvey (1995) explains the decision-making orientation of SMA. This source is scholarly guidance and contains no further implication for my research.

- Stainer (1997) scrutinizes 'productivity' as a performance measure for the manufacturing area of an organization and its connection to SMA. Relating this contribution to my research leads to the result that it does not provide implications which would support my project.

- Dixon (1998) endorses the basic idea of SMA but sees restrictions in its application in practice and states that an organization does not have to put into action the entire SMA process in order to get out necessary information for strategic decision making. In relation to my research, this contribution contains no implication as it does not accept the work that would be connected with the introduction of the conceptual framework/the model.

- Larsen, Tonge, and Ito (1998) investigated the priorities that extremely fast-growing organizations have in defining their strategic targets. According to the authors, these companies draw attention to 'cash flow' and 'employee motivation' as opposed to companies focusing on their performance in order to enhance their status in relation to their competitors. With regard to my research, the emphasis of the nature of the business being observed is different from this project. Therefore, this contribution does not provide implications for my project.

Within the decade 2000 - 2010 Robin Roslender and Susan Hart contributed several publications which I will review in relation to my research in the following.

The authors (Hart \& Roslender, 2002; Roslender \& Hart, 2002) emphasize the market orientation of SMA and scrutinized brand management in a field study conducted in ten both manufacturing and service companies. The authors identified a close collaboration between marketing and management accounting in the area of a respective reporting in order to monitor the brand performance based on measures such as, for example, market share. 
Roslender and Hart (2003, as also mentioned in the section dealing with the emergence of SMA) identified three different stages of relationships of the collaboration between marketing and controlling.

The traditional relationship is characterized by a relatively small amount of commonly used instruments. This kind of relationship has developed over a long period of time and hence is prevalent.

Transitional relationships are based on successfully existing collaborations between marketing and management accounting. Based on the success experienced, both disciplines are now open for additional projects to be realized such as, for example, balanced scorecard (Kaland \& Wömpener, 2007).

Synergistic relationships "...involve functions cooperating in ways that require their practitioners to abandon their former function or discipline-based practices in favour of greater inter-functional co-ordination" (Roslender \& Hart, 2003, p. 264). The authors look at teamwork and also social interacting as central elements of a close collaboration between marketing and management accounting. In relation to my research, the collaboration between the functions of marketing/sales and control formed a precondition of generating the data particularly coming from the subsidiaries of the focus company and would presumably be beneficial for future projects in this area.

Even though the authors advocate a close collaboration between the areas of marketing and finance they express their critique in applying too many management accounting techniques in marketing domains and name explicitly customer accounting (Roslender \& Hart, 2010b).

Yi and Tayles (2009) and Lay and Jusoh (2012) focus in their articles on the change of the role of management accountants in the context of the increased importance of SMA. The authors see a close link between performance measurement and a company's strategic targets. According to the authors, management accountants need to fill a more managerial role if they want to meet the requirements coming from the interdisciplinary approach of SMA. In relation to my research, this contribution confirms the role of management accountants as business partners of management in decision-making processes according to Coad (1999) and Wolf et al. (2015) and in this context underlines the importance of a holistic view in SMA/competitor accounting/analysis.

Said, Wee Shu, Othman, and Taylor (2010) scrutinized the effect of the application of SMA on organizational learning. The authors confirmed that companies applying SMA to a higher degree than other companies are in the position to get adjusted to changes in their 
environment faster than companies with lower degree of application of SMA. In addition, the authors observed that applying SMA supported the financial performance of the companies sustainably. The focus of this contribution is organizational learning, which does not have direct implications on my research.

Seal (2010) analyzes the role that texts play regarding the theoretical discourse about a management accounting concept for the acceptance of a particular concept in practice. The author compared the management accounting concepts of return on investment (ROI), valuebased management (VBM) and SMA and states that whereas ROI and VBM have been accepted by practitioners, SMA does not have a comparable place in practice. Seal $(2010, \mathrm{p}$. 95) critically describes SMA as “... a loose collection of academic texts..." and sees this as an explanation for the low level of acceptance of SMA, in his view. In relation to my research, this text emphasizes the need for a common strategic framework to which this project seeks to contribute.

Abdel Al and McLellan (2013), Cadez and Guilding (2008), Guilding et al. (2000) and also Pantea, Cuc, and Lile (2013) describe in their articles the development of SMA and how an organization can benefit from applying SMA techniques. These articles have no implications for my research.

Cadez and Guilding (2012) also base this work on Slovenian manufacturing companies and analyse whether contingency-based management accounting systems reflect the fit between strategy, SMA and performance appropriately. The authors see the alignment of these three pillars as key and suggest dealing with questions of measuring performance based on a given strategy. By using the term configuration, Cadez and Guilding (2012) further develop this train of thoughts. Rather than identifying one dominant variable or a set of variables for measuring performance the authors suggest ascertaining the connecting elements between variables because this enables to reflect different structures, thus building a configuration of strategy, SMA and performance. The authors assign competitor accounting to SMA but do not provide a separate concept of competitor accounting. The major connecting elements to my research aim are the consideration of competitor accounting in SMA along with attaching a central role to performance orientation. Therefore, the importance of having resilient assumptions about competitors financial performance is also emphasized by configurational analysis as described by Cadez and Guilding (2012).

Mohamed (2010, doctoral thesis) and Mohamed and Jones (2014, article based on doctoral thesis) develop a strategic profitability model for the Egyptian information and 
communication sector and describe the development from traditional management accounting to SMA as a change of the target course from monitoring "...efficiency..." ("doing the thing right", Mohamed \& Jones, 2014, p. 2) to “...a more holistic view...” ("doing the right things", Mohamed \& Jones, 2014, p. 2). In the view of the authors the model can also be applied e. g. to other industries. According to the authors, profitability in a strategic context can also be driven by factors external to the company and explicitly mention competition. In addition, Mohamed and Jones (2014) advocate including non-financial information to assist with, for example, measuring non-financial indicators such as customer satisfaction. The authors suggest creating a collaboration across all functions of the organization and explicitly name marketing and management accounting. Regarding the task of management accounting, the authors see conducting product costings, observing financial performance and reporting of this information as especially important. A comprehensive use of management accounting information in the context of elaborating better informed assumptions about competitors' financial performance is not discussed. With respect to the duties of marketing, Mohamed and Jones (2014, p. 13) accommodate collecting and analysing information, for example, relating to "...customer satisfaction and loyalty". The authors emphasize the need for establishing effective communication and coordination within the suggested cross-functional team. With regard to my research aim, the major related aspect is the holistic view on SMA as a common task of all functions in the organization. In addition, the integration of nonfinancial information into a strategic model supports the approach of my project.

The aspect of establishing cross-functional collaboration, for example, between the functions of marketing and control (Mohamed \& Jones, 2014), is connected with the role of management accountants in the organization. Aver and Cadez (2009) see in this context a development of the traditional role of management accountants exceeding the traditional task of providing decision-relevant information. Wolf et al. (2015, p. 24) support this view and see management accountants “... as Business Partners in managerial decision-making” which supports the view of the role of management accountants required in practice.

Juras (2014) describes the current status of SMA and refers to the lost-relevance debate and the missing acceptance of the concept in practice. However, Juras (2014, p. 76) emphasizes that "...SMA..." is “...future orientated,...less rules led and more creative as ...traditional Management Accounting". Furthermore, the author agrees with Burns and Nixon (2009) when outlining that reducing the gap between SMA literature and practice should be one of the future foci of SMA research which supports the approach of my project. 
With respect to my research objectives, the literature discussed in this section 'Strategic orientation and competitive advantage' can be outlined as follows:

- Market and decision orientation

The origination of cost and market pricing are independent from each other (Simmonds, 1982). The traditional contingency-based management accounting approach derives sales price from internal product costing whereas SMA techniques follow the law of supply and demand and connect the internal cost-related perspective with the market view. This approach enables SMA to provide decision-relevant information to top management for strategic decision making.

- Comparison versus competitors

SMA explicitly allows making estimations about competitors' processes and benchmarking them against one's own processes. This procedure has the potential to uncover areas of improvement.

- Holistic view of SMA

The traditional efficiency-orientated management accounting approach has been further developed at a level where the perspectives of various organizational functions can be considered. The provision for, for example, opinions of marketing and management accounting requires an interfunctional collaboration and a platform for communication. Such a basis for communication needs to be flexible and, for example, capable of assigning indefinite values (for example, textual information) to variables (for example, specific key performance indicator). This enables the integration of non-financial information in SMA.

- Role of management accountants

In order to meet the requirements of SMA, management accountants have to take a more managerial role which involves, for example, a profound knowledge of the business and to look at things from the perspective of other functions of the organization.

In the course of the review of the literature in the area of SMA I found the work of Christine Bullen and John Rockart (Bullen \& Rockart, 1981) which describes the system of critical success factors (CSF). The CSF system supports me in achieving my research objectives and aim and will therefore be used in this project. In addition, I considered contributions of the 2017 annual meeting of the Schmalenbach Society regarding the increased use of textual 
information in context analysis of published financial information (in particular regarding the observation of the "change in tone": Ernstberger, Link, Stich, \& Vogler, 2017; Feldman, Govindaraj, Livnat, \& Segal, 2010).

The last area of literature to be reviewed with respect to my research aim is the field of competitor accounting which is closely related to SMA.

\subsubsection{Competitor accounting/analysis}

In this section, I will first look into the literature in the area of competitor accounting and thereafter into the field competitor analysis, both in a strategic context.

Regarding competitor accounting, I found Guilding (1999, Competitor - focused accounting An exploratory note). In the section about "Focal Points in SMA - Literature relating to Research Question 2 and Research Objective 2" also Hoque (2006) relates to Guilding (1999). Guilding (1999) and Cravens and Guilding (2001) analyzed the dissemination of usage of 'competitor-focused accounting (CFA)' in practice and ascertained that this is more often the case than he expected. Guilding (1999) identified 'company size', 'competitive strategy' and 'strategic mission' as important factors for the use of CFA. Guilding et al. (2000, p. 113) investigated the benefit received from 'strategic management accounting' in large companies in New Zealand, the United Kingdom and the United States and in essence found, that "...practising accountants have a limited appreciation of what that term means". This basic tendency has also been recognized for Germany (Dahms \& Siemes, 2005).

In the following, I aim to focus on the literature referring to competitor analysis. I found a definition of "competitor analysis" in the Bloomsbury Business Library Business \& Management Dictionary (2007, p. 1750):

Competitor Analysis embraces "...the identification and quantification of the relative strengths and weaknesses of a product or service which could be of significance in the development of a successful competitive strategy".

From the management accounting perspective, this definition of competitor analysis appears to be too tight as it focuses on particular cost objects and does not consider their integration in the balance sheet and P\&L statement. A company may have a relative cost advantage regarding a particular product or service compared to its competitors, but complementing that observation by, for example, looking into the question of inventories to be made available (balance sheet) may lead to a different evaluation of the relative competitive advantage. 
Bloodgood and Bauerschmidt (2002) study the question of if, and if so, to what extent, direct competitors are acquainted with their rivals' position. The authors base their work on Porter (1980a) who analyzes broadly defined categories such as, for example, 'plant and equipment', 'customer service' and 'experience of personnel'. Regarding 'cost' the authors differentiate between 'level of labour cost', 'tightness of overall cost control', 'level of operating costs' and 'level of overhead costs'. Aspects relating to management accounting concentrate on the cost category and do not consider balance sheet and P\&L statement. In relation to my research, this article shows the need for an accepted common conceptual framework of competitor accounting/analysis to which this project aims to contribute.

Brock (1984) centres in his article on techniques assisting with estimating competitor's costs. The author approaches the topic mainly from the perspective of cost accounting at the level of single entity. Brock (1984) first draws upon the 'strategic triangle' (customers, company, competitors) according to Ohmae (1983) and emphasizes 'cost differentials as the connecting element between the company and its competitors. The author then differentiates between secondary and primary sources of information and gives for example, competitors press releases or commercial industry surveys/databases as secondary sources. Regarding primary sources of information, Brock (1984, p. 227) identifies “...customers, suppliers, key neutral parties..." and "...competitors themselves". The author continues by describing techniques for estimating competitor's costs. The first technique the author describes focuses on differentiating between fixed and variable costs in order to calculate an estimation of the competitor's contribution margin. In this context, Brock (1984, p. 230) explains three wellknown cost accounting techniques ("visual curve fitting, high-low method, regression analysis method"). The second technique relates to "...categorical cost estimation" (Brock, 1984, p. 231). Basically, this method uses published totals and differentiates according to, for example, industry -averages and more differentiated cost types. The approach described by Brock (1984) does not consider globally acting organizations. In groups, centralized services (for example, global purchasing, legal department, marketing, taxes and other corporate departments), provided services to a subsidiary (single entity) are charged as a respective fee. These fees contain various cost types (for example, personnel costs, travel expenses etc.) which can only be analysed in more detail with the expertise of group cost accounting. In addition, Brock (1984) focuses on estimation of competitor's costs and does not consider the relationship to other areas like capacity of production or financial resources. Furthermore, the author draws upon a dependency between sales and costs. This approach needs to be based on 
product lines differentiated margin accounting because different products cause different manufacturing costs. For example, a sales increase in a product line which has a very high share of merchandize does not create utilization and fixed cost coverage in the production area. It appears also relevant to note that the author does not consider involving knowledge already existing in the organization. Finally, even though relating to cost accounting techniques for estimating competitors' costs, the author does not make the step to use techniques of variance analysis of one's own costs versus competitor's costs. However, the techniques explained relate to my research objectives in the area of cost accounting at the level of single entity and can basically be used, for example, to verify outcomes of the model that I am going to develop in the course of this work.

Chen (1996) generates a scenario of two competitors facing similar market conditions and using similar resources. However, the appearance of these two rivals in the market is different. Based on these assumptions, the author then develops a mathematical model attempting to predict the behaviour of the rivals. The author uses the variables 'marketcommonality' and 'resource-similarity' and applies this to the case of two competing airlines. Obviously, this work is not based on management accounting information and therefore does not relate to my research aim.

The work of Harkleroad (1993) deals with the use of financial data in the context of competitive intelligence. The author concentrates on the analysis of published financial statements and the application of key performance indicators in order to observe the growth of a competitor over time. This article is not about building a model of competition. In addition, it is not about applying cost accounting - techniques and respective variance analyses for observing competitor's performance. Therefore, this article has a very limited relation to my research project.

Neal (1999) describes simulation method of competitor's behaviour and approaches the topic of competitor accounting/analysis from the perspective of the function of marketing. In the introductory section (Figure 2 on page 11), I placed my project in the area of SMA and management accounting and defined the intersecting set to the function of marketing only to the extent that is necessary from the perspective of SMA/management accounting. Therefore, this article does not belong to the scope of my project.

Oxenfeldt and Moore (1981, p. 23) stress the importance of a "...model of competition..." which the authors define as “... an insightful view of competitor's behaviour, position, and objectives - and of the competitive market process". This definition of a model of 
competition reflects the marketing background of the authors. Oxenfeldt and Moore (1981) observe a further development in SMA in adding to the customer-orientation the competitor focuses on the strategic radar. The authors relate to Porter (1980a) when elaborating on the cost-leader strategy and respective techniques to make estimations regarding competitors' cost position. In the view of the authors, a pricing strategy which is orientated on local markets needs to be complemented as opposed to a global pricing approach. With respect to my research objective this article is placed in the intersecting set between SMA/management accounting and marketing (Figure 2 on page 11) because it emphasizes the need for a strategic model of competition and therefore strengthens the approach of my project to support that from the stance of management accounting.

Porter (1980b, Portfolio Techniques in Competitor Analysis) and Porter (1980a, Competitive Strategy: Techniques for Analyzing Industries and Competitors) first provide a structure for studying an industry sector and the competing participants within this market. In a second step Porter (1980a) elaborates how the structure can be utilized to develop strategies. Eventually three different groups of strategic decisions (namely 'vertical integration', 'major capacity expansion' and 'entry into new businesses') are illustrated. Regarding the analysis of competing participants within a market, the author suggests a framework which outlines a procedure to identify competitors' “...nature of success". (Porter, 1980a, p. 47) This framework consists of the elements 'future goals', 'current strategy', 'assumptions' and 'capabilities'. The author admits that “...the lack of good information makes it very hard to do sophisticated competitor analysis”. (Porter, 1980a, p. 48) Within the area of competitor's 'future goals' the author inter alia refers to 'financial goals' and relates that to the long- and short-term financial performance. In order to acquire informed assumptions regarding competitor's future financial performance the author mentions the practised accounting system and questions, for example, relating to evaluating inventory and cost position. However, the author does not elaborate on how to prepare such informed assumptions about competitor's financial performance. In fact, the author relates to particular accounting components (for example, costs) but does not put this in a common consistent context. So far Porter (1980a) focused at the level of single entity acting within a particular country (presumably the USA). Thereafter the author relates to the international parent company and remarkably does not even mention the need to elaborate informed assumptions about competitor's consolidated financial performance. Porter (1980a, p. 72) emphasizes the need for a “...Competitor Intelligence System..." and complains about the (very often in practice 
missing) assignment of this task to an organizational function. In addition, Porter (1980a, p. 74) underlines the necessity "...to put..." the data generated in a competitor intelligence system “...in a concise and usable form to top management”. This requirement implicitly calls for elaborating informed assumptions about competitor's financial performance at the level of single entity as well as at the group level. However, the author does not provide techniques for resolving this requirement.

Rosen (1991) looks into the field of competitor accounting from the perspective of the function of marketing. She scrutinizes how information collected is interpreted depending on the hierarchy level of the individual conducting the analysis. Whereas top management is focusing on a more aggregated (industry) level, middle managers relate their analysis to specific competitors. Rosen (1991) examines the question of so-called strategic moves and relates that implicitly to for example, the scope of products. The author does not draw upon connections between SMA/competitor accounting and management accounting.

Rothschild (1979) takes the perspective of an US-based single entity facing domestic and international competition. The author states that competitor analysis has remained an ignored managerial task. According to the author, people in the organization confronted with the task to conduct competitor analysis are overstrained. Regarding accounting data, Rothschild (1979, p. 26) defines the following aspiration level:

'In essence, we wish to know the competitors' total financial situations, determine whether they have profitable and balanced portfolios, and identify their serious problems and opportunities they are trying to pursue".

Looking into this statement in more detail reveals the following inconsistencies in this article:

- “...profitable and balanced portfolios..."

Regarding competitors analysis, Rothschild (1979, p. 26, Figure 3) does not define any KPI or measurement relating to $\mathrm{P} \& \mathrm{~L}$ statement. This is a prerequisite to draw conclusions regarding profitability. In order to be in the position to scrutinize the profitability of the company's portfolio, respective margin accounting information is necessary. The author does not include this in his overview of information to be collected about competition.

- “...identify their problems..."

Identifying problems in the finance area would involve calculating variances or analysing the development of KPIs over time and in comparison to a benchmark. 
Rothschild (1979) has not defined a respective variance analysis or KPIs. In addition, the author is not emphasizing the need to scrutinize the plausibility of the financial information collected in relation to the other areas of competitor analysis suggested ('conceive/design', 'produce', 'market' and 'manage').

- Analysis of multinational competitors

Even though Rothschild (1979) elaborates on MNCs as competitors of US-based companies, he is not elaborating on consolidation of figures and information. This limits the usability of the article to US-based single entities which is a major restriction in the light of increased globalization because management accounting techniques such as, for example, consolidated margin accounting are not considered.

- Sources of data

Rothschild (1979) defines: (a) information published by competitors about themselves, (b) information given by others about competition, and (c) own information collected through observation as secondary sources. The author is not considering using one's own internal information as a reference for estimating, for example, competitor's financial performance. This approach neglects considering information and expertise as easy to obtain.

- $\quad$ Testing validity

Even though the author elaborates on how and where to collect information about competition and the necessity to validate the outcome (competitor profile), there is no explanation of how a validation can be conducted. Since elaborating a competitor profile includes making assumptions it is necessary to examine whether the end result is reasonable. Therefore, a validation procedure needs to be defined.

The articles of Albayrak (2015), Amit, Domowitz, and Fershtman (1988) and Bee-Lan, Drew, and Runeson (2010) are not in line with my research objectives and aims and will therefore not be discussed in more detail. Furthermore, the research articles of Chow (2011), Fahey (2002), Fratto (2008), Garland (2005), Hiles (2016), Hitchings and Peckham (2010), Pinczés-Pressing, Sebestyén, Berkics, and Fülöp (2015) Platonova and Krivosheeva (2015) are not in line with my project.

With regard to my research, objectives the literature identified in the field of competitor accounting and -analysis can be summarized as follows:

- Prediction of competitors' future actions 
One major strand of the competitor accounting literature is about anticipating competitor's strategic moves. In particular this is related to questions of pricing. However, approaches that I identified in the course of my literature review are not connected with the entire P\&L statement and balance sheet of competition. This is necessary because sales price and total sales as presented in P\&L statement are linked inseparably. In addition, the consolidated level is not considered. These proceedings overlook resulting impacts due to the increasingly internationalization of business in the past decades.

- Identifying competitors's strength and weaknesses

Another direction competitor accounting/analysis suggests to develop is strategic profiles of competition using criteria which are seen as relevant to gain a competitive advantage (for example, 'technical competence'). These approaches see criteria like such as, for example, 'financial position' at most to cover the entire area of management accounting. In addition, links between these 'soft criteria' and the accounting/finance area are not described. Consequently, a possible impact of this quantitative measured information on competitors' financial performance is not measured.

- Assumptions about competitors' costs

Literature in this field dealing with techniques estimating competitors' costs is written by authors not from a management accounting background. These contributions work, for example, with assumptions about competitors' factor costs and derive depending on the technique applied, for example, competitors' break-even point or costs for relevant processes. In the course of my literature review, I could not identify contributions elaborating a margin accounting system estimating the competitor's profitability for his major product lines. This would be a prerequisite when drawing conclusions about the profitability of competitors' portfolio. In addition, the consolidated view of competitors' costs or margin accounting as well as a validation of the results is not considered.

As a summary, it can be observed that the literature in the field of competitor accounting/analysis is at an early stage (Inglis, 2008) and “...only a few contributions on competitor accounting are of an empirical nature". (Heinen \& Hoffjan, 2005, p. 20; similar: Juras, 2014). 
After having reviewed the relevant literature in relation to my research objectives in the fields of consolidated cost accounting/management accounting and SMA, I will now elaborate on the gap in literature identified.

\subsection{Gap in literature identified}

It can be summarized that the German body of literature of consolidated cost/management accounting is more present in literature compared to the UK/US based literature. Regarding the field of SMA, the Anglo-Saxon literature is clearly setting the trend in this domain. However, the 'lost relevance debate' revealed areas of improvement.

Increasing globalization has led to more internationally operating industrial organizations. In the light of this development, the field of group cost accounting has generated respective techniques to provide top management with information to control the organization, both at the level of group and at the level of single entity. A similar development cannot be observed in the area of competitor accounting/analysis.

Figure 6 illustrates the outcome of my literature review. I compared in Figure 6 what the group cost accounting and competitor accounting/analysis contributed, on both the level of group and single entity, in terms of respective techniques. Relevant criteria from the viewpoint of my research objectives are balance sheet items (especially working capital related lines like such as, for example, inventory), P\&L statement, cash flow statement and margin accounting. Group cost accounting techniques allow assigning these statements to product lines which in turn reflects its profitability (green colour in Figure 6). Product lines reflect the organization's portfolio and therefore are of central importance for competitor accounting/analysis. However, competitor accounting/analysis uses published financial statements as a basis (yellow colour in Figure 6). This information does not contain information by product line and therefore does not provide details about the profitability of the competitor's portfolio. Margin accounting is an integral part of the entire accounting system. This in turn assures consistency and resilient information about the profitability of the product lines of the organization. In addition to this in the accounting system, embedded calculation also delivers information about the impacts on other areas, for example, cash flow-statement. On the contrary, competitor accounting/analysis is missing this differentiation by product lines within a consistent accounting system, especially at the group level. Alongside, competitor accounting/analysis is not in the position to consider connections between the profitability of a product line and the organizational resources based on a coherent integrated system. This lack of a respective system in the area of competitor 
accounting/analysis on the one hand and existing techniques in the area of group cost accounting on the other hand reveals the Gap in Literature (red colour in Figure 6).

Figure 6: Gap in Literature identified

\begin{tabular}{|c|c|c|c|c|}
\hline \multirow{2}{*}{\multicolumn{2}{|c|}{ Consolidation level }} & \multicolumn{2}{|c|}{ Group Cost Accounting } & \multirow{2}{*}{$\begin{array}{l}\text { SMA/competitor } \\
\text { accounting/analysis }\end{array}$} \\
\hline & & $\begin{array}{l}\text { Consolidated cost } \\
\text { accounting }\end{array}$ & $\begin{array}{l}\text { UK/US management } \\
\text { accounting }\end{array}$ & \\
\hline \multirow{4}{*}{ Single entity } & Balance sheet items & $\checkmark$ & $\checkmark$ & $\checkmark$ \\
\hline & P\&L statement & $\checkmark$ & $\checkmark$ & $\checkmark$ \\
\hline & Cash flow statement & $\checkmark$ & $\checkmark$ & $\checkmark$ \\
\hline & Margin accounting & $\checkmark$ & $\checkmark$ & \multirow{2}{*}{ Gap in Literature } \\
\hline \multirow{4}{*}{$\begin{array}{c}\text { Consolidated/ } \\
\text { group level }\end{array}$} & Margin accounting & $\checkmark$ & & \\
\hline & P\&L statement & $\checkmark$ & $\checkmark$ & $\checkmark$ \\
\hline & Balance sheet items & $\checkmark$ & $\checkmark$ & $\checkmark$ \\
\hline & P\&L statement & $\checkmark$ & $\checkmark$ & $\checkmark$ \\
\hline
\end{tabular}

The logic of the colours and symbols used in Figure 6 is similar to the logic of the colours of a traffic light: green colour indicates that academic literature is abundant detailing the respective techniques are available in the respective subject area (for example, 'margin accounting' at the group level is available in consolidated cost accounting). Yellow colour indicates that academic literature basically provides the techniques relevant for my research (for example, SMA/competitor accounting/analysis uses published financial statements as a basis). Red colour seeks to suggest that a lack of academic literature can be observed regarding respective techniques (for example 'Margin accounting' is not available in SMA/competitor accounting/analysis). The tick-marks attempt to hint at that respective techniques have been adopted in practice.

Contributing to closing this gap in literature would provide a concept of how to develop better informed assumptions regarding competitors' performance. This in turn sheds more light on "...doing the right things..." (Mohamed \& Jones, 2014, p. 2) in order to prepare the next strategic move and in addition supports improving one's own performance (Heinen \& Hoffjan, 2005).

In addition, contributing to closing this gap in literature would support building a model of the major competitor of the focus company focusing on the latter's performance. Furthermore, such a model could be based, to a large extent, on existing knowledge of the 
markets in the focus company and in-use management accounting techniques and tools, in particular at the group level.

In the next section, I seek to tie the gap in literature to the requirements of a conceptual framework.

\subsection{Connecting the gap in literature with requirements of a conceptual framework}

Generating the required information would need an interface to be built up between management accounting and marketing, as suggested by Roslender and Hart (2003). A model integrating both the levels of single entity and group could be the basis for a meaningful collaboration between the corporate functions of control and marketing. In this context, Hopper and Powell (1985, p. 448) agree with Cooper (1981) that accounting may provide “...a 'common language' for the discussions and resolutions of contentious issues".

As outlined in the previous section, SMA/competitor accounting is not in a position to provide a respective consistent and integrated information system, especially at the international consolidated level. According to Kajüter (2003), group cost accounting has developed respective techniques which would help with working on the deficit of SMA/competitor accounting in this particular area.

Rothschild (1979) emphasizes the following key points:

- Performance by Product Line

Rothschild (1979, p. 26) obviously relates to Margin Accounting when he determines information regarding the competition's "...profitable and balanced portfolios..." as relevant for SMA/competitor accounting and analysis. At the same time, this requirement supports integrating margin accounting into one of the dimensions of the conceptual framework.

- Globalization

Rothschild (1979) relates to MNCs and globally acting competition in the context of SMA/competitor accounting and analysis. This supports incorporating the dimension consolidation hierarchy into the requirements a conceptual framework would have to meet.

- Data

Regarding data to be considered, Rothschild (1979) cites information published by competition themselves, information about competition produced by others and own information collected. This approach supports including different views on 
competitors' performance which outlines possible proceedings regarding the data to be scrutinized based on the conceptual framework.

Techniques developed in consolidated cost accounting (Dusemond, 1994; Kajüter, 2003; Rein, 1993) would help to fill the gap in literature. Therefore, the conceptual framework would benefit from integrating these approaches in its design.

In the next chapter I seek to elaborate on the research methodology applied in this project. 


\section{$3 \quad$ Research methodology: identifying philosophical tradition adopted}

\subsection{Research and development of knowledge}

Research is closely intertwined with the development of knowledge. In this context, the researchers' understanding of reality forms an important pillar. In addition, the researchers' belief regarding the question of which knowledge in a specific area of research is valid constitutes the second set of essential assumptions (Saunders, Lewis, \& Thornhill, 2009).

In this section, I seek to explain the Philosophical Tradition on which this research is based.

The researchers' understanding of the nature of reality relates to ontological assumptions. The belief regarding the question of what can be considered as valid knowledge in a specific field of research is reflected in the epistemological assumptions.

In order for the decision about the choice of a philosophical tradition for the research to have a firm basis, it appears reasonable to systemize ontological and epistemological assumptions. Saunders et al. (2009) and other authors (for example, Bryman \& Bell, 2011; Easterby-Smith, Thorpe, \& Jackson, 2008; Ryan, Scapens, \& Theobald, 2002) use the concept of research paradigms to systemize their approach to philosophical traditions and recommend the systemization of paradigms introduced in the work of Burrell and Morgan (1979).

In order to explain the choice of the philosophical tradition for this project it makes sense to focus on the literature that appears to describe the best fitting approach for this project. Therefore, I will concentrate on Hopper and Powell (1985) and Chua (1986) who base their articles also on Burrell and Morgan (1979). This will be elaborated in the next sections.

\subsection{Most influential authors for this project}

\subsubsection{Burrell and Morgan (1979)}

\subsubsection{Dimensions for categorizing paradigms}

Grounded on the assumption “...that all theories of organization are based upon a philosophy of science and a theory of science..." (Burrell \& Morgan, 1979, p. 1) the authors first define four sets of assumptions (ontology, epistemology, human nature and methodology 'subjective - objective') under which they analyse different approaches to social science.

Ontology deals with assumptions about reality. Realism as an objective approach to social science defines reality as a "...given out there in the world..." whereas nominalism, representing the subjective angle, looks at reality as “...the product of one's mind”. (Burrell \& Morgan, 1979, pp. 1, 3). 
Epistemological assumptions are about the nature of knowledge. The objective view, covered by positivism, recognizes knowledge as something concrete and tangible. On the contrary, the subjective view (anti-positivism) emphasizes softer elements primarily based on personal experience and insight as the nature of knowledge (Burrell \& Morgan, 1979).

Regarding the assumptions about human nature, the authors differentiate between determinism (objectivist approach) and voluntarism (subjectivist approach). Determinism sees human beings basically only reacting mechanically to what the external world requires whereas voluntarism accentuates “...free will..." and “...creativity...” (Burrell \& Morgan, 1979, pp. 2, 3).

Assumptions made regarding ontology, epistemology and human nature are essential for the assumption made concerning the methodological nature. The authors differentiate between nomothetic (objectivist approach) and ideographic (subjectivist approach) (Burrell \& Morgan, 1979).

The authors show in the second dimension of their categorization of paradigms (Burrell \& Morgan, 1979, p. 29) one extreme as "...radical change..." and at the opposing end “...regulation”.

\subsubsection{The four paradigms}

By combining the two dimensions described in the previous section the authors now develop a categorization of paradigms and define paradigm as "...a term which is intended to emphasise the commonality of perspective which binds the work of a group of theorists together in such a way that they can be usefully regarded as approaching social theory within the bounds of the same problematic". (Burrell \& Morgan, 1979, p. 23)

In this system, the two paradigms of radical change are 'radical humanism' (subjective position) and 'radical structuralism' (objective position). Central to radical humanism is the bearing down social hurdles and boundaries. Radical structuralism is focusing on questions of dominance and deprivation within society (Burrell \& Morgan, 1979).

Central to the 'functionalist' paradigm (objective/regulation position) is the assumption, that there are objective social facts that determine the social relationships between the members of a social group as well as the consciousness of the group's individuals. (Burrell \& Morgan, 1979)

The 'interpretive paradigm' (subjective position) is based on the assumption of a society that is functioning more or less without social conflicts which consequently do not have that 
importance (Burrell \& Morgan, 1979). Central to the interpretive paradigm is the inside perspective" and the assumption, that "...a priori knowledge..." is "...independent of any external reality and the sense data which it 'emits'..." (Burrell \& Morgan, 1979, p. 227). The authors see this as the key for understanding 'mind' and 'intuition' and emphasize in this context the method of 'Verstehen' (understanding) as the way to understand the inner minds of the members of a social group and how this is expressed in "...outward actions and achievements..." (Burrell \& Morgan, 1979, p. 229).

\subsubsection{Chua (1986)}

Chua (1986) states, that the philosophical assumptions underlying mainstream accounting research have "...limited the type of problems studied, the use of research methods, and the possible research insights that could be obtained..." (Chua, 1986, p. 602).

Even though the assumptions for the classifications Chua (1986) uses seem to be the same as Burrell and Morgan (1979) are using, Chua (1986) points out the following major differences due to the fact that Burrell and Morgan (1979):

- are using mutually exclusive dichotomies (for example, determinism vs. voluntarism),

- interpret Kuhn (1970) wrongly in stating, that the choice of a paradigm is irrational,

- encourage “...latent relativism of truth and reason...” (Chua, 1986, p. 603),

- make a differentiation between 'radical structuralist and humanist' paradigms which appears to be doubtful.

As such, she does not adopt the framework of Burrell and Morgan (1979) and suggests to differentiate between assumptions about "...knowledge, the empirical phenomena under study, and the relationship between theory and the practical world of human affairs..." (Chua, 1986, p. 603). An overview of the 'Classification of Assumptions' chosen by Chua (1986) is given in Figure 7. 
Figure 7: Classification of Chua's (1986, p. 605) Assumptions

A Classification of Assumptions

\section{A. Beliefs about Knowledge}

Epistemological

Methodological

B. Beliefs about Physical and Social Reality

Ontological

Human Intention and Rationality

Societal Order / Conflict

C. Relationsship between Theory and Practice

Using this categorization Chua (1986) then scrutinizes how this set of assumptions is reflected in Mainstream Accounting, Interpretative Accounting Research and the Critical Accounting Research Figure 8. 
Figure 8: Dominant Assumptions of Mainstream Accounting according to Chua (1986, p. 611)

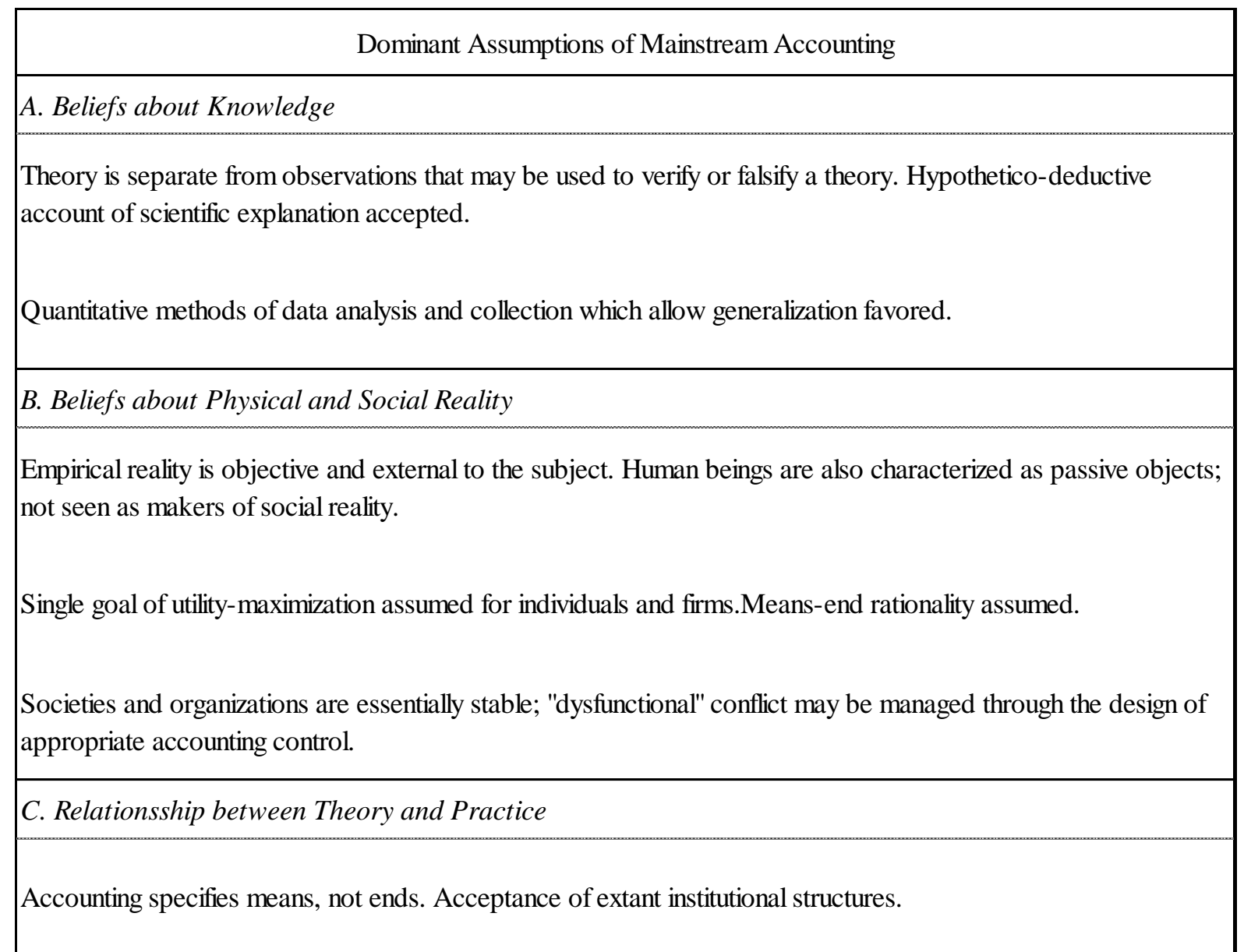

She states that the Mainstream Accounting approach is seeking to generate "...generalizable knowledge..." under the condition of maintaining certain standards of scientific research (namely validity, rigor and objectivity), but in doing so “....ignored new questions being raised in other disciplines..." (Chua, 1986, p. 613).

Chua (1986, p. 618) relates to Burchell, Clubb, and Hopwood (1980) when she describes the emphasis of interpretative accounting research in seeking “...the actor's definition of the situation and..." analysing "...how this is woven into a wider social framework..." (Chua, 1986, p. 618) and similar Boland Jr and Pondy (1981). Figure 9 illustrates the assumptions. 
Figure 9: Dominant Assumptions of the Interpretative Perspective according to Chua (1986, p. 615)

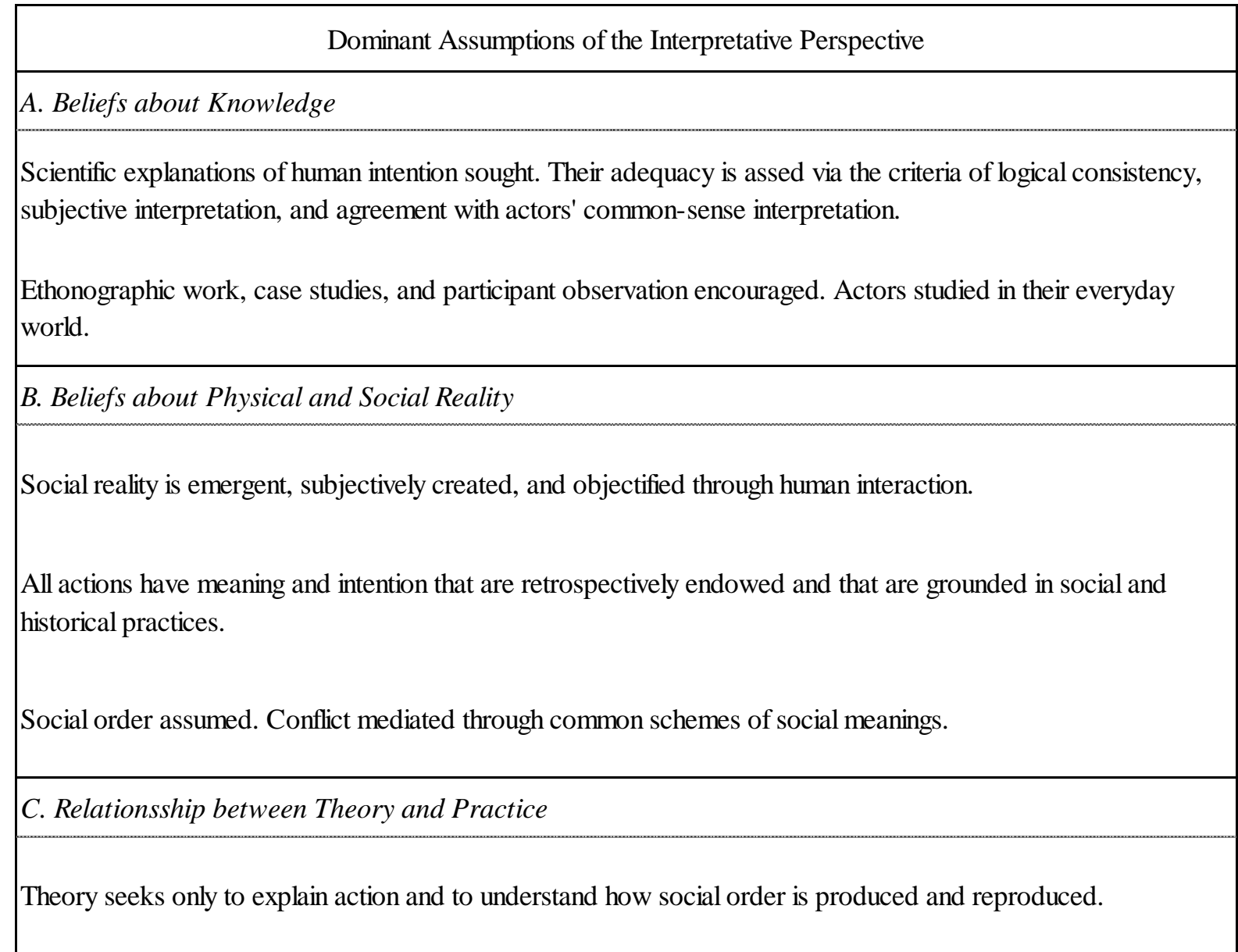

Chua (1986) sees the increasing importance of accounting information in both the public and the private sector and along with that the fact that accountants play an important role in the process of policy making as the areas where the critical perspective can make meaningful contributions.

In the next section the Hopper and Powell (1985) approach will be described as these authors are major proponents of the ideas of Burrell and Morgan (1979).

\subsubsection{Hopper and Powell (1985)}

The authors see a close connection between organization theory and management accounting and look at the work of Burrell and Morgan (1979) and its categorization of paradigms as “... a useful bridge between the two areas..." (Hopper \& Powell, 1985, p. 430).

However, Hopper and Powell (1985) do not differentiate between 'Radical Humanism' and 'Radical Structuralism' and build one category - 'Radical' - instead (Hopper \& Powell, 1985). Figure 10 visualizes the categorization. 
Figure 10: Hopper and Powell (1985) Taxonomy of Accounting Research (adopted from Ryan et al., 2002, p. 40)

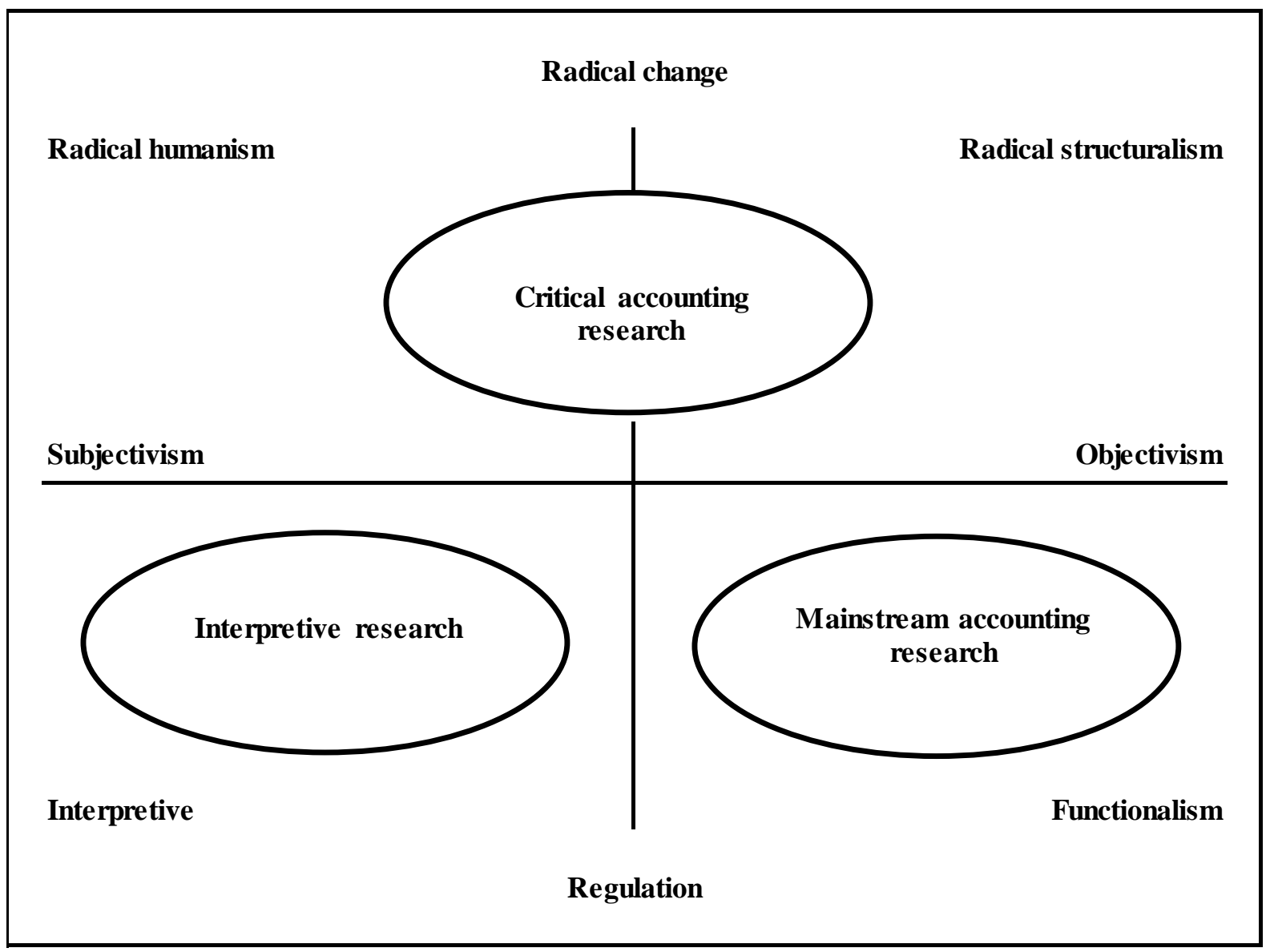

The authors then continue to use the Burrell and Morgan (1979) framework in differentiating the literature assigned to functionalism into 'pluralism', 'social science theory' and 'objectivism'.

Classical Management Theories are mainly developed in an analogy with physical laws meaning describing precise “...cause and effect relationships..." (Hopper \& Powell, 1985, p. 433). As examples for this 'objective' orientation, the authors name Standard Costing and Marginal Costing.

Social Systems Theory offers the possibility to build more complex organizational models within objectivism (Hopper \& Powell, 1985) whereas Pluralism recognizes that different interest groups within organizations are interacting with each other and, as such, open up the possibility of “...fresh ideas and insights into management accounting...” (Hopper \& Powell, 1985, p. 443). 
The authors agree to locating interpretivism in the subjective area of the Burrell and Morgan (1979) framework and, with regard to methodologies to be employed, qualitative approaches are preferred (Hopper \& Powell, 1985).

The authors share Cooper's (1981) view “...that accounting may be regarded as a 'common language' for discussion and resolution of contentious issues..." (Hopper \& Powell, 1985, p. 448) and in addition to that they follow Earl and Hopwood (1979) in stating that “...accounting systems should be 'idea machines' rather than 'rationalization machines'...” (Hopper \& Powell, 1985, p. 449).

Radical paradigms cover an area which is not subject to this work and hence will not be considered further.

Based on the discussion of the authors being of essential importance for this work, an appropriate positioning regarding the philosophical tradition will follow in the next section.

\subsection{Philosophical tradition adopted}

With regard to ontology, this project is based on my individual perspective. Consequently, reality cannot be viewed at as "...given out there in the world...” (Burrell \& Morgan, 1979, pp. 1, 3).

My position regarding Epistemology is near to anti-positivism as I will use text/other verbal information and 'concrete tangible facts'.

Regarding 'human nature', my position is clearly Voluntarism as I am convinced that mechanical reacting to some one's requirements cannot reach a level of active contributing to the development of the organization.

As a consequence of these decisions, a subjective position regarding assumptions about the methodological nature is appropriate and hence my stance is close to ideographic.

I feel motivated by Bromwich (1989)/Bromwich and Bhimani (1994), who focused with their works on the further development of (strategic) management accounting emphasizing the practitioner's perspective (for example local: Birkett, 1998; Macintosh, 1998) and by doing so making new questions and insights possible (also for example: Alnoor Bhimani \& Langfield-Smith, 2007; Al Bhimani \& Roberts, 2004).

The differences which Chua (1986) pointed out between her stance and the Burrell and Morgan (1979) framework are not restrictions for this project.

I agree with Gummesson (2000) that personal experience is essential for the interpretative paradigm. In addition, a very high degree of empathy and sensitivity is important and 
underlines that interpreting data is far more than "...taking apart and putting together..." (Thorne, 2008, p. 142). The complexity of the issue to be investigated requires a thorough understanding of the business context and the organization to be scrutinized in order to interpret and evaluate the information available.

As a result, I conclude by adopting interpretism as the world view, as according to Hopper and Powell (1985) (see Figure 10 on page 64), even though the differentiation subjectiveobjective has been challenged Ahrens (2008).

Based on the choice of interpretivism as the philosophical tradition and the gap in literature identified I will subsequently focus on the research method. 


\section{$4 \quad$ Research Method: case study as the Best Fitting Approach}

\subsection{Connecting gap in literature and task to resolve}

The increasing internationalization of German mechanical engineering companies creates the necessity of making available worldwide consolidated information for strategic decision making. Since competition is also acting on a worldwide basis, the respective competitorrelated information has to be available at the level of single entities as well as at the group level.

In section 2.8 on page 57 , the link between the gap in literature and the requirements the conceptual framework has to meet have been outlined. I use this to develop a conceptual framework in order to identify data which supports making better informed assumptions regarding major competitors' performance and achieving a competitive advantage which is in line with the research aim. Utilizing techniques developed in group cost accounting in the context of SMA/competitor accounting and analysis would support achieving my research aim.

This situation can be related to the focus company which is an internationally operating German mechanical engineering company with 30 consolidated and 10 non-consolidated subsidiaries. The company has production sites and repair shops in Germany and abroad. I head the corporate function of control and my superior is the company's CFO. The management accountants in the international sales and service subsidiaries report to me according to the dotted line principle. The function of corporate marketing reports to the CEO and CFO.

During the course of the 2011 planning process, the difference between the estimation of competitors' volume reported by the subsidiaries and what appeared to be reasonable according to simple comparisons with the published financial statements was c.30\% which led to the $\mathrm{CEO}$ and $\mathrm{CFO}$ asking me to prepare more comprehensive and reliable data for at least the major competitor.

This situation, along with the gap in literature identified, forms the point of departure for my conceptual framework.

\subsection{Conceptual framework}

The conceptual framework contains a 3-step approach which connects finance/accounting and marketing in one model in order to elaborate competitor information in order to generate competitive advantage. 
The conceptual framework sets the following basic boundaries for the project: information (marginal accounting \& KPIs, balance sheet and P\&L statement, cash flow \& KPIs, other competitive intelligence), consolidation hierarchy (single entity, group/corporate) and function (cost and financial accounting, marketing, interface SMA). The major critical area identified is located at the group/corporate level in the information categories. In Figure 11, information that is easy to obtain is marked by green arrows and information which is difficult to get hold of is marked in red colour. The task of a respective model would be to reduce this lack of information and eventually help to elaborate competitor relevant information as critical success factors according to Bullen and Rockart (1981).

Figure 11: Conceptual Framework

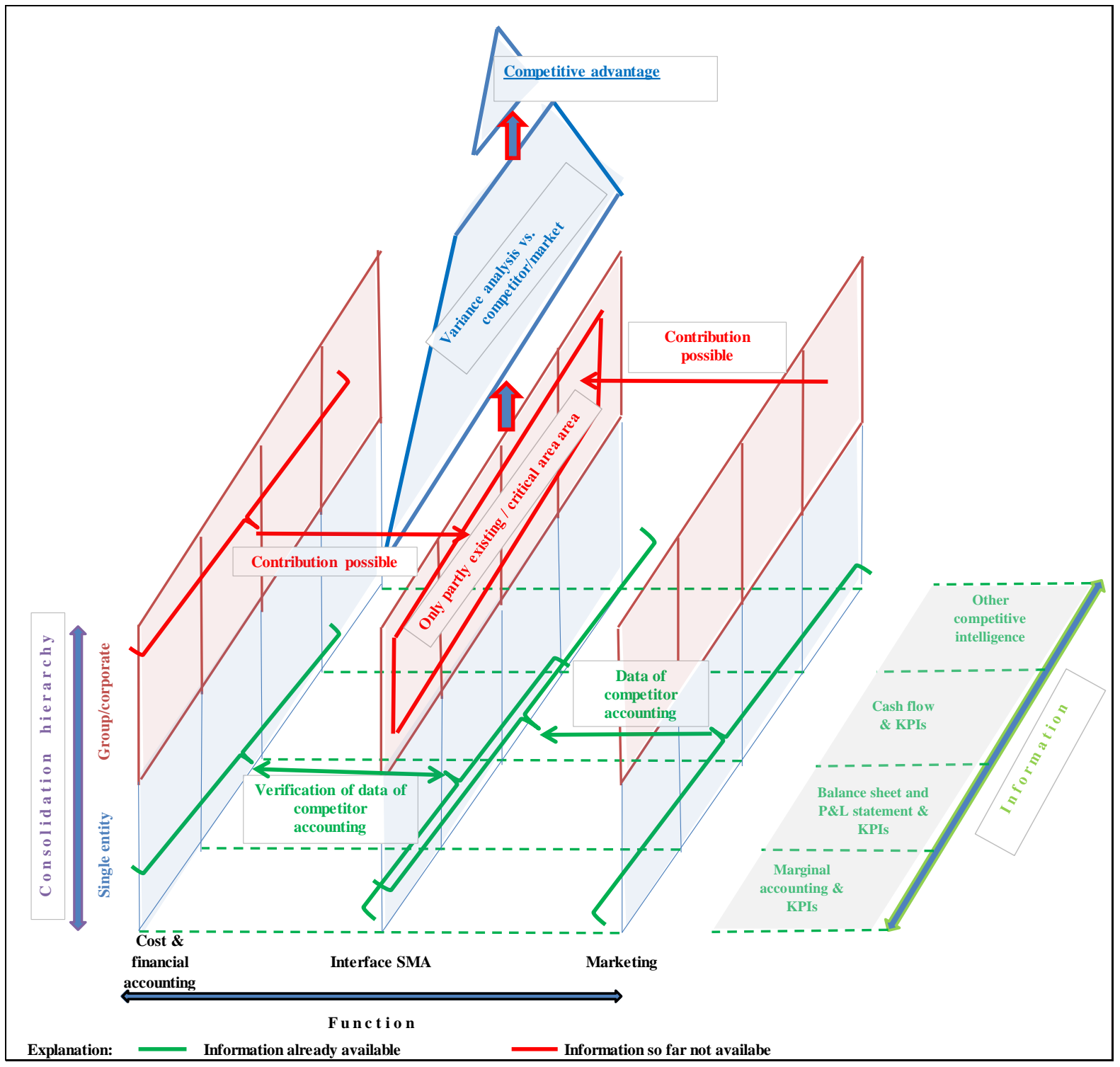


The red marked area 'Only partly existing/critical area' relates to the gap in literature identified. In addition, it seeks to offer a platform for collaboration between the corporate functions of control and marketing as described by Hopper and Powell (1985).

With regard to my research objective, my conceptual framework is based on the literature review (Research Objective 1: 'to evaluate the relevant literature and information available in the area of SMA'). Research Objective 2 ('to critically evaluate the performance relevant information available in management accounting to assist with competitor accounting in the focus company') can now be approached beginning from the 'accounting slice' as illustrated in Figure 11. Once Research Objective 2 (red marked area in Figure 11) has been achieved, it is then reasonable 'to analyze, how a strategic model of competitor accounting can provide information to aid in the creation of a competitive advantage', which is Research Objective 3. In this section, I have derived my conceptual framework from the gap in literature identified and the task to resolve it in the focus company and then related it to my research objectives. This provides the basis for focusing on the method to be applied in my project.

\subsection{Case study approach}

\subsubsection{Rationale for case study approach and course of action}

In this section, I will argue that given the research aim to achieve and the task to resolve in the focus company, the case study method suits well. Thereafter I will develop this project's case study avenue.

Several authors emphasize the increased importance of case study research in the field of international business/management and in particular in context with MNEs (Fetscherin et al., 2010; Oesterle \& Wolf, 2011; Poulis et al., 2013; Z. Yang, Wang, \& Su, 2006). Otley and Berry (1998, p. 105) underline the concern of the "...initial theoretical position..." and the interpretation of the results.

The active role that I have as a researcher in the project and the philosophical tradition of interpretivism that I have adopted advocate a case study approach.

In addition, case study research accepts the internal perspective and in connection with that allows the application of an existing theory (in this case existing theory of management accounting at the level of single entity and group) in a new context which is in this case competitor accounting ('theoretical generalization' according to Ryan et al., 2002).

In order to counteract objections from the positivist tradition that case study does not have “...the rigor of natural scientific designs..." (Easterby-Smith et al., 2008, p. 97; Verschuren, 
2003), I will demonstrate evidence of maintaining accepted quality standards as described by Farquhar (2012) who follows Lincoln and Guba (1985) in suggesting credibility, transferability, dependability and confirmability as quality criteria in the case of a study that is based on qualitative methods.

Farquhar (2012) relates credibility especially to clear structured background information. The data that will be used in this project and the way it is structured will be presented in the course of the description of the approach. In addition, the author emphasizes the importance of experience and perspective; this is due to my professional experience and length of service in the case study company. The internal perspective is supported by the fact that I have known all the key persons in the case study company for a number of years personally (Eisenhardt, 1989).

Regarding transferability, Farquhar (2012) refers in a positivistic context to external validity or generalizability. Concerning generalizability, I will follow the concept of theoretical generalization as described by Ryan et al. (2002, application of an existing theory in a new context). As for 'external validity', I will conduct verification and proof of consistency based on the conception of triangulation.

Dependability applies to the situation "...that a researcher may make or have to make changes in the way they collect and analyze for reasons that were not appreciated at the outset of research..." (Farquhar, 2012, p. 107). Due to this project's system, deviations from the procedure defined can be identified early and implications for the project explained.

Confirmability alludes to proving that the research "...is not overly influenced by personal values or theoretical inclinations..." (Farquhar, 2012, p. 108). According to the author, the interpretivism view accepts triangulation as a way to prove confirmability.

It can be summarized that according to standard textbooks in the field of business and management, this project is formed by a configuration which is reasonable for applying the case study method (Bryman \& Bell, 2011; Easterby-Smith et al., 2008; Farquhar, 2012; Ryan et al., 2002; Saunders et al., 2009; Yin, 2009).

Based on this rationale for applying the case study method I will now seek to elaborate on this project's methodological approach. 


\subsubsection{Case study point of departure}

\subsubsection{Approach according to Yin (2009)}

According to Yin (2009), Case Study Research has developed from a mere data collection technique to an independent research method. In order to develop a definition of case study research, Yin (2009, p. 18) first focuses on the basis boundaries and emphasizes 'real-life phenomenon' and 'context'-focus:

" 1 . A case study is an empirical inquiry that

- investigates a contemporary phenomenon in depth and within its real-life context, especially when

- the boundaries between phenomenon and context are not clearly evident."

In concrete situations, it may become difficult to differentiate between phenomenon and context. Therefore Yin (2009, p. 18) extended the definition by, for example "...data collection and data analysis strategies...:

2. The case study inquiry

- copes with the technically distinctive situation there will be many more variables of interest than data points, and as one result

- relies on multiple sources of evidence, with data needing to converge in a triangulating fashion, and as another result.

- benefits from the prior development of theoretical propositions to guide data collection and analysis".

In order to ensure that this point of departure is in line with my research aim I will reconcile this approach with my research objectives. Thereafter I will focus on the research design.

\subsubsection{Connecting case study approach and research objectives}

The research objectives centre on generating better informed assumptions regarding competitors' financial performance (Research Objective 2: ‘...critically evaluate performance relevant information available in management accounting to assist with competitor accounting in the focus company') in order to produce competitive advantage (Research Objective 3: '...analyse how a strategic model of competitor accounting can provide competitive advantage').

The respective corresponding information categories have been outlined in the conceptual framework ('margin accounting', 'P\&L statement', 'balance sheet', 'cash flow statement', 
'other', see Figure 11) and form one pillar of this Case Study. These types of information relate to the financial performance according to Research Objective 2.

In addition, the areas of information (internal and external data) need to be taken into consideration and be connected with the aforementioned information categories. This refers to defining what information/data (for example, relating to sales/P\&L statement) can be generated from which information area (internal/external). The term information area will be elaborated in more detail later.

Furthermore, the conceptual framework relates to the international/global perspective of business through using the dimension 'consolidation hierarchy'. This accounts in particular for the levels of subsidiaries and group and the respective financial performance according to the information categories/areas defined above.

The aforementioned elements form the basis for describing the case study design, which I will attempt to do in the next section.

\subsubsection{Case study design}

\subsection{Propositions}

Yin (2009) mentions as basic elements of a case study the questions the case study tries to find an answer for, its propositions, the units of analysis, linking data to propositions and the criteria for interpreting the findings.

The research questions have already been developed and been connected with the conceptual framework.

In addition to defining research questions, Yin (2009, p. 28) points out that propositions guide the research into the direction intended through "...reflecting an important theoretical issue..." and that propositions "...tell... where to look for relevant evidence”.

Applying this view to my project, undoubtedly the model of competition can be labelled as an 'important theoretical issue'. The leading proposition of my project is the approach to come to better informed assumptions about competitors' financial resources through applying existing management accounting techniques and data in connection with competitor accounting. Along with the positioning of this study mainly on the consolidated level of the corporate function of control, this in turn focuses on management accounting techniques/data at a consolidated level and the connection to the corporate function of marketing.

Based on these propositions, decisions regarding the units of analysis can be drawn. 


\subsection{Units of analysis}

The following overview illustrates the basic categories of the Case Study design according to Yin (2009, p. 46) which is also used by Farquhar (2012, p. 41).

Figure 12: Basic Types of Designs for Case Studies, adopted from Yin (2009, p. 46)

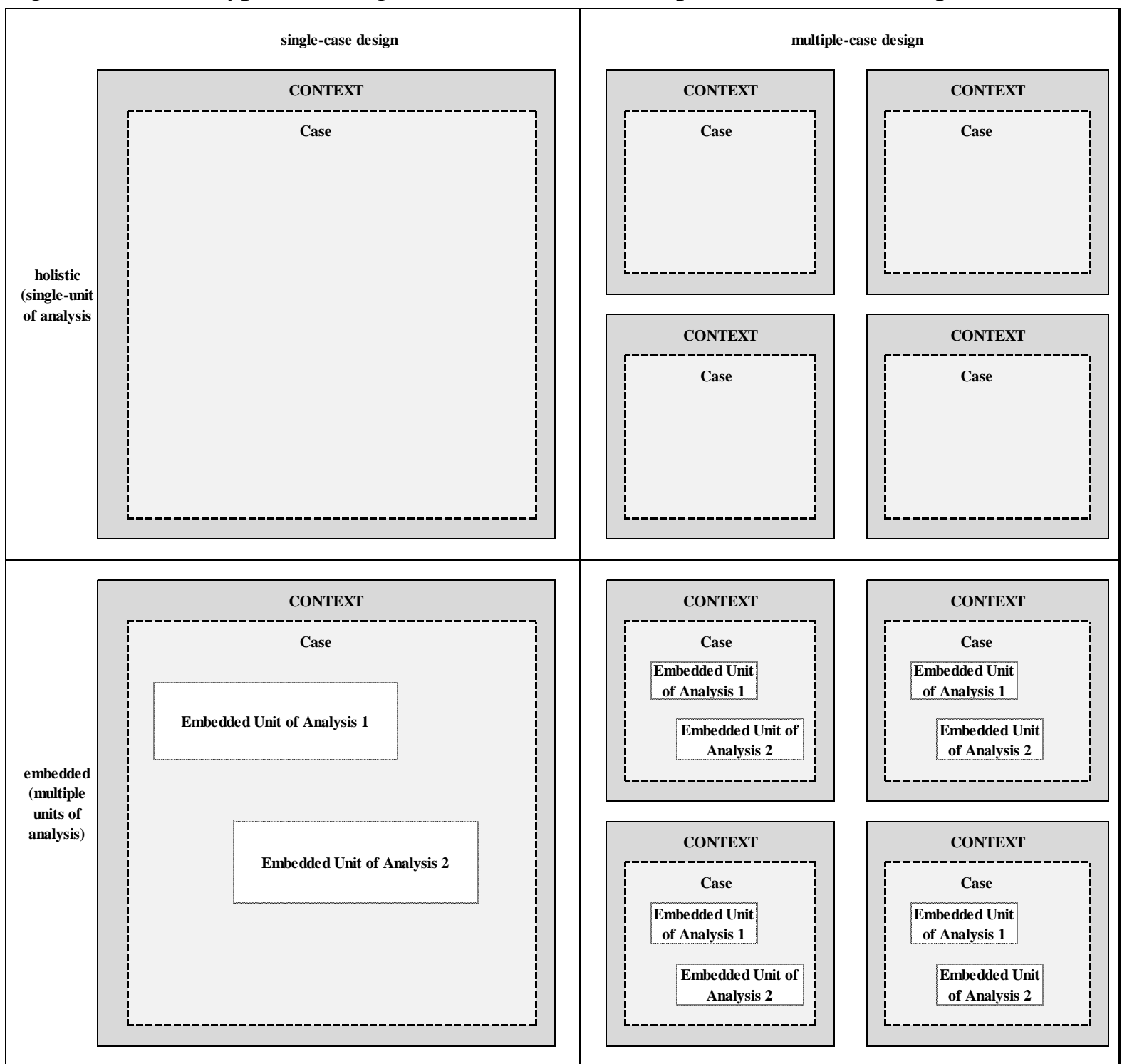

Figure 12 uses in the vertical dimension the number of cases and in the horizontal dimension the number of units as criteria for differentiation. The focus organization is a German mechanical engineering company and member of the VDMA (Association of German Mechanical Engineering Companies) which is to a certain extent representative as described by Yin (2009).

According to the conceptual framework, the basic unit of analysis is the single entity which eventually is the basis for the consolidated financial statements. From the perspective of consolidation hierarchy level, the financial statements of the single entities (basic units of analysis) are embedded in the consolidated financial statements. 
The context of this case is determined by the business environment which is characterized by an increasing internationality of business in general, the increasing demand of food and energy and chemical/pharmaceutical related products in particular due to an increasing global population.

In addition, the competitor and the focus company are estimated to have one-third world market share each, which in total covers two-third of world market, which can be evaluated as significant and therefore justifies conducting a case study approach with just one case.

These overall conditions form the context in which the major competitor and the focus company are acting and advocate an embedded single-case case study design and allow to centre on the lower left quadrant of Figure 12 according to Figure 13.

Figure 13: Embedded (multiple units of analysis) case study Design for this Project

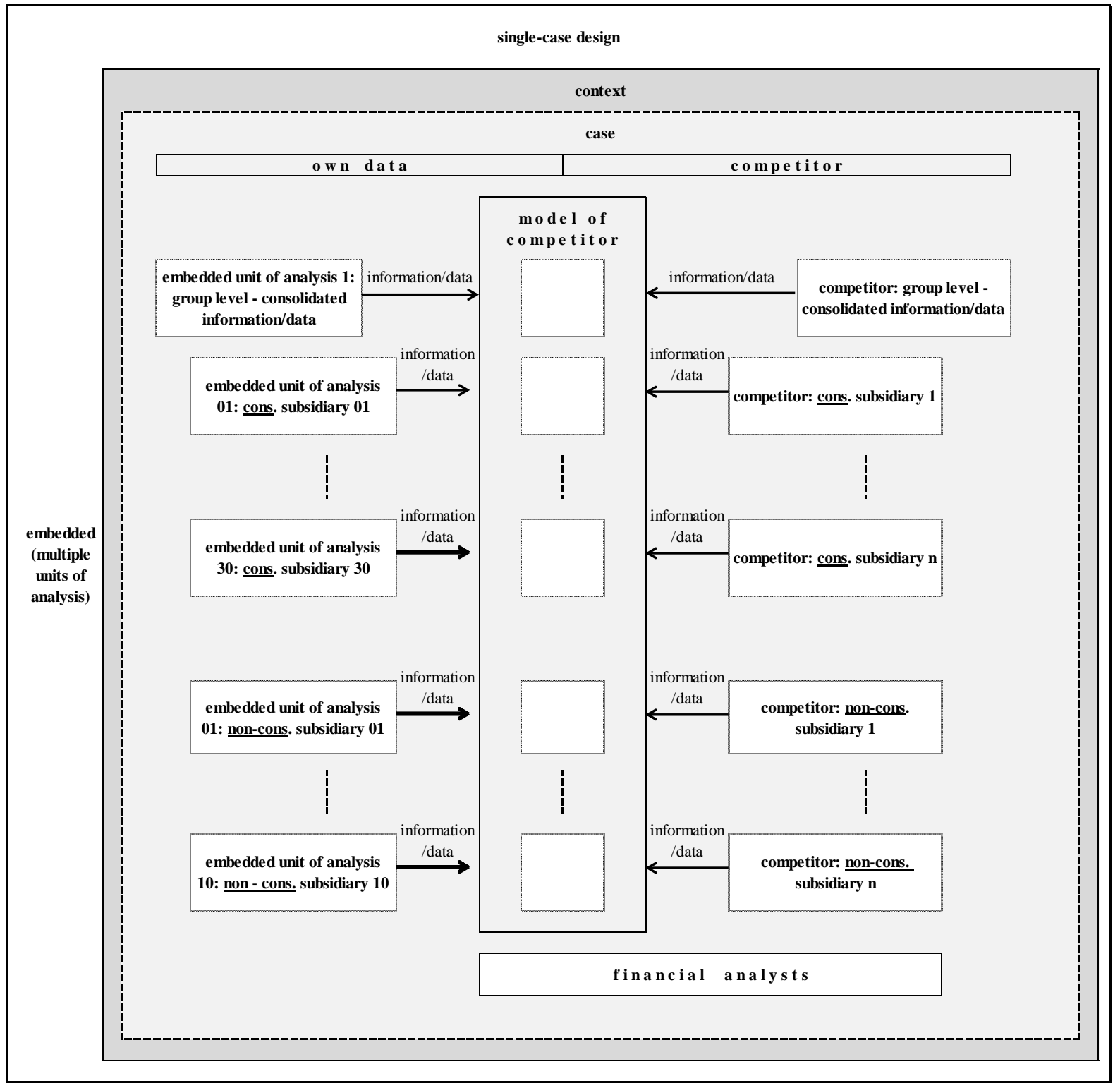


Based on the case study design outlined in Figure 13, I will go into areas of data to be investigated in the next section.

\subsection{Areas of data sources}

The areas of information / -data sources can be outlined according to Figure 13 as follows:

- Internal data

Examples are monthly Comments on Month End Closing, Contribution Margin

Accounting by Product Line on levels of single entity and group, Budget Presentation and Executive Summaries on Budget.

- From Competitor published Data

Examples are competitors' annual and quarterly press conferences, published financial statements (primarily at a consolidated level) and competitors' web sites.

- Data published by Financial Analysts

This area includes comments of financial analysts on both, actual and prospective figures and, in addition, estimations of Financial Analysts regarding future developments. Also, information provided by credit agencies is considered where available/reasonable.

The next section deals with the necessity to unify information which is available in various forms.

\subsection{Linking textual information and figures}

Data is available in the form of figures, graphs derived from figures, text and combinations of the aforementioned forms and addresses the need to merge these data in order to build a model of the major competitor according to my conceptual framework (Figure 11 on page 69).

The model of the major competitor comprises assumptions regarding relations between figures (structure, for example, in balance sheet days outstanding of trade receivables, in $\mathrm{P} \& \mathrm{~L}$ statement material usage ratio or the percentage of working capital over sales as a combination of balance sheet/P\&L statement) or variables such as, for example, sales.

In order to prepare the data for interpretation, textual information and figures containing information regarding structure and variable need to be joined to one common assumption according to Figure 14. 
Figure 14: Preparing textual information and figures for interpretation and designing

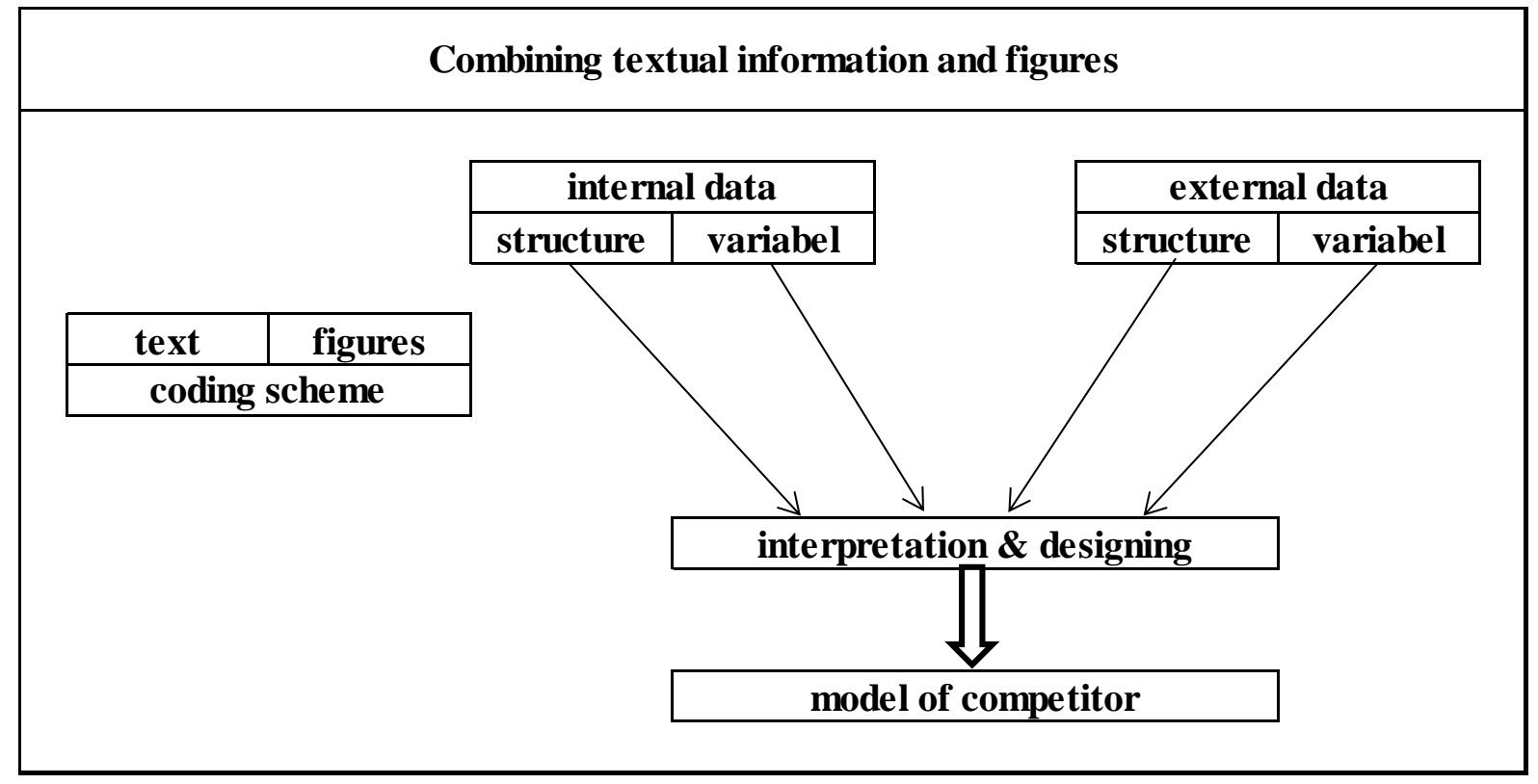

Elaborating a respective coding scheme leads to looking into the field of language and communication. "The study of meaning, language and communication has been approached from various theoretical viewpoints, including those developed in philosophy, semiotics, linguistics, psychology and media studies” (Hronsky \& Houghton, 2001, p. 124). Central to many studies in this context is the 'Semantic Differential Technique' according to Osgood, Suci, and Tannenbaum (1957) in which the respondents are asked to define for extreme pairs of terms to measure (for example stimulus word 'Father' and measure terms could be 'goodbad', 'active-passive', 'strong-weak'; example according to Haried, 1972). This technique has also been applied by, for example, Canale and Tuzet (2005); Justis and Flowers (1976); Lebar (1982); Tzeng and May (1975).

Early discussions about a communication model in the accounting context date back to the early 1960s (Bedford \& Baladouni, 1962; Belkaoui, 1980). Other works focused, for example, on conflicts between the contents of comments and figures ( $\mathrm{Li}, 1963$; Littleton, 1929; Macintosh, 2006, 2009), differences in interpretation between local GAAP and IFRS (Doupnik \& Richter, 2004; Durocher \& Gendron, 2011), 'financial language' and perceived effectiveness of financial department (Pierce \& O’Dea, 2003; Weißenberger \& Angelkort, 2011; Weißenberger, Angelkort, \& Holthoff, 2012), language used by financial analysts in the context of general economic developments (Pellens \& Lehmann, 2012) and differences in international accounting due to translation (Evans, 2004) and changes in the meaning of words over time (Evans, 2010). 
From the perspective of the organizational culture it has been observed that there is a culture of a specific function independent from the particular organization/employer. For example, "...accountants...share the same basic assumptions about the nature of their work..." and “...top managers in all organizations share a similar environment and similar concerns..." (Schein, 2010, pp. 57, 63).

Following the literature and the specifics of this project, a technique for merging and synchronizing textual information and figures has to consider industry specifics and internationality, the general economic business environment, the requirements of a communication model and provide the possibility to integrate textual information and figures.

The aforementioned requirements are met due to the following conditions:

- Internal documents (for example, monthly comments of subsidiaries, budget review presentations) are prepared by the subsidiaries' Managing Director and Management Accountant which are in all cases experienced staff and have been with the focus company for a number of years. This covers the precondition 'industry specific' and 'internationality'. In addition, the documents 'monthly comment' and 'budget review meeting presentation' contain information regarding the 'general and economic business environment' which requires the subsidiary representatives to include this in their explanations.

- The use of common internal documents is supported by the observation made by Schein (2010) relating to common assumptions of the character of the work environment of Managing Directors and Management Accountants. This makes internal documents comparable even though they are prepared by colleagues of different nationalities.

- The requirements of a communication model apply to internal documents and are fulfilled because the 'sender-receiver' relationship does not imply the risk of misunderstandings or unclear language.

The next section aims to focus on how verification and consistency will be conducted.

\subsection{Verification and consistency}

The data will be used in two ways. Firstly, based on the data coming from the years 20082012, a strategic model of the major competitor will be developed. Secondly, the model will be tested against its ability to predict competitors' 2013 actual KPIs. 
Due to the research design verification and consistency of the model can be conducted through triangulation according to Farquhar (2012); Saunders et al. (2009); Yin (2009).

Within internal data, consistency can be verified within the 'same root' (check against same type of document of the same reporting unit) and other data root (check against same type of document of other reporting units).

Verification within data published by competitor can be through checking plausibility of KPIs.

Consistency of the data published by financial analysts can be conducted by comparison of the prospective consolidated figures they calculate for the focus company with the case study company's midterm planning. Figures of midterm planning are not published. If financial analysts' estimation of the development of the case study company's figures appears to be reasonable, then their estimations of prospective figures of our competitor can be regarded as reasonable too because we act in the same context/business environment as the competition (Figure 13 on page 75 ).

After having assured consistency within the data collected from the three major sources, it is then possible to verify the consistency of the elaborated model of competition according to the concept of triangulation as follows:

- internal data used for building the model of competition

- data published by competition used for the model of competition

- data about competition published by financial analysts.

In the next section, I aim to focus on aligning the case study approach described with the method that supports identifying the criteria being relevant for making informed assumptions regarding competitor's performance.

\subsection{Critical success factors}

The research aim of this project is to improve competitor accounting through the comprehensive use of management accounting information in order to produce competitive advantage (see section 1.3.1 Research questions, objectives and aim). A contribution to producing competitive advantage would be achieved if corporate management could be provided with informed assumptions about competitors' performance because this leads to improving one's own performance (Heinen \& Hoffjan, 2005).

In this context, the recognition of Critical Success Factors is of significant importance. Bullen and Rockart (1981, p. 7) define Critical Success Factors (CSFs) as follows: "CSFs are the 
limited number of areas in which satisfactory results will ensure successful competitive performance for individual, department or organization. CSFs are the few key areas where 'things must go right' for the business to flourish and for manager's goals to be attained."

Connecting the research aim with the notion of critical success factors leads to the question what are major competitor's critical success factors where can they be identified. Rockart (1979, pp. 86-87) determined in his research following “...prime sources of critical success factors...:

1. Structure of the particular industry

2. Competitive strategy, industry position, and geographic location

3. Environmental factors

4. Temporal factors"

Regarding "Structure of the particular industry", the author mentions the specifics that all industries have. On the basis of Rockart's (1979) explanations, an example for this project could be level of sales price in certain product lines.

Concerning "Competitive strategy, industry position, and geographic location" Rockart (1979) refers to the uniqueness of every company in especially due to its development and distinctive strategy and that this may lead to the need to consider this as CSFs. Based on Rockart's (1979) understanding of this prime source for critical success factors, a basically comparable initial position can be assumed.

As for "environmental factors", Rockart (1979) refers to economic and political impacts of economy that may viewed as a CSF. In regard to the focused company and its major competitor, an acceptable example would be the financial crisis (2009-2010) and its impact on economies and the respective consequences for the business in the respective product lines.

Rockart (1979, p. 87) defines "temporal factors" as "....areas of activity that are significant for the success of an organization for a particular period of time..." and assigns this to the internal organization. Relating to the focused company and its major competitor it can be assumed that for the periods under observation neither organization had to face major temporal factors in terms of Rockart (1979).

Regarding the information to be considered, Rockart (1979) and Bullen and Rockart (1981) emphasize the importance of information external to the organization for CSFs. Furthermore, Rockart (1979, p. 92) states that "A small but significant part of the information concerning 
the status of CSFs requires subjective assessment ... and top executives are used to these soft but useful status measures." In this context, it is important to mention that this requirement is supported by the structure of the process and the method of evaluation of textual information (see chapter 5 in particular section 5.2.5.2 Evaluating textual information).

Following the conceptual framework (Figure 11 on page 69) the next step is defined by Research Objective 3 ('to analyse how a strategic model of competitor accounting can provide competitive advantage') which the next section seeks to illuminate.

\subsubsection{Linking research method and design}

The basic component of a case study is the unit of analysis (Farquhar, 2012; Yin, 2009). Since this project attempts to use cost accounting/management accounting techniques in a new context, the concepts 'unit of analysis' and its accounting equivalent need to be aligned. Therefore, a respective assignment has to be undertaken first.

The cost accounting/management accounting techniques I strive to apply in the area of competitor accounting are closely related to budgeted cost accounting. This is in line with my conceptual framework as it provides the basis for contribution margin accounting according to Franz and Hieronimus (2003, consolidated cost accounting); Kilger et al. (2007); Rein (1993, consolidated cost accounting); Vormbaum and Rautenberg (1985). Therefore, in the second step, I will attempt to explain the basic theoretical system.

Subsequently, I will aim to use the essential elements of the consolidated cost accounting system of the focus company in order to elaborate a model of the major competitor. The build-up of this model follows the structure displayed in my conceptual framework (Figure 11: margin Accounting, P\&L statement, balance sheet and cash flow-statement). This is the

phase of the project where management accounting theory is applied in the area of competitor accounting which is a new field of its use (new context).

Afterwards I will endeavour to test and verify the model using the method of Triangulation.

In the following section, I seek to align the research method and research questions and objectives.

\subsubsection{Alignment of research method with research questions and objectives}

According to Farquhar (2012, p. 101), an important element of supporting the quality of research is inter alia construct validity. The author (2012, p. 101) states more precisely that "...the reader..." needs to be offered the possibility "...to follow how the researcher went from research question to conclusion". In order to accomplish this requirement, I aim to 
explain how the research questions and objectives aligned with the model of the major Competitor (chapter 5).

The first research objective ("To evaluate the relevant literature and information available in the area of strategic management accounting") has been dealt with in the scope of the Literature Review (chapters 2 and 4). As a result, a gap in the literature could be identified and case study could be justified as a suitable approach to conduct the research.

The second research question ("How can management accounting data/techniques be utilized to develop informed assumptions regarding competitor performance?") and the related research object ("To critically evaluate the performance relevant information available in management accounting to assist with competitor accounting in the case study company") are in particular connected with the section "5.1 Introduction" and "5.3 Numerical information and accounting basis".

In order to be able to deal with the second research question/object, the textual and numerical information has been organized in a similar structure according to the conceptual framework. Regarding the textual information, the NVivo node structure has been aligned with the units of analysis. This created the basis for evaluating performance-relevant textual information and to transfer the result of this evaluation process into the respective numerical parts of the project.

Within the numerical parts of the project, this input has been employed to build, for example, the information categories of the conceptual framework (margin accounting, P\&L statement, balance sheet and cash flow statement) using respective relationships from the focus company automatically. This procedure enabled answering of the question if, and in case of to what extent, performance relevant information in management accounting can assist with competitor accounting in the focus company. As a result, better informed assumptions regarding competitors' performance are available.

The third research question ("How could a strategic model of competitor accounting provide competitive advantage?") and the related research object ("To analyse how a strategic model of competitor accounting can provide competitive advantage") are especially related to the section "5.4 Integrating the strategic angle". The results yielded out of the strategic model of the major competitor will be contrasted against competitors' communicated strategic focus and targets. This approach allows verifying whether competitors communicated strategy is reasonable and what would be a reasonable next strategic move. In addition, the focus company could adjust its own strategy accordingly. This in turn allows answering of the 
question if, and in case of to what extent, a strategic model of competitor accounting can provide competitive advantage.

In the following section, I seek to align the concepts 'unit of analysis' and its accounting equivalent.

\subsection{The entrepreneurial unit and its corresponding element in accounting}

Luther et al. (2010) identified as a major difference between Anglo-Saxon and German Accounting that German accounting strictly differentiates between cost accounting and Financial Accounting (relating section "2.3 German cost accounting and Anglo-Saxon management accounting").

Even though this project has an international orientation, it clearly has a strong German background. Both Anglo-Saxon and German accounting are inseparable from the organizational structure of the firm. In this case study, the organizational structure in turn is related to the concept of 'unit of analysis'. Therefore, it is necessary to describe how the different accounting areas are connected with the organizational structure. I will use Figure 15 in order to illustrate the different functions of German financial accounting/cost accounting and how these areas are connected. I translated the original illustration from German into English but retained the German phrases. 
Figure 15: Entrepreneurial Unit and Cost Accounting - adopted from Lorson, Melcher, and Zündorf (2013, p. 15), slightly modified and amended

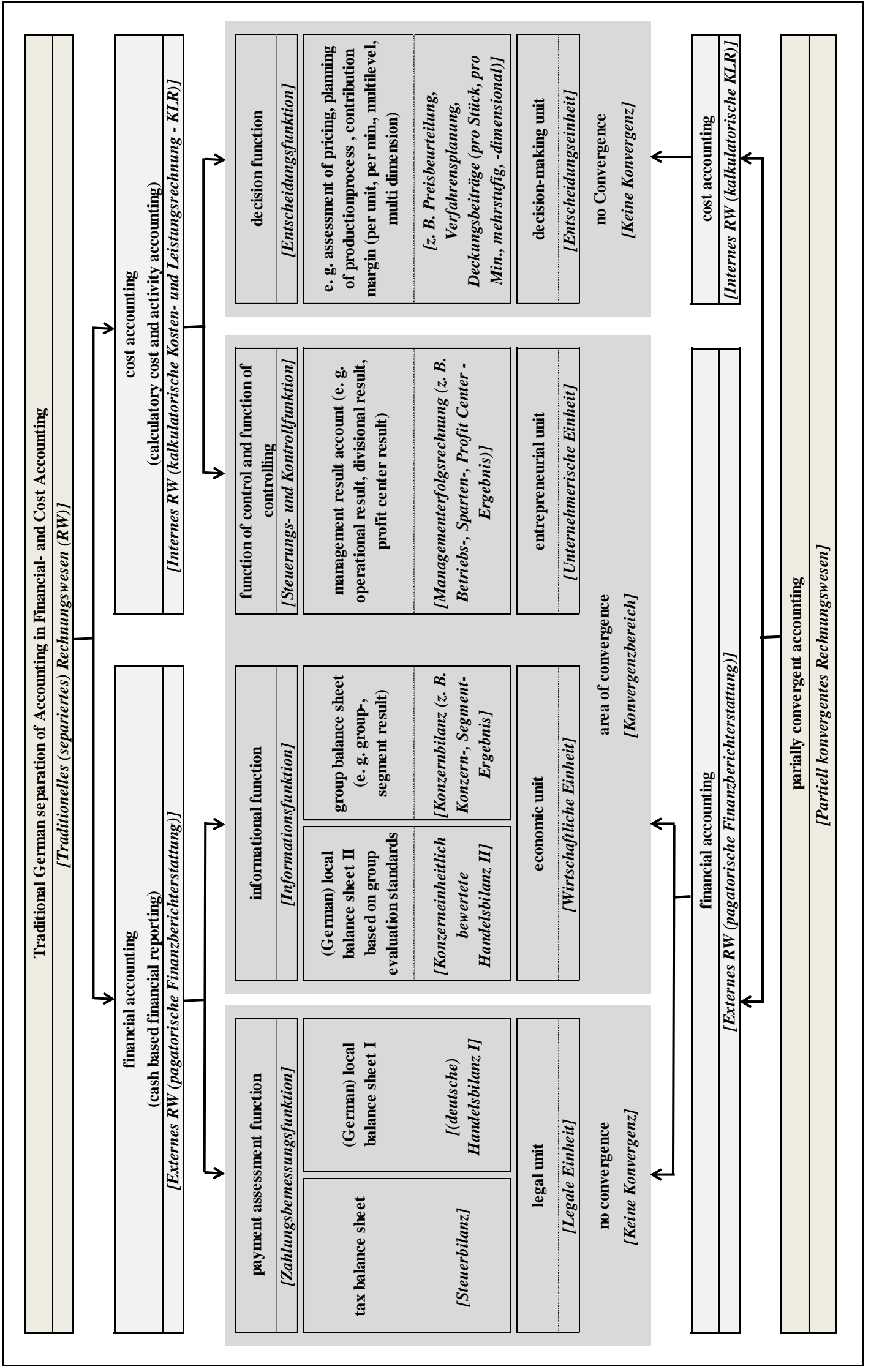


Figure 15 visualizes that Financial Accounting primarily generates information (balance sheet and P\&L statement) for external addressees and focuses on the balance sheet preparing unit. Luther et al. (2010, p. 17) emphasizes that in “...German financial accounting...focus[es]...its shaping by capital maintenance and tax requirements".

In its beginnings, cost accounting focused on generating information for internal addressees only. However, in the light of the IFRS management approach, cost accounting is contributing information to the IFRS closing which are not available in financial accounting. The phrase 'area of convergence' in Figure 15 describes this associated collaboration. Cost accounting seeks to generate information to steer the organization. The relevant unit can deviate from the legal unit and, for example, focus on a division being independent from the legal perspective. The dominant view is the entrepreneurial perspective which has a more strategic emphasis. Luther et al. (2010, p. 17) mentions 'contribution costing' and 'flexible standard costing' as dominating cost accounting systems in German cost accounting.

The strategic orientation of this project is very close to the concept and orientation of German cost accounting. This leads to the conclusion, that organizational structures as applied in Cost Accounting (for example, reporting units, cost centers, product lines) suit the concept of 'unit of analysis' well. In addition, it enables elaboration of the model of the major competitor's functions (for example, production) across legal entities according to Figure 13. Therefore, the entrepreneurial unit will be applied when scrutinizing 'units of analysis'.

In the next section, I attempt to align the Concept of Decision Usefulness with the design of the model.

\subsection{Aligning concept of decision usefulness with design of the model of the major competitor}

In this section, I firstly strive to outline the accounting basis to the extent necessary. Based on the German background of this project, I have differentiated between financial accounting and cost accounting (Figure 15). The starting point in this project is financial accounting which will then be supplemented by cost accounting on both the level on single entity and the group.

The use of cost accounting systems has increasingly developed towards decision usefulness (Figure 16). Cost accounting systems within single entities have been developed first and due to the increasing internationalization of business cost accounting systems at the group level have been derived from the respective systems of the legal entities of the group (Kajüter, 2003). 
Figure 16: Differentiation of Cost Accounting Systems - adopted from Ossadnik (2008, p. 46) and Vormbaum and Rautenberg (1985, p. 22), slightly modified and amended

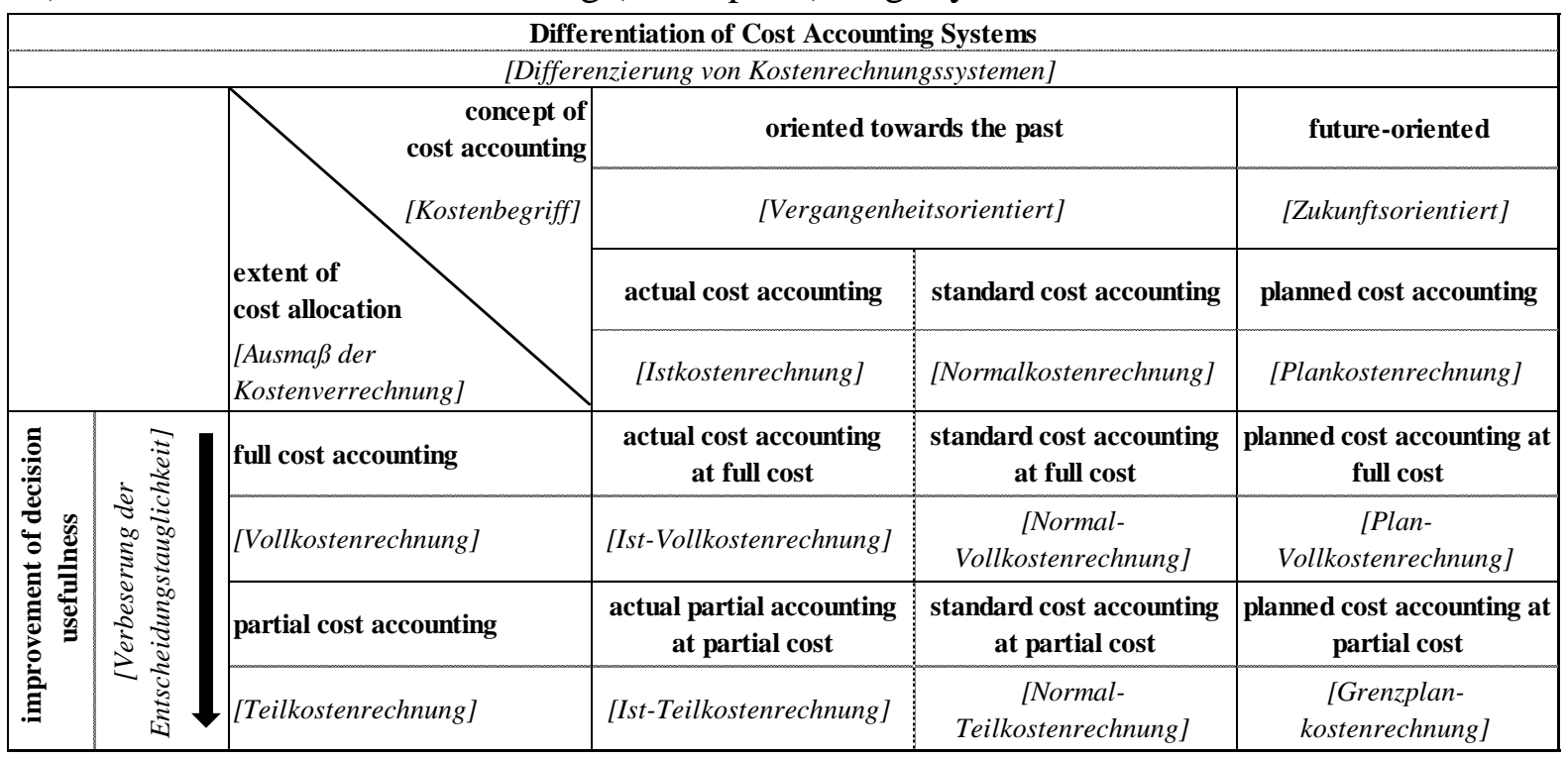

Figure 16 distinguishes in a horizontal direction between full cost and partial cost accounting systems whereas in vertical direction it uses the dimension time for differentiation.

Considering the element of decision usefulness in the design of the model of major competitor leads to the question of how this can be connected with the entrepreneurial unit (unit of analysis) and the different functions on both corporate level and the level of single entity. In Figure 17, I delineate the form of the organizational Basis of the structure of the model of the major competitor.

Figure 17: Organizational Basis for Designing Cost Accounting Structures

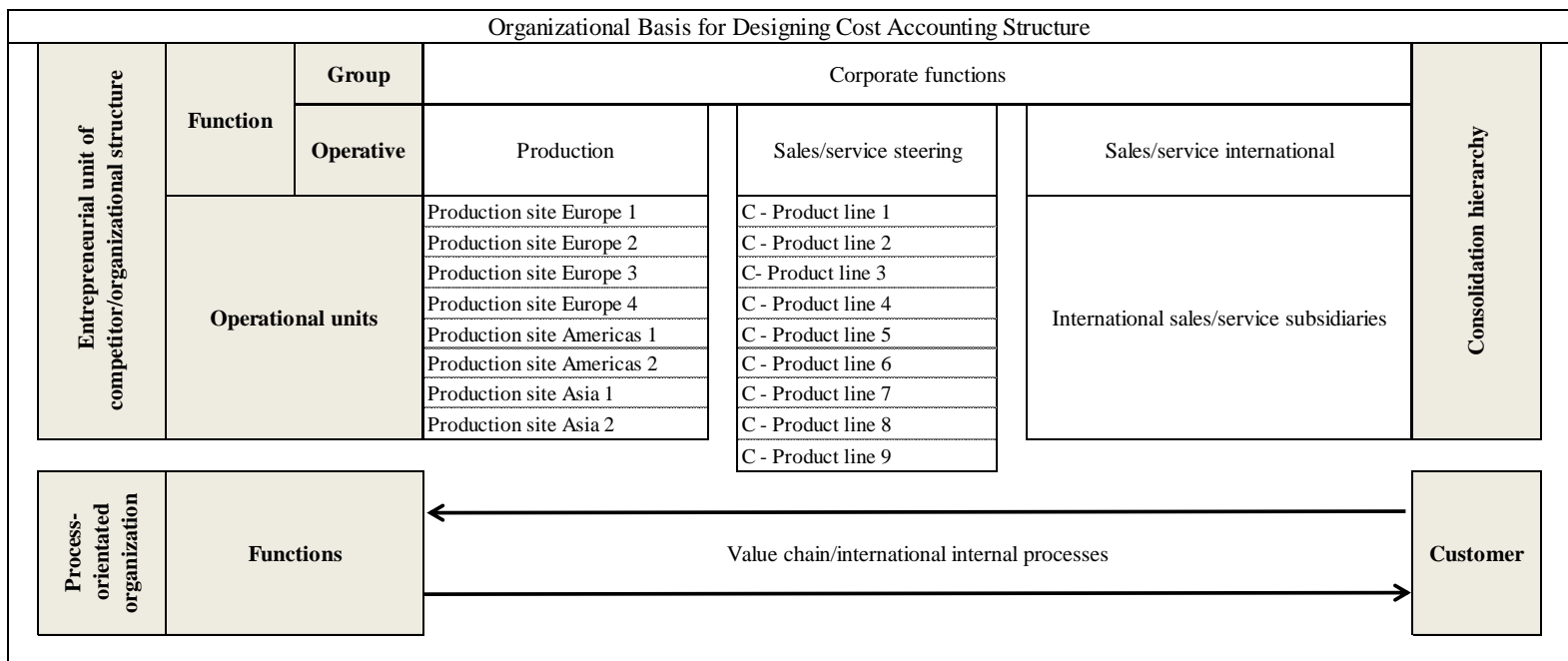

The upper part of Figure 17 displays on the left side how the term 'entrepreneurial unit' has to be understood in this project. It contains the organizational functions at the group level (for example, corporate functions of control and marketing) as well as the operative functions 
which are differentiated in production, sales- and service steering and the international salesand service organization.

At the operational level these functions are formed by respective organizational units. The operational units summarized in the function of production relate to the international production sites of the major competitor of the focus company.

The function of sales- and service steering is divided into product lines and has also an international set up which allows steering of the international sales and servicing organization.

The international sales and service organization represents the organization's local contact to the end customer.

The lower part of Figure 17 visualizes the basic flow of information regarding the customer related value chain (Kim \& Berry, 2011) within the organization and between the customer and the organization. Emphasis is put on the connecting role of the product line orientated sales and service steering organization. Information coming from the international sales and service organization is communicated to the function of production through the market orientated product line view.

The right side of Figure 17 adds the perspective of consolidation. The information generated in the operative units needs to be consolidated in order to produce a performance-orientated view of product lines for top management at the group level in order to support decision making processes. This approach is in accordance with the conceptual framework as it relates to the three boundaries of this project (namely 'function', 'information category', 'consolidation hierarchy').

Based on the essential design developed in this section, further considerations in context with the information categories of the conceptual framework can now be conducted.

\subsection{Information available}

\subsubsection{Textual and numerical information}

This project is designed to employ textual and numerical information according to the information categories of the conceptual framework (margin accounting, P\&L statement, balance sheet and other) and to connect this information in order to come to better informed assumptions regarding the major competitor's performance in order to yield competitive advantage; this is supported by Roslender et al. (1998) as it integrates financial and nonfinancial information into one tool. Furthermore, this position is supported by the view of 
SMA of Roslender and Hart (2003, p. 260) “...as an attempt to integrate insights from management accounting and marketing management within a strategic management framework". In addition, Hoque (2006, p. 137) sees it as the task of management accountants to collect and coordinate information in order to "...to bring together many ideas into one whole strategic management accounting...”.

In addition to the differentiation regarding information categories, the organizational structure and the internationality of the organization under observation requires to distinguish the information between the level of single entity and the group (section 4.6.2).

Furthermore, it has to be considered that this project follows the concept of Triangulation which leads to considering information coming from three different perspectives (section 4.6.3).

I frequently found textual and numerical information within one source document for both level of single entity and the group. This is particularly the case in published financial statements. In particular as regards the major competitor these statements have been the core area of information. In many cases these published financial statements had been prepared by well-known auditing firms and apply international reporting standards. Due to reporting obligations in particular countries, these published financial statement contain both explanations regarding figures and comments on the economic position of the company and risks. At least at the level of group, estimations regarding competition's sales in particular markets and guidance regarding the expected development of profitability have been communicated in particular to inform capital markets. This guidance was textual information. However, internationally the obligations regarding data disclosure are diverse and in many cases published financial statements were not available, particularly because of the size of the local organization or missing compulsory regulations. In the instances published financial statements have been available but are in languages other than English or German I was able to organize brief translations through the international organization of the focus company.

As with the source documents of the major competitor, the documents of financial analysts contain textual and numerical information. Very often these documents deal with the development of the share price of major competitor and respective explanations and rationales for these estimations. Also, in some documents approximate P\&L statements and balance sheets have been provided. In almost all cases the information given was based on mathematical models like Economic Value Added (EVA). Furthermore, the information available from financial analysts is mainly relating to the level of the group. It is worthy to 
note, a master's thesis taking the stance of financial analysts at the group level and covering more than the periods under observation was available.

As for the information available from the focus company it can be asserted that both textual and numerical information is available completely. Regarding textual information, comments of the monthly closing considering developments of the Product Lines and information regarding competition has been extremely useful in this project. In addition, textual and numerical information, for example, concerning competition in the context of strategic planning, was available. Regarding numerical information, it needs to be pointed out that the project benefitted from estimations of the subsidiaries of the focus company regarding the development of competitors' sales by product line and year (2008 to 2012).

In next section, I aim to illuminate the information used in this project from the angle of the dimension of consolidation hierarchy of the conceptual framework.

\subsubsection{Consolidation hierarchy}

Based on the previous section I seek to elaborate on the information categories of the conceptual framework from the angle of the dimension of consolidation hierarchy first. Thereafter, I will turn to the question of how contents given on different levels of the consolidation hierarchy can be utilized for both complementing missing information in particular at the level of single entity and for verifying information especially coming from the level of the group. Lastly, I strive to supplement these topics with information on how I dealt with the question of the basis of consolidation and related questions regarding methods of consolidation.

Looking into the different information categories of the conceptual framework, it became obvious that textual and numerical information closely connected the developments of profitability of the organization and the development of sales. In those situations, where published financial statements of the major competitor was not available at the level of single entity, the missing information particularly relating to sales could be derived from the published consolidated financial statements. In addition, supplementing information especially coming from the focus company was supportive. Furthermore, the major competitor gave information regarding the definition and development of goals and targets relating to certain KPIs at a consolidated level. This helped to derive other KPIs and their development as well as estimating relationships in $\mathrm{P} \& \mathrm{~L}$ statement and balance sheet particularly at the group level. 
Concerning the topic of the basis of consolidation, the question of how to deal with nonconsolidated companies needs consideration. In this context, consolidation regulations help in that they require that the total of the non-consolidated companies does not limit the expressiveness of the consolidated financial statement. This is in essence relating to sales, balance sheet total and number of employees. Regarding consolidation methods, I have used in the area of external accounting (particularly P\&L statement and balance sheet) actual consolidation percentages of the focus company of the periods under observation and hereby considered obligatory consolidation rules. Concerning internal accounting (margin accounting and related cost accounting) I applied the consolidation method developed by Rein (1993) adequately (see literature review section 2.4.2).

In the last section of "4.6 Information available", I seek to supplement the aspect of triangulation through describing the perspectives of focus company, major competitor and financial analysts.

\subsubsection{Perspectives of focused company, major competitor and financial analysts}

In this section, I aim to finalize the part of outlining the nature of the information utilized in this project. Firstly, I will attempt to connect the perspectives of the focus company, major competitor and financial analysts with the concept of triangulation. Secondly, I want to outline how the different perspectives are used for both supplementing in the case of missing information in one perspective and for verification of the information. Lastly, I aim to summarize section "4.6 Information available" and to lead over to the area of textual information.

The data used in this project comes from three different sources and different stakeholders who all have an independent view on the performance of the major competitor of the focus company. Financial analysts are interested in providing reliable and relevant prospective information regarding the performance of the major competitor to potential investors and the capital market respectively. This involves challenging the performance communicated to the capital market by the major competitor whereas the major competitor has an interest in communicating positive information regarding its performance to the capital market. The focus company, however, has an interest in having differentiated information regarding the performance of the major competitor in order to have better informed assumptions regarding competitor's performance in order to yield competitive advantage. Contrasting and supplementing these different initial points of interest and sources forms the basis for outlining a notion of the prospective performance of the major competitor. At this point, a 
connection between the three different perspectives of focus company, the major competitor and financial analysts can now be established. According to Bryman and Bell (2011, p. 397) "Triangulation entails using more than one method or source of data in the study of the social phenomena. The Triangulation metaphor is taken from navigation and the military strategy, where it refers to the process whereby multiple refence points are used to locate an object's exact position." Now that the approach of using three different views on the performance of the major competitor of the focus company has been intertwined with the concept of triangulation the aspect of both supplementing and contrasting data can be dealt with.

As mentioned earlier in the previous sections of "4.6 Information available", information particularly at the level of single entity may be missing due to respective obligations concerning disclosure of data in that country. Due to the precondition of a common background of a case study, it is acceptable to apply, for example, the information regarding a competitor's position in that local market in that particular product line of the focus company as a starting point for developing a resilient assumption concerning the missing information. Also, in case the information provided by one perspective appears to be implausible, it can be verified by contrasting this with the information given by another perspective.

Embracing the section of information available, it is no surprise that the information coming from the major competitor is in essence relating to compulsory disclosure regulations. In this context, numerical information is often explained and commented on by textual information. In addition, textual information is often used to comment on the economic situation of the company and to inform about risks. This applies to both the level of single entity and the group. Furthermore, the applied concept of using three perspectives is in line with the concept of triangulation. Based on this and in conjunction with the requirement of a common background, data can be both supplemented and verified.

Even though the source documents very often contain both numerical and textual information, I will deal with these areas in two different sections (5.1 and 5.3).

Based on these grassroots, the area of textual information can now be elaborated in more detail.

\subsubsection{Software used for handling of textual information: NVivo}

The sheer number of Source Documents used for this project (1979 source documents, see Figure 22 on page 102) requires the support of software. Researchers have been working with qualitative data analysis software (QDAS) for more than two decades now with an increasing importance and acceptance (Paulus, Woods, Atkins, \& Macklin, 2017). The authors (2017) 
refer to NVivo as a well-known software tool in the context of qualitative research. Edhlund and McDougall (2016, p. 3) refer to NVivo as “...the world's most popular qualitative data analysis software." Regarding the scope of supply of NVivo, Edhlund and McDougall (2016, p. 12) state that NVivo “...allows researchers to organize and analyse a wide variety of data, including but not limited to documents, images, audio, video, questionnaires and web/social media content."

The 1979 source documents used in this project relate to complex organizational structures which are reflected in the conceptual framework. More than 40 entrepreneurial units (units of analysis), 9 different product lines, 2 different consolidation levels and 6 different regions and 3 different perspectives have to be considered appropriately. Sinkovics (2012) addresses complexity in qualitative research in business and management and sees in NVivo a Software Tool which supports maintaining quality in research in complex structures.

Aligning the number of source documents to be scrutinized along with the complexity of the structures to be considered with the scope of supply offered by NVivo it appears reasonable to employ the NVivo software for managing and analyzing the textual information in this project. In addition, NVivo provides the possibility to exchange data with MS-Excel which supports creating an interface between textual and numerical information.

In order to ensure a robust build-up of the organization of the textual information, it is essential to master both the high number of source documents and the complexity of the project. Therefore, I decided to establish two basic organizational elements: differentiation of the project in three phases and consistency in the build-up of the reports.

With regard to the differentiation of the project in three phases Baird (2004) demonstrates a respective research design in the context of international business and management. Looking into the contents of the three phases, Baird (2004) allocates primary research work like literature review and definition of the research questions to the first phase. In the second phase, Baird (2004) allots the case study itself and in the third phase analytical work takes place.

Appropriately modified, the three-phase approach described by Baird (2004) appears to be able to support the work in this project in the area of organizing and analyzing textual information. A meaningful way forward in the sense of the work with textual information in this project appears to be to look at phase 1 as the initial and in essence manual work of coding references according to the conceptual framework. Based on this fundamental work 
within phase 2 a differentiation of the references in the periods 2008 to 2012 can follow with the almost automatic means provided by NVivo. This allows identification of changes between the periods under observation. In addition, an evaluation of the information scrutinized can be conducted on a defined scale and the result be exported to MS-Excel. This enables a verification of the evaluation conducted in NVivo and enables an iterative process at this point between the analysis of textual and numerical information. This iterative element within phase 2 relates to Baird (2004) who mentions an iterative process even between the different phases of the project. Based on the data verified in phase 2, noticeable issues identified can be scrutinized in more detail and a supporting thematic analysis can be conducted in phase 3 .

With respect to the element of consistency in the build-up of the reports, it is essential to integrate the EPUs appropriately. This is constituted in the organizational structure of this Case Study and the involved allocation of all source documents to EPUs. This requirement is particularly supported in NVivo through matrix coding queries which are defined as "...queries in a matrix...where contents in each cell..." is "...the result of a row and a column combined with a certain operator." (Edhlund \& McDougall, 2016, p. 368) Based on this definition of a matrix in NVivo and the organizational structure of this project, all matrix queries based on phase 1 (see sections "5.2.1 Structure of sources" and "5.2.2 Phase 1: Categories of conceptual framework") have all EPUs in the rows initially. This ensures completeness regarding the source documents. The parameters in the columns are performance-orientated according to the information categories of the conceptual framework. Due to the organization of the source documents, references coded in phase 1 were then analysed by year and perspective (financial analysts, focus company and major competitor) and if necessary, by consolidation level. The results of the queries generated were then copied in the node structure of phase 2 . These basic reports have then been supplemented by matrix queries having other criteria than EPUs in the rows (for example, "region" in the rows and "product line" in the columns) in phase 3 along with other queries such as simple wordsearch queries.

Aligning these two organizational elements accounts for a robust organization and management of the textual information along with an appropriate consideration of the complex structure under observation.

In the subsequent section, I aim to demonstrate the structure of the source documents and the corresponding references coded. 


\subsubsection{Design of classification sheets}

\subsubsection{Role and tasks of NVivo classification sheets in the project}

This project consists of a huge amount of source documents (and related references, see section 5.2.2 and in particular Figure 22 on page 102) and the organization it deals with has a complex structure. In addition, the data has to be compatible with the conceptual framework which has in its dimensions accounting-orientated structures. Furthermore, the data needs to be aligned with the concept of triangulation. These comprehensive requirements regarding both the structure of the textual information and the ability to interpret the data leads to the need of overlaying supportive means. An orientation in this context could be the meaning of master data in the accounting environment.

With respect to the element of overarching structures, NVivo employs the concept of “...customized meta-data called Node Classifications" (Edhlund \& McDougall, 2016, pp. 133-134). According to Edhlund and McDougall (2016) NVivo is also designed for assigning meta-data to source documents.

In the next two sections, I seek to illuminate how the notion of applying meta-data in NVivo has been implemented in this project.

\subsubsection{Source classification}

According to Edhlund and McDougall (2016, p. 145), "Classifications are defined by NVivo as a collective name for a certain set of Attributes that will be assigned to certain Source Items or Cases. They fall into two types: Node Classification and Source Classifications".

Regarding Source Classification the Attributes and respective values displayed in Figure 18 have been applied.

Figure 18: Structure of Source Classifications

\begin{tabular}{|c|c|c|c|c|c|c|c|}
\hline \multicolumn{8}{|c|}{ Structure of Source Classification } \\
\hline Attribute & Value & Value & Value & Value & Value & Value & Value \\
\hline Consolidation level & Group & Single entity & & & & & \\
\hline Number & $\begin{array}{c}\text { Number of } \\
\text { reporting unit }\end{array}$ & & & & & & \\
\hline Perspective & $\begin{array}{c}\text { Financial } \\
\text { analysts }\end{array}$ & $\begin{array}{l}\text { Focus } \\
\text { company }\end{array}$ & $\begin{array}{c}\text { Major } \\
\text { competitor }\end{array}$ & & & & \\
\hline Type of document & Consensus & $\begin{array}{l}\text { Earnings call } \\
\text { transcription }\end{array}$ & $\begin{array}{c}\text { Internal } \\
\text { document }\end{array}$ & KPIs & Master thesis & $\begin{array}{l}\text { Published } \\
\text { financials }\end{array}$ & Other \\
\hline Year & 2008 & 2009 & 2010 & 2011 & 2012 & & \\
\hline
\end{tabular}


The Attribute "Consolidation level" can have the values group (consolidated level) and "Single Entity" (reporting unit). Number refers in the case of the focus company to the number of the reporting unit and in case of major competitor or financial analysts directly to the EPU.

In order to apply the concept of triangulation, the attribute "perspective" contains the values "financial analysts", "focus company" and "major competitor".

The attribute "type of document" enables selection according to the different nature of the source documents.

The attribute "year" consists of the year the source document relates to.

\subsubsection{Case classification}

Regarding the case classification of the EPUs, I decided to implement the A-B-C classification by product line into the case classification of the entrepreneurial units. Therefore, a lot of attributes relate to the A-B-C classification. Figure 19 contains the attributes which are not part of the A-B-C classification of the product lines.

The first column in Figure 19 on page 96 supports referring to the attributes which I seek to explain in the following.

Numbers 206 and 207 contain the key of the cost distribution sheet which has been used in the respective EPU.

Information on whether the EPU is a BRIC country is provided through Attribute 208.

Attributes 209 to 218 relate to the core products which can be produced in a production site. The underlying logic which core product goes into which product line is not contained in NVivo.

Attributes 219 to 223 refer to the names which are necessary to link an EPU to a region or country.

Function (number 224) provided the information whether the EPU is a holding, a production site or a sales and service unit.

Number 225 gives an information regarding the quality of the reports and 226 and 227 contain the link to the respective reporting unit of the focus company.

Numbers 228 and 229 contain additional links to regions, whereas Attributes 230 to 239 give, for production sites, information on whether a product line belongs to scope of the production site or not. 
Figure 19: Structure of Case Classification of Entrepreneurial Units

\begin{tabular}{|c|c|c|}
\hline \multicolumn{3}{|c|}{ Structure of Case Classification of Entrepreneurial Units } \\
\hline$\#$ & Attribute & Explanation of value of Attribute \\
\hline 206 & BAB-Key_Name & Name of cost distribution sheet \\
\hline 207 & BAB-Key_Number & Number of cost distribution sheet \\
\hline 208 & BRIC & EPU belongs to a BRIC - country \\
\hline 209 & CP_A_large & Poduction of core product A_large (yes/no) \\
\hline 210 & CP_A_medium & Production of core product A_medium (yes/no) \\
\hline 211 & CP_A_other & Production of core product A_other (yes/no) \\
\hline 212 & CP_A_service & Production of core product A_service (yes/no) \\
\hline 213 & CP_A_small & Production of core product A_small (yes/no) \\
\hline 214 & CP_B_large & Production of core product B_large (yes/no) \\
\hline 215 & CP_B_medium & Production of core product B_medium (yes/no) \\
\hline 216 & CP_B_other & Production of core product B_other (yes/no) \\
\hline 217 & CP_B_service & Production of core product B_service (yes/no) \\
\hline 218 & CP_B_small & Production of core product B_small (yes/no) \\
\hline 219 & Cluster & EPU belongs to a group of defined countries \\
\hline 220 & Country & Name of the country EPU is located \\
\hline 221 & Currency & Currency of the country EPU is acting in \\
\hline 222 & EPU name long & Long name of EPU \\
\hline 223 & EPU name short & Short name of EPU \\
\hline 224 & Function & Values: holding, production sales\&service \\
\hline 225 & Quality of reports & A-B-C "mark" for quality of reports \\
\hline 226 & Reference unit_name & Reference unit is respective reporting unit of FC \\
\hline 227 & Reference unit_number & Reference unit is respective reporting unit of FC \\
\hline 228 & Region_1 & Aggregated name of the region in which the EPU is operating \\
\hline 229 & Region_2 & More detailled name of the region in the EPU is operating \\
\hline 230 & Scope C-PL1 & \\
\hline 231 & Scope C-PL2 & \\
\hline 232 & Scope C-PL3 & \\
\hline 233 & Scope C-PL4 & \\
\hline 234 & Scope C-PL5 & \\
\hline 235 & Scope C-PL6 & roduct line belongs to the scope of the production site (yes/no) \\
\hline 236 & Scope C-PL7 & \\
\hline 237 & Scope C-PL8 & \\
\hline 238 & Scope C-PL9 & \\
\hline 239 & Scope service & \\
\hline
\end{tabular}

Figure 20 contains information regarding the structure of the case classification of the major competitor's product lines.

The first attribute refers to the identification of the product lines, the second one to the respective EPU-production sites. 
The third attribute provides an estimation of the exposure of major competitor regarding the product line and the respective exposure of the focus company (measured in high, medium and low).

The last attribute informs about the allocation of the product line to the areas of customized or standardized end applications.

Figure 20: Structure of Case Classification of Major Competitor's Product Lines

\begin{tabular}{|l|l|}
\hline \multicolumn{2}{|c|}{ Structure of Case Classification of MC's Product Lines } \\
\hline \multicolumn{1}{|c|}{ Attribute } & \multicolumn{1}{|c|}{ Explanation of values of Attributes } \\
\hline Product line MC & C-PL1 to C-PL9 / service \\
\hline Production site MC & EPUs 110 to 117 \\
\hline Competitors exposure & High, medium, low \\
\hline Own exposure & High, medium, low \\
\hline Product area & More customized / standardized / service \\
\hline
\end{tabular}

Figure 21 informs about the structure of classifications of regions. The attributes relate to the growth perspective, the level of wages and salaries (current and perspective), the political stability and whether there is a production site in this region (both, major competitor and focus company).

Figure 21: Structure of Classification of Regions

\begin{tabular}{|l|l|}
\hline \multicolumn{2}{|c|}{ Structure of Classification of Regions } \\
\hline \multicolumn{1}{|c|}{ Attribute } & \multicolumn{1}{|c|}{ Explanation of values of Attributes } \\
\hline Name & Name of region \\
\hline Growth perspective & High, medium, low \\
\hline Level wages and salaries status & High, medium, low \\
\hline Level wages and salaries trend & High, medium, low \\
\hline Political stability & High, medium, low \\
\hline Production competitor & yes/no \\
\hline Production focus company & yes/no \\
\hline
\end{tabular}

Based on the work conducted so far, the next step of handling numerical information can be conducted which will be the focus of the following section.

\subsubsection{Software used for handling of numerical information: MS Excel}

MS Excel is a very common computer program specifically for working with numerical data. This applies also for the subjects of strategic management accounting/management accounting. 
France (2010) conducted an analysis of job advertisements in the area of Australian manufacturing and service organisations. The author relates to Chenhall and Langfield-Smith (1998) when he states that Australian manufacturing and service organisations have high adoption rates of management accounting practices compared to the US, UK and Europe. Because of the manufacturing and service background of the study and the existence of a management accounting practice comparable to Europe and the USA, it can be assumed that the outcome of the study is relevant for this project too. Relating to expertise regarding computer programs which employers expect the applicants to have, France (2010) emphasizes MS Excel and SAP. In particular, France (2010) points out the importance of skills and knowledge regarding MS Excel. This result coincides with the existing practice of the focus company. Within the focus company numerical data is handled and processed based on SAP-ERP and the SAP Business Warehouse platform in conjunction with MS Office and especially with MS Excel. Data available from financial analysts or the major competitor is in most cases not available in MS Excel but as pdf files. This information is exploited in NVivo. Alam (2016) describes the increasing importance of strategic performance measurement and competitor accounting in the pharmaceutical industry in Bangladesh. Due to the increasing internationality of manufacturing, the pertinence of this study can be assumed for this project too. The author uses MS Excel in his study for scrutinizing data and reporting of results. This confirms the application of MS Excel also in research in the area of strategic management accounting, competitor accounting and performance management research.

In accordance with the literature and contemporary practice, numerical data used in this project has been transported from mainly SAP Business Warehouse to MS Excel. This approach supports organizing numerical data according to the conceptual framework and building up structures in Excel similar to the structures in NVivo. NVivo provides the possibility to import and export information through Excel based classification sheets and reports. This in turn facilitates an exchange of information between textual and numerical data through NVivo classification sheets and NVivo reports.

In the next section, I seek to describe the build-up of the Excel-based part of the model of the major competitor of the focus company.

\subsubsection{Organizational structure and processes to be considered in context of numerical information}

The starting point of the evaluation of the textual information is the estimations of the reporting units of the focus company regarding the sales of the major competitor. The 
outcome of this process has been brought into a respective Interface which contains in essence sales information.

Within the numerical part of the project respective relationships of the lines of the P\&L statement to sales of the reporting units of the focus company deliver percentages which are applied on the sales provided by the interface. The respective calculation will be described in section 5.3.

In order to monitor the development from the starting point to the final stage within the years 2008-2012, I installed following levels:

Level 1: Basis estimation of major competitor's sales

Level 2: +- Difference to Value from Test (NVivo)

All values are calculated as a difference to the first level. This enables to see the impact of the evaluation process of the textual information

Level 3: +- Differences added due to plausibility check of KPIs (Excel)

If KPIs delivered implausible results. Correction on this level. This enables monitoring to what extent corrections have been conducted in the area of numerical information.

Level 4: $=$ Final values used

As a result, no major corrections have been conducted on level 3. Basis for developing 2013 figures is level 4.

In the next section, I seek to summarize this chapter.

\subsection{Summary of chapter}

Before starting to work on the model of the major competitor, it appears reasonable to summarize the results yielded until now and to connect this with the development of the case. Therefore, I will briefly describe the status of this work first and thereafter explain the plan of action I seek to apply.

So far, the foundation of the case study to be conducted has been elaborated. The study has been located (Figure 2: Positioning of study on page 11) using the dimensions 'subject area' (SMA, management accounting, marketing) and 'organizational classification' (decentralized and centralized). However, emphasis is put on the area SMA/management accounting on corporate (centralized) level.

In the next stage, the research aim has been defined as a contribution to improve competitor accounting through comprehensive use of management accounting information in order to produce competitive advantage. Along with the definition of the research aim, the focus company (internationally acting German mechanical engineering organization) and my role 
as a researcher (within the focus company heading the corporate function of control in that phase) has been outlined.

Based on this studies' angle, my literature review focused on the areas of management accounting/consolidated cost accounting and SMA including competitor accounting/analysis. The lack of a coherent integrated system in the area of competitor accounting/analysis and at the same time already existing techniques in the area of group cost accounting revealed the gap in literature (Figure 6 on page 56).

Given the research aim and the gap in literature identified, my conceptual framework (Figure 11 on page 69) connects the functions of finance/accounting and marketing in one model in order to elaborate competitor information in order to generate competitive advantage.

Constitutive of my research aim and the gap in literature identified in conjunction with my conceptual framework, I concluded that the case study method is well suited.

Grounded on the outcome elaborated so far, I will now report on the case study's findings. 


\section{$5 \quad$ Case Study Findings: Developing a Model of the Major Competitor}

\section{$5.1 \quad$ Introduction}

In this section, I aim to demonstrate the outcome of the findings in relation to the conceptual framework.

This case study uses textual and numerical data. Textual information has been analyzed first and has then been processed further in order to connect it with numerical data. The structure of this chapter follows this process.

Firstly, I seek to report the findings in the area of textual information and thereafter elaborate on the findings in the field of numerical information (sections 5.2 and 5.3).

Secondly, I aim to illuminate the strategic aspect of the findings of this case study and thus include the point of competitive advantage (section 5.4).

I will start with findings in the area of textual information in the next section.

\section{$5.2 \quad$ Textual information}

\subsubsection{Structure of sources}

In this section, I give an overview of how the documents are distributed according to the structure determined in the conceptual framework outlined in Section 4.2 and Figure 11 on page 69. Edhlund and McDougall (2016, p. 366) define a document as "an item in NVivo that is usually imported from a source document". In this project these source documents are mainly pdf - and some txt - files. The overview is based on Figure 22. 
Figure 22: Quantity Structure of Textual Information

Conceptual Framework: Quantity Structure of textual Information

\begin{tabular}{|l|r|r|r|r|}
\hline & $\begin{array}{c}\text { Financial } \\
\text { analysts }\end{array}$ & $\begin{array}{c}\text { Focus } \\
\text { company }\end{array}$ & $\begin{array}{c}\text { Major } \\
\text { competitor }\end{array}$ & Total \\
\hline \multicolumn{5}{|c|}{ Sources/documents by year and perspective } \\
\hline 2008 & 3 & 367 & 22 & 392 \\
\hline 2009 & 3 & 384 & 22 & 409 \\
\hline 2010 & 5 & 354 & 24 & 383 \\
\hline 2011 & 4 & 369 & 19 & 392 \\
\hline 2012 & 14 & 370 & 19 & 403 \\
\hline Total & 29 & 1.844 & 106 & 1.979 \\
\hline
\end{tabular}

References by information category and perspective 2008 - 2012

\begin{tabular}{|l|r|r|r|r|}
\hline Margin accounting & 55 & 28.013 & 1.396 & 29.464 \\
\hline P\&L statement & 117 & 6.425 & 991 & 7.533 \\
\hline Balance sheet & 34 & 1.887 & 112 & 2.033 \\
\hline Cash flow statement & 5 & 21 & 35 & 61 \\
\hline Other & 158 & 2.782 & 1.616 & 4.556 \\
\hline \multicolumn{1}{|c|}{ Total } & 369 & 39.128 & 4.150 & 43.647 \\
\hline
\end{tabular}

Average references coded per document by perspective 2008 - 2012

\begin{tabular}{|l|r|r|r|r|}
\hline Average & 13 & 21 & 39 & 22 \\
\hline
\end{tabular}

The upper part of Figure 22 relates to the sources imported into the NVivo software. In the columns I differentiate between the three different perspectives (financial analysts, focus company, major competitor) according to the conceptual framework. Furthermore, the lines in this part of Figure 22 are distinguished by year (2008 to 2012). In total, 1979 documents have been imported into NVivo. The vast majority are documents coming from the focus company (1844). The number of documents over the years 2008 to 2012 is almost constant within all three perspectives.

A start of explaining the method of calculating/deriving the combinations of EPU/product line is to see how the number of sources illustrated in Figure 22 go into the groups "A", "B" and "C". The rationale for this approach was to make sure that I have the data of the most important EPUs available. Furthermore, this approach ensures that adequate information has been generated. 
In order to do so I grouped the EPUs (sale- and service subsidiaries) according to the estimated sales of the EPU for the years under observation. Following the concept of the Pareto analysis, I considered the share of the EPU relative to the total across all EPUs regarding a particular product line. On that basis I decided that the most important EPUs were those representing a cumulated share of $80 \%$ relative to the total across all EPUs regarding a particular product line. I have labelled this group as "A". Group "B" represents the next 10\% and the remaining $10 \%$ is allocated to group " $\mathrm{C}$ ". I did not ignore the EPUs of the groups "B" and " $\mathrm{C}$ " and scrutinized this data in the same way I analyzed the data of the "A"-group. After this initial analysis of the data, this study has shown that in this particular industry scrutinizing the "A" - group may produce resilient results and thus safe time resources. This enabled grouping the sources accordingly (Figure 23). Regarding the exchange rate applied, I conducted this analysis on the average exchange rates for the respective year and in addition on the basis of the 2008 average exchange rates for all periods under observation (2008 to 2012). Both variants come to an almost similar A-B-C classification which allows the conclusion that the relationships between the 26 different currencies to be considered in this project did not change. The sources relating to EPUs group or production are not considered in the A-B-C analysis and are displayed in a separate line in Figure 23. In total $32 \%$ of the sources relate to subsidiaries representing $80 \%$ of the estimated sales and $3 \%$ refer to group and production. 
Figure 23: Total Perspectives: Distribution of Sources by A-B-C Classification by Year

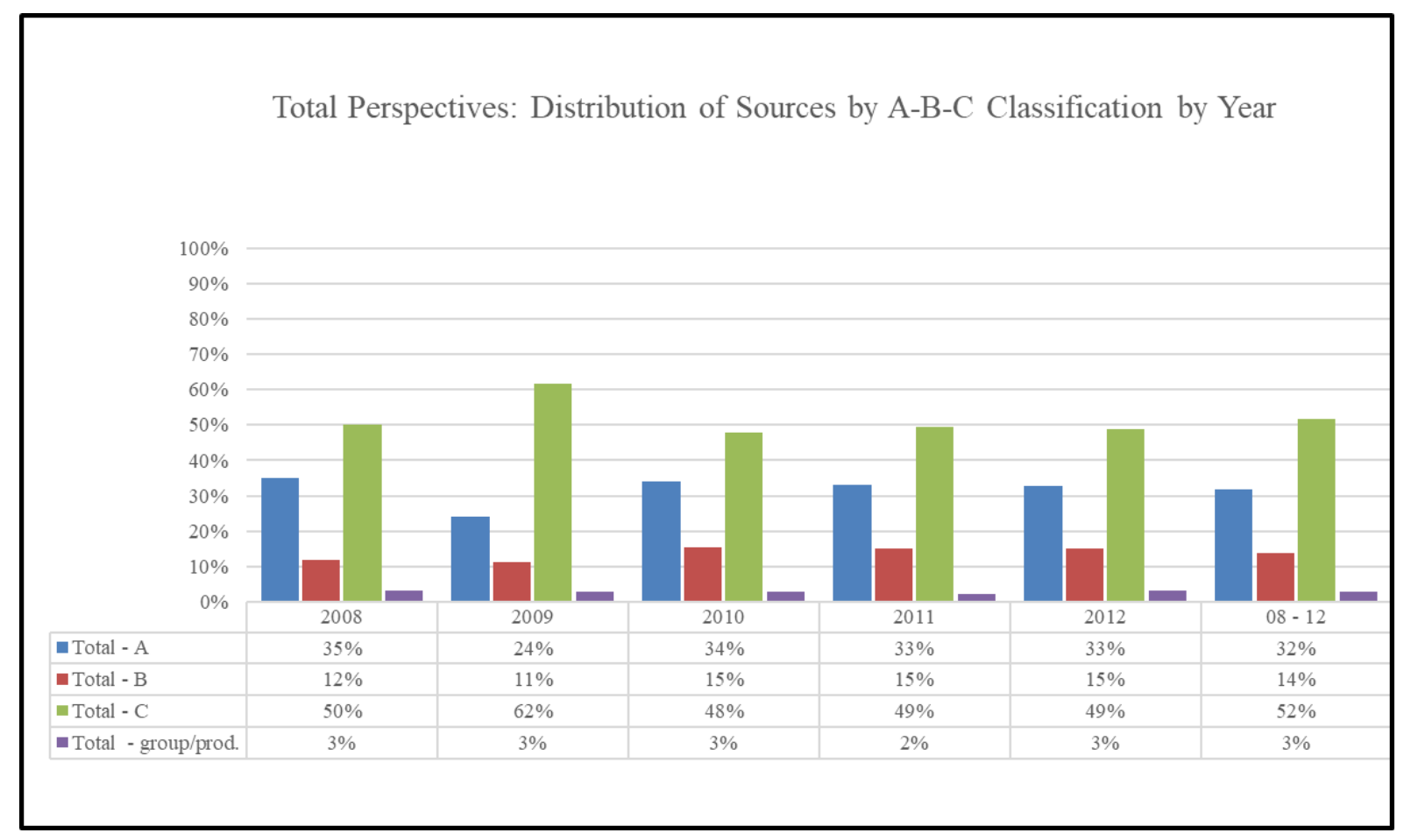

In the following three figures (Figure 24, Figure 25, Figure 26) I will do this analysis for the three perspectives (financial analysts, focus company and major competitor).

The A-B-C - structure of the sources of the focus company (see Figure 24) is very similar to the overall picture illustrated in Figure 23. This is due to the fact that the number of sources of the focus company is dominating the A-B-C structure. The most important difference is that only $1 \%$ of the sources are relating to group and production compared to $3 \%$ in the total picture. This indicates already at this point that the documents of the perspectives financial analysts and major competitor are referring to group and production. 
Figure 24: Perspective Focus Company: Distribution of Sources by A-B-C Classification by Year

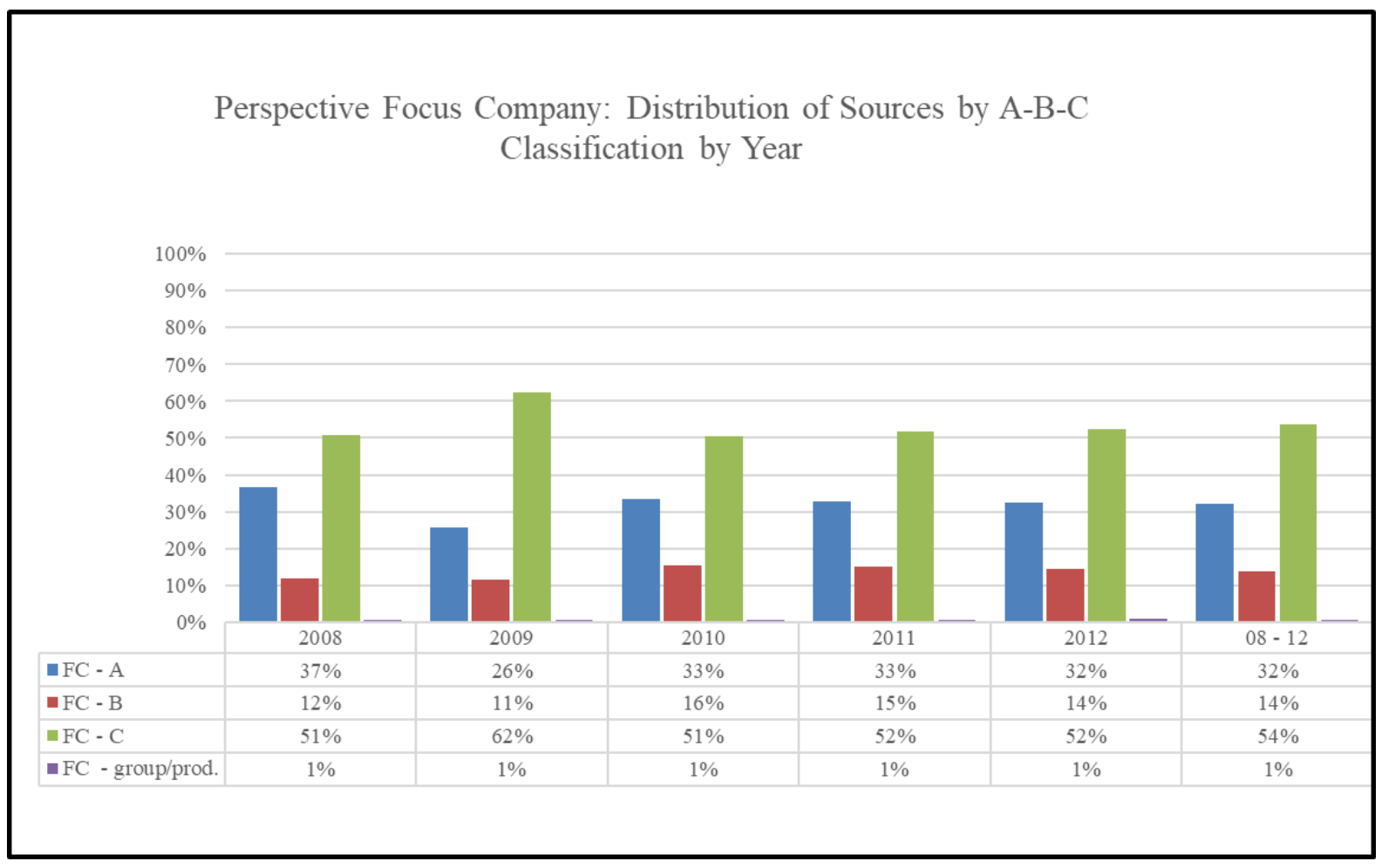

Most of the documents obtained from the focus company are relate to the level of single entity. In most cases, a comment of the monthly closing of the subsidiaries has been imported into NVivo. This monthly comment is a structured document which gives the Managing Directors of the subsidiaries the opportunity to explain the market situation and to provide information which is important to come to an appropriate understanding of the environment in which the subsidiary is acting. Besides the aspect of having explanatory information available, this project also benefits from the fact that this material has an identical structure for all sales and service subsidiaries. In addition, documents of the strategic planning of the focus company at the level of (sub-) group have been brought into NVivo.

Looking into the A-B-C - structure of the source documents of the major competitor (see Figure 25) the documents displayed in the line group/production have the biggest share (35\% in total). The second largest group are in this case "A" - sources (in total 25\%). 
Figure 25: Perspective of Major Competitor: Distribution of Sources by A-B-C Classification by Year

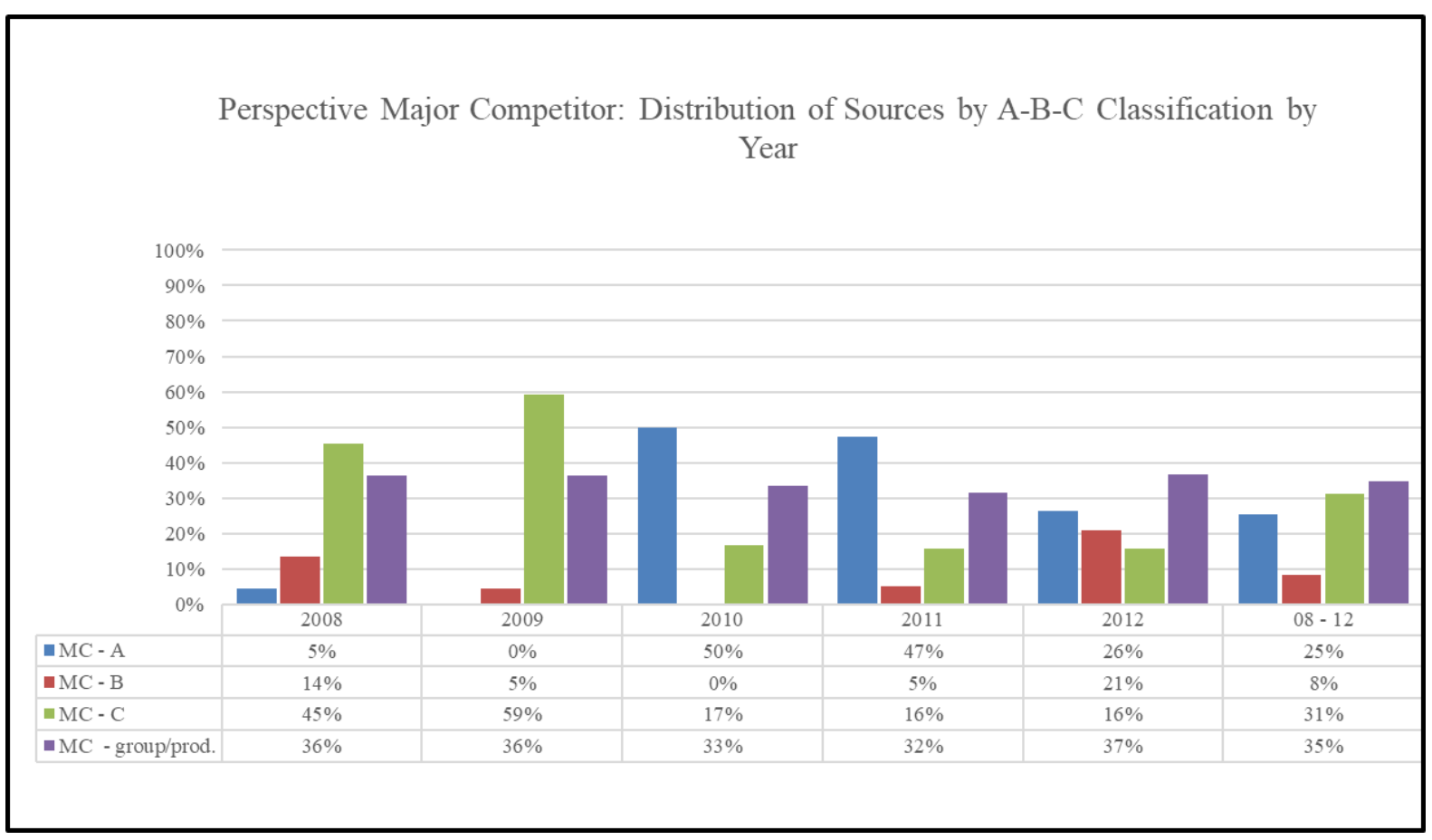

The sources pertaining to the major competitor consist in essence of published consolidated financial statements at the level of the group and documents relating to quarterly closing and respective press conferences. All published consolidated financial closings have an almost identical structure in the periods under observation. The same applies to the notes relating to press conferences.

The documents in the groups $\mathrm{A}, \mathrm{B}$ and $\mathrm{C}$ allude to published financial statements of legal entities of the major competitor. The background in these cases is disclosure obligations in the respective countries. Most of these published financial statements are prepared by wellknown international auditing firms and have a similar build-up meeting international standards. This allows to a certain extent comparability between the published financial statements.

Regarding the A-B-C classification of the documents of the financial analysts (see Figure 26), it can be observed that documents at the level of group/production have the biggest share (31\%) which is comparable to the major competitor (35\%, see Figure 25). Significant is the increase of the share of "B" - documents in the years 2010 (80\%) and $2011(75 \%)$ compared to the total of $41 \%$ for all periods under observation. Notably, the international financial crisis hit this industry in particular in the years 2009 and 2010. It appears reasonable, that financial 
analysts produce more papers due to an increased sensitivity of investors because of the financial crisis.

Figure 26: Perspective Financial Analysts: Distribution of Sources by A-B-C Classification by Year

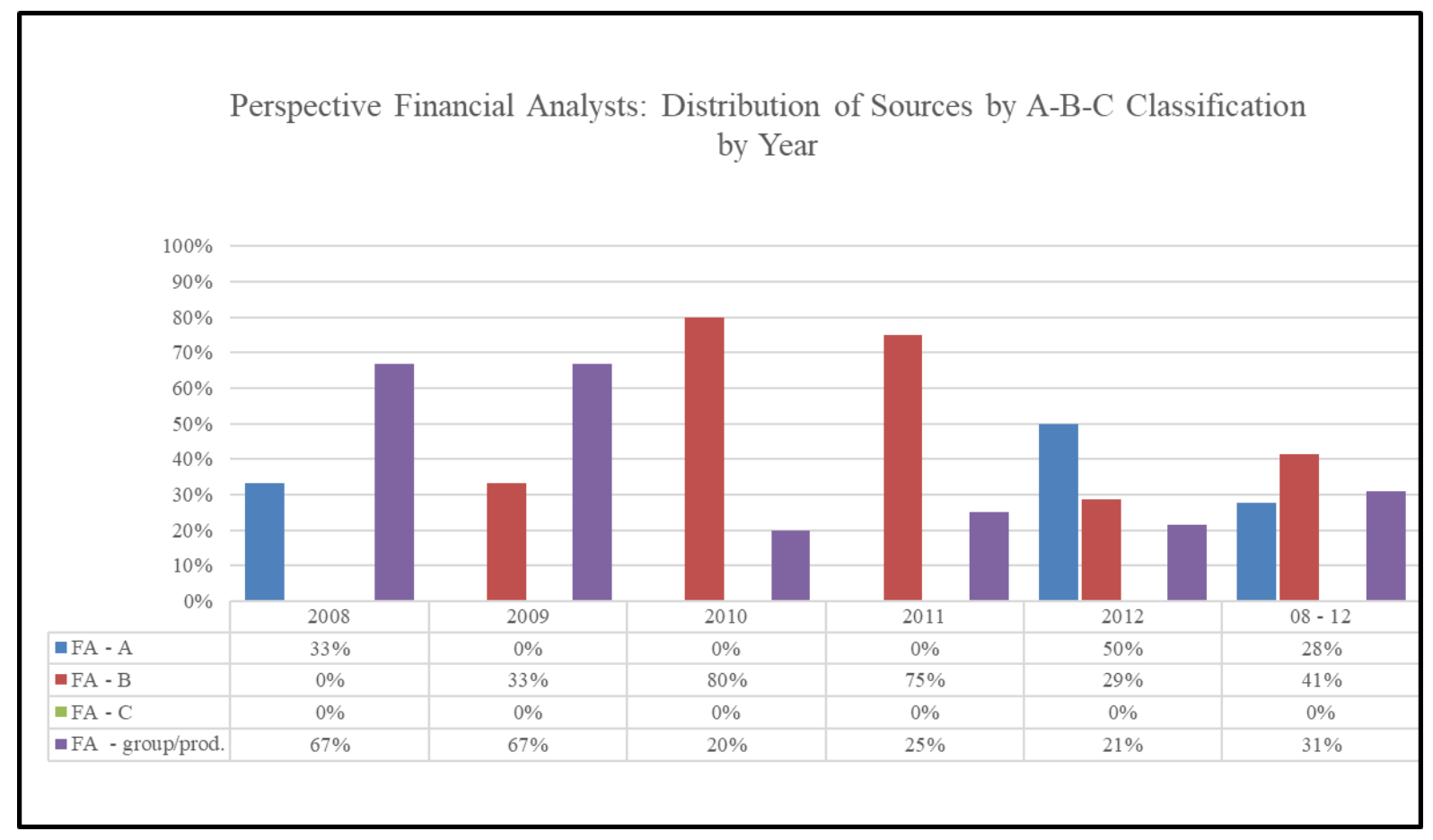

The sources associated with the perspective of financial analysts are publications of financial analysts. A very useful source in this context is a master thesis adopting the view of Financial Analysts explicitly.

The compliance of reporting standards supports the comparability of the documents within one perspective and between the three perspectives. This is in particular important in context of allocating contents of the documents to the information categories according to the conceptual framework. The allocation of contents to the information categories has been conducted in NVivo through coding which Edhlund and McDougall (2016, p. 366) describe as "the work that associates a certain element of a Source item at a certain Node". Furthermore, the authors $(2016$, p. 369) characterize Nodes as being “...often used in the context of a 'container' of selected topics or themes". This concept of nodes supports this project in particular in relation to the information categories according to the conceptual framework.

This connection of Nodes and Information Categories builds the basis for the second half of Figure 22 on page 102. In this part, the number of references coded from the 1979 sources are 
amended. The structure of Figure 22 is maintained in the columns which delivers the number of references from 2008 to 2012 by perspective. In total, I have coded 43647 references out of the 1979 sources. I distinguished between the information categories of the conceptual framework (margin accounting, P\&L statement, balance sheet, cash flow and other) within the lines.

The information given in Figure 22 in the last line is the average number of sources coded from a document by perspective. The significantly highest average has been yielded out of the documents available from the major competitor (39 references per document in average from 2008 to 2012). This indicates that the sources available from major competitor provide a lot of information which appears to be important for this project.

The contents of the source documents had been connected with the conceptual framework through coding references into nodes. The structure of the nodes is based on the conceptual framework.

After having outlined the structure of the source documents, I aim to contour the structure of the references.

\subsubsection{Phase 1: Categories of conceptual framework}

\subsubsection{Survey of quantity structure}

The number of references is coined by the directly performance related information categories margin accounting and $\mathrm{P} \& \mathrm{~L}$ statement which in total represent $85 \%$ of the references (see Figure 27). The references relating to the information categories balance sheet and cash flow statement constitute c. $5 \%$ whereas $10 \%$ have been coded to Other. 
Figure 27: References by Information Category 2008-2012

\section{References by Information Category 2008 - 2012}

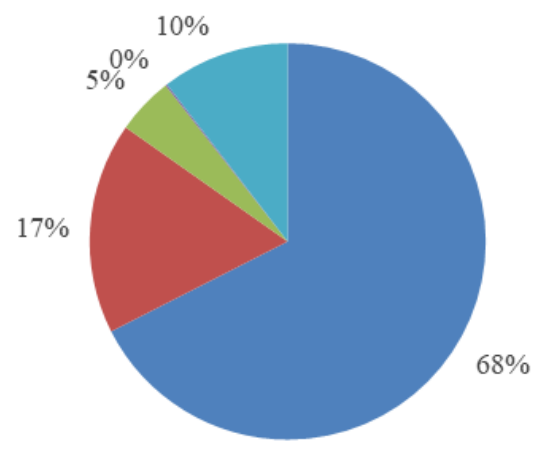

Margin accounting

- P\&L statement

Balance sheet

Cash flow

- Other

The large number of sources of the focus company is also reflected in the distribution of the references by perspectives (see Figure 28). In total c. $90 \%$ of the references are related to the focus company whereas c. $10 \%$ refer to the major competitor. Only $1 \%$ of the references allude to financial analysts.

Figure 28: References by Perspectives 2008-2012

References by Perspectives 2008 - 2012

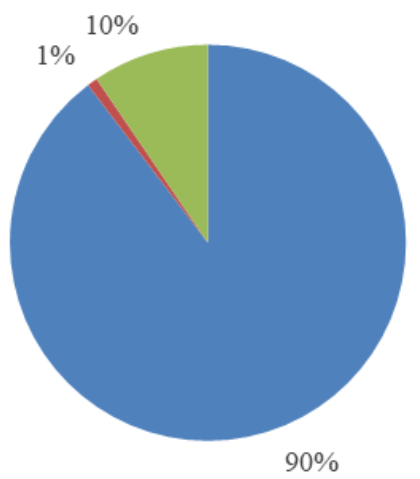

- Focus company

- Financial analysts

Major competitor 
In order to be able to connect the textual information coded with the respective calculations in Excel, a further differentiation has been conducted. In the following section, I attempt to describe the structure of the references of the information categories defined in the conceptual framework (namely margin accounting, P\&L statement, balance sheet, cash flow statement and other) in more detail.

\subsubsection{Aligning the NVivo node structure with the conceptual framework}

\subsection{Margin accounting}

In order to accomplish both developing a sense of the structure of the information available and giving and overview of the contents of the information, I decided to follow a three-stepapproach. I will start this section with describing how the references are distributed over the periods 2008 to 2012 within the three different perspectives (Figure 29). This will be followed by an account of how the references are distributed with regard to contents (Figure 30). Eventually I will to show how the references of the information category margin accounting are linked to the three perspectives (Figure 31).

Figure 29 illustrates the share of references of the information category margin accounting within the three different perspectives over the years 2008 to 2012 and in total (see details in Annex 22).

The lowest value can be observed in the perspective of financial analysts (only 15\% in 2012 and no references before) whereas the focus company and the major competitor show an almost constant share of references throughout all periods. The focus company's share of references is $70 \%-72 \%$ and that of the major competitors is in total one-third. The total value across all perspectives is c. two-third in all periods. This indicates the leading role of this information category within the references of the focus company and the major competitor. 


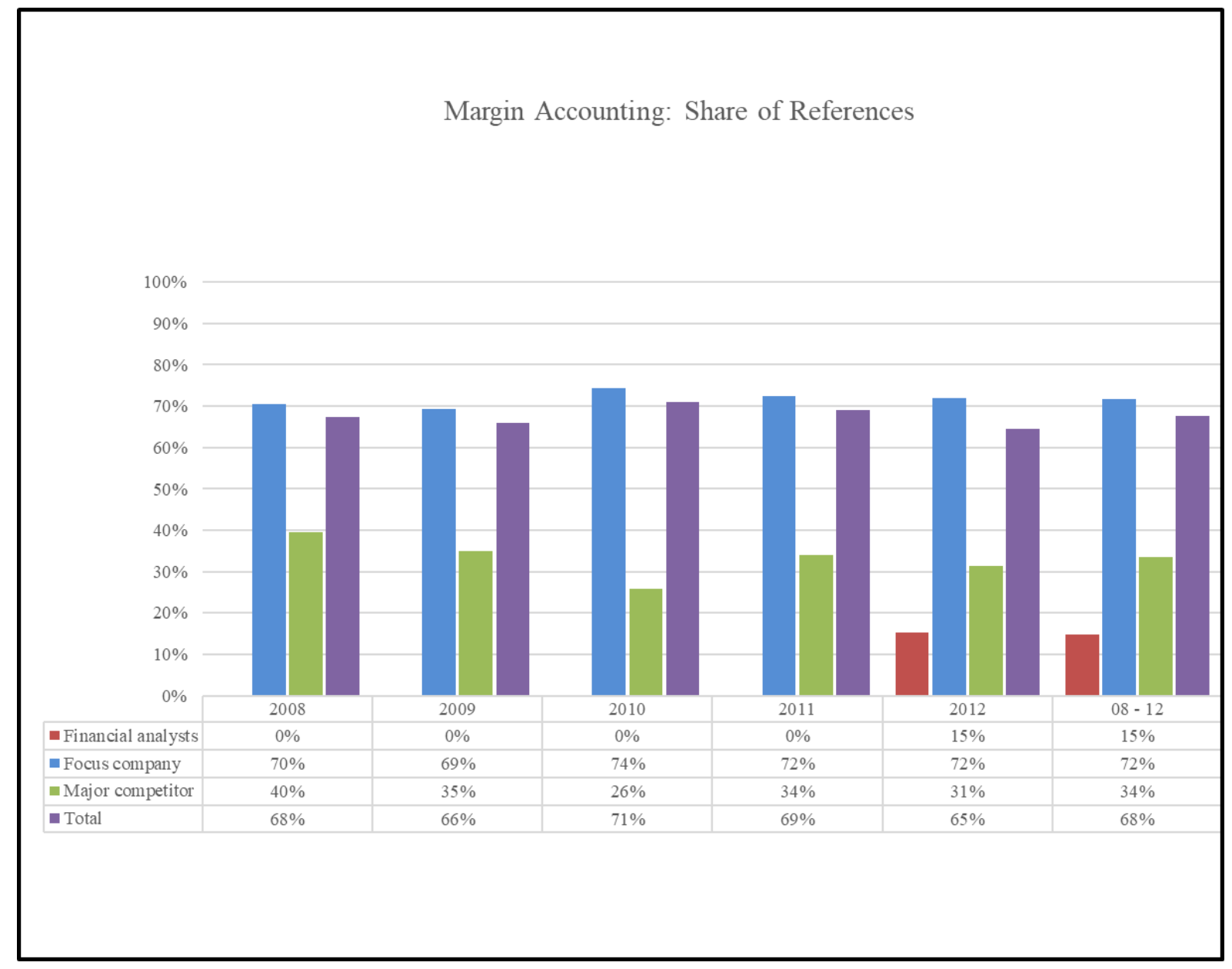

Whereas Figure 29 explains the development of the share of references within the three different perspectives, Figure 30 seeks to portray how the references have been coded within the information category margin accounting across the perspectives.

Zooming into the information category margin accounting it can be observed that a differentiation between information relating to a particular product line and information referring to all product lines can be conducted (see details in Annex 23). In this context, Figure 30 distinguishes between the shares of references allocated to the defined product lines (C-PL 1 to 9) and general. References coded into one of these "C-PL" nodes contain information regarding, for example, tenders, orders and in many cases competition. The organization of this area in nine different product lines corresponds to the build-up of the respective field in the Excel spreadsheet. 
Figure 30: Margin Accounting: References by Product Line 2008-2012

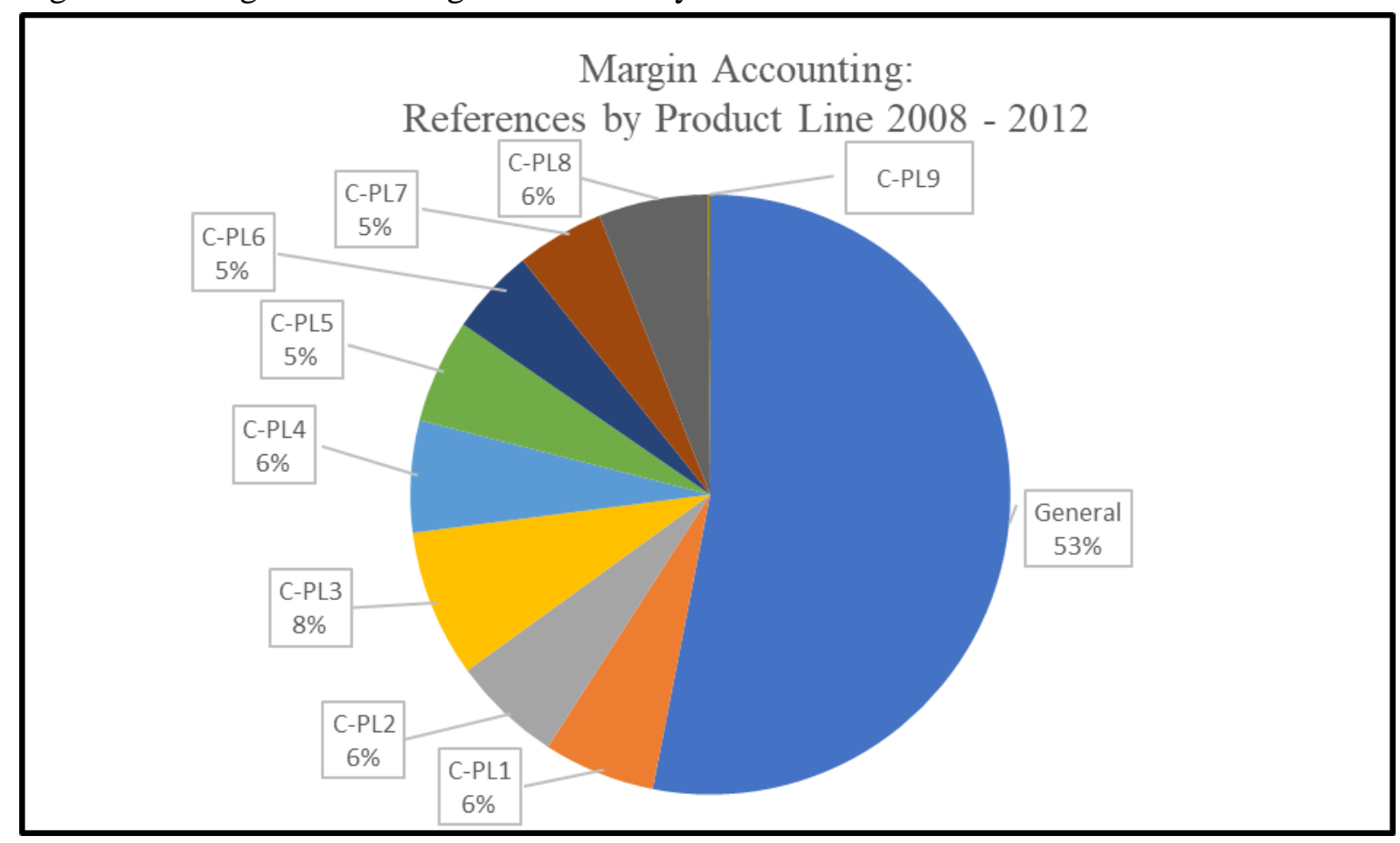

Figure 30 shows how the references of the information category margin accounting are distributed to the three different perspectives. Only a few references of this information category (below 1\%) is related to financial analysts and c. 5\% are linked to the major competitor. The vast majority of the references of this information category are connected with the perspective of the focus company. 


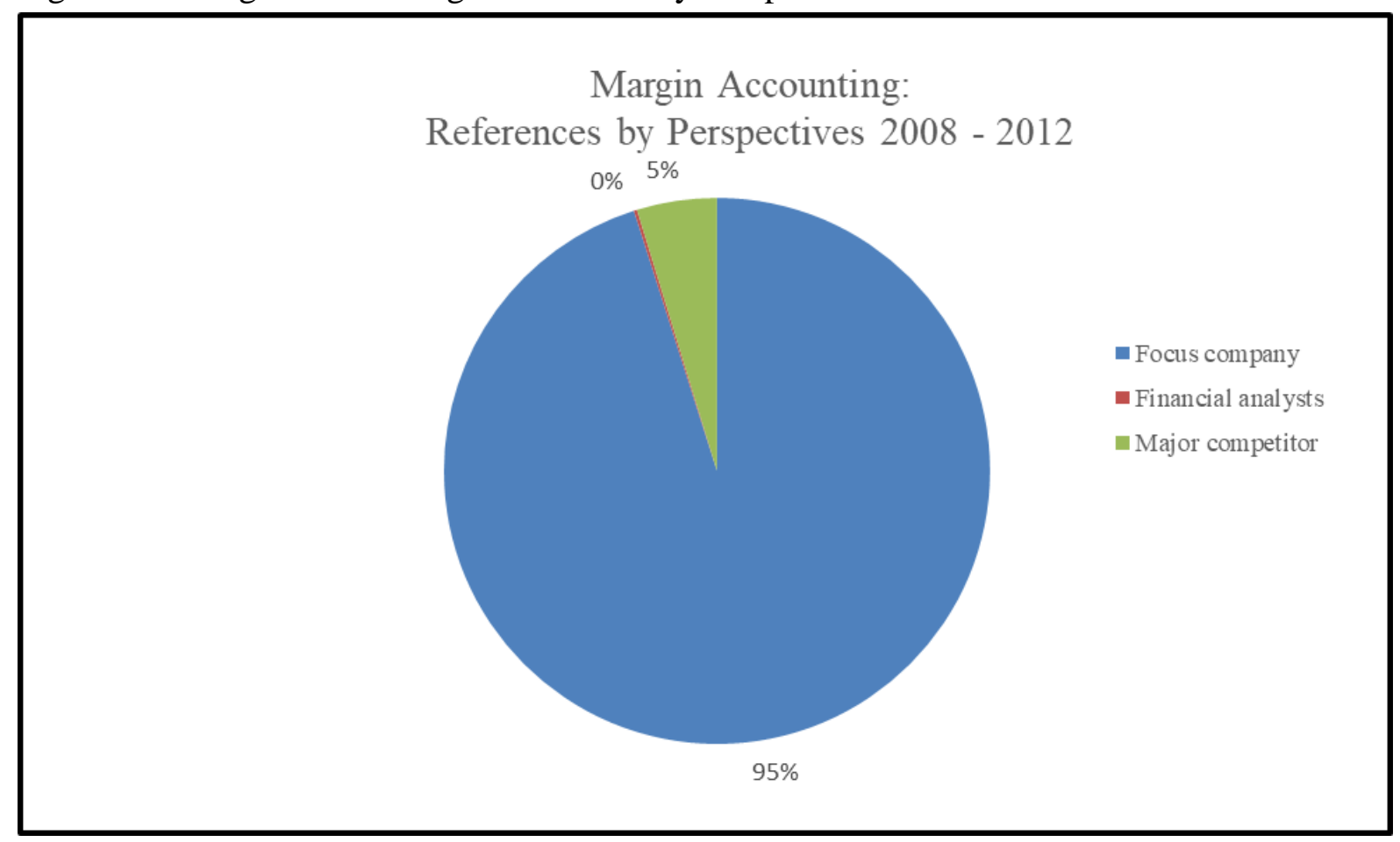

In this section, the prevailing impact of the information category margin accounting has been identified. Within the three perspectives c. $70 \%$ of the references of the focus company are linked to margin accounting. This dominates the total picture in this information category (95\% in this category are linked to the focus company). Also, a strong share of the references of the major competitor is referring to margin accounting (c. 34\%). The overall picture is coined by two-thirds of the references being connected with the information category margin accounting (see Figure 22 on page 104 and Figure 29 on page 111).

According to the conceptual framework the information category P\&L statement is the next area to be illuminated.

\subsection{P\&L statement}

In this section, I will also apply the three-stage approach of the previous section. However, additional consideration is necessary relating to the two different forms of the P\&L statement reported. These different forms are the total cost format according to German GAAP and the cost of sales format according to IFRS and more Anglo-Saxon orientated accounting (see section 2.3 German cost accounting and Anglo-Saxon management accounting). Firstly, I will focus on the distribution of references throughout all periods under observation within the three different perspectives (Figure 32 on page 114). Steps two (description of contents) and three (description of distribution across the three perspectives) will be conducted separately. The information regarding TCF will be described in Figure 33 on page 115 
(contents: references by accounts) and Figure 34 on page 116 (distribution across perspectives) whereas the information regarding $\mathrm{CoS}$ format will described in Figure 35 on page 117 (contents: references by accounts) and Figure 36 on page 118 (distribution across perspectives).

Regarding the share of references within the three different perspectives (see Figure 32 on page 114), it is visible that within the perspective financial analysts the share of references is one-third which is compared to the perspective margin accounting very high (15\% see Figure 29 on page 111). This is not surprising because margin accounting is not available in published financial statements out of which financial analysts extract elementary accounting information. However, the references coded in this area are solely from the year 2012.

For the perspective of the focused company, Figure 32 shows throughout the years 2008 to 2012 a level between $15 \%$ and $18 \%$ and for major competitor values between $17 \%$ and $28 \%$ (in total 24\%) respectively (see details in Annex 22).

Figure 32: P\&L statement: Share of References

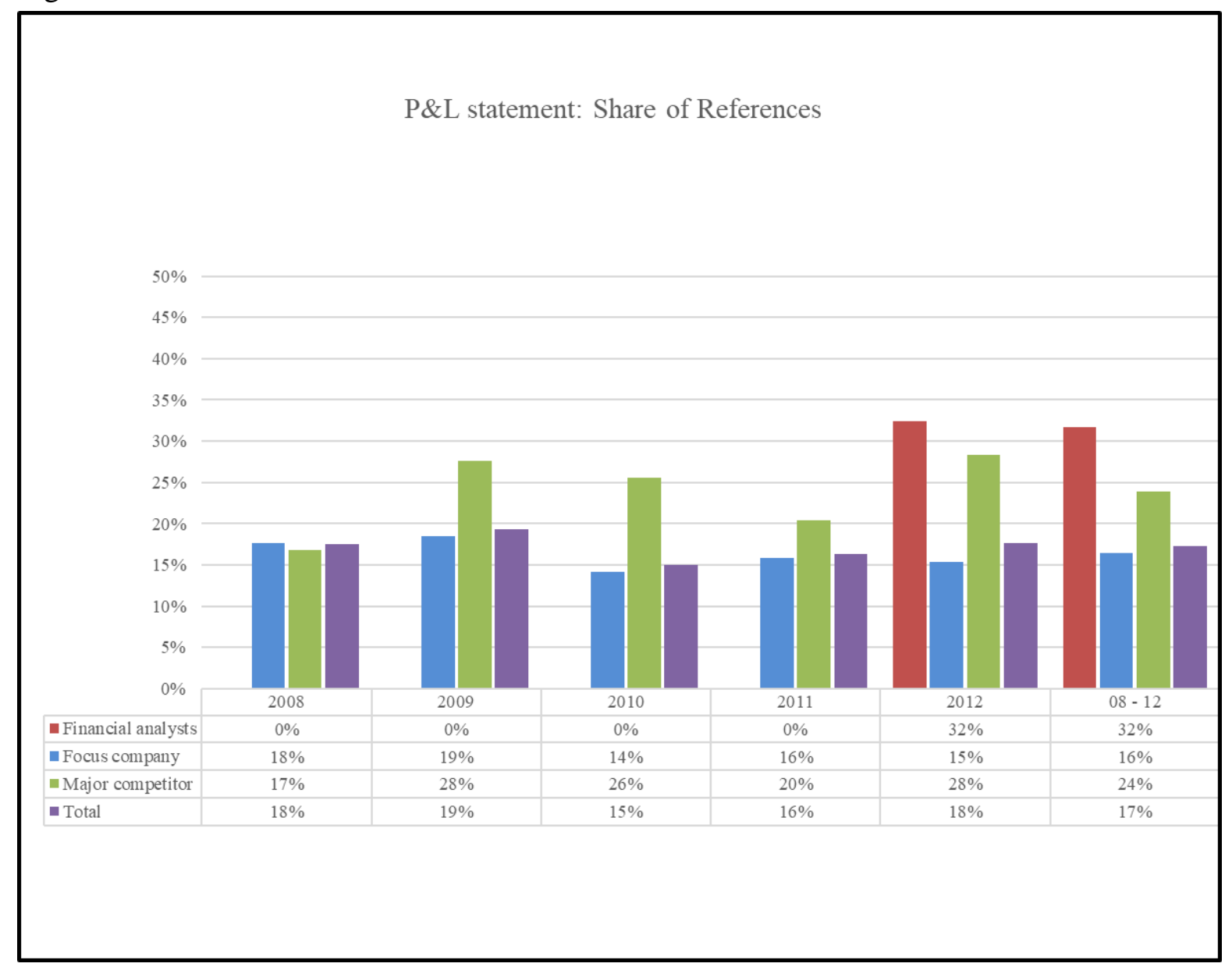

Looking into the contents (references by accounts) according to TCF (see Figure 33) it becomes obvious that volume (order intake and sales $28 \%$ each), EBIT (21\%) and personnel 
expenses (19\%) hold a major position in this area. I have integrated order intake in this area even though it is part of the P\&L statement because of its close relationship to Sales. All other accounts are regarding the number of references not significant and are therefore contained in the line rubric "remaining" which is spread in more detail in the right part of Figure 33 (see details in Annex 24). The percentages in the right part relate to the share of the rubric "remaining".

Figure 33: P\&L statement (Total Cost Format): References by Accounts 2008-2012

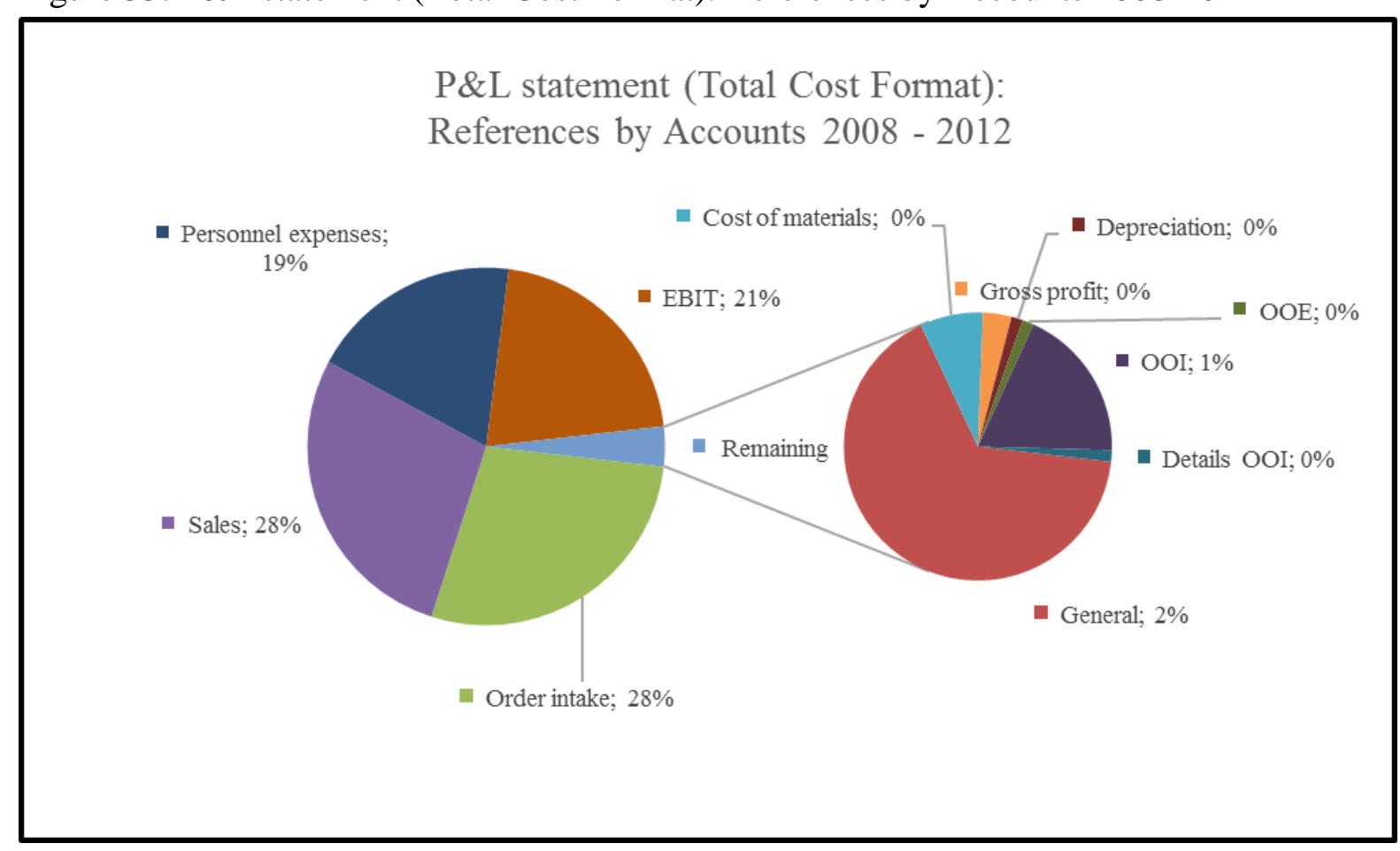

Regarding the share of references in context of TCF across all three different perspectives (Figure 34) the focus company has the highest share (89\%). This is not only related to the high number of sources of the focus company. Background here is in particular the German origin of the focus company and the respective relationship to the P\&L statement according to TCF. The major competitor has a few subsidiaries in Germany which means that $9 \%$ of the references in this area are allocated to this perspective. 
Figure 34: P\&L statement (Total Cost Format): References by Perspectives 2008-2012

P\&L statement (Total Cost Format):

References by Perspectives 2008 - 2012

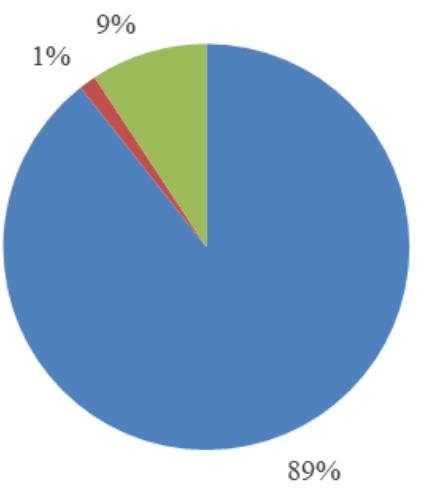

- Focus company

- Financial analysts

- Major competitor

Going into the structure of the P\&L statement according to the $\mathrm{CoS}$ format (Figure 35, see details in Annex 25) the share of volume-related references (order intake and sales 32\% each) is on a similar level to the P\&L statement according to TCF (28\%, see Figure 33). Only a few references refer to the individual lines of functional expenses (for example, selling expenses). However, a few references could be identified which relate to a description of the margin and a respective indication of the margin (see right part of Figure 35, rubrics "MC margin descry." and "MC margin indic."). This information given by the major competitor is labelled as the so-called "guidance" for the capital market. 
Figure 35: P\&L statement (Cost of Sales Format): References by Accounts 2008-2012

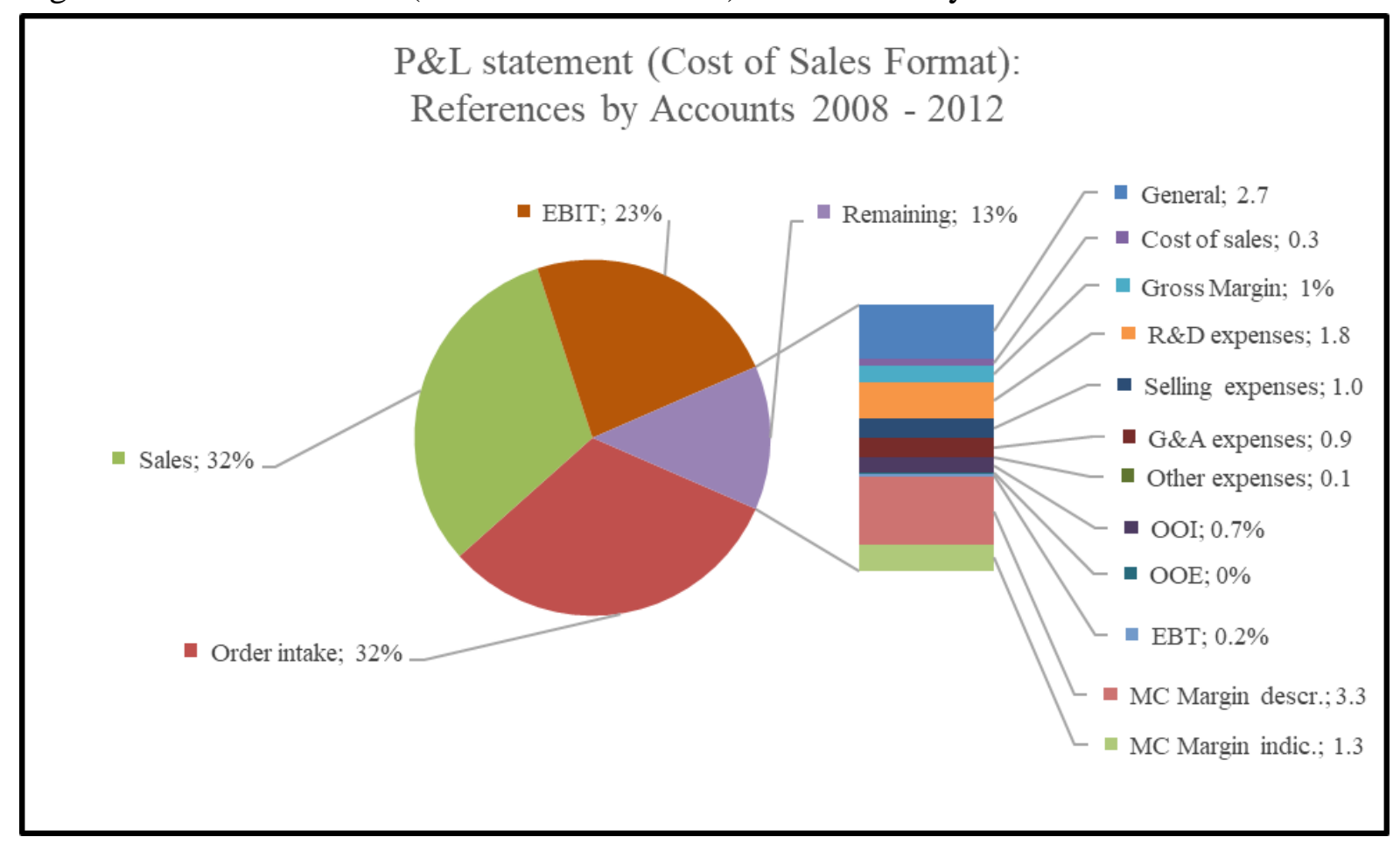

The overview of the distribution of the references of the P\&L statement according to CoS format (Figure 36) shows that the share of the focus company ( $81 \%$, see Figure 36 ) is not as dominant as it is in the P\&L statement according to TCF (89\%, see Figure 34). The respective shares of major competitor are in $\operatorname{CoS}$ format higher (18\%, see Figure 36) compared to TCF reporting (9\%, see Figure 34). This can mainly be explained with the fact that the major competitor is reporting in his consolidated financial statements according to CoS format only. 
P\&L statement (Cost of Sales Format):

References by Perspectives 2008 - 2012

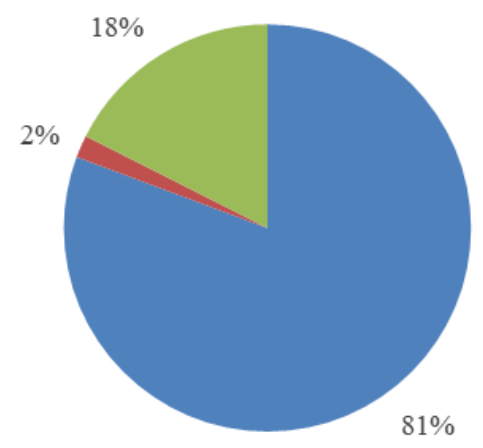

-Focus company

- Financial analysts

- Major competitor

In this section, the structures of the references relating the P\&L statements according to TCF and $\operatorname{CoS}$ format have been described. In both formats of the P\&L statement the share of volume-related information is dominating and on a similar level (28\% in TCF and $32 \%$ in $\mathrm{CoS}$ format, see Figure 33 on page 115 and Figure 35 on page 117). Due to the fact that the major competitor publishes its consolidated financial statements according to $\mathrm{CoS}$ format only, its share in the references is significantly higher in this area and the share of the references of the focus company lower. In addition, major competitor gives descriptive and indicative information regarding his margin in his published consolidated financial statements.

Following the dimensions information category of the conceptual framework, the field of balance sheet needs to be looked at.

\subsection{Balance sheet}

As in the previous section, I will also apply a three-stage approach complemented with additional considerations. Firstly, I will centre on describing the share of references allocated to the entire rubric balance sheet within the three different perspectives (Figure 37). Thereafter I will differentiate between the two sides of the balance sheet. For describing the contents (description of accounts), I prepared for the asset side Figure 38 and for equity and liabilities Figure 40. Regarding the description of the distribution across the different perspectives, I arranged for assets Figure 39 and for the liabilities side Figure 41 on page 122. 
Due to the fact that in all three perspectives balance sheet relevant information has been given under the term working capital, I created a respective rubric which Figure 42 on page 123 will deal with (distribution of references by perspective).

In total $5 \%$ of the references refer to balance sheet (see Figure 22 on page 102 and Figure 37). The highest share can be observed within the perspective financial analysts (9\%). However, references coded in this perspective refer to 2012 only. The share of references within the perspective focus company are on a level of c. 5\% throughout 2008 to 2012. Within the perspective of the major competitor, the share of references is from 2008 to 2011 on a level of $1 \%$ and in 2012 on $8 \%$ which increases the total to 3\% (see details in Annex 22).

Figure 37: Balance sheet: Share of References

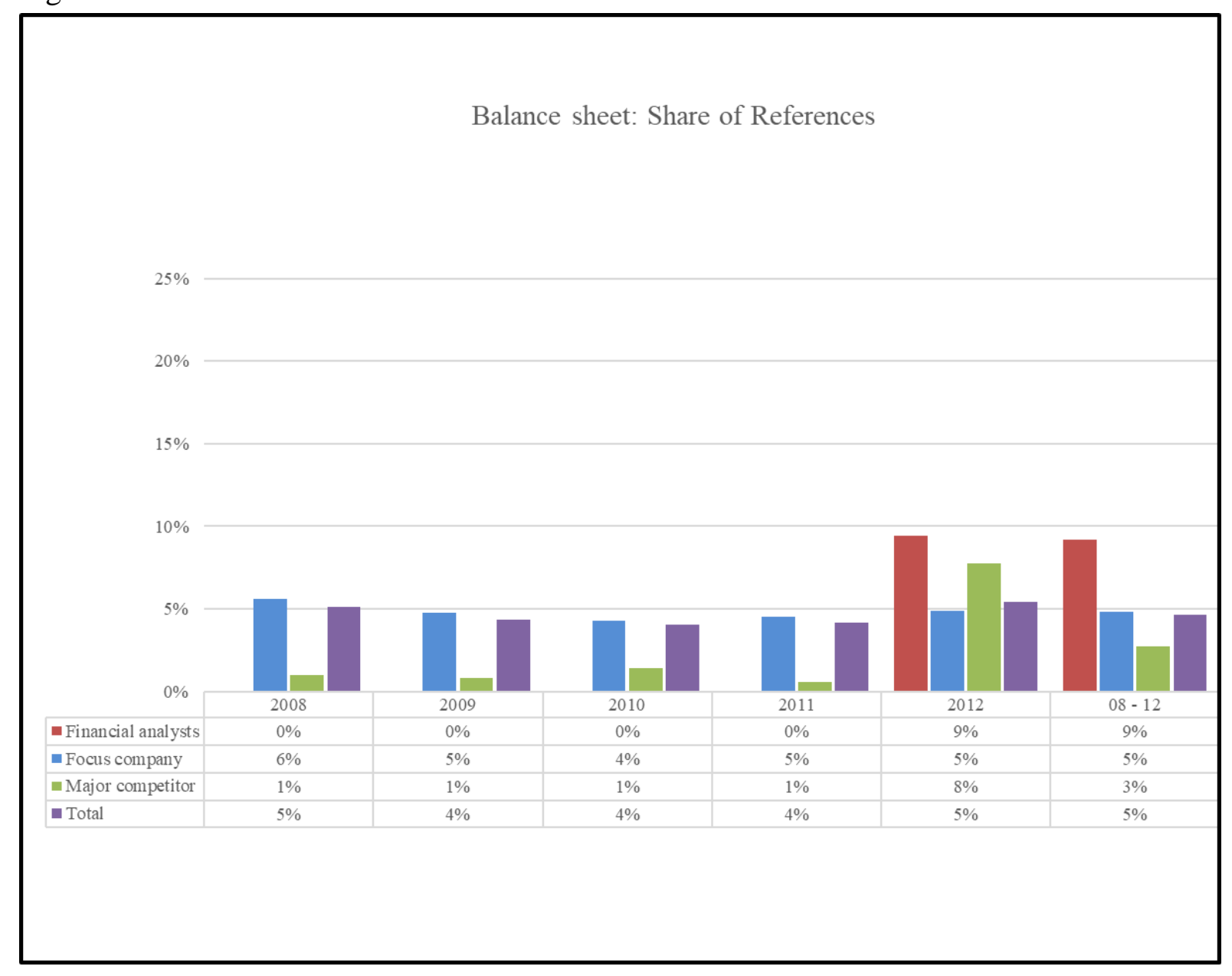

Going into the description of the contents of the asset side (Figure 38, see details in Annex 26) two major accounts can be identified. $45 \%$ of the references of the asset side refer to the rubric tangible assets whereas $43 \%$ refer to cash. The distribution of the remaining accounts (ca. 12\% of the references) are displayed on the right part of Figure 38. Like in the area of P\&L statement according to $\mathrm{CoS}$ format (Figure 35) the major competitor gives information 
regarding particular themes. In order to reflect this accordingly, respective rubrics have been created ("MC invoicing" and "MC investment", see Figure 38).

Figure 38: Balance sheet Assets: References by Accounts 2008-2012

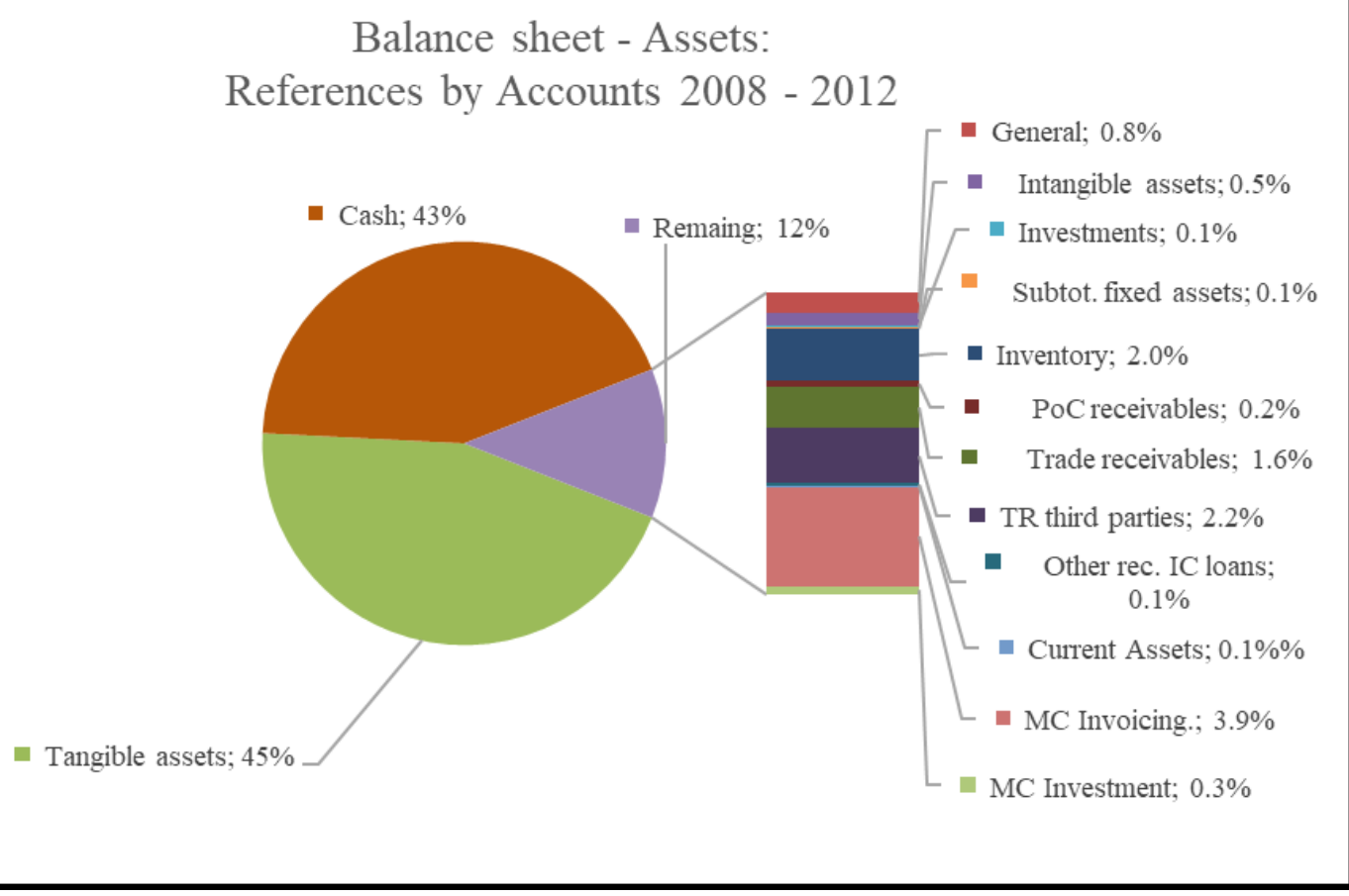

Concerning the share of references across the three perspectives (Figure 39), it is not surprising that the share of the perspective focus company is prevailing (c. 91\%). This is due to the high number of source documents of the focus company. However, the share of references relating to the perspective of major competitor is c. $7 \%$ whereas the share of the perspective of financial analysts is c. $2 \%$. 
Figure 39: Balance sheet Assets: References by Perspectives 2008-2012
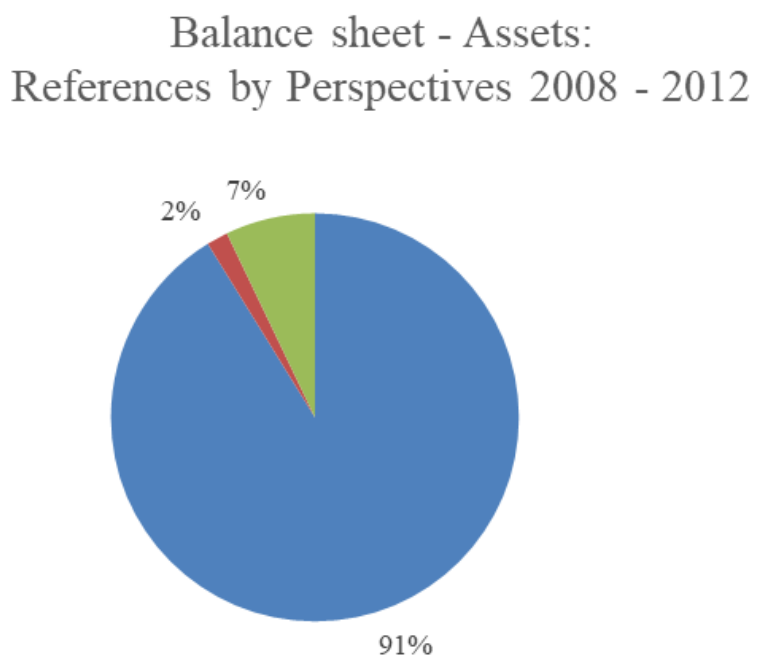

-Focus company

- Financial analysts

Major competitor

Looking into the structure of references on the liability side (Figure 40, see details in Annex $27)$, three major areas can be identified: advance payments (48\%), equity (24\%) and general $(16 \%)$.

Figure 40: Balance sheet Equity and Liabilities: References by Account 2008-2012

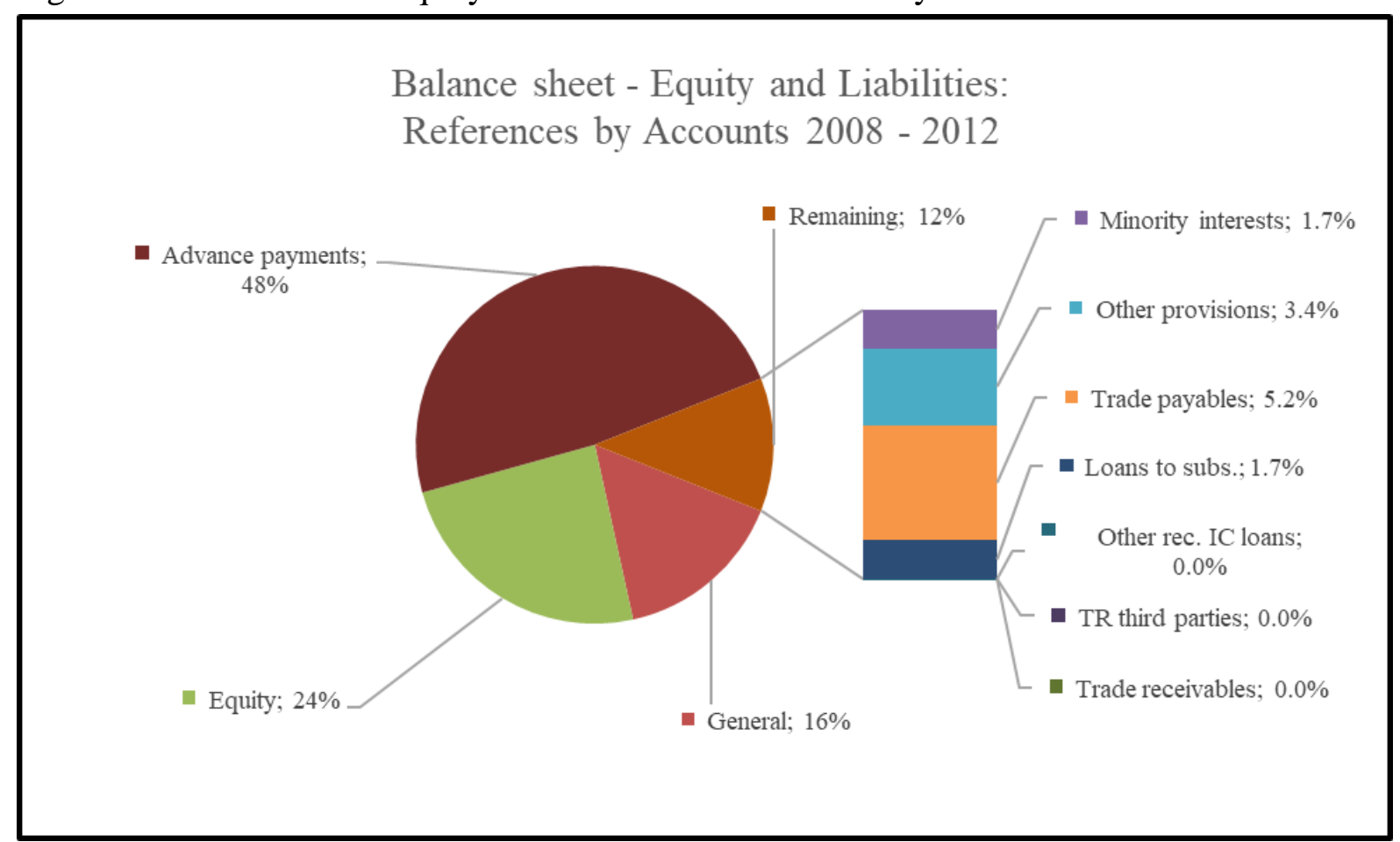

With reference to the structure of references across the three perspectives (Figure 41), a shift can be observed comparing this to the respective structure of the Asset Side (Figure 39). The 
perspective of financial analysts has a share of $10 \%$ (2\% on the asset side); $76 \%$ are related to the focus company (91\% on the asset side) and $14 \%$ are referring to the perspective of the major competitor ( $7 \%$ on the asset side).

Figure 41: Balance sheet - Equity and Liabilities: References by Perspectives 2008-2012

Balance sheet - Equity and Liabilities:

References by Perspectives 2008 - 2012

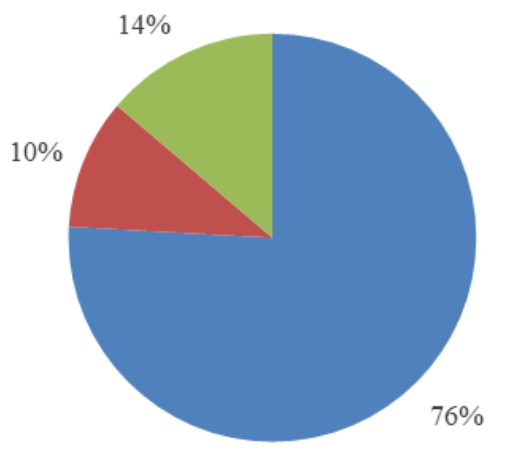

- Focus company

- Financial analysts

- Major competitor

As for the distribution of the references across the three perspectives within the rubric working capital (Figure 42, see details in Annex 28) it can be observed that the share of the perspective of the focus company dominates $(97 \%)$. 

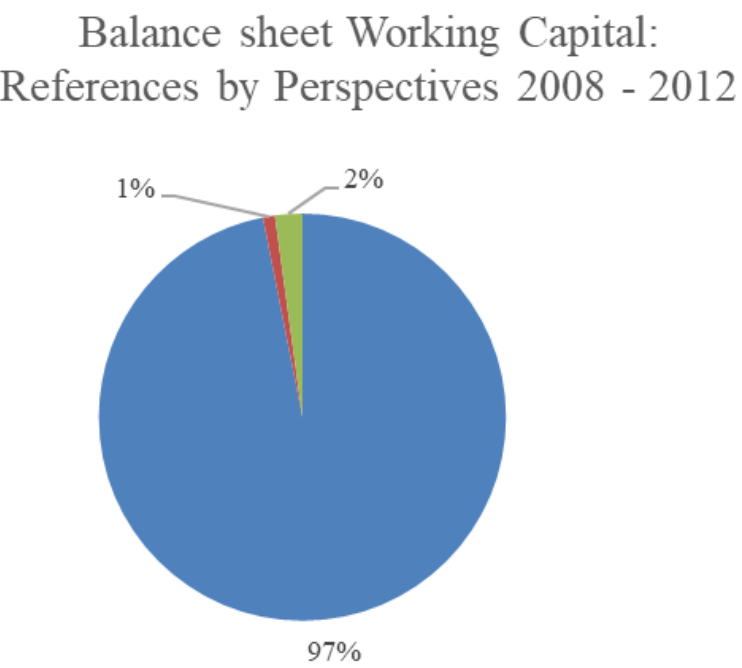

-Focus company

- Financial analysts

"Major competitor

In this section, the distribution of references allocated to the information category balance sheet has been outlined. In total $5 \%$ of the references have been allocated to this information category (Figure 22 on page 102 and Figure 37). Core areas on the asset side are tangible assets and cash (Figure 38) and on the liability side advance payments, equity and general issues (Figure 40). Regarding the distribution of references across the three perspectives, a shift from the perspective focused company (91\% share on the asset side and $76 \%$ on the liability side) to financial analysts and the major competitor can be observed.

Consistent with the conceptual framework the subject area cash flow statement is the next to be dealt with.

\subsection{Cash flow statement}

In this section, I seek to describe the structure of the references which refer to the information category cash flow statement. As in the previous section, I will first describe the distribution of references within the three perspectives (Figure 43) followed by the description of the distribution of references across major rubrics identified (Figure 44).

Only a few references (in total 61, see Figure 22) refer to this information category. In Figure 43 (see details in Annex 22) it can be observed that these 61 references represent less than $1 \%$ of total references. For financial analysts, the share is $1 \%$ referring to 2012 only, whereas within the perspective of the major competitor a constant share of $1 \%$ can be seen. Within the perspective of focus company there have been no references coded to this information 
category. Background for this is that the cash-relevant lines have already been dealt within the information category balance sheet (Figure 38).

Figure 43: Cash Flow Statement: Share of References

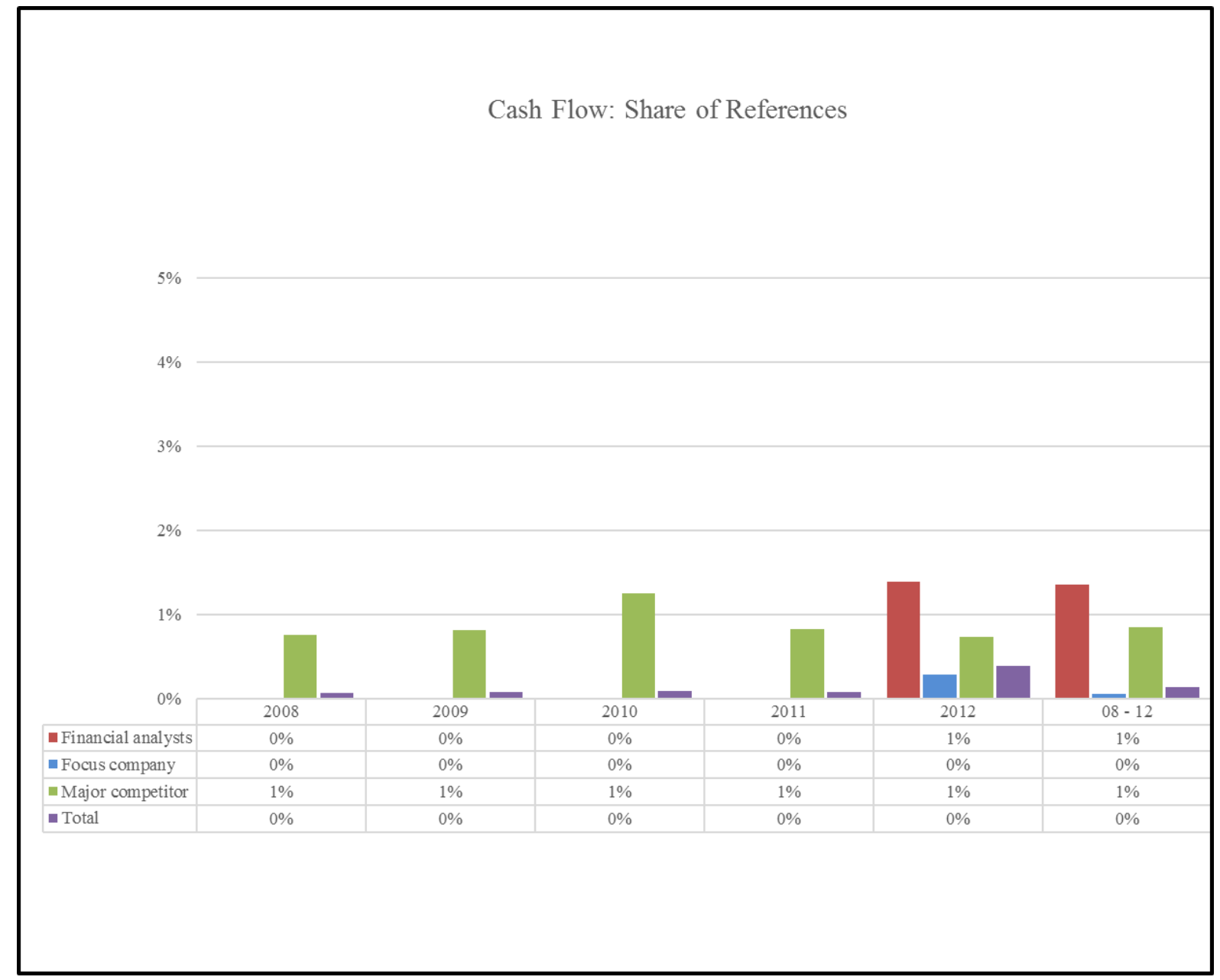

In respect of major rubrics within the information category cash flow statement (Figure 44, see details in Annex 29), the most important one is "target" (57\%). These references relate to the perspective of the major competitor and embrace the definition of targets on the context of cash flow. The other two rubrics ("general" with $34 \%$ and "total" with a share of $8 \%$ ) are of a more widespread character within this information category. 


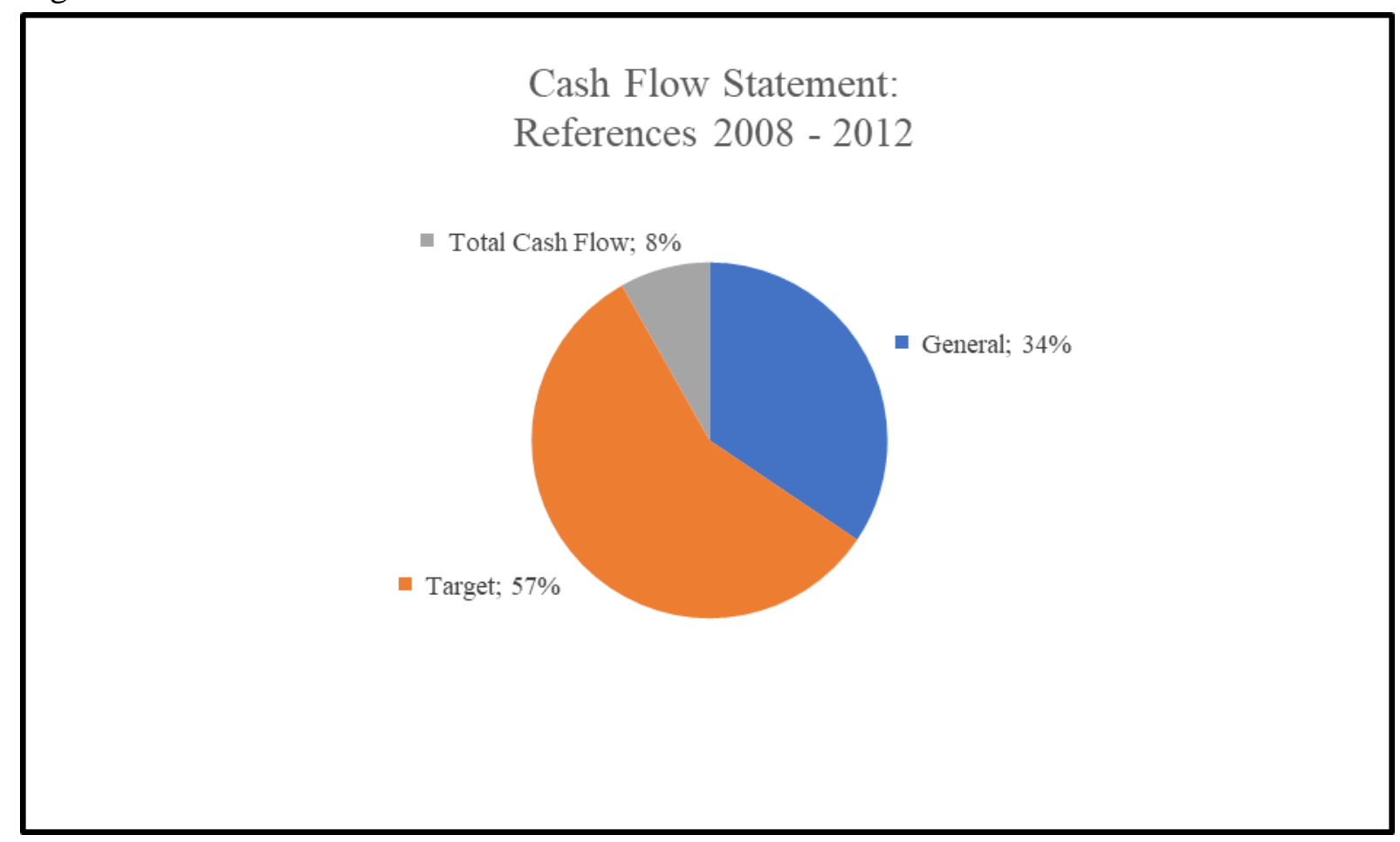

On the subject of the share of references across all perspectives (Figure 45), it can be seen that the share of references of the perspective of the major competitor (57\%) is highest. Background for this is that the documents relating to this perspective are mainly published financial statements in which the cash flow statement in most countries is an obligatory part. The share of references of the perspective focus company is $34 \%$. It is worth mentioning that the documents relating to the perspective focus company are solely internal documents in which information regarding cash flow is mainly derived from the cash relevant balance sheet lines. The share of references relating to the perspective of financial analysts is $8 \%$ and compared to its share within the other information categories this is high. This is due to the low number of references coded into this Information Category. 


\section{Cash Flow Statement: \\ References by Perspectives 2008 - 2012}

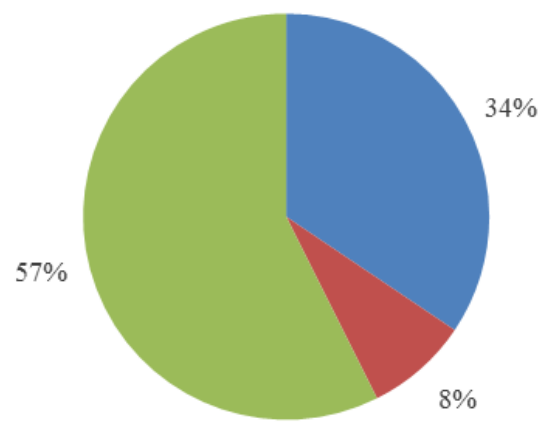

- Focus company

- Financial analysts

" Major competitor

As a summary, the number of references coded into the information category cash flow statement is very low. However, it is striking that the major competitor gives information regarding targets in this context (Figure 44) which goes beyond obligatory requirements in consolidated published financial statements.

According to the conceptual framework the last information category to be demonstrated is other.

\subsection{Other}

Also, in this final section regarding the distribution of information within the Information Categories I will apply the three-stage approach used in the previous sections.

Firstly, I will describe the distribution of references within the three different perspectives (Figure 46). Secondly, I will focus on the distribution of references among different topics (starting with Figure 47 on page 128). This will be more extensive than in the previous sections because it covers various heterogeneous rubrics (namely "KPIs", "consolidation hierarchy", "regions" and "strategic planning and competitor's highlights"). Due to the heterogeneity of the rubrics in this section, the third step (description of the distribution across the three different perspectives) will be conducted for each of the rubrics individually.

C. $10 \%$ of the references are connected with this information category (Figure 22 on page 102 and Figure 46, see details in Annex 22). The highest share of this information within the 
three perspectives can be observed in financial analysts (43\%). However, obviously the references are very unequally distributed across the periods under observation within this perspective. The respective picture for the perspective focus company is very constant: the share of references within this perspective remains at the level of c. $7 \%$ throughout 2008 to 2012. As to the perspective of the major competitor, the share various between $32 \%$ and $42 \%$. Figure 46: Other: Share of References

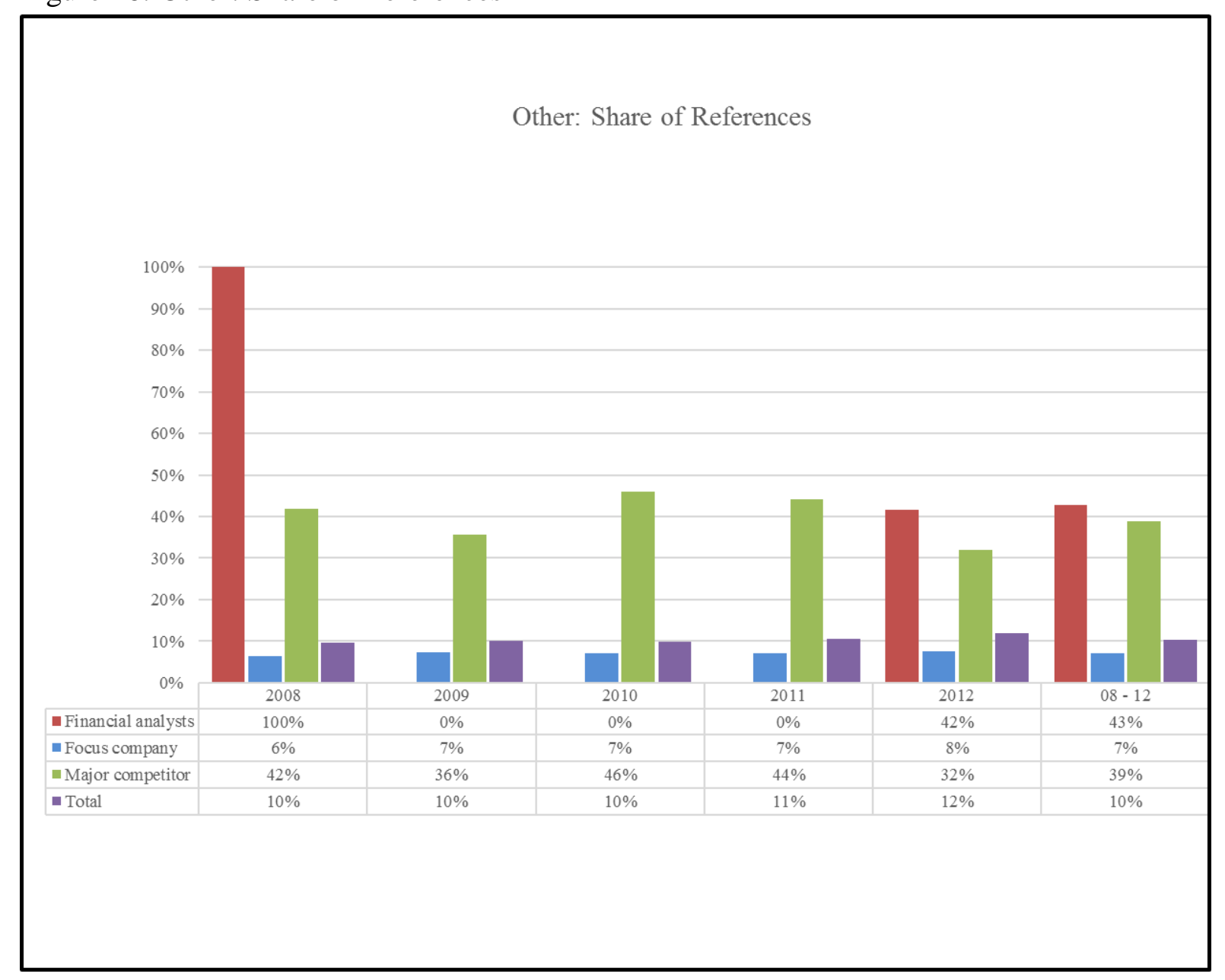

Focusing on the rubric "KPIs" (Figure 47, see details in Annex 30), headcount is the dominant KPI with $80 \%$ of the references in this rubric coded to this node. The highest shares of the remaining KPIs have the KPIs General (10\% of remaining KPIs) and Utilization (9\% of remaining KPIs, see right part of Figure 47). 
Figure 47: Statistics \& Other: References by KPIs/Themes 2008-2012

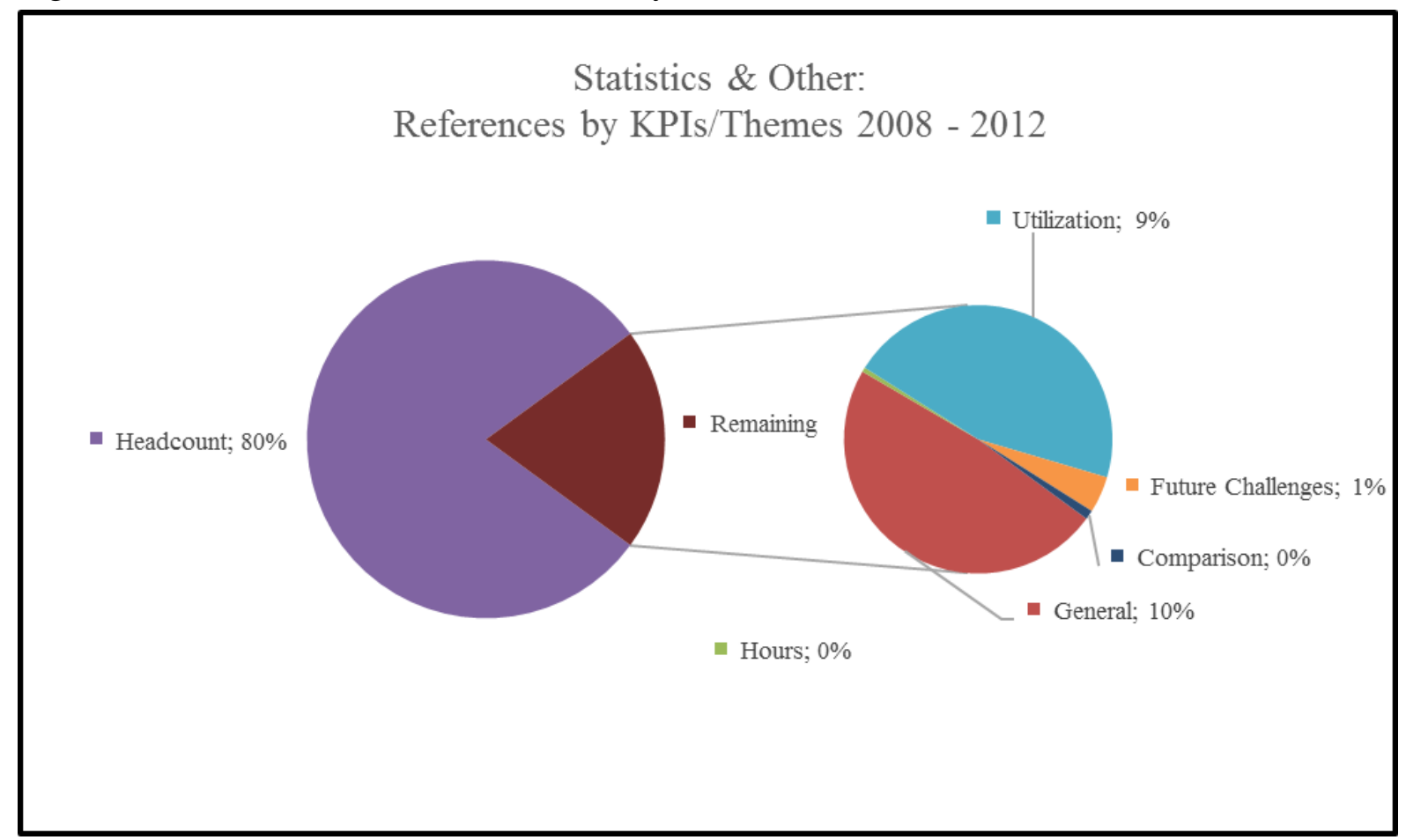

Within the rubric "KPIs" (Figure 48) the perspective of financial analysts has the lowest one (3\%), the perspective of the focus company the highest value $(77 \%)$ and $20 \%$ of the references in rubric relate to the perspective of the major competitor. This distribution does not reflect the dominant number of documents related to the focused company. Based on this comparison, the share of references referring to the perspective of the major competitor can be evaluated as high. 
Figure 48: Statistics \& Other: References by Perspectives 2008-2012

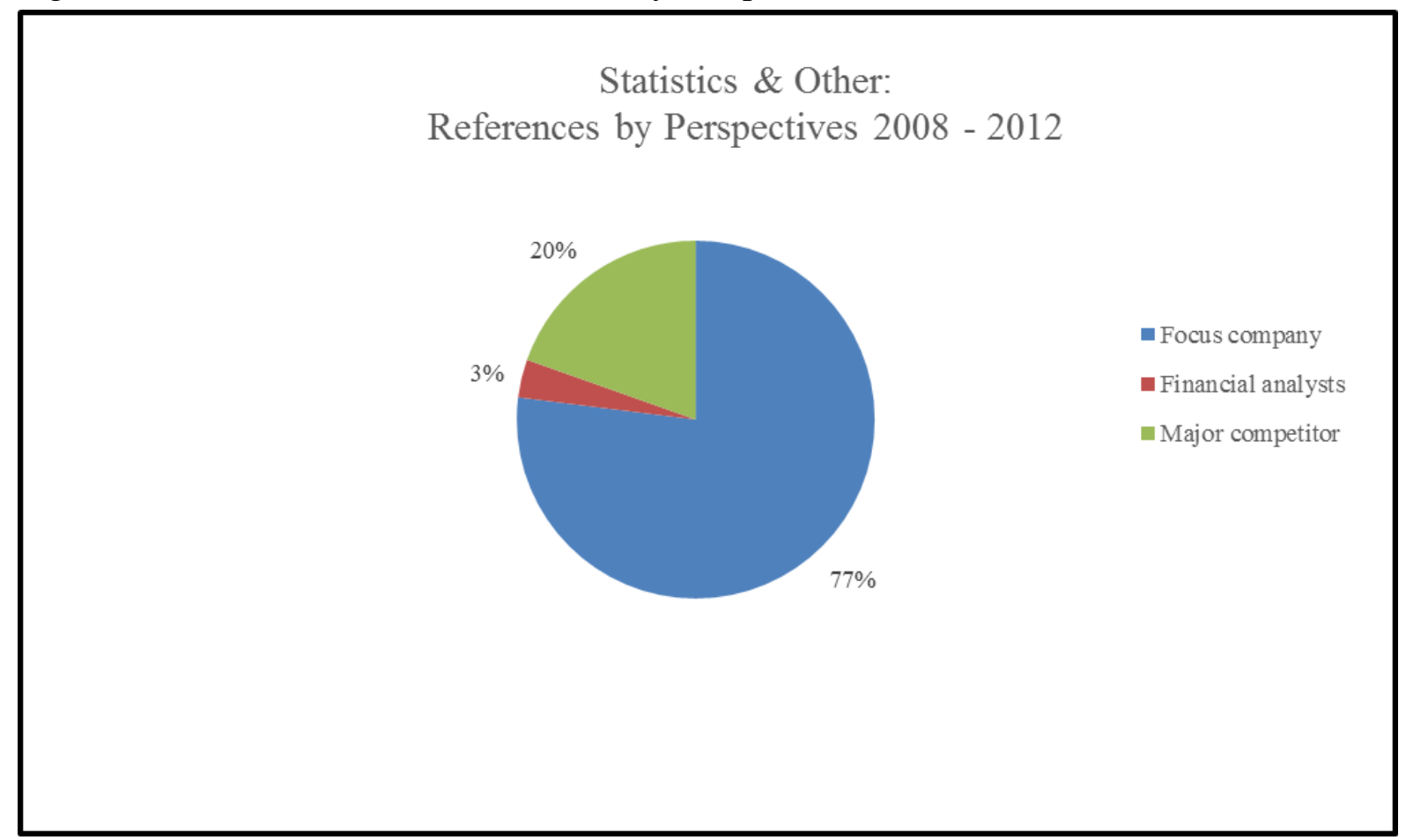

The rubric "consolidation hierarchy" (Figure 49, see Annex 31) relates to one of the dimensions of the conceptual framework. The vast majority of the references coded into this rubric relate to the group (82\%).

\section{Other - Consolidation Hierarchy:}

References by Level of Consolidation 2008 - 2012

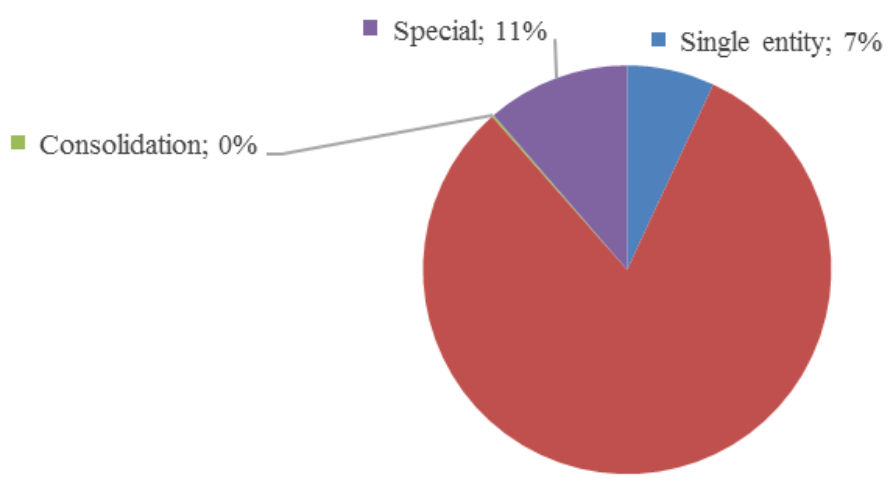

- Group; $82 \%$ 
Regarding the distribution of the references across the three perspectives (Figure 50), the perspective of the major competitor dominates due to the fact that most documents related to the perspective of the major competitor are published consolidated financial statements.

Figure 50: Other/Consolidation Hierarchy: References by Perspectives 2008-2012

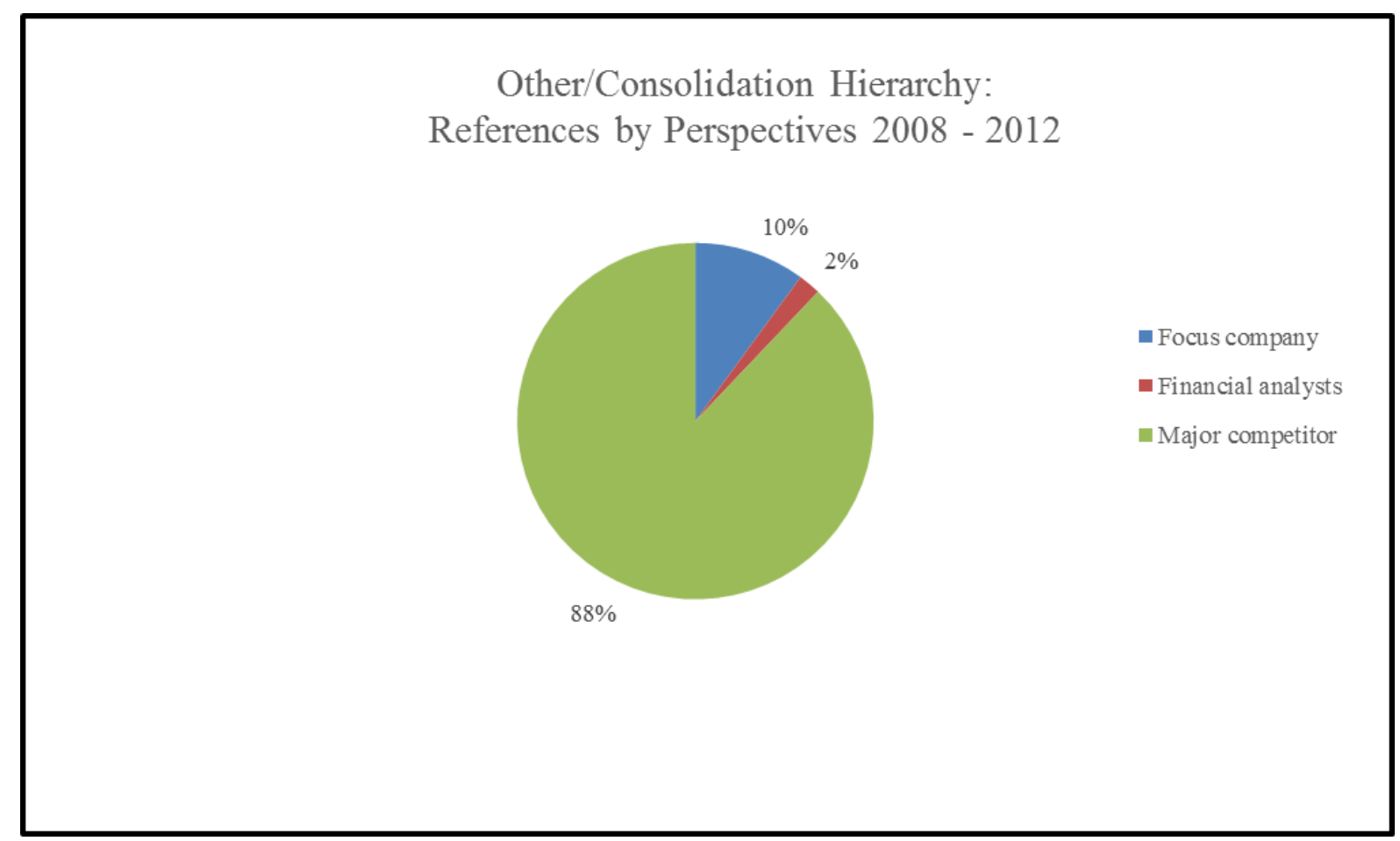

Concerning the rubric "regions" (Figure 51, see details in Annex 32), 62\% of the references coded here relate to three regions (Region 4 with $44 \%$, Region 2 with $25 \%$ and Region 7 with $13 \%)$. 


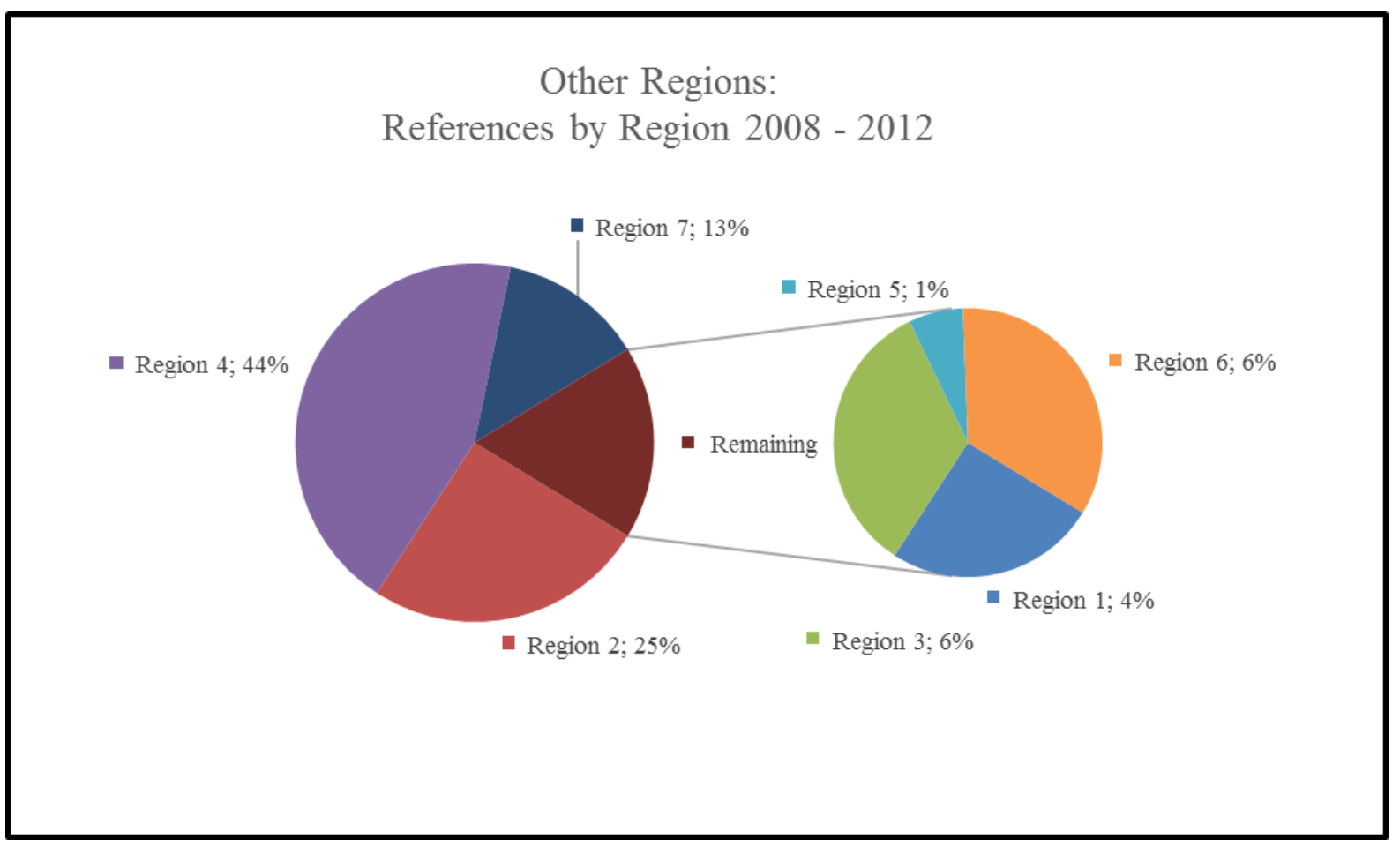

The vast majority of the references coded in the rubric "regions" (Figure 52 on page 132) relates to the perspective focus company (83\%). The background is that within the leading document of the focus company ("Monthly Comment") a separate section for the development of the region the subsidiary is acting is offered. The Managing Directors use this section in order to explain in particular impacts related to politics (for example, presidential elections) or national economic circumstances (for example, economic growth). This information has been coded into the respective region. 
Other Regions:

References by Perspectives 2008 - 2012

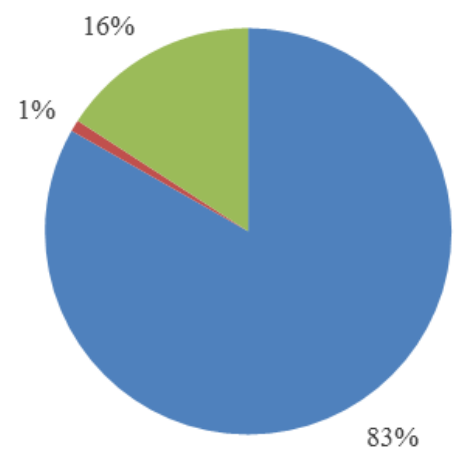

- Focus company

- Financial analysts

- Major competitor

Information regarding strategic planning of the focus company and comparable information given by the major competitor are displayed in Figure 53 on page 133 (see details in Annex 33). $51 \%$ of the references in this rubric have been coded to the node "entire strategy" and $26 \%$ to the node "goals". The node goals contain solely information provided by the major competitor referring to defined goals and the development of respective KPIs. The same applies to the node "highlights" (see right part of Figure 53). 


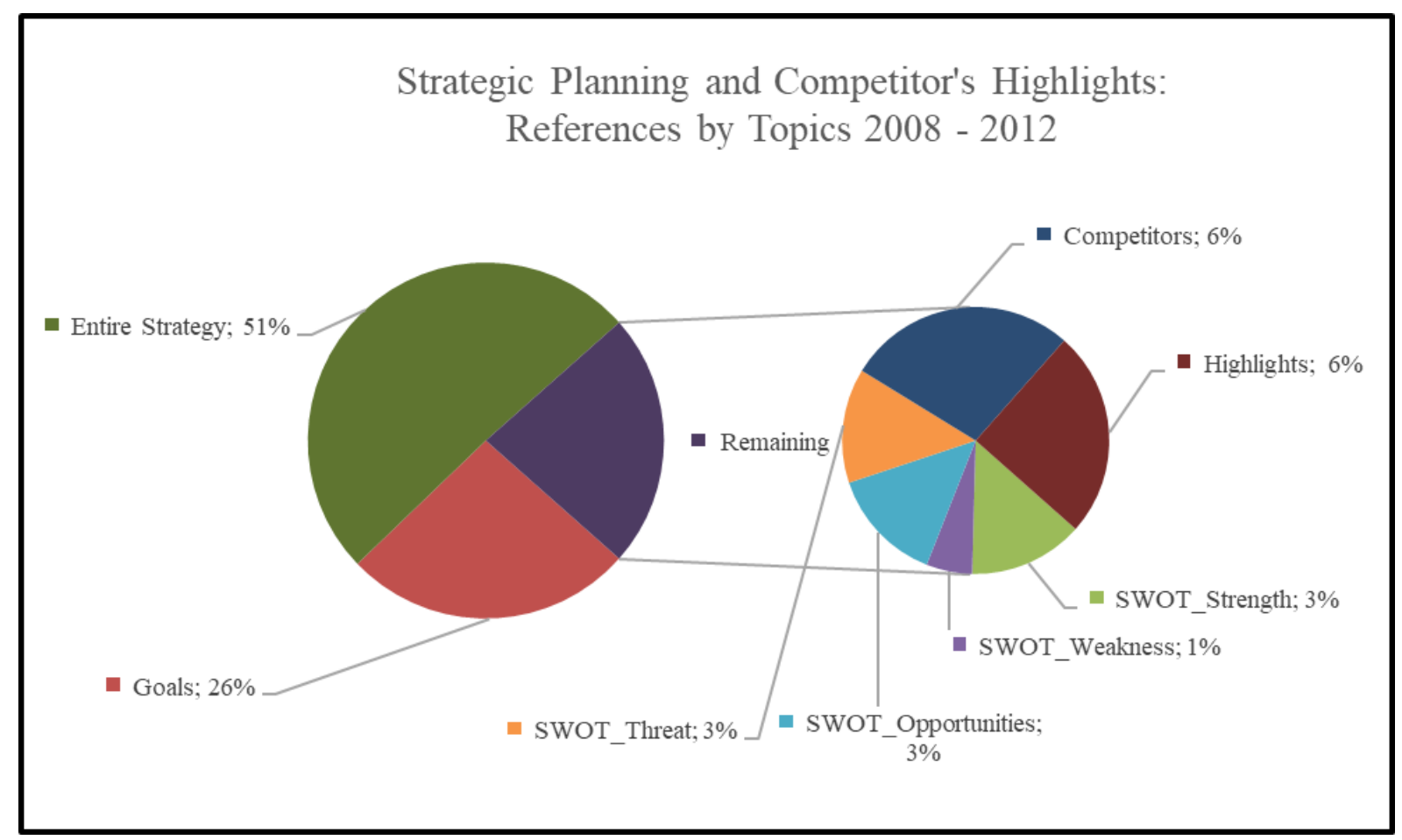

Regarding the distribution of the references across the three perspectives (Figure 54), it can be seen that focus company (52\%) and major competitor (44\%) have the biggest shares in this rubric.

Figure 54: Strategic Planning and Competitor's Highlights: References by Perspectives 2008 - 2012

Strategic Planning and Competitor's Highlights:

References by Perspectives 2008 - 2012

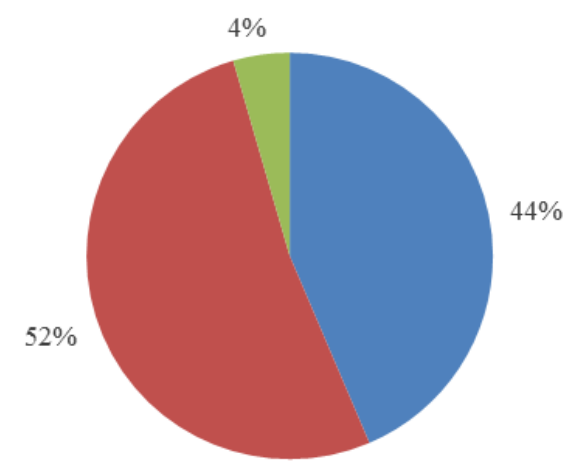

- Focus company

- Financial analysts

Major competitor 
In this section, the rubric other has been described. $10 \%$ of the references are related to this area (Figure 22 on page 102 and Figure 46 on page 127). This rubric is further differentiated into the nodes "KPIs" (Figure 47 on page 128), "Consolidation Hierarchy" (Figure 49 on page 129), "Regions" (Figure 51on page 131) and "Strategic Planning and Competitor's Highlights" (Figure 53). Strikingly the topic "Strategic Planning and Competitor's Highlights" contains information regarding Goals and Highlights which has been identified in competitor's published consolidated financial statements.

After having dealt with the single information categories of the conceptual framework, I seek to recapitulate this in the remaining part of this section.

Taken as a whole section "5.2.2.2 Aligning the NVivo node structure with the conceptual framework" delivered information regarding the structure of the references coded in NVivo and how this information is connected with the information categories of the conceptual framework.

Two-third $(68 \%)$ of the references are connected to the information category margin accounting (Figure 22 and Figure 29 on page 111). Within the perspective of the focus company $95 \%$ of the references are linked to margin accounting (Figure 29). Also, within the perspective of the major competitor a significant share of the references (34\%, see Figure 29) relate to this information category.

The second highest share of references (17\%) alludes to the information category P\&L statement (Figure 22 and Figure 32 on page 112) in which I have differentiated between the total cost format (German accounting orientated) and the cost of sales format (IFRS and Anglo-Saxon accounting orientated). Within both formats of the P\&L statement volumerelated Information is dominating (28\% within TCF and $32 \%$ within CoS format, see Figure 33 on page 115 and Figure 35 on page 117). Besides volume information provided in this information category it appears noteworthy that the major competitor gives descriptive and indicative information regarding the development of margin in his published consolidated financial statements (Figure 35).

$5 \%$ of the references are linked with the information category balance sheet (Figure 22 and Figure 37 on page 119). I differentiated this Information Category into two parts: asset side and liability side. Core areas on the asset side are tangible assets and cash and on the liability side advance payments, equity and general issues.

In total, less than $1 \%$ (rounding leads to $0 \%$ ) of the references have been coded to the information category cash flow statement (Figure 22 on page 102 and Figure 43 on page 
124). It is noteworthy, that the major competitor gives information regarding targets in this area (Figure 44 on page 125).

$10 \%$ of the references refer to the information category Other (Figure 22 and Figure 46 on page 127). This information category has been differentiated in the rubrics "KPIs", "Consolidation Hierarchy", "Regions" and "Strategic Planning and Competitor's Highlights". Remarkably "Highlights" contains information regarding goals and highlights in business (for example, large orders) identified in major competitor published consolidated financial statements (Figure 53 on page 133).

At this point it can be observed that volume related information has a significant share in the dominant information categories margin accounting and P\&L statement.

This summary closes the description of the structure of the references coded in Phase 1 of the project and the alignment of the NVivo structure with the conceptual framework. Phase 1 forms the basis for Phases 2 and 3.

\subsubsection{Phase 2: Differentiation by periods and alignment with numerical Information}

In this phase, I differentiated the references coded in Phase 1 into the Nodes EPUs, product lines and regions using respective queries. Through this, the references are organized according to the dimension year which suits to the organization of the numerical information. The nodes "product lines" and "regions" contain the results of queries grouping the references relating to product lines and regions by year by perspective. I created these nodes in order to see the full picture of an EPU. Background is, for example, an incident in region A also has impact on other regions (for example, region B). In this example it can be the case that this incident is not mentioned by the EPUs in region B. A comparable constellation can be the case in the area of product (an incident is relevant for more than one product line).

In addition, I allocated the results of reports based on the case node for "product lines" and "regions" in the respective node folders of Phase 2.

\subsubsection{Phase 3: identifying trends and themes with strategic context}

\subsubsection{Purpose and motivation}

Based on the manual coding in Phase 1 and the subsequent differentiation of the references by years in Phase 2, the background of the process of evaluation of textual information (see section 5.2.5.2) is constituted. In addition, the textual information can now be enhanced through connecting it with the notion of critical success factors which has been integrated in the case study approach in section 4.3.2.3.6. 
The motivation to link CSFs with the data coded in Phases 1 and 2, is to identify "...the limited number of areas in which satisfactory results will ensure successful competitive performance for...” the “...organization” (Bullen \& Rockart, 1981, p. 7). In the context of this project, CSFs relate to the organization of the major competitor. Having informed assumptions regarding the major competitor's CSFs would add to information regarding the major competitor's performance and therefore increase the competitive advantage because according to Heinen and Hoffjan (2005) this contributes to improving one's own performance.

The aspect of having better informed assumptions regarding the major competitors' performance and respective CSFs needs to be related to the nature of the business of the focus company and its major competitor are acting in. The mechanical engineering sector is coined by its dependency on the utilization of production capacities which includes strategic vendors as well. Furthermore, engineering expertise and experience regarding production, products and respective knowledge of customers' processes are prerequisites for being competitive in the markets. In this context, it is important to anticipate the time and the resources it takes to build up and to change the utilization of the production capacities and the engineering expertise in strategic decision-making.

Rockart (1979, p. 86) identified four “...prime sources of critical success factors...” out of which three appear to be applicable in this project ("Structure of the particular industry", "Competitive strategy, industry position, and geographic location" and "Environmental factors").

In this context, the process of interpretation of textual information in Phase 3 needs to be described briefly. References have been coded manually into the nodes determined by the conceptual framework/the model in Phase 1 and thereafter allocated to years automatically in Phase 2. In order to identify the textual information which supports making a judgement on the direction of sales revenue a process of interpreting data has been conducted in NVivo in Phase 3. In a first step, nodes have been created in which the results of Phase 3 were stored. These nodes are determined by the "...prime sources of critical success factors..." (Rockart, 1979, p. 86) and will be explained in more detail in the next three sections. The starting point within Phase 3 is the references of the focus company. Very informative descriptions of the markets and more general explanations of the political and economic environment enable identification of relevant themes (for example, investment climate). Due to the assumption of the common background in which the focus company and the major competitor are acting, it 
could be assumed that these themes are also relevant for major competitor. Furthermore, simple text searches of the references coming from the focus company using the major competitor's name as a search term helped identifying themes which are related to the major competitor. Due to the organization of the textual information, the themes identified could be related to product lines. Thereafter, the data coming from the major competitor has been scrutinized regarding these themes. For example, one theme identified in the data of focus company has been financial crisis. Due to the organization of the data by year, comparisons of the data of the focus company with the data from the major competitor could be conducted. This allowed identification of the product line in which the focus company and major competitor started to use financial crisis as an explanation for the development of business and when this stopped. Based on the assumption of a common background, this time frame should have been identical. Since the major competitor used this theme for significantly longer, it became obvious that there were reasons for this behaviour. This in turn led to further analysis, again using the references of the focus company as a starting point.

In order to create the basis for identifying the major competitors' CSFs, I aim to align the analysis of textual information conducted in the first two phases with the "...prime sources of the..." (Rockart, 1979, p. 86) CSF system in the following sections.

\subsubsection{Comparisons versus the major competitor and financial analysts}

According to the conceptual framework of this project, the data has been differentiated regarding the dimension information category between margin accounting, $\mathrm{P} \& \mathrm{~L}$ statement, balance sheet, cash flow statement and other. In addition, the dimensions can be differentiated by the perspectives financial analysts, focus company and the major competitor.

This approach supports verifying the data related to one of the perspectives contained in one information category with the other two information categories. For example, $95 \%$ of the references coded to the information category margin accounting are relating to the focus company whereas $5 \%$ are linked to the major competitor (see section 5.2.2.2.1). This is due to the fact that internal information of the focus company is also available, which is not the case for the major competitor. Based on the assumption of a case study of a common background the information gap can basically be closed, for example, by concluding from data of the focus company on the respective parameter value for the major competitor.

A reasonable addition to this mode of operation is to narrow this, for example, down to the data regarding a particular region which is supported through the allocation of EPUs to 
regions. Within regions, variables such as, for example, the economic and political situation or consumers' behaviour, tend to be similar. Therefore, the data of EPUs relating to one region can reasonably be viewed and analyzed in one step. For example, an analysis regarding the level of a sales price relating to a particular product line can be based on the data of one region because the market conditions in that region (for example, Western Europe) can be assumed to be similar.

Based on the organisation of the data (see examples given in this section) a link to the “...prime sources of critical success factors..." (Rockart, 1979, p. 86) can be established. The "structure of the particular industry" can be analyzed through the information category margin accounting. Regarding the prime source "competitive strategy, industry position, and geographic location", the possibility of narrowing the data to regions (all EPUs are assigned to regions and all references are assigned to EPUs) allows analysis of data according to these criteria. Rockart (1979, p. 86) defines, for example, “...the gross national product and..." changing "...political factors..." as variables referring to the prime source "environmental factors". I have coded information relating to "environmental factors" in NVivo in a separate node.

After having described the link between the structure of the data in this project and the “...prime sources of critical success factors...” (Rockart, 1979, pp. 86-87), I aim to focus on performance relevant incidents in the next section.

\subsubsection{Incidents}

The motivation for applying the criterion "incident" in the analysis of textual information is its potential performance-relevance. Incidents may reveal problems that the major competitor has to cope with and support identification of the major competitor's critical success factors in a particular area. For example, the fall of the European milk quota has an impact on the business of a particular product line in particular regions. The analysis of the textual information available from the major competitor sheds light on how the major competitor deals with the environmental incident. This, in turn, supports identification of respective CSFs of the major competitor.

The identification of the major competitor's CSFs would have, in the example of the fall of the European milk quota, allowed the anticipation of the lower demand in the markets and the respective impact on production capacities. In order to find compensation for the missing sales, the major competitor needs to find alternative business in order to ensure sufficient utilization for his production sites. According to Bullen and Rockart (1981, p. 7), "CSFs are 
the few areas where 'things must go right' for the business to flourish and for manager's goals to be attained." In the example developed regarding compensating alternatives for missing business due to the fall of the European milk quota, respective variables might be viewed as CSFs. Fields where “...things must go right...” (Bullen \& Rockart, 1981, p. 7) are, for example, the qualification of the strategic vendors, for example, to work with new casting patterns which are needed for new products and the availability of respective engineering expertise and capacity. The information if the major competitor goes into new applications is available in publications of the major competitor and specialist literature. Furthermore, a source of information concerning availability of engineering capacity can at least partly be gained through the observation of job advertisements.

Regarding textual data available from the major competitor, the way the wording regarding the same incident varies over time illuminates the significance of the incident and the ability to deal with it. In this context, it can be observed that the informative value of published financial statements has improved (Bratten, Choudhary, \& Schipper, 2013; Brown \& Tucker, 2011; Clor-Proell \& Maines, 2014; Glaum, Baetge, Grothe, \& Oberdörster, 2013; Lang \& Stice-Lawrence, 2015; Merkley, 2014) and that a change of the wording can be identified (Ernstberger et al., 2017; Feldman et al., 2010; Guay, Samuels, \& Taylor, 2016).

Concerning the internal textual data of the focus company, respective queries (for example, simple text searches identifying in what context the major competitor's name is mentioned explicitly) can support identifying incidents and CSF.

This section has outlined how identifying incidents supports recognizing the major competitor's respective CFSs. In the next section, I seek to supplement how strategic textual information is considered in this context.

\subsubsection{Strategic match}

Rockart $(1979$, p. 86$)$ refers to the strategic context in the second prime source "...of critical success factors..." when he mentions "competitive strategy" explicitly. In the previous section, I have delineated that the informative value of the consolidated financial statement has increased. The major competitor communicates in his consolidated published financial statements information regarding his strategy. For example, if the major competitor has made an acquisition, he explains this in many cases with the "strategic fit" and describes this as an amendment of an existing product line and a strengthening of the strategic position in the respective market. 
Due to the complexity of particularly the production processes an acquisition and respective CSFs would have to anticipate the integration of the acquired organization into the processes because this forms a field where “...things must go right...” (Bullen \& Rockart, 1981, p. 7). Details like, for example, harmonization of material master data and alignment of production planning are prerequisites for a successful integration of an acquisition. Furthermore, a harmonization of the IT - landscape would have to be accomplished. Problems in this area become visible very early for example, through late quarterly reporting to the financial markets and would be challenged by financial analysts.

Furthermore, major competitor communicates in his consolidated financial statements Goals and Targets regarding certain KPIs (for example, ROCE) and gives information to what extent this has been achieved. In addition, major competitor also communicates in his consolidated quarterly press conferences his expectations regarding the prospective development of profit ("Guidance") in which in particular financial analysts are interested in.

Regarding the structure of the textual information in this context I have considered data relating to strategic information or targets and goals in respective nodes in NVivo. Furthermore, I have differentiated the information regarding targets and goals in descriptive and indicative data in Phase 1 of the coding process (section 5.2.2.2 Aligning the NVivo node structure with the conceptual framework). Descriptive data refers to explaining the reported values whereas indicative information gives orientation regarding the expected development of the KPI being illuminated.

The criteria for analyzing textual information in relation to CSFs have been aligned with the “...prime sources of critical success factors...” (Rockart, 1979, pp. 86-87) in this section. These criteria support identifying CSF and the process of Evaluating textual Information (section 5.2.5.2). In addition, to that, the overall picture which major competitor seeks to communicate to especially Financial Analysts can be compared with the model (section 5.4.2).

In the following section I aim to demonstrate how a notion of major competitor's sales can be developed.

\subsubsection{Developing a notion of a reasonable Sales Figure}

\subsubsection{Course of Action}

The textual Information used in this project has been described in the previous section. Based on these grassroots I seek to carry over the textual information into the numerical context of the Information Categories of the conceptual framework in this section. 
As a first cornerstone of this section I strive to explain how I evaluated textual Information (section 5.2.5.2). The result of this procedure will then be integrated in a decision-making model and along with the underlying workflow be explained in section 5.2.5.3.

As a second basic element in this section I decided to employ four examples which shall support the explanation of the context and the workflow applied. These four examples will be used and further developed in section "5.3 Numerical information".

As mentioned above, the starting point of this section is the evaluation of textual Information which is the subject of the next section.

\subsubsection{Evaluating textual information}

As core criteria for analysing textual Information (section 5.2.4 Phase 3: identifying trends and themes with strategic context) "Comparisons vs. MC and FA", "Incidents" and "Strategic match" have been identified. These core criteria need now to be incorporated in an evaluation approach (for example, relevant in case of pricing according to Laitinen, 2011).

The approach of Evaluation of textual Information applied in this project is illustrated in Figure 55.

Figure 55: Evaluation of textual Information

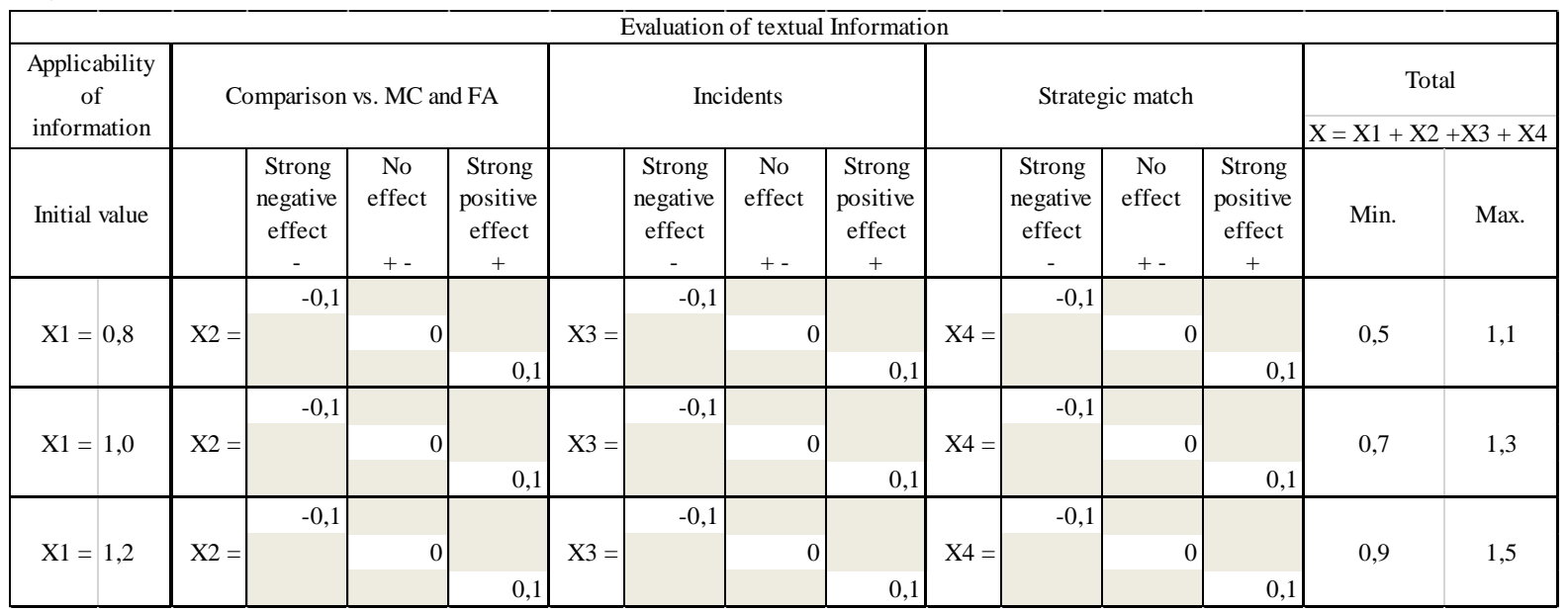

In particular in accordance with the Information Category "Margin Accounting" of the conceptual framework/the model the evaluation of the textual Information needs to be connected with the product line structure (see section 5.2.2.2.1 Margin accounting). In a first step, this can be conducted through employing Initial Values $(0.8,1.0$ and 1.2) which have been developed based on the total "Bottom-Up - Sales" - estimation considering the related growth rate and providing a respective bandwidth from 0.8 to 1.2. This in turn is then connected with tenths of steps reflecting the impact of the core areas of textual analysis. 
The rationale for this procedure is to consider, if there is no support in the textual information the Initial Value will not increase whereas if there is support in the textual information it can increase up to 1.5. This approach ensures the appropriate consideration of textual information when developing the "NVivo - related Sales".

In Figure 55 this first connection is established in the lines which relate to the applicability of the textual information available regarding the particular product line.

A second connection between the textual information and the evaluation procedure illustrated in Figure 55 is set-up through the involvement of core criteria for analyzing textual information. All of these three criteria can take one of the three values ("Strong negative impact" leads to -0.1 , "No effect" causes 0 and "Strong positive effect" delivers to +0.1 ). These values are labelled with X2 (“Comparison vs. MC and FA"), X3 (“Incident”) and X4 ("Strategic match"). The sum of X1 to X4 will only be calculated for the line of the initial value, for example, in the example mentioned above for the third line because in that particular product line the Initial Value is 1.2. The minimum value in this example is 0.9 (in case the values of $\mathrm{X} 2, \mathrm{X} 3$ and $\mathrm{X} 4$ would be -0.1 ) and the maximum value 1.5 (in case the values of X2, X3 and X4 would be +0.1). The Min./Max. - values are displayed in Figure 55 in the last two columns for each line.

The process of Evaluation textual Information starts with internal documents from the focus company. Background for this is that the information available from focus company covers all areas under observation. In addition, both levels of consolidation are covered by this information.

Within the core criteria for analyzing textual information "Comparison vs. MC and FA" for example, information regarding sales in a particular product line is verified against information available from major competitor and Financial Analysts.

Enclosed by the criterion "Incident" extraordinary effects like for example, impacts caused by the Financial Crisis in 2009/2010 are evaluated. Also, an Incident can for example, be indicated by a change in the major competitor's comments on a particular topic during the periods under observation (Feldman et al., 2010, "Management's tone change").

Inside of the criterion "Strategic match" the information for example, regarding a particular product line is evaluated as to what extent its accordance to major competitor's communicated Strategy, Goals and Targets in the consolidated financial statements can be verified. 
The above described procedure considers the core criteria for evaluating textual information and connects this with the relevance of for example, that particular EPU by product line by year. The points of intersection make transparent which of the core criteria contributed to the total of the evaluation process to what extent. The result of this process becomes an integral part in the area of "NVivo - related Sales" in the next section.

\subsubsection{Options and Process of decision-making}

\subsection{Preparation of Options}

In this section, I firstly seek to give an overview of the process of decision-making between the different options of Sales-Figures. Thereafter I will go into the description of the preparative steps.

Figure 56 contains in the form of a flow-chart the entire workflow of the Process of Testing Options of Estimations of Competitor's Sales.

The process is differentiated in the parts "Preparation of Options" (this section), "Testphase" and "Outcome/Result" (next two sections).

Within this section I will go into the question how the four different options of this process are defined and how they are prepared for this process. In the subsequent section I strive to zoom into the Testphase. This includes the question what tests will be conducted and what are the decision-relevant criteria. Lastly, I attempt to explain how the outcome of this test is furthermore used and processed in this project. 
Figure 56: Process of Testing Options of Estimations of Competitor's Sales

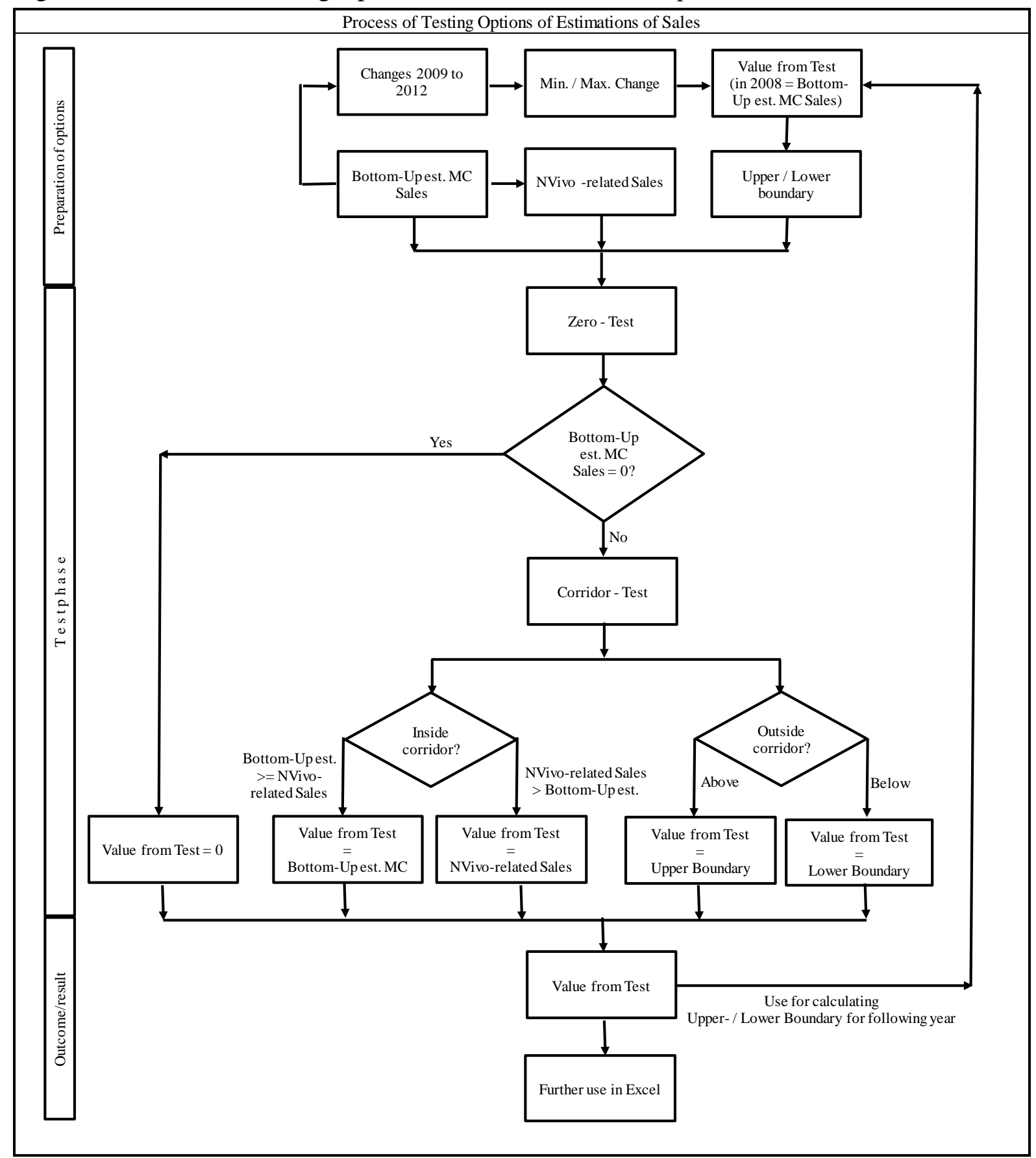

The options to be explained in this preparative step are "Bottom-Up est. MC Sales", "NVivorelated Sales" and "Upper-/Lower Boundary".

"Bottom-Up est. MC Sales" relates to an estimation of the subsidiaries of the focus company regarding the sales that they estimate competition to make. This information has been produced in order to use the expertise of the worldwide sales-force of the focus company. The major competitor was one of the competitors for which estimations had been given. These estimations were differentiated by product line by year for new equipment and service business in total. This information has in this preparative step also been used to calculate 
changes. The first change which could be calculated was the one for 2009 (as difference between 2009 and 2008). The motivation for calculating these differences is to see to what extent Sales can vary from year to year in both directions, increase (Max. Change) and decrease (Min. Change) based on what sales major competitor is expected to make.

The calculated changes have in the first year (2008) be connected with the "Bottom-Up est. MC Sales" - Sales figure in order to build a corridor around the estimated values. In the following periods the outcome of the test (= "Value from Test") has been used to replace the "Bottom-Up est. MC Sales" - figure and to use the "Value from Test" of the previous year as basis for developing the "Value from Test" for the next year. The corridor is defined through its Upper- and Lower Boundary and gives an idea to what extent the sales can change based on the estimations made regarding the development of major competitor's sales.

The result of the evaluations of the textual information explained in the previous section, is now connected in the first year with the "Bottom-Up est. MC Sales" - Sales figure and thereafter with the "Value from Test" - figure through multiplying for example, 1.2 with the "Bottom-Up est. MC Sales" - Sales figure or the "Value from Test" - figure respectively.

In this preparative section the basis for the testing has been established. The testing can now be used to make a decision between the four possible outcomes of the process: "Bottom-Up est. MC Sales", "NVivo - related Sales" and "Upper-/Lower Boundary".

\subsection{Testing}

In order to explain the testing described in Figure 56 I prepared four examples (Figure 57 on page 146 to Figure 64 on page 154). I seek to demonstrate the logic applied in the tests (Figure 56) based on the year 2009 in Figure 57 and Figure 58 whereas the behaviour of the tests will be illustrated for the years 2009 to 2012 for the four examples (Figure 61 on page 151 to Figure 64 on page 154). All numbers used in this section can be reconciled in Figure 57 to Figure 64. The reason for not considering the year 2008 is, that it is not possible to calculate changes for 2008. This is due to the fact that for calculating changes for 2008 the year 2007 would have to be part of this project which is not the case.

Figure 57 starts with establishing the prerequisites of calculating the Acceptable Range (corridor). 
Figure 57: Examples Introduction Part 1 of 2

\begin{tabular}{|c|c|c|c|c|c|c|c|c|c|}
\hline [1] & [2] & [3] & [4] & [5] & [6] & [7] & [8] & [9] & [10] \\
\hline \multirow{3}{*}{\multicolumn{4}{|c|}{$\begin{array}{c}\text { Ex a m p l e } \\
\text { changes } 2009-2012\end{array}$}} & \multicolumn{6}{|c|}{ Delta vs. PY } \\
\hline & & & & 2009 & 2010 & 2011 & 2012 & Min & Max \\
\hline & & & & \multicolumn{6}{|c|}{ Changes $2009-2012$} \\
\hline \multirow[t]{2}{*}{ EPU } & \multirow[t]{2}{*}{$\begin{array}{l}\text { Example } \\
\text { Number }\end{array}$} & \multirow[t]{2}{*}{ Level } & \multirow[t]{2}{*}{ Key } & $\begin{array}{c}{[5]} \\
= \\
{[26]-} \\
{[12]}\end{array}$ & $\begin{array}{c}{[6]} \\
= \\
{[45]-} \\
{[26]}\end{array}$ & $\begin{array}{c}{[7]} \\
= \\
{[64]-} \\
{[45]}\end{array}$ & $\begin{array}{c}{[8]} \\
= \\
{[83]-} \\
{[64]}\end{array}$ & Min. & Max. \\
\hline & & & & \multicolumn{6}{|c|}{ Sales units } \\
\hline 200 & Example 1 & Single entity & $200 \times x 2008$ & -10.600 & 12.000 & 2.020 & 400 & -10.600 & 12.000 \\
\hline 202 & Example 2 & Single entity & $202 \times x 2008$ & -7.521 & 6.393 & -4.149 & 1.199 & -7.521 & 6.393 \\
\hline 204 & Example 3 & Single entity & $204 \times x 2008$ & 325 & -265 & 275 & -85 & -265 & 325 \\
\hline 206 & Example 4 & Single entity & $206 \times x 2008$ & -2.800 & -1.200 & 780 & -530 & -2.800 & 780 \\
\hline 1 & Total & Group & & & & & & & \\
\hline
\end{tabular}

The numbers in brackets in the first line of Figure 57 indicate the number of the column. In order to explain for example, calculations I will refer to the numbering of columns.

Columns [1] to [4] of Figure 57 contain descriptive information like the number of the Entrepreneurial Unit (EPU), the number of the example, the consolidation level and an identifying key.

The columns [5] to [8] of Figure 57 comprise the calculation of the changes of sales in the years 2009 to 2012 whereas the column [9] identifies the lowest value and column [10] the highest value of the changes calculated in [5] to [8]. The rows contain the respective calculations for the examples one to four. For instance, for example, one a change of -10600 (decrease) in 2009 (column [5]) has been calculated. This is because the Bottom-Up estimation of the Sales of major competitor in this particular product line in 2009 was zero (see column [26] in Figure 58 on page 147 and also in Figure 61 on page 151) and the respective 2008 value was 10600 (column [12] in Figure 58). The 2010 change (= 12000, see column [6] in Figure 57) is calculated by subtracting the 2009 sales (which is zero) from 2010 sales $(=12000$, see Figure 61). Subtracting the 2010 sales $(=12000)$ from the 2011 sales $(=14020$, see Figure 61$)$ delivers a change in 2011 of 2020 for example, one. In a last step the 2011 sales $(=14020)$ is subtracted from the 2012 sales $(=14420$, see Figure 61) which gives a 2012 change of 400 (see column [8] in Figure 57). The lowest value for 
example, one is obviously the 2009 change of -10600 and the highest value the 2010 change of 12000 which is displayed in columns [9] und [10] of Figure 57.

Based on the prerequisites determined in Figure 57 the examples one to four can be developed for 2009 in Figure 58.

Figure 58: Examples Introduction Part 2 of 2 - developing 2009 Value from Test

\begin{tabular}{|c|c|c|c|c|c|c|c|c|c|c|c|c|c|c|c|c|c|c|}
\hline \multirow{4}{*}{$\begin{array}{c}\text { Exa m p l e } \\
2009 \\
\text { Value from } \\
\text { Test }\end{array}$} & {$[12]$} & [13] & {$[14]$} & [15] & {$[16]$} & {$[17]$} & {$[18]$} & {$[19]$} & {$[20]$} & {$[21]$} & {$[22]$} & {$[23]$} & [24] & {$[25]$} & [26] & [27] & {$[28]$} & [29] \\
\hline & \begin{tabular}{|r|} 
Start \\
2008 \\
\end{tabular} & $\begin{array}{l}\text { Acceptal } \\
\text { "Corr }\end{array}$ & $\begin{array}{l}\text { able range } \\
\text { ridor" }\end{array}$ & \multicolumn{11}{|c|}{ Evaluation of textual Information conducted in NVivo } & 2009 & Zero - Test & Corridor - Test & $\begin{array}{l}2009 \text { Value from } \\
\text { Test }\end{array}$ \\
\hline & \multirow{4}{*}{$\begin{array}{c}\text { Bottom- } \\
\text { Up } \\
\text { estim. }\end{array}$} & Lower & Upper & Compari & on vs. $N$ & and FA & & Incidents & & & ategic $m$ & & \multirow[b]{2}{*}{ Total } & \multirow{2}{*}{\begin{tabular}{|c|}
2009 \\
Relating \\
sales \\
units \\
\end{tabular}} & \multirow{3}{*}{\begin{tabular}{|c|} 
Bottom- \\
Up \\
estim.
\end{tabular}} & \multirow[b]{3}{*}{ Fail if $[26]=0$} & \multirow[b]{2}{*}{$\left|\begin{array}{l}\text { Fail if }[25]>[14] \\
\text { Fail if }[25]<[13]\end{array}\right|$} & \multirow{3}{*}{\begin{tabular}{|c|} 
NVivo - relating \\
sales units [25] \\
or \\
Bottom-Up est. \\
[26] \\
or \\
Upper [14] \\
or \\
Lower [13] \\
Boundary
\end{tabular}} \\
\hline & & Boundary & Boundary & & +- & + & & +- & + & & + & + & & & & & & \\
\hline \multirow[t]{2}{*}{ Key } & & $\begin{array}{c}{[13]} \\
= \\
{[12]+[9]}\end{array}$ & $\begin{array}{c}{[14]} \\
= \\
{[12]+[10]}\end{array}$ & \multirow{2}{*}{\multicolumn{3}{|c|}{$\begin{array}{l}\text { EXAMPLES } 1 \text { a } \\
\text { EXAMPLE } 3 \text { : } \\
\text { EXAMPLE 4: }\end{array}$}} & 2: X1 & $=1,0->$ & Min. $=0$ & .7 / Max. & $=1,3$ & & \multirow[t]{2}{*}{$\begin{array}{c}\text { Min. }= \\
0,5 \\
\text { Max. }= \\
1,5\end{array}$} & \multirow[t]{2}{*}{$\begin{array}{c}{[25]} \\
= \\
{[12] x} \\
{[24]}\end{array}$} & & & $\begin{array}{l}\text { Fail if }[26]>[14] \\
\text { Fail if }[26]<[13]\end{array}$ & \\
\hline & & Sales unit & & & & & & & & & & & & & & & Sales units & \\
\hline $200 \times x 2009$ & 10.600 & 0 & 22.600 & & & 0,1 & & & 0,1 & & & 0,1 & 1,1 & 11.660 & 0 & 0 & 0 & 0 \\
\hline $202 \times x 2009$ & \begin{tabular}{|l|}
18.643 \\
\end{tabular} & 11.122 & 25.036 & & & 0,1 & & & 0,1 & & & 0,1 & 1,1 & 20.507 & 11.122 & 11.122 & 11.122 & 20.507 \\
\hline $204 \times x 2009$ & 600 & 335 & 925 & & 0,0 & & & 0,0 & & & & 0,1 & 1,1 & 660 & 925 & 925 & 335 & 925 \\
\hline $206 \times x \times 2009$ & 14.200 & 11.400 & 14.980 & & 0,0 & & & 0,0 & & $-0,1$ & & & 1,1 & 15.620 & 11.400 & 11.400 & 14.980 & 14.980 \\
\hline
\end{tabular}

Firstly, I seek to describe the build-up of Figure 58 and thereafter explain the logic of the tests according to Figure 56 based on the four examples already introduced.

Figure 58 starts with an identifying key in column [11]. The first three digits in column [11] represent the number of the EPU, the following two digits contain a reference to the product line (here place holder $\mathrm{xx}$ in order not to enable a conclusion to the original product line) and the last three digits contain the year. Column [12] comprises the starting value for 2009 which is in 2009 the Bottom-Up estimation for 2008. In the years 2010 to 2012 the starting value is the Value from Test of the previous year (for example, starting value for 2010 is Value from Test 2009).

Columns [13] and [14] of Figure 58 contain the calculation of the Lower- (column [13]) and Upper (column [14]) Boundary which form the Acceptable Range or "Corridor". The lower boundary for example, one $($ Key $=200 \times x 2009)$ is calculated by adding the 2009 minimum value (= -10600 taken from column [9] in Figure 57) to the 2009 start value of 10600 (column [13] in Figure 58) which delivers zero as lower boundary $(0=10600-10600)$. The upper boundary for example, one is generated by adding the 2009 maximum value $(=12000$ taken from column [10] in Figure 57) to 2009 start value of 10600 which gives an upper boundary of $22600(=10600+12000)$.

In the columns [15] to [25] the connection to the analysis of the textual information conducted in NVivo is constructed. The structure of this part relates to the core areas of the textual analysis displayed in Figure 55 on page 141 (Evaluation of textual Information). Correspondingly, the columns are assigned to these core areas: the values for "Comparison 
vs. MC and FA" are contained in columns [15] to [17], those for "Incidents" are included in columns [18] to [20] and columns [21] to [23] consist the values of "Strategic match". Three columns for each core area are needed because the values can vary between "Strong negative impact" (value $=-0.1)$, "No impact" (value $=0$ ) and "Strong positive impact" (value $=+0.1)$. The evaluation for example, one has led in all three core areas to a strong positive impact (contained in columns [17], [20] and [23] of Figure 58 and the respective value of +0.1 in each of these areas. The headline in this area provides the information, that examples one and two have an initial value of 0.8 which leads a total evaluation of $1.1(=0.8+0.1+0.1+0.1$ in column [24] of Figure 58). Based on this evaluation of the textual information the relating sales can now be derived for example, one by multiplying 1.1 with the 2009 start value in column [12] $(=1.1 \times 10600=11660$ in column [25] of Figure 58).

The 2009 Bottom-Up estimation is displayed in Column [26] and is one of four possible outcomes. The respective value for example, one is zero, for example, two 11122, for example, three 925 and for example, four 11400.

After having outlined the contents of the four possible outcomes of the process illustrated in Figure 56 on page 144 in Figure 58 on page 147 I strive to explain the tests based on the four examples already introduced for the year 2009.

Column [27] contains the result of the Zero-Test whereas the result of the Corridor-Test is displayed in column [28] (both columns relate to Figure 58).

According to Figure 56 the first test to be conducted is the Zero-Test. I have excerpted the for this explanation relevant part of Figure 56 in Figure 59.

Figure 59: Zero - Test as first test to be conducted

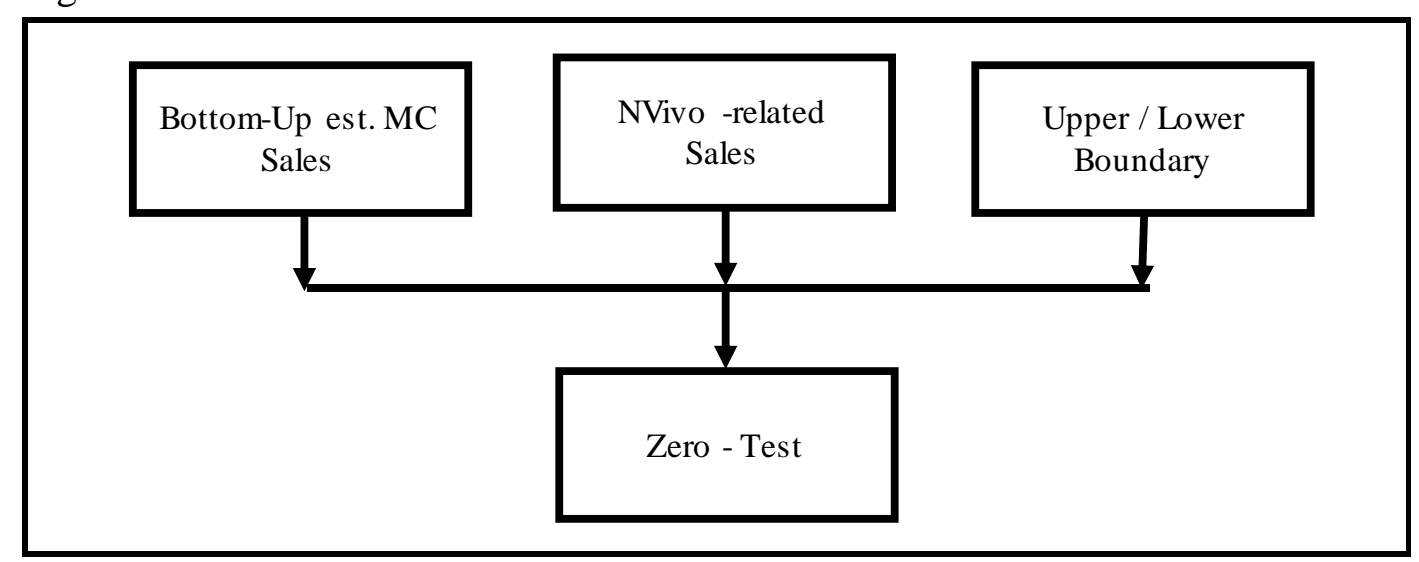

The Zero-Test focuses on the Bottom-Up estimation of competitor's sales in a particular product line ("Bottom-Up est. MC Sales") of a specific year. 
The decision rule of the Zero - Test is: where "Bottom-Up est. MC Sales" is equal to zero, "Value from Test" is equal to zero.

With regards to the examples used in Figure 58 example one $($ Key $=200 x x 2009)$ shows a zero for the Bottom-Up estimation in column [26] which leads to a Value from Test in column [29] of zero. In all other examples the Bottom-Up estimation is greater than zero and therefore the Zero - Test does not apply in these cases.

The background for the Zero-Test is, that if the reporting unit of the focus company estimates that major competitor has no business in that product line in that year this assumption should dominate all other decision-rules. It needs to be emphasized, that the Zero - Test is a special case of one of the four possible outcomes (Bottom-Up estimation) and not additional outcome.

Following the Process of Testing Options of Estimations of Competitor's Sales (Figure 56 on page 144) the next test to be conducted is the Corridor-Test in case the Zero-Test has failed. This test ensures that the outcome of this process of evaluation stays within the corridor. I have summarized the values of the four examples in Figure 60 (which is an excerpt of Figure 58 "Examples Introduction Part 2 of 2 - developing 2009 Value from Test”). Based on this I seek to explain the logic applied in the corridor-test.

Figure 60: Summary of Examples 1 to 4

\begin{tabular}{|c|c|c|c|c|c|c|c|}
\hline [11] & [13] & [14] & [25] & [26] & [27] & [28] & [29] \\
\hline \multirow{2}{*}{$\begin{array}{c}\text { E x a m p l e } \\
2009 \\
\text { Value from } \\
\text { Test }\end{array}$} & \multicolumn{2}{|c|}{$\begin{array}{c}\text { Acceptable range } \\
\text { "Corridor" } \\
\end{array}$} & $\begin{array}{c}\text { NVivo related } \\
\text { sales }\end{array}$ & 2009 & Zero - Test & Corridor - Test & $\begin{array}{l}2009 \text { Value from } \\
\text { Test }\end{array}$ \\
\hline & \begin{tabular}{|c|} 
Lower \\
Boundary
\end{tabular} & $\begin{array}{c}\text { Upper } \\
\text { Boundary }\end{array}$ & $\begin{array}{c}2009 \\
\text { Relating } \\
\text { sales }\end{array}$ & Bottom- & & $\begin{array}{l}\text { Fail if }[25]>[14] \\
\text { Fail if }[25]<[13]\end{array}$ & $\begin{array}{c}\text { NVivo - relating } \\
\text { sales units [25] } \\
\text { or }\end{array}$ \\
\hline \multirow[t]{2}{*}{ Key } & $\begin{array}{c}{[13]} \\
= \\
{[12]+[9]}\end{array}$ & $\begin{array}{c}{[14]} \\
= \\
{[12]+[10]}\end{array}$ & $\begin{array}{c}{[25]} \\
= \\
{[12] \times[24]}\end{array}$ & estim. & Fail if $[26]=0$ & $\begin{array}{l}\text { Fail if }[26]>[14] \\
\text { Fail if }[26]<[13]\end{array}$ & $\begin{array}{c}\text { or } \\
\text { Upper [14] } \\
\text { or } \\
\text { Lower [13] } \\
\text { Boundary } \\
\end{array}$ \\
\hline & \multicolumn{2}{|c|}{ Sales units } & Sales units & \multicolumn{4}{|c|}{ Sales units } \\
\hline $200 \times x 2009$ & 0 & 22.600 & 11.660 & 0 & 0 & 0 & 0 \\
\hline $202 \times x 2009$ & 11.122 & 25.036 & 20.507 & 11.122 & 11.122 & 11.122 & 20.507 \\
\hline $204 \times x 2009$ & 335 & 925 & 660 & 925 & 925 & 335 & 925 \\
\hline $206 \times x 2009$ & 11.400 & 14.980 & 15.620 & 11.400 & 11.400 & 14.980 & 14.980 \\
\hline
\end{tabular}


Firstly, it is tested whether the NVivo related sales (column [25]) are above the upper boundary (column [14]) or below the lower boundary (column [13]). Thereafter the same test is conducted for the bottom-up estimation (column [26]).

The decision-rule in these cases is: where NVivo-related sales (bottom-up estimation) is greater than the upper boundary, use upper boundary. Where NVivo-related sales (bottom-up estimation) is smaller than lower boundary, use lower boundary.

In Figure 60 (Figure 58 respectively) example one $($ key $=200 x x 2009)$ is covered by the zerotest already, because the bottom-up estimation (column [26]) equals zero. Both, example two $($ key $=202 \times x 2009)$ and three $($ key $=204 \times x 2009)$ are not meeting the requirement of being above the upper or below the lower boundary.

In example two (key = 202xx2009), the bottom-up estimation (= 11122 in column [26]) is not below the lower boundary (= 11122 in column [13]) and the NVivo-related sales $(=20507$ in column [25]) is below the upper boundary of 25036 (column [14]). This case is covered by the decision path "Inside Corridor" illustrated in Figure 56. The decision-rule in this case is to take the higher value: where bottom-up Sales estimation (NVivo-related sales) is greater than NVivo-related sales (bottom-up sales estimation), but within the acceptable range, use bottom-up sales estimation (NVivo-related sales). In example two the NVivo-related sales of 20507 (column [25]) is greater than the bottom-up Sales estimation of 11122 (column [26]) and therefore the Value from Test (column [29]).

The values of example three $(k e y=204 \times x 2009)$ are inside the corridor as well. The NVivorelated sales (=660, see column [25]) are above the lower boundary of 335 (column [13]), whereas the bottom-up estimation (=925, see column [26]) is not above the upper boundary of 925 (column [14]). Comparing 925 (bottom-up estimation) with 660 (NVivo-related sales) delivers the bottom-up estimation as Value from Test (column [29]).

In example four (key = 206xx2009), the bottom-up estimation is inside the acceptable range because it is not below the lower boundary (both values are 11400, see columns [26] and [13]) whereas NVivo-related sales of 15620 (column [25]) are greater than the upper boundary of 14980 (column [14]). This example connects two aspects. Firstly, the greater value of bottom-up estimation and NVivo-related sales is identified. Secondly, the value identified (NVivo-related sales of 15620) is compared with the upper boundary of 14980 (column [14]). In this case, the Value from Test (column [29]) is limited to the upper boundary. This is justified through the argument, that it not reasonable to assume an increase in sales which is above the highest year-to-year increase in the periods under observation. 
The respective decision-rule is: where one of the values of bottom-up estimation or NVivorelated sales is within the acceptable range and one of these values is greater than the upper boundary, use the upper boundary as Value from Test.

The Value from Test (column [29] in Figure 58 on page 147) contains the decision between one of the four possible outcomes of this process. In the case of example one (key = 200xx2009) the zero-test leads to zero, in example two (key = 202xx2009) NVivo-related sales delivers a value of 20507, for example three (key $=204 \times x 2009)$ the bottom-up estimation of 925 becomes Value from Test and in example four the upper boundary limits the result of this process to 14980 .

I have conducted this procedure in the same manner for the years 2010 to 2012 as well (see Annex 39, Annex 40 and Annex 41). Based on this, I illustrated the development of the four possible outcomes of this process for the examples one to four in Figure 61 on page 151 to Figure 64 on page 154. Regarding the evaluation of textual information, I have used the same figures as for 2009 which leads to 1.1 for all four examples.

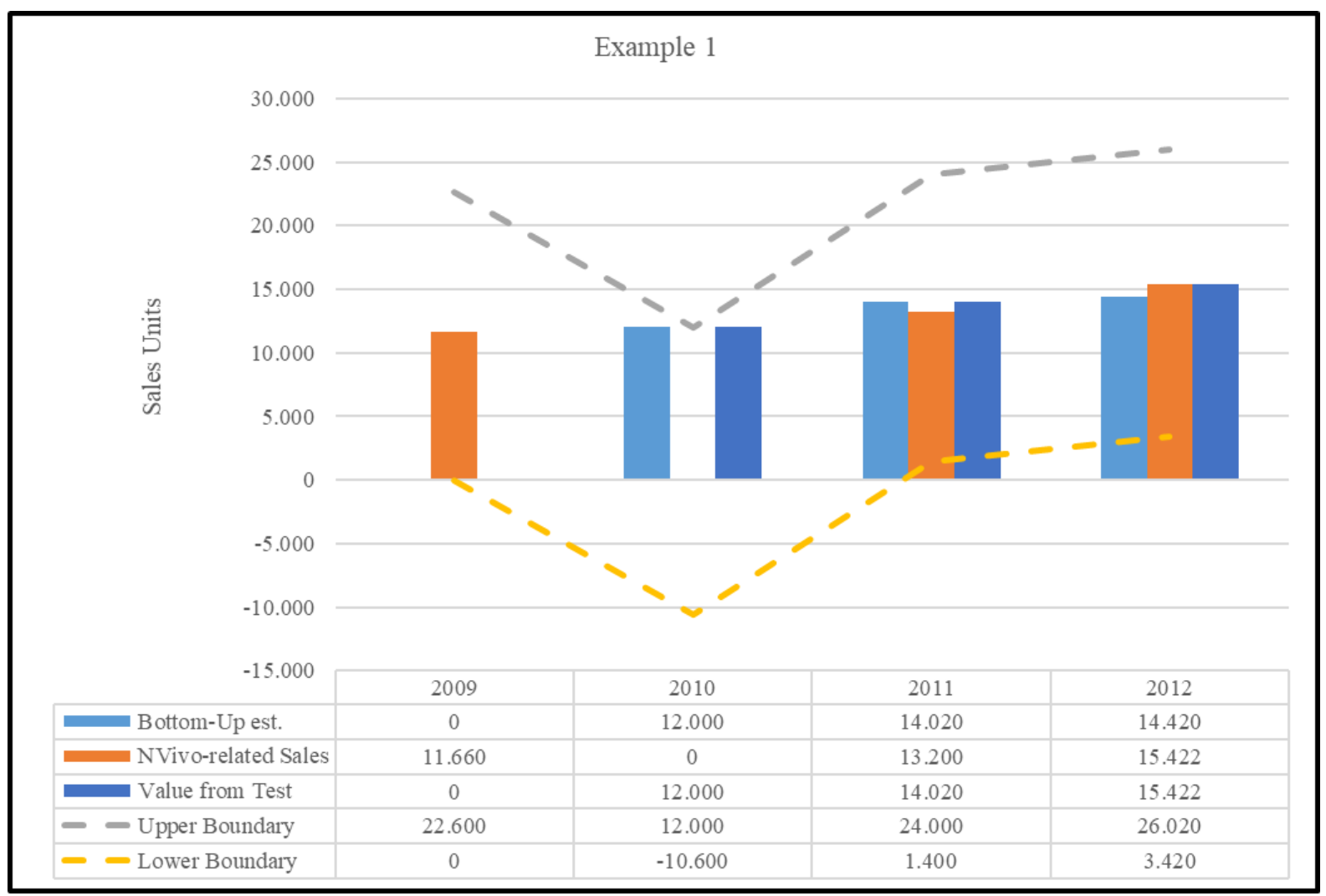

Figure 61 (example one, key $=200 \times x 2009$ ) shows a negative lower boundary for 2010 of 10600 which is due to the fact that the 2009 Value from Test is zero and the value for the minimum change is -10600 (2010 lower boundary $=0-10600)$. This shows that in the case 
of a negative lower boundary the process does not deliver a negative Value from Test. In the years 2011 and 2012 bottom-up estimation and NVivo-related sales are in the acceptable Range and the higher value has been selected as Value from Test.

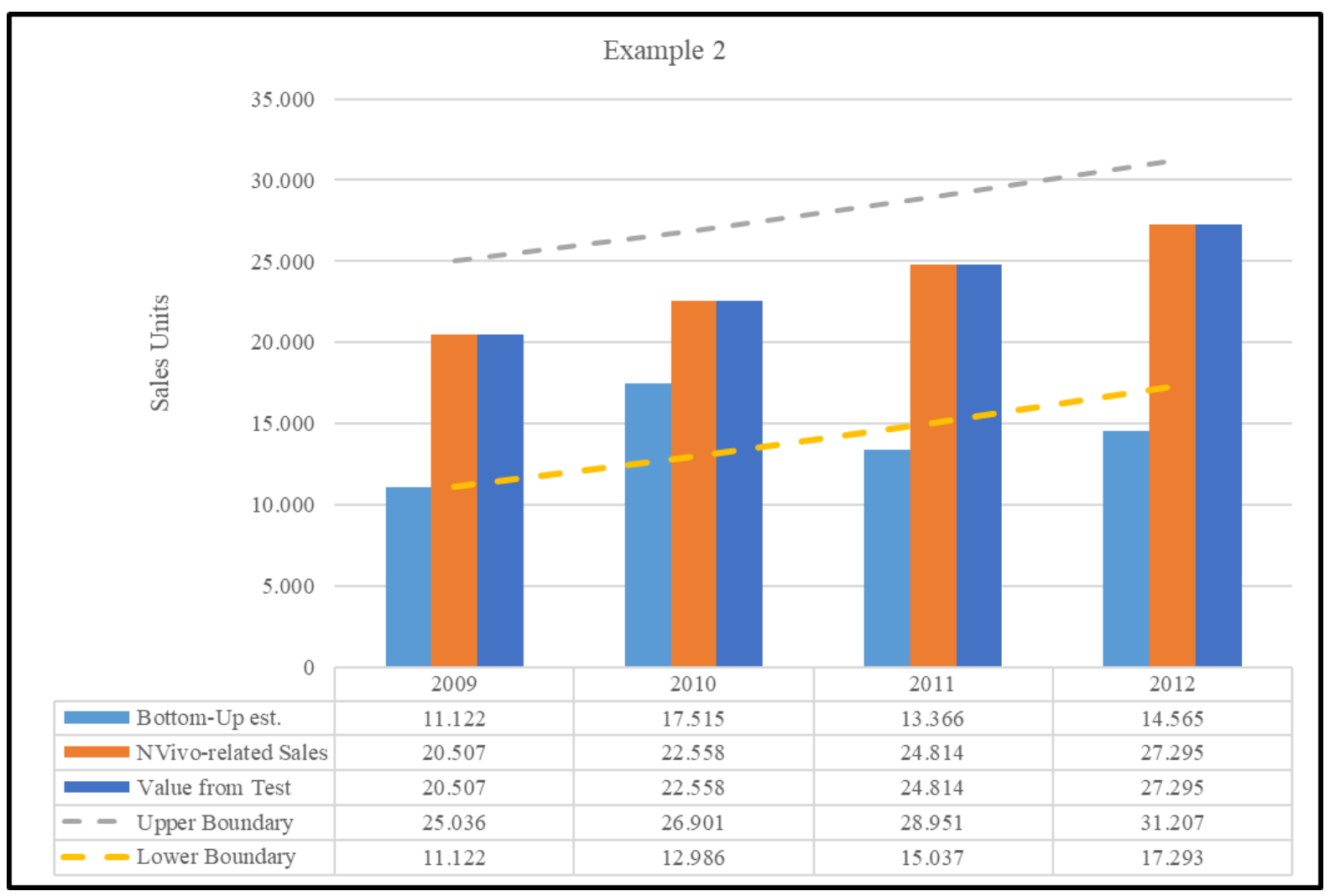

Example two (key $=202 \times x 2009$, Figure 61) shows values for bottom-up estimation and NVivo-related sales which are within the acceptable range in all periods. Within the Boundaries the higher value has been selected as Value from Test. 


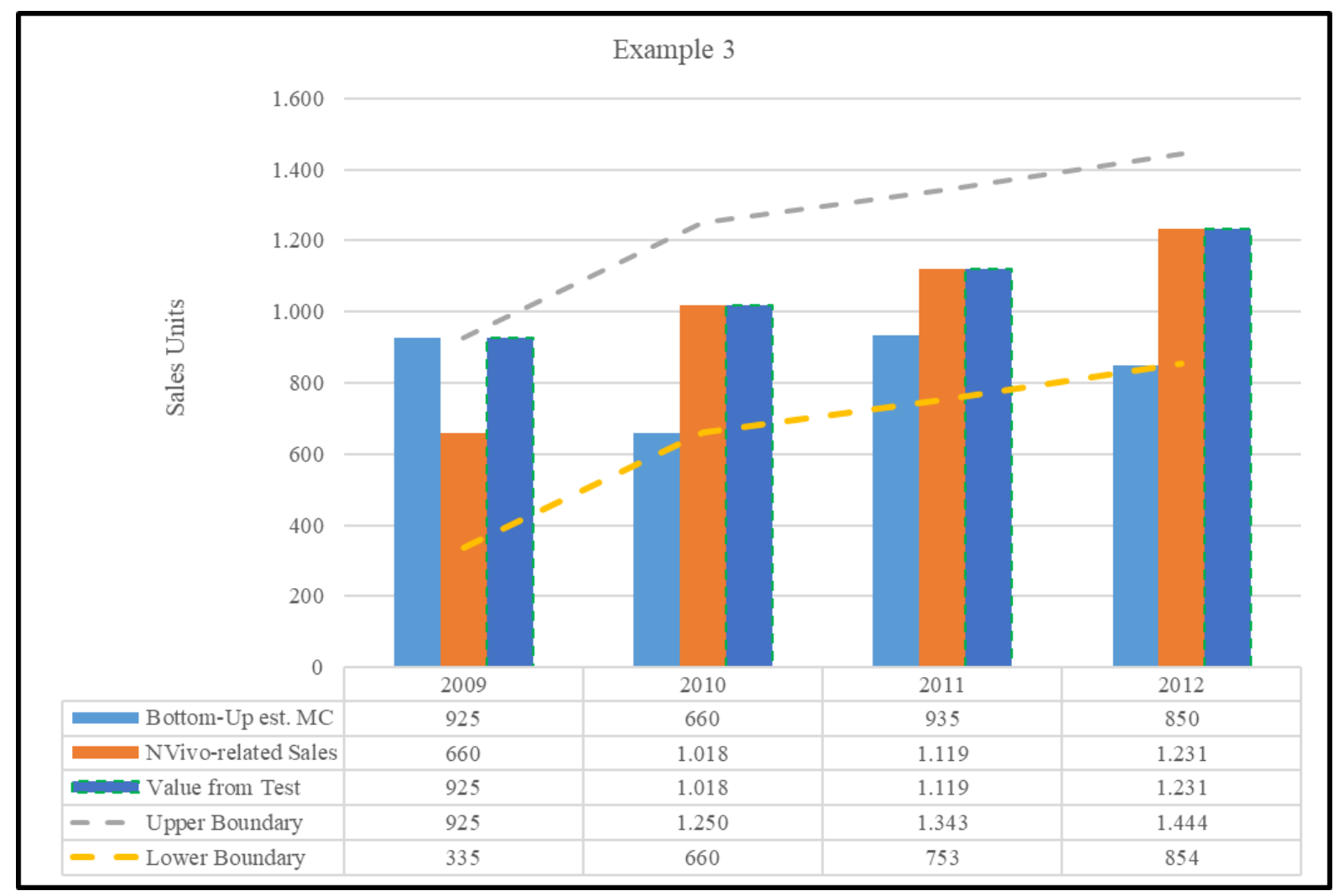

In example three $(\mathrm{key}=206 \times x 2009$, Figure 63), the Value from Test is in the years 2010 to 2012 the NVivo-related sales. The boundaries appear not to be so wide as in the previous examples. 


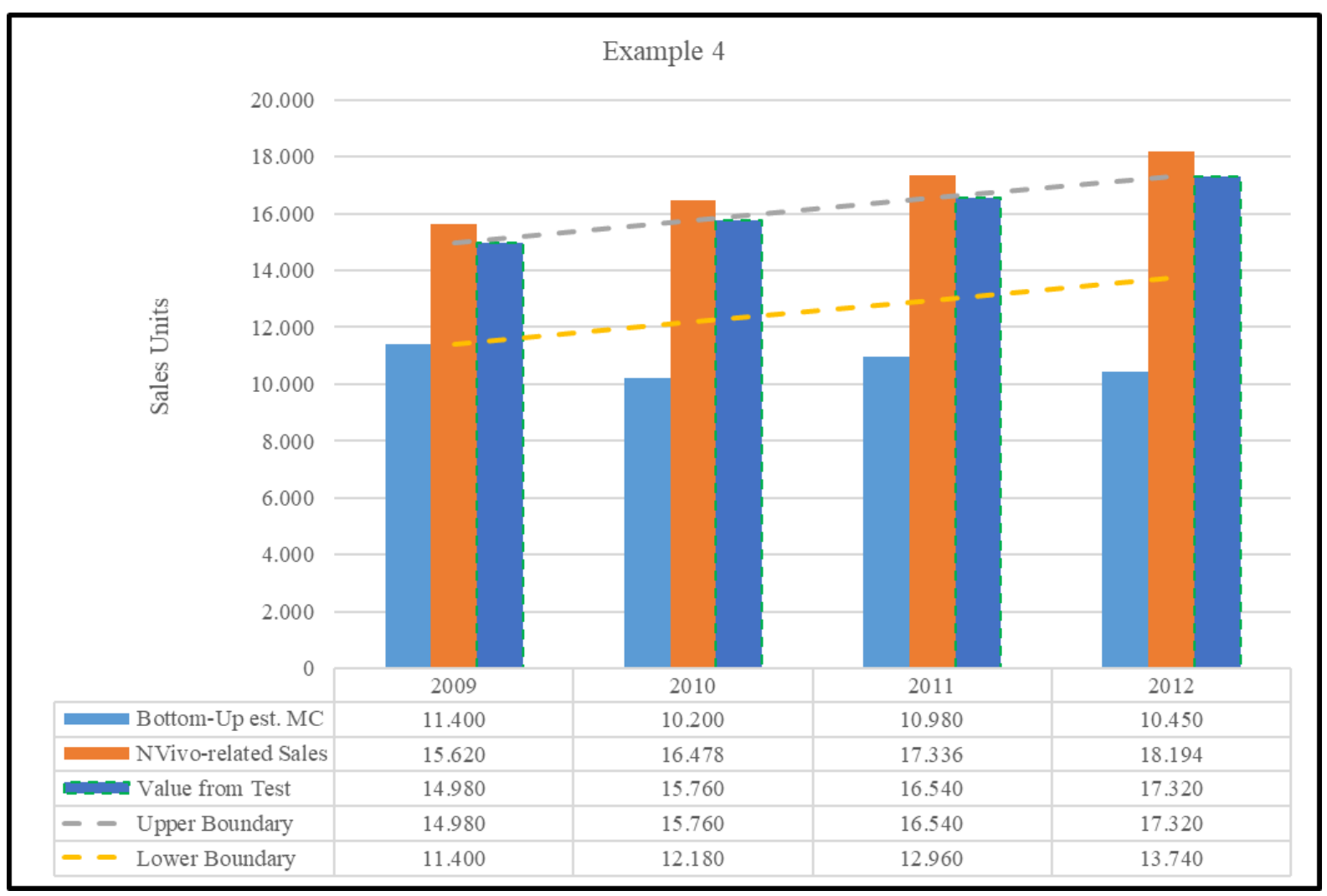

In example four (key $=206 \times x 2009$, Figure 64), the upper boundary represents the Value from Test in all periods. In addition, NVivo-related sales are in the years 2010 to 2012 above the upper boundary and the bottom-up estimation below the lower boundary which underlines the performance-orientated approach of the process to accept the highest value but limited to the boundaries of the acceptable range.

In the next section, I seek to illuminate the last phase of the process of testing options of estimations of competitors' sales illustrated in Figure 56.

\subsection{Outcome}

The process delivers Values from Test for 2009 as the first year. The Values from Test build the basis for the following year (for example two the Value from Test equals 20507 for that particular product line which is observable in Figure 58 on page 147, Figure 60 on page 149 and Figure 62 on page 152). In addition, the Values from Test become the information around which the numerical information in section 5.3 is centered. In this respect, textual information and its interpretation form the basis of the work with the numerical data in this project. The structure of the file, which forms the interface between textual and numerical information, will be described in section 5.2.6. 
Due to the approach of focussing on sales and related information, a strong performance orientation forms the basis for the process of evaluation of textual information. In addition, the structure of the textual information is in accordance with the information categories of this project. In particular, the product line-based structure of the information category margin accounting is reflected in the textual information. The evaluation of textual information (Figure 55 on page 141) covers the core areas identified of the textual data and includes weighting through an A-B-C classification by EPU by product line and year based on sales estimation of the reporting units of the focus company.

With the process of process of testing options of estimations of sales (Figure 56 on page 144) performance orientated limitations have been implemented. Upper and lower boundaries are based on the maximum/minimum year-to-year changes of the EPUs in the respective product lines. This supports that the Estimations are in a range which appears to be reasonable and in addition is based on the expertise of the international sales force of the focus company.

This aspect leads over to the check of verification and consistency of the textual information in the next section.

\subsubsection{Validity}

In order to establish procedures that support maintaining a sufficient level of quality, I seek to follow Ryan et al. (2002). According to the authors, “...the notion of contextual validity..." replaces "... in case study research...the traditional criteria of internal validity..." (Ryan et al., 2002, p. 155). In the opinion of the authors, contextual validity is closely linked to "...the case study evidence and the conclusions that are drawn therefrom" (Ryan et al., 2002, pp. 155 - 156). In this context, the authors mention the method of triangulation explicitly. Furthermore, the authors emphasize the importance of data triangulation and refer to it as a “...process of collecting multiple sources of evidence...” (Ryan et al., 2002).

Due to the nature of this project having the two different strands textual and numerical information, I decided to implement the requirements of validity in the respective stages of the project. Therefore, sections "5.1 Introduction" and "5.3 Numerical information" describe how the requirement of validity has been implemented.

For both textual and numerical information, all information is collected and assigned to EPUs. In addition, the information categories (margin accounting, P\&L statement, balance sheet, cash flow-statement and other) are organized in similar structures. In addition, all source data can be differentiated between the three different perspectives (financial analysts, focus company and major competitor). 
With regards to textual information, I identified core criteria for analyzing the information ("Comparisons vs. MC and FA", "Incidents" and "Strategic match"). Due to the organization of the data, it is possible to relate the information to regions. This allows comparisons of the information of one region given by the focus company, major competitor and financial analysts regarding, for example, the incident "financial crisis". In addition, a comparison of the information given by the major competitor on the levels of single entities and group can be conducted. This supports verifying if, for example, the information regarding the impacts of the financial crisis given by published financial statements of a single entity of the major competitor suits the respective information given in the published consolidated financial statements. The core criteria for analyzing textual information "Strategic match" supports analyzing whether information, in particular given at a consolidated level, is in accordance with the "Strategic Direction" communicated in consolidated financial statements. Contradictions between, for example, the evaluation of the impact of the financial crisis on business and the respective comments in the consolidated financial statements of the major competitor may be comprehensible. For example, according to VDMA (2013, the source documents of focused company give similar information) recovery from financial crisis came for Asia faster than for Europe or the USA, which may clarify the contradiction. This procedure applies in particular to comments and explanations regarding the development of the business in a specific product line.

Another important element is reading the source documents intensively and often (Farquhar, 2012). I read, for example, the documents of the focus company for the first time when they were part of the regular reporting of the focus company. Later on, these reports were also a good source in case detailed explanation of, for example, a certain development needed to be explained. In the course of this project, I coded in total more than 43000 references manually which again led to dealing with the information and in doing so supported the work of verifying and checking of consistency.

In the next section, I aim to describe NVivo-Excel interface.

\subsubsection{Interface between textual and numerical information}

During the process of developing the 2009 Value from Test (see Figure 58 on page 147) the "Evaluation of textual information" has been considered (see columns [15] to [25] in Figure 58) based on a system of identifying values between 0.5 and 1.5 (see Figure 55) which are then applied on the estimated sales of the major competitor. In this last section regarding 
textual information, I aim to explain how the data supporting the evaluation has been identified in NVivo.

I created nodes in Phase 3 for "Comparison vs. MC and FA", "Incidents" and "Strategic match" where I allocated the results of respective queries (for example, text searches for competitors' names). Below each of these nodes I established nodes regarding the expected effects (strong negative, none and strong positive).

Based on the organization of the data, all source documents are assigned to EPUs. Therefore, all references are assigned to EPUs as well. In addition, it can be identified if a reference relates to a particular product line and/or region. The differentiation of the references by year has been conducted in Phase 2.

I defined Matrix Queries according to the structure "Comparison vs. MC and FA" "strong negative" AND "product line 1" AND "2008” with columns financial analysts x focus company $\mathrm{x} \mathrm{MC}$ and EPUs in the rows. The information regarding the A-B-C classification is available in Excel already and does therefore not have to be considered in the interface. The results of these Quires were then exported to Excel.

Within Excel the initial value (according to Figure 55 on page 141) of an EPU for a product line is already existing. The Information transmitted through the interface can be conducted using the number of the EPU as a key.

After having explained how the element of validation is implemented in the organization of the data and the procedure of analyzing the textual information the data can now be prepared for further processing in the area of numerical information.

\subsection{Numerical information and accounting basis}

\subsubsection{Utilizing Value from Test for deriving additional competitor information}

Firstly, I aim to explain briefly the procedure of developing sales figures based on an example with textual data identified in Phase 3. Subsequently, I seek to develop this example further and demonstrate how additional competitor information has been derived from the primary variable "Sales by product line". This additional competitor information relates to margin accounting (section 5.3.2), P\&L statement (section 5.3.3), balance sheet (section 5.3.4) and cash flow statement (section 5.3.5).

Regarding the primary variable "Sales by product line" the core criteria for analyzing textual information ("Comparisons vs. MC and FC", "Incidents", "Strategic match") have been structured according to the impact on sales into the rubrics "negative", "none" and "positive" 
(see Figure 55 on page 141). For example, I classified a reference coming from the focus company: "We hope to have enough power to kick off [major competitor] ..." into "incidents" because this reference related to a project which was about replacing major competitor's equipment at an important customer. As this was negative from the perspective of the major competitor, I coded this into the negative rubric which gave -0.1 evaluation points. This in turn led to a respective reduction of the initial value. Based on an initial value of 0.8 and no further changes, the initial value would change to 0.7. Subsequently, this value has been multiplied with the bottom-up sales estimation which was in this example 3500 sales units and delivered the variable "NVivo related Sales" of 2450 sales units.

The procedure described above was conducted across all product lines and delivered for each year under observation the primary variable "sales by product line" which is now used to develop the variables of the categories margin accounting, P\&L statement, balance sheet and cash flow statement of the dimension information of the conceptual framework/the model.

In order to develop margin accounting (section 5.3.2 on page 159) in a next step the intercompany processes between sales and service EPUs and production sites need to be considered based on the organizational structure as outlined in Figure 17 on page 86. Sales and service EPUs order from production sites which in turn determines the utilization of the production sites. Due to the fact that the focus company has in all relevant cases production sites in the region where the major competitor has its production sites, it is possible to utilize this knowledge (for example, level of wages and salaries, level of energy costs etc.) and connect it with information provided by the major competitor and financial analysts.

In this context, it has to be considered, that defined production lines are assigned to determined production sites due production related reasons. Therefore, the volume sales and service EPUs have to order from production has been allocated to production sites by estimating respective percentages based on information contained in major competitors consolidated financial statements in combination with respective knowledge existing in the focus company. This forms the basis for developing margin accounting as described in section 5.3.2 on page 159 .

The processes and structures developed in context of margin accounting are closely related to the P\&L statement (section 5.3.3 on page 160) according to both, cost sales format and total cost format. Total sales across all product lines represents sales, gross margin and gross profit in P\&L statement. Furthermore, utilizing the system of cost type and cost centre accounting would enable additional check of plausibility to be derived. 
In a next step the core components of the balance sheet can be derived based on the P\&L statement developed in the previous step in conjunction with KPIs taken from the focus company (for example, "Days outstanding Trade Receivables"). This approach is justified because of the assumption of the case study method of a common background. For example, in a particular country and industry the KPI "Days outstanding Trade Receivables" can be assumed to be similar for the focus company and the major competitor because both are acting in the identical environment. Section 5.3.4 on page 161 seeks to deal with the development of the major competitor's balance sheet.

The last category of the dimension information of the conceptual framework/the model is the cash flow statement which has been developed based on P\&L statement and balance sheet. I seek to specify the development of the cash flow statement in section 5.3.5 on page 163 .

In this section, I aimed to outline how the primary variable "Value from Test" has been used for deriving additional competitor information. An important element in this context is the connection of the knowledge of the business the focus company and the major competitor are acting in with well-known KPIs and techniques management accounting provides.

In the next sections, I aim to illuminate how this has been conducted in the categories of the dimension information of the conceptual framework/the model. I will start with margin accounting in the next section.

\subsubsection{Margin accounting}

This part of the model contains four steps and starts with two preparatory strides. Firstly, the GP- and GM- percentages of focus company have been retrieved by product line by reporting unit by year (2008 to 2012) from the official reporting. In a second step, these percentages have then been connected in the model with the respective structures, particularly with product line by EPU.

Measure three is divided as follows:

- Alignment with total sales

This information is steered from the evaluation process started in NVivo. The "Value from Test" sales by EPU by product line by year is developed.

- Generate product GM and GP

The sale described above is then multiplied with the GP\%/GM\% of the reporting units of the focus company.

- Outcome GP/GM structure and IC-sales for production sites 
The two previous steps deliver a structure of absolute values of GP and GM by EPU by product lines based on estimated sales and margin\% of the focus company. This result will be used in the next step. Based on an assignment of product lines to Production Sites and the information regarding merchandise in the P\&L - Statements of the EPUs the IC - sales of the production sites can be derived by product line.

Measure four uses the GP- and GM- information produced in the previous step in order to support calculation by product line of averages, minimum-/maximum values for the years 2008 to 2012 in order outline ranges of reasonable margins for 2013.

In the next section, I will focus on the P\&L statement.

\subsubsection{P\&L statement}

In this section, I attempt to describe how the two formats of the P\&L statement are produced. Central to this process is the performance orientation and along with this the alignment with the information category margin accounting. This involves that all variables within the two P\&L statements are closely connected to the respective process in NVivo (5.2.5) of deriving sales. This information has then been connected with the respective relationships and structure of the reporting units of the focus company of the years 2008 to 2012.

Regarding the P\&L statement according to the Total Cost Format (TCF) the total sales is divided by the average sales per employee of the focus company which delivers the calculated number of employees in that particular EPU. This in turn is multiplied with the average personnel expenses per employee of the focus company which gives the total personnel expenses of the EPU. In doing so, potential different levels of wages and salaries in the counties of the EPUs have been considered. The total across all EPUs delivers the calculated total number of employees of that part group of major competitor because no consolidation measures are necessary in this area.

In a next step the line total performance is calculated based on the respective relationship between sales and total performance in the P\&L statements (TCF) of the reporting units of the focus company. Since this Model uses total performance as the basis for calculating merchandize, impairment on tangible and intangible assets and other income/expenses these variables can now be calculated applying the structure of the respective reporting unit of the focus company. Gross profit can then be calculated by deducting Cost of Material from Total Performance.

Eventually, EBIT according to TCF is calculated subtracting personnel expenses, impairment on tangible and intangible assets and other expenses whereas other operating income is 
added. Based on the P\&L statements at the level of single entity the consolidated P\&L statement can be developed by eliminating the inter-company relationships which is primarily the inter-company sales between production site and sales and service EPUs.

The Costs identified in TCF also form also the bases for the primary costs to be considered in cost accounting. In the model, six different cost center structures have been considered based on the respective experience in the focus company. Criteria for defining these cost centre structures are whether the EPU is a production site or a sales and service activity and the size (measured in sales and personnel) of the EPU. Respective allocation cycles of secondary costs have been defined and in doing so enabled a deeper understanding and verification of the cost structure of an EPU (regarding the design of cost centre accounting in this project see section 4.5 (Aligning concept of decision usefulness with design of the model of the major competitor). Also, respective considerations at group level according to Rein (1993) can be conducted on this basis.

Concerning the P\&L statement according to the cost of sales format is primarily based on the sales derived from the evaluation process in NVivo (see section 5.2.5). The next step is to apply the structure of the $P \& L$ statement of the respective reporting unit of the focus company on this sales figure. Cost of material and cost of sales have been developed following this procedure which then enables calculating gross margin by subtracting cost of sales from sales. Research and development expenses, selling expenses and general and administration expenses are derived by applying the relative structure of the reporting unit of the focus company as well. In order to calculate EBIT, these expenses are subtracted from gross margin. Other income/expenses have also been developed following the procedure of applying the structure of the reference reporting unit of the focus company on the sales derived through the evaluation process conducted in NVivo. Considering these two variables enables the calculation of EBIT according to the P\&L statement according to the CoS format.

\subsubsection{Balance sheet}

After having described how the P\&L statements of the major competitor have been developed, I strive to focus now on the balance sheet. This section is differentiated into two parts: assets and liabilities, and equity. The relationship between the performance orientation of the P\&L statement and the related sources needed form the approach chosen to develop the balance sheet.

Management accounting provides KPIs which can be used in this context. In particular the KPIs "Days outstanding Trade Receivables" (= (Trade Receivables/Sales) x 360), "Days 
worth of stockholding" (= (Inventory/Cost of Sales) x 360) on the asset side and "Days outstanding Accounts payable" (= (Accounts payable/Cost of Material) x 360) on the liabilities side support this performance driven approach. The KPIs chosen display the resources needed to operate a business such as the focus company and the major competitor. For example, in certain markets one has to accept the payment conditions the customer insists on having. This is reflected in the KPI "Days outstanding Trade Receivables". Also, a certain level of inventory (for example, spare parts) is needed to ensure that customers' production processes are safe. In addition, one's own production sites or repair workshops need a certain level of inventory. As in the area of P\&L statement, the structure of the reference reporting unit is used and in particular the above explained coverage KPIs are transferred from reference reporting units of the focus company to the major competitor.

The procedure to create the asset side is to start with inventory and thereafter trade receivables. Inventory is computed with the formula (Days outstanding Trade Receivables $\mathrm{x}$ Cost of Sales)/360 as mentioned above based on the structure of the reference reporting unit of the focus company. Trade Receivables are considered by dividing the product of 'Days outstanding Trade Receivables' and 'Sales' by 360. These two variables build the basis for calculation major positions on the asset side.

The positions Tangible and Intangible Assets, PoC, AR Intercompany and Cash are calculated by multiplying the sum of Inventory and 'Trade Receivables' with a percentage expressing this relationship of the respective position in the balance sheet of the reference reporting unit of the focus company.

Current Assets is calculated as the total of Inventory, PoC, Trade Receivables, AR Intercompany and Cash.

The lines Deferred Tax Assets (DTA) and Prepaid Expenses are calculated by multiplying the sum of Intangible/Tangible Assets and Current Assets with a percentage expressing this relationship of the respective line in the balance sheet of the reference reporting unit of the focus company.

Total Assets w/o Financial Assets is calculated as the sum of Intangible/Intangible Assets, Current Assets plus DTA and Prepaid Expenses.

The procedure applied to produce the equity and liability side is for Accounts Payable (AP) based on the KPI 'Days outstanding', whereas the majority of all other variables on the liability side have been derived from the percentage of that Variable from Total Assets from the respective reference reporting unit of the focus company. Liabilities equals the total of 
Advance Payments, Accounts Payable, Liabilities Intercompany and Other Liabilities. The variables Deferred Income and Deferred Taxes are calculated by multiplying the sum of Equity, Accruals and Provisions and Liabilities with a percentage expressing this relationship of the respective variable in the balance sheet of the reference reporting unit of the focus company.

In order to analyse major competitor's performance in more detail and to align this with the textual information communicated by major competitor (see section "5.4 Integrating the strategic angle") following balance sheet-based KPIs have been produced.

- Working Capital

Working Capital is calculated as the difference between Current Assets and Liabilities. The components of the KPI Working Capital will be discussed in the section "5.3.5 Cash flow statement" in more detail. Management accounting uses in this context the KPI Working Capital as a percentage of Sales. A decreasing development of this KPI is looked at as an increased efficiency as the organization needs less resources for its output.

- ROCE

This KPI relates Capital Employed (= Working Capital plus fixed Assets) to EBIT and represents an additional performance orientated KPI. The major competitor of the focus company has formulated respective goals in his consolidated financial statements for his entire business.

- CAPEX\%

The KPI CAPEX is viewed as measure whether the organization is maintaining its resources on a competitive level. The KPI is calculated as a percentage of CAPEX of the respective reference reporting unit of the focus company on the derived Tangible Assets of the respective EPU of the major competitor.

\subsubsection{Cash flow statement}

P\&L statement and balance sheet form the basis for deriving the Cash Flow Statement. The elements forming the cash flow statement are in accordance with the performance orientated approach of this project.

The variables of this calculation are EBIT, change vs. prior year (PY) in Working Capital and change vs. prior year in CAPEX. 
The calculation of the Cash Flow starts with EBIT as the outcome of the P\&L statement (see section 5.3.3). Both formats of the P\&L statement are based on the sales derived from the evaluation process conducted in NVivo (see section 5.2.5).

The components of Working Capital (see section 5.3.4) are the Change vs. PY in Current Assets and the Change in Liabilities.

Current Assets is further differentiated in Inventory, PoC-Receivables, Trade Receivables, AR - Inter-Company and Cash. With regard to the calculation of the Cash Flow these components of the Current Assets have an impact which is very close to the performance of the EPU. For example, an increase in sales will necessarily lead to an increase in Trade Receivables. This is related to the required issuance of the invoice to the customer. An increase of the positions of the Current Assets (for example, Trade Receivables) would lead to a decrease of the Cash Flow at this point.

The components of Current Liabilities are advance payments received, accounts payable, liabilities inter-company and other liabilities. Also, in this area the performance orientation of this project becomes visible. The above-mentioned example can be continued using the account liabilities inter-company. The sales and service EPU receives a customer order and has to order the related machine from a production site. This in turn leads to an increase in the line accounts liabilities inter-company. An increase in this line vs. PY would lead to an increase of the cash at this point.

With regard to the consolidated financial statement, it is important to consider that the intercompany relationships are eliminated. Also, the margin of the production sites contained in the Inventory (new machines and spare parts) of the sales and service EPUs (single entity) has to be eliminated within the consolidation process.

The variable CAPEX impacts the Cash Flow positively in case it decreases and vice versa due to its cash-binding effect.

After the explanations regarding the calculations of the Cash Flow statement, I attempt to continue the three examples in the following.

\subsubsection{Verification and consistency}

The balance sheet check contains the difference between Total Assets and Total Equity and Liabilities. Basically, this should be zero because the liability side has principally been developed in context with the asset side. However, the variable 'Accounts Payable' is calculated based on 'Days outstanding AP' which is closely connected with Cost of Sales 
which in turn is linked to sales derived out of the process conducted in NVivo (see section 5.2.5). Because of this constellation the balance sheet check can be viewed at as verification as to the structure of the balance sheet is in line with NVivo Sales. Also, the balance sheet based KPIs support verifying if the applied arithmetic and logic is reasonable.

In context of the discussion regarding P\&L statement and the related performance orientation the plausibility of the development of volume is essential. This relates to both, Order Intake and Sales. Given this background the calculation of Order Backlog supports both verifying plausibility of development of Order Intake and Sales and prospective calculation of the Utilization of the production capacities. This KPI is calculated based on the Order Backlog of the previous period, adding Order Intake and deducting Sales. Order Intake is calculated as a percentage of Sales which is transferred from the respective reference reporting unit of the focus company to the EPU of the major competitor.

\section{$5.4 \quad$ Integrating the strategic angle}

\subsubsection{Major competitor's communicated story and goals}

The major competitor communicates in its consolidated financial statements a strategy of continued profitable growth accompanied by a respective development of cash flow which is measured as a defined percentage of sales.

As a strategy to achieve this, the major competitor focuses on the increasing demand in specific product lines due to the increasing world population.

\subsubsection{Contrasting competitors' strategic view with the model}

Based on the developed "Values from Test" I produced growth rates (Min. 08-12, Max. 0812, Avg. Min./Max., Avg. 08-12, CAGR 10-12, CAGR 08-12). Using the "Min. 08-12" growth rates and comparing this with the values taken from the published financial statements delivered the results listed in Figure 65.

The first Values from Test have been calculated for 2009 and were $30 \%$ below the actual value which the major competitor published. In following years, the Values from Test are significantly closer to the actual figures. However, using the other growth rates delivers significantly too high values. 
Figure 65: Deviation between Total Values from Test and the major competitor Actual Sales by Year

\begin{tabular}{|c|c|}
\hline Year & $\begin{array}{c}\text { Delta in \% } \\
\text { EST-ACT }\end{array}$ \\
\hline 2008 & $-35 \%$ \\
\hline 2009 & $-30 \%$ \\
\hline 2010 & $-6 \%$ \\
\hline 2011 & $2 \%$ \\
\hline 2012 & $6 \%$ \\
\hline 2013 & $-3 \%$ \\
\hline
\end{tabular}

Since the difference between the estimations (Total of "Values from Test") and the actuals are becoming smaller it appears reasonable to focus on the information regarding sales.

The major competitor is primarily concentrating on the business generated in one particular product line and in addition it is operating with aggressive pricing. The products of that product line are produced in a low-wage country in order to benefit from the cost advantage. The major competitor connects that with very short delivery times. This is connected with a respective level of inventory in order to feed production with raw material and on a corresponding with level finished and semi-finished goods. The required high utilization of capacities generates an advantage because of the degression of fix costs per unit. In case of problems this system of dependencies collapses. That appeared to be the case when the major competitor had to report quality problems in the above-mentioned production site. In addition, the major competitor used the financial crisis almost for almost one year longer as the focus company as an argument for explaining missing sales in this product line. This coincides with the observation that both estimated and actual profitability are below the profitability of the focus company. The major competitor has obviously failed to establish a risk compensating profitable business. In addition, it can be observed, that growth rates are on the lower scenarios of the model of the major competitor and that a significant positive development cannot be seen. As a summary, the major competitor's business model appears to be very fragile.

In the next section, I seek to apply the CSF - system on to the major competitor. 


\subsubsection{Identifying critical success factors}

\subsubsection{Change in tone and its reflection in the model}

In the previous sections the strategic direction of the major competitor aims to follow along with communicated targets and goals have been contrasted against the model.

In Phase 3 (section 5.2.4) the core areas of the analysis of textual information ("Comparisons versus MC and FA", "Incidents" and "Strategic match") have been intertwined with the “...prime sources of critical success factors...”(Rockart, 1979, pp. 86-87).

It can now be verified, if there are differences between the communicated strategy, goals and targets and the model and if these deviations can be explained with major competitor's critical success factors.

Due to the organization of the textual information in this project, CSFs can be derived from the textual information. A change in, for example, the wording regarding a particular CSF over the periods under observation can indicate an impact on performance.

Feldman et al. (2010, p. 915) analyzed whether the 'Management Discussion and Analysis' (MD\&A) as part of the forms $10-\mathrm{Q}$ and $10-\mathrm{K}$ for stock-listed companies in the USA also contains information which goes “...beyond financial measures such as earnings surprises and accruals". The authors $(2010$, p. 915) applied in their research "...a classification scheme of words into positive and negative categories to measure the tone change...". According to the authors, statistical tools such as, for example, the "Flesch Index" which measures the simplicity and the general trend of the tone, are available.

The authors $(2010$, p. 917) define tone change as “...Optimism or pessimism of the information embedded in qualitative verbal disclosures by managers in the MD\&A section of firm's periodic SEC filings as compared with prior periodic filings of the same firm". The authors (2010) state that well-performing companies publish financial statements which are easy to comprehend due to the uncomplicated explanations.

Ernstberger et al. (2017) emphasize in this context the negative impact of mandatory quarterly reporting on the long-term performance of the organization. The authors $(2017$, p. 33) point out that management is focusing in its decisions on meeting or being above the targeted quarterly KPIs “... even on the expense of long-term performance".

With regard to the consideration of the change in tone and its reflection in the model, I have demonstrated that this takes place in particular in the course of the evaluation of textual 
information (section 5.2.5) and the identification of the major competitor's CSFs which is based on Phase 3 (section 5.2.4) of the analysis of textual information.

Based on the core areas of the textual analysis, the major competitor's CSFs become more visible. For example, the topic "turn key solutions vs. single machines" has been identified in Phase 3 in the textual data of the focus company and it has been mentioned in the major competitor's consolidated financial statements. The major competitor seeks to be successful by offering complete solutions for customers' entire production processes rather than offering single components. This leads to an impact of the business of the respective product line. In this example, the respective sales of that product line would be monitored respectively over the periods under observation. Furthermore, the development of the comments can be observed over time and the expected impact of this CSF on major competitor performance be observed.

In the next section, I aim to outline how numerical information is going to be analyzed.

\subsubsection{Variance analysis}

Textual analysis has been concluded with identification of the major competitor's critical success factors.

Regarding the numerical information, a variance analysis of the estimation of the 2013 numbers versus the 2013 actuals has to be conducted. The major competitor's 2013 actual sales at the division level as a percentage from total sales has been published at the group level. The product line structure developed in the model (see section 5.3 Numerical information and accounting basis) has been applied on the 2013 division total sales and been used as the 2013 actual sales by product line.

Figure 66 contains a schematic representation of the variance analysis by product line. This scheme can be used on both the level of single entity and consolidated financial statements. In order to demonstrate the mechanism of the calculations contained in Figure 66, I inserted in Annex 42 an overview of the results of the basic scenarios (in particular changing the actual exchange rate, actual sales and GM-\%). 
Figure 66: Schematic representation of Variance Analysis by product line

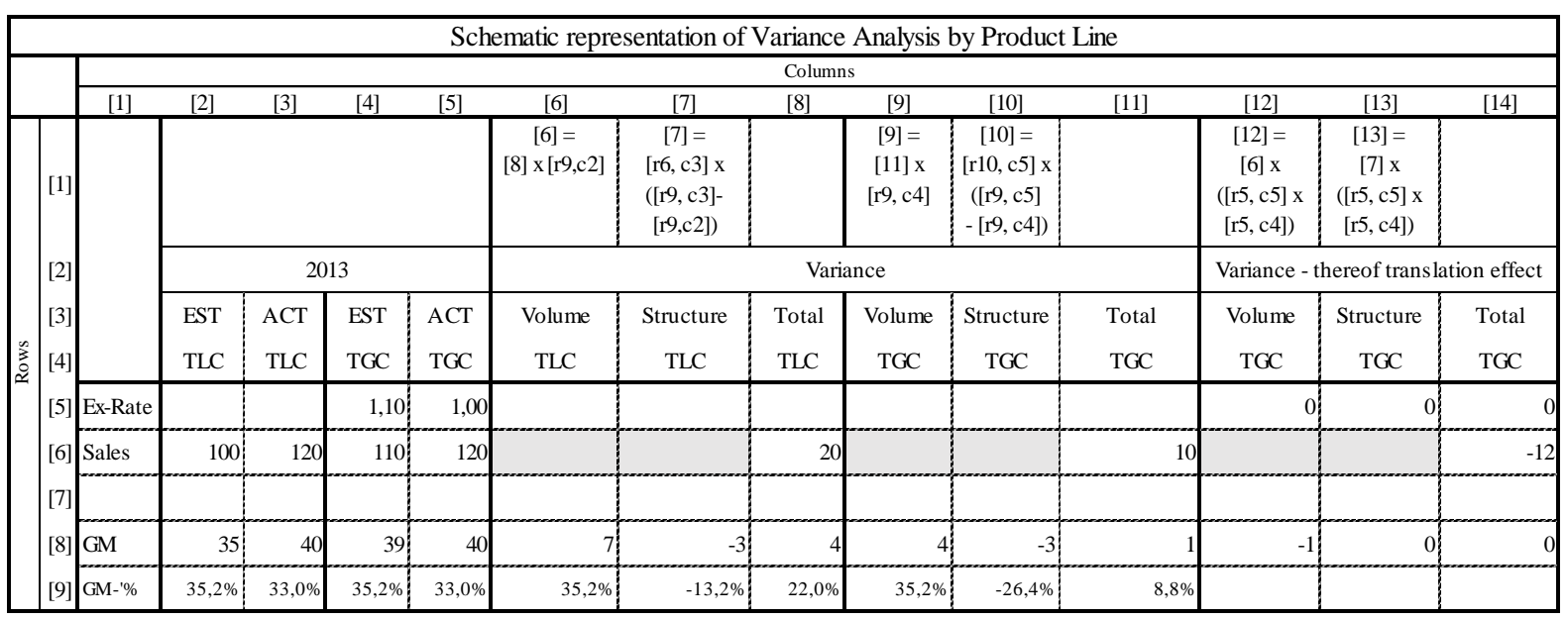

Columns [2] to [5] contain the values regarding 2013 Sales and Gross Margin according to the model (labelled as EST) and derived actual (labelled as ACT). In order to enable to make the effect coming from different currencies in estimation and actual the example contains both local (TLC $=$ Thousand Local Currency) and group (TGC $=$ Thousand group Currency) currency. This relates to the columns [12] to [14] and the translation effect explained in this area.

The variance analysis is conducted in the columns [6] to [11] and is divided into the variances which can be allocated to sales and structure for both currencies. As mentioned before, columns [12] to [14] explain the exchange - rate effect included in the Variance Analysis.

The example is based on the assumption of an exchange rate of $1 \mathrm{LC}=1,10 \mathrm{GC}$ in the model (estimation) and $1 \mathrm{LC}=1 \mathrm{GC}$ as actual. This leads in line [6] in local currency to a positive variance of 20 and 10 in TGC. Due to the fact that the actual exchange rate is below the estimated rate, there is a negative effect contained of -12 TGC which means that sales in actual would have been $22(=10+12)$ if estimated and actual exchange-rate would have been equal.

Regarding gross margin (lines [8] and [9]) there is a positive effect in local currency because of the higher sales. Based on the estimated GM\% of $35.2 \%$, this gives additional margin related to volume of 7 TLC. Unfortunately, the actual GM\% is below the estimation $(35.2 \%$ EST vs. $33.0 \%$ ACT) which generates a negative effect regarding structure of $-13.2 \%$ and -3 TLC respectively. Measured in local currency the positive volume effect (+7 TLC) compensates the negative structure effect of -3 TLC to an amount of +4 TLC in total. 
Concerning the variances of GM measured in TGC the variances in TLC are multiplied with the delta of the exchange rates. This leads in total to a positive GM-effect coming with the additional sales of 1 TGC and an additional GM relating to these sales of $8 \%$ compared to $22.0 \%$ based on TLC.

On consolidated level these analyses can be conducted by product line differentiated by EPUs in the lines. This adds the information of the country included in the Variances related to Volume and Structure.

In order to look at the situation of a product line in its entirety, the numerical information can contribute important information through employing management accounting techniques of analysing data which are not possible to conduct with solely textual information.

In the next section, I aim to connect the analyses of textual and numerical information conducted in the previous two sections.

\subsubsection{Reporting and monitoring}

In alignment with the information categories of the conceptual framework (margin accounting, P\&L statement, balance sheet and cash flow statement) I designed components of a respective visualization of the Information generated.

The performance orientated approach of this project is focusing on assumptions regarding the major competitor's sales. Therefore, the first information generated centres on the major competitor's sales and the corresponding references coded in NVivo. The left chart of Figure 67 compares the "Value from Test" for the years 2008 to 2013 and in addition displays the estimate made for 2013 and the respective ACT. The second chart of Figure 67 shows the number of references coded in order to assist with building the "Value from Test". This information is grouped according to the A-B-C classification for sales and service EPUs plus references relating to the level of group and production.

Figure 67: Development of Sales and Related Textual Information

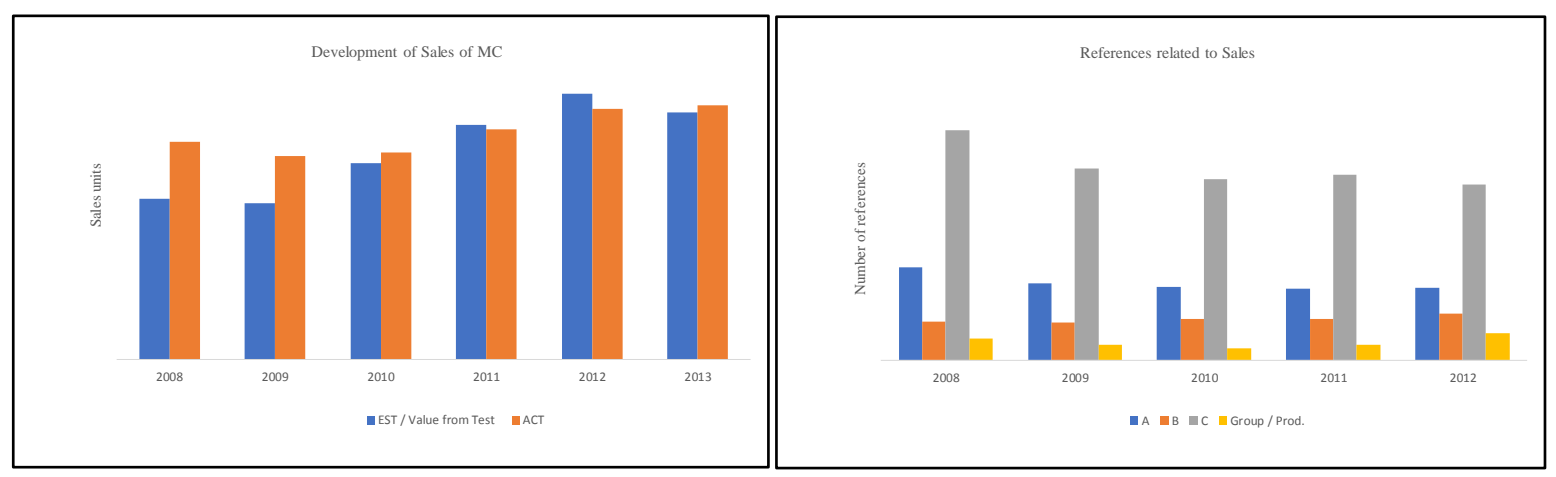


Closely related to the sales information is the respective margin by product line generated which is displayed in Figure 68. The right chart of Figure 68 entails a variance analysis which differentiates between volume- and structure (see on page 169 Figure 66). This area could be enriched with information regarding the major competitor's CSFs. For example, the major competitor indicates that stronger environmental legislation forms the basis for growth in a particular product line and the number of public tenders available and yielded could be added to the charts.

Figure 68: 2013 Sales and Gross Margin - Comparisons ACT vs. EST by Product Line

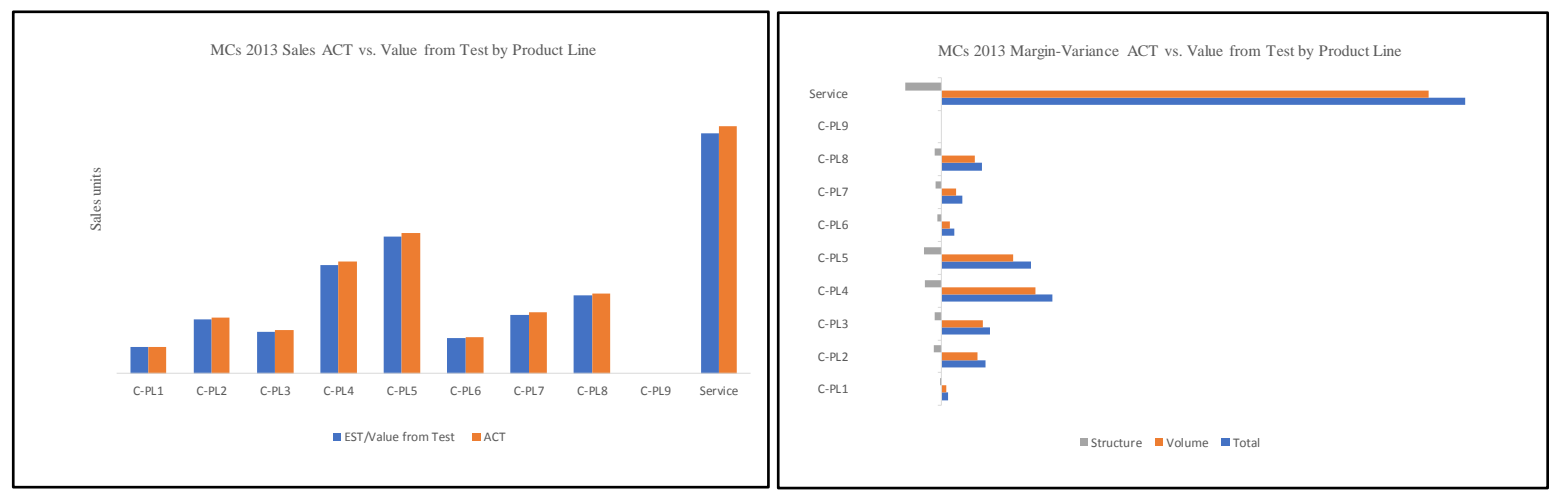

Figure 69 is refers to the information categories balance sheet and cash flow statement. Based on the model of the major competitor, it can be assumed that the tendency of working capital is that it increases rather than to decreases. This is in contradiction to the image that the major competitor communicates to the capital market. 
Figure 69: Development of the Major Competitor's Working Capital and Operational Cash Flow

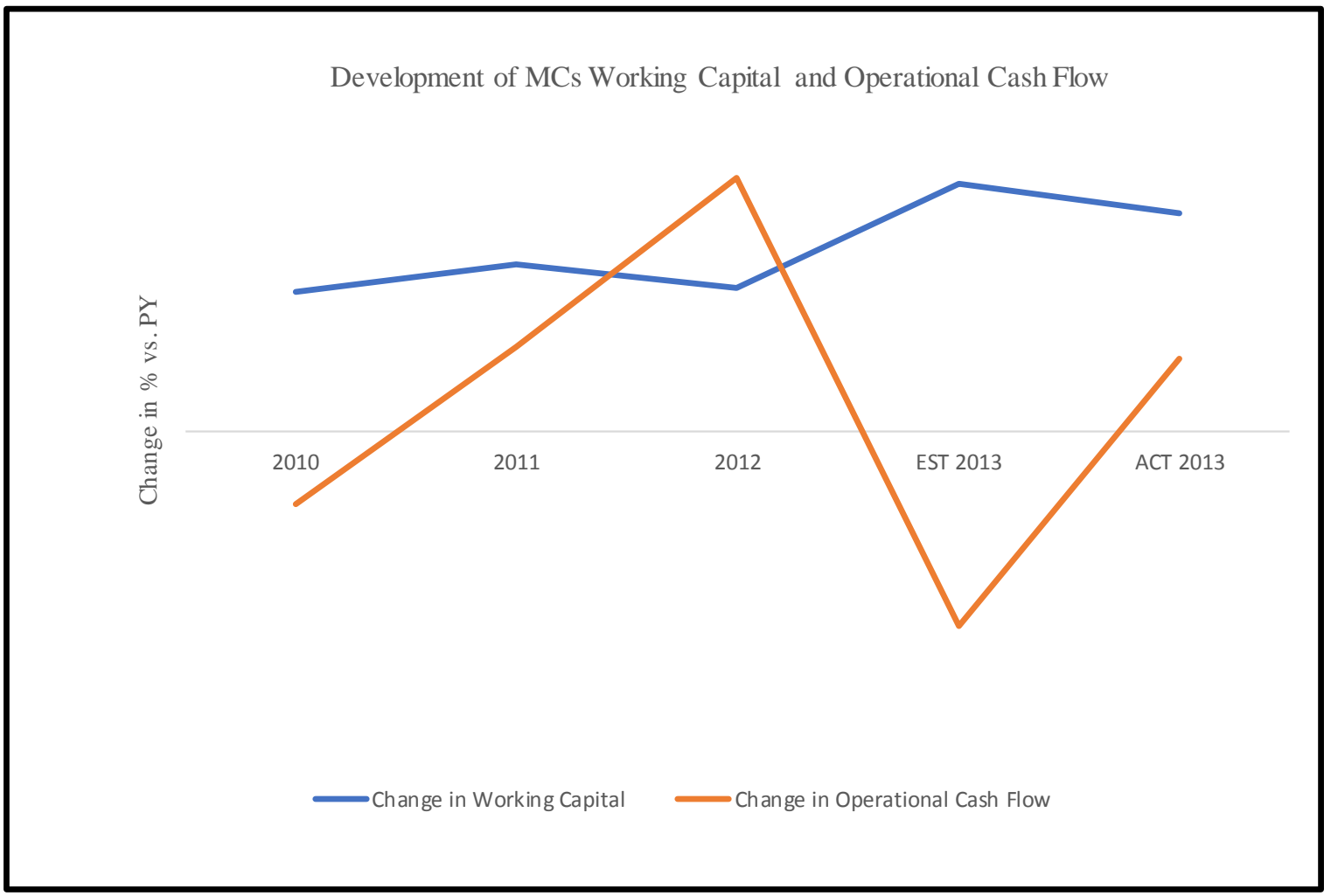

The Value from Test for sales forms the basis for developing figures according to the information categories of the conceptual framework and to apply management accounting techniques such as, for example, calculating KPIs or conduct Variance Analysis.

In the next section, I seek to summarize chapter 5.

\subsection{Summary of chapter}

In the first part of this chapter, textual information has been prepared for analysis by grouping references according to the information categories of the conceptual framework. This included considering more detailed structures such as, for example, the product line structure of the focus company in the information category margin accounting. Thereafter, the references have been differentiated by periods and aligned with the structure needed for the Interface between textual and numerical information.

The outcome of the analysis of textual information has then be connected with numerical information through reports in NVivo which have been exported to MS Excel where it has been integrated in an already prepared model of the major competitor. This model used relationships of the information categories of the subsidiaries of the focus company. Due to the performance-orientated approach of this project the information exported from NVivo to MS Excel was mainly relating to sales. 
This was followed by scrutinizing the references regarding the strategic foci of the major competitor. Connecting textual and numerical information enabled contrasting the major competitor's communicated image with the model and to identify respective gaps. In essence the major competitors' business model appears to be based on very aggressive assumptions regarding the price-demand function and the respective utilization of the production capacities whereas risk compensating components are not in place to a reasonable extent. The model of the major competitor allows now the making of better-informed assumptions about how developments in the markets can impact the major competitor's performance.

In the next chapter, I aim to discuss the case study's findings. 


\section{Discussion and Analysis of Findings}

\subsection{Introduction}

So far this work's focus has primarily been on deriving a model of the major competitor of the focus company based on the conceptual framework developed in section 4.2. In this chapter, I seek to critically evaluate the conceptual framework/model based on the findings given in chapter 5 .

Firstly, I aim to prepare the basis for the discussion of the conceptual framework/model in section 6.2 and which focuses on the information relevant for this project in the field of strategic management accounting and the respective literature. This relates at the same time to Research Question 1/Research Objective 1.

Secondly, the discussion of the core elements of the conceptual framework/model will be conducted in section 6.3. To connect and align textual and numerical information with the performance-orientated approach embedded in this project, focus will be given to the structuring of textual and numerical information.

Thirdly, in section 6.4 I seek to illuminate the aspect of competitive advantage provided through the application of the conceptual framework/model.

In section 6.5, I aim to discuss the limitations of the model.

In the next section, I strive to focus on the discussion of the information relevant for this project in the domain of strategic management accounting and the respective literature.

\subsection{Connecting the conceptual framework/model with SMA literature}

To evaluate the relevant literature and information in the field of SMA, I decided to look for a conceptual framework in the area of SMA literature in which this project could be embedded. As a result, I ascertained, that such a conceptual framework in the field of SMA literature which builds the basis for literature and practice is needed (Nixon \& Burns, 2012b; Nixon \& Burns, 2005). Therefore, I tried to identify the understanding of SMA in literature which could serve as a basis for this project and found Roslender and Hart (2003, p. 260), who see SMA “...as an attempt to integrate insights from management accounting and marketing management within a strategic management framework". This position emphasizes the need for resilient contributions from SMA and that the use of management accounting knowledge would support development of this and also support consideration of a collaboration across organizational functions (Mohamed \& Jones, 2014; Roslender \& Wilson, 2012). Concerning information which SMA should provide regarding competition, Alnoor Bhimani and 
Bromwich (2010, p. 49) see "...the provision and analysis of financial and now non-financial information..." of the "...competitors' costs..." as the relevant information needed. Cadez and Guilding (2012) emphasize the importance of having resilient assumptions regarding competitors' financial performance which is in line with the increasing performance orientation of management accounting literature (Busco et al., 2006; Hoque, 2003; Hossain et al., 2011; Nixon \& Burns, 2005).

When scrutinizing the textual data it was obvious that pricing decisions are also relevant for this project which is in line with literature (Laitinen, 2011) and therefore, in accordance with literature, respective information has been incorporated in developing the "Value from Test" (Figure 55 on page 141 and Figure 56 on page 144).

Rothschild (1979) states, that competitor analysis has remained an ignored managerial task. Without defining how to produce the information for feeding the information-needs regarded as necessary, the author $(1979$, p. 26) defines the following aspiration level concerning competitors' accounting data: "In essence, we wish to know the competitors' total financial situations, determine whether they have profitable and balanced portfolios, and identify their serious problems and opportunities they are trying to pursue". The ambition defined by Rothschild (1979) goes beyond the estimation of competitors' costs towards an approach of scrutinizing competitors' financial performance and identifying reasons for competitors' performance. Furthermore, the author appears to focus on margin accounting when relating to “...profitable and balanced portfolios..." (Rothschild, 1979, p. 26).

Due to internationalization of business and respective complex international organizational structures, the information needs to be consolidated for reporting it to top management at the group level in order to support decision-making at the group level. Porter (1999) emphasizes the need for a group strategy and is in line with other well-known authors regarding focusing on competitors' cost position (for example, Alnoor Bhimani \& Bromwich, 2010) but does not discuss requirements that group cost accounting would have to meet. This missing presence of cost accounting at the group level in anglophone cost accounting practice at the group level and respective literature coincides with Kajüter and Schröder (2014). According to Kajüter (2003) and Franz and Hieronimus (2003), German cost accounting literature (Dusemond, 1994; Rein, 1993) has offered solutions for cost accounting at the group level. This literature has been supplemented by, for example, suggestions how to put this into practice in a SAP Business Warehouse environment (Schöb, 2008a, 2008b, 2009). In addition, in the light of the development of IFRS regulations, a process of convergence of 
German cost and financial accounting could be observed (Schaier, 2007) along with respective contributions from practice (Beißel \& Steinke, 2004). In the case study developed in this project, it was possible to apply available techniques and tools of management accounting at the group level in the context of competitor accounting/analysis at the group level and to align the design of the conceptual framework/model with the element of decision usefulness through a potential organizational structure of the major competitor (Figure 17 on page 86). In addition, the consideration of textual information at both the level of single entity and the group has also been incorporated in the conceptual framework/model which is in line with literature (Ernstberger et al., 2017; Feldman et al., 2010; Guay et al., 2016). The textual information (section 5.1) stems from respective documents generated from the three different perspectives of the major competitor, financial analysts and the focus company which enables using triangulation for validating the data in many cases at the level of EPU/single entity and at the group level for the performance-relevant variable sales (section 5.2.5.4) and is in line with literature (Farquhar, 2012; Yin, 2009). Numerical information (section 5.3) is based on estimations of the subsidiaries of the focus company regarding the major competitor's sales by product line which were then connected with textual information in order to develop the Value from Test (section 5.2.5) and then further processed in the model into the information categories starting with margin accounting which is in line with literature (Dusemond, 1994; Kajüter, 2003; Kilger, 1990; Kilger et al., 2007; Ossadnik, 2008; Rein, 1993; Varnholt et al., 2009; Vormbaum \& Rautenberg, 1985). Validation of numerical data (section 5.3.6) could be conducted based on respective KPIs and in particular for the performance-relevant parameter sales through comparison of the 2013 estimated sales versus actual sales.

Relating to my research aim to improve competitor accounting, through the comprehensive use of management accounting information in order to produce competitive advantage, that the concept of critical success factors (CSFs) according to Bullen and Rockart (1981) is of significant importance (section 4.3.2.3.6). Bullen and Rockart (1981, p. 7) point out, in their definition of CSFs, that these "....are the limited numbers of areas in which satisfactory results will ensure successful competitive performance for ... organizations..." and "...are the few key areas where 'things must go right' for the business to flourish". Integrating the concept of CSFs in the conceptual framework (section 5.4.3) is in line with the literature. 
Regarding the software employed in this project for organizing and analysing the data I found confirmation in the literature (MS Excel: Alam, 2016; NVivo: Baird, 2004; MS Excel: France, 2010).

In this section, I have discussed what information would be needed to build a strategic model of the major competitor of the focus company and have related that to the respective literature in management accounting on both level of single entity and group. I found ascertained that a common conceptual framework in SMA-literature is needed (Nixon \& Burns, 2012b; Nixon $\&$ Burns, 2005). Concerning the information available in the area of strategic management accounting and the way it has been used in the case study, the project is in line with management accounting literature regarding both numerical (Dusemond, 1994; Kajüter, 2003; Rein, 1993) and textual data (Ernstberger et al., 2017; Feldman et al., 2010; Guay et al., 2016). Furthermore, the integration of the concept of CSFs supports achieving the research aim of this project and is in line with the literature (Bullen \& Rockart, 1981). With regard to trends and major directions in management accounting, the increasing performance orientation in management accounting literature (Busco et al., 2006; Hoque, 2003; Hossain et al., 2011; Nixon \& Burns, 2005) has been emphasized and forms the basis for the discussion in context of core elements of the conceptual framework/model in the next section.

\subsection{Discussion of core elements of the conceptual framework/model}

\subsubsection{Overview}

An essential component of the conceptual framework/model is its performance-orientated approach which relates particularly to the data and the information categories. This basis needs to be aligned with this project's approach of utilizing management accounting tools and techniques in connection with textual and numerical data which is in line with the literature (Ernstberger et al., 2017; Feldman et al., 2010; Guay et al., 2016). Management accounting tools and techniques can only be applied if textual and numerical data is available in a similar structure. Therefore, I will discuss this prerequisite in section 6.3.2 and how this has been considered in this project.

The conceptual framework/model, in its dimensions of 'information category' and 'consolidation hierarchy', is strongly related to cost and financial accounting. In addition, the conceptual framework/model must focus on performance-relevant information in order to be in line with this project's performance-orientation. Therefore, I seek to critically evaluate if the accounting approach chosen in the conceptual framework/model is in line with the prerequisite of using performance-relevant information which is the focus of section 6.3.3. 
The conceptual framework/model discussed so far consists regarding the data of two strands: one handling the textual data which is organized in NVivo and the second one in MS Excel providing numerical data to calculate ratios and KPIs of the subsidiaries of the focus company along with respective management accounting techniques and tools. These two strands need to be connected and the result of this process needs to be led over in the model in MS Excel to produce estimations for the year 2013 for the performance-relevant variables which assists with competitor accounting in the focus company. The respective discussion will be conducted in section 6.3.4.

Based on the processes, considerations and calculations described above, the model is in the position to generate values for the performance-relevant variables for the year 2013 for the major competitor of the focused company. I seek to critically evaluate the outcome of this process of the case study in section 6.3.5.

I will start the discussion in the next section, which aims to focus on how the data used in this project has been structured.

\subsubsection{Structuring textual and numerical information}

Firstly, I seek to discuss the process of generating data and thereafter what data regarding the major competitor has been produced in the focus company.

The subsidiaries of the focus company were asked to estimate the major competitor's sales by product line for their area of responsibility. This procedure was integrated in the budget process and the KPI calculated was relative competitiveness (= Sales of Subsidiary by product line by Year of focus company/estimated Sales by product line by Year of major competitor) along with the respective YoY - change of that KPI. In addition, the market share (= Sales of Subsidiary by product line by Year of focus company/estimated Sales by product line by Year of all Competitors) and the respective YoY - change has been calculated. This part of the budget process formed the first part of the respective budget review meeting which allowed discussing rationales and problems of the position of a subsidiary by product line versus competition. In doing so, we were able to learn about the major competitor's position in relation to the product line structure of the focus company and based on the knowledge of the MDs of the focus company being in charge in a particular country which had elements of the view to look at SMA“... as an attempt to integrate insights from management accounting and marketing management within a strategic management framework" (Roslender \& Hart, 2003 , p. 260). In addition, this approach is regarding the collaboration across functions in SMA context supported by Roslender and Wilson (2012) as well as Mohamed and Jones 
(2014). The outcome of this part of the budget process formed the basis of the numerical data which in this project has been connected later on with textual data (see section 6.3.4).

An essential aspect of this project is the structure of the textual and numerical information. In addition, management accounting related data has been connected with information provided from mainly marketing/sales functions of the organization of the focus company on one platform. This implies a close collaboration between the managers working in these two different areas of the organization of the focus company. The collaboration relates in this context to a common understanding of the structure of the information to be reported and discussed, for example, in review meetings.

An undertaking like this needs to consider the different skills of marketing/sales managers and finance managers (Roslender \& Wilson, 2012). An experience from this project is that room for flexibility in the database is essential for the willingness of the marketing/sales managers to collaborate. This flexibility could be facilitated through offering making textual input. For example, one of the most important documents in this project (monthly comments) begins with an explanation of the political/economic situation of the country the marketing/ sales manager is acting in. Notably, the marketing/sales managers of the larger reporting units reported in a very high quality. This in turn, allowed a better understanding and appropriate allocation of the information on the Finance Side which requires the capability "...to relate to the context in which marketing managers operate" (Roslender \& Wilson, 2012, p. I).

In order to align textual and numerical information with the conceptual framework/model, I organized the data according to the dimensions information category and consolidation hierarchy of conceptual framework/model. With reference to the source documents, I created folders in NVivo. In order to be able to meet the requirements of the concept of triangulation I assigned the first level of folders related to the three perspectives (financial analysts, focus company, major competitor), the second level to the EPU (Figure 15 on page 84) and the third level to the year of observation (2008 to 2012). The information relating to the perspectives of financial analysts and major competitor are publicly available documents which could be assigned to the dimensions 'Information Category' and 'Consolidation Hierarchy' of the conceptual framework. In order to be able to relate the source documents to the performance-relevance of the respective EPU, I labelled all documents according to their A-B-C rank in the source classification sheets. The A-B-C classification was based on the estimation of the subsidiaries of the focus company regarding the sales of the major competitor by product line by year. In total, I have imported 1979 documents into NVivo 
(Figure 22 on page 102). The performance-orientated overall view shows that $32 \%$ of the sources relate to EPUs representing $80 \%$ of the estimated sales and 3\% refer to group and production (Figure 23 on page 104). The organization of the source documents builds the basis for the coding process in NVivo which I arranged in three phases which is in line with literature (Baird, 2004).

Phase 1 of the process of this project comprises the initial and in essence manual work of coding references according to the dimensions 'Information Categories' and 'Consolidation Hierarchy' of the conceptual framework. In total, I have coded 43647 references manually (Figure 22). In essence, verbal explanations or comments which are performance-relevant have been critically evaluated and coded in NVivo. The performance-orientated view shows that the majority of the references $(85 \%)$ are related to margin accounting and P\&L statement whereas c. $5 \%$ relate to balance sheet and cash flow statement and c. $10 \%$ to other (Figure 27 on page 109). Unsurprisingly, most of the references are related to the focus company (90\%, Figure 28). However, comparing the average of references per source document, most references (avg. per document) are relating to documents published by major competitor (Figure 22) which depicts that it was possible to allocate information contained in officially published documents can be assigned to the dimension 'Information Category' of the conceptual framework to a huge extent. Furthermore, this could on a lower level of occurrence also be observed concerning the references coded from documents of the financial analysts. This observation supports the viewpoint, that the concept of triangulation is regarding the total of references applicable. Looking into the information categories of the conceptual framework it can be ascertained that this is also the case, in particular in the primarily performance-orientated information category 'margin accounting' in which overall $15 \%$ of the references of financial analysts, $72 \%$ of the focus company and $34 \%$ of the major competitor (total 'Margin Accounting' $=68 \%$ ) had been coded to (Figure 29 on page 109). Analysing the Information Category 'P\&L statement' confirms that references from financial analysts (32\%), focus company (16\%) and the major competitor (24\%) had been coded to this primarily performance-orientated information category (total 'P\&L statement' $=17 \%$, Figure 32 on page 114). In addition, the information categories 'P\&L statement' and 'balance sheet' could be structured down to the level of performance-relevant groups of accounts according to the structure of the P\&L statements (Total Cost Format: Figure 33 on page 115 and Cost of Sales Format: Figure 35 on page 117) and balance sheet (Assets: Figure 38 on page 120 and 
Equity and Liabilities: Figure 40 on page 121) which enabled verification of the outcome of the calculations conducted in Excel with the textual information.

Phase 2 could be based upon the manual coding conducted in Phase 1. Due to the organization of the source documents by perspective (financial analysts, focus company, major competitor) by EPU by year, the references coded in Phase 1 could be differentiated by perspective, EPU and year. This differentiation enabled identifying changes between the periods under observation and provided additional possibilities of verification of the outcome of the calculations conducted in MS Excel. In particular, the references coded into the product line structure of the information category 'margin accounting' could be assigned to the respective year automatically. The differentiation by year represents is one of the prerequisites of the interface between textual and numerical data in section 6.3.4.

Phase 3 is based upon the structure of the data prepared in Phase 2. The data is now going to be enhanced through connecting it with the concept of CSF which enables identification of "...the limited number of areas in which the satisfactory results will ensure competitive performance..." for the organisation of the major competitor (Bullen \& Rockart, 1981, p. 7). This serves both recognizing these sensitive areas and preparing a performance-orientated evaluation of the textual information. Regarding the aspect of preparing a performanceorientated evaluation of the textual information, those references supporting the assumption that the comparison of the performance of the focus company vs. performance of the major competitor is possible (section 5.2.4.2), incidents affecting the major competitor's performance (section 5.2.4.3) and a fit of the reference with the major competitor's strategy can be assumed (section 5.2.4.4) to have been identified through respective queries and coded regarding their impact (positive impact, no impact and negative impact on the major competitor's performance). This procedure is in line with Feldman et al. (2010, p. 915) who applied in their research a "... classification scheme of words into positive and negative categories to measure the tone change..." Concerning the aspect of identifying particular CSFs, a change in wording regarding a particular CSF over the periods under observation can indicate an impact on the major competitor's performance which is in line with the literature (Ernstberger et al., 2017) and be observed through a respective performance-orientated reporting (section 5.4.3.3).

The conceptual framework/model is designed to utilize management accounting data/techniques which relates also to numerical information contained in the model in MS Excel. Regarding the information category 'margin accounting', margin percentages by EPU 
by product line by year of the subsidiaries of the focus company have particularly assisted as a basis for a respective ratio for the major competitor (section 5.3.1) and have been set into relation to the "Value from Test". As for the information category 'P\&L statement', the structure of the P\&L statement of the subsidiaries of the focus company served particularly as a basis for developing a respective structure of the major competitor which has been aligned with margin accounting (section 5.3.3). For the development of major competitor's balance sheet (section 5.3.4) a performance-orientated approach has been chosen based on the "Value from Test" and respective KPIs relating to the "Value from Test". Starting point was the Asset Side calculating the KPIs "Days outstanding Trade Receivables" (= (Trade Receivables/Sales) x 360) and "Days 'worth of stockholding" (= (Inventory/Cost of Sales) x 360 ) and thereafter on the liabilities side "Days outstanding Accounts payable" (= (Accounts payable/Cost of Material) x 360). Further KPIs developed from balance sheet were "Working Capital", "ROCE" and "CAPEX\%" which were useful for both developing the balance sheet and conducting plausibility checks. In addition, the information category 'cash flow statement' could also be derived from the balance sheet (section 5.3.5).

In this project, the discussion of structuring textual and numerical data could be conducted considering performance-orientated criteria at the level of both single entity and group. In addition, textual and numerical data could be organized in identical structures. Furthermore, a well-organized collaboration between the functions of marketing and control could be organized in the focus company and supported the exchange of knowledge and information which is in line with literature (Roslender \& Wilson, 2012).

In order to enable that informed assumptions regarding competitors' performance can be developed, management accounting data is processed and management accounting techniques are applied in the model which needs to be based on a performance-orientated basic principle. The conceptual framework/model is designed to apply management accounting knowledge and techniques in context of competitor accounting. The performance orientation of the conceptual framework/model can now be discussed by seeking support in the management accounting literature outlined in section 6.2, which I aim to conduct in the next section.

\subsubsection{Performance-orientated approach in management accounting literature and its integration in the conceptual framework/model}

Firstly, I attempt to contour the term performance in relation to the conceptual framework/model in particular in context of competitor accounting. 
According to Franz (2003) German consolidated cost accounting comprises the term 'performance'. Based on this understanding, Franz (2003) intertwines the term 'performance' with the terms 'Erlösrechnung' (no official translation available, reasonable translation of the German term 'revenue accounting') and 'Erfolgsrechnung' (no official translation available, reasonable translation of the German term 'earnings statement'). According to Franz (2003) these two terms are used by practitioners identically. This classification of the term performance and the understanding of its relationship towards cost accounting appears to be compatible with Anglo-Saxon management accounting literature (Luther et al., 2010).

Connecting the concept of performance orientation in management accounting literature with the conceptual framework/model leads to its dimensions 'information category' and 'consolidation hierarchy'. The first information category is margin accounting, which in particular at the level of group is strongly related to both contributions from theory (Dusemond, 1994; Kajüter, 2003; Rein, 1993) and practice (Schöb, 2008a, 2008b, 2009). The build-up of margin accounting uses in its top line the term revenue identically to the term sales and furthermore structures sales by product lines to reflect the different markets in which the organization is acting.

In the area of margin accounting, I managed to develop a notion of the profitability of the major competitor's product lines using core elements and tools of the systems of AngloSaxon direct costing and German margin accounting on the levels of both single entity and group (within the meaning of Dusemond, 1994; Kajüter, 2003; Rein, 1993). Both systems were led over the respective P\&L statements (cost of sales and total cost format). Through this, I had an additional possibility of verifying the results. For example, average FTEs per EPU could be derived by average sales per FTE which in turn was multiplied with average personnel expenses per FTE and delivered personnel expenses in the P\&L statement according to total cost format. A similar verification of other operating expenses was also possible. This enabled plausibility at the level of major accounts of the EPUs and at the group level to be checked.

According to Ossadnik (2008) and Vormbaum and Rautenberg (1985), cost accounting has developed and improved the element of decision usefulness (see Figure 16 on page 86). Applying cost accounting methods and tools in the field of competitor accounting allows development of a view through the lens of the major competitor. For example, through assigning sales volume to product lines and product lines to production sites, an idea of the utilization of the major competitor's production capacities can be developed. A low 
utilization of the production capacities can stand in context with respective textual information. For instance, a low utilization of capacities became visible in the domain of cost accounting and in the textual information through a respective precise remark in major competitor's consolidated financial statements. In this context, it could be observed that the variance analysis conducted in the sector of cost accounting benefitted from the respective explanations in the textual information.

From the viewpoint of the conceptual framework/model, sales by product line is the elementary variable of the performance-orientated approach which is the reason for developing Values from Test for Sales by product line by year. In the model the Values from Test build the basis for developing further components of the margins by product line by year which in turn enable deriving the variables in the information categories 'P\&L statement', 'balance sheet', 'cash flow statement' and 'other' which is in alignment with the performance-orientated approach of producing a model of the major competitor of the focus company (Busco et al., 2006; Hoque, 2003; Hossain et al., 2011; Nixon \& Burns, 2005).

The development of the balance sheets (section 5.3.4) had primarily been conducted based on KPIs (Asset side: "Days outstanding Trade Receivables", "Days 'worth of stockholding" and on liabilities side: "Days outstanding Accounts payable") which are connected with the Value from Test for Sales in their formulas. This build-up in the model ensured a performance orientation due to the close dependency to the variable sales. The application of the KPIs calculated and used in the model is in line with standard techniques in management accounting literature and practice. Furthermore, values for the information category 'cash flow statement' could be derived from the P\&L statement and balance sheet which is in line with the performance-orientated approach of the conceptual framework/model and management accounting literature and practice.

In addition, to developing values for the variables of the information categories of the conceptual framework/model, the conceptual framework/model supports identifying the major competitor's “...limited numbers of areas in which satisfactory results will ensure successful competitive performance..." and "...the few key areas where "things must go right' for the business to flourish" (Bullen \& Rockart, 1981, p. 7).

In this section, I have discussed whether the performance-orientated approach of the conceptual framework/model is supported by management accounting literature. The understanding of the term 'performance' used in the conceptual framework/model establishes a close link to the primary variable sales by product line by year which directly leads to the 
information category 'margin accounting'. The values of the variables of the Information Categories 'P\&L statement', 'balance sheet' and 'cash flow statement' could be derived from the primary variable sales by product line which could be accomplished in accordance with management accounting literature and techniques. This approach enabled performance orientation according to management accounting literature in all information categories of the conceptual framework/model.

After the discussion regarding the structure of the data (previous section) and the performance orientation of the conceptual framework/model, in this section I seek to conduct the discussion of the process of connecting the textual information generated in NVivo and the respective process for calculating the values of the variables of the Information Categories in the next section.

\subsubsection{Connecting textual and numerical data}

In the last section I have connected the term 'performance' with 'revenue accounting' and 'earnings statement' adopting the view of German consolidated cost accounting as Franz (2003) has put it. Furthermore, the relationship towards the information category margin accounting and particularly the primary variable "Sales by product line by Year" has been outlined.

In order to be in line with this performance-orientated approach, textual information has been organized in NVivo synchronously to the numerical information and the structure of the model in MS Excel. In particular, the coding of references regarding the primary variable "Sales by product line by Year" was conducted accordingly.

The textual information which is designed to be part of the interface between NVivo and MS Excel needs to be evaluated (section 5.2.5.2). Due to the performance-orientated approach which is anchored in the conceptual framework/model and is in line with management accounting literature, the evaluation of textual information focuses on sales by product line by year.

Initial values of $0.8,1.0$ and 1.2 (section 5.2.5.2 on page 141) built the basis for the evaluation of textual information (Figure 55 on page 141). This has been complemented by an evaluation regarding the impact (positive impact $=+0.1$, no impact $=0$ or negative impact $=-0.1$ added to/deducted from the initial value) on the core criteria of textual information regarding a performance-orientated evaluation ("Comparisons vs. MC and FA", "Incidents" and "Strategic match"). This approach is in line with management accounting literature (Feldman et al., 2010). 
The criterion "Comparisons vs. MC and FA" supports verifying the data related to one of the perspectives regarding the variable sales in a particular product line with the other two perspectives (section 5.2.4.2).

The criterion "Incidents" (section 5.2.4.3) aids recognizing potential or existing problems which may impact the major competitor's sales in specific product lines. Incidents may occur in the business or political environment.

The criterion "Strategic match" (section 5.2.4.4) helps recognizing whether the strategy which the major competitor has communicated in its published consolidated financial statements is covered by development, in particular over the years of the sales in the respective product lines.

Based on the coding conducted in NVivo in Phase 3, respective queries could be generated and be transferred into the interface with MS Excel. The result of this process (Figure 55 on page 141) delivered the option "NVivo-related Sales" in the process of testing options of estimations of the major competitor's sales (Figure 56 on page 144) which had been conducted in the phases 'Preparation of Options', 'Test' and 'Outcome/Result' (section 5.2.5.3).

The four options of the test for identifying sales by product line by year are "bottom-up est. major competitor sales", "NVivo-related sales" and "Upper/lower boundary". "Bottom-up est. MC sales" refers to estimations of major competitor's sales by product line by year which had been provided by the subsidiaries of the focus company and in addition built the basis for calculating YoY -changes on this level of detail. These YoY changes enabled to get an estimation to what extent the sales by product line for a particular EPU can go down or up in the periods under observation. The "Upper/lower boundary" is then calculated by adding the maximum change to and deducting the minimum change from the "Value from Test" of the previous year. Concerning the entire period of observation, the two boundaries form a corridor in which plausible values from the test can be expected.

After these preparatory steps, the test of the four options follows (Figure 56). Firstly, the 'Zero-Test' sets the "Value from Test" equal to zero in case the "bottom-up est. MC sales" is equal to zero. This ensures that the estimation of the subsidiary of the focus company is overruling all other options and, for example, is not bringing the "Value from Test" into the corridor and thus avoids leading to a potentially too high "Value from Test". If the "bottomup est. MC sales" is not equal to zero, the "Corridor Test" follows and differentiates if the "bottom-up est. MC sales" is inside or outside the corridor. If the "bottom-up est. MC sales" 
is inside the corridor and is bigger or equal to the "NVivo-related Sales", it becomes the "Value from Test" otherwise "NVivo-related Sales" becomes "Value from Test". If the "bottom-up est. MC sales" is outside the corridor the "upper boundary" becomes "Value from Test", otherwise the "lower boundary" becomes "Value from Test". The "Value from Test" for a specific year represents the outcome of the process of testing options of estimations of major competitor's sales and is used for calculating "Upper/lower boundary" for the following year and is used in the information category 'margin accounting' as sales for that particular product line in that particular year in the respective EPU.

Prior to discussing the processing of numerical data and the application of management accounting techniques I seek to amplify the process of testing options of estimations of the major competitor's sales (Figure 56 on page 144) in relation to Research Question 2/Research Objective 2.

Firstly, I managed to organize textual and numerical data in identical structures. In addition, I connected the term 'performance' with 'sales by product line by year' which is in line with management accounting literature (Franz, 2003). The approach of using criteria (in this project "Comparisons vs. MC and FA", "Incidents" and "Strategic match") which are prepared for evaluation by coding them into respective Nodes (positive impact, no impact, negative impact) is in line with management accounting literature (Ernstberger et al., 2017; Feldman et al., 2010). Within the process of testing options of estimations of the major competitor's sales (Figure 56) numerical Data ("bottom-up est. MC sales" = estimations of the Subsidiaries of the focus company regarding major competitor's Sales) have been connected with the evaluated textual information ("NVivo-related Sales"). Regarding RO2 ("to critically evaluate the performance relevant information available in management accounting to assist with competitor accounting in the focus company") it can be ascertained that the textual information available could be transferred into the identical structure of the numerical data and a process of evaluating the textual information be applied. The result of this evaluation process could be tested whether it ensures to stay in a corridor of plausible values. The outcome/the results of this test ("Value from Test") could be transferred into the numerical part of the model of the major competitor of the focus company which now leads over to the discussion of performance-relevant numerical data and management accounting techniques "...available in management accounting to assist with competitor accounting in the focus company" (Research Objective 2). 
The result/outcome - namely "Value from Test" as sales by product line by year for the salesand service EPUs - had been led over to the information category 'margin accounting' of the numerical part of the model and had been multiplied with respective GP and GM percentages of the sales and service subsidiaries of the focus company (section 5.3.1). The respective utilization of the production EPUs has been derived based on an assignment of product lines to production units in conjunction with the information regarding total merchandize in the P\&L statement of the EPUs the IC sales of the EPUs assigned to the function of production can be derived by product line ("Sales of production units"). The outcome of the information category 'margin accounting' formed the basis of the P\&L statements according to total costand cost of sales format (section 5.3.3). Total sales across all product lines by EPU built sales in both formats of the P\&L statement whereas total GM was led over to the cost of sales and total GP to the total cost format for each year under observation. The information generated at the level of the P\&L statement of single entity had then related to the respective relationships and KPIs (for example, average sales per FTE) of the subsidiaries of the focus company. This procedure is geared to the "Value from Test" and ensures a performanceorientated development of the information categories 'margin accounting' and $\mathrm{P} \& \mathrm{~L}$ statement. Furthermore, the identification of the IC-relationships enabled to generate performance-orientated structure of the information categories 'margin accounting' and ' $\mathrm{P} \& \mathrm{~L}$ statement' at a group level and is therefore in line with the dimension 'consolidation hierarchy' of the conceptual framework. The terms 'performance' and 'revenue accounting' as well as 'earnings statement' have been connected and are in line with management accounting literature (Franz, 2003) and can in addition in this context also be applied to the terms 'margin accounting' and P\&L statement (Dusemond, 1994; Kajüter, 2003; Rein, 1993). The performance orientation of the procedure itself is supported by the increased performance orientation in SMA/competitor accounting and analysis literature as confirmed by Busco et al. (2006), Hossain et al. (2011) and Nixon and Burns (2005).

The information category 'balance sheet' (section 5.3.4) had been developed in two steps. Firstly, the asset side has been configured and thereafter the liability side. The rationale for this line of action lies in the performance orientation and particularly in the respective resources, for example, the level of inventory needed for a defined volume of business. Respective KPIs had been calculated from the data of the subsidiaries of the focus company for the years under observation and related to the performance-relevant data developed in the information categories 'margin accounting' and 'P\&L statement'. Particularly, the variables 
'Sales', 'Cost of Sales' and 'Cost of Material' had related to the KPIs "Days outstanding Trade Receivables", "Days' worth of stockholding" on the asset side and "Days outstanding Accounts payable" on the liability side. These KPIs reflect both, the market conditions the focus company and its major competitor is acting in and the resources needed for the performance implied in the "Value from Test". For example, payment conditions in distinguished markets may be a given parameter which one has to accept, and which is reflected in the KPI "Days outstanding Trade Receivables". Furthermore, an appropriate level of spare part inventory is required to be able to react in time in order to ensure that customer's processes are not jeopardized. In addition, a certain level of inventory is needed for one's own production sites and repair workshops. These circumstances are reflected in the KPI "Days' worth of stockholding”. Furthermore, 'Working Capital', 'ROCE' and 'CAPEX\%' had been calculated based on P\&L statement and balance sheet as these are KPIs which the major competitor refers to in his comments in his published consolidated financial statements which offers the opportunity to compare the message the major competitor seeks to communicate to the capital market with the model and will be dealt with in context of Research Question 3/Research Objective 3. This approach ensures, that the level of resources needed for the performance developed in the information categories 'margin accounting' and 'P\&L statement' goes into the calculation of the respective KPIs, which are part of common management accounting literature and practice.

The information category 'cash flow statement' (section 5.3.5) is derived from P\&L statement and balance sheet and calculated for both, level of single entity and group which is accordance with the information category 'consolidation hierarchy' of the conceptual framework. The variables used in this calculation are EBIT, change vs. prior year in working capital and change vs. prior year in CAPEX which is in line with respective approaches in management accounting literature and practice. In addition, all variables used in this calculation relate to the primary variable sales either through applying ratios of the subsidiaries of the focus company in P\&L statement or via considering them in one of the formulas which assisted in creating the balance sheet (KPIs "Days outstanding Trade Receivables", "Days' worth of stockholding" on the asset side and "Days outstanding Accounts payable" on the liability side).

The first variable in the calculation of the cash flow statement is EBIT which is the outcome of the P\&L statement which starts with the primary variable sales ("Value from Test"). Working Capital is constituted of the change vs. prior year in current assets and the change in 
liabilities. Current assets consist of the variables inventory, PoC receivables, trade receivables, AR-IC and cash which are calculated based on KPIs applied in the process of developing the balance sheet and which are closely related to the performance of the EPU. Current liabilities contain the variables advance payments received, accounts payable, liabilities IC and other liabilities. The example developed for the variables of the current assets can be viewed from the liability side: the sales and service EPU receives a customer order and in turn has to order this from the production sites. This business transaction causes IC processes, for example, liabilities IC due to ordering the new machine or spare part from the production site as well as the advance payments received from the customer in case of a new machine project.

The impact on the cash flow statement of the variable CAPEX is positive in case less CAPEX has been spent vs. prior year and vice versa.

Because IC relationships are tracked on separate accounts the view according to the dimension consolidation hierarchy could also be built through elimination of the IC accounts at the group level and elimination of the margin of the production sites contained in the inventory of the sales and service subsidiaries. Through this organisation of the variables and the procedure applied it is ensured, that the consolidation rules according to management accounting literature are applied (Dusemond, 1994). In addition, it can be ascertained, that all variables and KPIs applied are closely related to the performance of the respective EPU. The procedure applied is in line with the increased performance orientation in management accounting literature (Busco et al., 2006; Hossain et al., 2011; Nixon \& Burns, 2005).

The sheer amount of data in particular in the area of textual information (Figure 22 on page 102) along with the complex structure had been a challenge in this project which hardly would have been manageable without the support of software. In the area of numerical information accepted software (in particular MS Excel, see section 4.6.6) is available. Regarding textual information (section 4.6.4), the most popular software is NVivo (Edhlund \& McDougall, 2016). However, QDAS software is comparatively young (c. 20 years). Concerning this project, it was possible to build the structures needed and the system performed all queries defined. Connecting these two areas of information is one of the key tasks which had to be managed. In this context, it was extremely useful that NVivo is in the position to exchange data with MS Excel which has been described in section 5.2.6.

In this section, I have discussed the process of connecting textual and numerical data/management accounting techniques. Based on similarly structured textual and numerical 
data a respective process had been applied starting with the evaluation of the performancerelevant variable "Sales by product line by Year". The outcome/the result of this process the "Value from Test" - had been transferred into the numerical part of the model in MS Excel starting with the information category 'margin accounting' of the conceptual framework first. Upon connecting the "Value from Test" with GP and GM percentages respective profitability per product line could be calculated and the total across all product lines for sales and GM/GP could be led over to the P\&L statement. In addition, KPIs for developing the information category 'balance sheet' could be calculated through integrating performance-relevant variables into the formulas which are in line with management accounting literature and practice. Based on the information categories 'P\&L statement' and 'balance sheet' the information category 'cash flow statement' could be derived for both level of single entity and group according to the dimension consolidation hierarchy of the conceptual framework. In relation to Research Objective 2, I have illuminated the process of connecting textual and numerical data in order "to critically evaluate the performance relevant information available in management accounting to assist with competitor accounting in the focused company".

In the next section, I aim to discuss whether the performance-relevant variables produced by the model are meeting the requirements as defined in SMA/competitor accounting and analysis literature.

\subsubsection{Discussion by performance-relevant variable}

The term performance has been intertwined with the terms 'revenue accounting', 'earnings statement' and 'margin accounting' in accordance with literature (Franz, 2003) in section 6.3.3. Concerning the expectations of SMA/competitor accounting and analysis literature as to what information regarding competitors' performance is relevant, a very wide spectrum can be observed. It appears non-controversial that "...financial and now non-financial information..." regarding "...competitor's costs and the monitoring of..." competitor's achievement of his strategies in defined "...markets over a period of time" (Alnoor Bhimani \& Bromwich, 2010, p. 49) belongs to the information which SMA literature requires. Rothschild (1979) stresses the aspect of identifying reasons for competitors' performance. Regarding the method the performance-relevant information can be developed Porter (1999) suggests estimating, for example, competitors' costs. Laitinen (2011) emphasizes in this context the importance of information regarding pricing decisions. Furthermore, Bullen and Rockart (1981) provide their concept of CSFs. 
In this project, the term 'performance' is substantiated through the dimensions information category and consolidation hierarchy of the conceptual framework. In particular the variable 'Sales by product line by Year' of information category 'margin accounting' had been developed based on financial and non-financial data for the product lines "...over a period of time" (Alnoor Bhimani \& Bromwich, 2010, p. 49). Financial data has been used through applying the GM/GP percentages of the subsidiaries of the focus company on the "Value from Test" which delivered margins derived from the primary variable sales and in addition built the basis for calculating variables in the information category 'P\&L statement'. The derived variables 'Margin by product line by Year' enable to see whether major competitor has "...profitable and balanced portfolios..." and allows to "...identify their problems" (Rothschild, 1979, p. 26). However, SMA/competitor accounting and analysis literature is not explicit regarding the information about competitors' profitability. In this context, it can be ascertained, that the model produced GM/GM by product line by year and in total across all product lines for consideration in the information category 'P\&L statement' of the conceptual framework. In addition, the variable EBIT of the information category 'P\&L statement' had been developed which provides the possibility of a differentiated analysis regarding the major competitor's profitability and related problems in the sense of Rothschild (1979). The process of determining the "Value from Test" considered also the option "NVivo-related Sales" which included the evaluation of textual information which can be related to the consideration of non-financial information according to Alnoor Bhimani and Bromwich (2010). This in turn enabled calculating KPIs based on the primary variable sales and derived variables regarding the information category 'balance sheet'. Eventually, the information category 'Cash Flow Statement' could be built based on the information categories 'P\&L statement' and 'balance sheet'. Aligning the information categories 'balance sheet' and 'Cash Flow Statement' with the requirements defined in SMA/competitor accounting and analysis literature unfolds that this is not in the scope as defined by Alnoor Bhimani and Bromwich (2010). However, Bullen and Rockart (1981) provide the possibility to consider variables of the information categories 'balance sheet' and 'Cash Flow Statement' in their concept of CSFs. Although the aspect of increasing international business has been acknowledged and the necessity of a respective group strategy been emphasized (Porter, 1999), SMA/competitor accounting and analysis literature does not provide the means to develop performanceorientated information at group level which is reflected in the gap identified in literature (section 2.7). 
Surprisingly, SMA/competitor accounting and analysis literature does not foresee procedures regarding verification and consistency of the data produced regarding competitors' performance. The model suggested in this project included respective steps in the area of textual information (section 5.2.5.4) and numerical information (section 5.3.6) for the periods 2008 to 2012. In section 5.2.5, I described how an idea of the major competitor's 2013 sales can be developed. Based on the "Value from Test" of sales other variables of the information categories 'margin accounting', 'P\&L statement', 'balance sheet' and 'cash flow statement' have been derived. In order to test validity, the 2013 estimations of sales were then compared with the major competitor's published consolidated financial statements which represents a verification of the values produced for the variables of the information categories at the group level in accordance with the dimension consolidation hierarchy of the conceptual framework. The 2013 sales figure available from the major competitor, which this project seeks to come close to, is reported within the consolidated published financial statements as the sales of one division. It is published as a percentage without decimal place of group sales which in turn is specified in thousands of group currency (TGC). This allows to compare the 2013 sales figure produced by the model of the major competitor with the 2013 reported sales. All other variables had been derived from the 2013 reported sales using the relationships calculated in the model.

The estimated sales were $3 \%$ below the reported sales which is a significant improvement compared to the initial estimation which was c. $35 \%$ below the comparable value. In addition, the relationships build in the model are based on a reasonable assumption regarding sales.

Due to the significant different profitability among the product lines the respective GM and GP percentages are differentiating respectively (information category 'margin accounting'). GM/GP represent the essential part of EBIT (information category 'P\&L statement'). Therefore, EBIT is strongly impacted by the product line structure of sales and the applied GM/GP percentages. If the estimation regarding 2013 EBIT is close to the derived reported 2013 EBIT, it can be argued that the estimation regarding the product line structure and the respective GM/GP percentages are reasonable. The estimated 2013 EBIT\% was above the 2013 derived actual EBIT at a consolidated level. Considering that the estimated sales figure was reasonable whereas the GM\% applied has not changed the regarding the variable EBIT is that the GM/GP percentages or the estimation of the overhead expenses leads to a too high estimation of EBIT. 
The validity of the information category 'balance sheet' can best be tested by comparing the estimated working capital versus the derived 2013 actual figure. In addition, working capital has been developed closely to the "Values from Test". The estimation regarding working capital was at the level of derived 2013. It can be asserted that it is possible to include balance sheet items which are derived from sales in the model.

The information category 'cash flow statement' could only be based on the performancerelevant variables which have been considered in the information categories 'P\&L statement' and 'balance sheet'. Other parameter impacting the variable cash (for example, additional bank loans) could not be included in this calculation. Therefore, it can be ascertained that it is possible to make reasonable assumptions regarding a performance-based cash flow statement which is in alignment with the information category 'P\&L statement' and performancerelevant variables in the information category 'balance sheet', however, this view is not complete due to possible non-performance relevant impacts. The estimated 2013 cash flow was above the respective derived 2013 actual figure due to the too high estimation of EBIT. As a result, regarding the aspect of testing validity and consistency it can be argued that based on a respective organization of the data a test of validity in the area of competitor accounting appears to be practicable at least at the level of group of the dimension consolidation hierarchy of the conceptual framework.

In this section, I have discussed to what extent the performance-relevant variables of the conceptual framework/model meet the requirements of SMA/competitor accounting and analysis literature which closes the discussion in context of the core elements of the conceptual framework/model.

In the next section, I aim to extend the discussion through including the aspect of competitive advantage.

\subsection{Identifying competitive advantage provided through the application of the conceptual framework/model}

\subsubsection{Overview}

The conceptual framework (Figure 11 on page 69) foresees that based on the information produced through the model, the creation of competitive advantage is supported. In this context, two basic routes were developed in section 5.4, namely identifying the major competitor's CSFs according to Bullen and Rockart (1981) and contrasting the major competitor's communicated strategy with the model, and will be discussed in the next sections. These two routes are designed to complement each other and are in line with 
management accounting literature in both the area of textual data (Ernstberger et al., 2017; Feldman et al., 2010; Guay et al., 2016) and numerical data (Dusemond, 1994; Franz, 2003; Kajüter, 2003; Rein, 1993; Schöb, 2008a, 2008b, 2009). Furthermore, SMA/competitor accounting and analysis literature supports the use of financial and non-financial information (Alnoor Bhimani \& Bromwich, 2010). The discussion of these two routes needs to consider the aspect of identifying to what extent it can be verified whether this approach supports in generating data which is suitable to support in the creation of competitive advantage.

Identifying the major competitor's CSFs (section 5.4.3) according to Bullen and Rockart (1981) and being in the position to make informed assumptions regarding the impact of the CSFs identified on the major competitor's performance enables monitoring of the major competitor's prospective performance through the strategic lens which I seek to discuss in section 6.4.2.

The second route is adopting the strategic view as well as, in comparison to, the concept of observing the major competitor's CSFs designed to consider the information produced by the model from a holistic view which I aim to discuss in section 6.4.3.

I attempt to conduct the discussion regarding test and verification in section 6.4.4.

I seek to begin with the discussion of the two routes developed in section 5.4 in the next section.

\subsubsection{The major competitor's critical success factors}

The system of CSF according to Bullen and Rockart (1981) seeks to identify and monitor things which are crucial for a positive development of the organisation's business. Applying the concept of CSFs according to Bullen and Rockart (1981) in context of competitor accounting/analysis enables focus on crucial points.

The focus of the core areas of the textual analysis ("Comparisons vs. MC and FA", "Incidents" and "Strategic match") was aligned with the concept of CSFs in Phase 3 of the textual analysis (section 5.2.4).

Due to the organization of the data, in particular in the information category 'margin accounting' by product line, it was possible to identify CSFs of the major competitor in particular product lines and to make them observable through respective reporting and monitoring (section 5.4.3.3). For example, the importance of the environmental legislation can be viewed at as a CSF, according to Bullen and Rockart (1981), in a certain product line. Due to the high share of government authorities, the CSF 'number of public tenders' appears 
to be reasonable. Due to the organisation of the data, it is now possible to monitor this CSF along with the development of the performance-related numerical data. In addition, the data can be analysed by EPU, which in essence is an analysis by country and supports further understanding, for example, of whether a stricter environmental legislation relates to a particular region (for example, developing countries). This in turn can potentially deliver information which enables generating information to aid in the creation of competitive advantage because the conceptual framework/model is designed to provide related performance-orientated information, for example, the impact on the utilization of the respective production sites which potentially supports in the area of pricing-decisions (Laitinen, 2011) in the product line concerned from this CSF.

In the following section, I aim to discuss the second route the conceptual framework/model provides to support creating competitive advantage.

\subsubsection{The holistic view: comparing the model with the major competitor's communicated strategy}

The second route of the conceptual framework/model seeks to challenge the major competitor's business model and the underlying strategic approach in general.

The Model provided estimations for the major competitor's 2013 information categories according to the dimension consolidation hierarchy developed from textual and numerical data coming from the periods 2008 to 2012 and conducted in alignment with management accounting literature.

In section 5.4, I compared the image which the major competitor seeks to communicate to the financial market with the model of the major competitor developed in this project. This image is coined by a successful and profitable prospective development with a respective advancement of, for example, cash flow which is measured as a defined percentage of sales. The conceptual framework/model provides a separate information category 'cash flow statement' which allows a comparison of the 2013 estimated percentage with the percentage communicated by the major competitor in his published consolidated financial statements. Due to the integration of the calculation of the cash flow statement in the conceptual framework/model it is now possible to trace back from what variables of the cash flow statement an impact is coming. In relation to the variable "EBIT" of the information category 'P\&L statement' the variance analysis (Figure 66 on page 169) conducted by product line in the information category 'margin accounting' supports identifying where (what product line in which EPU) an impact on performance ("Value from Test" and derived variables GM/GP) 
is coming from. Through conducting the variance analysis in the information category 'margin accounting' in conjunction with the respective textual data coded in NVivo in the same product line folder it became obvious that a strong negative impact on performance is related to one of the major competitor's major product lines. Scrutinizing this in context with the major competitor's aggressive pricing, particularly in one of the major product lines laid open that the major competitor seeks to gain cost advantage through the degression of fix cost per unit through high utilization of the production capacities which enables it to offer respective competitive prices in the market. In addition, the major competitor follows the strategy of taking advantage of conducting production of this major product line in a lowwage country. Furthermore, the major competitor offers comparably short delivery times. This constellation requires a respective level of inventory of raw material to keep the utilization of production constantly at an appropriate level along with a resulting level of semi-finished and finished goods. Consequently, the major competitor has two basic dependencies at the same time: the pressure to have high utilization in conjunction with an efficiently working production and the related level of inventory. This system of dependencies collapsed when the major competitor had to report quality problems in the respective production site which had its impact on performance which was visible in the model and laid open that the major competitor is not prepared to react in such a situation with risk-compensating options. In addition, the information provided by the model does not support the assumption of significant growth in this specific product line which is reflected in the information category 'margin accounting' of the conceptual framework. Furthermore, it can be observed that the 2013 estimation for the growth of working capital is above the respective ACT which coincides with the development in cash flow: the 2013 ACT growth is above the respective estimation because of the lower growth in working capital. Looking at the development over the periods (Figure 69 on page 172) 2010 to 2013 it can be ascertained that both the 2013 EST and ACT are above 2012 for working capital and below for operational cash flow.

With regard to the requirement of generating information which potentially aids in the creation of competitive advantage, the model made the connection between performance in information category 'margin accounting' and related resources to be held available in terms of working capital and cash visible. From a strategic viewpoint, the model provided information regarding the sensitivity of the major competitor's business model and the related aggressive pricing behaviour. In essence, the major competitor's performance in one of its 
major product lines is based on a business model which appears to be fragile and does not consider sufficient risk-compensating options. This information in turn can potentially support in re-considering the strategy that the focus company is following in this particular product line in the area of pricing (Laitinen, 2011). In addition, the focus company has the possibility to reflect on the quality issues reported by the major competitor in its production site abroad in order to ensure foresight in order to avoid such a situation regarding its own production capacities. In this scenario, the conceptual framework/model can potentially outline areas where more stable processes would support avoiding respective error-related costs in the own organization and thus support in generating information which potentially can lead to the creation of competitive advantage.

The discussion in this section included elements of all information categories of the conceptual framework/model. In addition, the level of single entity and group in conjunction with textual and numerical data is necessary to be considered in order to make a potential competitive advantage visible. This, in turn, underlines that a holistic approach appears to be beneficial because it reflects the complex structure required in the business in which the focus company and its major competitor are acting. On the contrary, the education of management accountants appears to be increasingly focusing on specialisation which seems to not consider connections appropriately within complex and internationally acting manufacturing organizations and their business environment.

The holistic approach as described above coincides with the role of management accountants in the organisation. The more management accountants are involved in discussions with other functions of the organization, the more they are in the position to contribute with their knowledge and to connect this with issues and topics the organization is seeking to resolve. This understanding of management accountants looks at management accountants as business partners and includes involvement in managerial decision-making (Coad, 1999; Wolf et al., 2015).

In this section, I have outlined how a holistic approach, considering particularly the connections and relationships between the information categories of the conceptual framework, can support the generation of information which potentially supports in the creation of a competitive advantage. This has been complemented by a brief consideration regarding the trend of specialisation in management accounting education and the role of management accountants as business partners of management in decision-making processes (Coad, 1999; Wolf et al., 2015). 
In the next section, I aim to approach the issue of testing whether the routes discussed above (sections 6.4.2 and 6.4.3) are providing information to help in the generation of competitive advantage.

\subsubsection{Test and verification}

Firstly, it seems useful to describe the chronology of the project in the context of test and verification regarding the generation of information which potentially would support achieving a competitive advantage.

The Model provided 2013 estimations according the information categories of the conceptual framework which are based on data coming from the years 2008 to 2012. The Model itself has been developed in the course of this project and was not available in 2013. Therefore, the situation that decisions had been made in 2013 based on the information produced through the model cannot be tested directly as regards to the question whether it was supportive in the creation of competitive advantage.

Alternatively, it appears to be reasonable to observe whether the information provided by the model during the periods under observation including 2013 would have supported strategic decision-making in the mid- and long-term view and in addition aided in the creation of competitive advantage. This approach is in accordance with the more mid- and long-term orientated character of strategic decision-making. Regarding the question of what kind of information can be evaluated as strategic and mid-/long-term orientated, it seems safe to say that information in the context of acquisitions is relevant given the background of this project. Strategic relevant acquisitions in the business that the focus company and the major competitor are acting in are characterized through a significant amount to be invested and have to be reported in the published consolidated financial statements. Furthermore, it can be assumed that strategic relevant acquisitions relate to a specific business and are adding, for example, a new product line or stand in context with an existing business/product line. Depending on what strategic relevant acquisition had been conducted further development of scenarios is supported and can be aligned with the model. This alignment can then be conducted by scrutinizing if it is possible to evaluate whether the acquisition is reasonable from a strategic point of view. Furthermore, this consideration has to be based on the development of the performance-orientated primary variable "Sales by product line by Year" which is supported by the outcome of the development of the variable "Total Sales" which is varying from ACT sales in the years 2010 to 2013 in a bandwidth of $+6 \%$ to $-6 \%$ (Figure 65 
on page 166) which is a significant improvement compared to the starting point of $-35 \%$ in 2008 .

In the 2010 , the major competitor conducted an acquisition which can be characterized as strategic relevant according to the assumptions made above. Furthermore, the major competitor mentioned this acquisition from 2010 onwards and described it as strategic investment in a specific business which in turn can be related to a distinguished product line. In addition, the major competitor described this acquisition as a supplementation of the business in a specific product line which is meant to offer customers a broader spectrum of solutions which competition does not offer. According to the major competitor's publications this supplementation of the business is also expected to have a positive effect on the existing business in this product line. Looking into the development of the respective product line confirms a significant growth of the primary variable "Sales by product line by Year" in the year of the acquisition. However, only two-third of the 2010 growth rate in that product line can be observed in the years 2011 and 2012 including a slight drop of the growth rate in 2012 compared to 2011. Zooming in to 2013 reveals a growth rate compared to 2012 for the 2013 EST which is slightly above the growth rate before the acquisition and regarding 2013 ACT slightly negative. This in turn raises the question of whether the performance of the acquisition has dropped or if the existing business has dropped and this drop could at least partly be compensated for by the acquisition. However, both of the prior developed explanations are not resulting in a positive analysis of the development of the business in one of the major competitor's important product lines and the strategic acquisition. The information can now be used to work on creating a competitive advantage. For example, since the major competitor seems not to be successful in one of is leading product lines, it may want to be more aggressive in other product lines in order to find compensation for the missing business. Being prepared for such a scenario would potentially bring the focus company into a more favourable position compared to the major competitor. In this context, the conceptual framework/model would have provided information which supported in achieving a competitive advantage.

In this section, I have outlined an alternative way of testing whether the conceptual framework/model is in the position to contribute information which potentially would be supportive in the generation of competitive advantage. As a summary, it can be ascertained that a verification of the success of strategic acquisitions can be conducted through comparison with the development of the performance-orientated variable "Sales by product 
line by Year" in connection with a respective interpretation that produces information which potentially assists in producing competitive advantage.

This section closes the discussion and analysis of the findings given in chapter 5 . In the next section, I aim to outline the research limitation of the conceptual framework/model.

\subsection{Limitations}

\subsubsection{Overview}

The composition of the project supported working on the research questions/research objectives and the research aim. Also, the project required to make decisions regarding the conceptual framework/model. These decisions determined the choice of the dimensions of the conceptual framework/model and the selection of the respective variables and processes. With the benefit of hindsight, it is possible to identify both limitations caused through the composition of the project and respective potential approaches of enhancements of the conceptual framework/model in order to reduce the limitations identified.

Therefore, I aim to design a structure in section 6.5.2 which supports this reflective approach. In sections 6.5.2.1 to 6.5.2.6, I seek to discuss the limitations identified, whereas in section 6.5.2.7, I strive to outline ways of reducing these limitations. This in turn leads to a delineation of a revised version of the conceptual framework/model in section 6.5.2.8 and in conjunction with the general research limitations prepares the ground for potential foci of future research (section 7.6). General research limitations will be outlined in section 7.5.

In the next section, I seek to discuss the limitations identified in the conceptual framework/model.

\subsubsection{Limitations and relating potential enhancements of the conceptual framework/model}

\subsubsection{Evaluation of textual information and availability of data}

The process of evaluation of textual information (Figure 55 on page 141) had closely been related to core areas of analysis of textual information (section 5.2.5.2), namely "Comparisons vs. MC and FA", "Incidents" and "Strategic match" which had been aligned with the concept of CSFs according to Bullen and Rockart (1981) in Phase 3 of the coding process in NVivo (section 5.2.4). The choice of these core areas of textual analysis is coined by its performance orientation which in turn is closely related to the primary variable "Sales by product line by Year" of the information category 'Margin Accounting' of the conceptual framework/model. In the numerical part of the model this primary variable forms the basis 
for the derived variables of the information categories 'P\&L statement' and 'balance sheet' which in turn forms the basis for the 'cash flow statement'.

Given the composition of the project, it can be ascertained that the number of core areas of textual analysis was limited to three which had been aligned with their performanceorientation, namely "Sales by product line by Year". Due to the nature of the business the focus company and the major competitor are acting, it appeared reasonable to scrutinize these three core areas of textual analysis and to connect them with the primary variable "Sales by product line by Year". In case other than the used core areas of textual information would have been of relevance, they would not have been considered by the primary variable. Also, I have not incorporated weights for these core areas of textual analysis because this appeared not to be appropriate in this project. However, a weighting mechanism could basically be integrated in the process of evaluation of textual information (Figure 55 on page 141).

Furthermore, the model operates with relationships and ratios of the subsidiaries of the focus company and connects them with the "Value from Test". In case these relationships/ratios are not precise enough, the calculated/derived variables would potentially not be plausible. However, the model foresees the check and verification of the calculated/derived variables in the numerical part. In fact, no material manual adjustments had been conducted in the numerical part of the model.

The evaluation of textual information (Figure 55) is based on initial values $(0.8,1.0$ and 1.2, see right column in Figure 55 on page 141) which have been developed based on total "Bottom-Up-Sales" estimation. This is then complemented by values of either -0.1 and +0.1 and delivers a value to be multiplied with the "Bottom-Up Sales" between 0.5 and 1.5. The limitation which appears to exist here is that steps of 0.1 in changing the initial value can lead to a change of the lower initial value of $37.5 \%$ ( 0.8 can change down to 0.5 and up to 1.1 ), $30 \%$ of medium initial value of 1.0 and $25 \%$ of the upper initial value of 1.2 . This in turn, can lead to striking corridors of plausible values.

Regarding the availability of compulsory financial publications at local level, it can be ascertained that there are significant differences between countries. This limitation could partly be compensated for through either providing details relating to the respective regions in the major competitor's published consolidated financial statements or through respective information of focus company/financial analysts referring to the region to be observed.

In the next section, I seek to discuss the limitations identified in the process of developing the "Value from Test". 


\subsubsection{Development of "Value from Test"}

The "Value from Test" has been developed through a defined procedure using the four possible options "bottom-up est. MC sales", "NVivo-related Sales" and "Upper-/lower boundary" and is focusing on the primary variable "Sales by product line by Year" only (Figure 56 on page 144).

This limitation reduces the number of primary variables to be tested compared to the situation of testing more than one primary variable and delivered plausible results in this project. In hindsight it appears that considering more than one primary variable could have amplified the possibilities regarding recognizing major competitor's performance. This relates particularly to the variables GM\% and GP\% where the values of these variables of the subsidiaries of the focus company could have been used as a benchmark and support of a deviation from this benchmark would have to be identified in the data. This, in turn, might make a modification necessary of the test phase as defined in Figure 56. In addition, the relationships between the variables within and between the information categories of the conceptual framework/model would become more complex. Contrariwise, a second way of developing the values of the variables of the information categories of the conceptual framework provides an extra option of verification. The additional efforts caused through considering more than one primary variable would have to be balanced against the benefits.

The discussion of the limitations so far is based on the approach of the conceptual framework to consider an interface of collaboration between the function of marketing/sales and the function of control only. The input related to the function of marketing/sales was to a large extent coming from the Managing Directors of the subsidiaries of the focus company. In the next section, I seek to discuss this limitation.

\subsubsection{Interfaces with other functions of the organization of the focus company}

Considering the Interface between the functions of marketing/sales and control only implies the assumption that regarding the perspective of the focus company it is concerning performance-relevant information sufficient to only take account of this interface. One could argue that the outcome of the "Value from Test" lies in an acceptable corridor of $-6 \%$ to $+6 \%$ around the variable "Actual Total Sales" and provides reasonable values of the derived variables of the information categories of the conceptual framework/model. This stance would look at the information produced by the model as sufficient and thus not see considering only the interface between the functions of marketing/sales and control as a limitation. This point of view would be open to question as the performance of an 
organization is dependent on contributions of all functions and a good working collaboration between these functions (Mohamed \& Jones, 2014). Furthermore, fast changing developments of trends in the markets as well as changes in technologies make a close collaboration of, for example, marketing/sales and R\&D indispensable. This in turn, has implications for the conceptual framework/model. A feasible way of considering the collaboration between the functions of, for example, marketing/sales and $R \& D$ would be to insert R\&D in the model and to install an interface between these two functions. A reasonable way to conduct this would be a combined input of these two functions regarding the major competitor's "Sales by product line by Year" and could be processed in the test of options of estimating the major competitor's sales (Figure 56 on page 144). Also, other functions (for example, production) could be integrated in the conceptual framework/model through additional interfaces. In this case the primary variable to be tested could be different from sales and, for example, be "Cost of Material" instead. Furthermore, it would have to verified if the test of options would need modification.

The conceptual framework/model considers the perspectives financial analysts, focus company and the major competitor. Explicitly including the perspective of customers was not possible due to lack of data. In the next section, I seek to discuss this limitation.

\subsubsection{Perspective of customers}

The fact that data related to customers regarding the major competitor's performance was not available in this project does not exclude this perspective in principle. This limitation could be handled by filtering out respective information out of the data available from the perspectives financial analysts, focus company and the major competitor. This could then be connected with information customers are publishing, for example, on their internet sites and thus support in designing the perspective of customers.

Aligning the perspective of customers regarding the major competitor's performance with its communicated strategies would support verifying to what extent the major competitor's strategy is meeting customers' demands. For example, based on the constructed perspective of the customer it could be verified as to what extent the major competitor's aggressive pricing strategy is appreciated by customers. In fact, the major competitor's aggressive pricing across all product lines was one of the major topics in the documents of the focus company and as well emphasized in the major competitor's publications. Considering the perspective of customers would enable to be drawn attention to other components of a strategy such as, for example, quality and behaviour/reliability in case of problems 
particularly in customers' production processes. Furthermore, the level of the technological solutions offered to customers could be considered. The perspective of customers can, for example, be incorporated by the information regarding customers' choices of strategic vendors. This in turn, would support having a more complete picture of the major competitor's performance and align this with the conceptual framework/model.

In the course of the discussion conducted so far, it became obvious that the conceptual framework/model has to be based on an understanding of the role of management accountants which requires interaction with other functions of the organization. This requires involvement of management accountants in respective discussions in the organisation. Furthermore, it sees management accountants adopting a holistic view on business. In the next section, I aim to discuss the limitations if this understanding of the role of management accountants does not exist.

\subsubsection{Role of management accountants and a holistic view on business}

In the course of the discussion of Research Question 3/Research Objective 3, I touched on the topic of the understanding of the role of management accountants in the organization, and that this in turn requires management accountants to adopt a holistic view on business (section 6.4.3). Depending on the extent these prerequisites are present in the organization, they can limit the potential the conceptual framework/model offers.

Roslender and Wilson (2012) point out the different skills that Marketing/Sales Managers and Finance Managers have. Concerning Finance Managers, the authors emphasize that knowledge regarding markets and products support the communication with their marketing/sales colleagues.

The background of the focus company is mechanical engineering in which Finance Managers can contribute with their skills the more they manage both, to follow technical discussions and to get the "scent" of the markets in a specific country. This relates, for example, to different cultures or unwritten habits in certain industries.

Another important aspect regarding the role of management accountants is to look at information also through the lens of marketing/sales. For example, there was an information given in the consolidated financial statement of the major competitor regarding the purchase of several acres in a low-wage country. The background for this was expansion plans in production which must relate to respective moves in the market. At first sight, this piece of information has not been identified because it occurred in another area of the document and particularly has not been given where order intake and sales have been explained. Giving this 
view/interpretation to the function of marketing supported enhancing their view on the competition's strategic moves. Therefore, Finance Managers can contribute to developing a notion of the major competitor sales if they manage to look at information they have available also with the view of their colleagues in the marketing/sales department. This leads to the aspect of looking at things from a holistic view (section 6.4.3). Due to the complex structure of the business in which the focus company and the major competitor are acting, strategic elements of discussions can occur across all dimensions and particularly across all information categories and of the conceptual framework/model. This constellation requires a holistic approach regarding the subject areas concerned and the functions in the organization to consult. However, the necessary holistic approach appears not to be supported in the current education programmes of management accountants.

One of the core elements in the Process of developing the "Value from Test" (Figure 56) is the option "bottom-up est. MC sales" which contains estimations of the subsidiaries of the focused company regarding the major competitor's sales by product line by Year. These estimations had been requested in the process of the annual budget process and been discussed in respective review meetings. In the next section, I aim to discuss to what extent this context potentially leads to limitations.

\subsubsection{Behavioural aspects in the domain of focus company}

In context of the annual budget process basic information for the strategic planning have been requested. This supported the alignment of group strategy with the strategy of the subsidiaries of the focus company. Also, respective KPIs have been discussed with the subsidiaries of the focus company during the annual budget process.

The essential task of KPIs in the field of management accounting/strategic management accounting is to monitor performance. This relates in context of this project particularly to the estimation of the major competitor's sale by product line. This estimation has been made by the Managing Directors of the reporting units of the focus company. Total market in a specific country is calculated as the sum of the sales of the reporting unit of the focus company and the estimations for the relevant competitors in that market. The market share is calculated as the sales of the market participant divided by total market volume. This enables a comparison of the market share of the focus company with the respective share of the major competitor and builds a connection of the performance of the focus company with the estimated respective performance of the major competitor. An already very high own market share of, for example, $50 \%$ justifies the argument, that an increase on such a high level is 
hardly to achieve and therefore a higher budget not realistic. Estimating the major competitor's sale higher would increase total market volume and consequently decrease the market share of the reporting unit of the focus company which in turn would give room to increase budget of that reporting unit because it appears that "a lot more is possible". This situation reveals that there is a potential conflict of interests in which the Managing Directors of the subsidiaries of the focus company are in. Running into a situation where top management increases the bottom-up budget of the subsidiary of the focus company bears the risk of not achieving it with respective frustration in the organization of the subsidiary potentially conjoined with a lower budget-fulfilment and respective lower bonus payments. Providing too low estimations of the major competitor's sales in the respective markets bears the risk that top management at the group level underestimates the major competitor's performance in the respective markets in turn runs into the risk of potentially making not the strategic decisions appropriate in case of having more precise estimations available. A potential solution to this conflict could be to detach this part of the strategic planning from the annual budget process and to organize it separately.

Based on the limitations discussed in the previous sections I seek to discuss how these could be used to develop potential enhancements of the conceptual framework/model in the next section.

\subsubsection{Potential approaches of enhancements of the conceptual framework/model}

The limitations discussed (sections 6.5.2.1 to 6.5.2.6) relate in essence to the areas of evaluation of information, restrictions regarding the view on the data and constraints caused by the process of evolving basic data. Developing solutions for these areas of limitations would support providing approaches for potential enhancements of the conceptual framework/model.

Regarding the limitations in the area of evaluation of information the core areas of textual information in this project ("Comparisons vs. MC and FA", "Incidents" and "Strategic match") had been discussed in section 6.5.2.1. These core areas of the textual analysis are linked to the primary variable "Sales by product line by Year" which in case of the existence of other relevant core areas would lead to the situation that these areas are considered as primary variables. This potentially has impact on the derived variables. Due to the nature of the business in which the focus company and the major competitor are acting, these core areas of textual analysis reflected performance-relevant fields to be scrutinized appropriately and thus enabled the evaluation of textual information (Figure 55 on page 141). Identifying 
performance-relevant core areas of textual information in other industries would support making the conceptual framework/model applicable in these industries as well and would be supported through the input of experienced experts of these industries. In addition, separate weights for the core areas of textual analysis could be included in the process of evaluation of textual information and thus make it more flexible for applying it in other industries. Another limitation identified in the process of evaluation of textual information (Figure 55) was that steps of 0.1 which are used to supplement the initial values $(0.8,1.0$ and 1.2$)$ appear to be a too big step size and thus can lead to noticeable corridors of plausible values. Applying smaller units which are supplemented to the initial values would support reducing the range of the corridors of reasonable values and thus help in being more precise in developing the value of the multiplier to be applied on the "Bottom-Up est. MC Sales".

The analysis of the textual data took a significant amount of time due to the fact that I scrutinized the data of all three groups ("A", "B" and "C"). The research in this context and industry has shown, that focusing on the " $\mathrm{A}$ " - group would have led to resilient results as well and would have reduced the number of sources scrutinized by approximately two third. Future research in this area would have to analyse the context and the industry the research takes place to determine if focus should be on the "A" - group only.

The element of using on one primary variable only appears again in the process of the development of the "Value from Test" where a defined procedure using the four possible options "bottom-up est. MC sales", "NVivo-related Sales" and "Upper-/lower boundary" had been conducted (Figure 56 on page 144), as has been discussed in section 6.5.2.2. Considering the variables GM\% and GP\% as primary variables would support improving the informative value of the model in this particular sector. Furthermore, a separate process of testing options may have to be designed and could use the margin percentages of the subsidiaries of the focus company as benchmark. In addition, the relationships between the primary variables and the respective derived variables would potentially have to be reconsidered.

Concerning the restrictions regarding the view on the data (sections 6.5.2.3, 6.5.2.4 and 6.5.2.5) three options appear to be promising. Firstly, including the input of other functions of the organization of the focus company would potentially enhance the informative value of the information produced by the conceptual framework/model. This could relate for example, to an input from the $\mathrm{R} \& \mathrm{D}$ department which could support for example, in considering technological aspects of the major competitor's machine types and respective knowledge 
regarding concrete applications. Secondly, looking on the data through the lens of customers could potentially support pulling the information produced by the conceptual framework/model more into direction of demands coming from the markets. This approach could be supplemented by considering data retrieved from customers internet sites. Thirdly, management accountants need to be involved in respective discussion with other functions of the organization. This exchange of information creates the basis for a respective collaboration in which management accountants are perceived as business partners of and top management and business functions regarding the strategic direction of the organization. Management accountants in turn, should ensure a holistic approach in their work and in the discussions with top management and other functions.

With reference to the constraints caused by the process of evolving basis data, the fact that the estimations regarding the major competitor's sales by product line by year are incorporated in the annual budget process has been discussed in section 6.5.2.6. In order to avoid potential conflicts of interest, it appears advisable to establish procedures which lead to a separate discussion of the estimations of the focus company regarding the major competitor's sales but within the context of strategic planning. However, a dissolving of the dilemma that the estimations of the focus company regarding the major competitor sales can potentially lead to increasing the bottom-up budget of the respective subsidiary of the focus company appears to remain difficult.

In this section, I tried to outline ways of using the areas of limitations for improving the conceptual framework/model. Based on the approaches discussed in this section, I aim to lead this over into core elements of a revised version of the conceptual framework/model in the next section.

\subsubsection{Cornerstones of a revised version of the conceptual framework/model}

The potential enhancements of the conceptual framework/model refer primarily to the areas of evaluation of textual information, the view on the data and behavioural aspects. Connecting the enhancements with the conceptual framework/model would potentially contribute to amplifying its applicability.

The area of evaluation of textual information (Figure 55 on page 141) that it is conducted by product line by year at the level of EPU. Its composition could be reasonably modified in relation to the number of core areas of textual analysis and regarding considering a weight for these core areas. This would enable changing the impact a single core area has on the evaluation of the textual information through the multiplier and consequently for the primary 
variable which is going to be evaluated. Furthermore, the size of the steps of 0.1 which is added to the initial value can be reduced which would have an impact on the upper/lower boundaries (Figure 56 on page 144) and thus make the corridor of acceptable values smaller which appears more reasonable. This enhancement of the conceptual framework/model would for example, enable to consider the variables GM\% and GP\% as primary variables. A respective preparation of the data in NVivo would be required and a respective process of evaluation of textual information for these newly defined primary variables be determined. Since these variables are considered in the existing version of the model as derived variables, a respective modification of the consideration of these variables would have to incorporated in the model. With regard to the aspect of considering more functions of the organization of the focus company in the conceptual framework/model it would now be prepared to handle these.

Regarding the view on the data separate core areas of analysis of textual information would enable to consider a wider range of information. As mentioned above, considering information of, for example, the R\&D department in context with the function of marketing/sales could be reflected through an extended process of evaluation of textual information. However, the outcome would be summarized in one variable. With reference to the perspective of the customer, it can be generated through coding respective passages from the existing data into separate nodes according to the structure applied in the existing perspectives and information categories of the conceptual framework/model. The aspect of the role of management accountants as business partners in the organization and a holistic way of looking at the topics to discuss with top management and other business functions forms a basic precondition of conducting the potential enhancements of the conceptual framework/model discussed in this section.

Concerning behavioural aspects, the potential conflict of interests caused by the process of developing estimation of the major competitor's sales by product line by year during the regular budget process it appears difficult to conduct this separately. A reasonable way to handle this situation could be to base further discussions regarding competitors' performance on the level developed on an annually updated version of the model.

In this section, I aimed to extend the applicability of the conceptual framework/model through incorporating the potential approaches of its enhancements developed in section 6.5.2.7.

In the next section, I aim to summarize this Chapter. 


\subsection{Summary of chapter}

In this chapter I aimed to conduct the discussion and analysis of the case study findings (chapter 5). The area illuminated in this chapter focused on the critical evaluation of the conceptual framework/model.

In a first step I attempted to connect the approach of the conceptual framework/model with SMA literature and found confirmed, that resilient contributions from SMA are needed and that management accounting knowledge would support to develop this (Roslender \& Hart, 2003). Cadez and Guilding (2012) emphasize the importance of having information regarding competitors' financial performance which is in line with the increased performance orientation in management accounting literature (Busco et al., 2006; Hoque, 2003; Hossain et al., 2011; Nixon \& Burns, 2005). Also, the way textual and numerical information available in management accounting is utilized in this project is in line with literature (Dusemond, 1994; Ernstberger et al., 2017; Feldman et al., 2010; Guay et al., 2016; Kajüter, 2003; Rein, 1993). In addition, the integration of the concept of CSFs according to Bullen and Rockart (1981) supports achieving the research aim of this project. The step of connecting the conceptual framework/model with SMA literature is closely related to Research Question 1/Research Objective 1.

Based on the alignment of the conceptual framework/model with SMA literature focus has then been laid on the ability of the conceptual framework/model to employ management accounting data and techniques to produce informed assumptions regarding competitor performance. In this context, a critical evaluation of the performance relevant information in the field of competitor accounting in the focused company has been conducted. This project utilizes textual and numerical data which need to have equal structures based on the information categories of the conceptual framework (section 6.3.2). The design of the conceptual framework/model is regarding the dimensions 'Information Category' and 'Consolidation Hierarchy' strongly related to cost and financial accounting which has been aligned with the prerequisite of using performance-relevant information in section 6.3.3. The performance orientation led to focusing on the primary variable "Sales by product line by Year" which led to identifying respective textual information which has been evaluated (Figure 55 on page 141) and used as an option in the development of the "Value from Test" (Figure 56 on page 144) in section 6.3.4. The outcome of the calculation of the variables of the information categories of the conceptual framework/model measured according to the variable "Total Sales" was in the years 2010 to 2013 in the corridor of $-6 \%$ to $+6 \%$ (Figure 
65 on page 166) deviating from the respective actual and in the year $2013-3 \%$ below actual which has been discussed in section 6.3.5.

The foundation prepared during the discussion of the core elements of the conceptual framework/model (section 6.3) enabled in context of the illuminating the competitive advantage which the conceptual framework/model is supposed to provide in section 6.4. The design of the conceptual framework/model and the steps conducted so far enabled identifying CSFs of the major competitor according to Bullen and Rockart (1981) in section 6.4.2 which supports making informed assumptions regarding the major competitor's strategic next move in the area concerned. The holistic view discussed in section 6.4.3 enabled a comparison of the model and MCs communicated strategy which unfolded that the major competitor's business model in one of his most important product lines appears to be very fragile.

Section 6.4.4 illuminates the point of testing whether the conceptual framework/model would have supported strategic decision-making in the focus company and thus would have provided competitive advantage.

The discussion regarding the limitations of the conceptual framework/model focused on the process of evaluating textual information (Figure 55 on page 141) and developing the "Value from Test" (Figure 56 on page 144). The topics discussed in sections 6.5.2.1 (on page 201) and 6.5.2.2 (on page 203) related to improving the measurability of the evaluation process through considering more core areas of textual analysis and weighting them and in addition reducing the increment of the value added to the initial value $(0.8,1.0,1.2)$. The discussion conducted in sections 6.5.2.3 (on page 203) and 6.5.2.4 (on page 204) related to extend the view on the major competitor's performance through including the input of other functions of the focus company and adding the perspective of customers. In the sections 6.5.2.5 (on page 205) and 6.5.2.6 (on page 206) the limitations related to an inadequate role of management accountants including a missing holistic view and potential conflicts of interests in the organization of the focused company have been discussed. The limitations discussed have then been reflected in respective discussions regarding potential enhancements of the conceptual framework/model (section 6.5.2.7 on page 207) and cornerstones of a revised version (section 6.5.2.8 on page 209).

In the next chapter, I aim to elaborate on the conclusions of this project. 


\section{$7 \quad$ Conclusions}

\subsection{Introduction}

In Chapter 6, I focused on the findings made in chapter 5 and particularly related that to the conceptual framework/model. In this chapter, I aim to supplement the more general perspective and to draw conclusions from the project.

In section 7.2 the critical evaluation of the conceptual framework/model will be conducted by Research Question/Research Objective. Aim of the critical evaluation is to analyse if and in case of to what extent the conceptual framework/model is in the position to answer the Research Questions and to achieve the respective Research Objectives. Furthermore, I seek to supplement this step by conclusions on a more general level.

In a next step, I aim to analyse if the conceptual framework/model is of use in a wider context which relates in particular to the question whether the conceptual framework/model is of use beyond the case developed in chapter 5 and discussed in chapter 6 . This includes both, the viewpoint of practice and theory. These considerations build the basis for the theoretical generalization conducted in section 7.3.

Thereafter, I aim to delineate the contributions made by this project to both, theory and practice (section 7.4).

Based on the critical evaluation of the conceptual framework/model its limitations will be illuminated in section 7.5.

Through the reflection of the limitations of the initial approach (sections 6.5.2.1 to 6.5.2.6 starting on page 201) potential enhancements of the conceptual framework/model have been outlined in section 6.5.2.7 (on page 207) and will find consideration in conjunction with the general research limitations (7.5) in the suggestions regarding future research in section 7.6. This may serve other researchers as a starting point for their projects.

Section 7.7 finalizes this chapter and this thesis.

Based on the work conducted so far, I seek to critically evaluate the conceptual framework/model in the next section.

\subsection{Critical evaluation of the conceptual framework/model by Research Question}

\subsubsection{Overview}

This section is based on the discussion and analysis of the conceptual framework/model conducted in chapter 5 and supplemented by more general considerations. 
I aim to analyse whether the Research Questions could be answered, and Research Objectives could be achieved in both, the context of this case study and on a more general level.

In the next section, I will start with Research Question 1/Research Objective 1.

\subsubsection{Research Question 1: What information would be needed to use competitor accounting to build a strategic model of competition?}

In order to answer Research Question 1, I had "to evaluate the relevant literature and information available in the area of strategic management accounting" (Research Objective 1).

In the context of the discussion and analysis of the findings (chapter 6 starting on page 174) I connected the conceptual framework/model with SMA literature in section 6.2 (starting on page 174).

In relation to this case study the outcome of the discussion and analysis regarding SMA literature, I found ascertained that a common conceptual framework in SMA literature is needed (Nixon \& Burns, 2012b; Nixon \& Burns, 2005). As to the information available in the area of strategic management accounting and the way it has been used in the case study, the project is in line with management accounting literature regarding both, numerical (Dusemond, 1994; Kajüter, 2003; Rein, 1993) and textual data (Ernstberger et al., 2017; Feldman et al., 2010; Guay et al., 2016). Also, the integration of the concept of CSFs supports achieving the research aim of this project and is in line with literature (Bullen \& Rockart, 1981). Concerning trends and major directions in management accounting, the increasing performance orientation in management accounting literature (Busco et al., 2006; Hoque, 2003; Hossain et al., 2011; Nixon \& Burns, 2005) has been emphasized and forms the basis for the discussion in context of core elements of the conceptual framework/model.

With regard to Research Question 1 / Research Objective 1, it can be ascertained that this has been accomplished in relation to the conceptual framework/model developed in this project.

On a more general level it can be observed that a gap in literature in the field of SMA/competitor accounting/analysis is existing (section 2.7 starting page on 55) in general and is not limited to a certain industry or region. The view that contributions from management accounting would support building a conceptual framework in SMA literature can be seen in context of the complexity of the nature of the topic. The complexity relates to both, theory and practice. In theory more than one subject area is concerned and in practice more than one function would have to be involved which unfolds fundamental problems such as missing common terms and definitions and a missing common understanding of 
verification and testing of the results yielded. On a more general level this project contributes a notion of how such a common fundament could be developed in both, theory and practice. In the next section, I seek to focus on Research Question 2/Research Objective 2.

\subsubsection{Research Question 2: How can management accounting data/techniques be utilized to develop informed assumptions regarding competitor performance?}

In order to answer Research Question 2, I had "to critically evaluate the performance relevant information available in management accounting to assist with competitor accounting in the focused company" (Research Objective 2).

In relation to the conceptual framework/model I discussed the aspects of structuring and connecting textual and numerical data and linked this with the performance-orientated approach of management accounting literature in sections 6.3.1 (starting on page 177) to 6.3.4 (starting on page 185) and discussed the values of the performance-relevant variables developed in section 6.3.5 (starting on page 191).

Regarding the conceptual framework/model developed in this case it can be ascertained that a common structure for textual and numerical information could be developed and values for major competitor's performance-relevant variables could be derived from data based on consistently applied processes.

On a more general level the concepts of the processes developed for the evaluation of textual information (Figure 55 on page 141 and Figure 56 on page 144) and the interface between textual and numerical information (section 5.2.6 starting on page 156) appear to appropriate to build a bridge between different subject areas in theory (particularly marketing and management accounting) and practice (particularly functions of marketing and control). For example, in case of verbal comments the flexibility needed in marketing is provided and enables at the same time to connect this information with management accounting tools and techniques. However, the interpretation of the textual information and the use of management accounting tools and techniques needs to be conducted through manual interpretation and be based on respective knowledge and experience. This forms a pre-condition which was existent in this project but on a more general level may lead to respective limitations.

In the next section, I strive to focus on the aspect of competitive advantage. 


\subsubsection{Research Question 3: How could a strategic model of competitor accounting aid in the creation of competitive advantage?}

In order to work on Research Question 3, I had "to analyse how a strategic model of competitor accounting can provide information to aid in the creation of a competitive advantage" (Research Objective 3).

In relation to the conceptual framework/model developed in this project, it can be ascertained that the foundation prepared in context of Research Questions 1 and 2/Research Objectives 1 and 2 enabled supporting for the creation of a competitive advantage through providing information regarding the major competitor's critical success factors (section starting 6.4.2 on page 195) according to Bullen and Rockart (1981) and contrasting the major competitor's communicated strategy with the model (section 6.4.3 starting on page 196). The conceptual framework/model foresees, that the results are tested (section 6.4.4 starting on page 199). With regard to the conceptual framework/model developed in this project it can be ascertained that the Research Question could be answered, and the Research Objective be accomplished.

On a more general level, it becomes obvious, that the identification of competitions critical success factors appears to be possible if the pre-condition for the application of the case study method of a common background exists. Also, respective knowledge and experience in the respective businesses is essential to identify Critical Success Factors. However, more case studies in this field would support building a common fundament in this field in case the Research Objectives defined in this project are fulfilled.

In the next section, I aim to focus on how the aspect of Generalization has been considered in this project.

\subsection{Generalization}

\subsubsection{Case study method and theoretical generalization}

The research methodology of interpretivism adopted in this project (section 3.3) has been aligned with the research method of case study in chapter 4. This approach supports employing theoretical generalization of the conceptual framework/model as explained by Ryan et al. (2002) who differentiate between two types of theoretical generalization. According to the authors, the first type deals with the recognition of relationships between the context of the case study and the context it has been transferred to and the second type is primarily concerned with the extension of "...the applicability of the case study findings to other contexts.” (Ryan et al., 2002, p. 149) 
In this case study, I seek to apply the second type of theoretical generalization through scrutinizing the applicability of the case study findings into other contexts, namely other industries.

\subsubsection{Extending applicability of case study findings to other contexts}

Firstly, I aim to illuminate the relevance of the background of the business and the organization which the conceptual framework/model is based on for its applicability in other industries. Subsequently, I try to connect the criteria for testing the applicability of the conceptual framework/model in other industries with the case study findings (chapter 5).

The focused company is embedded in a background which is coined by the internationally acting and manufacturing German mechanical engineering sector (section 1.3.2) which has implications for the criteria for testing the applicability of conceptual framework/model in other industries.

The composition of the conceptual framework/model was aligned with the industries in which the focused company and its major competitor are acting. Particularly, the variables of the information category 'Margin Accounting' reflect the industries through a respective product line structure. Furthermore, the conceptual framework/model reflects the organizational build-up of a matrix organisation with sales and service units in its lines and a product line organization embedded in the strong parent company in its columns. With regard to criteria for testing the applicability of the conceptual framework/model in other industries it appears necessary that both the estimations regarding the major competitor's "Sales by product line by Year" and the respective textual data regarding the actual development (for example, textual information retrieved from the major competitor consolidated published financial statements) can be collected according to one's own product line structure according to the information category 'Margin Accounting' or the other variables of the dimension information category ('P\&L statement', 'balance sheet' and 'cash flow statement'). Furthermore, it must be ensured that the data collected can be used to reflect the levels of consolidation according to dimension consolidation hierarchy of the conceptual framework/model.

This alignment of the background of the business and the organization the conceptual framework/model is based regarding its applicability of the conceptual framework/model in other industries forms now the basis for connecting criteria for respective testing with the case study findings (chapter 5). 
The first part of the case study findings relates to textual data (section 5.2 starting on page 101 ) and the second part to numerical data (section 5.3 starting on page 157), both structured according to the information categories of the conceptual framework/model. The performance orientation of this project is reflected through its primary variable "Sales by product line by Year" and based on this further performance-relevant variable are derived. In order to enable the concept of triangulation, textual information has been collected from the three perspectives: financial analysts, focus company and the major competitor (Figure 22 on page 102). With regard to the applicability of the conceptual framework/model in other industries the performance-orientation of the primary variables are a prerequisite. Furthermore, the connection between the primary variables and the variables derived from the primary variable needs to be plausible and comprehensible which can be ensured by, for example, comparing the value of variable calculated with respective KPIs/ratios of the focused organization. Ensuring the resilience of the textual data would be supported through the consideration of the concept of triangulation which in the case of companies listed on the stock exchange should be possible to organize. Furthermore, a process of evaluation of textual information (Figure 55 on page 141) is a prerequisite for the applicability of the conceptual framework/model in other industries.

This process of evaluation of textual information is linked with the process of developing the "Value from Test" (Figure 56 on page 144). Regarding the applicability of the conceptual framework/model in other industries it must be ensured, that the respective requirements of data needed are met. This refers to estimations regarding competitor's performance by year which needs to deliver values for several years which enables to calculate the minimum/ maximum YoY - change in order to develop the "Upper/lower boundary" of the test options. This core element of developing the "Value from Test" needs to be available for the primary variable which in this project is "Sales by product line by Year". As mentioned in section 6.5.2.8 (starting on page 209), this process can be enhanced and respectively adjusted in case it appears reasonable to employ other primary variables as well. However, the applicability of the conceptual framework/model in other industries requires the existence and execution of these processes (Figure 55 on page 141 and Figure 56 on page 144).

Considering the enhancements regarding the evaluation of textual information (section 6.5.2.1 on page 201) of the conceptual framework/model it would also be possible to consider more core areas of textual information (in this project "Comparison vs. MC and FA", "Incidents" and "Strategic match") and to work with weights for these core areas. 
Furthermore, the step-size of 0.1 can be smaller so as to achieve smaller corridors of acceptable values.

The applicability of the conceptual framework/model in other industries is closely related to the existence of a cost accounting system at the group level in the own organisation and respective professional experience in the industry. If this prerequisite is not given, respective verifications regarding plausibility of the values of the variables appear to be difficult to develop. On the other hand, it appears safe to say that if a well-organized cost accounting on group-level is in place, the more the conceptual framework/model can benefit from this.

If the above explained prerequisites are given, the possibility of integrating the strategic level (section 5.4) appears to be even more consistent because it is now possible to contrast the major competitor's communicated strategy, goals and targets with the model (section 5.4.2 starting on page 165). Also, identifying the major competitor's CSFs appears to be achievable (section 5.4.3 starting on page 167).

In this section, I have outlined elements which appear to be relevant to scrutinize regarding the applicability of the conceptual framework/model in other industries. In the next section, I seek to use the elements for testing the applicability of the conceptual framework/model in other industries. In section 7.3.3, I aim to focus on the manufacturing sector and in section 7.3.4 the possibilities to extend this outlying the manufacturing sector will be illuminated.

\subsubsection{Applicability of the conceptual framework/model in the mechanical engineering Sector and subsequent Sectors}

The mechanical engineering sector contains several branches of the capital goods industry. The branch in which the focus company is acting is contained in the mechanical engineering sector which is coined by its dependency from the utilization of its production capacities and accordingly has a high focus on generating the respective sales. For example, the branch "print- and paper technology" is part of the mechanical engineering sector as well because they produce machines and equipment for firms active in producing and selling, for example, paper products. Also, the subsequent sector, in this example the paper mill, is exposed to a high dependency of the utilization of its production capacities, in this example paper machines. This, in turn, leads to a high focus on sales. With reference to the applicability of the conceptual framework/model in other industries it can be ascertained that the precondition of performance orientation is existent in the mechanical engineering and the subsequent sectors as well. 
This performance orientation forms the basis of the applicability of the information category 'Margin Accounting' and allows reflecting values for the major competitor's variable of "Sales by production line by Year". The applicability would be supported through considering more core areas of textual information and introducing weights for these core areas (section 6.5.2.1 on page 201). Furthermore, considering a smaller size of the steps of 0.1 which is added to the to the initial value would lead to smaller corridor of acceptable values and thus support developing reasonable "Upper-/lower boundaries". These set screws allow adjusting the models' parameters to the specific needs of other branches of the mechanical engineering and subsequent sectors and thus support to apply the conceptual framework/model in other industries.

Regarding the organizational build-up of the model of the major competitor, it essential to consider that this is based on a matrix organisation with the sales and service organization in the lines and the product lines in its columns. Furthermore, the model considers one level of consolidation. These assumptions regarding the organization build-up are in line with requirements of more complex organizations. Furthermore, the model can handle different currencies which meets the requirements of internationally acting organizations and respective internationally organized processes (Figure 17 on page 86). Concerning the applicability of the conceptual framework/model in other industries, it can be ascertained that organizational preconditions are defined and are in line with the requirements of the mechanical engineering and the subsequent sectors as well.

The requirements for being able to apply the conceptual framework/model in other industries regarding the structure and organization of the data are closely linked to the requirements of a case study which in essence is the common background in which the focus company and the major competitor are acting. If this is existent the data collected from the three perspectives (financial analysts, focus company, major competitor) can be organized and structured accordingly and the processes for evaluating the textual information (Figure 55 on page 141) and developing the "Value from Test" (Figure 56 on page 144) can be conducted.

Based on the application of the conceptual framework/model so far, the data is now prepared for the integration of the strategic level (section 5.4 starting on page 165) which is not a question of transferability but dependent on the individual industry to which it has been transferred.

In this section, I have illuminated the applicability of the conceptual framework/model in the branches of the capital goods industry and the subsequent sectors which are coined by the 
utilization of their production capacities and respective foci on the primary variable "Sales by product line by Year". In the next section, I seek to deal with sectors which are not covered by this spectrum.

\subsubsection{Requirements regarding the applicability of the conceptual framework/model outlying the mechanical engineering sector and subsequent sectors}

With the industries "outlying the mechanical engineering sector and subsequent sectors", I seek to define non-productive industries, such as the insurance sector. These industries need to be distinguished from the mechanical engineering sector due to their different way of chain of economic value added. The mechanical engineering sector chain of value added is closely related to its production capacities and sales in its markets. This comprises a direct relation between performance and costs which enables deriving variables regarding costs from the primary variable sales. This is different in the industry outlying the mechanical engineering sector and subsequent sectors. For example, in an insurance firm, turn over can change almost independently from the cost situation. The term "capacity of production sites" is of central importance in the mechanical engineering sector and does not have its counterpart in the industries in non-productive industries, such as the insurance sector.

These differences in the nature of the business of the mechanical engineering sector and the non-productive industries appear to make the application of the conceptual framework/model in these industries open to question. Therefore, I seek to illuminate to what extent the criteria for testing the applicability of the conceptual framework/model (section 7.3.2 on page 217) in these industries would support its use in this context.

A major aspect of the conceptual framework/model is its performance-orientation. In the mechanical engineering sector this could be related to the primary variable "Sales by product line by Year". Furthermore, the performance-orientated primary variable could be related to derived variables representing the costs and in addition could be connected with other variables of the information categories of the conceptual framework/model. In order to apply the conceptual framework/model in non-productive industries, the identification of a performance-orientated primary variable must be accomplished. A requirement which this identified variable would have to meet is the possibility to derive other variables of the information categories of the conceptual framework/model from it.

The performance orientation leads to the question to what extent the information category 'Margin Accounting' does reflect the markets and industries in which the non-productive organization is acting. If this approach is not existent in the non-productive organisation to an 
acceptable degree, it appears as if the nature of the business of the non-productive organisation and the conceptual framework/model are not comparable enough to support its application in this context.

Regarding the organization build-up it must be ensured that the major competitor's structure can be aligned with the model.

Concerning the data, the non-productive organisation would have to make certain that estimations of the major competitor's performance by product line by year in its own product line structure are available. In addition, information enabling deriving the variables of the other information categories of the conceptual framework/model needs to be available. Furthermore, in case of a more complex organization the respective consolidation logic must be defined separately if it deviates from the model.

If the aforementioned prerequisites for applying the conceptual framework/model in other industries are existent, it needs to be ensured that the processes of evaluation textual information (Figure 55 on page 141) and developing the "Value from Test" (Figure 56 on page 144) are possible to conduct. Based on this, the integration of the strategic level (section 5.4) would be possible.

It appears that the application of the conceptual framework/model in the non-productive industries would have to manage many open issues. However, a group-wide cost accounting system which is in place would support such an endeavour. Further support for the application of the conceptual framework/model in the non-productive industries would be available through the additional flexibility (for example, adding core areas of textual analysis and weighting them) explained in section 6.5.2.8 (starting on page 209).

The discussion of the limitations (section 6.5 starting on page 201) of the conceptual framework also included the discussion regarding the resulting reasonable enhancements (section 6.5.2.7) of the conceptual framework/model and were considered in a revised version in the form of cornerstones (section 6.5.2.8). To what extent these cornerstones would support the applicability of the conceptual framework/model in other industries has been outlined in context of its theoretical generalization in section 7.3 (starting on page 216). In the next section, I aim to supplement more general aspects.

\subsubsection{Overarching aspects}

Based on the outcome of the sections 7.3.3 and 7.3.4, it appears as if theoretical generalization of the conceptual framework/model is possible to conduct in the manufacturing area and difficult to conduct outside the manufacturing industries. In order to 
verify this observation, it would be beneficial to see respective case studies scrutinizing the application of the conceptual framework/model in non-manufacturing industries.

Within the German mechanical engineering sector, theoretical generalization appears to deliver resilient results which encourages applying the conceptual framework/model to other industries of the VDMA (German Association of Mechanical Engineering Companies). In this context, the creation of a respective tool-box for customizing the conceptual/framework to the needs of a particular industry would support an efficient implementation.

So far, theoretical generalization has been conducted for the German mechanical engineering sector. It appears reasonable to scrutinize if this would also be possible for international acting mechanical engineering organizations which are based abroad. The results of a study scrutinizing the applicability of the conceptual framework/model outside the German mechanical engineering sector would potentially enable to learn more about international competition.

In the next section, I aim to focus on the contributions to Theory and Practice made by this project.

\subsection{Contributions to theory and practice}

\subsubsection{Introduction}

The trend of increasing internationalization of business and competition in general and particularly within the German mechanical engineering sector, as one of the country's most important industrial sectors, forms the economical background of this project.

Reflecting on the extent to which my organisation was prepared for this international competitive business environment, I felt in my company and industry the need for having better informed assumptions regarding international competitors' performance.

Looking into the literature, I found confirmed that resilient contributions regarding competitor accounting/analysis from SMA are needed and that management accounting knowledge would support developing this (Roslender \& Hart, 2003). I concluded that applying management accounting knowledge in the context of competitor accounting/analysis would particularly support developing better informed assumptions regarding competitors' performance. Furthermore, I concluded that this approach would support contributions to closing the gap in literature and practice which I seek to illuminate in section 7.4.2. 
Applying management accounting knowledge in the context of competitor accounting/analysis would best be embedded in a conceptual framework which is based on SMA literature. I ascertained that such a conceptual framework in the field of SMA literature is needed but not existent (Nixon \& Burns, 2012a; Nixon \& Burns, 2005). Therefore, I concluded that designing a conceptual framework/model in the context of competitor accounting/analysis would support working on closing the gap in literature and practice identified, which I attempt to outline in section 7.4.3.

The conceptual framework/model developed in this project has been tested in a case study and has led to conclusions regarding its contributions to theory and practice which I aim to delineate in sections 7.4.4 and 7.4.5.

This introductory section will now be followed by the section regarding the gap in theory and practice identified in this project.

\subsubsection{Gap in theory and practice}

In context of Research Question 1/Research Objective 1, I had "to evaluate the relevant literature and information available in the field of strategic management accounting" (Research Objective 1).

SMA literature emphasizes the importance of having resilient assumptions regarding competitors' financial performance which is in line with the increasing performanceorientation of management accounting literature (section 6.3.3 starting on page 182). Management accounting literature ties performance-orientation very closely with margin accounting. The gap identified in SMA literature lies particularly in its missing margin accounting on both the level of single entity and group (Figure 6 on page 56). The conclusion at this point is that utilizing the performance orientation of management accounting's margin accounting in SMA/competitor accounting/analysis would support achieving the aim of having resilient assumptions regarding competitors' performance.

The situation regarding information relating to competitors' performance appears to be better in practice than in theory because there are estimations regarding competitors' "Sales by product line by Year" available in the focus company. However, this information was not processed further in a consistent system because such a system had not been available and thus no verification could be conducted. Furthermore, building up such a system needs to consider the input of staff of the international organisation of the focus company and therefore requires processes to integrate such information. Integrating respective information includes both considering ratios and structures already known in management accounting 
and, for example, textual information which would have to be collected and evaluated in a structure which is identical to the numerical data. The conclusion at this point is that utilizing management accounting knowledge in the context of SMA/competitor accounting/analysis supports achieving the aim of producing resilient assumptions regarding competitors' performance, however, it needs to be supplemented with additional processes in order to consider particularly textual information.

In this section, I tried to outline the gap in theory and practice identified which I seek to lead over into a potential solution in the next section.

\subsubsection{The conceptual framework/model and its performance-orientation}

In context of Research Question 1/Research Objective 1, I managed to identify the literature and information available in the area of SMA which now would have to be processed further within a consistent system.

Textual and numerical data is prepared in terms of identical structures which relates particularly to the market-orientated product lines which are closely related to the structures defined in management accounting's margin accounting and creates at this point a relationship with respective performance-orientated variables (sections 6.3 .3 on page 182 and 7.2.3 on page 215). At the same time the ground is prepared for looking into Research Question 2/Research Objective 2 which focuses on evaluating “...the performance relevant information available in management accounting to assist with competitor accounting in the focus company" (Research Objective 2).

The approach of aligning data with the market-orientated product line structure of margin accounting forms also the first variable of the dimension 'Information Category' of the conceptual framework. The variables of the information categories 'P\&L statement', 'balance sheet' and 'Cash Flow Statement' are derived with a strong impact of the outcome of the primary variable "Sales by product line by Year" which underlines the performanceorientation of the conceptual framework/model. The processes for evaluating textual information (Figure 55 on page 141) and the respective integration of the option "NVivo Sales" into the process of deriving the "Value from Test" could also be incorporated in the conceptual framework/model (sections 6.3 .3 on page 182 and 7.2.3 on page 215). The estimations of the variable "Total Sales" on group level could be tested against the major competitor's published consolidated financial statements with an acceptable deviation. 
The conclusion which can be made in this context relates to the areas of connecting textual and numerical data and to the possibility of developing performance-relevant information regarding the major competitor based on the conceptual framework/model.

Regarding the element of connecting textual and numerical data it can be ascertained, that both kinds of data relate to the same performance- and market-orientated object which is the product line. Therefore, the evaluation of the textual information could be intertwined with the respective numerical data through deriving an initial value (values of $0.8,1.0$ and 1.2) and supplementing it with an impact value derived from the core criteria of textual information (values of $-0.1,0,+0.1$ ). The sum of initial value plus impact value had been multiplied with the "bottom-up estimation of Sales by product line by Year" and been transferred into the process of deriving the "Value from Test". The "Total Sales" across all product lines became the variable "Sales" in the information category "P\&L Statement" basis for deriving further variables. This procedure ensured a clear chain of evidence from the textual information (references in NVivo) via the processes of evaluation (Figure 55 on page 141) and deriving the "Value from Test" (Figure 56 on page 144) into the numerical part of the model in MS Excel. The conclusion which can be drawn from this procedure is that, based on identical structures of textual and numerical data and a common object (in this case "Sales by product line by Year"), the evaluation of the textual information is possible and able to be integrated into the numerical part of the model. Furthermore, it can be concluded that the capability to consider multiple core areas of analysis, the consideration of textual information supports aligning the business environment with the evaluation process.

Concerning the aspect of developing performance-relevant information regarding the major competitor based on the conceptual framework, the strong integration of the primary variable "Sales by product line by Year" supports pursuing this market-orientated impact in the other information categories of the conceptual framework/model as well. For example, employing coverage-based ratios enabled deriving working capital relevant components of the balance sheet. These ratios, in turn, could be linked with the performance-relevant variable "Total Sales" which has also been used in the information category 'P\&L statement'. The components of the information category 'Cash Flow Statement' could entirely be derived based on the information categories 'P\&L statement' and 'balance sheet'. This procedure allowed linking the development of the variables of the information category 'Margin Accounting' with the variables of the other information categories where reasonable based on ratios provided by management accounting. This procedure supported applying the concept 
of performance-orientation in areas which have not been the focus of competitor accounting/analysis so far. The information regarding the major competitor derived from "balance sheet" and "Cash Flow Statement" enables considering the resources which the major competitor needs for delivering the performance it is expected to make. Inconsistencies would become visible through striking ratios. The conclusion which can be drawn at this point is that it is possible to develop values for the variables of the information categories of the conceptual framework which are representing the requirements regarding the financial resources needed for the performance estimated.

In the context of Research Question 3/Research Objective 3, I had "to analyse how a strategic model of competitor accounting can provide information to aid in the creation of competitive advantage" (Research Objective 3). The conceptual framework/model supports achieving this objective through offering two routes which are designed to complement each other (sections 6.4 on page 194 and 7.2.4 on page 216). Firstly, the identification of the major competitor's CSFs and being in the position to make informed assumptions regarding the impact of these CSFs on the variables of the information categories of the conceptual framework and, secondly, the comparison of the model with the major competitor published consolidated financial statement which relates to a more holistic approach. Based on the data available, both routes could be utilized, and the major competitor's communicated strategy be contrasted against the Model and the fragility of Major Competitor's business model could be made transparent to an extent which would not have been possible without the conceptual framework/model. Therefore, the conclusion in this context is that the conceptual framework/model is in the position "to provide information to aid in the creation of competitive advantage" (Research Objective 3).

In this section, I aimed to delineate the conclusions regarding the textual and numerical data utilized and consistently processed in the model. Values for the performance-relevant variables were derived and, based on this, information aiding in the creation of competitive advantage could be provided. In the next section, I strive to focus on the contributions to theory made by this project.

\subsubsection{Contributions to theory}

\subsubsection{Contribution to closing the gap in literature identified}

The conceptual framework/model developed in this project is closely related to the fact that an accepted conceptual framework in the field of SMA literature is needed (Nixon \& Burns, 2012b; Nixon \& Burns, 2005). The understanding of SMA on which the conceptual 
framework/model developed in this project is based on sees SMA “...as an attempt to integrate insights from management accounting and marketing management within a strategic management framework" (Roslender \& Hart, 2003, p. 260).

The term "insights" addressed by Roslender and Hart (2003), regarding the literature, can be related to performance-orientated contributions particularly in the area of group cost accounting which in essence refers to the works of Dusemond (1994), Kajüter (2003) and Rein (1993). Important performance-orientated elements, particularly from the area of consolidated margin accounting, have been transferred into the context of SMA/competitor accounting/analysis and been applied in the conceptual framework/model. The aspect of generalization in this context is considered through applying an existent theory (cost accounting at the group level) in a new context (SMA/competitor accounting) which can be referred to as theoretical generalization (Ryan et al., 2002). These "insights" related to the function of control have been brought together with respective input of the function of marketing/sales which reflects the approach of connecting information and knowledge in a common conceptual framework (Roslender \& Hart, 2003).

The outcome of my literature review (Figure 6 on page 56) is, that there is a lack of respective methods and tools in the area of SMA/competitor accounting/analysis whereas at the same time respective techniques in the area of group cost accounting are available. Based on existing methods described in accounting literature, a model for developing better informed assumptions regarding competitors' performance has been developed. Therefore, this project is a contribution to close the gap identified in the SMA/competitor accounting/analysis literature.

In this section, I aimed to outline the contribution of this project to literature. Within this project, I aimed to emphasize the element of decision usefulness which I strive to illuminate in the next section.

\subsubsection{Contribution to support decision-making in the area of SMA/competitor accounting and analysis}

Lorenz (2015) relates to Johnson and Kaplan (1987) when she emphasizes that a major criticism to which management accounting has been exposed to since the end of the 1980s is that the information provided by management accounting does not support management in decision-making sufficiently.

Almost in the same period, the development of cost accounting systems focused on increasing decision usefulness (Figure 16 on page 86). Through transferring important 
elements of the respective approaches of cost accounting/management accounting into SMA/competitor accounting/analysis the tool for improving decision usefulness in this area is available.

The conceptual framework/model is capable to consider different areas of textual analysis in the development of its primary variables. This, in turn, provides the possibility to include multiple core areas of textual analysis which the functions working on the model deem as decision-relevant can be considered in the evaluation process (Figure 55 on page 141) and the process of deriving the "Value from Test" (Figure 56 on page 144). The resilience of the values of the variables developed on the basis of the conceptual framework/model are tested at several points in the processes and the model. This approach is in line with the position that resilient contributions from SMA are needed and that management accounting knowledge would support developing this (Roslender \& Hart, 2003).

The conceptual framework/model suggested in this project contributes to theory based on the consideration of tools which support improving decision-usefulness, the capability to include multiple areas which appear decision-relevant and applying ways of testing the processes at several points.

In this section, I attempted to outline the contribution of the conceptual framework/model in the area of improving the decision usefulness of SMA/competitor accounting/analysis. In the next section, I aim to delineate the contribution of the conceptual framework/model in the area of approaches of testing in the context with competitor accounting/analysis.

\subsubsection{Providing an approach for test and verification in competitor accounting/analysis}

The requirements regarding what information SMA/competitor accounting/analysis should be able to produce would benefit from being more precise than for example "...profitable and balanced portfolios..." (Rothschild, 1979, p. 26) which presumably relates to margin accounting. In addition, more advice regarding how to test/validate the estimations produced would be beneficial.

In this context, the conceptual framework/model suggested in this project offers to contributions which can complement each other.

Firstly, the estimations produced by the model for the forecast year (in the case study: 2013) could be compared with competitors' respective actual figures at least at the group level if published consolidated financial statements are available. This comparison can be supplemented by comparisons for the years observed. Based on the information produced, a 
variance analysis according to management accounting logic can be conducted and supplemented with additional analysis of textual information which is available in the structure of the numerical data. In addition, textual information can be traced back to the original reference and source document. This provides the possibility of conducting in-depth analysis.

Secondly, the conceptual framework/model provides the possibility of testing it in strategic contexts. For example, it can be tested if the conceptual framework/model would have supported a certain decision which the major competitor communicated in in published consolidated financial statements (for example, acquisitions). This, in turn, supports achieving competitive advantage because the conceptual framework/model would in such a constellation be able to make informed assumptions regarding the major competitor's strategic moves.

In this section, I have outlined how the conceptual framework/model contributes to theory through providing procedures of testing and validating including the level of strategic decision-making.

This section closes the area of contributions to theory and will be followed by respective managerial implications which I strive to outline in the next section.

\subsubsection{Managerial implications}

\subsubsection{Utilizing knowledge of the international organization}

The focus company and its major competitor are internationally operating industrial organizations with respective international structures. In order to be close to the requirements of the local markets, the respective knowledge regarding local markets needs to be present in the local regional organization whereas corporate functions are organized centrally.

The knowledge existing in the functions of marketing and control is also present in both the central and regional part of the organization. Regarding the function of marketing, a close collaboration between corporate and local organization ensures that the implementation of strategies is based on international coordination conjoined with the expertise of the local markets. Concerning the function of control, a similar approach enables both local and corporate reporting requirements to be met.

Connecting this organizational set-up with the approach of Roslender and Hart (2003, p. 260) to look at SMA “... as an attempt to integrate insights from management accounting and 
marketing management within a strategic management framework" has managerial implications regarding the utilization of knowledge of the international organizations.

Relating the aspect of knowledge in the international organisation to the conceptual framework/model developed in this project, one experience gained was that it appears beneficial to offer flexible ways of exchange of information to the local staff. For example, giving room for making comments or explanations enabled to achieve both, giving local staff the room they find appropriate and the possibility for the corporate functions to ask further questions and thus increase their understanding of the local markets. The use of textual information in the context of reporting is supported by literature (Ernstberger et al., 2017; Feldman et al., 2010; Guay et al., 2016). Furthermore, the integration of knowledge of both functions could be conducted on one reporting platform and could be incorporated in the conceptual framework/model which is in line with Roslender and Hart (2003) and Hossain et al. (2011). In addition, the conceptual framework/model could be developed towards considering the knowledge of more functions of the organisation, which is supported by Mohamed and Jones (2014) and Roslender and Wilson (2012).

In this section, I aimed to illuminate the managerial implications of using knowledge available in the international organisation in the context of SMA/competitor accounting/analysis and the conceptual framework/model. The adequate use of the knowledge of the international organisation needs now to be focused on performancerelevant information which I seek to do in the next section.

\subsubsection{Identifying performance-relevant information}

The importance of having resilient assumptions regarding competitors' financial performance has been addressed by, for example, Cadez and Guilding (2012). In the context of the conceptual framework/model this requirement has managerial implications.

The conceptual framework/model foresees in the process of evaluating textual information (Figure 55 on page 141) the definition of core areas of textual analysis which subsequently are transferred to the process of deriving the "Value from Test" (Figure 56 on page 144) as the option "NVivo Sales".

This offers management at the group level the choice to give guidance regarding what core areas of textual analysis should be considered and with what weight. This could then be aligned with management at the local level. Furthermore, management at the group level has the possibility to define if more functions of the organization need to be considered in the design of the conceptual framework/model in order to support the performance-orientation. 
Concerning the aspect of considering CSFs according to Bullen and Rockart (1981), management at the group level has the possibility to give guidance on what CSFs from the group point of view need to be considered and to align this with management at the local level. Within the conceptual framework/model, this would then be an additional way to aid in the creation of competitive advantage.

In this section, I have outlined how management at the group level could give guidance regarding the basic parameters of the processes of the identification of performance-relevant information. In the next section, I aim to delineate organizational implication.

\subsubsection{Organizational implications}

In addition to the considerations regarding the utilization of knowledge and the identification of relevant data, the ground for a respective collaboration needs to be prepared and contains organizational implications.

The conceptual framework/model has been developed from the perspective of management accounting which is reflected in its dimensions 'Information Category' and 'Consolidation Hierarchy'. This leads to the aspect of the role of management accountants in the organisation.

According to Coad (1999) and Wolf et al. (2015), management accountants have increasingly taken the role as business partners of management in decision-making processes. This understanding of the role of management accountants requires involvement in respective discussions in the organisation which enables building a common basis of knowledge and exchange of information which supports designing the conceptual framework/model across functions (Mohamed \& Jones, 2014). The managerial implication in this context lies in preparing the ground for a respective organizational environment.

In this section, I aimed to delineate the organizational set-up in which the conceptual framework/model could be embedded, and which potentially can contribute to closing the gap in competitor accounting/analysis which I seek to focus on in the next section.

\subsubsection{Closing the gap in competitor accounting/analysis}

The contributions regarding the aspect of closing the gap identified in literature (Figure 6) has been dealt with in section 7.4.4.1 (on page 227). In this section, I aim to outline the managerial implications regarding the point of closing the gap in competitor accounting/analysis. 
Closing the gap in literature (Figure 6 on page 56) focused on transferring performanceorientated contributions particularly from the area of group cost accounting/margin accounting into the field of competitor accounting/analysis (section 7.4.4.1). The managerial implication in this context would be to execute this this step of transferring knowledge from the area of group cost accounting/management accounting into competitor accounting/analysis in practice as well. The conceptual framework/model contributes to closing the gap in competitor accounting/analysis through providing both the theoretical foundation and the application in practice.

In this section, I aimed to outline the contribution the conceptual framework/model made to closing the gap in competitor accounting/analysis in practice which prepares the ground for illuminating the contribution towards achieving competitive advantage which I seek to conduct in the next section.

\subsubsection{Competitive advantage and potential future growth}

The conceptual framework/model is designed to aid in the creation of competitive advantage through two routes which are designed to complement each other. Firstly, it supports the identification of CSFs according to Bullen and Rockart (1981) and, secondly, it enables contrasting the values of the major competitor's performance-relevant variables with the communicated strategy.

Based on the information produced by the conceptual framework/model, the organisation has now better-informed assumptions regarding the major competitor's performance available. Furthermore, contrasting the model with communicated strategy enables the unfolding of strong and weak areas in the major competitor's prospective performance. In conjunction with the consideration of the major competitor's CSFs, a precise picture of the major competitor's possibilities to realize his communicated strategy can be developed based on the conceptual framework/model.

The managerial implication in this context lies in taking advantage of this information in order to identify potential strategies to counteract the major competitor's next strategic move and to prepare the ground for developing risk-compensating business and thus support safeguarding of potential future growth. The contribution of the conceptual framework/model lies in aiding in the creation of competitive advantage.

This section closes the field of managerial implications of the conceptual framework/model. In the next section, I seek to illuminate general research limitations related to this project. 


\subsection{General research limitations}

\subsubsection{Overview}

In context of the discussion and analysis of findings (Chapter 6 starting on page 174), I have outlined the research limitations relating to the conceptual framework/model in section 6.5 (starting on page 201). This now needs to be complemented by more general research limitations.

I will start this part with general limitations relating to access to internal data.

\subsubsection{Access to internal data}

This project is based on the use of textual and numerical data which is identically structured and then connected based on consistent processes. Since the share of internal data is higher than the share of external data, access to the former is essential for conducting a such project. It appears open to question whether such a project would have been possible to conduct without the involvement of a member of the organisation of the focus company. This aspect leads to the next general research limitation.

\subsubsection{Access to tacit and explicit knowledge}

In this project, tacit and explicit knowledge was of essential importance. This relates to both knowledge in the sector of marketing/sales and management accounting.

Regarding marketing/sales, this project would not have been possible without the knowledge of the international colleagues in the area marketing/sales which has found its way into internal documents such as, for example, monthly comments. Also, the knowledge in the domain of consolidated management accounting was of central importance for this project.

On a more general level, tacit knowledge (particularly in the field of international marketing/sales relating to markets, applications and regional specifics) was indispensable for this project. In relation to consolidated management accounting, it appears that this is basically explicit knowledge but needs to be connected with the respective businesses in which it is applied. This point leads to the aspect of the tools processing the data which has been generated based on the knowledge outlined in this section.

\subsubsection{Availability and knowledge of respective software}

The nature and the amount of the data used in this project requires the use of software. As illustrated in Figure 22 (on page 102) more than c. 2000 pdf-file have been coded in more than 43000 references and thereafter, through respective queries, has been transported into 
Excel and processed further. This required the researcher to be able to employ NVivo and MS Excel on an advanced level.

The communication in international projects is in English. Therefore, it is essential that, besides the knowledge regarding the software, the researcher must be in the position to speak English at an advanced level. In addition, access to colleagues who speak English and a respective other local language must be available for translation needs.

This section closes the remarks regarding limitations and will be followed by the potential foci of future research.

\subsection{Future research}

\subsubsection{Overview}

Firstly, I seek to illuminate areas of future research regarding the mechanics of connecting textual and numerical data because it supports developing the contents of the subsequent sections.

The integration of other functions of the organisation of the focus company into the conceptual framework/model would necessarily increase its complexity regarding the mechanics employed and in addition produce information which supports competitor accounting/analysis and build a respective range of topics for future research.

An additional area of future research is the allowance of the perspective of customers in the conceptual framework/model which needs to consider how the mechanics of connecting textual and numerical data have to be enhanced and how the information generated can be used for competitor accounting/analysis.

The conceptual framework/model seeks through its dimensions 'Information Category' and 'Consolidation Hierarchy' to provide a platform for collaboration between the functions of control and marketing in the context of competitor accounting/analysis. The related requirements regarding the role of management accountants forms the range of topics to be illuminated in this context of future research.

I seek to start the discussion with the considerations regarding the mechanics of connecting textual and numerical information.

\subsubsection{Connecting performance-relevant textual and numerical information}

This section deals with areas of evaluation of textual information (section 6.5.2.1 starting on page 201) and the development of the "Value from Test" (section 6.5.2.2 starting on page 203). 
Regarding the evaluation of textual data, the core areas of analysis of textual information (in this project "Comparisons vs. MC and FA", "Incidents" and "Strategic match") represent a basic element of this project inasmuch they define what contents impacts the "NVivo related Sales". This process focuses on the performance-orientation of the primary variable "Sales by Product by Year" and has been aligned with the concept of CSFs according to Bullen and Rockart (1981). The limitation ascertained lies in the number of three core areas of textual analysis which in case of more performance-relevant core areas would lead to the situation that the model would not consider these. Furthermore, the model does not work with weights for these core areas of textual analysis. In addition, the model works with relationships/ratios to calculate the values of the derived variables which in case of imprecise ratios could limit the informative value of the derived variables. Also, regarding the evaluation of textual information, increments of 0.1 potentially lead to striking corridors of plausible values.

Future research could focus on the identification of more performance-relevant core areas of textual information within the perspectives to be considered. In conjunction with the consideration of respective weights, this potentially could support the applicability of the conceptual framework/model in other industries. Furthermore, the information produced by the model could support learning more about the major competitor's performance and CSFs according to Bullen and Rockart (1981).

Another area of future research could be to create further processes of developing the "Value from Test" (Figure 56 on page 144). This would support the use of more than one primary variable because for each additional primary variable a separate process of developing the "Value from Test" could be applied. This, in turn, would require scrutinizing what ratios have to be used in order to develop the derived variables. Furthermore, depending on the kind of primary variables added, the respective consideration in the model would have to be adjusted. The consideration of more than one primary variable and respective additional processes of developing the "Value from Test" could be organized in a modular manner which would lead to a system of developing "Values from Test" which are interlaced and thus would enable reflecting dependencies between each other.

In the next section, I aim to focus on the aspect of integrating the input of other functions in the conceptual framework/model. 


\subsubsection{Integrating other functions of the organization into the conceptual framework/model}

The conceptual framework/model considers in its current version an interface between the functions of marketing and control which has been identified as a potential limitation (section 6.5.2.3 starting on page 203) and a respective enhancement of this has been outlined in section 6.5.2.7 (starting on page 207).

Considering the input of other functions of the focus company into the conceptual framework/model relates to the notion that fast-changing developments of trends in the markets as well as changes in the respective technologies could be reflected through, for example, an interface between the functions of marketing/sales and R\&D.

Future research could focus on the implications and benefits that considering additional interfaces in the conceptual framework/model would have (Figure 55 on page 141 and Figure 56 on page 144). For example, would it make sense to include additional core areas of textual information for the function of $R \& D$ and what processes of evaluation of textual information (Figure 55) would it be necessary to establish? Or in the case where the function of R\&D is the driver regarding specific technologies and creating trends in the markets, would it be beneficial for the conceptual framework/model to establish separate primary variables to make the impact in competitor accounting/analysis more visible? Dealing with questions of adding input of other functions of the organisation of the focus company would be supported by a modular build-up of the processes of evaluation of textual information (Figure 55) and the development of the "Value from Test" (Figure 56), as outlined in the previous section, and would enhance the flexibility of the conceptual framework/the model as delineated in section 6.5.2.7 (starting on page 207).

In the next section, I seek to focus on the point of incorporating the perspective of customers in the conceptual framework/model.

\subsubsection{Designing the perspective of customers}

The conceptual framework/model would benefit from considering the perspective of customers as this would support verifying to what extent the major competitor's communicated strategy can be aligned with customers' requirements. This aspect has been identified as a limitation (section 6.5.2.4 starting on page 204) and a respective enhancement of the conceptual framework/model has been delineated in section 6.5.2.7 (starting on page 207). 
Future research could scrutinize how the perspective of customers could be generated out of data already available and new data retrieved, for example, from customers' publications. A verification of the major competitor's communicated strategy relating particularly to pricing could be aligned with customers' requirements regarding for example, support to ensure stable processes or offering technological knowledge for improvements. Designing the perspective of customers could also necessitate introducing additional core areas of textual analysis (Figure 55 on page 141) and respective development of "Values from Test" (Figure 56 on page 144). The use of a modular system of these processes as outlined in section 7.6.2 (on page 235), would provide flexibility to consider respective enhancements of the conceptual framework/model.

In the next section, I seek to illuminate potential topics of future research regarding the role of management accountants in the context of competitor accounting/analysis.

\subsubsection{Defining management accountants' role in the context of competitor accounting/analysis}

To what extent the conceptual framework/model can be utilized is not merely dependant on the data available and the processes applied. The benefit that could be achieved for the organization in the area of competitor accounting/analysis is strongly related to the role of management accountants in the organization and to their ability to adopt a holistic view on business which has been identified as a potential limitation in section 6.5.2.5 (starting on page 205). In addition, current management accounting education programmes appear not to be based on a holistic view on business as they focus on offering courses conveying specialist knowledge. Therefore, future research could focus on how current management accounting education can be developed towards emphasizing the "eagle perspective" in strategic contexts and particularly in connection with competitor accounting/analysis. This would coincide with the approach of the conceptual framework/model to identify strategic topics and the major competitor's CSFs within complex structures across all its dimensions and be in alignment with the role of management accountants as business partners of management in decisionmaking processes (Coad, 1999; Wolf et al., 2015).

Another area of future research could be how the processes related to the conceptual framework/model can be conducted to achieve both getting better informed assumptions regarding the major competitor's performance based on the knowledge of the staff of the focus company in the local markets and avoiding potential conflicts of interest (section 6.5.2.6 starting on page 206). These conflicts can potentially occur in the context of the 
annual budget process and can lead to too low estimations of the major competitor's "Sales by product line by Year". The challenge for future research would be to suggest processes to avoid this limitation.

This section closes the discussion regarding topics for future research. In the next section, I aim to summarize this chapter.

\subsection{Summary of chapter and concluding remarks}

\subsubsection{Summary of chapter}

In section 7.2 (starting on page 213), a critical evaluation of the conceptual framework/model has been conducted by the Research Questions regarding both the level of this project and on the more general level. It can be ascertained that the Research Questions could be answered at the level of this project and under what pre-conditions this would be possible on a more general level.

Regarding the discussion of generalization, the application of theoretical generalization in the context of case study method has been conducted in section 7.3.1 (on page 216). Theoretical generalization is based on the application of the findings of the case study in other contexts which in this project relates primarily to other industries. The application of the case study findings in the mechanical engineering sector in Germany and abroad appears to be feasible (section 7.3.3 on page 219) whereas the application in the non-productive sector seems to be not appropriate (section 7.3.4 on page 221).

The contributions to theory and practice have been outlined in section 7.4 (starting on page 223) which emphasized the aspects of decision usefulness (section 7.4.4.2 on page 228) and regarding the managerial implications, particularly the support in the creation of competitive advantage (section 7.4.5.5 on page 233).

The conclusions related to future research have been derived from the discussions regarding the limitations of the conceptual framework/model (sections 6.5.2.1 on page 201 to 6.5.2.6 on page 206), its potential enhancements (section 6.5.2.7 on page 207) and resulting cornerstones of a revised version (section 6.5.2.8 on page 209). The topics for future research resulting from this project could be improving the connection between performance-relevant textual and numerical information (section 7.6.2 on page 235), enhancing the view on the major competitor's performance through integrating the input of other functions of the organisation of the focus company (section 7.6.3 on page 237) and customers' perspective (section 7.6.4 on page 237) and also designing the role of management accountants in the 
context of competitor accounting/analysis (section 7.6.5 on page 238) as business partners of management in strategic decision-making.

The next section contains concluding remarks on this project.

\subsubsection{Concluding remarks}

This study's background is the German mechanical engineering sector and its international competition. In this context, I felt the need for having better informed assumptions regarding international competitors' performance.

Respective resilient contributions regarding assumptions concerning competitions' financial performance are needed (Roslender \& Hart, 2003). The application of existing knowledge in the field of group cost accounting/management accounting in the context of SMA/competitor accounting/analysis forms the basis of the conceptual framework/model developed in this project and contributes to filling the gap in theory and practice identified.

The contribution made in this project referring to theory focuses on closing the gap identified in SMA/competitor accounting/analysis caused through missing guidance regarding developing informed assumptions regarding competitions' performance consistently due to a missing common strategic framework. In this context, respective elements of group cost accounting/management accounting have been transferred into the context of SMA/competitor accounting/analysis which contributed to improving the aspect of decision usefulness in SMA/competitor accounting/analysis. Furthermore, approaches of testing and verification of the outcome of the model have been provided whereas respective contributions are not available in the literature to date.

The contribution made to practice/the managerial implications focus on utilizing the knowledge existing in the international organization and identifying performance-relevant information. An endeavour like this benefits from an understanding of the role of management accountants as business partners of management in decision-making processes and supports the process of transferring knowledge of group cost accounting/management accounting into SMA/competitor accounting/analysis which contributes to closing the gap in this area.

The conceptual framework/model is designed to support in the area of SMA/competitor accounting/analysis and respective strategic decision-making in the area of both theory and practice. Regarding theory, a set of tools has been provided which enables definition of a set of boundaries in order to manage such a complex project containing potential to study more in the field of SMA/competitor accounting/analysis. Concerning practice, the application of 
the conceptual framework/model potentially supports safeguarding future growth which aids in the creation of competitive advantage. 


\section{References}

Abad, C., Laffarga, J., García-Borbolla, A., Larrán, M., Piñero, J. M., \& Garrod, N. (2000). An Evaluation of the Value Relevance of Consolidated versus Unconsolidated Accounting Information: Evidence from Quoted Spanish Firms. Journal of International Financial Management \& Accounting, 11(3), 156-177.

Abdel-Kader, M. G. (2011). Preface. In M. G. Abdel-Kader (Ed.), Review of Management Accounting Research (pp. Xii-XiV). London: Palgrave Macmillan.

Abdel Al, S. F., \& McLellan, J. D. (2013). Strategy and Management Accounting Practices Alignment and Its Effect on Organizational Performance. Journal of Accounting, Business \& Management, 20(1), 1-27.

Ahrens, T. (2008). Overcoming the subjective-objective divide in interpretive management accounting research, Editorial. Accounting, Organizations \& Society, pp. 292-297. Retrieved from http://search.ebscohost.com/login.aspx?direct=true \&db=bth\&AN=28071761\&site=eh ost-live

Ahrens, T., \& Chapman, C. S. (1999). The role of Management Accountants in Britain and Germany. Management Accounting: Magazine for Chartered Management Accountants, 77(5), 42.

Ahrens, T., \& Chapman, C. S. (2000). Occupational identity of management accountants in Britain and Germany. European Accounting Review, 9(4), 477-498. doi:10.1080/09638180020024070

Alam, S. (2016). Strategic Performance Measurement of Beximco Pharmaceuticals Limited with compare to Square Pharmaceuticals Limited: An Application of CORE Analysis. The Cost and Management, 44(2), 3-11.

Albayrak, T. (2015). Importance Performance Competitor Analysis (IPCA): A study of hospitality companies. International Journal of Hospitality Management, 48, 135142. doi:10.1016/j.ijhm.2015.04.013

Amit, R., Domowitz, I., \& Fershtman, C. (1988). Thinking one step ahead: The Use of Conjectures in Competitor Analysis. Strategic Management Journal, 9(5), 431-442.

Aver, B., \& Cadez, S. (2009). Management accountants' participation in strategic management processes: A cross-industry comparison. Journal for East European Management Studies, 14(3), 310-322. 
Babińska, D. (2013). The Role of Knowledge in the Internationalization Process of Firms - A Review of selected Research Literature. Journal of Economics \& Management(14), 920.

Bader, B., Berg, N., \& Holtbrügge, D. (2015). Expatriate performance in terrorismendangered countries: The role of family and organizational support. International Business Review, 24(5), 849-860. doi:10.1016/j.ibusrev.2015.03.005

Baird, M. (2004). Comparing Cases: studies of commitment systems in Australia and the United States. The International Journal of Human Resource Management, 15(3), 433-440.

Bedford, N. M., \& Baladouni, V. (1962). A communication theory approach to accountancy. The Accounting Review, 37(4), 650-659.

Bee-Lan, O. O., Drew, D. S., \& Runeson, G. (2010). Competitor analysis in construction bidding. Construction Management \& Economics, 28(12), 1321-1329. doi:10.1080/01446193.2010.520721

Beißel, J., \& Steinke, K.-H. (2004). Integriertes Reporting unter IFRS bei der Lufthansa. IFRS und Controlling, 63-70.

Belkaoui, A. (1980). The Interprofessional Linguistic Communication of Accounting Concepts: An Experiment in Sociolinguistic. Journal of Accounting Research, 18(2), 362-374.

Bhimani, A., \& Bromwich, M. (2010). Management Accounting : Retrospect and Prospect. Amsterdam: CIMA/Elsevier.

Bhimani, A., \& Langfield-Smith, K. (2007). Structure, formality and the importance of financial and non-financial information in strategy development and implementation. Management Accounting Research, 18(1), 3-31. doi: http://dx.doi.org/10.1016/j.mar.2006.06.005

Bhimani, A., \& Roberts, H. (2004). Management accounting and knowledge management: in search of intelligibility. Management Accounting Research, 15(1), 1-4.

Bierich, M. (1990). Kosten- und Erlösaspekte eines internationalen Fertigungs- und Entwicklungsverbundes. In R. Steffen \& R. Wartmann (Eds.), Kosten und Erlöse (pp. 3-19). Stuttgart: Schäffer Verl. für Wirtschaft und Steuern.

Birkett, W. P. (1998). Management accounting in Europe: a view from down-under. Management Accounting Research, 9(4), 485-494. 
Blödorn, N. (1998a). Die Organisation der Multinationalen Unternehmung. In S. G. Schoppe \& N. Blödorn (Eds.), Kompendium der internationalen Betriebswirtschaftslehre (pp. 281-294). München, Wien Oldenbourg.

Blödorn, N. (1998b). Internationales Controlling: Die ergebnisorientierte Steuerung von Geschäftsbereichen einer Multinationalen Unternehmung. In S. G. Schoppe \& N. Blödorn (Eds.), Kompendium der internationalen Betriebswirtschaftslehre (4., völlig überarb. Aufl. ed., pp. 295-364). München, Wien Oldenbourg.

Bloodgood, J. M., \& Bauerschmidt, A. (2002). Competitive Analysis: Do Managers Accurately Compare Their Firms To Competitors? Journal of Managerial Issues, 14(4), 418.

Boland Jr, R. J., \& Pondy, L. R. (1981). Accounting in Organizations: A Union of Natural and Rational Perspectives. In U. o. I. a. Urbana-Champaign (Ed.).

Bon, A. T., \& Kee, T. S. (2015, 3-5 March 2015). Implementation of Lean manufacturing for productivity improvement in Malaysia. Paper presented at the 2015 International Conference on Industrial Engineering and Operations Management (IEOM).

Bratten, B., Choudhary, P., \& Schipper, K. (2013). Evidence that Market Participants Assess Recognized and Disclosed Items Similarly when Reliability is Not an Issue. Accounting Review, 88(4), 1179-1210. doi:10.2308/accr-50421

Broadbent, M., \& Cullen, J. (2003). Managing Financial Resources. Oxford: ButterworthHeinemann.

Brock, J. J. (1984). Competitor Analysis: Some Practical Approaches. Industrial Marketing Management, 13(4), 225-231.

Bromwich, M. (1989). Management accounting evolution not revolution (1. publ. ed.). London: Chartered Institute of Management Accountants.

Bromwich, M. (1990). The Case for Strategic Management Accounting: The Role of Accounting Information for Strategy in competitive Markets. Accounting, Organizations \& Society, 15(1/2), 27-46.

Bromwich, M., \& Bhimani, A. (1994). Management accounting: Pathways to progress (Reprinted. ed.). London: Chartered Inst. of Management Accountants.

Brown, S. V., \& Tucker, J. W. (2011). Large-Sample Evidence on Firms' Year-over-Year MD\&A Modifications. Journal of Accounting Research, 49(2), 309-346. doi:10.1111/j.1475-679X.2010.00396.X 
Brutscher, P., Raschen, M., Schwartz, M., \& Zimmermann, V. (2012) KfW Economic Research Studien und Materialien. Internationalisierung im deutschen Mittelstand Step by Step zum Global Player -. Frankfurt am Main: KfW Bankengruppe.

Bryman, A., \& Bell, E. (2011). Business research methods (3rd ed. ed.). Oxford: Oxford University Press.

Bullen, C. V., \& Rockart, J. F. (1981). A primor on critical success factors. In C. f. I. S. Research, S. S. o. Management, \& M. I. o. Technology (Eds.), (pp. 1-75).

Burchell, S. C., Clubb, A. G., \& Hopwood, J. H. a. J. N. (1980). The Roles of Accounting in Organizations and Society. Accounting, Organizations \& Society, 1, 5-27.

Burns, J., \& Nixon, B. (2009). Special Issue of Management Accounting Research on Strategic Management Accounting. Management Accounting Research, 20(3), 222223. doi:10.1016/j.mar.2009.05.001

Burns, J., \& Vaivio, J. (2001). Management accounting change. Management Accounting Research, 12, 389-402.

Burrell, G., \& Morgan, G. (1979). Sociological paradigms and organisational analysis : elements of the sociology of corporate life. London: Heinemann Educational.

Busco, C., Frigo, M. L., Giovannoni, E., Riccaboni, A., \& Scapens, R. W. (2006). Integrating global Organizations through Performance Measurement Systems. Strategic Finance, 87(7), 30-35.

Cadez, S., \& Guilding, C. (2008). An exploratory investigation of an integrated contingency model of strategic management accounting. Accounting, Organizations \& Society, 33(7/8), 836-863. doi:10.1016/j.aos.2008.01.003

Cadez, S., \& Guilding, C. (2012). Strategy, strategic management accounting and performance: a configurational analysis. Industrial Management \& Data Systems, 112(3), 484-501. doi:10.1108/02635571211210086

Canale, D., \& Tuzet, G. (2005). Interpretive Scorekeeping. Analisti e dritto, 81-97.

Chakravarty, B. S. (1981). Managing Coal: A Challenge in Adaption. Albany, New York: Suny Press.

Chapman, C. S., Hopwood, A. G., \& Michael, D. S. (2006). Preface. In C. S. Chapman, A. G. Hopwood, \& D. S. Michael (Eds.), Handbooks of Management Accounting Research (Vol. Volume 1, pp. ix-xi): Elsevier.

Chapman, C. S., Hopwood, A. G., \& Shields, M. D. (2007). Preface. In C. S. Chapman, A. G. Hopwood, \& M. D. Shields (Eds.), Handbook of Management Accounting Research (Vol. 2, pp. Xi-Xiii). London: Elsevier. 
Chen, M.-J. (1996). Competitor Analysis and Interfirm Rivalry: Toward a theoretical Integration. Academy of Management Review, 21(1), 100-134. doi:10.5465/AMR.1996.9602161567

Chenhall, R. H., \& Langfield-Smith, K. (1998). Adoption and benefits of management accounting practices: an Australian study. Management Accounting Research, 9(1), 119.

Chow, C. M. (2011). Learning from Our Global Competitors: A Comparative Analysis of Science, Technology, Engineering and Mathematics (STEM) Education Pipelines in the United States, Mainland China and Taiwan. ProQuest LLC. Retrieved from http://search.ebscohost.com/login.aspx?direct=true\&db=eric\&AN=ED534335\&site=e host-live \&scope $=$ site http://gateway.proquest.com/openurl?url_ver=Z39.882004\&rft_val_fmt=info:ofi/fmt:kev:mtx:dissertation\&res_dat=xri:pqdiss\&rft_dat=xri: pqdiss:3477870 Available from EBSCOhost eric database.

Chua, W. F. (1986). Radical Developments in Accounting Thought. Accounting Review, 61(4), 601-632.

Clarke, P. J. (1995). The old and the new in management accounting. Management Accounting: Magazine for Chartered Management Accountants, 73(6), 46.

Clarke, P. J., \& Tagoe, N. (2002). Strategic Management Accounting--Do we need it? Accountancy Ireland, 34(6), 10.

Clinton, D. B., \& White, L. R. (2012). The Role of the Management Accountant: 2003-2012. Management Accounting Quarterly, 14(1), 40-74.

Clor-Proell, S. M., \& Maines, L. A. (2014). The Impact of Recognition Versus Disclosure on Financial Information: A Preparer's Perspective. Journal of Accounting Research, 52(3), 671-701. doi:10.1111/1475-679X.12053

Coad, A. F. (1999). Some survey evidence on the learning and performance orientations of management accountants. Management Accounting Research, 10(2), 109-135.

Coenenberg, A. G. (2005). Jahresabschluss und Jahresabschlussanalyse: Betriebswirtschaftliche, handelsrechtliche, steuerrechtliche und internationale Grundsätze - HGB, IFRS und US-GAAP: Schäffer-Poeschel.

Cooper, D. J. (1981). A social and organizational view of management accounting. In M. Bromwich \& A. G. Hopwood (Eds.), Essays in British Accounting Research. London: Pitmann.

Coopers and Lybrand. (1994). Marketing at the Crossroads. London. 
Cravens, K. S., \& Guilding, C. (2001). An Empirical Study of the Application of Strategic Management Accounting Techniques. In J. E. Lee \& M. J. Epstein (Eds.), Advances in Management Accounting (Vol. 10, pp. 95-124).

Dahms, S., \& Siemes, A. (2005). Strategisches Controlling im Mittelstand: - Empirische Erkenntnisse und Hilfestellung (MinD). Controller-Magazin, 30(3), 227-234.

Davis, L. N., \& Meyer, K. E. (2004). Subsidiary research and development, and the local environment. International Business Review, 13(3), 359. doi:10.1016/j.ibusrev.2003.06.003

Dictionary, B. B. L.-B. M. (2007). competitor analysis (pp. 1750-1750): A\&C Black Publishers Ltd.

Digman, L. A. (1999). Strategic Management: Concepts, Processes, Decisions. Houston, Texas: Dame Publications.

DIHK Bereich Wirtschaftspolitik, M., Innovation - Bereich International, AHK. (2011). Auslandsinvestitionen in der Industrie - Ergebnisse der DIHK-Umfrage bei den Industrie- und Handelskammern. In M. DIHK Bereich Wirtschaftspolitik, Innovation - Bereich International, AHK (Ed.). Berlin: Deutscher Industrie- und Handelskammertag (DIHK).

Dixon, R. (1998). Accounting for strategic management: A practical application. Long Range Planning, 31(2), 272-279.

Dominica Suk-yee, L. (2005). The Impact of the Big 8 Mergers on Market Power: Evidence from the Hong Kong Market. Journal of International Financial Management \& Accounting, 16(1), 69-96. doi:10.1111/j.1467-646X.2005.00112.x

Doupnik, T. S., \& Richter, M. (2004). The Impact of Culture on the Interpretation of "In Context" Verbal Probaliity Expressions. Journal of international Accounting Research, 3(1), 1-20.

Durocher, S., \& Gendron, Y. (2011). IFRS: On the Docility of Sophisticated Users in Preserving the Ideal of Comparability. European Accounting Review, 20(2), 233-262.

Dusemond, M. (1994). Die Konzernanschaffungs- und Konzernherstellungskosten nach $\S$ 304 HGB: Ermittlung, Bewertung sowie Informationsbeschaffung auf der Grundlage einer eigenständigen Konzernkostenrechnung. Stuttgart: Schäffer-Poeschel.

Earl, M. J., \& Hopwood, A. G. (1979). From management information to information management. Paper to IFIP Working Conference on the Information Systems Environment. Bonn. 
Easterby-Smith, M., Thorpe, R., \& Jackson, P. (2008). Management research (3rd ed. ed.). London: SAGE.

Eccles, R. G. (1991). The Performance Measurement Manifesto. Harvard Business Review, 69(1), 131-137.

Edhlund, B. M., \& McDougall, A. G. (2016). NVivo Essentials. Stallarholmen, Sweden: Form \& Kunskap AB.

Eisenhardt, K. M. (1989). Building Theory from Case Study Research. Academy of Management Review, 14(4), 532-550.

Erben, R. F. (2002). E-controlling: Ten Challenges for Controlling and Management Accounting. Journal of Corporate Accounting \& Finance (Wiley), 13(5), 55-62.

Ernstberger, J., Link, B., Stich, M., \& Vogler, O. (2017). The Real Effects of Mandatory Quarterly Reporting. Accounting Review, 92(5), 33-60. doi:10.2308/accr-51705

Evans, L. (2004). Language, translation and the problem of international accounting communication. Accounting, Auditing \& Accountability Journal, 17(2), 210-248.

Evans, L. (2010). Observations on the Changing Language of Accounting. Accounting History, 15(4), 439-462.

Ewert, R., \& Ernst, C. (1999). Target costing, co-ordination and strategic cost management. European Accounting Review, 8(1), 23-49. doi:10.1080/096381899336131

Ewert, R., \& Wagenhofer, A. (2007). Management Accounting Theory and Practice in German-Speaking Countries. In C. S. Chapman, A. G. Hopwood, \& M. D. Shields (Eds.), Handbook of Management Accounting Research (Vol. 2, pp. 1035-1070). London: Elsevier.

Fahey, L. (2002). Invented competitors: a new competitor analysis methodology. Strategy \& Leadership, 30(6), 5.

Farquhar, J. D. (2012). Case study research for business. London: SAGE.

Feldman, R., Govindaraj, S., Livnat, J., \& Segal, B. (2010). Management's tone change, post earnings announcement drift and accruals. Review of Accounting Studies, 15(4), 915953. doi:10.1007/s11142-009-9111-x

Fetscherin, M., Voss, H., \& Gugler, P. (2010). 30 Years of foreign direct investment to China: An interdisciplinary literature review. International Business Review, 19(3), 235-246. doi:10.1016/j.ibusrev.2009.12.002

France, A. (2010). Management Accounting Practices Reflected in Job Advertisments. Journal of New Business Ideas \& Trends, 8(2), 41-57. 
Franz, K.-P. (2003). Verbundbeziehungen und Komplexität im internationalen Konzern. Kostenrechnung im international vernetzten Konzern, 1-12.

Franz, K.-P., \& Hieronimus, A. (2003). Kostenrechnung im international vernetzten Konzern. Düsseldorf: Verl.-Gruppe Handelsblatt.

Fratto, G. M. (2008). A longitudinal retail price analysis of intra-channel and inter-channel competitors. (69), ProQuest Information \& Learning, US. Retrieved from http://search.ebscohost.com/login.aspx?direct=true \&db=psyh\&AN=2008-99171079\&site=ehost-live \&scope=site Available from EBSCOhost psyh database.

Friedl, G., Küpper, H.-U., \& Pedell, B. (2005). Relevance Added: Combining ABC with German Cost Accounting. Strategic Finance, 86(12), 56-61.

Frost, J., Vogel, R., \& Bagban, K. (2016). Managing Interdpendence in Multi-business Organizations - A Case Study of Management Control Systems. Schmalenbach Business Review (SBR), 17(2), 225-260. doi:10.1007/s41464-016-0019-2

Gardini, S., \& Grossi, G. (2014). Voluntary Adoption of the consolidated Financial Statement and Fair Value Accounting by Italian local governments. Journal of Public Budgeting, Accounting \& Financial Management, 26(2), 313-344.

Garland, S. W. (2005). An analysis of the pacing strategy adopted by elite competitors in $2000 \mathrm{~m}$ rowing. British Journal of Sports Medicine, 39(1), 39-42.

Gertler, M. S. (1996). Worlds Apart: The Changing Market Geography of the German Machinery Industry. Small Business Economics, 8(2), 87-106.

Glaum, M., Baetge, J., Grothe, A., \& Oberdörster, T. (2013). Introduction of International Accounting Standards, Disclosure Quality and Accuracy of Analysts' Earnings Forecasts. European Accounting Review, 22(1), 79-116. doi:10.1080/09638180.2011.558301

Gorecki, P. K. (1976). Determinants of entry by domestic and foreign enterprises in Canadian manufacturing industries: some comments and empirical results. Review of Economics \& Statistics, 58(4), 485.

Govindarajan, V., \& Shank, J. K. (1989). Profit Variance Analysis: A Strategic Focus. Issues in Accounting Education, 4(2), 396-410.

Grant, R. M. (2002). Contemporaray Analysis - Concepts, Techniques, Applications (4 ed.). London.

Guay, W., Samuels, D., \& Taylor, D. (2016). Guiding through the Fog: Financial statement complexity and voluntary disclosure. Journal of Accounting \& Economics, 62(2/3), 234-269. doi:10.1016/j.jacceco.2016.09.001 
Guilding, C. (1999). Competitor - focused accounting - An exploratory note. Accounting, Organizations and Society, 1999(24, 7), 583-596.

Guilding, C., Cravens, K. S., \& Tayles, M. (2000). An international comparison of strategic management accounting practices. Management Accounting Research, 11(1), 113135.

Gummesson, E. (2000). Qualitative methods in management research (2nd ed. ed.). Thousand Oaks ; London: SAGE.

Gummesson, E. (2017). Case theory in business and management : reinventing case study research (1st ed.).

Günther, T., \& Breiter, H. M. (2007). Strategisches Controlling - State of the Art und Entwicklungstrends. ZfCM, 51(Sonderheft 2), 6-14.

Haile, S., \& Williams, D. (2011). Factors that Influence Expatriate Compensation Problems. Academy of Business Journal, 1, 25-32.

Haller, A., \& Eierle, B. (2004). The Adaption of German accounting rules to IFRS: a legaslative balancing act. Accounting in Europe, 1, 27-50.

Haried, A. A. (1972). The Semantic Dimensions of Financial Statements. Journal of Accounting Research, 10(2), 376-391.

Harkleroad, D. (1993). Sustainable Growth Rate Analysis: Evaluating Worldwide Competitors' Ability to Grow Profitably. Competitive Intelligence Review, 4(2/3), 3645.

Hart, S., \& Roslender, R. (2002). Distinguishing marques. Financial Management, 32.

Harvey, M. (1995). Strategic management accounting and marketing: Study tips. Management Accounting: Magazine for Chartered Management Accountants, 73(4), 48.

Heinen, K. C., \& Hoffjan, A. (2005). The Strategic Relevance of Competitor Cost Assessment: an Empirical Study of Competitor Accounting. Journal of Applied Management Accounting Research(3, 1), 17-34.

Hesford, J. W., Lee, S.-H., Van der Stede, W. A., \& Young, S. M. (2006). Management Accounting: A Bibliographic Study. In A. G. H. Christopher S. Chapman \& D. S. Michael (Eds.), Handbooks of Management Accounting Research (Vol. Volume 1, pp. 3-26): Elsevier.

Hiles, J. (2016). Hidden variety: Competitor analysis in the government contracting market. (77), ProQuest Information \& Learning, US. Retrieved from 
http://search.ebscohost.com/login.aspx?direct=true\&db=psyh\&AN=2016-37850$273 \&$ site $=$ ehost-live \&scope $=$ site Available from EBSCOhost psyh database.

Hitchings, M. A., \& Peckham, J. (2010). VW China Uses Strategy to Outsell Competitors: Analysis. Global Refining \& Fuels Today, 2(23), 15-15.

Hoffjan, A., \& Wömpener, A. (2006). Comparative Analysis of Strategic Management Accounting in German- and English-Language General Management Accounting Textbooks. Schmalenbach Business Review (SBR), 58(3), 234-258.

Hopper, T., \& Powell, A. (1985). Making Sense of Research into the organizational and social aspects of Management Accounting: a review of its underlyying assumptions. Journal of Management Studies, 22(5), 429-465.

Hoque, Z. (2003). Strategic Management Accounting Concepts, Processes and Issues (2 ed.): Spiro Press, USA.

Hoque, Z. (2006). Strategic management accounting : concepts, processes and issues:

Frenchs Forest, N.S.W. : Pearson Education Australia, [2006], c2003.

2nd ed.

Hossain, D. M., Akter, M., \& Hoque, Z. (2011). Contemporary issues in strategic management accounting: Saarbrucken : Lap Lambert Academic Publishing, 2011.

Hronsky, J. J. F., \& Houghton, K. A. (2001). The meaning of a defined accounting concept: regulatory changes and the effect on auditor decision making. Accounting, Organizations \& Society, 26(2), 123-139.

Inglis, R. M. (2008). Exploring accounting and market orientation: an interfunctional case study. Journal of Marketing Management, 24(7/8), 687-710.

Innes, J. (1999). Management Accounting Trends. Management Accounting: Magazine for Chartered Management Accountants, 77(5), 40.

Innes, J., \& Kouhy, R. (2011). The Activity-Based Approach. In M. G. Abdel-Kader (Ed.), Review of management accounting research (pp. 243-274). Houndmills, Basingstoke, Hampshire ; New York: Palgrave Macmillan.

Jell-Ojobor, M., \& Windsperger, J. (2017). Determinants of the governance structure of the international franchise firm. International Marketing Review, 34(6), 814-884. doi:10.1108/IMR-10-2015-0208

Johnson, H. T., \& Kaplan, R. S. (1987). Relevance Lost: The Rise and Fall of Management Accounting (Hardcover) (pp. 1).

Johnson, H. T., \& Kaplan, R. S. (1991). Relevance lost : The Rise and Fall of Management Accounting: Boston, Mass : Harvard Business School Press, 1991. 
Juras, A. (2014). Strategic Management Accounting -- What Is the Current State of the Concept? Economy Transdisciplinarity Cognition, 17(2), 76-83.

Justis, R. I., \& Flowers, A. D. (1976). An Investigation of the Semantic Differential as an Instrument of Attitudinal Measurement. In A. o. M. Proceedings (Ed.), (pp. 34-37). Kajüter, P. (2003). Theoretische Grundlagen der Kostenrechnung im Konzern. Kostenrechnung im international vernetzten Konzern, 13-28.

Kajüter, P., \& Schröder, M. (2014). Kostenrechnung anglophoner Konzerne in Deutschland. Controlling \& Management Review, 6/2014, 34-43.

Kaland, A., \& Wömpener, A. (2007). Strategisches Controlling: Eingrenzung, Nutzung und Bezug zur Marketingfunktion. ZfCM, 51(Sonderheft 2), 30-36.

Kaplan, R. S. (1983). Measuring Manufacturing Performance: A New Challenge for Managerial Accounting Research. Accounting Review, 58(4), 686.

Kaplan, R. S. (1984a). The Evolution of Management Accounting. Accounting Review, 59(3), 390.

Kaplan, R. S. (1984b). Yesterday's accounting undermines production. Harvard Business Review, 62(4), 95-101.

Kaplan, R. S. (1986). Accounting Lag: The Obsolescence of Cost Accounting Systems. California Management Review, 28(2), 174-199.

Kaplan, R. S. (1990). Limitations of cost accounting in advanced manufacturing environments. In R. S. Kaplan (Ed.), Measures for Manufacturing Excellence (pp. 91126). Boston: Harvard Business School University Press.

Kaplan, R. S., \& Atkinson, A. A. (1998). Advanced Management Accounting (3 ed.). Singapure: Pearson Education.

Kaye, R. (2004). Questions of consolidation. Financial Management, 11-11.

Kilger, W. (1990). Contribution Costing. In E. Grochla (Ed.), Handbook of German Business Management (pp. 518-530). Berlin: Springer-Verlag.

Kilger, W., Pampel, J., \& Vikas, K. (2007). Flexible Plankostenrechnung und Deckungsbeitragsrechnung: Betriebswirtschaftlicher Verlag Gabler.

Kim, I.-w., \& Berry, E. (2011). Target Costing. In M. G. Abdel-Kader (Ed.), Review of management accounting research (pp. 275-294). Houndmills, Basingstoke, Hampshire ; New York: Palgrave Macmillan.

Kleber, H. (1993). Praktische Ermittlungsprobleme der Konzernherstellungskosten im Rahmen einer mehrstufigen Produktion - dargestellt am Beispiel eines weltweit 
tätigen Chemieunternehmens. In K. Küting \& C.-P. Weber (Eds.), Konzernmanagement (pp. 319-339). Stuttgart: Schäffer-Poeschel.

Koberstein, G. (1949). Das Rechnungswesen des Konzerns.

Kuhn, T. S. (1970). The Structure of Scientific Revolutions (2nd ed.): University of Chicago Press.

Kupka, B., Everett, A. M., \& Cathro, V. (2008). Home alone and often unprepared intercultural communication training for expatriated partners in German MNCs. International Journal of Human Resource Management, 19(10), 1765-1791. doi:10.1080/09585190802323819

Laitinen, E. K. (2011). Management Accounting in Pricing Decisions. In M. G. Abdel-Kader (Ed.), Review of management accounting research (pp. 311-342). Houndmills, Basingstoke, Hampshire ; New York: Palgrave Macmillan.

Lang, M., \& Stice-Lawrence, L. (2015). Textual analysis and international financial reporting: Large sample evidence. Journal of Accounting \& Economics, 60(2/3), 110135. doi:10.1016/j.jacceco.2015.09.002

Langfield-Smith, K. (2008). Strategic management accounting: how far have we come in 25 years? Accounting, Auditing \& Accountability Journal, 21(2), 225. doi:10.1108/09513570810854400

Larsen, P., Tonge, R., \& Ito, M. (1998). The Strategic Planning Process in Growing Companies. Journal of General Management, 24(1), 53-68.

Lay, T. A., \& Jusoh, R. (2012). Business Strategy, strategic Role of Accountant, Strategic Management Accounting and their Links to firm Performance: An exploratory Study of manufacturing Companies in Malaysia. Asia-Pacific Management Accounting Journal, 7(1), 59-94.

Lebar, M. A. (1982). A General Semantics Analysis of Selected Sections of the 10-K, the Annual Report to Shareholders, and the Financial Press Release. Accounting Review, 57(1), 176-189.

Lee, H.-J., Chua, C. H., Miska, C., \& Stahl, G. K. (2017). Looking out or looking up: gender differences in expatriate turnover intentions. Cross Cultural \& Strategic Management, 24(2), 288-309. doi:10.1108/CCSM-02-2016-0046

Leuz, C., \& Verrecha, R. (2000). The economic consequences of increased disclosure. Journal of Accounting Research, 38, 91-124.

Li, D. H. (1963). The Semantic Aspect of Communication Theory and Accountancy. Journal of Accounting Research, 1(1), 102-107. 
Lincoln, Y. S., \& Guba, E. G. (1985). Naturalistic inquiry. Beverly Hills, Calif. ; London: Sage.

Littkemann, J. (2004). Einführung in das Beteiligungscontrolling. In J. Littkemann \& H. Zündorf (Eds.), Beteiligungscontrolling. Ein Handbuch für die Unternehmens- und Beratungspraxis (pp. 1-20). Herne/Berlin: Verlag Neue Wirtschafts-Briefe.

Littkemann, J. (2009). Strategische und operative Unternehmensführung im Beteiligungscontrolling (Vol. 2). Herne/Berlin: Verl. Neue Wirtschafts-Briefe.

Littkemann, J., Derfuß, K., \& Holtrup, M. (2018). Unternehmenscontrolling:

Praxishandbuch für den Mittelstand, Konzepte, Instrumente, praktische Anwendungen mit durchgängiger Fallstudie (Vol. 2). Herne/Berlin: Verl. Neue Wirtschafts-Briefe.

Littleton, A. C. (1929). Value and Price in Accounting. The Accounting Review, IV(3), 147154.

Lord, B. R. (1996). Strategic management accounting: the emperor's new clothes? Management Accounting Research, 1996(7, 3), 347-366.

Lorenz, A. (2015). Contemporary management accounting in the UK service sector. (Thesis (Ph.D.)), University of Gloucestershire. Retrieved from http://eprints.glos.ac.uk/4260/

Lorson, P., Melcher, W., \& Zündorf, H. (2013). 20 Jahre Konvergenzdiskussion Geschichte einer wechselvollen Beziehung. Controlling \& Management Review, 6 /2013, 12-23.

Luostarinen, R., \& Gabrielsson, M. (2006). Globalization and marketing strategies of Born Globals in SMOPECs. Thunderbird International Business Review, 48(6), 773-801.

Luther, R., Jones, C. T., \& Saxl, A. (2009). Experiencing change in German controlling: management accounting in a globalising world. CIMA Research executive summaries series, 5(12), 1-6.

Luther, R., Jones, T. C., \& Saxl, A. (2010). Experiencing change in German controlling : management accounting in a globalizing world. Amsterdam: CIMA.

Macintosh, N. B. (1998). Management accounting in Europe: a view from Canada. Management Accounting Research, 9(4), 495-500.

Macintosh, N. B. (2006). Accounting-Truth, Lies, or "Bullshit"? A Philosophical Investigation. Accounting and the Public Interest, 6, 22-36.

Macintosh, N. B. (2009). Accounting and the Truth of Earnings Reports: Philosophical Considerations. European Accounting Review, 18(1), 141-175.

Mahefa, A. (1998). Internationales Marketing-Management. In S. G. Schoppe \& N. Blödorn (Eds.), Kompendium der internationalen Betriebswirtschaftslehre (4., völlig überarb. Aufl. ed., pp. 503-564). München, Wien Oldenbourg. 
Maisch, C. (1996) Beurteilungskriterien für Auslandsinvestitionen deutscher Unternehmen: Ergebnisse einer empirischen Studie. Volks- und Betriebswirtschaft: Vol. 1849. Frankfurt am Main: Peter Lang GmbH.

Marchand, J.-P. (1949). Konsolidierte Bilanz und Betriebsabrechnung in der Holding. McKinsey and Co. (1994). Marketing Metamorphosis. New York: McKinsey and Co.

McLellan, J. D. (2014). Management Accounting Theory and Practice: Measuring the Gap in United States Businesses. Journal of Accounting, Business \& Management, 21(1), 53 68.

Mella, P., \& Gazzola, P. (2018). Corporate social responsibility through stakeholder engagement and entrepreneurial communication processes. International Journal of Business Performance Management, 19(1), 36-54. doi:10.1504/IJBPM.2018.10008954

Merkley, K. J. (2014). Narrative Disclosure and Earnings Performance: Evidence from R\&D Disclosures. Accounting Review, 89(2), 725-757. doi:10.2308/accr-50649

Meyssonnier, F., \& Pourtier, F. (2013). Contrôle du périmètre et périmètre de contrôle -Réflexion sur le système d'information comptable des groupes. (French). Scope of Consolidation and Area of Control -- Reflection on the Accounting Information System of Groups. (English), 19(3), 117-146.

Mohamed, A. A. (2010). A proposed strategic management accounting model for profitability : an empirial study: Cheltenham : University of Gloucestershire, 2010.

Mohamed, A. A., \& Jones, T. (2014). Relationship between strategic management accounting techniques and profitability - a proposed model. Measuring Business Excellence, 18(3), 1-22. doi:doi:10.1108/MBE-04-2013-0023

Müller, H. (2000). Anforderungen an das interne Rechnungswesen für die operative Unternehmenssteuerung global agierender Unternehmen und Konzerne. In O. A. Altenburger, O. Janschek, \& H. Müller (Eds.), Fortschritte im Rechnungswesen (2., durchges ed., pp. 383-421). Wiesbaden: Gabler.

Neal, D. J. (1999). How consistent are winning strategies? The role of competitor analysis and budgets on performance in a simulation. Simulation \& Gaming, 30(2), 118.

Nixon, B., \& Burns, J. (2012a). The paradox of strategic management accounting. Management Accounting Research, 23(4), 229-244. doi:10.1016/j.mar.2012.09.004

Nixon, B., \& Burns, J. (2012b, 12//). Strategic management accounting, Editorial. Management Accounting Research, pp. 225-228. Retrieved from 
http://search.ebscohost.com/login.aspx ?direct=true \&db=bth\&AN=83166961\&site=eh ost-live \&scope $=$ site

Nixon, W. A. J., \& Burns, J. (2005). Management Control in the 21st century. Management Accounting Research, 16, 260-268. doi:10.1016/j.mar.2005.07.01

Noordin, R., Zainuddin, Y., \& Tayles, M. (2009). Strategic Management Accounting Information Elements: Malaysian Evidence. Asia-Pacific Management Accounting Journal, 4(1), 17-34.

Nuppeney, W. (2002). Konzernkalkulation - Managementreporting und Konzernkonsoliderung auf der Basis konsolidierter Herstellkosten am Beispiel eines internationalen Pharmakonzerns. Kostenrechnungspraxis, 46(5), 305-309.

Oesterle, M.-J., \& Wolf, J. (2011). 50 Years of Management International Review and IB/IM Research. Management International Review (MIR), 51(6), 735-754. doi:10.1007/s11575-011-0106-Z

Ohmae, K. (1983). The Mind of the Strategist. New York: Penguin.

Osgood, C. E., Suci, G. J., \& Tannenbaum, P. H. (1957). The Measurement of Meaning. [By] C. E. Osgood, George J. Suci, Percy H. Tannenbaum. (Second printing.) [With illustrations.]. Urbana: University of Illinois Press.

Ossadnik, W. (2008). Kosten- Und Leistungsrechnung: Springer Verlag.

Otley, D. T., \& Berry, A. J. (1980). Control, organisation and accounting. Accounting, Organizations and Society, 5(2), 231-244. doi: http://dx.doi.org/10.1016/03613682(80)90012-4

Otley, D. T., \& Berry, A. J. (1998). Case study research in management accounting and control. Accounting Education, 7, S105.

Oxenfeldt, A. R., \& Moore, W. L. (1981). Competitor analysis--A prize-centered approach. Management Review, 70(5), 23.

Pantea, M. F., Cuc, L. D., \& Lile, R. (2013). Strategic Managerial Accountancy -- The informational Resource for the Development of Managerial Decisions. Agricultural Management / Lucrari Stiintifice Seria I, Management Agricol, 15(3), 110-112.

Partridge, M., \& Perren, L. (1994). Cost analysis of the value chain: Another role for strategic management accounting. Management Accounting: Magazine for Chartered Management Accountants, 72(7), 22.

Paulus, T., Woods, M., Atkins, D. P., \& Macklin, R. (2017). The discourse of QDAS: reporting practices of ATLAS.ti and NVivo users with implications for best practices. 
International Journal of Social Research Methodology, 20(1), 35-47.

doi:10.1080/13645579.2015.1102454

Pawel, P. (2017). Agile Transformation in Project Organization - Issues, Conditions and Challenges. Project Management Development - Practice \& Perspectives, 190-206.

Pellens, B., \& Lehmann, K. (2012). Managementprognosen und Analystenschätzungen - Eine deskriptive Analyse auf Basis der HDAX-Unternehmen. Schmalenbachs Zeitschrift für betriebswirtschaftliche Forschung (zfbf), 64(8), 873-892.

Pierce, B., \& O’Dea, T. (2003). Management accounting information and the needs of managers Perception of managers and accountants compared. The British Accounting Review, 35(3), 257-290.

Pillania, K. K., \& Fetscherin, M. (2009). The State of Research on Multinationals and Emerging Markets. Multinational Business Review (St. Louis University), 17(2), 1-11.

Pinczés-Pressing, Z., Sebestyén, N., Berkics, M., \& Fülöp, M. (2015). Examination of young competitors' conceptions about competition, winning and losing using the associative group analysis method. Magyar Pszichológiai Szemle, 70(1), 159-177.

Platonova, N. y. A., \& Krivosheeva, T. y. M. (2015). DETERMINATION AND ANALYSIS OF COMPETITORS IN DEVELOPING THE REGION'S TOURISM STRATEGY. Regional Economics.(25), 2-12.

Porter, M. E. (1980a). Competitive Stragy: Techniques for Analyzing Industries and Competitors. New York: Free Press.

Porter, M. E. (1980b). Portfolio Techniques in Competitor Analysis (pp. 361-367).

Porter, M. E. (1985). Competitive Advantage. New York: Free Press.

Porter, M. E. (1986). Competition in Global Industries: A Conceptual Framework. In M. E. Porter (Ed.), Competition in global industries (pp. 15-60). Boston, Mass.: Harvard Business School Press.

Porter, M. E. (1999). Wettbewerbsvorteile: Spitzenleistungen erreichen und behaupten = (Competitive advantage) (5 ed.). Frankfurt/Main: Campus-Verl.

Porter, M. E. (2008). Competing Across Locations. In M. E. Porter (Ed.), On Competition (updated and expanded ed. ed., pp. 305-344). Boston, Mass.: Harvard Business School Publ.

Pötsch, H. D. (2008). Der IFRS-Abschluss aus der Sicht eines DAX-Unternehmens. In K. Küting, N. Pfitzer, \& C.-P. Weber (Eds.), Bilanz als Informations- und Kontrollinstrument (pp. 133-145). Stuttgart: Schäffer-Poeschel. 
Poulis, K., Poulis, E., \& Plakoyiannaki, E. (2013). The role of context in case study selection: An international business perspective. International Business Review, 22(1), 304-314. doi:10.1016/j.ibusrev.2012.04.003

Rangone, A. (1997). Linking organizational effectiveness, key success factors and performance measures: an analytical framework. Management Accounting Research, $8(2), 207-219$.

Rein, M. (1993). Konsolidierte Grenzplankostenrechnung: Instrument der Konzernplanung und -steuerung. Wiesbaden: Dt. Univ.-Verl.

Rockart, J. F. (1979). Chief executives define their own data needs. Harvard Business Review, 57(2), 81-93.

Rosen, D. E. (1991). The Competitor Analysis Process Model: A behavioral approach.

Roslender, R., Hart, S., \& Gosh, J. (1998). Strategic management accounting - refocusing the agenda. Management Accounting, 76(11), 44.

Roslender, R., \& Hart, S. J. (2002). Integrating Management Accounting and Marketing in the Pursuit of Competitive advantage: the case for strategic management accounting. Critical Perspectives on Accounting, 13(2), 255-277.

Roslender, R., \& Hart, S. J. (2003). In search of strategic management accounting theoretical and field study perspectives. Management Accounting Research, 2003(14, 3), 255-280.

Roslender, R., \& Hart, S. J. (2010a). Strategic Management Accounting: Lots in a Name.

Roslender, R., \& Hart, S. J. (2010b). Taking the customer into account: Transcending the construction of the customer through the promotion of self-accounting. Critical Perspectives on Accounting, 21(8), 739-753.

Roslender, R., \& Wilson, R. M. S. (2012). Introduction: The marketing / accounting interface. Journal of Marketing Management, 24(7-8), 1-7.

Rothschild, W. E. (1979). Competitor analysis: The missing link in the strategy. Management Review, 68(7), 22.

Ryan, B., Scapens, R. W., \& Theobald, M. (2002). Research method and methodology in finance and accounting (2nd ed. ed.). United Kingdom: Thomson.

Said, J., Wee Shu, H., Othman, R., \& Taylor, D. (2010). The mediating Effects of organizational Learning Orientation on the relationship between Strategic Management Accounting Information Use and Organizational Performance. AsiaPacific Management Accounting Journal, 5(2), 11-29. 
Saunders, M., Lewis, P., \& Thornhill, A. (2009). Research methods for business students (5th ed. ed.). Harlow: Financial Times Prentice Hall.

Schaier, S. (2007). Konvergenz von internem und externem Rechnungswesen: Bedarf für eine Neustrukturierung des Rechnungswesens? (1 ed.). Wiesbaden: Deutscher Universitäts-Verlag.

Schein, E. H. (2010). Organizational culture and leadership (4th ed. ed.). San Francisco, Calif.: Jossey-Bass ; [Chichester : John Wiley, distributor].

Schildbach, T. (1997). Cost accounting in Germany. Management Accounting Research, 8, 261-276.

Schnell, R. (1989). Konsolidierung der Einzelproduktergebnissevon verschiedenen Tochtergesellschaften. In A.-W. Scheer (Ed.), Rechnungswesen und EDV (pp. 299312). Saarbrücken.

Schöb, O. (2008a). Segmentberichterstattung nach IFRS (1. Aufl. ed.). Bonn: Galileo-Press.

Schöb, O. (2008b). Segmentberichterstattung nach IFRS: Konsequenzen und Umsetzungsempfehlungen für den Controller. Controller-Magazin, 33(9/10), 24-31.

Schöb, O. (2009). Schlankes Konzernreporting: Leitfaden für den Aufbau. ControllerMagazin, 34(6), 37-44.

Seal, W. (2010). Managerial discourse and the link between theory and practice: From ROI to value-based management. Management Accounting Research, 21(2), 95-109. doi:10.1016/j.mar.2010.02.007

Shank, J. K., \& Govindarajan, V. (1992). Strategic Cost Management: The Value Chain Perspective. Journal of Management Accounting Research, 4, 179-197.

Simmonds, K. (1981). The fundamentals of strategic management accounting: The Institute of Cost \& Management Accountants.

Simmonds, K. (1982). Strategic Management Accounting for Pricing: A Case Example. Accounting \& Business Research (Wolters Kluwer UK), 12(47), 206-214.

Sinkovics, R. R. a. E. A. A. (2012). "Facilitating the interaction between theory and data in qualitative research using CAQDAS, ". Qualitative organizational research: Core methods and current challenges. Sage Publications. London. Retrieved from http://www.manchester.ac.uk/escholar/uk-ac-man-scw:159596

Smith, M. (1997). Strategic management accounting : text and cases: Boston, Mass : Butterworth-Heinemann, 1997. 
Soo Young, K., \& Chang Joon, S. (1996). Test of Economic Entities Based on Intercompany Transactions and Debt Guarantees among Korean Group Companies. Journal of International Financial Management \& Accounting, 7(2), 102-124.

Spigarelli, F., Alon, I., \& Mucelli, A. (2015). Chinese M \& A in Europe. Competitiveness Review, 25(4), 346-370. doi:10.1108/CR-12-2014-0041

Stainer, A. (1997). Productivity and strategic management accounting. International Journal of Technology Management, 13(1), 57-67.

Taylor, L., Woods, M., \& Cheng Ge Fang, G. (2014). How using EVA target costing can align the interests of your shareholders and customers. Financial Management, 55-56.

TheWorldBank. (2014). Data. Available from The World Bank sp.pop.totl_Indicator_en_excel_v2 Retrieved May 11, 2014 http://data.worldbank.org/region/WLD

Thorne, S. E. (2008). Interpretive description. Walnut Creek, Calif.: Left Coast ; Biggleswade : Eurospan.

Tillmann, K., \& Goddard, A. (2008). Strategic management accounting and sense-making in a multinational company. Management Accounting Research, 19(1), 80-102. doi: http://dx.doi.org/10.1016/j.mar.2007.11.002

Tollington, T., \& Pilla, V. (2011). Throughput Accounting. In M. G. Abdel-Kader (Ed.), Review of management accounting research (pp. 295-310). Houndmills, Basingstoke, Hampshire ; New York: Palgrave Macmillan.

Tzeng, O. C. S., \& May, W. H. (1975). More than E, P and A in semantic differential scales: an answer to questions raised. International Journal of Psychology, 10(2), 101-117.

Vaivio, J. (1999). Exploring a `non-financial' management accounting change. Management Accounting Research, 10(4), 409-437. doi: http://dx.doi.org/10.1006/mare.1999.0112 Varnholt, N. T., Lebefromm, U., \& Hoberg, P. (2009). Kostenrechnung und operatives Controlling: Betriebswirtschaftliche Grundlagen und Anwendung mit SAP ERP. München: Oldenbourg.

VDMA. (2013). VDMA Mechanical Engineering - Figures and Charts 2013: Verband deutscher Maschinen- und Anlagenbauer.

Veil, T., \& Hess, T. (2000). Kalkulation in Unternehmensnetzwerken.

Verschuren, P. J. M. (2003). Case study as a research strategy: ambiguities and opportunities. International Journal of Research Methodology, 6(2), 121-139. doi:10.1080/13645570110106154 
Vormbaum, H., \& Rautenberg, H. G. (1985). Kostenrechnung III für Studium und Praxis Plankostenrechnung. Bad Homburg vor der Höhe - Baden-Baden: Verl. für Unternehmensführung Gehlen.

Ward, H., \& Callaway, J. (2004). Best practice reporting. Chartered Accountants Journal, 83(7), 26-32.

Ward, K. (1992). Strategic management accounting: Oxford

Ward, K., Wendy, H., \& Sri, S. (1992). Accounting for the competition. Management Accounting, 70(2), 19-23.

Wegmann, G. (2009). The Activity-Based Costing Method: Development and Applications. ICFAI Journal of Accounting Research, 8(1), 7-22.

Weißenberger, B. E., \& Angelkort, H. (2011). Integration of financial and management accounting systems: The mediating influence of a consistent financial language on controllership effectiveness. Management Accounting Research, 22(3), 160-180.

Weißenberger, B. E., Angelkort, H., \& Holthoff, G. (2012). MAS Integration and Controllership - Effectiveness: Evidence of a Preparer-User Perception Gap. BuR Business Research Official Open Access Journal of VHB, 5(2), 134-153.

Wolf, S., Weißenberger, B. E., Wehner, M. C., \& Kabst, R. (2015). Controllers as business partners in managerial decision-making. Journal of Accounting \& Organizational Change, 11(1), 24-46. doi:10.1108/JAOC-10-2012-010C

Wong, N., \& Ahuvia, A. (1998). Personal Taste and Family Face: Luxury Consumption in Confucian and Western Societies. Psychology and Marketing, 15, 423-441.

Woods, M., Taylor, L., \& Fang, G. C. G. (2012). Electronics: A case study of economic value added in target costing. Management Accounting Research, 23(4), 261-277. doi:10.1016/j.mar.2012.09.002

WTO. (2013). International Trade Statistics 2013. In W. T. Organization (Ed.): World Trade Organization.

Wullenkord, A. (1995). Kosten- und Erfolgs-Controlling im Konzern. München: Vahlen.

Yang, Y. (2015). Domestic R\&D, Foreign Direct Investment and Welfare. Review of Development Economics, 19(4), 908-924. doi:10.1111/rode.12188

Yang, Z., Wang, X., \& Su, C. (2006). A review of research methodologies in international business. International Business Review, 15(6), 601-617.

Yi, M., \& Tayles, M. (2009). On the emergence of strategic management accounting: an institutional perspective. Accounting \& Business Research, 39(5), 473-495. 
Yin, R. K. (2009). Case study reseach: design and methods (4 ed. Vol. 5): SAGE Publications, Inc. 


\section{Annexe}

Annex 1: Search on EBSCO database on March 11th, 2018, using

"strategic\&management\&accounting" as search terms page 1 of 21

\begin{tabular}{|c|c|c|c|c|c|c|}
\hline 䃂 & 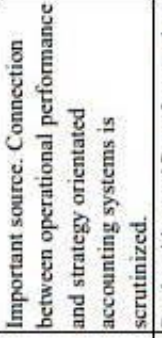 & 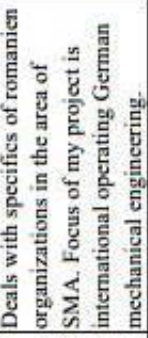 & 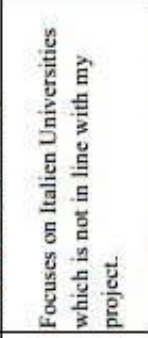 & 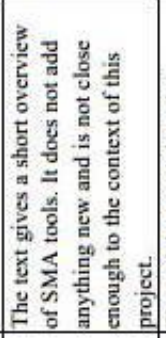 & 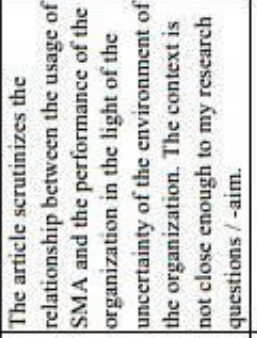 & 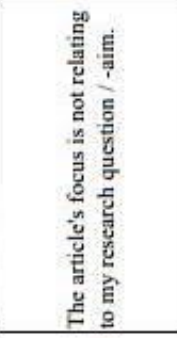 \\
\hline 苞 & $\check{0}$ & ஜ & ż & $\dot{z}$ & $\stackrel{2}{z}$ & $z$ \\
\hline 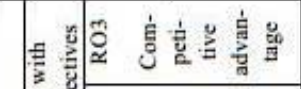 & $z$ & $z$ & $z$ & $z$ & $z$ & $z$ \\
\hline 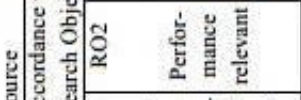 & $>$ & $z$ & $z$ & $z$ & $z$ & $z$ \\
\hline 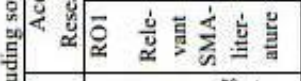 & $>$ & $z$ & $z$ & $z$ & $z$ & $z$ \\
\hline 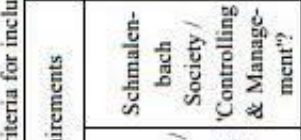 & $z$ & $z$ & z & z & z & $z$ \\
\hline 产容意 & $z$ & $z$ & $z$ & $z$ & $z$ & $z$ \\
\hline 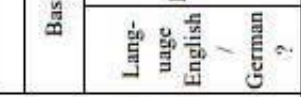 & w & is & $\omega$ & $\omega$ & $\omega$ & $\omega$ \\
\hline 善 & 递 & 递 & $\frac{\square}{2}$ & 产 & 递 & 造 \\
\hline 递 & 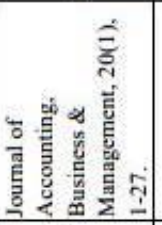 & 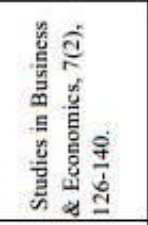 & 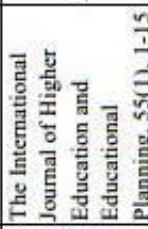 & 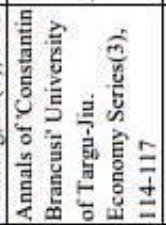 & 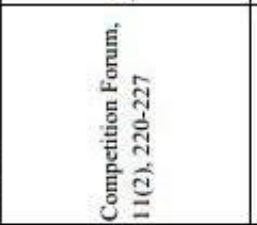 & 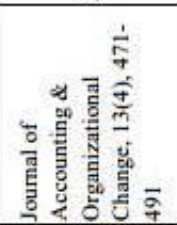 \\
\hline 总 & 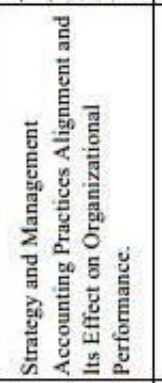 & 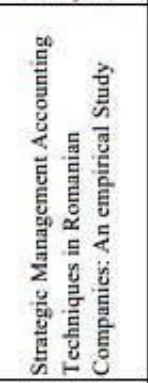 & 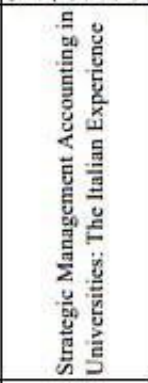 & 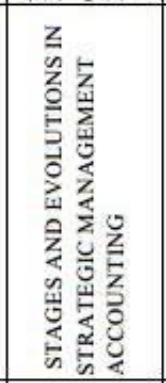 & 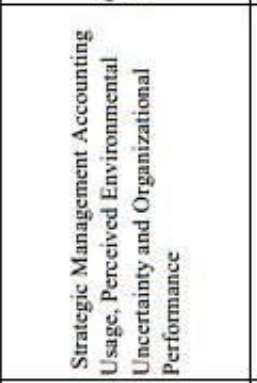 & 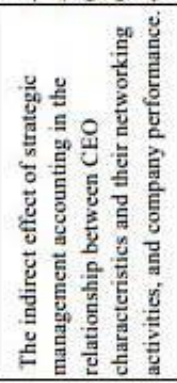 \\
\hline 恖 & 商 & 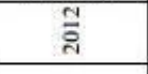 & ఫ్ & 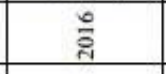 & m & है \\
\hline 总 & 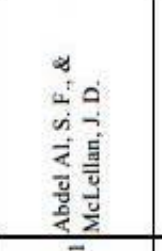 & 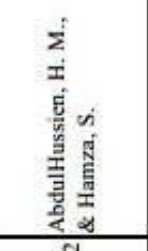 & 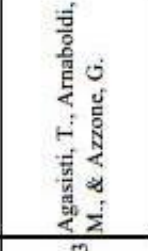 & 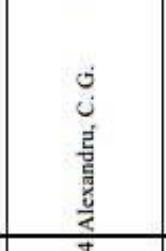 & 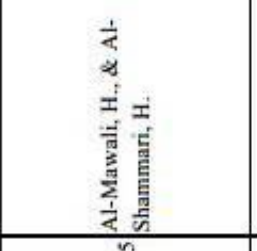 & 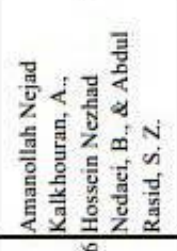 \\
\hline$\frac{\dot{s}}{2}$ & & & & & & \\
\hline
\end{tabular}




\begin{tabular}{|c|c|c|c|c|c|c|c|c|}
\hline है & 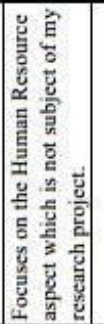 & 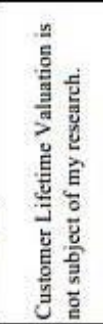 & 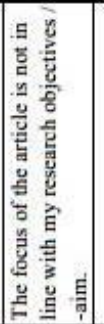 & 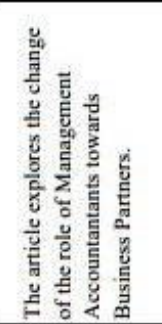 & 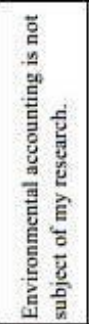 & 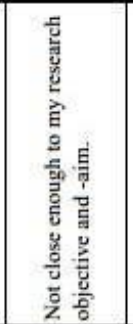 & 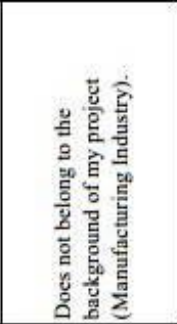 & 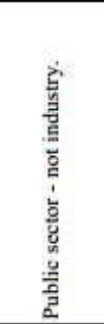 \\
\hline 要 & z & ż & z̊ & 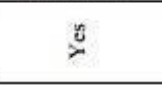 & z & zo & z̊ & $\check{z}$ \\
\hline 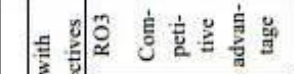 & z & $z$ & z & z & z & z & z & z \\
\hline 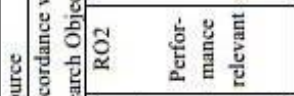 & $z$ & $z$ & $z$ & $>$ & $z$ & $z$ & z & $z$ \\
\hline 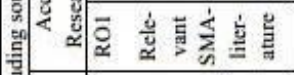 & z & $z$ & z & $>$ & z & z & z & z \\
\hline 掊 & $z$ & z & z & $z$ & z & z & z & z \\
\hline 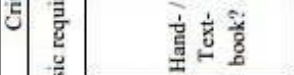 & z & $z$ & z & z & $z$ & z & z & z \\
\hline 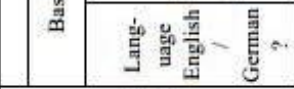 & w & $\mu$ & $\omega$ & $\omega$ & 山 & $\mu$ & $\omega$ & 4 \\
\hline 兑喜 & $\frac{2}{\underline{\underline{L}}}$ & 䓀 & $\frac{n}{\pi}$ & $\frac{2}{\underline{\underline{L}}}$ & $\frac{2}{\underline{\underline{g}}}$ & $\frac{\ddots}{5}$ & $\frac{2}{\underline{\underline{L}}}$ & $\frac{0}{\underline{\underline{u}}}$ \\
\hline 害 & 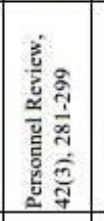 & 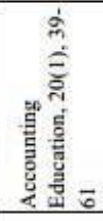 & 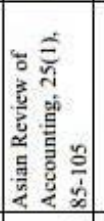 & 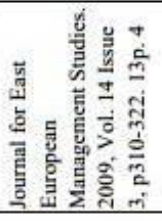 & 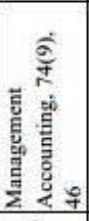 & 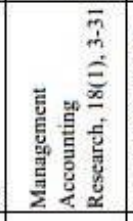 & 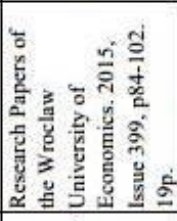 & 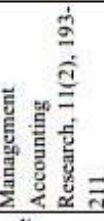 \\
\hline$\stackrel{\text { हn }}{E}$ & 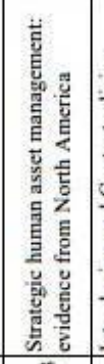 & 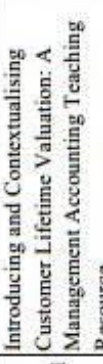 & 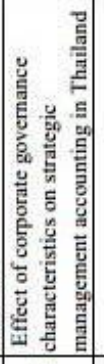 & 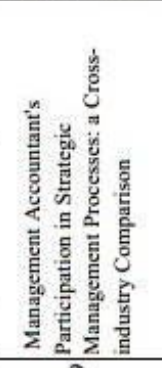 & 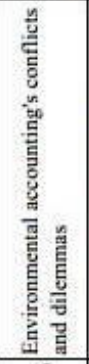 & 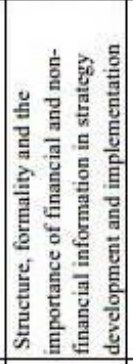 & 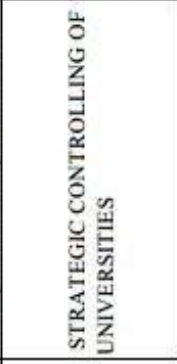 & 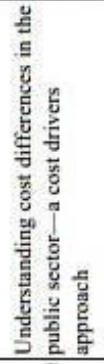 \\
\hline 总 & 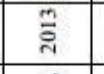 & $\overline{\bar{c}}$ & 唁 & ఫ్ & ま & 善 & $\frac{\text { nิ }}{n}$ & ఫ్ \\
\hline 制 & 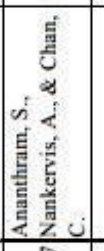 & 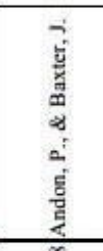 & 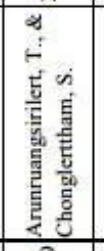 & 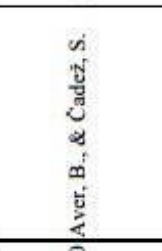 & 盖 & 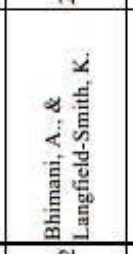 & 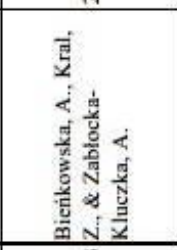 & 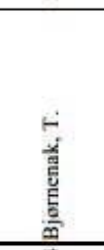 \\
\hline$\frac{8}{z}$ & & & & 9 & $=$ & $\simeq$ & 9 & \pm \\
\hline
\end{tabular}




\begin{tabular}{|c|c|c|c|c|c|c|c|c|}
\hline है & 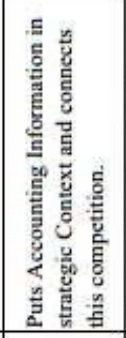 & 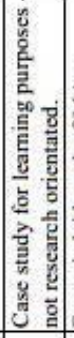 & 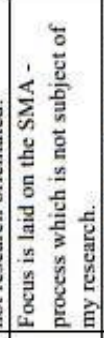 & 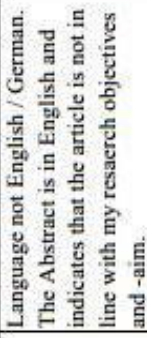 & 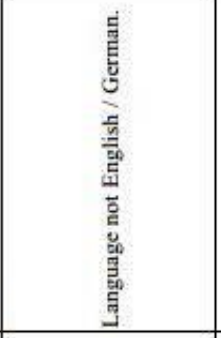 & 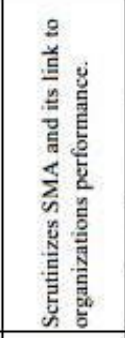 & 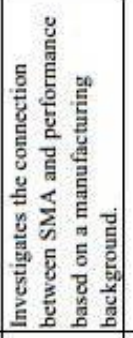 & 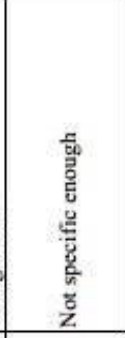 \\
\hline : & $\stackrel{5}{x}$ & z & z̊ & z̊ & ż & $\stackrel{x}{x}$ & $\stackrel{n}{x}$ & $\not ̊$ \\
\hline E & $z$ & z & z & z & z & z & $>$ & z \\
\hline 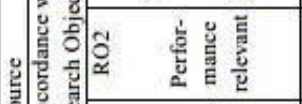 & $>$ & z & z & z & $>$ & $>$ & $>$ & z \\
\hline $\begin{array}{lll}0 \\
0\end{array}$ & $>$ & $z$ & z & $>$ & $z$ & $>$ & $z$ & z \\
\hline 结 & z & $z$ & $z$ & $z$ & $z$ & $z$ & $z$ & z \\
\hline 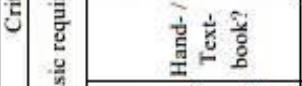 & $z$ & z & $z$ & $z$ & $z$ & z & z & z \\
\hline 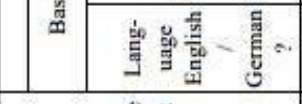 & (1) & 파 & $\Leftrightarrow$ & 总 & $\frac{\underline{g}}{\tilde{z}}$ & w & $\Leftrightarrow$ & is \\
\hline 善 & $\frac{\square}{2}$ & 这 & 黄 & $\frac{2}{20}$ & 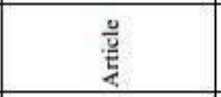 & 荧 & $\frac{u}{\underline{u}}$ & 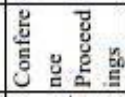 \\
\hline 参 & 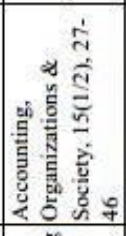 & 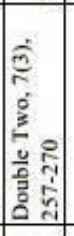 & 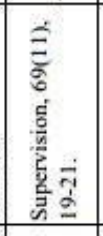 & 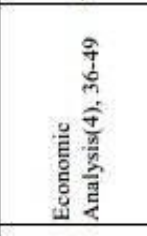 & 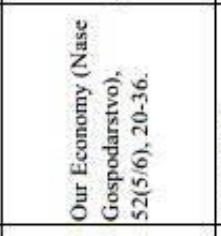 & 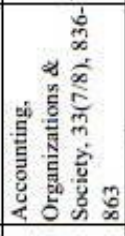 & 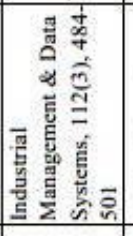 & 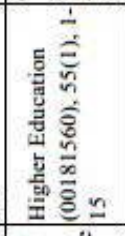 \\
\hline$\stackrel{\varrho}{\Xi}$ & 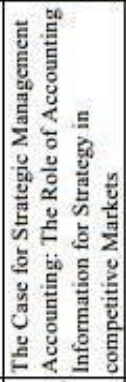 & 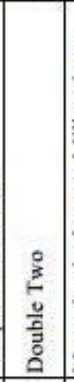 & 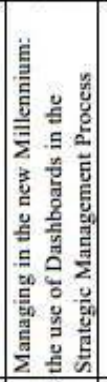 & 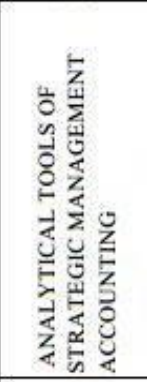 & 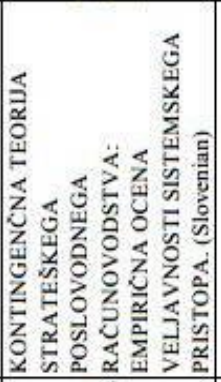 & 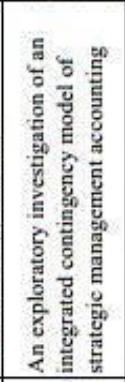 & 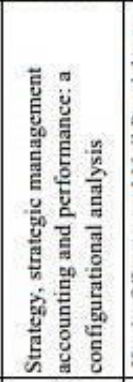 & 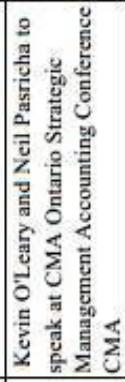 \\
\hline 恖 & $\vdots$ & 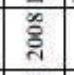 & 言 & ⿳亠े⿵冂卄. & 高 & 总 & 离 & $\overline{\bar{\Sigma}}$ \\
\hline 总 & 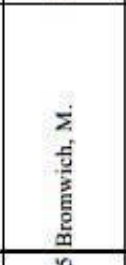 & 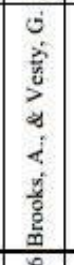 & 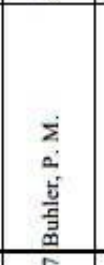 & 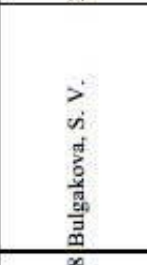 & 弪 & $\begin{array}{l}\text { है } \\
\text { है } \\
\text { है } \\
4 \\
0 \\
\text { है } \\
\text { है } \\
\end{array}$ & 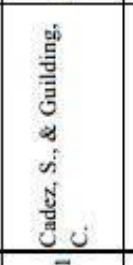 & 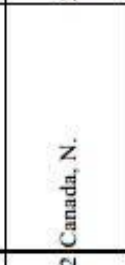 \\
\hline \& & $\underline{n}$ & 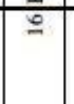 & $I$ & $\stackrel{\infty}{\underline{\infty}}$ & 9 & वे & $\overrightarrow{\mathrm{N}}$ & $\bar{d}$ \\
\hline
\end{tabular}




\begin{tabular}{|c|c|c|c|c|c|c|c|c|}
\hline 惫 & 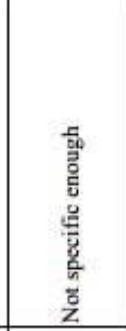 & 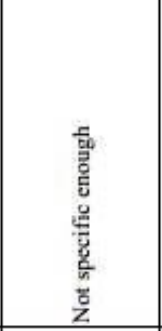 & 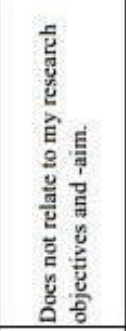 & 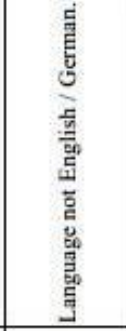 & 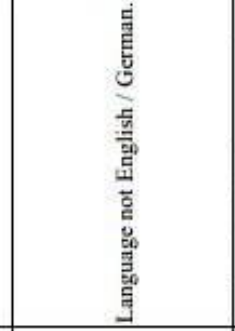 & 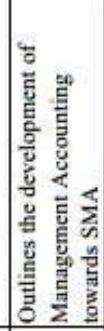 & 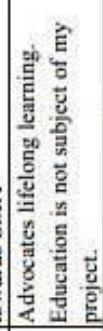 & 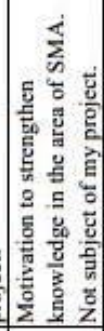 \\
\hline 总 & z̊ & $\AA$ & z̊ & z̊ & z̊ & $\stackrel{0}{;}$ & $\stackrel{0}{z}$ & z̊ \\
\hline 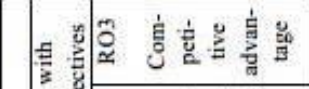 & z & $z$ & $z$ & $z$ & $z$ & $z$ & $z$ & $z$ \\
\hline 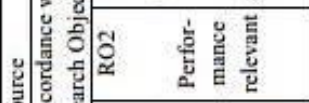 & $z$ & $z$ & $z$ & $>$ & $>$ & $>$ & $z$ & z \\
\hline 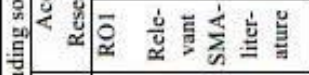 & z & z & z & $z$ & $z$ & $>$ & z & $\mathrm{z}$ \\
\hline 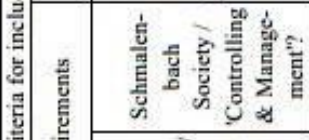 & z & z & $z$ & $z$ & $z$ & $z$ & $z$ & $z$ \\
\hline 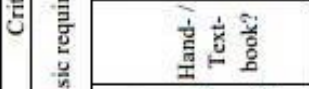 & z & z & z & $z$ & $z$ & z & $z$ & z \\
\hline 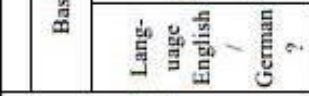 & 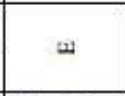 & H & $\omega$ & $\frac{\underline{s}}{5}$ & $\frac{\underline{\underline{n}}}{5}$ & is & 4 & هل \\
\hline 总总 & 总总 & 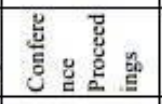 & $\frac{u}{\underline{\underline{n}}}$ & 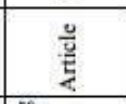 & 苋 & $\frac{u}{\frac{u}{2}}$ & $\frac{u}{\frac{u}{2}}$ & 党 \\
\hline 害 & & & 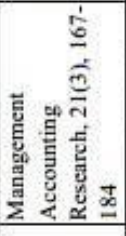 & 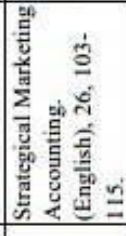 & 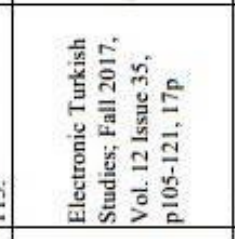 & 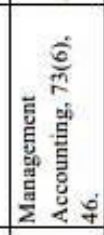 & 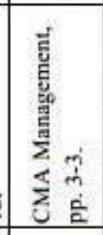 & 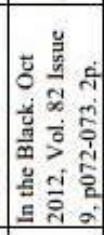 \\
\hline 号 & 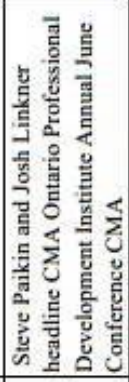 & 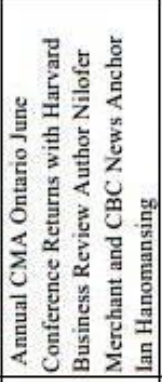 & 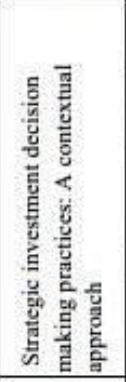 & 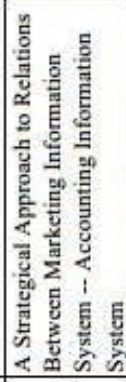 & 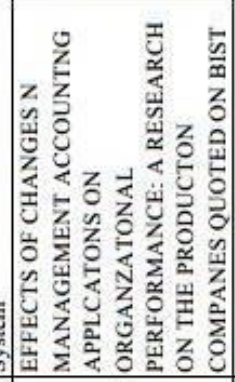 & 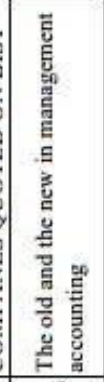 & 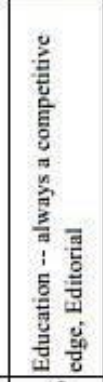 & 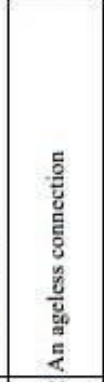 \\
\hline 总 & $\overbrace{}^{4}$ & $\stackrel{m}{\bar{n}}$ & 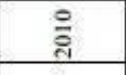 & है & 今ิ & 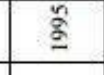 & ఫ్ & 离 \\
\hline 总 & $\begin{array}{l}z \\
\text { 哥 } \\
\text { 恶 } \\
\end{array}$ & $\begin{array}{l}z \\
\text { 吾 } \\
\text { 恶 } \\
\end{array}$ & 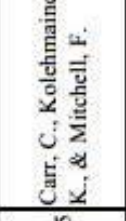 & 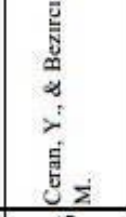 & 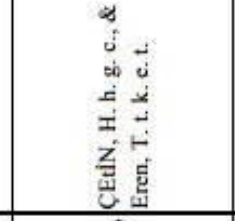 & 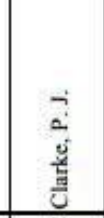 & $\begin{array}{l}2 \\
\text { if } \\
\text { 㢦 } \\
\end{array}$ & 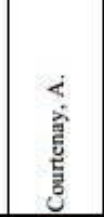 \\
\hline$\stackrel{8}{2}$ & $\overrightarrow{\text { ते }}$ & $\sqrt{4}$ & $y$ & $\check{\pi}^{\circ}$ & $\sqrt{n}$ & क्ते & शे & 市 \\
\hline
\end{tabular}




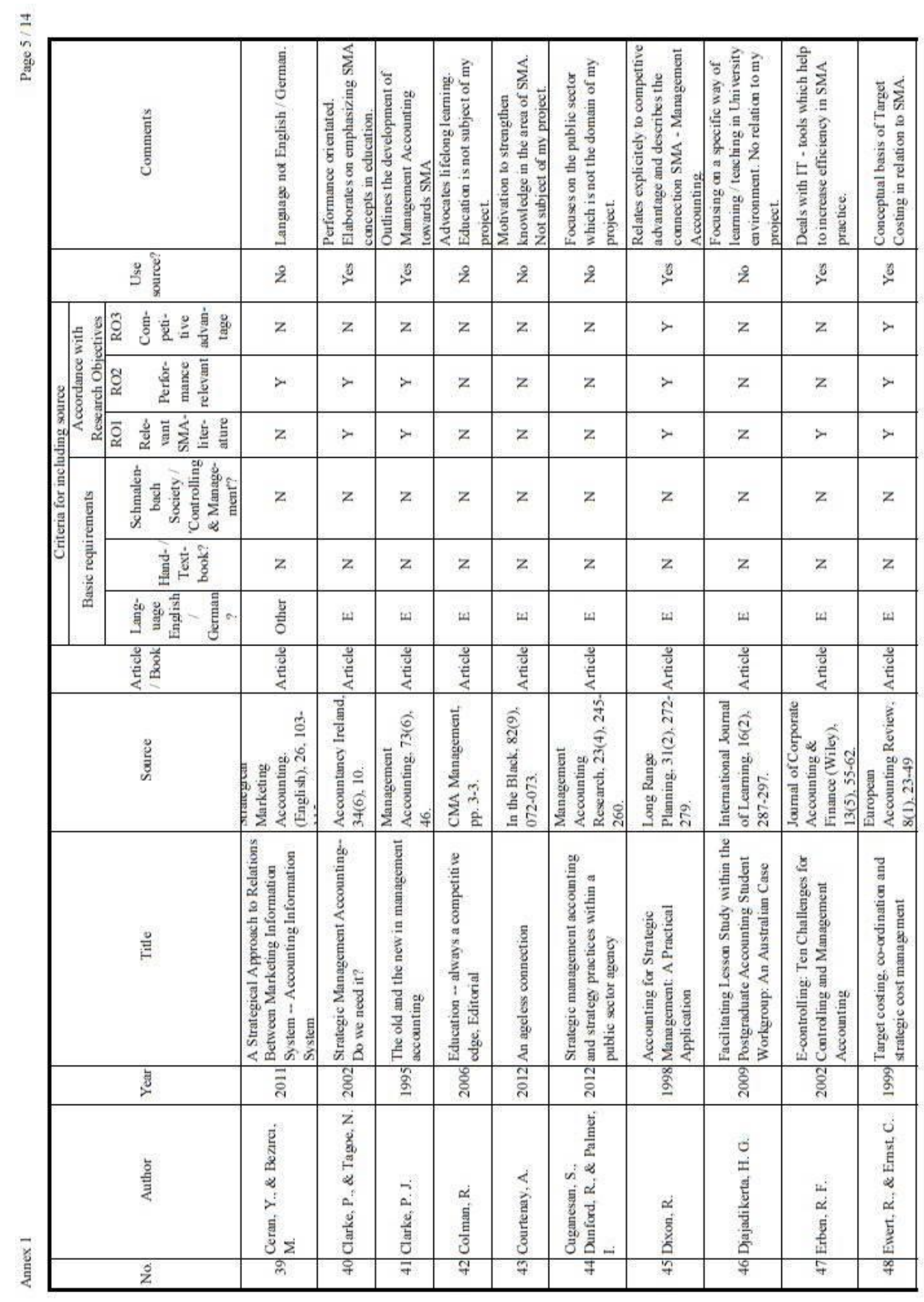




\begin{tabular}{|c|c|c|c|c|c|c|c|c|c|}
\hline 咅 & 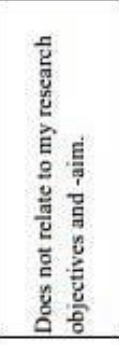 & 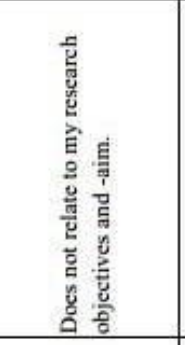 & 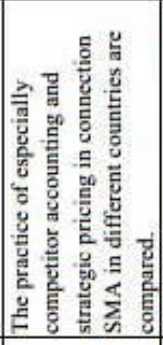 & 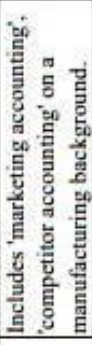 & 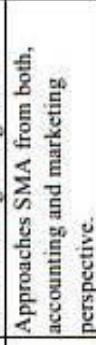 & 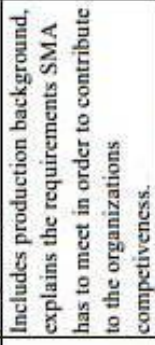 & 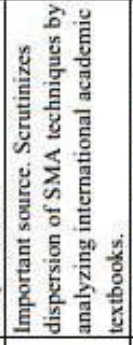 & 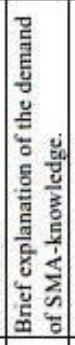 & 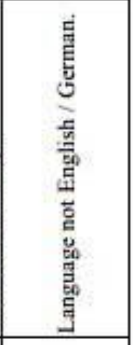 \\
\hline 总总 & $\stackrel{0}{z}$ & $\stackrel{0}{z}$ & $\stackrel{0}{\check{0}}$ & $\stackrel{0}{=}$ & $\stackrel{0}{\check{0}}$ & $\stackrel{0}{-}$ & $\stackrel{n}{=}$ & $\stackrel{0}{2}$ & ₹̊ \\
\hline \multirow{3}{*}{ 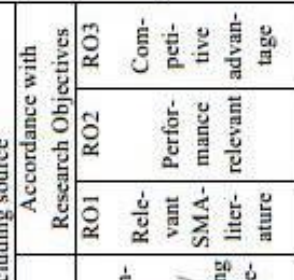 } & z & z & $>$ & $>$ & z & $>$ & z & $z$ & z \\
\hline & z & z & $>$ & $>$ & z & $>$ & z & $>$ & $>$ \\
\hline & z & z & $>$ & $>$ & $>$ & $>$ & $>$ & $z$ & z \\
\hline 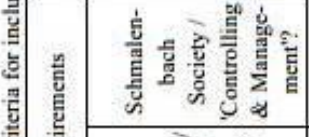 & z & $z$ & $z$ & z & z & z & $>$ & z & z \\
\hline 可言咅咅尊 & z & z & z & z & z & z & z & $z$ & z \\
\hline 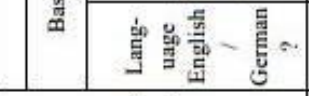 & 니 & w & 니 & H & w & $\omega$ & y & 4 & 喜 \\
\hline $\begin{array}{ll} \\
\end{array}$ & & & $\frac{\square}{\underline{\underline{L}}}$ & $\frac{2}{\frac{2}{2}}$ & 这 & 愛 & $\frac{2}{\underline{\underline{g}}}$ & 递 & $\frac{2}{\underline{\underline{g}}}$ \\
\hline 密 & 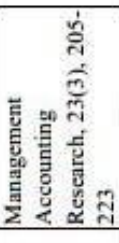 & 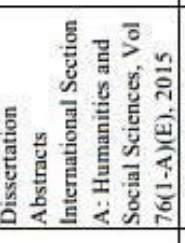 & 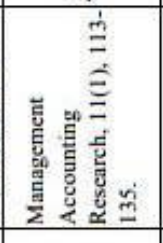 & 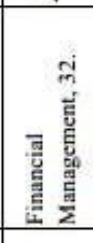 & 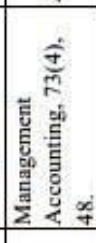 & 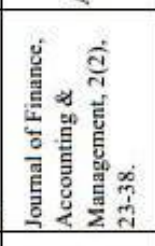 & 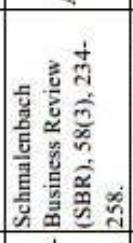 & 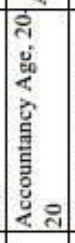 & 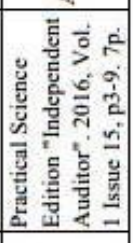 \\
\hline 总 & 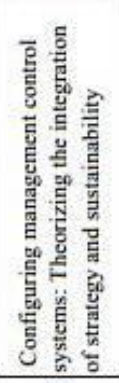 & 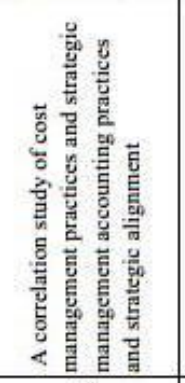 & 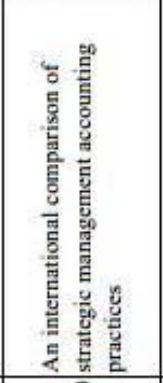 & 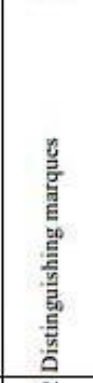 & 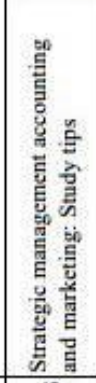 & 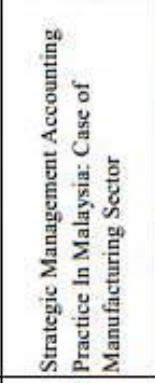 & 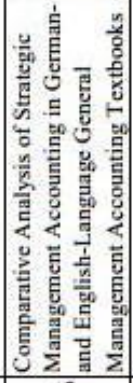 & 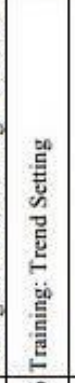 & 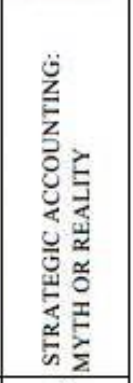 \\
\hline 点 & ปั & $\stackrel{n}{n}$ & ఫ్ & స్్ㅁ & 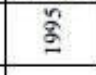 & $\overline{\vec{~}}$ & ङ્ّ̆ & 今్ & ¿ั้ \\
\hline 憘 & 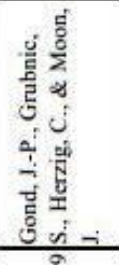 & 曾 & 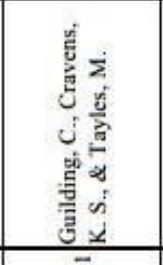 & 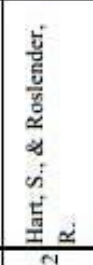 & 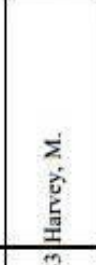 & 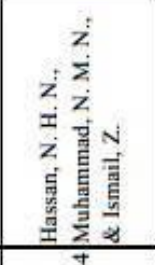 & 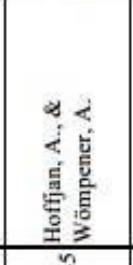 & 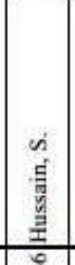 & 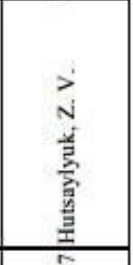 \\
\hline$\frac{1}{2}$ & p & q & $\overline{7}$ & 7 & 7 & 7 & f & o & 7 \\
\hline
\end{tabular}




\begin{tabular}{|c|c|c|c|c|c|}
\hline 起 & & 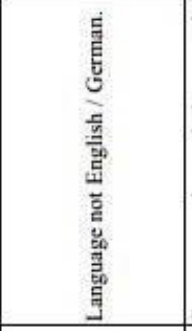 & 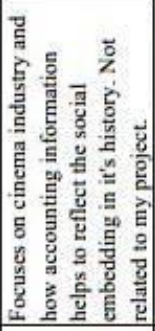 & 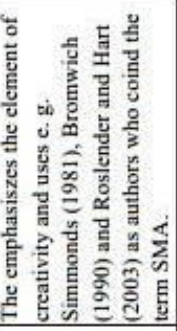 & 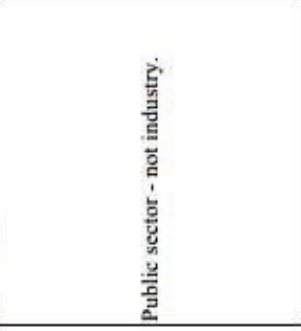 \\
\hline 䝔 & zำ & z̊ & ż & $\check{x}$ & z \\
\hline 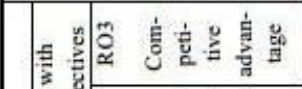 & z & $z$ & $z$ & $>$ & z \\
\hline 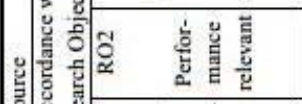 & z & $>$ & z & $>$ & z \\
\hline 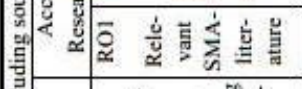 & z & z & $z$ & $>$ & z \\
\hline 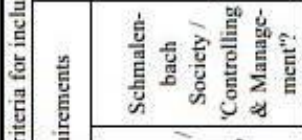 & z & z & z & z & z \\
\hline 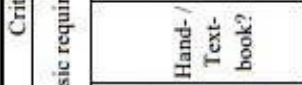 & $z$ & $z$ & $z$ & $z$ & z \\
\hline 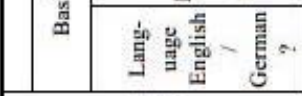 & $\Leftrightarrow$ & $\frac{\underline{\underline{t}}}{\tilde{z}}$ & 니 & ㅆ & 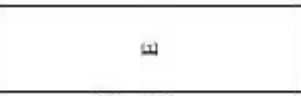 \\
\hline 步总 & $\frac{u}{\frac{u}{L}}$ & & $\frac{2}{2}$ & $\frac{2}{2}$ & 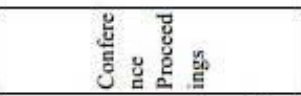 \\
\hline 参 & 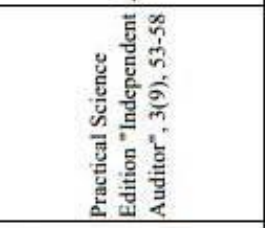 & 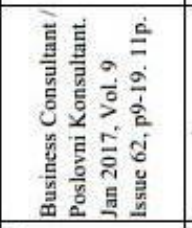 & 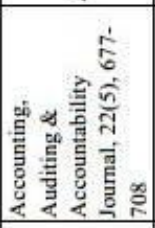 & 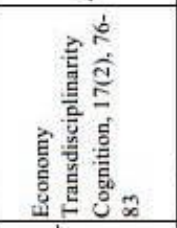 & 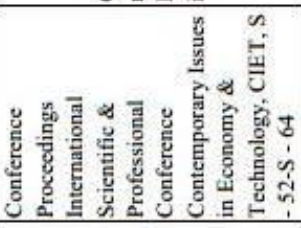 \\
\hline$\stackrel{\varrho}{ٍ ! ~}$ & 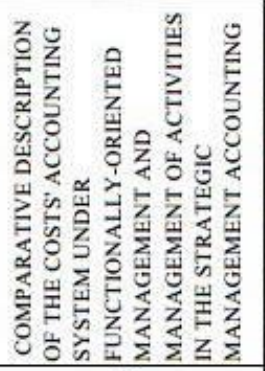 & 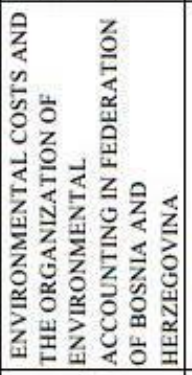 & 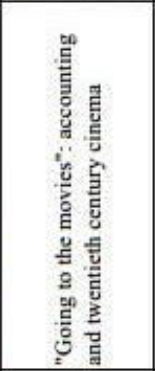 & 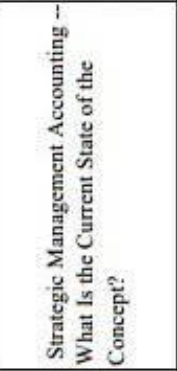 & 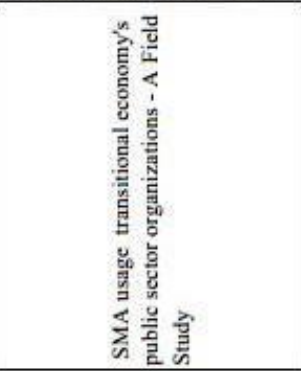 \\
\hline$\underset{2}{2}$ & $\stackrel{4}{\frac{\pi}{4}}$ & 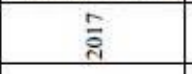 & ક્्ે & 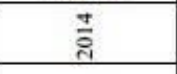 & ڤั้ \\
\hline 总 & 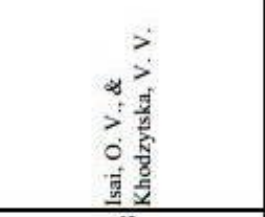 & 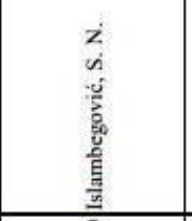 & 它 & 它 & 棉 \\
\hline$\stackrel{8}{2}$ & $\frac{1}{4}$ & q & के & $\bar{n}$ & जै \\
\hline
\end{tabular}




\begin{tabular}{|c|c|c|c|c|c|c|c|c|}
\hline है & 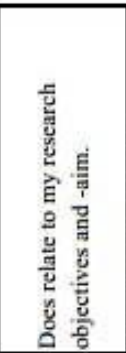 & 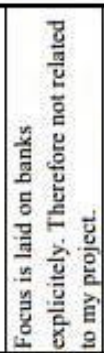 & 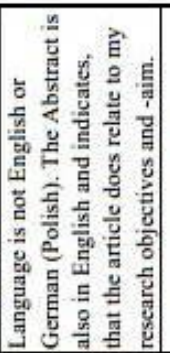 & 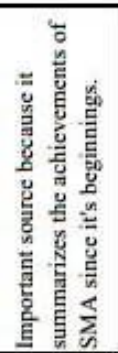 & 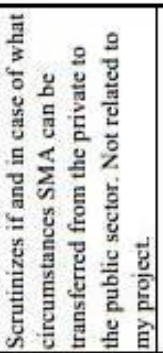 & 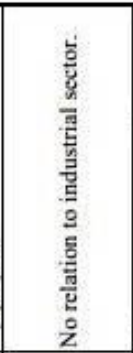 & 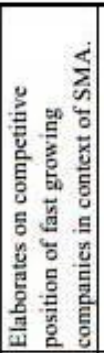 & 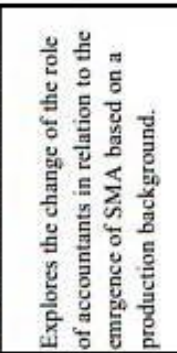 \\
\hline 跑 & z̊ & $\stackrel{z}{z}$ & z̊ & $\stackrel{0}{\check{x}}$ & $\stackrel{z}{z}$ & z̊ & $\stackrel{0}{2}$ & $\stackrel{0}{=}$ \\
\hline 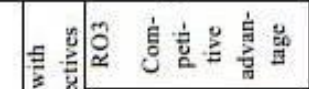 & $z$ & z & z & $>$ & z & $z$ & $>$ & z \\
\hline 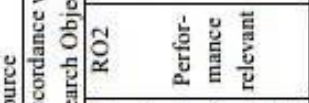 & z & $z$ & z & $>$ & z & z & $>$ & $>$ \\
\hline 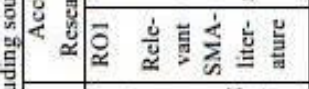 & z & $z$ & $z$ & $>$ & z & $z$ & $z$ & $>$ \\
\hline 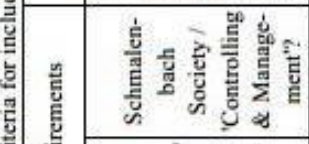 & $z$ & $z$ & $z$ & z & $z$ & $z$ & $z$ & $z$ \\
\hline 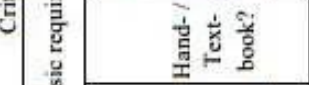 & z & $z$ & $z$ & z & z & z & $z$ & z \\
\hline 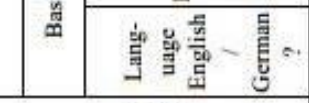 & $\mu$ & (4) & $\frac{\underline{\underline{g}}}{\tilde{z}}$ & 다 & $\omega$ & 山 & (1) & (i) \\
\hline 童总 & $\frac{\pi}{2}$ & $\frac{4}{4}$ & 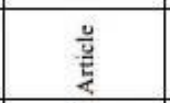 & 递 & $\frac{\square}{\underline{u}}$ & 递 & $\frac{n}{\frac{u}{2}}$ & $\frac{a}{2}$ \\
\hline 趈 & 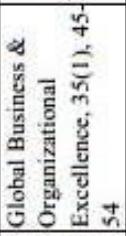 & 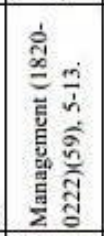 & 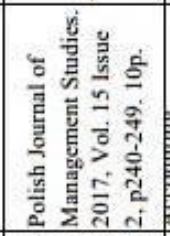 & 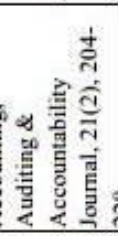 & 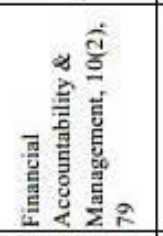 & 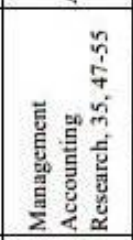 & 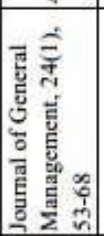 & 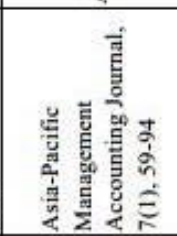 \\
\hline$\stackrel{\varrho}{\Xi}$ & 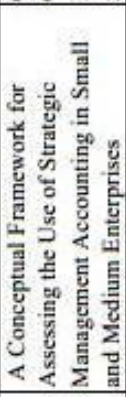 & 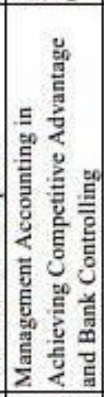 & 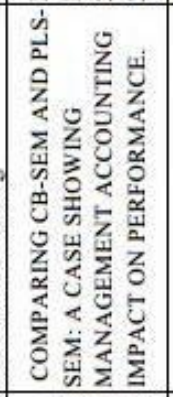 & 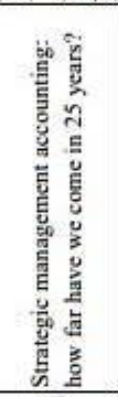 & 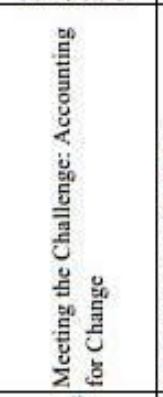 & 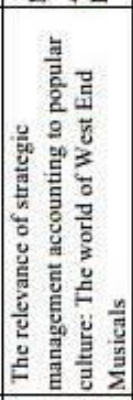 & 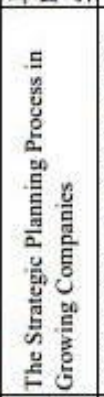 & 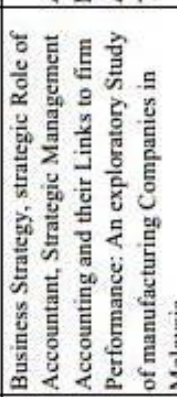 \\
\hline$\stackrel{5}{2}$ & $\stackrel{n}{\bar{n}}$ & $\overline{\vec{*}}$ & ลี่ & 荒 & $\stackrel{t}{g}$ & हิे & $\underline{\infty}$ & $\frac{4}{\overline{3}}$ \\
\hline 总 & 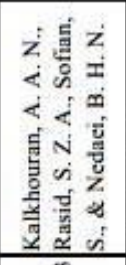 & 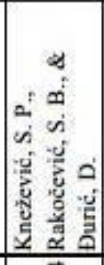 & is & 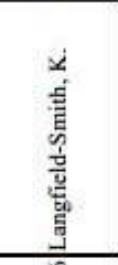 & 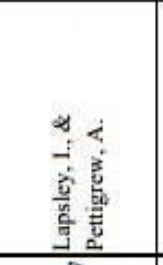 & 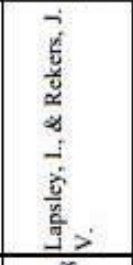 & 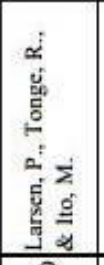 & 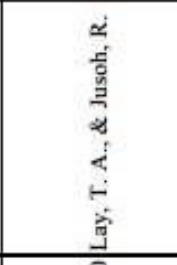 \\
\hline$\frac{j}{4}$ & in & it & n. & in & in & in & in & 8 \\
\hline
\end{tabular}




\begin{tabular}{|c|c|c|c|c|c|c|c|c|}
\hline है & 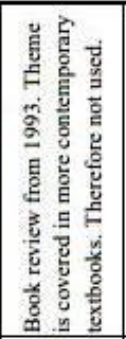 & 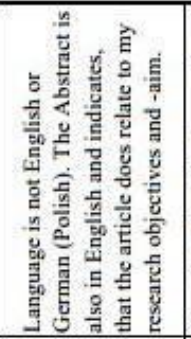 & 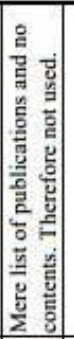 & 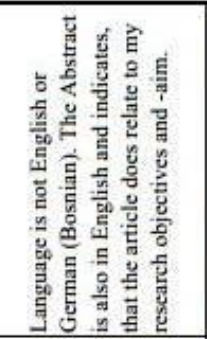 & 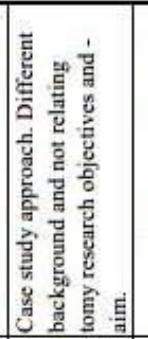 & 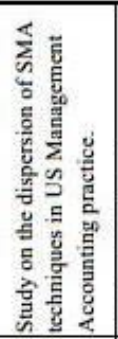 & 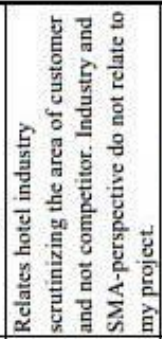 & 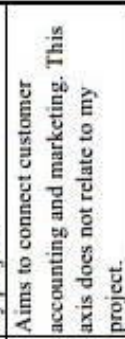 \\
\hline 总 & $\stackrel{2}{2}$ & z & $\not 2$ & ż & z & $\stackrel{0}{\nu}$ & z & z̊ \\
\hline 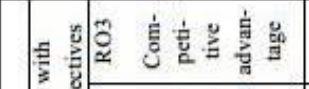 & $z$ & $z$ & $z$ & z & z & z & z & $z$ \\
\hline 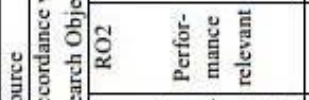 & z & $>$ & $z$ & $>$ & z & $>$ & z & $z$ \\
\hline 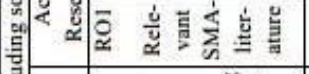 & z & z & $z$ & $z$ & $z$ & $>$ & z & z \\
\hline 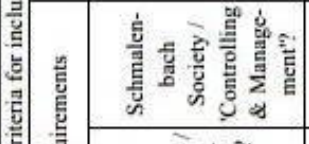 & z & $z$ & $z$ & z & z & z & $z$ & $z$ \\
\hline 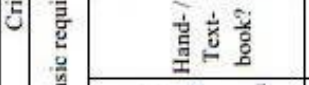 & z & $z$ & $z$ & $z$ & $z$ & z & z & $z$ \\
\hline 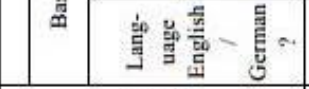 & 마 & है & $\Leftrightarrow$ & $\begin{array}{l}\text { 总 } \\
\text { है }\end{array}$ & 씨 & 마 & ar & 나 \\
\hline 童总 & 总高 & $\frac{2}{\frac{0}{L}}$ & $\frac{\pi}{I}$ & & $\frac{\square}{4}$ & $\frac{\square}{4}$ & $\frac{2}{2}$ & $\frac{0}{2}$ \\
\hline 参 & 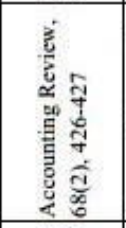 & 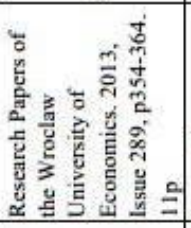 & 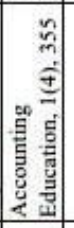 & 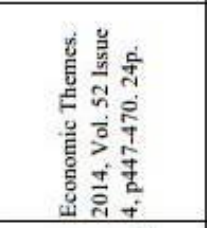 & 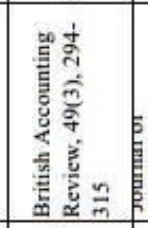 & 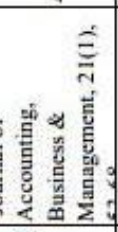 & 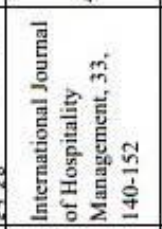 & 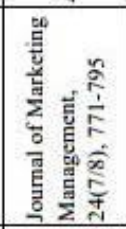 \\
\hline 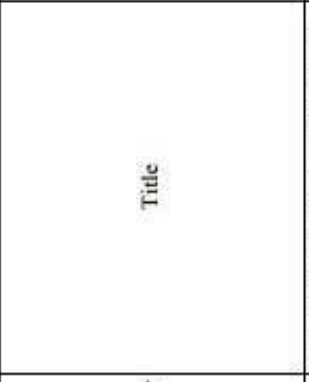 & 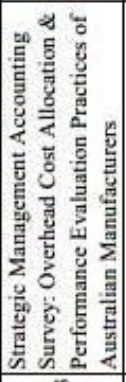 & 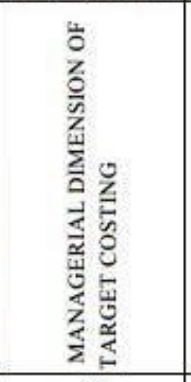 & 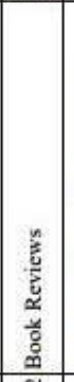 & 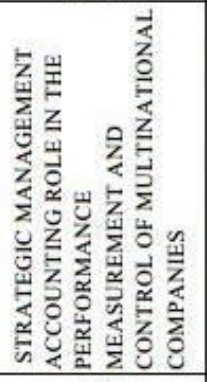 & 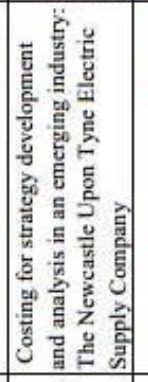 & 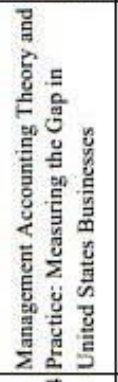 & 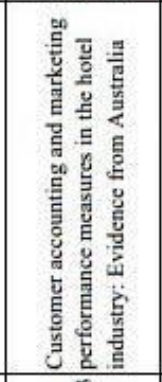 & 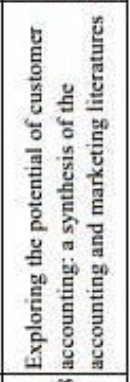 \\
\hline 竧 & g & ले & 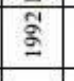 & 竎 & $\hat{\bar{ก}}$ & $\frac{\tilde{c}^{4}}{4}$ & 啇 & 总 \\
\hline $\begin{array}{l}\text { 高 } \\
\text { 竞 }\end{array}$ & 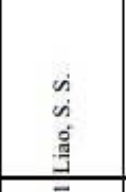 & 告 & 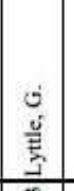 & 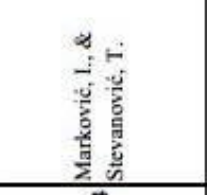 & 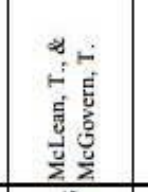 & $\begin{array}{l}0 \\
\vdots \\
i \\
\frac{1}{3} \\
\frac{0}{2} \\
\frac{0}{2}\end{array}$ & $\frac{1}{20}$ & 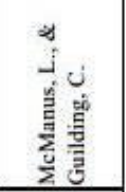 \\
\hline$\stackrel{8}{2}$ & $\bar{b}$ & कु & 3 & t & 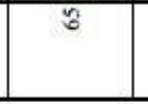 & 8 & 5 & $\mathscr{B}$ \\
\hline
\end{tabular}




\begin{tabular}{|c|c|c|c|c|c|c|c|c|c|c|c|}
\hline 咅 & 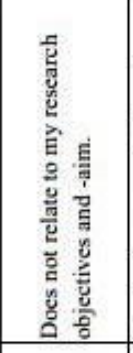 & 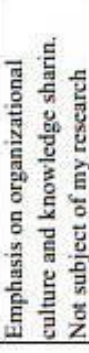 & 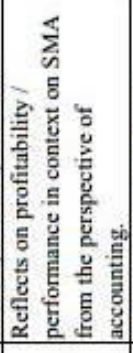 & 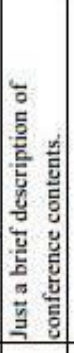 & 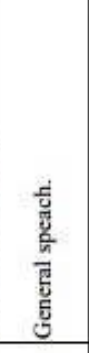 & 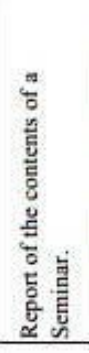 & 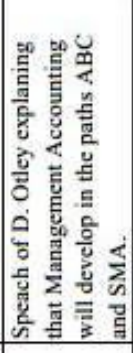 & 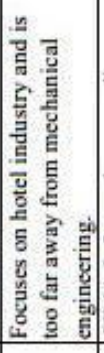 & 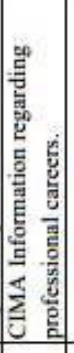 & 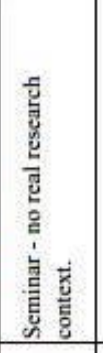 & 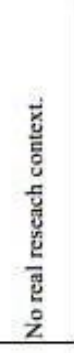 \\
\hline 总 & $\stackrel{0}{z}$ & z̊ & $\stackrel{0}{\sim}$ & z̊ & z̊ & z̊ & $\stackrel{0}{=}$ & z̊ & z & z̊ & z \\
\hline 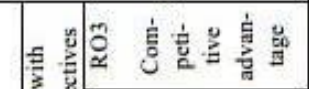 & z & z & $>$ & z & z & z & z & z & $z$ & z & z \\
\hline 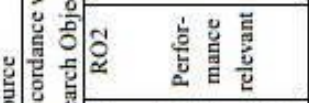 & z & $z$ & $>$ & z & z & z & $>$ & z & $z$ & z & z \\
\hline 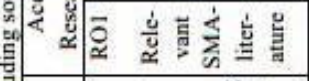 & z & z & $>$ & z & z & z & z & z & $z$ & z & $z$ \\
\hline 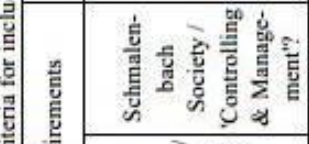 & z & z & z & z & z & z & $z$ & z & $z$ & z & z \\
\hline 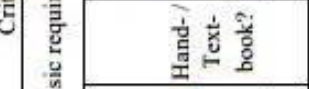 & z & z & z & z & z & z & z & z & $z$ & z & $z$ \\
\hline 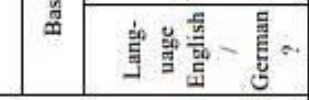 & $\mu$ & 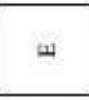 & 4 & $\mu$ & y & $\mu$ & 山 & $\Leftrightarrow$ & 따 & 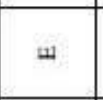 & $\omega$ \\
\hline 噌啻 & $\frac{y}{\underline{\underline{y}}}$ & $\frac{2}{\underline{\underline{u}}}$ & 案咅 & 总 & 总 & 亗 & 莺 & 递 & 递 & $\frac{u}{\underline{\underline{v}}}$ & $\frac{u}{\underline{u}}$ \\
\hline 蒫 & 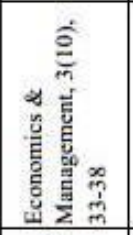 & 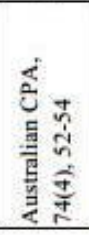 & 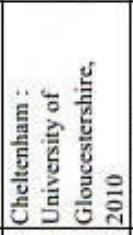 & 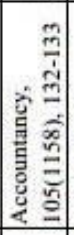 & 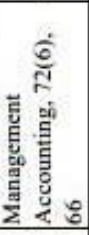 & 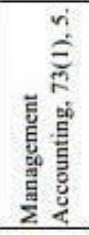 & 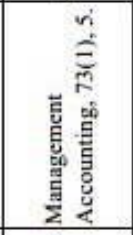 & 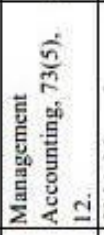 & 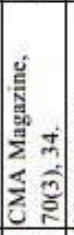 & 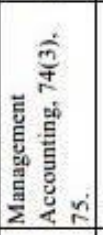 & 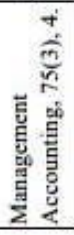 \\
\hline$\stackrel{\varrho}{ٍ ! ~}$ & 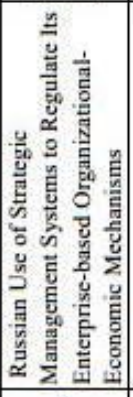 & 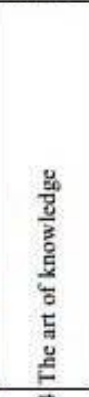 & 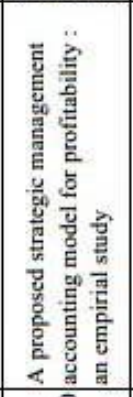 & 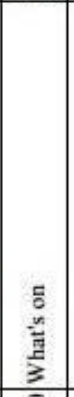 & 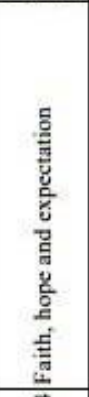 & 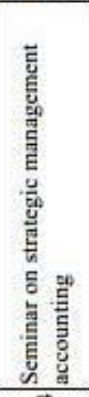 & 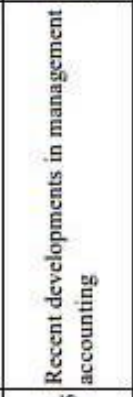 & 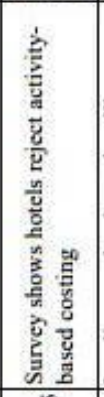 & 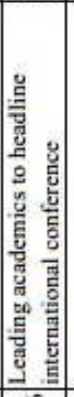 & 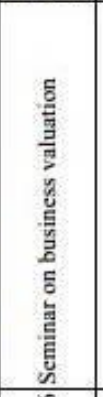 & 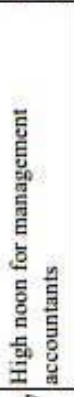 \\
\hline$\stackrel{5}{\circ}$ & 蒿 & 喜 & 高 & $\stackrel{\$}{\circ}$ & $\Phi$ & 紊 & $\xi$ & 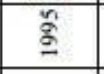 & $\stackrel{\circ}{\leftrightarrows}$ & 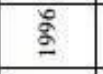 & g \\
\hline 总 & 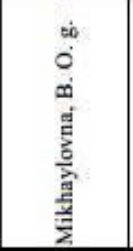 & 造 & 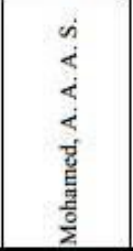 & 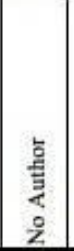 & 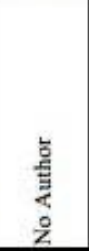 & 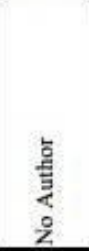 & 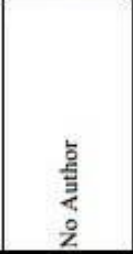 & 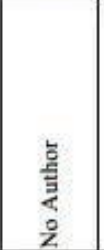 & 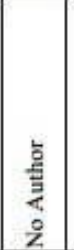 & 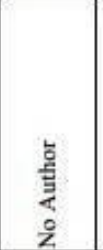 & 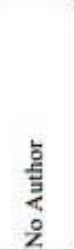 \\
\hline ฉ̀ & 8 & 2 & $\vec{F}$ & 2 & $\vec{r}$ & $\stackrel{7}{\square}$ & 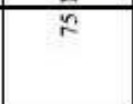 & 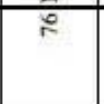 & $F$ & $\infty$ & 2 \\
\hline
\end{tabular}




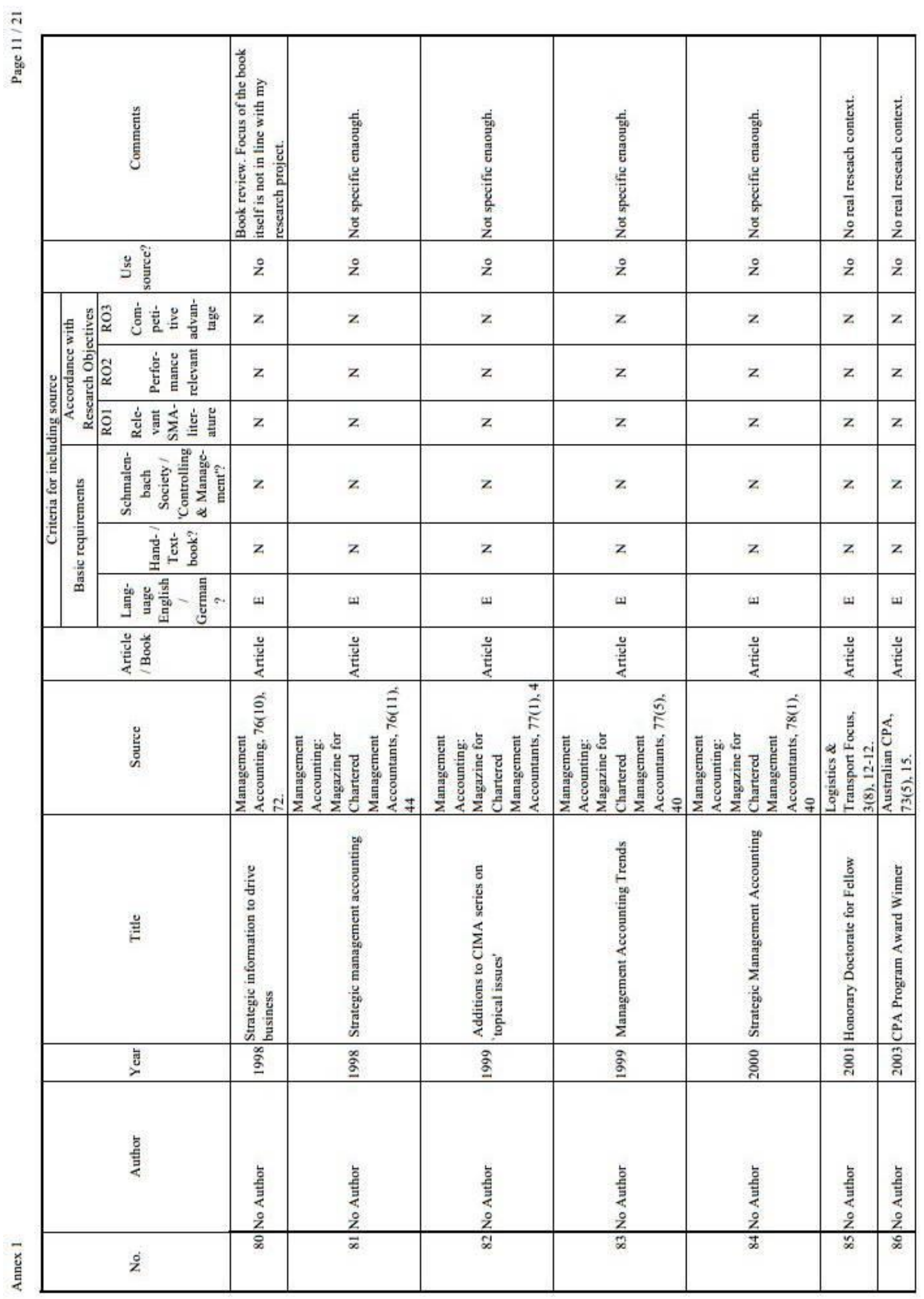




\begin{tabular}{|c|c|c|c|c|c|c|c|c|c|}
\hline 总 & 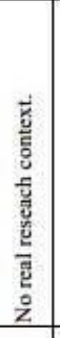 & 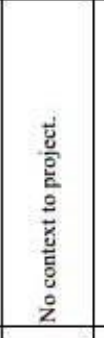 & 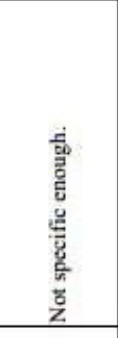 & 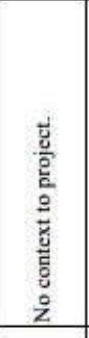 & 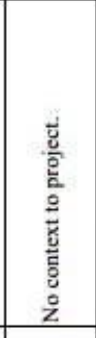 & 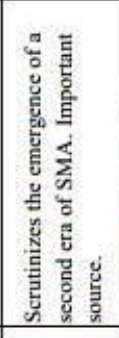 & 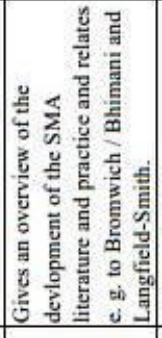 & 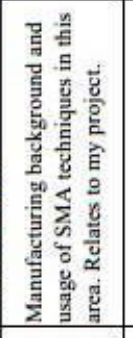 & 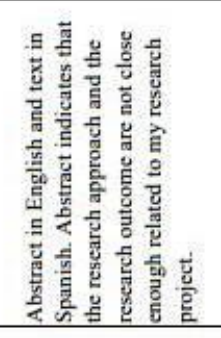 \\
\hline 害 & $\stackrel{0}{z}$ & z̊ & zo & z̊ & z̊ & $\stackrel{0}{0}$ & 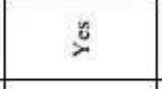 & $\stackrel{x}{x}$ & ஜ \\
\hline 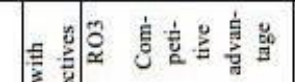 & $\mathrm{z}$ & $z$ & z & $z$ & z & $>$ & $>$ & z & z \\
\hline 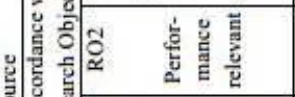 & $\mathrm{z}$ & z & z & z & z & $r$ & $>$ & $>$ & $>$ \\
\hline 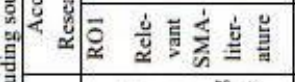 & $\mathrm{z}$ & z & z & $z$ & $\mathrm{z}$ & $>$ & $>$ & $>$ & z \\
\hline 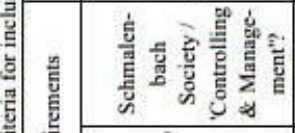 & $z$ & z & z & z & z & z & $z$ & z & $z$ \\
\hline 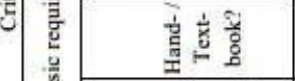 & $\mathrm{z}$ & z & $z$ & z & z & $z$ & z & z & z \\
\hline 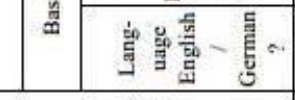 & thy & $\omega$ & $\mu$ & $\omega$ & 山د & $\omega$ & $\omega$ & $\omega$ & $\frac{5}{g}$ \\
\hline 恶尊 & 这 & $\frac{u}{\underline{u}}$ & $\frac{u}{\underline{\underline{u}}}$ & 这 & & $\frac{\square}{4}$ & 递 & $\frac{\square}{20}$ & 总 \\
\hline 产 & 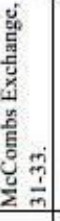 & 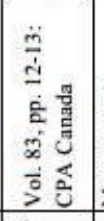 & 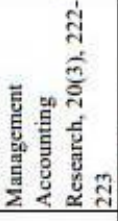 & 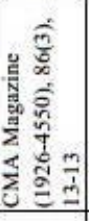 & 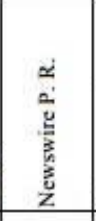 & 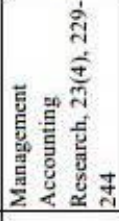 & 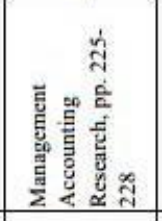 & 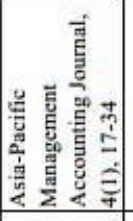 & 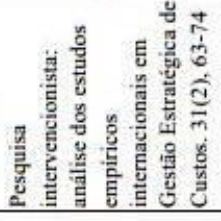 \\
\hline$\stackrel{\varrho}{\Xi}$ & 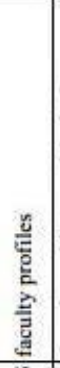 & 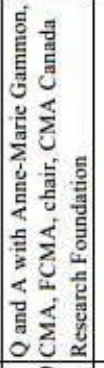 & 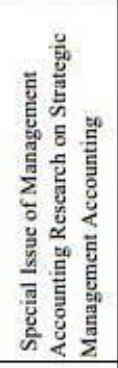 & 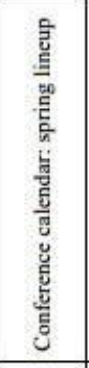 & 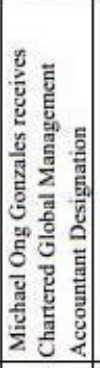 & 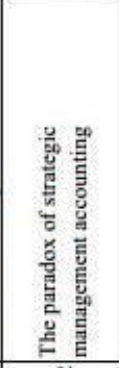 & 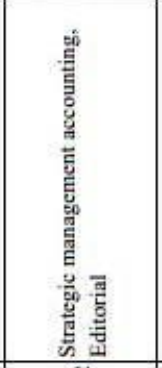 & 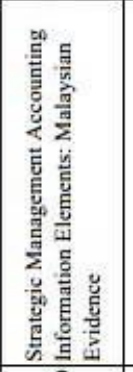 & 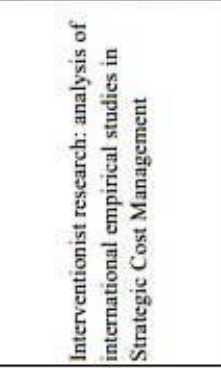 \\
\hline 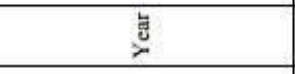 & 钫 & ह్ & हैं & 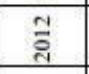 & $\stackrel{n}{i}$ & $\frac{4}{4}$ & $\frac{4}{4}$ & ह્山े & ल) \\
\hline 点 & 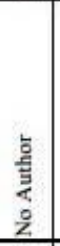 & 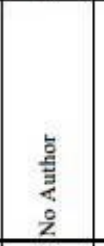 & 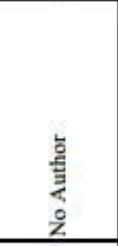 & 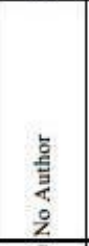 & $\begin{array}{l}\text { 点 } \\
\text { 章 } \\
\vdots \\
\vdots \\
\end{array}$ & 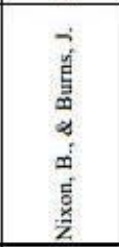 & 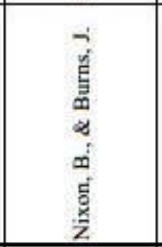 & 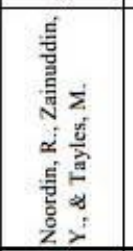 & 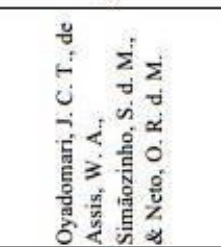 \\
\hline$\frac{\delta}{2}$ & $\infty$ & $\infty$ & 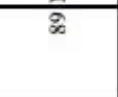 & \% & $\bar{a}$ & 2 & 2 & $\$$ & \% \\
\hline
\end{tabular}




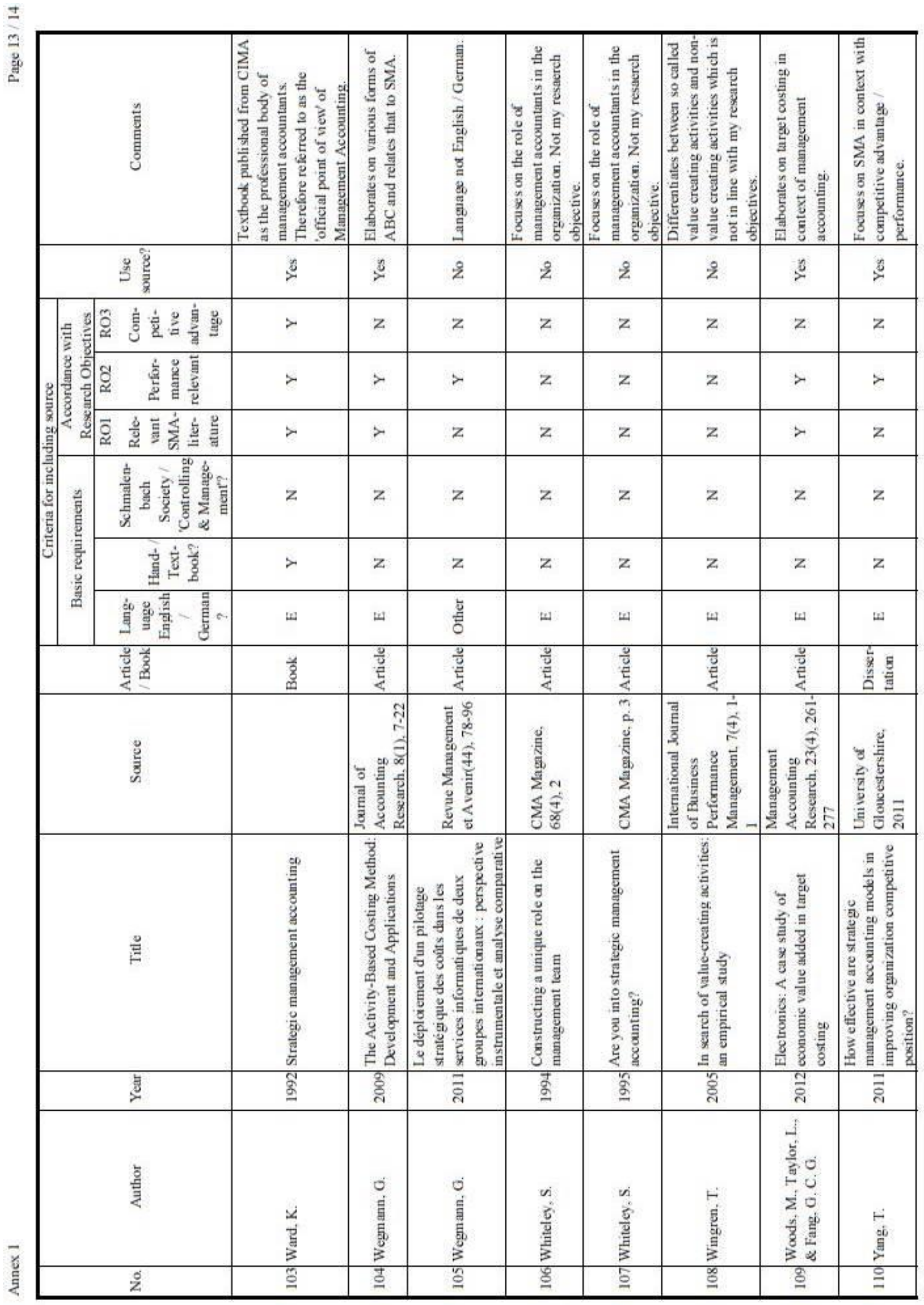




\begin{tabular}{|c|c|c|c|c|c|c|c|}
\hline 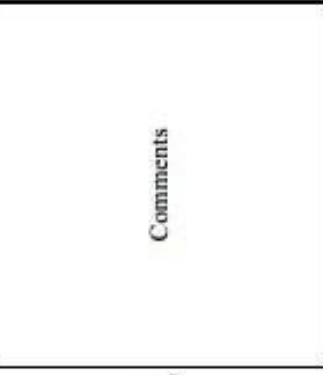 & 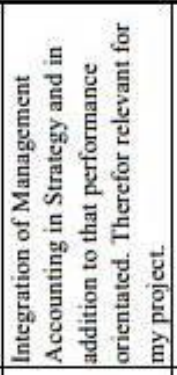 & 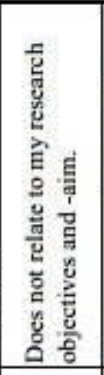 & 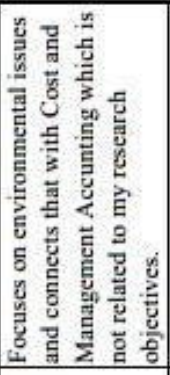 & 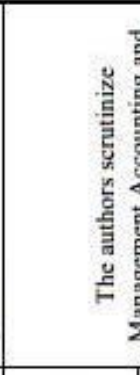 & 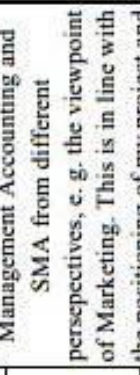 & 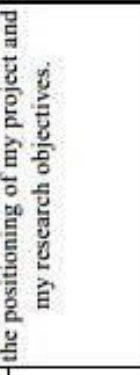 & 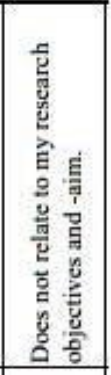 \\
\hline 施 & $\stackrel{n}{\sim}$ & z̊ & ż & $\stackrel{0}{0}$ & $\stackrel{x}{\sim}$ & $\stackrel{0}{0}$ & z \\
\hline 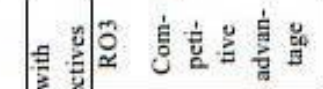 & $>$ & $z$ & $z$ & $>$ & $>$ & $x$ & $z$ \\
\hline 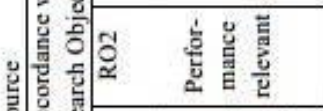 & $>$ & z & $z$ & $>$ & $>$ & $>$ & $z$ \\
\hline$=0$ & $>$ & z & z & $>$ & $>$ & $>$ & z \\
\hline 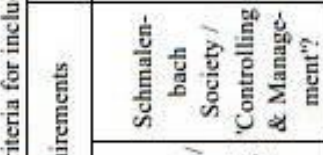 & $z$ & z & z & z & z & $z$ & $z$ \\
\hline 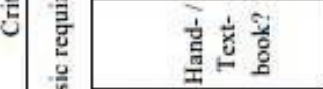 & $z$ & z & $z$ & $z$ & z & $z$ & $z$ \\
\hline 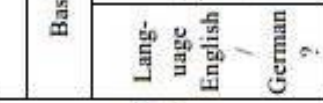 & 너 & 피 & Lلد & 시 & بلد & cul & 니 \\
\hline 总产 & $\frac{2}{20}$ & 这 & $\frac{n}{\underline{u}}$ & 这 & 递 & 递 & 这 \\
\hline 害 & 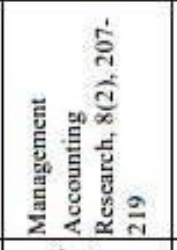 & 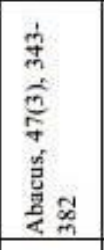 & 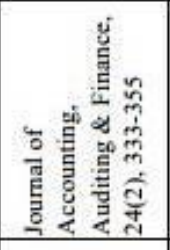 & 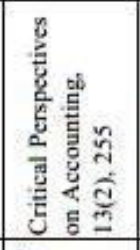 & 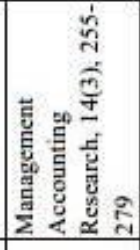 & 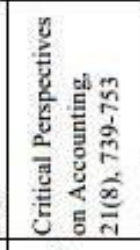 & 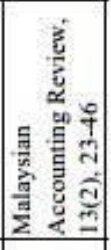 \\
\hline$\stackrel{\varrho}{ٍ ٍ ~}$ & 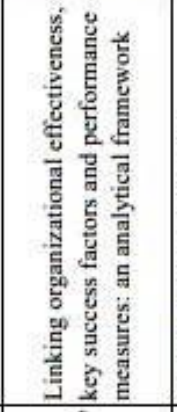 & 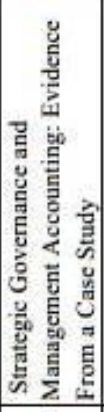 & 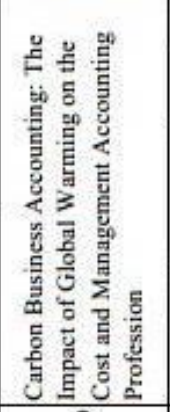 & 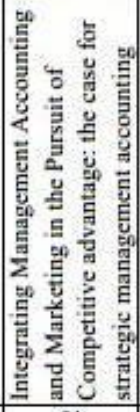 & 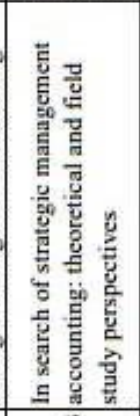 & 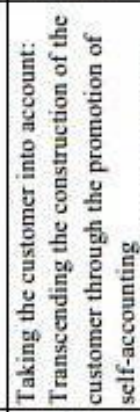 & 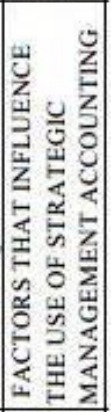 \\
\hline 恶 & $\underline{g}$ & $\overline{\bar{I}}$ & ఫ్సి & స్ క్ & छ़्ल & กั & 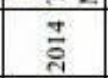 \\
\hline $\begin{array}{l}\text { 兽 } \\
\end{array}$ & 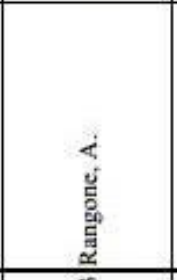 & 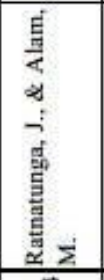 & 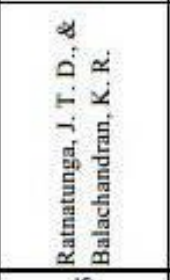 & 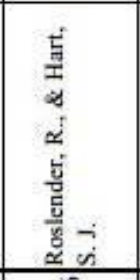 & 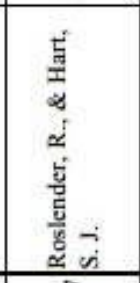 & 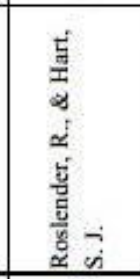 & 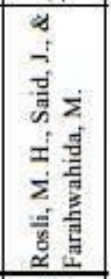 \\
\hline$\frac{8}{4}$ & $\underline{\varrho}$ & $\underline{\underline{g}}$ & $\stackrel{n}{\varrho}$ & $\underline{g}$ & $\underline{\underline{g}}$ & $\stackrel{m}{g}$ & $\underline{\xi}$ \\
\hline
\end{tabular}


Annex 15: Search on EBSCO database on March 11th, 2018, using "strategic\&management\&accounting" as search terms page 15 of 21

\begin{tabular}{|c|c|c|c|c|c|}
\hline 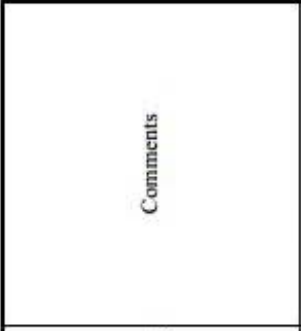 & 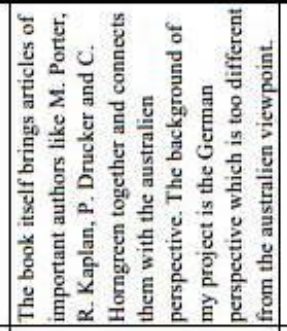 & 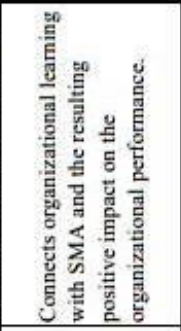 & 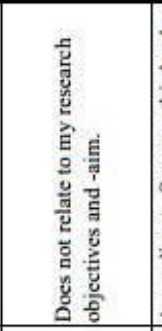 & 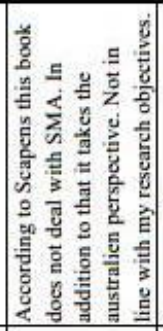 & 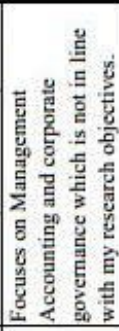 \\
\hline 品害 & $\stackrel{\circ}{z}$ & 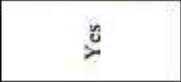 & $\stackrel{2}{2}$ & $\AA$ & $\stackrel{0}{2}$ \\
\hline 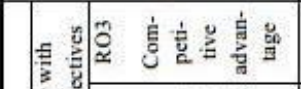 & $z$ & z & z & z & z \\
\hline 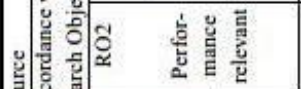 & z & $>$ & z & z & $z$ \\
\hline 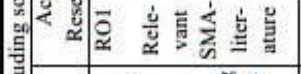 & $z$ & $>$ & z & $z$ & z \\
\hline 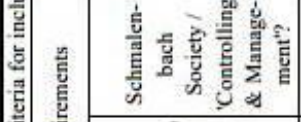 & $z$ & $z$ & z & z & $z$ \\
\hline 毫咅总 & z & z & $z$ & z & $z$ \\
\hline 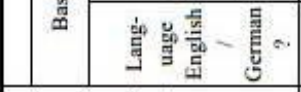 & $\omega$ & H & $\omega$ & $\omega$ & $\psi$ \\
\hline 总 & 范帝 & 产 & 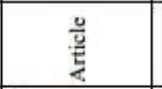 & 咅 & 党 \\
\hline 递 & 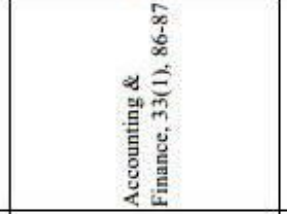 & 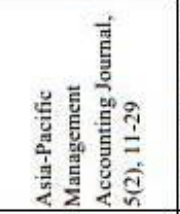 & 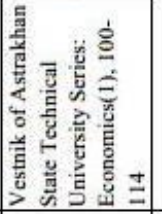 & 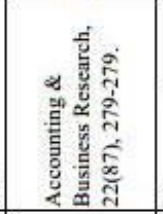 & 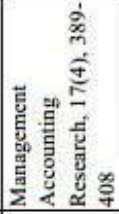 \\
\hline$\stackrel{\varrho}{\ddot{E}}$ & 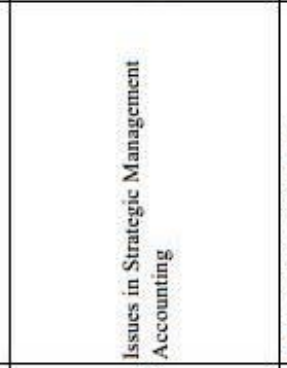 & 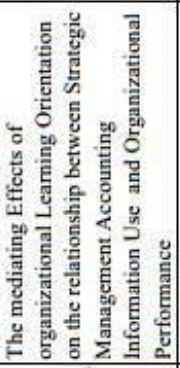 & 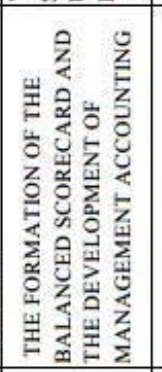 & 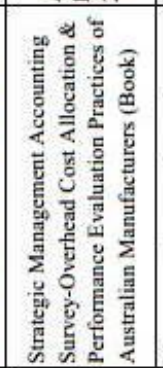 & 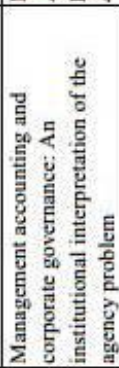 \\
\hline 曾 & $\underline{\xi}$ & มั่ & $\stackrel{n}{n}$ & 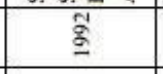 & 究 \\
\hline 喜 & 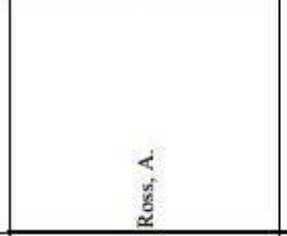 & 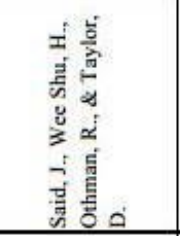 & 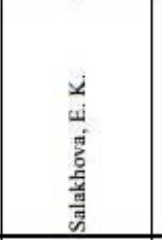 & 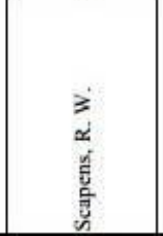 & $\begin{array}{l}3 \\
\text { 覀 }\end{array}$ \\
\hline$\stackrel{d}{z}$ & $\stackrel{\varrho}{\varrho}$ & $\equiv$ & 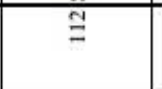 & $\stackrel{M}{\exists}$ & $\stackrel{ \pm}{ \pm}$ \\
\hline
\end{tabular}


Annex 16: Search on EBSCO database on March 11th, 2018, using "strategic\&management\&accounting" as search terms page 16 of 21

\begin{tabular}{|c|c|c|c|c|c|c|c|}
\hline 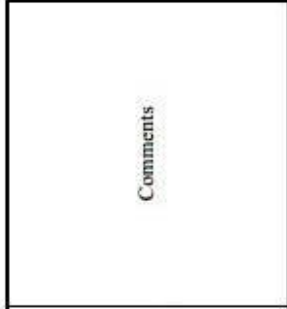 & 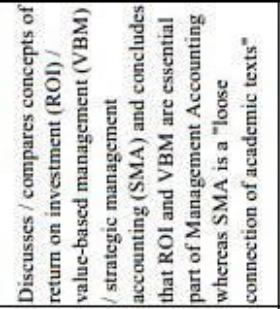 & 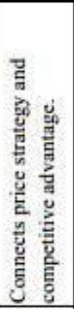 & 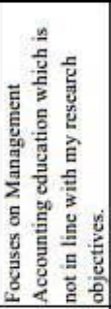 & 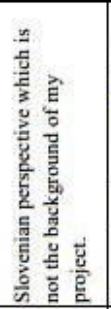 & 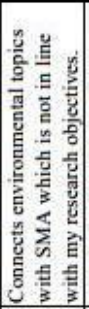 & 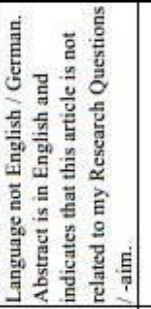 & 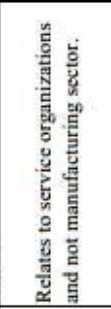 \\
\hline 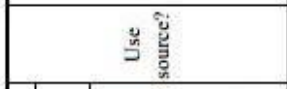 & $\stackrel{\circ}{>}$ & $\stackrel{n}{\sim}$ & $\approx$ & i & z & $\AA$ & z̊ \\
\hline 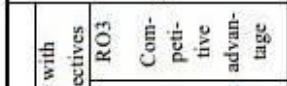 & $z$ & $>$ & $z$ & $z$ & $z$ & $z$ & z \\
\hline 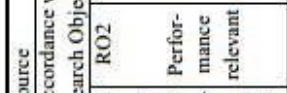 & $>$ & $>$ & $z$ & z & $z$ & $z$ & $z$ \\
\hline 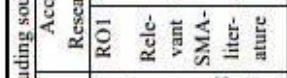 & $z$ & $>$ & $z$ & z & z & $z$ & $z$ \\
\hline 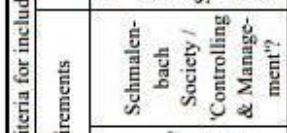 & z & $z$ & $z$ & $z$ & z & $z$ & z \\
\hline 言竞高 & $z$ & $z$ & $z$ & z & $z$ & $z$ & $z$ \\
\hline 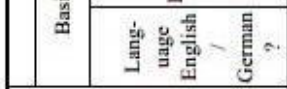 & $\omega$ & $山$ & is & is & $\mu$ & 总 & al \\
\hline $\begin{array}{ll} \\
\end{array}$ & 这 & $\frac{u}{\underline{\underline{u}}}$ & 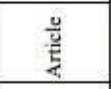 & 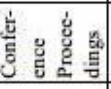 & $\frac{u}{\underline{\underline{u}}}$ & & $\frac{\square}{20}$ \\
\hline 意 & 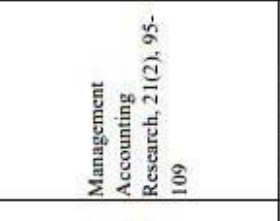 & 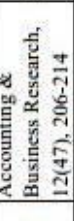 & 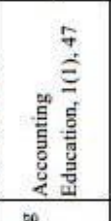 & & 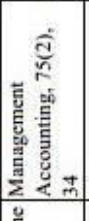 & 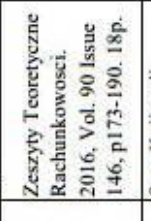 & 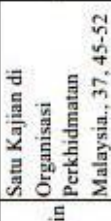 \\
\hline 号 & 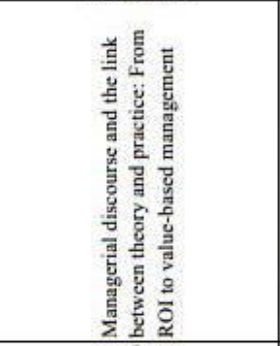 & 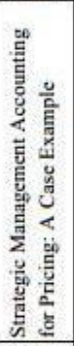 & 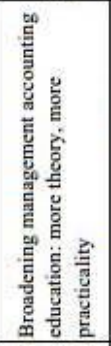 & 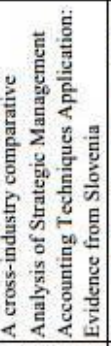 & 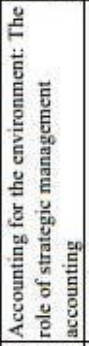 & 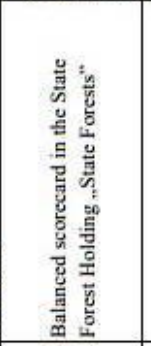 & 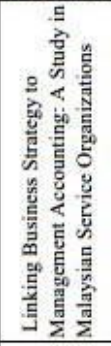 \\
\hline$\underset{\sim}{\stackrel{5}{g}}$ & 言 & $\stackrel{0}{\alpha}$ & פ & 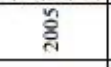 & \$ & 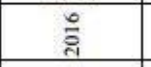 & 商 \\
\hline 总 & 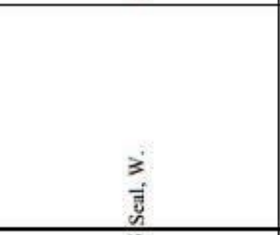 & 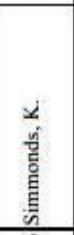 & 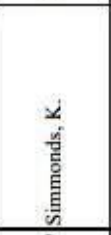 & 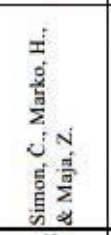 & 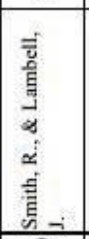 & 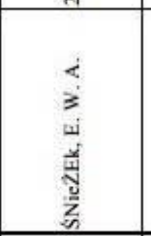 & 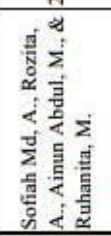 \\
\hline$\frac{\delta}{2}$ & $\stackrel{n}{=}$ & $\cong$ & $\cong$ & $\stackrel{\infty}{=}$ & $\stackrel{g}{\Xi}$ & ฐิ & $\overline{\mathrm{I}}$ \\
\hline
\end{tabular}


Annex 17: Search on EBSCO database on March 11th, 2018, using "strategic\&management\&accounting" as search terms page 17 of 21

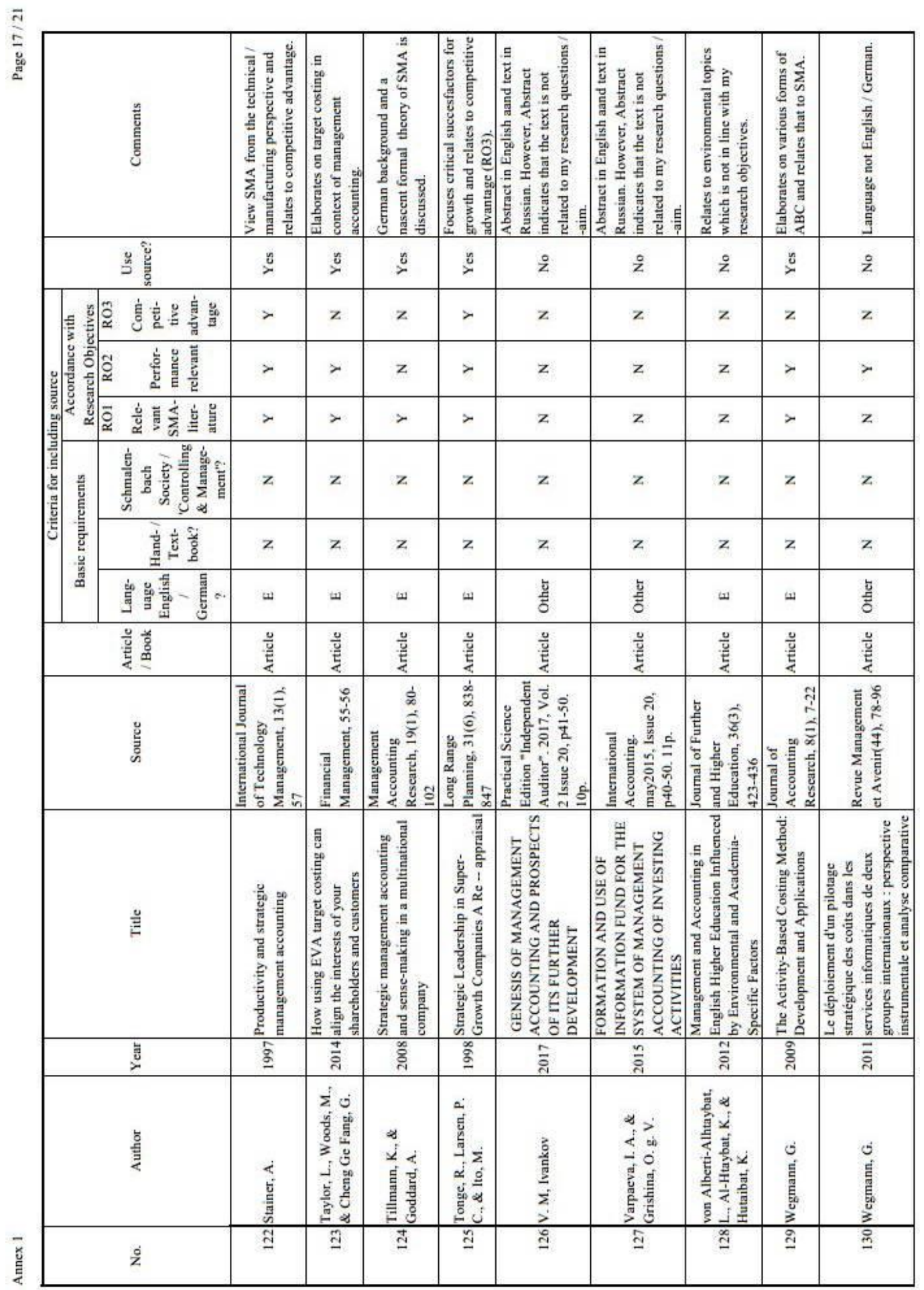


Annex 18: Search on EBSCO database on March 11th, 2018, using "strategic\&management\&accounting" as search terms page 18 of 21

\begin{tabular}{|c|c|c|c|c|c|c|c|c|}
\hline 咅 & 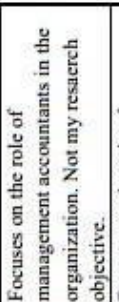 & 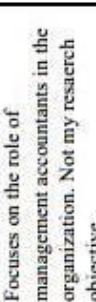 & 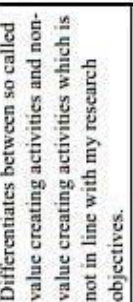 & 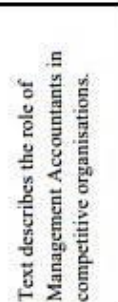 & 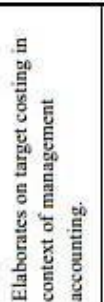 & 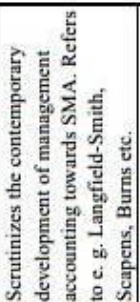 & 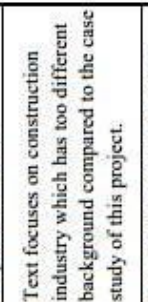 & 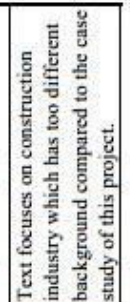 \\
\hline : & $\stackrel{2}{2}$ & z & $\approx$ & 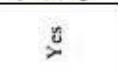 & $\stackrel{8}{2}$ & $\stackrel{x}{>}$ & z̊ & z̊ \\
\hline 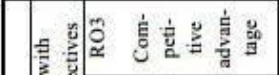 & z & z & z & $>$ & z & $>$ & z & z \\
\hline 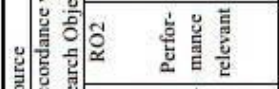 & z & z & $z$ & $>$ & $>$ & $>$ & z & z \\
\hline 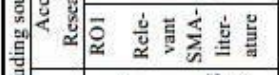 & z & z & $z$ & $>$ & $>$ & $>$ & z & z \\
\hline 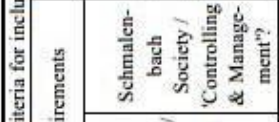 & z & z & z & z & z & z & z & z \\
\hline 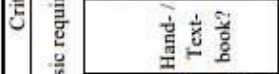 & z & z & z & $z$ & z & z & z & z \\
\hline 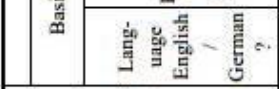 & $\mu$ & $\mu$ & $\mu$ & $\mu$ & $\mu$ & $\omega$ & $\omega$ & $\omega$ \\
\hline 递总 & $\frac{u}{\underline{\underline{u}}}$ & $\frac{\square}{\underline{\underline{g}}}$ & $\frac{u}{\underline{\underline{L}}}$ & $\frac{\square}{\underline{\underline{L}}}$ & $\frac{\square}{2}$ & 递 & $\frac{9}{2}$ & 苋 \\
\hline 参 & 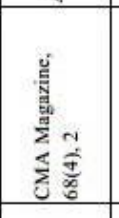 & 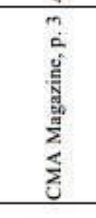 & 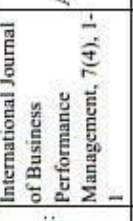 & 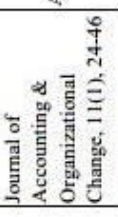 & 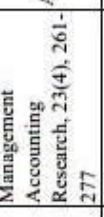 & 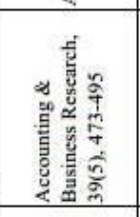 & 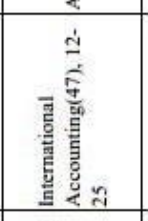 & 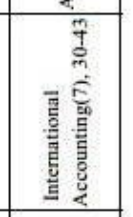 \\
\hline 号 & 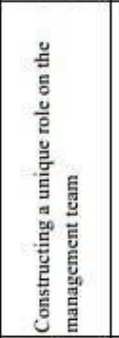 & 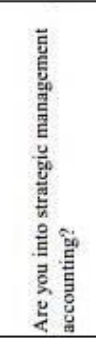 & 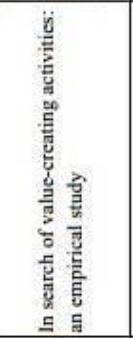 & 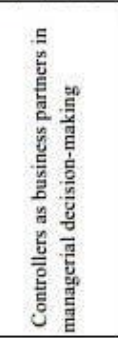 & 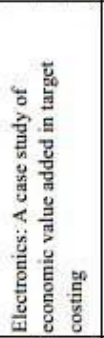 & 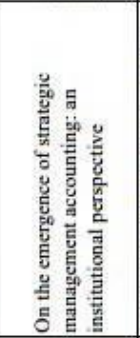 & 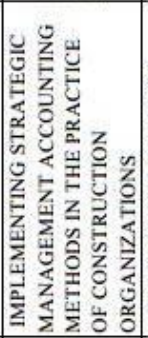 & 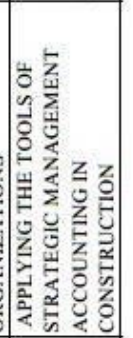 \\
\hline 曾 & 堇 & s & 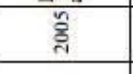 & $\sum_{n}^{n}$ & हूं & हूत्र & 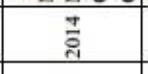 & 商 \\
\hline 喜 & 竞 & 尊 & 它 & 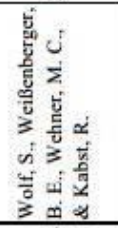 & 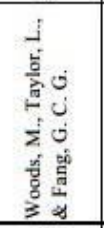 & 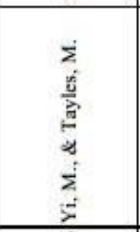 & 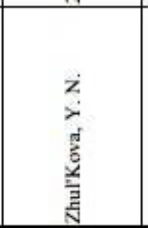 & 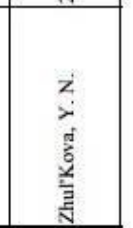 \\
\hline$\dot{s}$ & $\overline{7}$ & 글 & ⿳⺈. & \pm & $\stackrel{n}{\sim}$ & 年 & ff & 市 \\
\hline
\end{tabular}


Annex 19: Search on EBSCO database on March 11th, 2018, using "strategic\&management\&accounting" as search terms page 19 of 21

\begin{tabular}{|c|c|c|c|c|c|c|}
\hline 营 & 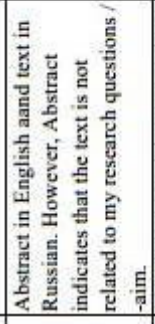 & 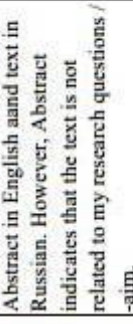 & 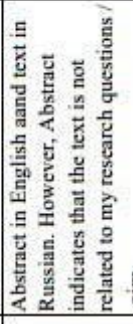 & 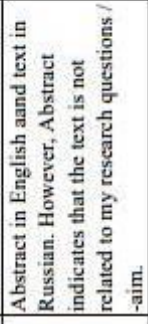 & 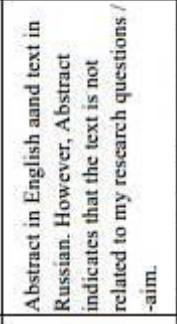 & 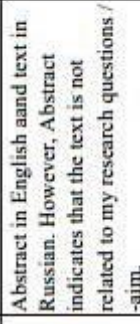 \\
\hline 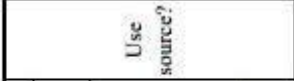 & 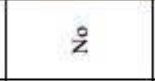 & $\stackrel{8}{2}$ & $\gtrless$ & ₹ & $\AA$ & z \\
\hline 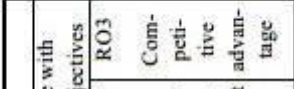 & z & z & $z$ & z & $z$ & $z$ \\
\hline 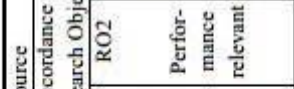 & $z$ & $z$ & $z$ & $z$ & $z$ & $z$ \\
\hline 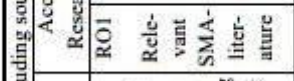 & $z$ & $z$ & $z$ & $z$ & $z$ & $z$ \\
\hline | & $z$ & z & $z$ & $z$ & $z$ & $z$ \\
\hline 高突总 & z & $z$ & $z$ & $z$ & z & z \\
\hline 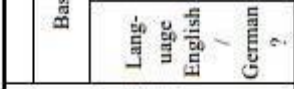 & है & है & है & है & 竎 & 竎 \\
\hline 鄫 & & & & & & \\
\hline 骂 & 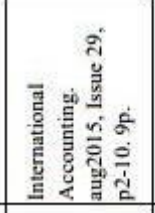 & 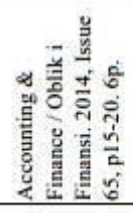 & 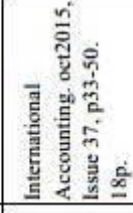 & 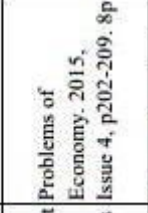 & 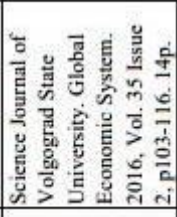 & 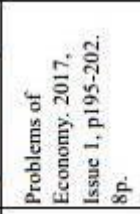 \\
\hline 号 & 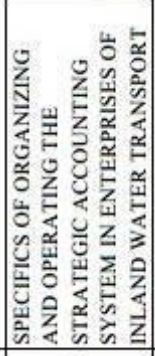 & 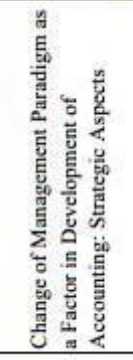 & 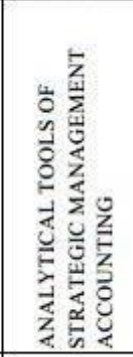 & 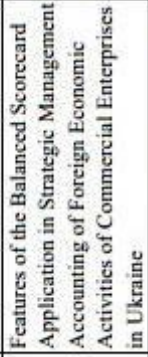 & 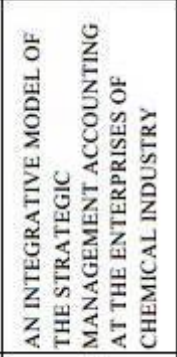 & 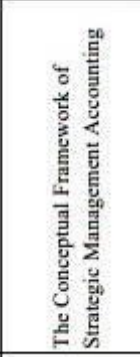 \\
\hline 点 & $\sum_{i=1}^{n}$ & गे & $\stackrel{n}{\bar{d}}$ & $\stackrel{n}{n}$ & $\stackrel{\circ}{\circ}$ & 惑 \\
\hline 然 & 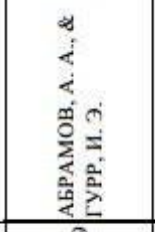 & 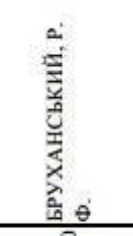 & 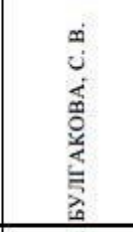 & 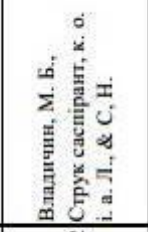 & 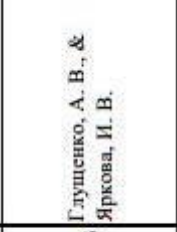 & 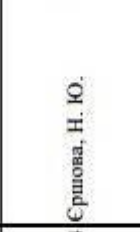 \\
\hline$\frac{8}{2}$ & शु & 早 & $\Xi$ & \pm & $q$ & \pm \\
\hline
\end{tabular}


Annex 20: Search on EBSCO database on March 11th, 2018, using "strategic\&management\&accounting" as search terms page 20 of 21

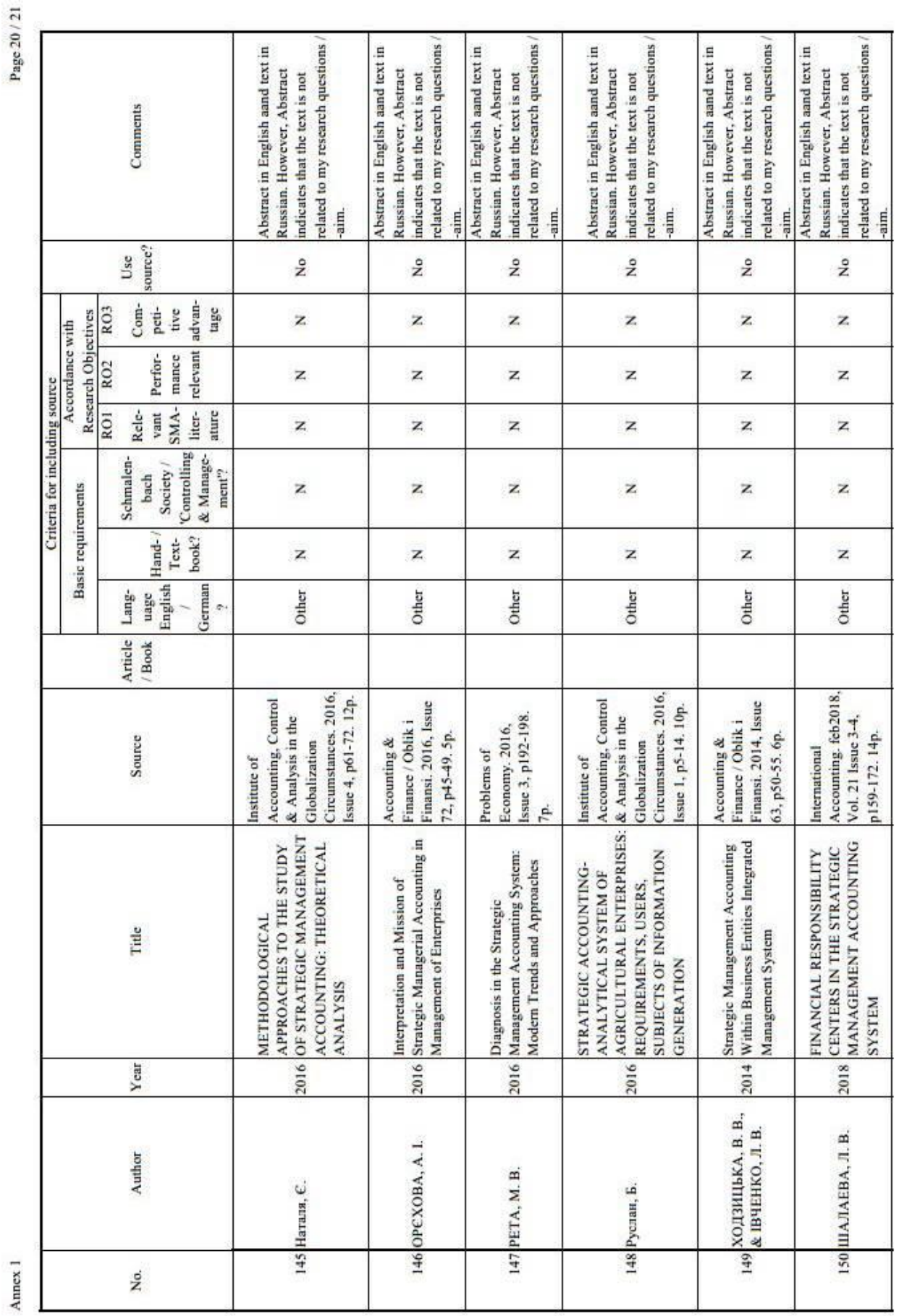


Annex 21: Search on EBSCO database on March 11th, 2018, using

"strategic\&management\&accounting" as search terms page 21 of 21

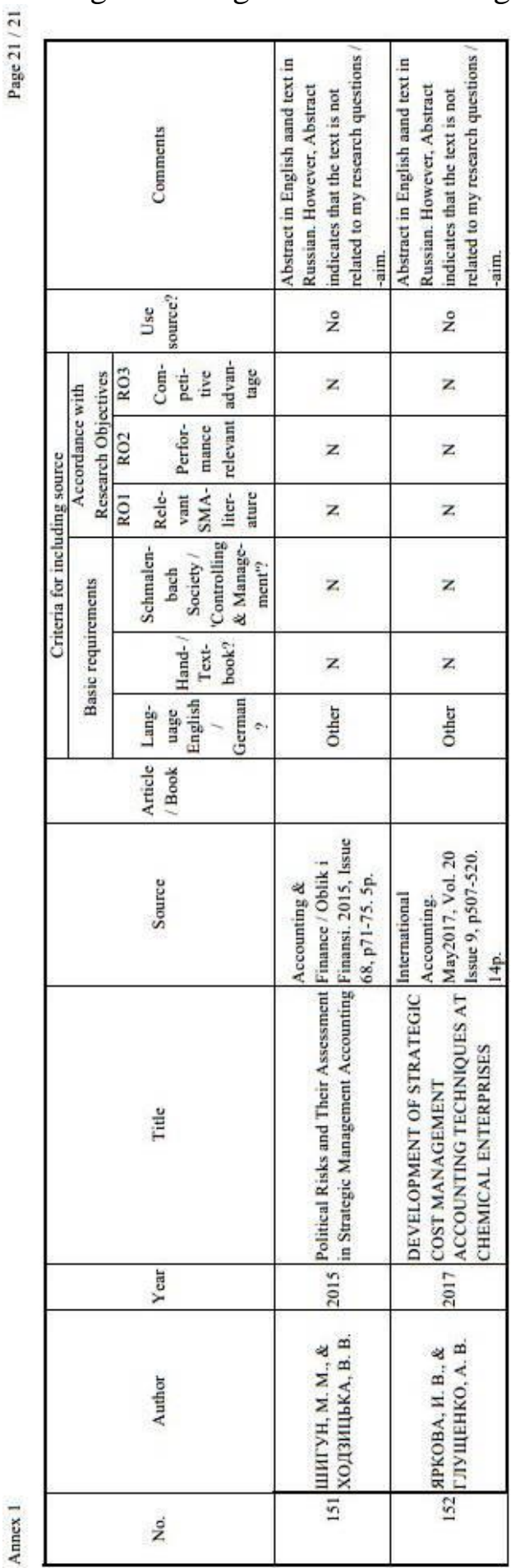


Annex 22: Conceptual Framework: References grouped according to Information Categories and Perspectives by year / Top level

\begin{tabular}{|c|c|c|c|c|c|c|c|c|c|c|c|c|c|c|c|c|c|c|c|c|c|c|c|c|c|}
\hline \multicolumn{26}{|c|}{ Conce } \\
\hline & & \multicolumn{6}{|c|}{ Financial Analysts } & \multicolumn{6}{|c|}{ Focused Company } & \multicolumn{6}{|c|}{ Major Competitor } & \multicolumn{6}{|c|}{ Total References } \\
\hline \multicolumn{2}{|c|}{ Category } & 2008 & 2009 & 2010 & 2011 & 2012 & $08-12$ & 2008 & 2009 & 2010 & 2011 & 2012 & $08-12$ & 2008 & 2009 & 2010 & 2011 & 2012 & $08-12$ & 2008 & 2009 & 2010 & 2011 & 2012 & $08-12$ \\
\hline \multirow{5}{*}{ 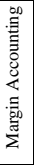 } & General & 0 & 0 & 0 & 0 & 24 & 24 & $\mid 3.331$ & 3.013 & 3.043 & 2.718 & 2.753 & 14.860 & 197 & 197 & 75 & 119 & 168 & $756 \|$ & 3.528 & $|3.210|$ & 3.118 & 2.837 & 2.945 & 15.640 \\
\hline & Product Line & 0 & 0 & 0 & 0 & 31 & 31 & 2.935 & 2.624 & 2.542 & 2.531 & 2.521 & 13.153 & 167 & 105 & 69 & 128 & 171 & $640 \|$ & 3.102 & \begin{tabular}{|l|}
2.729 \\
\end{tabular} & 2.611 & \begin{tabular}{|l|}
2.659 \\
\end{tabular} & 2.723 & $\mid 13.824$ \\
\hline & Total & 0 & 0 & 0 & 0 & 55 & 55 & 6.266 & 5.637 & 5.585 & 5.249 & 5.274 & 28.013 & 364 & 302 & 144 & 247 & 339 & 1.396 & 6.630 & 5.939 & 5.729 & 5.496 & 5.668 & 29.464 \\
\hline & Share Year & $0 \%$ & $0 \%$ & $0 \%$ & $0 \%$ & $1 \%$ & $0 \%$ & $95 \%$ & $95 \%$ & $97 \%$ & $96 \%$ & $93 \%$ & $95 \%$ & $5 \%$ & $5 \%$ & $3 \%$ & $4 \%$ & $6 \%$ & $5 \%$ & $100 \%$ & $\mid 100 \%$ & $100 \%$ & $100 \%$ & $100 \%$ & $100 \%$ \\
\hline & Share Category & $0 \%$ & $0 \%$ & $0 \%$ & $0 \%$ & $15 \%$ & $15 \%$ & $70 \%$ & $69 \%$ & $74 \%$ & $72 \%$ & $72 \%$ & $72 \%$ & $40 \%$ & $35 \%$ & $26 \%$ & $34 \%$ & $31 \%$ & $34 \%$ & $68 \%$ & $66 \%$ & $71 \%$ & $69 \%$ & $65 \%$ & $68 \%$ \\
\hline \multirow{5}{*}{ 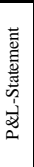 } & Total Cost & 0 & + & 0 & 0 & 54 & 54 & 871 & 841 & 594 & 641 & 629 & 3.576 & 53 & 100 & 46 & 56 & 116 & 371 & 924 & 941 & 640 & 697 & 799 & 4.001 \\
\hline & Cost of Sales & 0 & 0 & 0 & 0 & 63 & 63 & 697 & 664 & 475 & 511 & 502 & 2.849 & 102 & 138 & 97 & 92 & 191 & 620 & 799 & 802 & 572 & 603 & 756 & 3.53 \\
\hline & Total & 0 & 0 & 0 & 0 & 117 & 117 & \begin{tabular}{|l|}
1.568 \\
\end{tabular} & 1.505 & 1.069 & 1.152 & 1.131 & 6.425 & 155 & 238 & 143 & 148 & 307 & 991 & 1.723 & \begin{tabular}{|l|}
1.743 \\
\end{tabular} & 1.212 & 1.300 & 1.555 & 7.533 \\
\hline & Share Year & $0 \%$ & $0 \%$ & $0 \%$ & $0 \%$ & $8 \%$ & $2 \%$ & $91 \%$ & $86 \%$ & $88 \%$ & $89 \%$ & $73 \%$ & $85 \%$ & $9 \%$ & $14 \%$ & $12 \%$ & $11 \%$ & $20 \%$ & $13 \%$ & $100 \%$ & $100 \%$ & $100 \%$ & $100 \%$ & $100 \%$ & $100 \%$ \\
\hline & Share Category & $0 \%$ & $0 \%$ & $0 \%$ & $0 \%$ & $32 \%$ & $32 \%$ & $18 \%$ & $19 \%$ & $14 \%$ & $16 \%$ & $15 \%$ & $16 \%$ & $17 \%$ & $28 \%$ & $26 \%$ & $20 \%$ & $28 \%$ & $24 \%$ & $18 \%$ & $19 \%$ & $15 \%$ & $16 \%$ & $18 \%$ & $17 \%$ \\
\hline \multirow{6}{*}{ 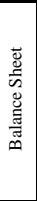 } & Assets & 0 & 0 & 0 & 0 & 21 & 21 & 298 & 227 & 198 & 196 & 210 & 1.129 & 5 & 6 & 7 & 3 & 67 & 88 & 303 & 233 & 205 & 199 & 298 & 1.238 \\
\hline & Equity \& & 0 & 0 & 0 & 0 & 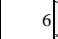 & 6 & 3 & 13 & 9 & 1 & 16 & 44 & 4 & 1 & 1 & 1 & 1 & 8 & 9 & 14 & 10 & 2 & 23 & 58 \\
\hline & Work. Cap. / ROCH & 0 & 0 & 0 & 0 & 7 & 7 & 193 & 145 & 113 & 130 & 133 & 714 & 0 & 0 & 0 & 0 & 16 & 16 & 193 & 145 & 113 & 130 & 156 & 737 \\
\hline & Total & 0 & 0 & 0 & 0 & 34 & 34 & 496 & 385 & 320 & 327 & 359 & 1.887 & 9 & 7 & 8 & 4 & 84 & 112 & 505 & 392 & 328 & 331 & 477 & 2.033 \\
\hline & Share Year & $0 \%$ & $0 \%$ & $0 \%$ & $0 \%$ & $7 \%$ & $2 \%$ & $98 \%$ & $98 \%$ & $98 \%$ & $99 \%$ & $75 \%$ & $93 \%$ & $2 \%$ & $2 \%$ & $2 \%$ & $1 \%$ & $18 \%$ & $6 \%$ & $100 \%$ & $100 \%$ & $100 \%$ & $100 \%$ & $100 \%$ & $100 \%$ \\
\hline & Share C & $0 \%$ & $0 \%$ & $0 \%$ & $0 \%$ & $9 \%$ & $9 \%$ & $6 \%$ & $5 \%$ & $4 \%$ & $5 \%$ & $5 \%$ & $5 \%$ & $1 \%$ & $1 \%$ & $1 \%$ & $1 \%$ & $8 \%$ & $3 \%$ & $5 \%$ & $4 \%$ & $4 \%$ & $4 \%$ & $5 \%$ & $5 \%$ \\
\hline \multirow{4}{*}{ 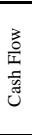 } & Cash Flow & 0 & 0 & 0 & 0 & 5 & 5 & 0 & 0 & 0 & 0 & 21 & 21 & 7 & 7 & 7 & 6 & 8 & 35 & 7 & & 7 & 6 & 34 & 61 \\
\hline & Total & 0 & 0 & 0 & 0 & 5 & 5 & 0 & 0 & 0 & 0 & 21 & 21 & 7 & 1 & 7 & 6 & 8 & 35 & 7 & & 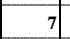 & 0 & 34 & 61 \\
\hline & Share Year & $0 \%$ & $0 \%$ & $0 \%$ & $0 \%$ & $15 \%$ & $8 \%$ & $0 \%$ & $0 \%$ & $0 \%$ & $0 \%$ & $62 \%$ & $34 \%$ & $100 \%$ & $100 \%$ & $100 \%$ & $100 \%$ & $24 \%$ & $57 \%$ & $100 \%$ & $100 \%$ & $100 \%$ & $100 \%$ & $100 \%$ & $100 \%$ \\
\hline & Share Category & $0 \%$ & $0 \%$ & $0 \%$ & $0 \%$ & $1 \%$ & $1 \%$ & $0 \%$ & $0 \%$ & $0 \%$ & $0 \%$ & $0 \%$ & $0 \%$ & $1 \%$ & $1 \%$ & $1 \%$ & $1 \%$ & $1 \%$ & $1 \%$ & $0 \%$ & $0 \%$ & $0 \%$ & $0 \%$ & $0 \%$ & $0 \%$ \\
\hline \multirow{9}{*}{. } & Strat. Plan & & & & & & 0 & 17 & 13 & 24 & 1 & 13 & 68 & & & & & & 0 & 17 & 13 & 24 & 1 & 13 & 68 \\
\hline & MC Highlights & 0 & 0 & 0 & 0 & 2 & 2 & & & & & & 0 & 2 & 0 & 0 & & 4 & 7 & -7 & 0 & & 1 & & \\
\hline & FA & 0 & 0 & 0 & 0 & 79 & 79 & & & & & & 0 & & & & & & 0 & 0 & 0 & 0 & 0 & 79 & 79 \\
\hline & Statistics & 4 & 0 & 0 & 0 & 27 & 31 & 159 & 167 & 118 & 126 & 126 & 696 & 64 & 49 & 12 & 27 & 25 & 177 & 227 & 216 & 130 & 153 & 178 & 904 \\
\hline & Cons. Hie & 4 & 0 & 0 & 0 & 21 & 25 & 21 & 33 & 42 & 14 & 13 & 123 & 227 & 210 & 209 & 220 & 211 & 1.077 & 252 & 243 & 251 & 234 & 245 & 1.225 \\
\hline & Regions & 0 & 0 & 0 & 0 & 21 & 21 & 367 & 391 & 357 & 376 & 404 & 1.895 & 92 & 49 & 35 & 72 & 107 & 355 & 459 & 440 & 392 & 448 & 532 & 2.271 \\
\hline & Total & 8 & . & 0 & 0 & 150 & 158 & 564 & 604 & 541 & 517 & 556 & 2.782 & 385 & 308 & 256 & 320 & 347 & 1.616 & 957 & 912 & 797 & 837 & .053 & 4.556 \\
\hline & Share Year & $1 \%$ & $0 \%$ & $0 \%$ & $0 \%$ & $14 \%$ & $3 \%$ & $59 \%$ & $66 \%$ & $68 \%$ & $62 \%$ & $53 \%$ & $61 \%$ & $40 \%$ & $34 \%$ & $32 \%$ & $38 \%$ & $33 \%$ & $35 \%$ & $100 \%$ & $100 \%$ & $100 \%$ & $100 \%$ & $100 \%$ & $100 \%$ \\
\hline & Share C & $100 \%$ & $0 \%$ & $0 \%$ & $0 \%$ & $42 \%$ & $43 \%$ & $6 \%$ & $7 \%$ & $7 \%$ & $7 \%$ & $8 \%$ & $7 \%$ & $42 \%$ & $36 \%$ & $46 \%$ & $44 \%$ & $32 \%$ & $39 \%$ & $10 \%$ & $10 \%$ & $10 \%$ & $11 \%$ & $12 \%$ & $10 \%$ \\
\hline \multirow{3}{*}{ 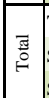 } & Total & 8 & 0 & 0 & 0 & 361 & 369 & \begin{tabular}{|l|}
8.894 \\
\end{tabular} & 8.131 & 7.515 & 7.245 & \begin{tabular}{|l|}
7.341 \\
\end{tabular} & 39.128 & 920 & 862 & 558 & 725 & 1.085 & 4.150 & 9.822 & \begin{tabular}{|l|}
8.993 \\
\end{tabular} & 8.073 & 7.970 & 8.787 & 43.647 \\
\hline & Share Y & $0 \%$ & $0 \%$ & $0 \%$ & $0 \%$ & $4 \%$ & $1 \%$ & $91 \%$ & $90 \%$ & $93 \%$ & $91 \%$ & $84 \%$ & $90 \%$ & $9 \%$ & $10 \%$ & $7 \%$ & $9 \%$ & $12 \%$ & $10 \%$ & $100 \%$ & $100 \%$ & $100 \%$ & $100 \%$ & $100 \%$ & $100 \%$ \\
\hline & Share Category & $100 \%$ & $0 \%$ & $0 \%$ & $0 \%$ & $100 \%$ & $100 \%$ & $100 \%$ & $100 \%$ & $100 \%$ & $100 \%$ & $100 \%$ & $100 \%$ & $100 \%$ & $100 \%$ & $100 \%$ & $100 \%$ & $100 \%$ & $100 \%$ & $100 \%$ & $100 \%$ & $100 \%$ & $100 \%$ & $100 \%$ & $100 \%$ \\
\hline
\end{tabular}


Annex 23: Conceptual Framework: References group according to Information Categories and Perspectives by year / Margin Accounting

\begin{tabular}{|c|c|c|c|c|c|c|c|c|c|c|c|c|c|c|c|c|c|c|c|c|c|c|c|c|c|}
\hline \multicolumn{26}{|c|}{ ers } \\
\hline & & \multicolumn{6}{|c|}{ Financial Analysts } & \multicolumn{6}{|c|}{ Focused Company } & \multicolumn{6}{|c|}{ Major Competitor } & \multicolumn{6}{|c|}{ Total References } \\
\hline \multicolumn{2}{|c|}{ Category } & 2008 & 009 & 2010 & 2011 & 2012 & $08-12$ & 2008 & 2009 & 2010 & 2011 & 2012 & $08-12$ & 2008 & 2009 & 2010 & 2011 & 2012 & $08-12$ & 2008 & 2009 & 2010 & 2011 & 2012 & $08-12$ \\
\hline \multirow[t]{3}{*}{ 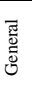 } & General & 0 & 0 & c & 0 & 24 & 24 & 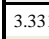 & \begin{tabular}{|l|l|} 
& 3.013 \\
\end{tabular} & 3.043 & 2.718 & 2.753 & 14.860 & 197 & 197 & 75 & 119 & 168 & $756 \|$ & 3.528 & $|3.210|$ & 3.118 & 2.837 & 2.945 & $\mid 15.640$ \\
\hline & Share Year & $0 \%$ & $0 \%$ & $0 \%$ & $0 \%$ & $1 \%$ & $0 \%$ & $94 \%$ & $94 \%$ & $98 \%$ & $96 \%$ & $93 \%$ & $95 \%$ & $6 \%$ & $6 \%$ & $2 \%$ & $4 \%$ & $6 \%$ & $5 \%$ & $100 \%$ & $100 \%$ & $100 \%$ & $100 \%$ & $100 \%$ & $100 \%$ \\
\hline & Share Ca & $0 \%$ & $0 \%$ & $0 \%$ & $0 \%$ & $44 \%$ & $44 \%$ & $53 \%$ & $53 \%$ & $54 \%$ & $52 \%$ & $52 \%$ & $53 \%$ & $54 \%$ & $65 \%$ & $52 \%$ & $48 \%$ & $50 \%$ & $54 \%$ & $53 \%$ & $54 \%$ & $54 \%$ & $52 \%$ & $52 \%$ & $53 \%$ \\
\hline \multirow{30}{*}{ 总 } & C-PL1 & 0 & 0 & & 0 & 1 & & 337 & 331 & 323 & 340 & 363 & .694 & 24 & 12 & 6 & 16 & 22 & 80 & 361 & 343 & 329 & 356 & 386 & 1.775 \\
\hline & Share Year & $0 \%$ & $0 \%$ & $0 \%$ & $0 \%$ & $0 \%$ & $0 \%$ & 93\% & $97 \%$ & $98 \%$ & $96 \%$ & $94 \%$ & $5 \%$ & $7 \%$ & $3 \%$ & $2 \%$ & $4 \%$ & $6 \%$ & $5 \%$ & $100 \%$ & $100 \%$ & $100 \%$ & $100 \%$ & $100 \%$ & $100 \%$ \\
\hline & Share Ca & $0 \%$ & $0 \%$ & $0 \%$ & $0 \%$ & $2 \%$ & $2 \%$ & $5 \%$ & $6 \%$ & $6 \%$ & $6 \%$ & $7 \%$ & $6 \%$ & $7 \%$ & $4 \%$ & $4 \%$ & $6 \%$ & $6 \%$ & $6 \%$ & $5 \%$ & $6 \%$ & $6 \%$ & $6 \%$ & $7 \%$ & $6 \%$ \\
\hline & C-PL2 & 0 & 0 & c & 0 & 1 & & 33 & 352 & 325 & 331 & 357 & 1.700 & 14 & 8 & 5 & & & 42 & 349 & 360 & 330 & 338 & 366 & 1.743 \\
\hline & Share Year & $0 \%$ & $0 \%$ & $0 \%$ & $0 \%$ & $0 \%$ & $0 \%$ & $96 \%$ & $98 \%$ & $98 \%$ & $98 \%$ & $98 \%$ & $3 \%$ & $4 \%$ & $2 \%$ & $2 \%$ & $2 \%$ & $2 \%$ & $2 \%$ & $100 \%$ & $100 \%$ & $100 \%$ & $100 \%$ & $100 \%$ & $100 \%$ \\
\hline & Share Category & $0 \%$ & $0 \%$ & $0 \%$ & $0 \%$ & $2 \%$ & $2 \%$ & $5 \%$ & $6 \%$ & $6 \%$ & $6 \%$ & $7 \%$ & $6 \%$ & $4 \%$ & $3 \%$ & $3 \%$ & $3 \%$ & $2 \%$ & $3 \%$ & $5 \%$ & $6 \%$ & $6 \%$ & $6 \%$ & $6 \%$ & $6 \%$ \\
\hline & C-PL3 & 0 & 0 & c & 0 & 1 & & 63 & 415 & 426 & 399 & 390 & 2.266 & 23 & 11 & 5 & 23 & 11 & 73 & 659 & 426 & 431 & 422 & 402 & 2.340 \\
\hline & Share Year & $0 \%$ & $0 \%$ & $0 \%$ & $0 \%$ & $0 \%$ & $0 \%$ & $97 \%$ & $97 \%$ & $99 \%$ & $95 \%$ & $97 \%$ & $97 \%$ & $3 \%$ & $3 \%$ & $1 \%$ & $5 \%$ & $3 \%$ & $3 \%$ & $100 \%$ & $100 \%$ & $100 \%$ & $100 \%$ & $100 \%$ & $100 \%$ \\
\hline & Share C & $0 \%$ & $0 \%$ & $0 \%$ & $0 \%$ & $2 \%$ & $2 \%$ & $10 \%$ & $7 \%$ & $8 \%$ & $8 \%$ & $7 \%$ & $8 \%$ & $6 \%$ & $4 \%$ & $3 \%$ & $9 \%$ & $3 \%$ & $5 \%$ & $10 \%$ & $7 \%$ & $8 \%$ & $8 \%$ & $7 \%$ & $8 \%$ \\
\hline & $\begin{array}{ll}\text { C-PL4 } \\
\end{array}$ & 0 & 0 & c & 0 & 0 & 0 & 39 & 356 & 346 & 326 & 310 & 735 & 10 & 9 & 6 & & & 40 & 407 & 365 & 352 & 334 & 317 & 1.775 \\
\hline & Share Year & $0 \%$ & $0 \%$ & $0 \%$ & $0 \%$ & $0 \%$ & $0 \%$ & $98 \%$ & $98 \%$ & $98 \%$ & $98 \%$ & $98 \%$ & $98 \%$ & $2 \%$ & $2 \%$ & $2 \%$ & $2 \%$ & $2 \%$ & $2 \%$ & $100 \%$ & $100 \%$ & $100 \%$ & $100 \%$ & $100 \%$ & $00 \%$ \\
\hline & Share Category & $0 \%$ & $0 \%$ & $0 \%$ & $0 \%$ & $0 \%$ & $0 \%$ & $6 \%$ & $6 \%$ & $6 \%$ & $6 \%$ & $6 \%$ & $6 \%$ & $3 \%$ & $3 \%$ & $4 \%$ & $3 \%$ & $2 \%$ & $3 \%$ & $6 \%$ & $6 \%$ & $6 \%$ & $6 \%$ & $6 \%$ & $6 \%$ \\
\hline & $\begin{array}{l}\text { C-PL5 } \\
\text { (a) }\end{array}$ & 0 & 0 & 0 & 0 & 17 & 17 & 36 & 305 & 271 & 267 & 274 & 1.479 & 41 & 27 & 14 & 29 & 46 & 157 & 403 & 332 & 285 & 296 & 33 & 1.653 \\
\hline & Share Year & $0 \%$ & $0 \%$ & $0 \%$ & $0 \%$ & $5 \%$ & $1 \%$ & $90 \%$ & $92 \%$ & $95 \%$ & $90 \%$ & $81 \%$ & $89 \%$ & $10 \%$ & $8 \%$ & $5 \%$ & $10 \%$ & $14 \%$ & $9 \%$ & $100 \%$ & $100 \%$ & $100 \%$ & $100 \%$ & $100 \%$ & $100 \%$ \\
\hline & Share Category & $0 \%$ & $0 \%$ & $0 \%$ & $0 \%$ & $31 \%$ & $31 \%$ & $6 \%$ & $5 \%$ & $5 \%$ & $5 \%$ & $5 \%$ & $5 \%$ & $11 \%$ & $9 \%$ & $10 \%$ & $12 \%$ & $14 \%$ & $11 \%$ & $6 \%$ & $6 \%$ & $5 \%$ & $5 \%$ & $6 \%$ & $6 \%$ \\
\hline & C-PL6 & 0 & 0 & c & 0 & 7 & 1 & 22 & 251 & 259 & 284 & 245 & 1.266 & 21 & 16 & 13 & 18 & 29 & 97 & 248 & 267 & 272 & 302 & 281 & 1.370 \\
\hline & Share Yea & $0 \%$ & $0 \%$ & $0 \%$ & $0 \%$ & $2 \%$ & $1 \%$ & $92 \%$ & $94 \%$ & $95 \%$ & $94 \%$ & $87 \%$ & $92 \%$ & $8 \%$ & $6 \%$ & $5 \%$ & $6 \%$ & $10 \%$ & $7 \%$ & $100 \%$ & $100 \%$ & $100 \%$ & $100 \%$ & $100 \%$ & $00 \%$ \\
\hline & Share Ca & $0 \%$ & $0 \%$ & $0 \%$ & $0 \%$ & $13 \%$ & $13 \%$ & $4 \%$ & $4 \%$ & $5 \%$ & $5 \%$ & $5 \%$ & $5 \%$ & $6 \%$ & $5 \%$ & $9 \%$ & $7 \%$ & $9 \%$ & $7 \%$ & $4 \%$ & $4 \%$ & $5 \%$ & $5 \%$ & $5 \%$ & $5 \%$ \\
\hline & $\begin{array}{l}\text { C-PL7 } \\
\end{array}$ & 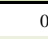 & 0 & c & 0 & 0 & & 24 & 270 & 256 & 275 & 286 & 1.33 & 15 & & & & 19 & 56 & 264 & 275 & 264 & 284 & 30 & 1.392 \\
\hline & Share Year & $0 \%$ & $0 \%$ & $0 \%$ & $0 \%$ & $0 \%$ & $0 \%$ & $94 \%$ & $98 \%$ & $97 \%$ & $97 \%$ & $94 \%$ & $96 \%$ & $6 \%$ & $2 \%$ & $3 \%$ & $3 \%$ & $6 \%$ & $4 \%$ & $100 \%$ & $100 \%$ & $100 \%$ & $100 \%$ & $100 \%$ & $100 \%$ \\
\hline & Share Ca & $0 \%$ & $0 \%$ & $0 \%$ & $0 \%$ & $0 \%$ & $0 \%$ & $4 \%$ & $5 \%$ & $5 \%$ & $5 \%$ & $5 \%$ & $5 \%$ & $4 \%$ & $2 \%$ & $6 \%$ & $4 \%$ & $6 \%$ & $4 \%$ & $4 \%$ & $5 \%$ & $5 \%$ & $5 \%$ & $5 \%$ & 5,0 \\
\hline & \begin{tabular}{|l|} 
C-PL8 \\
\end{tabular} & 0 & 0 & $c$ & 0 & 4 & 4 & 37 & 329 & 322 & 309 & 296 & 1.635 & 19 & 17 & 12 & 18 & 29 & 95 & 398 & 346 & 334 & 327 & 329 & 1.734 \\
\hline & Share Yeal & $0 \%$ & $0 \%$ & $0 \%$ & $0 \%$ & $1 \%$ & $0 \%$ & $95 \%$ & $95 \%$ & $96 \%$ & $94 \%$ & $90 \%$ & $94 \%$ & $5 \%$ & $5 \%$ & $4 \%$ & $6 \%$ & $9 \%$ & $5 \%$ & $100 \%$ & $100 \%$ & $100 \%$ & $100 \%$ & $100 \%$ & $100 \%$ \\
\hline & Share C & $0 \%$ & $0 \%$ & $0 \%$ & $0 \%$ & $7 \%$ & $7 \%$ & $6 \%$ & $6 \%$ & $6 \%$ & $6 \%$ & $6 \%$ & 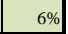 & $5 \%$ & $6 \%$ & $8 \%$ & $7 \%$ & $9 \%$ & $7 \%$ & $6 \%$ & $6 \%$ & $6 \%$ & $6 \%$ & $\%$ & $6 \%$ \\
\hline & C-PL9 & 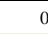 & 0 & c & 0 & 0 & & 1. & 15 & 14 & 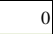 & 0 & 42 & & 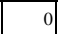 & 0 & & 0 & 0 & 13 & 13 & 14 & ${ }^{\circ}$ & & 42 \\
\hline & Share Y & $0 \%$ & $0 \%$ & $0 \%$ & $0 \%$ & $0 \%$ & $0 \%$ & $100 \%$ & $100 \%$ & $100 \%$ & $0 \%$ & $0 \%$ & $100 \%$ & $0 \%$ & $0 \%$ & $0 \%$ & $0 \%$ & $0 \%$ & $0 \%$ & $100 \%$ & $100 \%$ & $100 \%$ & $0 \%$ & $0 \%$ & $00 \%$ \\
\hline & Share Categor & $0 \%$ & $0 \%$ & $0 \%$ & $0 \%$ & $0 \%$ & $0 \%$ & $0 \%$ & $0 \%$ & $0 \%$ & $0 \%$ & $0 \%$ & $0 \%$ & $0 \%$ & $0 \%$ & $0 \%$ & $0 \%$ & $0 \%$ & $0 \%$ & $0 \%$ & $0 \%$ & $0 \%$ & $0 \%$ & $0 \%$ & $0 \%$ \\
\hline & Total C & 0 & & & 0 & 31 & 31 & 2.93 & 2.624 & 2.542 & 2.531 & 2.521 & \begin{tabular}{|l|}
13.153 \\
\end{tabular} & 167 & 105 & 69 & 128 & 171 & 640 & 3.102 & 2.729 & 2.611 & 2.659 & .723 & \begin{tabular}{|l|}
13.824 \\
\end{tabular} \\
\hline & Share Y & $0 \%$ & $0 \%$ & $0 \%$ & $0 \%$ & $1 \%$ & $0 \%$ & $95 \%$ & $96 \%$ & $97 \%$ & $95 \%$ & $93 \%$ & 95\% & $5 \%$ & $4 \%$ & $3 \%$ & $5 \%$ & $6 \%$ & $5 \%$ & $100 \%$ & $100 \%$ & $100 \%$ & $100 \%$ & $100 \%$ & $100 \%$ \\
\hline & Share Category & $0 \%$ & $0 \%$ & $0 \%$ & $0 \%$ & $56 \%$ & $56 \%$ & $47 \%$ & $47 \%$ & $46 \%$ & $48 \%$ & $48 \%$ & $47 \%$ & $46 \%$ & $35 \%$ & $48 \%$ & $52 \%$ & $50 \%$ & $46 \%$ & $47 \%$ & $46 \%$ & $46 \%$ & $48 \%$ & $48 \%$ & $47 \%$ \\
\hline & Total & 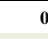 & 0 & 0 & 0 & 55 & 55 & 6.26 & 5.637 & 5.585 & 5.249 & 5.274 & 28.013 & 364 & 302 & 144 & 247 & 339 & 1.396 & 6.630 & 5.939 & 5.729 & 5.496 & 5.668 & \begin{tabular}{|l|}
29.464 \\
\end{tabular} \\
\hline & Share Y & $0 \%$ & $0 \%$ & $0 \%$ & $0 \%$ & $1 \%$ & $0 \%$ & 95\% & $95 \%$ & $97 \%$ & $96 \%$ & $93 \%$ & $95 \%$ & $5 \%$ & $5 \%$ & $3 \%$ & $4 \%$ & $6 \%$ & $5 \%$ & $100 \%$ & $\mid 100 \%$ & $100 \%$ & $100 \%$ & $100 \%$ & $100 \%$ \\
\hline & Share Category & $0 \%$ & $0 \%$ & $0 \%$ & $0 \%$ & $100 \%$ & $100 \%$ & $100 \%$ & $100 \%$ & $100 \%$ & $100 \%$ & $100 \%$ & $100 \%$ & $100 \%$ & $100 \%$ & $100 \%$ & $100 \%$ & $100 \%$ & $100 \%$ & $100 \%$ & $100 \%$ & $100 \%$ & $100 \%$ & $100 \%$ & $100 \%$ \\
\hline
\end{tabular}


Annex 24: Conceptual Framework: References grouped according to Information Categories and Perspectives by year / P\&L - Statement - Total Cost Format

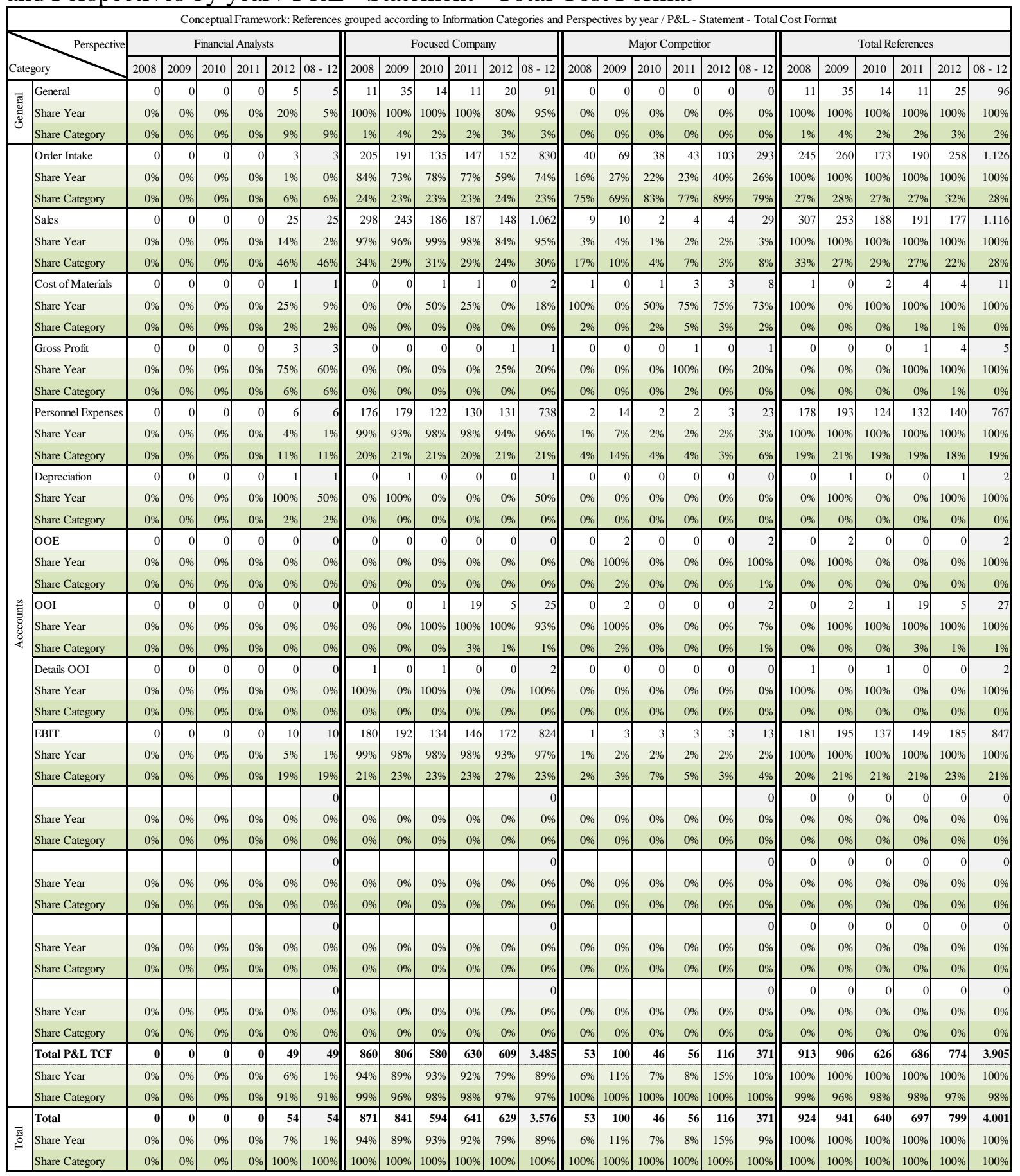


Annex 25: Conceptual Framework: References grouped according to Information Categories and Perspectives by year / P\&L - Statement - Cost of Sales Format

\begin{tabular}{|c|c|c|c|c|c|c|c|c|c|c|c|c|c|c|c|c|c|c|c|c|c|c|c|c|c|}
\hline \multicolumn{26}{|c|}{ r /P\&L-St } \\
\hline \multicolumn{2}{|c|}{ tegory } & 2008 & 2009 & 2010 & 2011 & 2012 & $08-12 \mid$ & || 2008 & 2009 & 2010 & 2011 & 2012 & $08-12$ & 2008 & 2009 & 2010 & 2011 & 2012 & $|08-12|$ & 2008 & 2009 & 2010 & 2011 & 2012 & $08-12$ \\
\hline \multirow[t]{3}{*}{ త } & General & 0 & & c & 0 & 4 & 4 & 11 & 35 & 14 & 11 & 20 & 91 & 0 & 0 & 0 & 0 & 0 & 0 & 11 & 35 & 14 & 11 & 24 & 95 \\
\hline & Share Year & $0 \%$ & $0 \%$ & $0 \%$ & $0 \%$ & $17 \%$ & $4 \%$ & $100 \%$ & $100 \%$ & $100 \%$ & $100 \%$ & $83 \%$ & $96 \%$ & $0 \%$ & $0 \%$ & $0 \%$ & $0 \%$ & $0 \%$ & $0 \%$ & $100 \%$ & $100 \%$ & $100 \%$ & $100 \%$ & $100 \%$ & $100 \%$ \\
\hline & Share Category & $0 \%$ & $0 \%$ & $0 \%$ & $0 \%$ & $6 \%$ & $6 \%$ & $2 \%$ & $5 \%$ & $3 \%$ & $2 \%$ & $4 \%$ & $3 \%$ & $0 \%$ & $0 \%$ & $0 \%$ & $0 \%$ & $0 \%$ & $0 \%$ & $1 \%$ & $4 \%$ & $2 \%$ & $2 \%$ & $3 \%$ & $3 \%$ \\
\hline \multirow{45}{*}{ 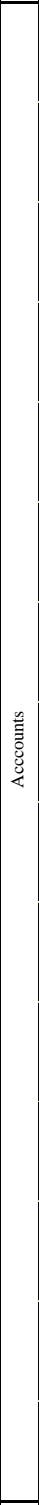 } & Order Intake & 0 & 0 & c & 0 & 3 & 3 & 205 & 191 & 135 & 147 & 152 & 830 & 40 & 69 & 38 & 43 & 103 & 293 & 245 & 260 & 173 & 190 & 258 & 1.126 \\
\hline & Share Year & $0 \%$ & $0 \%$ & $0 \%$ & $0 \%$ & $1 \%$ & $0 \%$ & $84 \%$ & $73 \%$ & $78 \%$ & $77 \%$ & $59 \%$ & $74 \%$ & $16 \%$ & $27 \%$ & $22 \%$ & $23 \%$ & $40 \%$ & $26 \%$ & $100 \%$ & $100 \%$ & $100 \%$ & $100 \%$ & $100 \%$ & $100 \%$ \\
\hline & Share Category & $0 \%$ & $0 \%$ & $0 \%$ & $0 \%$ & $5 \%$ & $5 \%$ & $29 \%$ & $29 \%$ & $28 \%$ & $29 \%$ & $30 \%$ & $29 \%$ & $39 \%$ & $50 \%$ & $39 \%$ & $47 \%$ & $54 \%$ & $47 \%$ & $31 \%$ & $32 \%$ & $30 \%$ & $32 \%$ & $34 \%$ & $32 \%$ \\
\hline & Cost of Sales & 0 & 0 & c & 0 & 2 & 2 & 1 & 0 & 1 & 1 & 0 & 3 & & 0 & 1 & & 4 & 7 & 2 & 0 & 2 & -6 & & 12 \\
\hline & Share Year & $0 \%$ & $0 \%$ & $0 \%$ & $0 \%$ & $33 \%$ & $17 \%$ & $50 \%$ & $0 \%$ & $50 \%$ & $50 \%$ & $0 \%$ & $25 \%$ & $50 \%$ & $0 \%$ & $50 \%$ & $50 \%$ & $67 \%$ & $58 \%$ & $100 \%$ & $0 \%$ & $100 \%$ & $100 \%$ & $100 \%$ & $100 \%$ \\
\hline & Share Category & $0 \%$ & $0 \%$ & $0 \%$ & $0 \%$ & $3 \%$ & $3 \%$ & $0 \%$ & $0 \%$ & $0 \%$ & $0 \%$ & $0 \%$ & $0 \%$ & $1 \%$ & $0 \%$ & $1 \%$ & $1 \%$ & $2 \%$ & $1 \%$ & $0 \%$ & $0 \%$ & $0 \%$ & $0 \%$ & $1 \%$ & $0 \%$ \\
\hline & Sales & 0 & 0 & c & 0 & 24 & 24 & 297 & 243 & 186 & 187 & 148 & 1.061 & 9 & 11 & 2 & 4 & 4 & 30 & 306 & 254 & 188 & 191 & 176 & 1.115 \\
\hline & Share Year & $0 \%$ & $0 \%$ & $0 \%$ & $0 \%$ & $14 \%$ & $2 \%$ & $97 \%$ & $96 \%$ & $99 \%$ & $98 \%$ & $84 \%$ & $95 \%$ & $3 \%$ & $4 \%$ & $1 \%$ & $2 \%$ & $2 \%$ & $3 \%$ & $100 \%$ & $100 \%$ & $100 \%$ & $100 \%$ & $100 \%$ & $100 \%$ \\
\hline & Share Category & $0 \%$ & $0 \%$ & $0 \%$ & $0 \%$ & $38 \%$ & $38 \%$ & $43 \%$ & $37 \%$ & $39 \%$ & $37 \%$ & $29 \%$ & $37 \%$ & $9 \%$ & $8 \%$ & $2 \%$ & $4 \%$ & $2 \%$ & $5 \%$ & $38 \%$ & $32 \%$ & $33 \%$ & $32 \%$ & $23 \%$ & $32 \%$ \\
\hline & Gross Margin & 0 & 0 & $c$ & 0 & 4 & + & 1 & 2 & 2 & 0 & 3 & 8 & 1 & 1 & 3 & 3 & 8 & 16 & 2 & 3 & 5 & 3 & 15 & 28 \\
\hline & Share Year & $0 \%$ & $0 \%$ & $0 \%$ & $0 \%$ & $27 \%$ & $14 \%$ & $50 \%$ & $67 \%$ & $40 \%$ & $0 \%$ & $20 \%$ & $29 \%$ & $50 \%$ & $33 \%$ & $60 \%$ & $100 \%$ & $53 \%$ & $57 \%$ & $100 \%$ & $100 \%$ & $100 \%$ & $100 \%$ & $100 \%$ & $100 \%$ \\
\hline & Share Category & $0 \%$ & $0 \%$ & $0 \%$ & $0 \%$ & $6 \%$ & $6 \%$ & $0 \%$ & $0 \%$ & $0 \%$ & $0 \%$ & $1 \%$ & $0 \%$ & $1 \%$ & $1 \%$ & $3 \%$ & $3 \%$ & $4 \%$ & $3 \%$ & $0 \%$ & $0 \%$ & $1 \%$ & $0 \%$ & $2 \%$ & $1 \%$ \\
\hline & R\&D Expenses & 0 & 0 & $c$ & 0 & 1 & 1 & 0 & 0 & 0 & 0 & 1 & 1 & 11 & 15 & 8 & 17 & 9 & 60 & 11 & 15 & & 17 & 11 & 62 \\
\hline & Share Year & $0 \%$ & $0 \%$ & $0 \%$ & $0 \%$ & $9 \%$ & $2 \%$ & $0 \%$ & $0 \%$ & $0 \%$ & $0 \%$ & $9 \%$ & $2 \%$ & $100 \%$ & $100 \%$ & $100 \%$ & $100 \%$ & $82 \%$ & $97 \%$ & $100 \%$ & $100 \%$ & $100 \%$ & $100 \%$ & $100 \%$ & $100 \%$ \\
\hline & Share Category & $0 \%$ & $0 \%$ & $0 \%$ & $0 \%$ & $2 \%$ & $2 \%$ & $0 \%$ & $0 \%$ & $0 \%$ & $0 \%$ & $0 \%$ & $0 \%$ & $11 \%$ & $11 \%$ & $8 \%$ & $18 \%$ & $5 \%$ & $10 \%$ & $1 \%$ & $2 \%$ & $1 \%$ & $3 \%$ & $1 \%$ & $2 \%$ \\
\hline & Selling Expenses & 0 & 0 & $c$ & 0 & 4 & 4 & 0 & 0 & 0 & 0 & 1 & 11 & 7 & 5 & 4 & 3 & 10 & 29 & 7 & 5 & 4 & 3 & 15 & 34 \\
\hline & Share Year & $0 \%$ & $0 \%$ & $0 \%$ & $0 \%$ & $27 \%$ & $12 \%$ & $0 \%$ & $0 \%$ & $0 \%$ & $0 \%$ & $7 \%$ & $3 \%$ & $100 \%$ & $100 \%$ & $100 \%$ & $100 \%$ & $67 \%$ & $85 \%$ & $100 \%$ & $100 \%$ & $100 \%$ & $100 \%$ & $100 \%$ & $100 \%$ \\
\hline & Share Category & $0 \%$ & $0 \%$ & $0 \%$ & $0 \%$ & $6 \%$ & $6 \%$ & $0 \%$ & $0 \%$ & $0 \%$ & $0 \%$ & $0 \%$ & $0 \%$ & $7 \%$ & $4 \%$ & $4 \%$ & $3 \%$ & $5 \%$ & $5 \%$ & $1 \%$ & $1 \%$ & $1 \%$ & $0 \%$ & $2 \%$ & $1 \%$ \\
\hline & G\&A Expenses & 0 & 0 & $c$ & 0 & 4 & 4 & 0 & 0 & 0 & 0 & 0 & 0 & 7 & 3 & 4 & & 10 & 29 & & & 4 & & 14 & 33 \\
\hline & Share Year & $0 \%$ & $0 \%$ & $0 \%$ & $0 \%$ & $29 \%$ & $12 \%$ & $0 \%$ & $0 \%$ & $0 \%$ & $0 \%$ & $0 \%$ & $0 \%$ & $100 \%$ & $100 \%$ & $100 \%$ & $100 \%$ & $71 \%$ & $88 \%$ & $100 \%$ & $100 \%$ & $100 \%$ & $100 \%$ & $100 \%$ & $100 \%$ \\
\hline & Share Category & $0 \%$ & $0 \%$ & $0 \%$ & $0 \%$ & $6 \%$ & $6 \%$ & $0 \%$ & $0 \%$ & $0 \%$ & $0 \%$ & $0 \%$ & $0 \%$ & $7 \%$ & $4 \%$ & $4 \%$ & $3 \%$ & $5 \%$ & $5 \%$ & $1 \%$ & $1 \%$ & $1 \%$ & $0 \%$ & $2 \%$ & $1 \%$ \\
\hline & Other Expenses & 0 & 0 & c & 0 & 0 & 0 & 0 & 0 & 0 & 0 & 0 & 0 & 0 & 1 & 1 & 0 & 0 & 2 & 0 & 1 & 1 & 0 & 0 & \\
\hline & Share Year & $0 \%$ & $0 \%$ & $0 \%$ & $0 \%$ & $0 \%$ & $0 \%$ & $0 \%$ & $0 \%$ & $0 \%$ & $0 \%$ & $0 \%$ & $0 \%$ & $0 \%$ & $100 \%$ & $100 \%$ & $0 \%$ & $0 \%$ & $100 \%$ & $0 \%$ & $100 \%$ & $100 \%$ & $0 \%$ & $0 \%$ & $100 \%$ \\
\hline & Share Category & $0 \%$ & $0 \%$ & $0 \%$ & $0 \%$ & $0 \%$ & $0 \%$ & $0 \%$ & $0 \%$ & $0 \%$ & $0 \%$ & $0 \%$ & $0 \%$ & $0 \%$ & $1 \%$ & $1 \%$ & $0 \%$ & $0 \%$ & $0 \%$ & $0 \%$ & $0 \%$ & $0 \%$ & $0 \%$ & $0 \%$ & $0 \%$ \\
\hline & OOI & 0 & 0 & c & 0 & 0 & 0 & 0 & 0 & 1 & 19 & 1 & 25 & 0 & 1 & 1 & 0 & 0 & 11 & 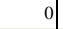 & 0 & 2 & 19 & & 26 \\
\hline & Share Year & $0 \%$ & $0 \%$ & $0 \%$ & $0 \%$ & $0 \%$ & $0 \%$ & $0 \%$ & $0 \%$ & $50 \%$ & $100 \%$ & $100 \%$ & $96 \%$ & $0 \%$ & $0 \%$ & $50 \%$ & $0 \%$ & $0 \%$ & $4 \%$ & $0 \%$ & $0 \%$ & $100 \%$ & $100 \%$ & $100 \%$ & $100 \%$ \\
\hline & Share Category & $0 \%$ & $0 \%$ & $0 \%$ & $0 \%$ & $0 \%$ & $0 \%$ & $0 \%$ & $0 \%$ & $0 \%$ & $4 \%$ & $1 \%$ & $1 \%$ & $0 \%$ & $0 \%$ & $1 \%$ & $0 \%$ & $0 \%$ & $0 \%$ & $0 \%$ & $0 \%$ & $0 \%$ & $3 \%$ & $1 \%$ & $1 \%$ \\
\hline & OOE & 0 & 0 & c & 0 & 0 & 0 & 1 & 0 & 0 & 0 & 0 & 1 & 0 & 0 & 0 & 0 & 0 & 0 & 1 & 0 & 0 & 0 & 0 & \\
\hline & Share Year & $0 \%$ & $0 \%$ & $0 \%$ & $0 \%$ & $0 \%$ & $0 \%$ & $\mid 100 \%$ & $0 \%$ & $0 \%$ & $0 \%$ & $0 \%$ & $100 \%$ & $0 \%$ & $0 \%$ & $0 \%$ & $0 \%$ & $0 \%$ & $0 \%$ & $100 \%$ & $0 \%$ & $0 \%$ & $0 \%$ & $0 \%$ & $100 \%$ \\
\hline & Share Category & $0 \%$ & $0 \%$ & $0 \%$ & $0 \%$ & $0 \%$ & $0 \%$ & $0 \%$ & $0 \%$ & $0 \%$ & $0 \%$ & $0 \%$ & $0 \%$ & $0 \%$ & $0 \%$ & $0 \%$ & $0 \%$ & $0 \%$ & $0 \%$ & $0 \%$ & $0 \%$ & $0 \%$ & $0 \%$ & $0 \%$ & $0 \%$ \\
\hline & EBIT & 0 & 0 & c & 0 & 6 & 6 & 177 & 192 & 136 & 146 & 171 & 822 & 0 & . & 0 & 0 & 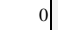 & 1 & 177 & 193 & 136 & 146 & 177 & 829 \\
\hline & Share Year & $0 \%$ & $0 \%$ & $0 \%$ & $0 \%$ & $3 \%$ & $1 \%$ & $\mid 100 \%$ & $99 \%$ & $100 \%$ & $100 \%$ & $97 \%$ & $99 \%$ & $0 \%$ & $1 \%$ & $0 \%$ & $0 \%$ & $0 \%$ & $0 \%$ & $100 \%$ & $100 \%$ & $100 \%$ & $100 \%$ & $100 \%$ & $100 \%$ \\
\hline & Share Category & $0 \%$ & $0 \%$ & $0 \%$ & $0 \%$ & $10 \%$ & $10 \%$ & $25 \%$ & $29 \%$ & $29 \%$ & $29 \%$ & $34 \%$ & $29 \%$ & $0 \%$ & $1 \%$ & $0 \%$ & $0 \%$ & $0 \%$ & $0 \%$ & $22 \%$ & $24 \%$ & $24 \%$ & $24 \%$ & $23 \%$ & $23 \%$ \\
\hline & EBT & 0 & 0 & $c$ & 0 & 0 & 0 & 4 & 1 & 0 & 0 & 1 & 6 & 0 & 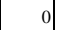 & 0 & 0 & 0 & 0 & 4 & & 0 & 0 & & \\
\hline & Share Year & $0 \%$ & $0 \%$ & $0 \%$ & $0 \%$ & $0 \%$ & $0 \%$ & $\mid 100 \%$ & $100 \%$ & $0 \%$ & $0 \%$ & $100 \%$ & $100 \%$ & $0 \%$ & $0 \%$ & $0 \%$ & $0 \%$ & $0 \%$ & $0 \%$ & $100 \%$ & $100 \%$ & $0 \%$ & $0 \%$ & $100 \%$ & $100 \%$ \\
\hline & Share Category & $0 \%$ & $0 \%$ & $0 \%$ & $0 \%$ & $0 \%$ & $0 \%$ & $1 \%$ & $0 \%$ & $0 \%$ & $0 \%$ & $0 \%$ & $0 \%$ & $0 \%$ & $0 \%$ & $0 \%$ & $0 \%$ & $0 \%$ & $0 \%$ & $1 \%$ & $0 \%$ & $0 \%$ & $0 \%$ & $0 \%$ & $0 \%$ \\
\hline & AL Margin de & 0 & 0 & c & 0 & 5 & 5 & 0 & 0 & 0 & 0 & 0 & 0 & 20 & 20 & 24 & 13 & 35 & 112 & 20 & 20 & 24 & 13 & 40 & 117 \\
\hline & Share Year & $0 \%$ & $0 \%$ & $0 \%$ & $0 \%$ & $13 \%$ & $4 \%$ & $0 \%$ & $0 \%$ & $0 \%$ & $0 \%$ & $0 \%$ & $0 \%$ & $100 \%$ & $100 \%$ & $100 \%$ & $100 \%$ & $88 \%$ & $96 \%$ & $100 \%$ & $100 \%$ & $100 \%$ & $100 \%$ & $100 \%$ & $100 \%$ \\
\hline & Share Category & $0 \%$ & $0 \%$ & $0 \%$ & $0 \%$ & $8 \%$ & $8 \%$ & $0 \%$ & $0 \%$ & $0 \%$ & $0 \%$ & $0 \%$ & $0 \%$ & $20 \%$ & $14 \%$ & $25 \%$ & $14 \%$ & $18 \%$ & $18 \%$ & $3 \%$ & $2 \%$ & $4 \%$ & $2 \%$ & $5 \%$ & $3 \%$ \\
\hline & AL Margin indic. & 0 & 0 & c & 0 & 6 & 6 & 0 & 0 & 0 & 0 & 0 & 0 & 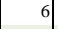 & 10 & 11 & 3 & 8 & 40 & 6 & 10 & 11 & 3 & 14 & 46 \\
\hline & Share Year & $0 \%$ & $0 \%$ & $0 \%$ & $0 \%$ & $43 \%$ & $13 \%$ & $0 \%$ & $0 \%$ & $0 \%$ & $0 \%$ & $0 \%$ & $0 \%$ & $100 \%$ & $100 \%$ & $100 \%$ & $100 \%$ & $57 \%$ & $87 \%$ & $100 \%$ & $100 \%$ & $100 \%$ & $100 \%$ & $100 \%$ & $100 \%$ \\
\hline & Share Category & $0 \%$ & $0 \%$ & $0 \%$ & $0 \%$ & $10 \%$ & $10 \%$ & $0 \%$ & $0 \%$ & $0 \%$ & $0 \%$ & $0 \%$ & $0 \%$ & $6 \%$ & $7 \%$ & $11 \%$ & $5 \%$ & $4 \%$ & $6 \%$ & $1 \%$ & $1 \%$ & $2 \%$ & $1 \%$ & $2 \%$ & $1 \%$ \\
\hline & Total P\&L CoS - F & 0 & 0 & a & 0 & 59 & 59 & 686 & 629 & 461 & 500 & 482 & 2.758 & 102 & 138 & 97 & 92 & 191 & 620 & 788 & 767 & 558 & 592 & 732 & 3.437 \\
\hline & Share Year & $0 \%$ & $0 \%$ & $0 \%$ & $0 \%$ & $8 \%$ & $2 \%$ & $87 \%$ & $82 \%$ & $83 \%$ & $84 \%$ & $66 \%$ & $80 \%$ & $13 \%$ & $18 \%$ & $17 \%$ & $16 \%$ & $26 \%$ & $18 \%$ & $100 \%$ & $100 \%$ & $100 \%$ & $100 \%$ & $100 \%$ & $100 \%$ \\
\hline & Share Category & $0 \%$ & $0 \%$ & $0 \%$ & $0 \%$ & $94 \%$ & $94 \%$ & $98 \%$ & $95 \%$ & $97 \%$ & $98 \%$ & $96 \%$ & $97 \%$ & $100 \%$ & $100 \%$ & $100 \%$ & $100 \%$ & $100 \%$ & $100 \%$ & $99 \%$ & $96 \%$ & $98 \%$ & $98 \%$ & $97 \%$ & $97 \%$ \\
\hline & Total & 0 & 0 & 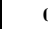 & 0 & 63 & 63 & 697 & 664 & 475 & 511 & 502 & 2.849 & 102 & 138 & 97 & 92 & 191 & 620 & 799 & 802 & 572 & 603 & 756 & 3.532 \\
\hline & Share Year & $0 \%$ & $0 \%$ & $0 \%$ & $0 \%$ & $8 \%$ & $2 \%$ & $87 \%$ & $83 \%$ & $83 \%$ & $85 \%$ & $66 \%$ & $81 \%$ & $13 \%$ & $17 \%$ & $17 \%$ & $15 \%$ & $25 \%$ & $18 \%$ & $100 \%$ & $100 \%$ & $100 \%$ & $100 \%$ & $100 \%$ & $100 \%$ \\
\hline & Share Categor & $0 \%$ & $0 \%$ & $0 \%$ & $0 \%$ & $100 \%$ & $100 \%$ & $100 \%$ & $100 \%$ & $100 \%$ & $100 \%$ & $100 \%$ & $100 \%$ & $100 \%$ & $100 \%$ & $100 \%$ & $100 \%$ & $100 \%$ & $100 \%$ & $100 \%$ & $100 \%$ & $100 \%$ & $100 \%$ & $100 \%$ & $100 \%$ \\
\hline
\end{tabular}


Annex 26: Conceptual Framework: References grouped according to Information Categories and Perspectives by year / Balance Sheet - Assets

\begin{tabular}{|c|c|c|c|c|c|c|c|c|c|c|c|c|c|c|c|c|c|c|c|c|c|c|c|c|c|c|}
\hline & & & & Financi & alys & & & & & Focuse & $\mathrm{d}$ Com & apany & & & & & Major $\mathrm{Cc}$ & ompetito & & & & & Total Re & ferences & & \\
\hline Ca & egory & 2008 & 2009 & 2010 & 2011 & 2012 & $08-12$ & 2008 & 2009 & 2010 & 201 & & $012 \quad 0$ & $08-12$ & 2008 & 2009 & 2010 & 2011 & 2012 & $08-12 \mid$ & 2008 & 2009 & 2010 & 2011 & 2012 & $08-12$ \\
\hline$=$ & General & 0 & 0 & 0 & 0 & 10 & 10 & 0 & & t & 0 & 0 & 0 & 0 & 0 & 0 & 0 & 0 & 0 & 0 & 0 & 0 & & 0 & 10 & 10 \\
\hline 气ूँ & Share Year & $0 \%$ & $0 \%$ & $0 \%$ & $0 \%$ & $100 \%$ & $100 \%$ & $0 \%$ & $0 \%$ & 0 & 0 & $\%$ & $0 \%$ & $0 \%$ & $0 \%$ & $0 \%$ & $0 \%$ & $0 \%$ & $0 \%$ & $0 \%$ & $0 \%$ & $0 \%$ & $0 \%$ & $0 \%$ & $100 \%$ & $100 \%$ \\
\hline & Share Category & $0 \%$ & $0 \%$ & $0 \%$ & $0 \%$ & $48 \%$ & $48 \%$ & $0 \%$ & $0 \%$ & $0^{c}$ & 0 & $\%$ & $0 \%$ & $0 \%$ & $0 \%$ & $0 \%$ & $0 \%$ & $0 \%$ & $0 \%$ & $0 \%$ & $0 \%$ & $0 \%$ & $0 \%$ & $0 \%$ & $3 \%$ & $1 \%$ \\
\hline & Tangible Assets & 0 & 0 & 0 & 0 & 1 & 1 & 114 & 11 & 4 & 10 & 01 & 132 & 543 & 1 & 3 & 2 & 0 & 1 & 7 & 115 & 117 & 84 & 101 & 134 & 551 \\
\hline & Share Year & $0 \%$ & $0 \%$ & $0 \%$ & $0 \%$ & $1 \%$ & $0 \%$ & $99 \%$ & $97 \%$ & 98 & 100 & & $99 \%$ & $99 \%$ & $1 \%$ & $3 \%$ & $2 \%$ & $0 \%$ & $1 \%$ & $1 \%$ & $100 \%$ & $100 \%$ & $100 \%$ & $100 \%$ & $100 \%$ & $100 \%$ \\
\hline & Share Category & $0 \%$ & $0 \%$ & $0 \%$ & $0 \%$ & $5 \%$ & $5 \%$ & $38 \%$ & $50 \%$ & $41^{\circ}$ & 52 & $\begin{array}{ll}\% & 6 \\
\end{array}$ & $63 \%$ & $48 \%$ & $20 \%$ & $50 \%$ & $29 \%$ & $0 \%$ & $1 \%$ & $8 \%$ & $38 \%$ & $50 \%$ & $41 \%$ & $51 \%$ & $45 \%$ & $45 \%$ \\
\hline & Intangible Assets & 0 & 0 & 0 & 0 & 4 & 4 & 1 & ( & 5 & 1 & 0 & 0 & 2 & 0 & 0 & 0 & 0 & 0 & 0 & 1 & 0 & 1 & 0 & 4 & \\
\hline & Share Year & $0 \%$ & $0 \%$ & $0 \%$ & $0 \%$ & $100 \%$ & $67 \%$ & $100 \%$ & $0 \%$ & $100^{\circ}$ & 0 & $\%$ & $0 \%$ & $33 \%$ & $0 \%$ & $0 \%$ & $0 \%$ & $0 \%$ & $0 \%$ & $0 \%$ & $100 \%$ & $0 \%$ & $100 \%$ & $0 \%$ & $100 \%$ & $100 \%$ \\
\hline & Share Category & $0 \%$ & $0 \%$ & $0 \%$ & $0 \%$ & $19 \%$ & $19 \%$ & $0 \%$ & $0 \%$ & 18 & 0 & $\%$ & $0 \%$ & $0 \%$ & $0 \%$ & $0 \%$ & $0 \%$ & $0 \%$ & $0 \%$ & $0 \%$ & $0 \%$ & $0 \%$ & $0 \%$ & $0 \%$ & $1 \%$ & $0 \%$ \\
\hline & Investments & 0 & 0 & 0 & 0 & 0 & 0 & c & ) & 5 & & 0 & 0 & 1 & 0 & 0 & 0 & 0 & c & 0 & 0 & 0 & & 0 & & \\
\hline & Share Year & $0 \%$ & $0 \%$ & $0 \%$ & $0 \%$ & $0 \%$ & $0 \%$ & $0 \%$ & $0 \%$ & 100 & 0 & $\%$ & $0 \%$ & $100 \%$ & $0 \%$ & $0 \%$ & $0 \%$ & $0 \%$ & $0 \%$ & $0 \%$ & $0 \%$ & $0 \%$ & $100 \%$ & $0 \%$ & $0 \%$ & $100 \%$ \\
\hline & Share Category & $0 \%$ & $0 \%$ & $0 \%$ & $0 \%$ & $0 \%$ & $0 \%$ & $0 \%$ & $0 \%$ & 19 & 0 & $\%$ & $0 \%$ & $0 \%$ & $0 \%$ & $0 \%$ & $0 \%$ & $0 \%$ & $0 \%$ & $0 \%$ & $0 \%$ & $0 \%$ & $0 \%$ & $0 \%$ & $0 \%$ & $0 \%$ \\
\hline & Subtot. fixed Assets & 0 & 0 & 0 & 0 & 0 & 0 & 0 & ) & t & 1 & 0 & 0 & 1 & 0 & 0 & 0 & 0 & 0 & 0 & 0 & 0 & 1 & 0 & 0 & \\
\hline & Share Year & $0 \%$ & $0 \%$ & $0 \%$ & $0 \%$ & $0 \%$ & $0 \%$ & $0 \%$ & $0 \%$ & 100 & 0 & $\%$ & $0 \%$ & $100 \%$ & $0 \%$ & $0 \%$ & $0 \%$ & $0 \%$ & $0 \%$ & $0 \%$ & $0 \%$ & $0 \%$ & $100 \%$ & $0 \%$ & $0 \%$ & $100 \%$ \\
\hline & Share Category & $0 \%$ & $0 \%$ & $0 \%$ & $0 \%$ & $0 \%$ & $0 \%$ & $0 \%$ & $0 \%$ & 19 & 0 & $\%$ & $0 \%$ & $0 \%$ & $0 \%$ & $0 \%$ & $0 \%$ & $0 \%$ & $0 \%$ & $0 \%$ & $0 \%$ & $0 \%$ & $0 \%$ & $0 \%$ & $0 \%$ & $0 \%$ \\
\hline & Inventory & 0 & 0 & 0 & 0 & 3 & 3 & 4 & t. & 3 & 5 & 2 & 1 & 15 & 1 & 1 & 3 & 1 & 1 & 7 & 5 & 4 & 8 & 3 & & 25 \\
\hline & Share Year & $0 \%$ & $0 \%$ & $0 \%$ & $0 \%$ & $60 \%$ & $12 \%$ & $80 \%$ & $75 \%$ & $63 c^{\circ}$ & 67 & & $20 \%$ & $60 \%$ & $20 \%$ & $25 \%$ & $38 \%$ & $33 \%$ & $20 \%$ & $28 \%$ & $100 \%$ & $100 \%$ & $100 \%$ & $100 \%$ & $100 \%$ & $100 \%$ \\
\hline & Share Category & $0 \%$ & $0 \%$ & $0 \%$ & $0 \%$ & $14 \%$ & $14 \%$ & $1 \%$ & 19 & 39 & 1 & $\%$ & $0 \%$ & $1 \%$ & $20 \%$ & $17 \%$ & $43 \%$ & $33 \%$ & $1 \%$ & $8 \%$ & $2 \%$ & $2 \%$ & $4 \%$ & $2 \%$ & $2 \%$ & $2 \%$ \\
\hline & PoC Receivables & 0 & 0 & 0 & 0 & 0 & 0 & 0 & ( & t & 1 & 2 & 0 & 3 & 0 & 0 & 0 & 0 & 0 & 0 & 0 & 0 & 1 & 2 & 0 & \\
\hline & Share Year & $0 \%$ & $0 \%$ & $0 \%$ & $0 \%$ & $0 \%$ & $0 \%$ & $0 \%$ & $0 \%$ & $100^{\circ}$ & 100 & & $0 \%$ & $100 \%$ & $0 \%$ & $0 \%$ & $0 \%$ & $0 \%$ & $0 \%$ & $0 \%$ & $0 \%$ & $0 \%$ & $100 \%$ & $100 \%$ & $0 \%$ & $100 \%$ \\
\hline & Share Category & $0 \%$ & $0 \%$ & $0 \%$ & $0 \%$ & $0 \%$ & $0 \%$ & $0 \%$ & $0 \%$ & 19 & $\%$ & $\%$ & $0 \%$ & $0 \%$ & $0 \%$ & $0 \%$ & $0 \%$ & $0 \%$ & $0 \%$ & $0 \%$ & $0 \%$ & $0 \%$ & $0 \%$ & $1 \%$ & $0 \%$ & $0 \%$ \\
\hline & Trade Receivables & 0 & 0 & 0 & 0 & 1 & 1 & 8 & 3 & 4 & 3 & 1 & 0 & 16 & 0 & 0 & 0 & 1 & 2 & 3 & 8 & 4 & 3 & 2 & 3 & 20 \\
\hline & Share Year & $0 \%$ & $0 \%$ & $0 \%$ & $0 \%$ & $33 \%$ & $5 \%$ & $100 \%$ & $100 \%$ & 100 & 50 & $\%$ & $0 \%$ & $80 \%$ & $0 \%$ & $0 \%$ & $0 \%$ & $50 \%$ & $67 \%$ & $15 \%$ & $100 \%$ & $100 \%$ & $100 \%$ & $100 \%$ & $100 \%$ & $100 \%$ \\
\hline & Share Category & $0 \%$ & $0 \%$ & $0 \%$ & $0 \%$ & $5 \%$ & $5 \%$ & $3 \%$ & 29 & 29 & 1 & $\%$ & $0 \%$ & $1 \%$ & $0 \%$ & $0 \%$ & $0 \%$ & $33 \%$ & $3 \%$ & $3 \%$ & $3 \%$ & $2 \%$ & $1 \%$ & $1 \%$ & $1 \%$ & $2 \%$ \\
\hline 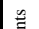 & \begin{tabular}{|l|} 
TR Third Parties \\
\end{tabular} & 0 & 0 & 0 & 0 & 1 & 1 & 2 & ( & $\pi$ & 0 & 3 & 0 & 24 & 0 & 1 & 1 & 0 & 0 & 2 & 21 & 1 & & 3 & & 27 \\
\hline & Share Year & $0 \%$ & $0 \%$ & $0 \%$ & $0 \%$ & $100 \%$ & $4 \%$ & $100 \%$ & $0 \%$ & $0^{c}$ & 100 & & $0 \%$ & $89 \%$ & $0 \%$ & $100 \%$ & $100 \%$ & $0 \%$ & $0 \%$ & $7 \%$ & $100 \%$ & $100 \%$ & $100 \%$ & $100 \%$ & $100 \%$ & $100 \%$ \\
\hline$\varangle$ & Share Category & $0 \%$ & $0 \%$ & $0 \%$ & $0 \%$ & $5 \%$ & $5 \%$ & $7 \%$ & $0 \%$ & 0 & 2 & $\%$ & $0 \%$ & $2 \%$ & $0 \%$ & $17 \%$ & $14 \%$ & $0 \%$ & $0 \%$ & $2 \%$ & $7 \%$ & $0 \%$ & $0 \%$ & $2 \%$ & $0 \%$ & $2 \%$ \\
\hline & Other Rec. IC & 0 & 0 & 0 & 0 & 0 & 0 & ( & ( & 5 & 0 & 0 & 0 & 0 & 1 & 0 & 0 & 0 & 0 & 1 & 1 & 0 & 0 & 0 & 0 & \\
\hline & Share Year & $0 \%$ & $0 \%$ & $0 \%$ & $0 \%$ & $0 \%$ & $0 \%$ & $0 \%$ & $0 \%$ & 0 & 0 & $\%$ & $0 \%$ & $0 \%$ & $100 \%$ & $0 \%$ & $0 \%$ & $0 \%$ & $0 \%$ & $100 \%$ & $100 \%$ & $0 \%$ & $0 \%$ & $0 \%$ & $0 \%$ & $100 \%$ \\
\hline & Share C & $0 \%$ & $0 \%$ & $0 \%$ & $0 \%$ & $0 \%$ & $0 \%$ & $0 \%$ & $0 \%$ & $0^{c}$ & 0 & $\%$ & $0 \%$ & $0 \%$ & $20 \%$ & $0 \%$ & $0 \%$ & $0 \%$ & $0 \%$ & $1 \%$ & $0 \%$ & $0 \%$ & $0 \%$ & $0 \%$ & $0 \%$ & $0 \%$ \\
\hline & Cash & 0 & 0 & 0 & 0 & 0 & 0 & 15 & 10 & 10 & & 87 & 77 & 524 & 2 & 1 & 1 & 1 & 2 & 7 & 152 & 107 & 105 & 88 & $79 \mid$ & 531 \\
\hline & Share Year & $0 \%$ & $0 \%$ & $0 \%$ & $0 \%$ & $0 \%$ & $0 \%$ & $99 \%$ & $99 \%$ & b 99 & $\%$ & \begin{tabular}{l|l}
$\%$ & 97
\end{tabular} & $97 \%$ & $99 \%$ & $1 \%$ & $1 \%$ & $1 \%$ & $1 \%$ & $3 \%$ & $1 \%$ & $100 \%$ & $100 \%$ & $100 \%$ & $100 \%$ & $100 \%$ & $100 \%$ \\
\hline & Share Category & $0 \%$ & $0 \%$ & $0 \%$ & $0 \%$ & $0 \%$ & $0 \%$ & $50 \%$ & $47 \%$ & 53 & \% 44 & $\% 37$ & $37 \%$ & $46 \%$ & $40 \%$ & $17 \%$ & $14 \%$ & $33 \%$ & $3 \%$ & $8 \%$ & $50 \%$ & $46 \%$ & $51 \%$ & $44 \%$ & $27 \%$ & $43 \%$ \\
\hline & Current Asset: & 0 & 0 & 0 & 0 & 1 & 1 & ( & ( & 5 & 0 & 0 & 0 & 0 & 0 & 0 & 0 & 0 & 0 & 0 & 0 & 0 & 0 & 0 & & \\
\hline & Share Year & $0 \%$ & $0 \%$ & $0 \%$ & $0 \%$ & $100 \%$ & $100 \%$ & $0 \%$ & $0 \%$ & 0 & 0 & $\%$ & $0 \%$ & $0 \%$ & $0 \%$ & $0 \%$ & $0 \%$ & $0 \%$ & $0 \%$ & $0 \%$ & $0 \%$ & $0 \%$ & $0 \%$ & $0 \%$ & $100 \%$ & $100 \%$ \\
\hline & Share Category & $0 \%$ & $0 \%$ & $0 \%$ & $0 \%$ & $5 \%$ & $5 \%$ & $0 \%$ & $0 \%$ & 0 & 0 & $\%$ & $0 \%$ & $0 \%$ & $0 \%$ & $0 \%$ & $0 \%$ & $0 \%$ & $0 \%$ & $0 \%$ & $0 \%$ & $0 \%$ & $0 \%$ & $0 \%$ & $0 \%$ & $0 \%$ \\
\hline & \begin{tabular}{|l} 
MC Invoicing. \\
\end{tabular} & & & & & & 0 & & & & & & & 0 & & & & & 48 & 48 & 0 & 0 & 0 & 0 & 48 & 48 \\
\hline & Share Year & $0 \%$ & $0 \%$ & $0 \%$ & $0 \%$ & $0 \%$ & $0 \%$ & $0 \%$ & $0 \%$ & $0^{c}$ & $\%$ & $\%$ & $0 \%$ & $0 \%$ & $0 \%$ & $0 \%$ & $0 \%$ & $0 \%$ & $100 \%$ & $100 \%$ & $0 \%$ & $0 \%$ & $0 \%$ & $0 \%$ & $100 \%$ & $100 \%$ \\
\hline & Share Category & $0 \%$ & $0 \%$ & $0 \%$ & $0 \%$ & $0 \%$ & $0 \%$ & $0 \%$ & $0 \%$ & $0 c$ & 0 & $\%$ & $0 \%$ & $0 \% \|$ & $0 \%$ & $0 \%$ & $0 \%$ & $0 \%$ & $72 \%$ & $55 \%$ & $0 \%$ & $0 \%$ & $0 \%$ & $0 \%$ & $16 \%$ & $4 \%$ \\
\hline & MC Inve & & & & & & 0 & & & & & & & 0 & & & & & 13 & 13 & 0 & 0 & 0 & 0 & 13 & 13 \\
\hline & Share Year & $0 \%$ & $0 \%$ & $0 \%$ & $0 \%$ & $0 \%$ & $0 \%$ & $0 \%$ & $0 \%$ & 0 & 0 & $\%$ & $0 \%$ & $0 \%$ & $0 \%$ & $0 \%$ & $0 \%$ & $0 \%$ & $100 \%$ & $100 \%$ & $0 \%$ & $0 \%$ & $0 \%$ & $0 \%$ & $100 \%$ & $100 \%$ \\
\hline & Share Category & $0 \%$ & $0 \%$ & $0 \%$ & $0 \%$ & $0 \%$ & $0 \%$ & $0 \%$ & $0 \%$ & 0 & 0 & $\%$ & $0 \%$ & $0 \%$ & $0 \%$ & $0 \%$ & $0 \%$ & $0 \%$ & $19 \%$ & $15 \%$ & $0 \%$ & $0 \%$ & $0 \%$ & $0 \%$ & $4 \%$ & $0 \%$ \\
\hline & & & & & & & 0 & & & & & & & 0 & & & & & & 0 & 0 & 0 & 0 & 0 & 0 & \\
\hline & Share Ye & $0 \%$ & $0 \%$ & $0 \%$ & $0 \%$ & $0 \%$ & $0 \%$ & $0 \%$ & $0 \%$ & 0 & $\%$ & $\%$ & $0 \%$ & $0 \%$ & $0 \%$ & $0 \%$ & $0 \%$ & $0 \%$ & $0 \%$ & $0 \%$ & $0 \%$ & $0 \%$ & $0 \%$ & $0 \%$ & $0 \%$ & $0 \%$ \\
\hline & Share Category & $0 \%$ & $0 \%$ & $0 \%$ & $0 \%$ & $0 \%$ & $0 \%$ & $0 \%$ & $0 \%$ & 0 & 0 & $\%$ & $0 \%$ & $0 \% \|$ & $0 \%$ & $0 \%$ & $0 \%$ & $0 \%$ & $0 \%$ & $0 \%$ & $0 \%$ & $0 \%$ & $0 \%$ & $0 \%$ & $0 \%$ & $0 \%$ \\
\hline & \begin{tabular}{|l} 
Tot. Bal. Sht. Ass. \\
\end{tabular} & 0 & 7 & 0 & 0 & 11 & 11 & 298 & 32 & \begin{tabular}{|l|l|}
7 & 19
\end{tabular} & \begin{tabular}{l|l|}
8 & 19 \\
\end{tabular} & 96 & 210 & 1.129 & 5 & 6 & 7 & 3 & 67 & 88 & 303 & 233 & 205 & 199 & 288 & 1.228 \\
\hline & Share Year & $0 \%$ & $0 \%$ & $0 \%$ & $0 \%$ & $4 \%$ & $1 \%$ & $98 \%$ & $97 \%$ & $97 c$ & \begin{tabular}{c|c|}
$\%$ & 98 \\
\end{tabular} & & $73 \%$ & $92 \%$ & $2 \%$ & $3 \%$ & $3 \%$ & $2 \%$ & $23 \%$ & $7 \%$ & $100 \%$ & $100 \%$ & $100 \%$ & $100 \%$ & $100 \%$ & $100 \%$ \\
\hline & Share Category & $0 \%$ & $0 \%$ & $0 \%$ & $0 \%$ & $52 \%$ & $52 \%$ & $100 \%$ & $100 \%$ & 100 & $\% 100$ & & $00 \%$ & $100 \%$ & $100 \%$ & $100 \%$ & $100 \%$ & $100 \%$ & $100 \%$ & $100 \%$ & $100 \%$ & $100 \%$ & $100 \%$ & $100 \%$ & $97 \%$ & $99 \%$ \\
\hline & Total & 0 & 0 & 0 & 0 & 21 & 21 & 298 & 22 & 19 & \begin{tabular}{l|l|}
8 & 19 \\
\end{tabular} & 96 & 210 & 1.129 & 5 & 6 & 7 & 3 & 67 & 88 & 303 & 233 & 205 & 199 & 298 & 1.238 \\
\hline 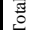 & Share Year & $0 \%$ & $0 \%$ & $0 \%$ & $0 \%$ & $7 \%$ & $2 \%$ & $98 \%$ & $97 \%$ & $97 c$ & $\%$ & & $70 \%$ & $91 \%$ & $2 \%$ & $3 \%$ & $3 \%$ & $2 \%$ & $22 \%$ & $7 \%$ & $100 \%$ & $100 \%$ & $100 \%$ & $100 \%$ & $100 \%$ & $100 \%$ \\
\hline & Share & $0 \%$ & $0 \%$ & $0 \%$ & $0 \%$ & $0 \%$ & $00 \%$ & $100 \%$ & $0 \%$ & $100^{\circ}$ & $\% \quad 100$ & & $0 \%$ & $100 \%$ & $00 \%$ & $100 \%$ & $00 \%$ & $00 \%$ & $100 \%$ & $00 \%$ & $00 \%$ & $100 \%$ & $100 \%$ & $100 \%$ & $100 \%$ & $100 \%$ \\
\hline
\end{tabular}


Annex 27: Conceptual Framework: References grouped according to Information Categories and Perspectives by year / Balance Sheet - Equity and Liabilities

\begin{tabular}{|c|c|c|c|c|c|c|c|c|c|c|c|c|c|c|c|c|c|c|c|c|c|c|c|c|c|}
\hline \multicolumn{26}{|c|}{ ouped according to Information Categories and Perspectives by year / Balance Sheet - Equity and Liabilities } \\
\hline & Perspec & \multicolumn{6}{|c|}{ Financial Analysts } & \multicolumn{6}{|c|}{ Focused Company } & \multicolumn{6}{|c|}{ Major Competitor } & \multicolumn{6}{|c|}{ Total References } \\
\hline \multicolumn{2}{|c|}{ Category } & 2008 & 2009 & 2010 & 2011 & 2012 & $08-12$ & 2008 & 2009 & 2010 & 2011 & 2012 & $08-12$ & 2008 & 2009 & 2010 & 2011 & 2012 & $08-12$ & 2008 & 2009 & 2010 & 2011 & 2012 & $08-12$ \\
\hline \multirow[t]{3}{*}{ ] } & General & 0 & 0 & 0 & 0 & 0 & 0 & 0 & 0 & 0 & 0 & 9 & 9 & 0 & 0 & 0 & 0 & 0 & 0 & 0 & 0 & 0 & 0 & 9 & \\
\hline & Share Year & $0 \%$ & $0 \%$ & $0 \%$ & $0 \%$ & $0 \%$ & $0 \%$ & $0 \%$ & $0 \%$ & $0 \%$ & $0 \%$ & $100 \%$ & $100 \%$ & $0 \%$ & $0 \%$ & $0 \%$ & $0 \%$ & $0 \%$ & $0 \%$ & $0 \%$ & $0 \%$ & $0 \%$ & $0 \%$ & $100 \%$ & $100 \%$ \\
\hline & Share Category & $0 \%$ & $0 \%$ & $0 \%$ & $0 \%$ & $0 \%$ & $0 \%$ & $0 \%$ & $0 \%$ & $0 \%$ & $0 \%$ & $56 \%$ & $20 \%$ & $0 \%$ & $0 \%$ & $0 \%$ & $0 \%$ & $0 \%$ & $0 \%$ & $0 \%$ & $0 \%$ & $0 \%$ & $0 \%$ & $39 \%$ & $16 \%$ \\
\hline \multirow{45}{*}{ 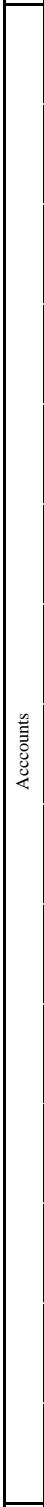 } & Equity & 0 & 0 & 0 & 0 & 4 & 4 & 1 & 3 & 0 & 0 & 6 & 10 & 0 & 0 & 0 & 0 & 0 & 0 & 1 & 3 & 0 & 0 & 10 & 14 \\
\hline & Share Year & $0 \%$ & $0 \%$ & $0 \%$ & $0 \%$ & $40 \%$ & $29 \%$ & $100 \%$ & $100 \%$ & $0 \%$ & $0 \%$ & $60 \%$ & $71 \%$ & $0 \%$ & $0 \%$ & $0 \%$ & $0 \%$ & $0 \%$ & $0 \%$ & $100 \%$ & $100 \%$ & $0 \%$ & $0 \%$ & $100 \%$ & $100 \%$ \\
\hline & Share Category & $0 \%$ & $0 \%$ & $0 \%$ & $0 \%$ & $67 \%$ & $67 \%$ & $20 \%$ & $23 \%$ & $0 \%$ & $0 \%$ & $38 \%$ & $23 \%$ & $0 \%$ & $0 \%$ & $0 \%$ & $0 \%$ & $0 \%$ & $0 \%$ & $11 \%$ & $21 \%$ & $0 \%$ & $0 \%$ & $43 \%$ & $24 \%$ \\
\hline & Minority Interests & 0 & 0 & 0 & 0 & 0 & 0 & 0 & 0 & 0 & 0 & 1 & 1 & 0 & 0 & 0 & 0 & 0 & 0 & 0 & 0 & 0 & 0 & & \\
\hline & Share Year & $0 \%$ & $0 \%$ & $0 \%$ & $0 \%$ & $0 \%$ & $0 \%$ & $0 \%$ & $0 \%$ & $0 \%$ & $0 \%$ & $100 \%$ & $100 \%$ & $0 \%$ & $0 \%$ & $0 \%$ & $0 \%$ & $0 \%$ & $0 \%$ & $0 \%$ & $0 \%$ & $0 \%$ & $0 \%$ & $100 \%$ & $100 \%$ \\
\hline & Share Category & $0 \%$ & $0 \%$ & $0 \%$ & $0 \%$ & $0 \%$ & $0 \%$ & $0 \%$ & $0 \%$ & $0 \%$ & $0 \%$ & $6 \%$ & $2 \%$ & $0 \%$ & $0 \%$ & $0 \%$ & $0 \%$ & $0 \%$ & $0 \%$ & $0 \%$ & $0 \%$ & $0 \%$ & $0 \%$ & $4 \%$ & $2 \%$ \\
\hline & Other Provisions & 0 & 0 & 0 & 0 & 1 & 1 & 0 & 0 & 0 & 0 & 0 & 0 & 1 & 0 & 0 & 0 & 0 & 1 & 1 & 0 & 0 & 0 & 1 & \\
\hline & Share Year & $0 \%$ & $0 \%$ & $0 \%$ & $0 \%$ & $100 \%$ & $50 \%$ & $0 \%$ & $0 \%$ & $0 \%$ & $0 \%$ & $0 \%$ & $0 \%$ & $100 \%$ & $0 \%$ & $0 \%$ & $0 \%$ & $0 \%$ & $50 \%$ & $100 \%$ & $0 \%$ & $0 \%$ & $0 \%$ & $100 \%$ & $100 \%$ \\
\hline & Share Category & $0 \%$ & $0 \%$ & $0 \%$ & $0 \%$ & $17 \%$ & $17 \%$ & $0 \%$ & $0 \%$ & $0 \%$ & $0 \%$ & $0 \%$ & $0 \%$ & $25 \%$ & $0 \%$ & $0 \%$ & $0 \%$ & $0 \%$ & $13 \%$ & $11 \%$ & $0 \%$ & $0 \%$ & $0 \%$ & $4 \%$ & $3 \%$ \\
\hline & Trade Payables & 0 & 0 & 0 & 0 & 1 & 1 & 0 & 0 & 0 & 0 & 0 & 0 & 2 & 0 & 0 & 0 & 0 & 2 & 2 & 0 & 0 & 0 & & \\
\hline & Share Year & $0 \%$ & $0 \%$ & $0 \%$ & $0 \%$ & $100 \%$ & $33 \%$ & $0 \%$ & $0 \%$ & $0 \%$ & $0 \%$ & $0 \%$ & $0 \%$ & $100 \%$ & $0 \%$ & $0 \%$ & $0 \%$ & $0 \%$ & $67 \%$ & $100 \%$ & $0 \%$ & $0 \%$ & $0 \%$ & $100 \%$ & $100 \%$ \\
\hline & Share Category & $0 \%$ & $0 \%$ & $0 \%$ & $0 \%$ & $17 \%$ & $17 \%$ & $0 \%$ & $0 \%$ & $0 \%$ & $0 \%$ & $0 \%$ & $0 \%$ & $50 \%$ & $0 \%$ & $0 \%$ & $0 \%$ & $0 \%$ & $25 \%$ & $22 \%$ & $0 \%$ & $0 \%$ & $0 \%$ & $4 \%$ & $5 \%$ \\
\hline & Loans to subs. & 0 & 0 & 0 & 0 & 0 & 0 & 0 & 0 & 0 & 0 & 0 & 0 & 1 & 0 & 0 & 0 & 0 & 1 & 1 & 0 & 0 & 0 & 0 & \\
\hline & Share Year & $0 \%$ & $0 \%$ & $0 \%$ & $0 \%$ & $0 \%$ & $0 \%$ & $0 \%$ & $0 \%$ & $0 \%$ & $0 \%$ & $0 \%$ & $0 \%$ & $100 \%$ & $0 \%$ & $0 \%$ & $0 \%$ & $0 \%$ & $100 \%$ & $100 \%$ & $0 \%$ & $0 \%$ & $0 \%$ & $0 \%$ & $100 \%$ \\
\hline & Share Category & $0 \%$ & $0 \%$ & $0 \%$ & $0 \%$ & $0 \%$ & $0 \%$ & $0 \%$ & $0 \%$ & $0 \%$ & $0 \%$ & $0 \%$ & $0 \%$ & $25 \%$ & $0 \%$ & $0 \%$ & $0 \%$ & $0 \%$ & $13 \%$ & $11 \%$ & $0 \%$ & $0 \%$ & $0 \%$ & $0 \%$ & $2 \%$ \\
\hline & \begin{tabular}{|l|} 
Advance Payments \\
\end{tabular} & 0 & 0 & 0 & 0 & 0 & 0 & 4 & 10 & 9 & 1 & 0 & 24 & 0 & 1 & 1 & 1 & 1 & 4 & 4 & 11 & 10 & 2 & & 28 \\
\hline & Share Year & $0 \%$ & $0 \%$ & $0 \%$ & $0 \%$ & $0 \%$ & $0 \%$ & $100 \%$ & $91 \%$ & $90 \%$ & $50 \%$ & $0 \%$ & $86 \%$ & $0 \%$ & $9 \%$ & $10 \%$ & $50 \%$ & $100 \%$ & $14 \%$ & $100 \%$ & $100 \%$ & $100 \%$ & $100 \%$ & $100 \%$ & $100 \%$ \\
\hline & Share Category & $0 \%$ & $0 \%$ & $0 \%$ & $0 \%$ & $0 \%$ & $0 \%$ & $80 \%$ & $77 \%$ & $100 \%$ & $100 \%$ & $0 \%$ & $55 \%$ & $0 \%$ & $100 \%$ & $100 \%$ & $100 \%$ & $100 \%$ & $50 \%$ & $44 \%$ & $79 \%$ & $100 \%$ & $100 \%$ & $4 \%$ & $48 \%$ \\
\hline & & & & & & & 0 & & & & & & 0 & & & & & & 0 & 0 & 0 & 0 & 0 & 0 & 0 \\
\hline & Share Year & $0 \%$ & $0 \%$ & $0 \%$ & $0 \%$ & $0 \%$ & $0 \%$ & $0 \%$ & $0 \%$ & $0 \%$ & $0 \%$ & $0 \%$ & $0 \%$ & $0 \%$ & $0 \%$ & $0 \%$ & $0 \%$ & $0 \%$ & $0 \%$ & $0 \%$ & $0 \%$ & $0 \%$ & $0 \%$ & $0 \%$ & $0 \%$ \\
\hline & Share Category & $0 \%$ & $0 \%$ & $0 \%$ & $0 \%$ & $0 \%$ & $0 \%$ & $0 \%$ & $0 \%$ & $0 \%$ & $0 \%$ & $0 \%$ & $0 \%$ & $0 \%$ & $0 \%$ & $0 \%$ & $0 \%$ & $0 \%$ & $0 \%$ & $0 \%$ & $0 \%$ & $0 \%$ & $0 \%$ & $0 \%$ & $0 \%$ \\
\hline & & & & & & & 0 & & & & & & 0 & & & & & & 0 & 0 & $t$ & 0 & 0 & 0 & \\
\hline & Share Year & $0 \%$ & $0 \%$ & $0 \%$ & $0 \%$ & $0 \%$ & $0 \%$ & $0 \%$ & $0 \%$ & $0 \%$ & $0 \%$ & $0 \%$ & $0 \%$ & $0 \%$ & $0 \%$ & $0 \%$ & $0 \%$ & $0 \%$ & $0 \%$ & $0 \%$ & $0 \%$ & $0 \%$ & $0 \%$ & $0 \%$ & $0 \%$ \\
\hline & Share Category & $0 \%$ & $0 \%$ & $0 \%$ & $0 \%$ & $0 \%$ & $0 \%$ & $0 \%$ & $0 \%$ & $0 \%$ & $0 \%$ & $0 \%$ & $0 \%$ & $0 \%$ & $0 \%$ & $0 \%$ & $0 \%$ & $0 \%$ & $0 \%$ & $0 \%$ & $0 \%$ & $0 \%$ & $0 \%$ & $0 \%$ & $0 \%$ \\
\hline & & & & & & & 0 & & & & & & 0 & & & & & & 0 & 0 & 0 & 0 & 0 & & 0 \\
\hline & Share Year & $0 \%$ & $0 \%$ & $0 \%$ & $0 \%$ & $0 \%$ & $0 \%$ & $0 \%$ & $0 \%$ & $0 \%$ & $0 \%$ & $0 \%$ & $0 \%$ & $0 \%$ & $0 \%$ & $0 \%$ & $0 \%$ & $0 \%$ & $0 \%$ & $0 \%$ & $0 \%$ & $0 \%$ & $0 \%$ & $0 \%$ & $0 \%$ \\
\hline & Share Category & $0 \%$ & $0 \%$ & $0 \%$ & $0 \%$ & $0 \%$ & $0 \%$ & $0 \%$ & $0 \%$ & $0 \%$ & $0 \%$ & $0 \%$ & $0 \%$ & $0 \%$ & $0 \%$ & $0 \%$ & $0 \%$ & $0 \%$ & $0 \%$ & $0 \%$ & $0 \%$ & $0 \%$ & $0 \%$ & $0 \%$ & $0 \%$ \\
\hline & & & & & & & 0 & & & & & & 0 & & & & & & 0 & 0 & 0 & 0 & 0 & 0 & 0 \\
\hline & Share Year & $0 \%$ & $0 \%$ & $0 \%$ & $0 \%$ & $0 \%$ & $0 \%$ & $0 \%$ & $0 \%$ & $0 \%$ & $0 \%$ & $0 \%$ & $0 \%$ & $0 \%$ & $0 \%$ & $0 \%$ & $0 \%$ & $0 \%$ & $0 \%$ & $0 \%$ & $0 \%$ & $0 \%$ & $0 \%$ & $0 \%$ & $0 \%$ \\
\hline & Share Category & $0 \%$ & $0 \%$ & $0 \%$ & $0 \%$ & $0 \%$ & $0 \%$ & $0 \%$ & $0 \%$ & $0 \%$ & $0 \%$ & $0 \%$ & $0 \%$ & $0 \%$ & $0 \%$ & $0 \%$ & $0 \%$ & $0 \%$ & $0 \%$ & $0 \%$ & $0 \%$ & $0 \%$ & $0 \%$ & $0 \%$ & $0 \%$ \\
\hline & & & & & & & 0 & & & & & & 0 & & & & & & 0 & 0 & 0 & 0 & 0 & & 0 \\
\hline & Share Year & $0 \%$ & $0 \%$ & $0 \%$ & $0 \%$ & $0 \%$ & $0 \%$ & $0 \%$ & $0 \%$ & $0 \%$ & $0 \%$ & $0 \%$ & $0 \%$ & $0 \%$ & $0 \%$ & $0 \%$ & $0 \%$ & $0 \%$ & $0 \%$ & $0 \%$ & $0 \%$ & $0 \%$ & $0 \%$ & $0 \%$ & $0 \%$ \\
\hline & Share Category & $0 \%$ & $0 \%$ & $0 \%$ & $0 \%$ & $0 \%$ & $0 \%$ & $0 \%$ & $0 \%$ & $0 \%$ & $0 \%$ & $0 \%$ & $0 \%$ & $0 \%$ & $0 \%$ & $0 \%$ & $0 \%$ & $0 \%$ & $0 \%$ & $0 \%$ & $0 \%$ & $0 \%$ & $0 \%$ & $0 \%$ & $0 \%$ \\
\hline & & & & & & & 0 & & & & & & 0 & & & & & & 0 & 0 & 0 & 0 & 0 & 0 & 0 \\
\hline & Share Year & $0 \%$ & $0 \%$ & $0 \%$ & $0 \%$ & $0 \%$ & $0 \%$ & $0 \%$ & $0 \%$ & $0 \%$ & $0 \%$ & $0 \%$ & $0 \%$ & $0 \%$ & $0 \%$ & $0 \%$ & $0 \%$ & $0 \%$ & $0 \%$ & $0 \%$ & $0 \%$ & $0 \%$ & $0 \%$ & $0 \%$ & $0 \%$ \\
\hline & Share Category & $0 \%$ & $0 \%$ & $0 \%$ & $0 \%$ & $0 \%$ & $0 \%$ & $0 \%$ & $0 \%$ & $0 \%$ & $0 \%$ & $0 \%$ & $0 \%$ & $0 \%$ & $0 \%$ & $0 \%$ & $0 \%$ & $0 \%$ & $0 \%$ & $0 \%$ & $0 \%$ & $0 \%$ & $0 \%$ & $0 \%$ & $0 \%$ \\
\hline & & & & & & & 0 & & & & & & 0 & & & & & & 0 & 0 & 0 & 0 & 0 & 0 & 0 \\
\hline & Share Year & $0 \%$ & $0 \%$ & $0 \%$ & $0 \%$ & $0 \%$ & $0 \%$ & $0 \%$ & $0 \%$ & $0 \%$ & $0 \%$ & $0 \%$ & $0 \%$ & $0 \%$ & $0 \%$ & $0 \%$ & $0 \%$ & $0 \%$ & $0 \%$ & $0 \%$ & $0 \%$ & $0 \%$ & $0 \%$ & $0 \%$ & $0 \%$ \\
\hline & Share Category & $0 \%$ & $0 \%$ & $0 \%$ & $0 \%$ & $0 \%$ & $0 \%$ & $0 \%$ & $0 \%$ & $0 \%$ & $0 \%$ & $0 \%$ & $0 \%$ & $0 \%$ & $0 \%$ & $0 \%$ & $0 \%$ & $0 \%$ & $0 \%$ & $0 \%$ & $0 \%$ & $0 \%$ & $0 \%$ & $0 \%$ & $0 \%$ \\
\hline & & & & & & & 0 & & & & & & 0 & & & & & & 0 & 0 & 0 & 0 & 0 & 0 & 0 \\
\hline & Share Year & $0 \%$ & $0 \%$ & $0 \%$ & $0 \%$ & $0 \%$ & $0 \%$ & $0 \%$ & $0 \%$ & $0 \%$ & $0 \%$ & $0 \%$ & $0 \%$ & $0 \%$ & $0 \%$ & $0 \%$ & $0 \%$ & $0 \%$ & $0 \%$ & $0 \%$ & $0 \%$ & $0 \%$ & $0 \%$ & $0 \%$ & $0 \%$ \\
\hline & Share Category & $0 \%$ & $0 \%$ & $0 \%$ & $0 \%$ & $0 \%$ & $0 \%$ & $0 \%$ & $0 \%$ & $0 \%$ & $0 \%$ & $0 \%$ & $0 \%$ & $0 \%$ & $0 \%$ & $0 \%$ & $0 \%$ & $0 \%$ & $0 \%$ & $0 \%$ & $0 \%$ & $0 \%$ & $0 \%$ & $0 \%$ & $0 \%$ \\
\hline & Tot. Bal. Sht. E\&I & 0 & 0 & 0 & 0 & 6 & 6 & 5 & 13 & 9 & 1 & 7 & 35 & 4 & 1 & 1 & 1 & 1 & 8 & 9 & 14 & 10 & 2 & 14 & 49 \\
\hline & Share Year & $0 \%$ & $0 \%$ & $0 \%$ & $0 \%$ & $43 \%$ & $12 \%$ & $56 \%$ & $93 \%$ & $90 \%$ & $50 \%$ & $50 \%$ & $71 \%$ & $44 \%$ & $7 \%$ & $10 \%$ & $50 \%$ & $7 \%$ & $16 \%$ & $100 \%$ & $100 \%$ & $100 \%$ & $100 \%$ & $100 \%$ & $100 \%$ \\
\hline & Share Category & $0 \%$ & $0 \%$ & $0 \%$ & $0 \%$ & $100 \%$ & $100 \%$ & $100 \%$ & $100 \%$ & $100 \%$ & $100 \%$ & $44 \%$ & $80 \%$ & $100 \%$ & $100 \%$ & $100 \%$ & $100 \%$ & $100 \%$ & $100 \%$ & $100 \%$ & $100 \%$ & $100 \%$ & $100 \%$ & $61 \%$ & $84 \%$ \\
\hline & Total & 0 & 0 & 0 & 0 & 6 & 6 & 5 & 13 & 9 & 1 & 16 & 44 & 4 & 1 & 1 & 1 & 1 & 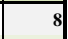 & 9 & 14 & 10 & 2 & 23 & 58 \\
\hline 苛 & Share Year & $0 \%$ & $0 \%$ & $0 \%$ & $0 \%$ & $26 \%$ & $10 \%$ & $56 \%$ & $93 \%$ & $90 \%$ & $50 \%$ & $70 \%$ & $76 \%$ & $44 \%$ & $7 \%$ & $10 \%$ & $50 \%$ & $4 \%$ & $14 \%$ & $100 \%$ & $100 \%$ & $100 \%$ & $100 \%$ & $100 \%$ & $100 \%$ \\
\hline & Share Category & $0 \%$ & $0 \%$ & $0 \%$ & $0 \%$ & $100 \%$ & $100 \%$ & $100 \%$ & $100 \%$ & $100 \%$ & $100 \%$ & $100 \%$ & $100 \%$ & $100 \%$ & $100 \%$ & $100 \%$ & $100 \%$ & $100 \%$ & $100 \%$ & $100 \%$ & $100 \%$ & $100 \%$ & $100 \%$ & $100 \%$ & $100 \%$ \\
\hline
\end{tabular}


Annex 28: Conceptual Framework: References grouped according to Information Categories and Perspectives by year / Balance Sheet - Working Capital / ROCE

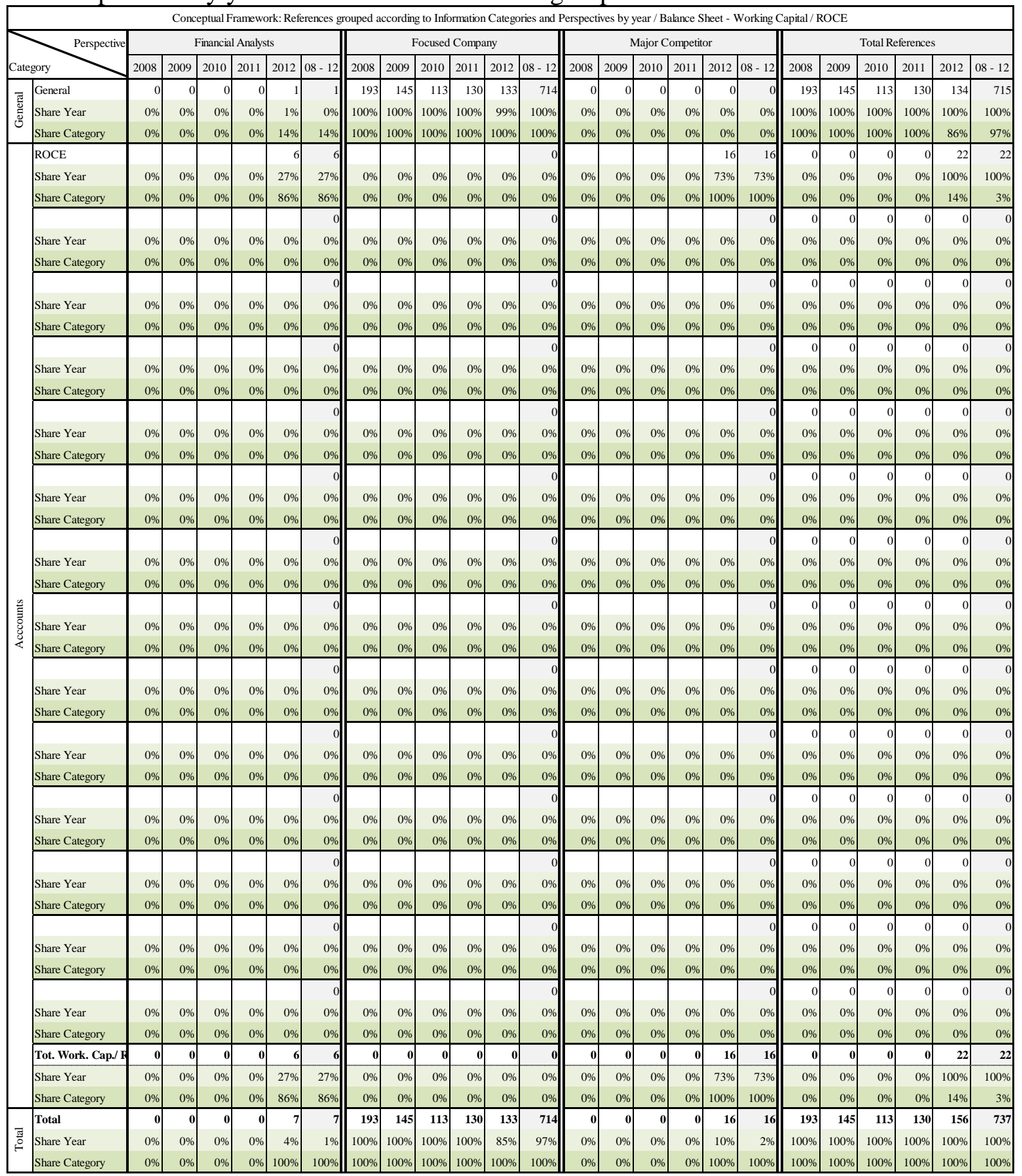


Annex 29: Conceptual Framework: References grouped according to Information Categories and Perspectives by year / Cash Flow Statement

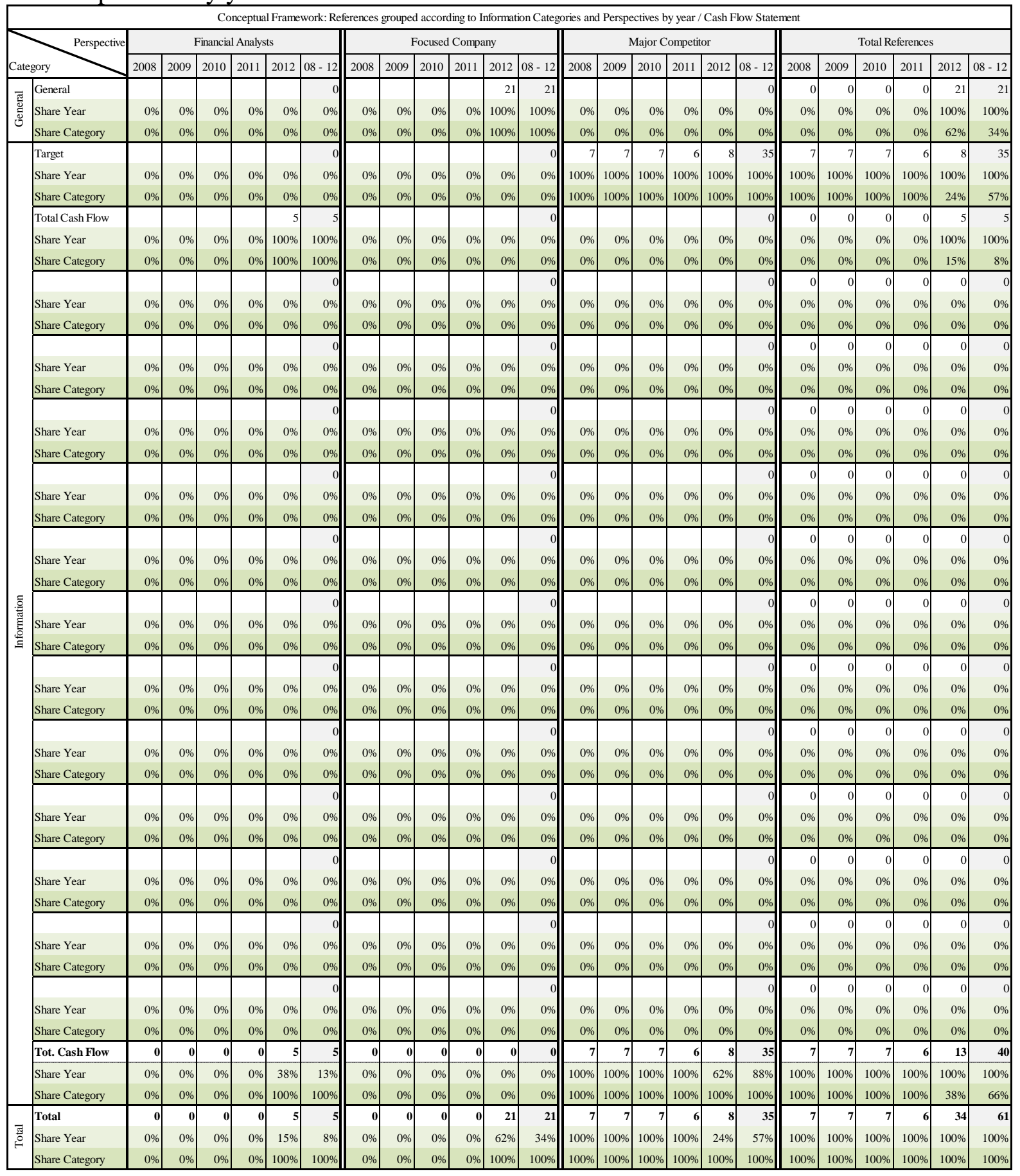


Annex 30: Conceptual Framework: References grouped according to Information Categories and Perspectives by year / Statistics \& Other

\begin{tabular}{|c|c|c|c|c|c|c|c|c|c|c|c|c|c|c|c|c|c|c|c|c|c|c|c|c|c|}
\hline \multicolumn{26}{|c|}{ rk: References grouped according to Information Categories and Perspectives by year / Statistics \& Other } \\
\hline & Perspective & \multicolumn{6}{|c|}{ Financial Analysts } & \multicolumn{6}{|c|}{ Focused Company } & \multicolumn{6}{|c|}{ Major Competitor } & \multicolumn{6}{|c|}{ Total References } \\
\hline \multicolumn{2}{|c|}{ Category } & 2008 & 2009 & 2010 & 2011 & 2012 & $08-12$ & 2008 & 2009 & 2010 & 2011 & 2012 & $08-12$ & 2008 & 2009 & 2010 & 2011 & 2012 & $08-12$ & 2008 & 2009 & 2010 & 2011 & 2012 & $08-12$ \\
\hline \multirow[t]{3}{*}{ ] } & General & 0 & 0 & 0 & 0 & 6 & 6 & 0 & 0 & 0 & 0 & 0 & 0 & 35 & 27 & 2 & 15 & 3 & 82 & 35 & 27 & 2 & 15 & 9 & 88 \\
\hline & Share Year & $0 \%$ & $0 \%$ & $0 \%$ & $0 \%$ & $67 \%$ & $7 \%$ & $0 \%$ & $0 \%$ & $0 \%$ & $0 \%$ & $0 \%$ & $0 \%$ & $100 \%$ & $100 \%$ & $100 \%$ & $100 \%$ & $33 \%$ & $93 \%$ & $100 \%$ & $100 \%$ & $100 \%$ & $100 \%$ & $100 \%$ & $100 \%$ \\
\hline & Share Category & $0 \%$ & $0 \%$ & $0 \%$ & $0 \%$ & $22 \%$ & $19 \%$ & $0 \%$ & $0 \%$ & $0 \%$ & $0 \%$ & $0 \%$ & $0 \%$ & $55 \%$ & $55 \%$ & $17 \%$ & $56 \%$ & $12 \%$ & $46 \%$ & $15 \%$ & $13 \%$ & $2 \%$ & $10 \%$ & $5 \%$ & $10 \%$ \\
\hline \multirow{45}{*}{ 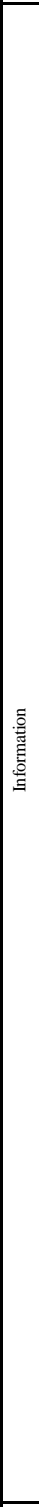 } & Hours & 0 & 0 & 0 & 0 & 0 & 0 & 0 & 0 & 1 & 0 & 0 & 1 & 0 & 0 & 0 & 0 & 0 & 0 & 0 & 0 & 1 & 0 & 0 & \\
\hline & Share Year & $0 \%$ & $0 \%$ & $0 \%$ & $0 \%$ & $0 \%$ & $0 \%$ & $0 \%$ & $0 \%$ & $100 \%$ & $0 \%$ & $0 \%$ & $100 \%$ & $0 \%$ & $0 \%$ & $0 \%$ & $0 \%$ & $0 \%$ & $0 \%$ & $0 \%$ & $0 \%$ & $100 \%$ & $0 \%$ & $0 \%$ & $100 \%$ \\
\hline & Share Category & $0 \%$ & $0 \%$ & $0 \%$ & $0 \%$ & $0 \%$ & $0 \%$ & $0 \%$ & $0 \%$ & $1 \%$ & $0 \%$ & $0 \%$ & $0 \%$ & $0 \%$ & $0 \%$ & $0 \%$ & $0 \%$ & $0 \%$ & $0 \%$ & $0 \%$ & $0 \%$ & $1 \%$ & $0 \%$ & $0 \%$ & $0 \%$ \\
\hline & Headcount & 0 & 0 & 0 & 0 & 5 & 5 & 159 & 167 & 117 & 126 & 126 & 695 & 7 & 6 & 1 & 3 & 5 & 22 & 166 & 173 & 118 & 129 & 136 & 722 \\
\hline & Share Year & $0 \%$ & $0 \%$ & $0 \%$ & $0 \%$ & $4 \%$ & $1 \%$ & $96 \%$ & $97 \%$ & $99 \%$ & $98 \%$ & $93 \%$ & $96 \%$ & $4 \%$ & $3 \%$ & $1 \%$ & $2 \%$ & $4 \%$ & $3 \%$ & $100 \%$ & $100 \%$ & $100 \%$ & $100 \%$ & $100 \%$ & $100 \%$ \\
\hline & Share Category & $0 \%$ & $0 \%$ & $0 \%$ & $0 \%$ & $19 \%$ & $16 \%$ & $100 \%$ & $100 \%$ & $99 \%$ & $100 \%$ & $100 \%$ & $100 \%$ & $11 \%$ & $12 \%$ & $8 \%$ & $11 \%$ & $20 \%$ & $12 \%$ & $73 \%$ & $80 \%$ & $91 \%$ & $84 \%$ & $76 \%$ & $80 \%$ \\
\hline & Utilization & 4 & 0 & 0 & 0 & 6 & 10 & 0 & 0 & 0 & 0 & 0 & 0 & 22 & 16 & 9 & 9 & 17 & 73 & 26 & 16 & 9 & 9 & 23 & 83 \\
\hline & Share Year & $15 \%$ & $0 \%$ & $0 \%$ & $0 \%$ & $26 \%$ & $12 \%$ & $0 \%$ & $0 \%$ & $0 \%$ & $0 \%$ & $0 \%$ & $0 \%$ & $85 \%$ & $100 \%$ & $100 \%$ & $100 \%$ & $74 \%$ & $88 \%$ & $100 \%$ & $100 \%$ & $100 \%$ & $100 \%$ & $100 \%$ & $100 \%$ \\
\hline & Share Category & $100 \%$ & $0 \%$ & $0 \%$ & $0 \%$ & $22 \%$ & $32 \%$ & $0 \%$ & $0 \%$ & $0 \%$ & $0 \%$ & $0 \%$ & $0 \%$ & $34 \%$ & $33 \%$ & $75 \%$ & $33 \%$ & $68 \%$ & $41 \%$ & $11 \%$ & $7 \%$ & $7 \%$ & $6 \%$ & $13 \%$ & $9 \%$ \\
\hline & Future Challenges & 0 & 0 & 0 & 0 & 8 & 8 & 0 & 0 & 0 & 0 & 0 & 0 & 0 & 0 & 0 & 0 & 0 & 0 & 0 & 0 & 0 & 0 & 8 & \\
\hline & Share Year & $0 \%$ & $0 \%$ & $0 \%$ & $0 \%$ & $100 \%$ & $100 \%$ & $0 \%$ & $0 \%$ & $0 \%$ & $0 \%$ & $0 \%$ & $0 \%$ & $0 \%$ & $0 \%$ & $0 \%$ & $0 \%$ & $0 \%$ & $0 \%$ & $0 \%$ & $0 \%$ & $0 \%$ & $0 \%$ & $100 \%$ & $100 \%$ \\
\hline & Share Category & $0 \%$ & $0 \%$ & $0 \%$ & $0 \%$ & $30 \%$ & $26 \%$ & $0 \%$ & $0 \%$ & $0 \%$ & $0 \%$ & $0 \%$ & $0 \%$ & $0 \%$ & $0 \%$ & $0 \%$ & $0 \%$ & $0 \%$ & $0 \%$ & $0 \%$ & $0 \%$ & $0 \%$ & $0 \%$ & $4 \%$ & $1 \%$ \\
\hline & Comparison & 0 & 0 & 0 & 0 & 2 & 2 & 0 & 0 & 0 & 0 & 0 & 0 & 0 & 0 & 0 & 0 & 0 & 0 & 0 & 0 & 0 & 0 & 2 & 2 \\
\hline & Share Year & $0 \%$ & $0 \%$ & $0 \%$ & $0 \%$ & $100 \%$ & $100 \%$ & $0 \%$ & $0 \%$ & $0 \%$ & $0 \%$ & $0 \%$ & $0 \%$ & $0 \%$ & $0 \%$ & $0 \%$ & $0 \%$ & $0 \%$ & $0 \%$ & $0 \%$ & $0 \%$ & $0 \%$ & $0 \%$ & $100 \%$ & $100 \%$ \\
\hline & Share Category & $0 \%$ & $0 \%$ & $0 \%$ & $0 \%$ & $7 \%$ & $6 \%$ & $0 \%$ & $0 \%$ & $0 \%$ & $0 \%$ & $0 \%$ & $0 \%$ & $0 \%$ & $0 \%$ & $0 \%$ & $0 \%$ & $0 \%$ & $0 \%$ & $0 \%$ & $0 \%$ & $0 \%$ & $0 \%$ & $1 \%$ & $0 \%$ \\
\hline & & & & & & & 0 & & & & & & 0 & & & & & & 0 & 0 & 0 & 0 & 0 & & \\
\hline & Share Year & $0 \%$ & $0 \%$ & $0 \%$ & $0 \%$ & $0 \%$ & $0 \%$ & $0 \%$ & $0 \%$ & $0 \%$ & $0 \%$ & $0 \%$ & $0 \%$ & $0 \%$ & $0 \%$ & $0 \%$ & $0 \%$ & $0 \%$ & $0 \%$ & $0 \%$ & $0 \%$ & $0 \%$ & $0 \%$ & $0 \%$ & $0 \%$ \\
\hline & Share Category & $0 \%$ & $0 \%$ & $0 \%$ & $0 \%$ & $0 \%$ & $0 \%$ & $0 \%$ & $0 \%$ & $0 \%$ & $0 \%$ & $0 \%$ & $0 \%$ & $0 \%$ & $0 \%$ & $0 \%$ & $0 \%$ & $0 \%$ & $0 \%$ & $0 \%$ & $0 \%$ & $0 \%$ & $0 \%$ & $0 \%$ & $0 \%$ \\
\hline & & & & & & & 0 & & & & & & 0 & & & & & & 0 & 0 & 0 & 0 & 0 & 0 & 0 \\
\hline & Share Year & $0 \%$ & $0 \%$ & $0 \%$ & $0 \%$ & $0 \%$ & $0 \%$ & $0 \%$ & $0 \%$ & $0 \%$ & $0 \%$ & $0 \%$ & $0 \%$ & $0 \%$ & $0 \%$ & $0 \%$ & $0 \%$ & $0 \%$ & $0 \%$ & $0 \%$ & $0 \%$ & $0 \%$ & $0 \%$ & $0 \%$ & $0 \%$ \\
\hline & Share Category & $0 \%$ & $0 \%$ & $0 \%$ & $0 \%$ & $0 \%$ & $0 \%$ & $0 \%$ & $0 \%$ & $0 \%$ & $0 \%$ & $0 \%$ & $0 \%$ & $0 \%$ & $0 \%$ & $0 \%$ & $0 \%$ & $0 \%$ & $0 \%$ & $0 \%$ & $0 \%$ & $0 \%$ & $0 \%$ & $0 \%$ & $0 \%$ \\
\hline & & & & & & & 0 & & & & & & 0 & & & & & & 0 & 0 & 0 & 0 & 0 & 0 & \\
\hline & Share Year & $0 \%$ & $0 \%$ & $0 \%$ & $0 \%$ & $0 \%$ & $0 \%$ & $0 \%$ & $0 \%$ & $0 \%$ & $0 \%$ & $0 \%$ & $0 \%$ & $0 \%$ & $0 \%$ & $0 \%$ & $0 \%$ & $0 \%$ & $0 \%$ & $0 \%$ & $0 \%$ & $0 \%$ & $0 \%$ & $0 \%$ & $0 \%$ \\
\hline & Share Category & $0 \%$ & $0 \%$ & $0 \%$ & $0 \%$ & $0 \%$ & $0 \%$ & $0 \%$ & $0 \%$ & $0 \%$ & $0 \%$ & $0 \%$ & $0 \%$ & $0 \%$ & $0 \%$ & $0 \%$ & $0 \%$ & $0 \%$ & $0 \%$ & $0 \%$ & $0 \%$ & $0 \%$ & $0 \%$ & $0 \%$ & $0 \%$ \\
\hline & & & & & & & 0 & & & & & & 0 & & & & & & 0 & 0 & 0 & 0 & 0 & 0 & 0 \\
\hline & Share Year & $0 \%$ & $0 \%$ & $0 \%$ & $0 \%$ & $0 \%$ & $0 \%$ & $0 \%$ & $0 \%$ & $0 \%$ & $0 \%$ & $0 \%$ & $0 \%$ & $0 \%$ & $0 \%$ & $0 \%$ & $0 \%$ & $0 \%$ & $0 \%$ & $0 \%$ & $0 \%$ & $0 \%$ & $0 \%$ & $0 \%$ & $0 \%$ \\
\hline & Share Category & $0 \%$ & $0 \%$ & $0 \%$ & $0 \%$ & $0 \%$ & $0 \%$ & $0 \%$ & $0 \%$ & $0 \%$ & $0 \%$ & $0 \%$ & $0 \%$ & $0 \%$ & $0 \%$ & $0 \%$ & $0 \%$ & $0 \%$ & $0 \%$ & $0 \%$ & $0 \%$ & $0 \%$ & $0 \%$ & $0 \%$ & $0 \%$ \\
\hline & & & & & & & 0 & & & & & & 0 & & & & & & 0 & 0 & 0 & 0 & 0 & 0 & 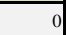 \\
\hline & Share Year & $0 \%$ & $0 \%$ & $0 \%$ & $0 \%$ & $0 \%$ & $0 \%$ & $0 \%$ & $0 \%$ & $0 \%$ & $0 \%$ & $0 \%$ & $0 \%$ & $0 \%$ & $0 \%$ & $0 \%$ & $0 \%$ & $0 \%$ & $0 \%$ & $0 \%$ & $0 \%$ & $0 \%$ & $0 \%$ & $0 \%$ & $0 \%$ \\
\hline & Share Category & $0 \%$ & $0 \%$ & $0 \%$ & $0 \%$ & $0 \%$ & $0 \%$ & $0 \%$ & $0 \%$ & $0 \%$ & $0 \%$ & $0 \%$ & $0 \%$ & $0 \%$ & $0 \%$ & $0 \%$ & $0 \%$ & $0 \%$ & $0 \%$ & $0 \%$ & $0 \%$ & $0 \%$ & $0 \%$ & $0 \%$ & $0 \%$ \\
\hline & & & & & & & 0 & & & & & & 0 & & & & & & 0 & 0 & 0 & 0 & 0 & & 0 \\
\hline & Share Year & $0 \%$ & $0 \%$ & $0 \%$ & $0 \%$ & $0 \%$ & $0 \%$ & $0 \%$ & $0 \%$ & $0 \%$ & $0 \%$ & $0 \%$ & $0 \%$ & $0 \%$ & $0 \%$ & $0 \%$ & $0 \%$ & $0 \%$ & $0 \%$ & $0 \%$ & $0 \%$ & $0 \%$ & $0 \%$ & $0 \%$ & $0 \%$ \\
\hline & Share Category & $0 \%$ & $0 \%$ & $0 \%$ & $0 \%$ & $0 \%$ & $0 \%$ & $0 \%$ & $0 \%$ & $0 \%$ & $0 \%$ & $0 \%$ & $0 \%$ & $0 \%$ & $0 \%$ & $0 \%$ & $0 \%$ & $0 \%$ & $0 \%$ & $0 \%$ & $0 \%$ & $0 \%$ & $0 \%$ & $0 \%$ & $0 \%$ \\
\hline & & & & & & & 0 & & & & & & 0 & & & & & & 0 & 0 & 0 & 0 & 0 & 0 & 0 \\
\hline & Share Year & $0 \%$ & $0 \%$ & $0 \%$ & $0 \%$ & $0 \%$ & $0 \%$ & $0 \%$ & $0 \%$ & $0 \%$ & $0 \%$ & $0 \%$ & $0 \%$ & $0 \%$ & $0 \%$ & $0 \%$ & $0 \%$ & $0 \%$ & $0 \%$ & $0 \%$ & $0 \%$ & $0 \%$ & $0 \%$ & $0 \%$ & $0 \%$ \\
\hline & Share Category & $0 \%$ & $0 \%$ & $0 \%$ & $0 \%$ & $0 \%$ & $0 \%$ & $0 \%$ & $0 \%$ & $0 \%$ & $0 \%$ & $0 \%$ & $0 \%$ & $0 \%$ & $0 \%$ & $0 \%$ & $0 \%$ & $0 \%$ & $0 \%$ & $0 \%$ & $0 \%$ & $0 \%$ & $0 \%$ & $0 \%$ & $0 \%$ \\
\hline & & & & & & & 0 & & & & & & 0 & & & & & & 0 & 0 & 0 & 0 & 0 & 0 & 0 \\
\hline & Share Year & $0 \%$ & $0 \%$ & $0 \%$ & $0 \%$ & $0 \%$ & $0 \%$ & $0 \%$ & $0 \%$ & $0 \%$ & $0 \%$ & $0 \%$ & $0 \%$ & $0 \%$ & $0 \%$ & $0 \%$ & $0 \%$ & $0 \%$ & $0 \%$ & $0 \%$ & $0 \%$ & $0 \%$ & $0 \%$ & $0 \%$ & $0 \%$ \\
\hline & Share Category & $0 \%$ & $0 \%$ & $0 \%$ & $0 \%$ & $0 \%$ & $0 \%$ & $0 \%$ & $0 \%$ & $0 \%$ & $0 \%$ & $0 \%$ & $0 \%$ & $0 \%$ & $0 \%$ & $0 \%$ & $0 \%$ & $0 \%$ & $0 \%$ & $0 \%$ & $0 \%$ & $0 \%$ & $0 \%$ & $0 \%$ & $0 \%$ \\
\hline & & & & & & & 0 & & & & & & 0 & & & & & & 0 & 0 & 0 & 0 & 0 & 0 & 0 \\
\hline & Share Year & $0 \%$ & $0 \%$ & $0 \%$ & $0 \%$ & $0 \%$ & $0 \%$ & $0 \%$ & $0 \%$ & $0 \%$ & $0 \%$ & $0 \%$ & $0 \%$ & $0 \%$ & $0 \%$ & $0 \%$ & $0 \%$ & $0 \%$ & $0 \%$ & $0 \%$ & $0 \%$ & $0 \%$ & $0 \%$ & $0 \%$ & $0 \%$ \\
\hline & Share Category & $0 \%$ & $0 \%$ & $0 \%$ & $0 \%$ & $0 \%$ & $0 \%$ & $0 \%$ & $0 \%$ & $0 \%$ & $0 \%$ & $0 \%$ & $0 \%$ & $0 \%$ & $0 \%$ & $0 \%$ & $0 \%$ & $0 \%$ & $0 \%$ & $0 \%$ & $0 \%$ & $0 \%$ & $0 \%$ & $0 \%$ & $0 \%$ \\
\hline & Total & 4 & 0 & 0 & $\mathbf{0}$ & 21 & 25 & 159 & 167 & 118 & 126 & 126 & 696 & 29 & 22 & 10 & 12 & 22 & 95 & 192 & 189 & 128 & 138 & 169 & 816 \\
\hline & Share Year & $2 \%$ & $0 \%$ & $0 \%$ & $0 \%$ & $12 \%$ & $3 \%$ & $83 \%$ & $88 \%$ & $92 \%$ & $91 \%$ & $75 \%$ & $85 \%$ & $15 \%$ & $12 \%$ & $8 \%$ & $9 \%$ & $13 \%$ & $12 \%$ & $100 \%$ & $100 \%$ & $100 \%$ & $100 \%$ & $100 \%$ & $100 \%$ \\
\hline & Share Category & $100 \%$ & $0 \%$ & $0 \%$ & $0 \%$ & $78 \%$ & $81 \%$ & $\mid 100 \%$ & $100 \%$ & $100 \%$ & $100 \%$ & $100 \%$ & $100 \%$ & $45 \%$ & $45 \%$ & $83 \%$ & $44 \%$ & $88 \%$ & $54 \%$ & $85 \%$ & $88 \%$ & $98 \%$ & $90 \%$ & $95 \%$ & $90 \%$ \\
\hline \multirow{3}{*}{ 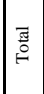 } & Total Stat. \& Oth. & 4 & 0 & 0 & 0 & 27 & 31 & 159 & 167 & 118 & 126 & 126 & 696 & 64 & 49 & 12 & 27 & 25 & 177 & 227 & 216 & 130 & 153 & 178 & 904 \\
\hline & Share Year & $2 \%$ & $0 \%$ & $0 \%$ & $0 \%$ & $15 \%$ & $3 \%$ & $70 \%$ & $77 \%$ & $91 \%$ & $82 \%$ & $71 \%$ & $77 \%$ & $28 \%$ & $23 \%$ & $9 \%$ & $18 \%$ & $14 \%$ & $20 \%$ & $100 \%$ & $100 \%$ & $100 \%$ & $100 \%$ & $100 \%$ & $100 \%$ \\
\hline & Share Category & $100 \%$ & $0 \%$ & $0 \%$ & $0 \%$ & $100 \%$ & $100 \%$ & $100 \%$ & $100 \%$ & $100 \%$ & $100 \%$ & $100 \%$ & $100 \%$ & $100 \%$ & $100 \%$ & $100 \%$ & $100 \%$ & $100 \%$ & $100 \%$ & $100 \%$ & $100 \%$ & $100 \%$ & $100 \%$ & $100 \%$ & $100 \%$ \\
\hline
\end{tabular}


Annex 31: Conceptual Framework: References grouped according to Information Categories and Perspectives by year / Other - Consolidation Hierarchy

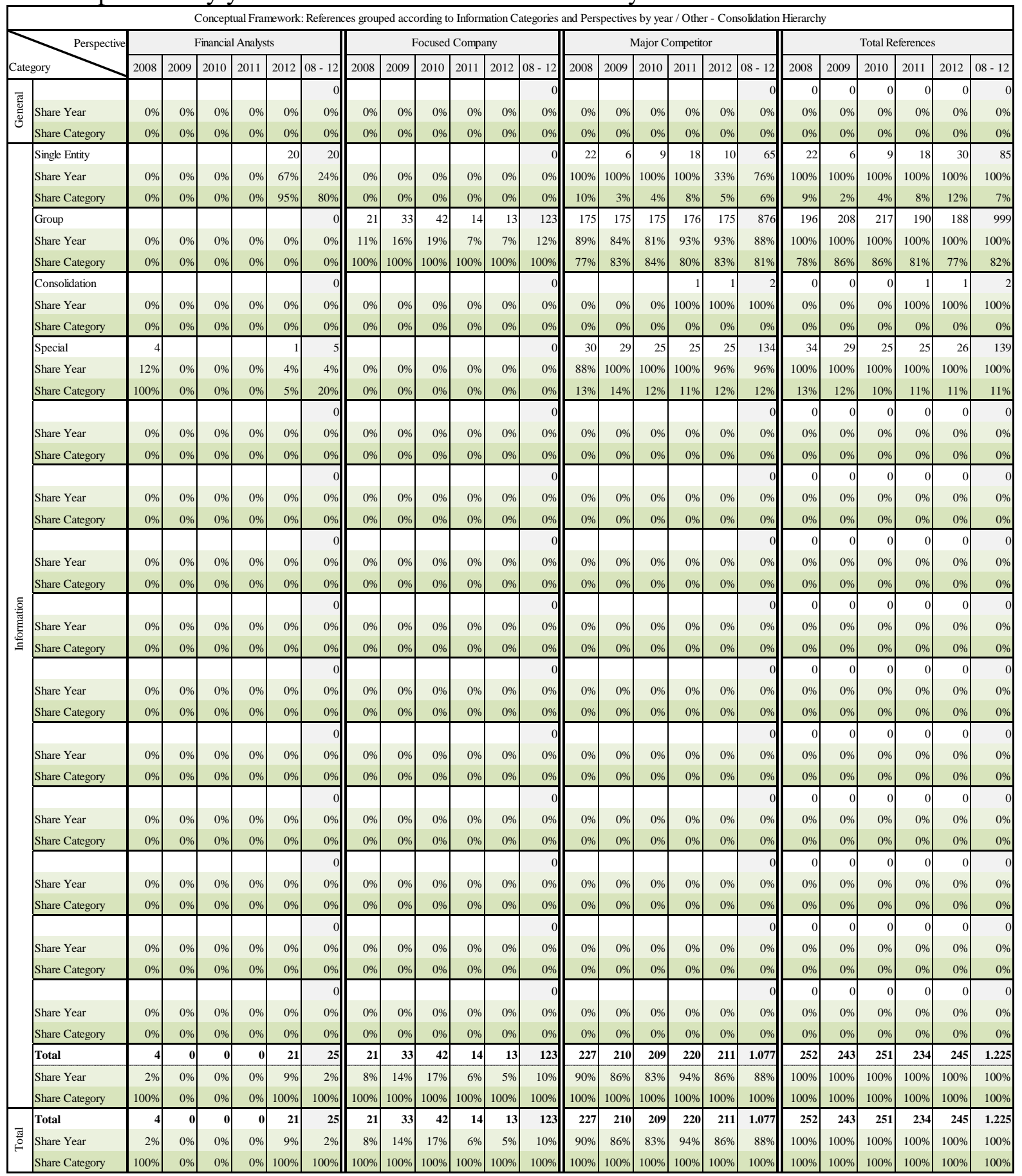


Annex 32: Conceptual Framework: References grouped according to Information Categories and Perspectives by year / Other - Region

\begin{tabular}{|c|c|c|c|c|c|c|c|c|c|c|c|c|c|c|c|c|c|c|c|c|c|c|c|c|c|}
\hline \multicolumn{26}{|c|}{ k: References grouped according to Information Categories and Perspectives by year / Other - Regions } \\
\hline & & \multicolumn{6}{|c|}{ Financial Analysts } & \multicolumn{6}{|c|}{ Focused Company } & \multicolumn{6}{|c|}{ Major Competitor } & \multicolumn{6}{|c|}{ Total References } \\
\hline \multicolumn{2}{|c|}{ Category } & 2008 & 2009 & 2010 & 2011 & 2012 & $08-12$ & 2008 & 2009 & 2010 & 2011 & 2012 & $08-12$ & 2008 & 2009 & 2010 & 2011 & 2012 & $08-12$ & 2008 & 2009 & 2010 & 2011 & 2012 & $08-12$ \\
\hline \multirow{3}{*}{ 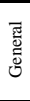 } & & & & 0 & 0 & 0 & 0 & 0 & 0 & 0 & 0 & 0 & 0 & 0 & 0 & 0 & 0 & 0 & 0 & 0 & 0 & 0 & 0 & 0 & \\
\hline & Share Year & $0 \%$ & $0 \%$ & $0 \%$ & $0 \%$ & $0 \%$ & $0 \%$ & $0 \%$ & $0 \%$ & $0 \%$ & $0 \%$ & $0 \%$ & $0 \%$ & $0 \%$ & $0 \%$ & $0 \%$ & $0 \%$ & $0 \%$ & $0 \%$ & $0 \%$ & $0 \%$ & $0 \%$ & $0 \%$ & $0 \%$ & $0 \%$ \\
\hline & Share Category & $0 \%$ & $0 \%$ & $0 \%$ & $0 \%$ & $0 \%$ & $0 \%$ & $0 \%$ & $0 \%$ & $0 \%$ & $0 \%$ & $0 \%$ & $0 \%$ & $0 \%$ & $0 \%$ & $0 \%$ & $0 \%$ & $0 \%$ & $0 \%$ & $0 \%$ & $0 \%$ & $0 \%$ & $0 \%$ & $0 \%$ & $0 \%$ \\
\hline \multirow{45}{*}{ 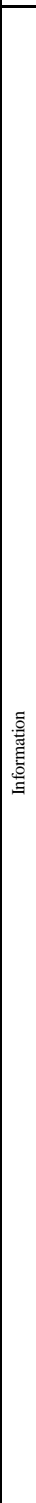 } & Region 1 & 0 & 0 & 0 & 0 & 1 & 1 & 11 & 22 & 22 & 23 & 22 & 100 & 0 & 0 & 0 & 0 & 0 & 0 & 11 & 22 & 22 & 23 & 23 & 101 \\
\hline & Share Year & $0 \%$ & $0 \%$ & $0 \%$ & $0 \%$ & $4 \%$ & $1 \%$ & $100 \%$ & $100 \%$ & $100 \%$ & $100 \%$ & $96 \%$ & $99 \%$ & $0 \%$ & $0 \%$ & $0 \%$ & $0 \%$ & $0 \%$ & $0 \%$ & $100 \%$ & $100 \%$ & $100 \%$ & $100 \%$ & $100 \%$ & $100 \%$ \\
\hline & Share Category & $0 \%$ & $0 \%$ & $0 \%$ & $0 \%$ & $5 \%$ & $5 \%$ & $3 \%$ & $6 \%$ & $6 \%$ & $6 \%$ & $5 \%$ & $5 \%$ & $0 \%$ & $0 \%$ & $0 \%$ & $0 \%$ & $0 \%$ & $0 \%$ & $2 \%$ & $5 \%$ & $6 \%$ & $5 \%$ & $4 \%$ & $4 \%$ \\
\hline & Region 2 & 0 & 0 & 0 & 0 & 10 & 10 & 71 & 91 & 94 & 95 & 112 & 463 & 26 & 16 & 7 & 20 & 38 & 107 & 97 & 107 & 101 & 115 & 160 & 580 \\
\hline & Share Year & $0 \%$ & $0 \%$ & $0 \%$ & $0 \%$ & $6 \%$ & $2 \%$ & $73 \%$ & $85 \%$ & $93 \%$ & $83 \%$ & $70 \%$ & $80 \%$ & $27 \%$ & $15 \%$ & $7 \%$ & $17 \%$ & $24 \%$ & $18 \%$ & $100 \%$ & $100 \%$ & $100 \%$ & $100 \%$ & $100 \%$ & $100 \%$ \\
\hline & Share Category & $0 \%$ & $0 \%$ & $0 \%$ & $0 \%$ & $48 \%$ & $48 \%$ & $19 \%$ & $23 \%$ & $26 \%$ & $25 \%$ & $28 \%$ & $24 \%$ & $28 \%$ & $32 \%$ & $19 \%$ & $27 \%$ & $35 \%$ & $30 \%$ & $21 \%$ & $24 \%$ & $26 \%$ & $26 \%$ & $30 \%$ & $25 \%$ \\
\hline & Region 3 & 0 & 0 & 0 & 0 & 1 & 1 & 15 & 15 & 12 & 19 & 23 & 84 & 15 & 7 & 7 & 10 & 9 & 49 & 30 & 22 & 19 & 29 & 33 & 134 \\
\hline & Share Year & $0 \%$ & $0 \%$ & $0 \%$ & $0 \%$ & $3 \%$ & $1 \%$ & $50 \%$ & $68 \%$ & $63 \%$ & $65 \%$ & $69 \%$ & $63 \%$ & $50 \%$ & $32 \%$ & $37 \%$ & $35 \%$ & $28 \%$ & $36 \%$ & $100 \%$ & $100 \%$ & $100 \%$ & $100 \%$ & $100 \%$ & $100 \%$ \\
\hline & Share Category & $0 \%$ & $0 \%$ & $0 \%$ & $0 \%$ & $5 \%$ & $5 \%$ & $4 \%$ & $4 \%$ & $3 \%$ & $5 \%$ & $6 \%$ & $4 \%$ & $16 \%$ & $14 \%$ & $19 \%$ & $14 \%$ & $9 \%$ & $13 \%$ & $7 \%$ & $5 \%$ & $5 \%$ & $6 \%$ & $6 \%$ & $6 \%$ \\
\hline & Region 4 & 0 & 0 & 0 & 0 & 3 & 3 & 207 & 205 & 177 & 177 & 180 & 946 & 14 & 9 & 4 & 12 & 15 & 54 & 221 & 214 & 181 & 189 & 198 & 1.003 \\
\hline & Share Year & $0 \%$ & $0 \%$ & $0 \%$ & $0 \%$ & $2 \%$ & $0 \%$ & $94 \%$ & $96 \%$ & $98 \%$ & $94 \%$ & $91 \%$ & $94 \%$ & $6 \%$ & $4 \%$ & $2 \%$ & $6 \%$ & $8 \%$ & $5 \%$ & $100 \%$ & $100 \%$ & $100 \%$ & $100 \%$ & $100 \%$ & $100 \%$ \\
\hline & Share Category & $0 \%$ & $0 \%$ & $0 \%$ & $0 \%$ & $14 \%$ & $14 \%$ & $56 \%$ & $52 \%$ & $50 \%$ & $47 \%$ & $45 \%$ & $50 \%$ & $15 \%$ & $18 \%$ & $11 \%$ & $16 \%$ & $14 \%$ & $15 \%$ & $48 \%$ & $49 \%$ & $46 \%$ & $42 \%$ & $37 \%$ & $44 \%$ \\
\hline & Region 5 & 0 & 0 & 0 & 0 & 3 & 3 & 4 & 2 & 2 & 1 & 2 & 11 & 10 & 0 & 1 & 0 & 1 & 12 & 14 & 2 & 3 & 1 & 6 & 26 \\
\hline & Share Year & $0 \%$ & $0 \%$ & $0 \%$ & $0 \%$ & $50 \%$ & $12 \%$ & $29 \%$ & $100 \%$ & $67 \%$ & $100 \%$ & $33 \%$ & $42 \%$ & $71 \%$ & $0 \%$ & $33 \%$ & $0 \%$ & $17 \%$ & $46 \%$ & $100 \%$ & $100 \%$ & $100 \%$ & $100 \%$ & $100 \%$ & $100 \%$ \\
\hline & Share Category & $0 \%$ & $0 \%$ & $0 \%$ & $0 \%$ & $14 \%$ & $14 \%$ & $1 \%$ & $1 \%$ & $1 \%$ & $0 \%$ & $0 \%$ & $1 \%$ & $11 \%$ & $0 \%$ & $3 \%$ & $0 \%$ & $1 \%$ & $3 \%$ & $3 \%$ & $0 \%$ & $1 \%$ & $0 \%$ & $1 \%$ & $1 \%$ \\
\hline & Region 6 & 0 & 0 & 0 & 0 & 2 & 2 & 14 & 13 & 14 & 14 & 13 & 68 & 15 & 9 & 9 & 11 & 22 & 66 & 29 & 22 & 23 & 25 & 37 & 136 \\
\hline & Share Year & $0 \%$ & $0 \%$ & $0 \%$ & $0 \%$ & $5 \%$ & $1 \%$ & $48 \%$ & $59 \%$ & $61 \%$ & $56 \%$ & $35 \%$ & $50 \%$ & $52 \%$ & $41 \%$ & $39 \%$ & $44 \%$ & $59 \%$ & $49 \%$ & $100 \%$ & $100 \%$ & $100 \%$ & $100 \%$ & $100 \%$ & $100 \%$ \\
\hline & Share Category & $0 \%$ & $0 \%$ & $0 \%$ & $0 \%$ & $10 \%$ & $10 \%$ & $4 \%$ & $3 \%$ & $4 \%$ & $4 \%$ & $3 \%$ & $4 \%$ & $16 \%$ & $18 \%$ & $25 \%$ & $15 \%$ & $20 \%$ & $18 \%$ & $6 \%$ & $5 \%$ & $6 \%$ & $6 \%$ & $7 \%$ & $6 \%$ \\
\hline & Region 7 & 0 & 0 & 0 & 0 & 1 & 1 & 45 & 43 & 36 & 47 & 52 & 223 & 13 & 9 & 8 & 20 & 23 & 73 & 58 & 52 & 44 & 67 & 76 & 297 \\
\hline & Share Year & $0 \%$ & $0 \%$ & $0 \%$ & $0 \%$ & $1 \%$ & $0 \%$ & $78 \%$ & $83 \%$ & $82 \%$ & $70 \%$ & $68 \%$ & $75 \%$ & $22 \%$ & $17 \%$ & $18 \%$ & $30 \%$ & $30 \%$ & $25 \%$ & $100 \%$ & $100 \%$ & $100 \%$ & $100 \%$ & $100 \%$ & $100 \%$ \\
\hline & Share Category & $0 \%$ & $0 \%$ & $0 \%$ & $0 \%$ & $5 \%$ & $5 \%$ & $12 \%$ & $11 \%$ & $10 \%$ & $13 \%$ & $13 \%$ & $12 \%$ & $14 \%$ & $18 \%$ & $22 \%$ & $27 \%$ & $21 \%$ & $20 \%$ & $13 \%$ & $12 \%$ & $11 \%$ & $15 \%$ & $14 \%$ & $13 \%$ \\
\hline & & & & & & & 0 & & & & & & 0 & & & & & & 0 & 0 & 0 & 0 & 0 & 0 & \\
\hline & Share Year & $0 \%$ & $0 \%$ & $0 \%$ & $0 \%$ & $0 \%$ & $0 \%$ & $0 \%$ & $0 \%$ & $0 \%$ & $0 \%$ & $0 \%$ & $0 \%$ & $0 \%$ & $0 \%$ & $0 \%$ & $0 \%$ & $0 \%$ & $0 \%$ & $0 \%$ & $0 \%$ & $0 \%$ & $0 \%$ & $0 \%$ & $0 \%$ \\
\hline & Share Category & $0 \%$ & $0 \%$ & $0 \%$ & $0 \%$ & $0 \%$ & $0 \%$ & $0 \%$ & $0 \%$ & $0 \%$ & $0 \%$ & $0 \%$ & $0 \%$ & $0 \%$ & $0 \%$ & $0 \%$ & $0 \%$ & $0 \%$ & $0 \%$ & $0 \%$ & $0 \%$ & $0 \%$ & $0 \%$ & $0 \%$ & $0 \%$ \\
\hline & & & & & & & 0 & & & & & & 0 & & & & & & 0 & 0 & 0 & 0 & 0 & 0 & 0 \\
\hline & Share Year & $0 \%$ & $0 \%$ & $0 \%$ & $0 \%$ & $0 \%$ & $0 \%$ & $0 \%$ & $0 \%$ & $0 \%$ & $0 \%$ & $0 \%$ & $0 \%$ & $0 \%$ & $0 \%$ & $0 \%$ & $0 \%$ & $0 \%$ & $0 \%$ & $0 \%$ & $0 \%$ & $0 \%$ & $0 \%$ & $0 \%$ & $0 \%$ \\
\hline & Share Category & $0 \%$ & $0 \%$ & $0 \%$ & $0 \%$ & $0 \%$ & $0 \%$ & $0 \%$ & $0 \%$ & $0 \%$ & $0 \%$ & $0 \%$ & $0 \%$ & $0 \%$ & $0 \%$ & $0 \%$ & $0 \%$ & $0 \%$ & $0 \%$ & $0 \%$ & $0 \%$ & $0 \%$ & $0 \%$ & $0 \%$ & $0 \%$ \\
\hline & & & & & & & 0 & & & & & & 0 & & & & & & 0 & 0 & 0 & 0 & 0 & 0 & \\
\hline & Share Year & $0 \%$ & $0 \%$ & $0 \%$ & $0 \%$ & $0 \%$ & $0 \%$ & $0 \%$ & $0 \%$ & $0 \%$ & $0 \%$ & $0 \%$ & $0 \%$ & $0 \%$ & $0 \%$ & $0 \%$ & $0 \%$ & $0 \%$ & $0 \%$ & $0 \%$ & $0 \%$ & $0 \%$ & $0 \%$ & $0 \%$ & $0 \%$ \\
\hline & Share Category & $0 \%$ & $0 \%$ & $0 \%$ & $0 \%$ & $0 \%$ & $0 \%$ & $0 \%$ & $0 \%$ & $0 \%$ & $0 \%$ & $0 \%$ & $0 \%$ & $0 \%$ & $0 \%$ & $0 \%$ & $0 \%$ & $0 \%$ & $0 \%$ & $0 \%$ & $0 \%$ & $0 \%$ & $0 \%$ & $0 \%$ & $0 \%$ \\
\hline & & & & & & & 0 & & & & & & 0 & & & & & & 0 & 0 & 0 & 0 & 0 & & 0 \\
\hline & Share Year & $0 \%$ & $0 \%$ & $0 \%$ & $0 \%$ & $0 \%$ & $0 \%$ & $0 \%$ & $0 \%$ & $0 \%$ & $0 \%$ & $0 \%$ & $0 \%$ & $0 \%$ & $0 \%$ & $0 \%$ & $0 \%$ & $0 \%$ & $0 \%$ & $0 \%$ & $0 \%$ & $0 \%$ & $0 \%$ & $0 \%$ & $0 \%$ \\
\hline & Share Category & $0 \%$ & $0 \%$ & $0 \%$ & $0 \%$ & $0 \%$ & $0 \%$ & $0 \%$ & $0 \%$ & $0 \%$ & $0 \%$ & $0 \%$ & $0 \%$ & $0 \%$ & $0 \%$ & $0 \%$ & $0 \%$ & $0 \%$ & $0 \%$ & $0 \%$ & $0 \%$ & $0 \%$ & $0 \%$ & $0 \%$ & $0 \%$ \\
\hline & & & & & & & 0 & & & & & & 0 & & & & & & 0 & 0 & 0 & 0 & 0 & 0 & 0 \\
\hline & Share Year & $0 \%$ & $0 \%$ & $0 \%$ & $0 \%$ & $0 \%$ & $0 \%$ & $0 \%$ & $0 \%$ & $0 \%$ & $0 \%$ & $0 \%$ & $0 \%$ & $0 \%$ & $0 \%$ & $0 \%$ & $0 \%$ & $0 \%$ & $0 \%$ & $0 \%$ & $0 \%$ & $0 \%$ & $0 \%$ & $0 \%$ & $0 \%$ \\
\hline & Share Category & $0 \%$ & $0 \%$ & $0 \%$ & $0 \%$ & $0 \%$ & $0 \%$ & $0 \%$ & $0 \%$ & $0 \%$ & $0 \%$ & $0 \%$ & $0 \%$ & $0 \%$ & $0 \%$ & $0 \%$ & $0 \%$ & $0 \%$ & $0 \%$ & $0 \%$ & $0 \%$ & $0 \%$ & $0 \%$ & $0 \%$ & $0 \%$ \\
\hline & & & & & & & 0 & & & & & & 0 & & & & & & 0 & 0 & 0 & 0 & 0 & 0 & 0 \\
\hline & Share Year & $0 \%$ & $0 \%$ & $0 \%$ & $0 \%$ & $0 \%$ & $0 \%$ & $0 \%$ & $0 \%$ & $0 \%$ & $0 \%$ & $0 \%$ & $0 \%$ & $0 \%$ & $0 \%$ & $0 \%$ & $0 \%$ & $0 \%$ & $0 \%$ & $0 \%$ & $0 \%$ & $0 \%$ & $0 \%$ & $0 \%$ & $0 \%$ \\
\hline & Share Category & $0 \%$ & $0 \%$ & $0 \%$ & $0 \%$ & $0 \%$ & $0 \%$ & $0 \%$ & $0 \%$ & $0 \%$ & $0 \%$ & $0 \%$ & $0 \%$ & $0 \%$ & $0 \%$ & $0 \%$ & $0 \%$ & $0 \%$ & $0 \%$ & $0 \%$ & $0 \%$ & $0 \%$ & $0 \%$ & $0 \%$ & $0 \%$ \\
\hline & & & & & & & 0 & & & & & & 0 & & & & & & 0 & 0 & 0 & 0 & 0 & 0 & \\
\hline & Share Year & $0 \%$ & $0 \%$ & $0 \%$ & $0 \%$ & $0 \%$ & $0 \%$ & $0 \%$ & $0 \%$ & $0 \%$ & $0 \%$ & $0 \%$ & $0 \%$ & $0 \%$ & $0 \%$ & $0 \%$ & $0 \%$ & $0 \%$ & $0 \%$ & $0 \%$ & $0 \%$ & $0 \%$ & $0 \%$ & $0 \%$ & $0 \%$ \\
\hline & Share Category & $0 \%$ & $0 \%$ & $0 \%$ & $0 \%$ & $0 \%$ & $0 \%$ & $0 \%$ & $0 \%$ & $0 \%$ & $0 \%$ & $0 \%$ & $0 \%$ & $0 \%$ & $0 \%$ & $0 \%$ & $0 \%$ & $0 \%$ & $0 \%$ & $0 \%$ & $0 \%$ & $0 \%$ & $0 \%$ & $0 \%$ & $0 \%$ \\
\hline & Total & 0 & 0 & 0 & 0 & 21 & 21 & 367 & 391 & 357 & 376 & 404 & 1.895 & 93 & 50 & 36 & 73 & 108 & 361 & 460 & 441 & 393 & 449 & 533 & 2.277 \\
\hline & Share Year & $0 \%$ & $0 \%$ & $0 \%$ & $0 \%$ & $4 \%$ & $1 \%$ & $80 \%$ & $89 \%$ & $91 \%$ & $84 \%$ & $76 \%$ & $83 \%$ & $20 \%$ & $11 \%$ & $9 \%$ & $16 \%$ & $20 \%$ & $16 \%$ & $100 \%$ & $100 \%$ & $100 \%$ & $100 \%$ & $100 \%$ & $100 \%$ \\
\hline & Share Category & $0 \%$ & $0 \%$ & $0 \%$ & $0 \%$ & $100 \%$ & $100 \%$ & $100 \%$ & $100 \%$ & $100 \%$ & $100 \%$ & $100 \%$ & $100 \%$ & $100 \%$ & $100 \%$ & $100 \%$ & $100 \%$ & $100 \%$ & $100 \%$ & $100 \%$ & $100 \%$ & $100 \%$ & $100 \%$ & $100 \%$ & $100 \%$ \\
\hline & Total & 0 & 0 & 0 & 0 & 21 & 21 & 367 & 391 & 357 & 376 & 404 & 1.895 & 93 & 50 & 36 & 73 & 108 & 361 & 460 & 441 & 393 & 449 & 533 & 2.277 \\
\hline & Share Year & $0 \%$ & $0 \%$ & $0 \%$ & $0 \%$ & $4 \%$ & $1 \%$ & $80 \%$ & $89 \%$ & $91 \%$ & $84 \%$ & $76 \%$ & $83 \%$ & $20 \%$ & $11 \%$ & $9 \%$ & $16 \%$ & $20 \%$ & $16 \%$ & $100 \%$ & $100 \%$ & $100 \%$ & $100 \%$ & $100 \%$ & $100 \%$ \\
\hline & Share Category & $0 \%$ & $0 \%$ & $0 \%$ & $0 \%$ & $100 \%$ & $100 \%$ & $100 \%$ & $100 \%$ & $100 \%$ & $100 \%$ & $100 \%$ & $100 \%$ & $100 \%$ & $100 \%$ & $100 \%$ & $100 \%$ & $100 \%$ & $100 \%$ & $100 \%$ & $100 \%$ & $100 \%$ & $100 \%$ & $100 \%$ & $100 \%$ \\
\hline
\end{tabular}


Annex 33: Conceptual Framework: References grouped according to Information Categories and Perspectives by year / Strategic Planning \& Competitor's Highlights

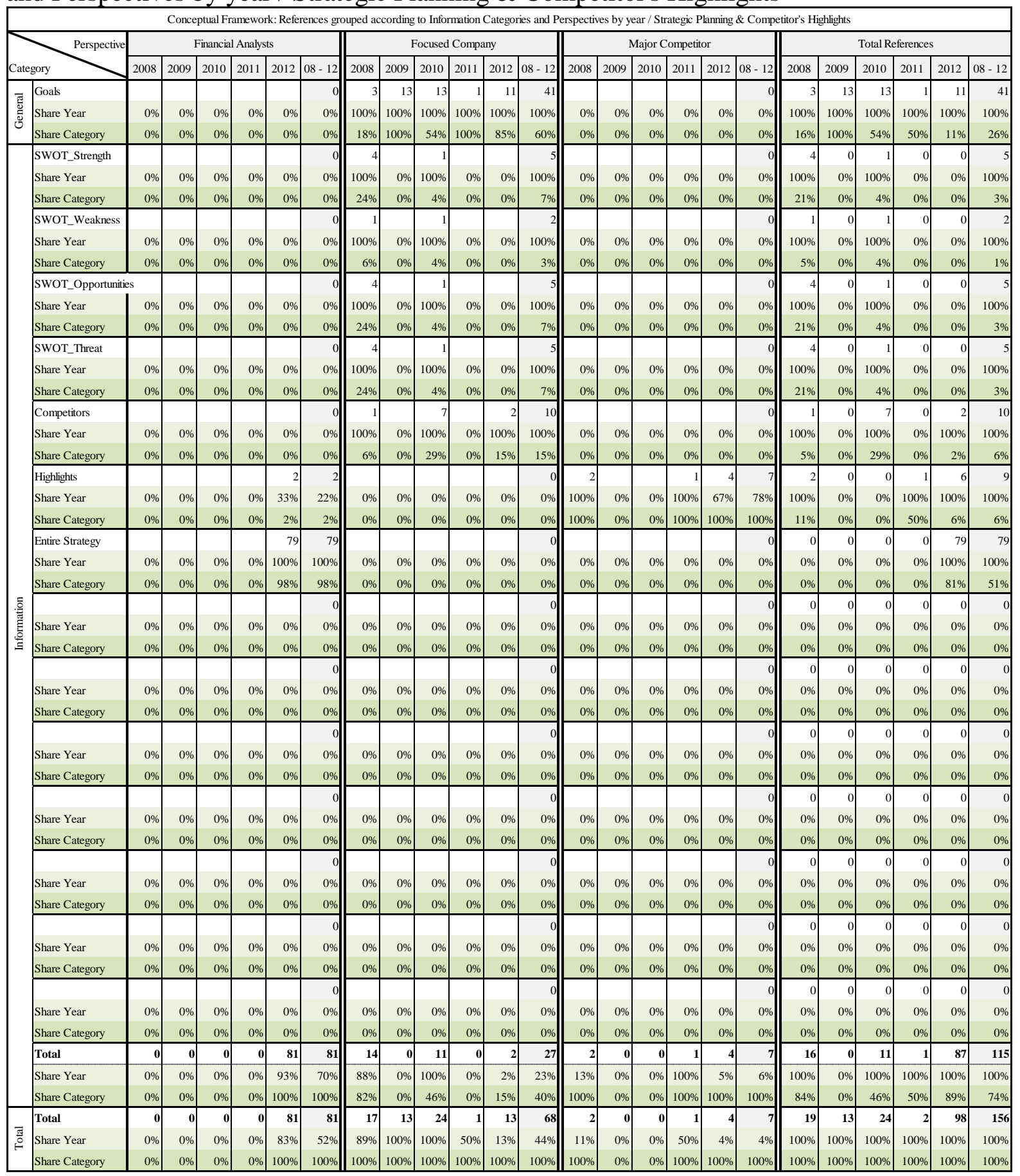


Annex 34: Structure of Case Classification of Entrepreneurial Units Part 1 of 5

\begin{tabular}{|c|c|c|}
\hline \multicolumn{3}{|c|}{ Structure of Case Classification of Entrepreneurial Units } \\
\hline \# & Attribute & Explanation of Value of Attribute \\
\hline & 01 EPU & Number of EPU \\
\hline 2 & $2008-2012$ SC-Key C-PL- 1 & Key buildt of Numbers of EPU and Product Line for years 2008 - 2012 \\
\hline & $2008-2012$ SC-Key C-PL-2 & Key buildt of Numbers of EPU and Product Line for years 2008 - 2012 \\
\hline 4 & $2008-2012$ SC-Key C-PL-3 & Key buildt of Numbers of EPU and Product Line for years 2008 - 2012 \\
\hline 5 & $2008-2012$ SC-Key C-PL-4 & Key buildt of Numbers of EPU and Product Line for years $2008-2012$ \\
\hline 6 & $2008-2012$ SC-Key C-PL-5 & Key buildt of Numbers of EPU and Product Line for years 2008 - 2012 \\
\hline 7 & $2008-2012$ SC-Key C-PL-6 & Key buildt of Numbers of EPU and Product Line for years $2008-2012$ \\
\hline 8 & $2008-2012$ SC-Key C-PL-7 & Key buildt of Numbers of EPU and Product Line for years 2008 - 2012 \\
\hline 9 & $2008-2012$ SC-Key C-PL-8 & Key buildt of Numbers of EPU and Product Line for years 2008 - 2012 \\
\hline 10 & 2008 - 2012_SC-Key C-PL-9 & Key buildt of Numbers of EPU and Product Line for years 2008 - 2012 \\
\hline 11 & 2008 -2012_SC-Key Grand Total & Key buildt of Numbers of EPU and Product Line for years 2008 - 2012 \\
\hline 12 & $2008-2012$ SC-Key Total NM & Key buildt of Numbers of EPU and Product Line for years $2008-2012$ \\
\hline 13 & 2008 - 2012_SC-Key Total Service & Key buildt of Numbers of EPU and Product Line for years 2008 - 2012 \\
\hline 14 & 2008 - 2012_Scoring 2008 Ex-Rate C-PL-1 & A - B - C Value based on 2008 exchange rate \\
\hline 15 & 2008 -2012_Scoring 2008 Ex-Rate C-PL-2 & A - B - C Value based on 2008 exchange rate \\
\hline 16 & 2008 - 2012_Scoring 2008 Ex-Rate C-PL-3 & A - B - C Value based on 2008 exchange rate \\
\hline 17 & 2008 - 2012 Scoring 2008 Ex-Rate C-PL-4 & A - B - C Value based on 2008 exchange rate \\
\hline 18 & 2008 - 2012_Scoring 2008 Ex-Rate C-PL-5 & A - B - C Value based on 2008 exchange rate \\
\hline 19 & 2008 - 2012_Scoring 2008 Ex-Rate C-PL-6 & A - B - C Value based on 2008 exchange rate \\
\hline 20 & 2008 - 2012_Scoring 2008 Ex-Rate C-PL-7 & A - B - C Value based on 2008 exchange rate \\
\hline 21 & 2008 - 2012 Scoring 2008 Ex-Rate C-PL-8 & A - B - C Value based on 2008 exchange rate \\
\hline 22 & 2008 - 2012 Scoring 2008 Ex-Rate C-PL-9 & A - B - C Value based on 2008 exchange rate \\
\hline 23 & 2008 - 2012_Scoring 2008 Ex-Rate Grand Total & A - B - C Value based on 2008 exchange rate \\
\hline 24 & 2008 - 2012 Scoring 2008 Ex-Rate Total NM & A - B - C Value based on 2008 exchange rate \\
\hline 25 & 2008 - 2012_Scoring 2008 Ex-Rate Total Service & A - B - C Value based on 2008 exchange rate \\
\hline 26 & 2008 - 2012_Scoring CY Ex-Rate C-PL-1 & A - B - C Value based on CY exchange rate \\
\hline 27 & 2008 - 2012_Scoring CY Ex-Rate C-PL-2 & A - B - C Value based on CY exchange rate \\
\hline 28 & 2008 - 2012_Scoring CY Ex-Rate C-PL-3 & A - B - C Value based on CY exchange rate \\
\hline 29 & 2008 - 2012_Scoring CY Ex-Rate C-PL-4 & A - B - C Value based on CY exchange rate \\
\hline 30 & 2008 - 2012_Scoring CY Ex-Rate C-PL-5 & A - B - C Value based on CY exchange rate \\
\hline 31 & 2008 - 2012_Scoring CY Ex-Rate C-PL-6 & A - B - C Value based on CY exchange rate \\
\hline 32 & 2008 - 2012_Scoring CY Ex-Rate C-PL-7 & A - B - C Value based on CY exchange rate \\
\hline 33 & 2008 - 2012_Scoring CY Ex-Rate C-PL-8 & A - B - C Value based on CY exchange rate \\
\hline 34 & 2008 - 2012_Scoring CY Ex-Rate C-PL-9 & A - B - C Value based on CY exchange rate \\
\hline 35 & 2008 - 2012_Scoring CY Ex-Rate Grand Total & A - B - C Value based on CY exchange rate \\
\hline 36 & 2008 - 2012_Scoring CY Ex-Rate Total NM & A - B - C Value based on CY exchange rate \\
\hline 37 & 2008 - 2012_Scoring CY Ex-Rate Total Service & A - B - C Value based on CY exchange rate \\
\hline 38 & 2008_SC-Key C-PL-1 & Key buildt of Numbers of EPU and Product Line for year 2008 \\
\hline 39 & 2008 SC-Key C-PL-2 & Key buildt of Numbers of EPU and Product Line for year 2008 \\
\hline 40 & 2008 SC-Key C-PL-3 & Key buildt of Numbers of EPU and Product Line for year 2008 \\
\hline 41 & 2008_SC-Key C-PL-4 & Key buildt of Numbers of EPU and Product Line for year 2008 \\
\hline 42 & 2008 SC-Key C-PL-5 & Key buildt of Numbers of EPU and Product Line for year 2008 \\
\hline 43 & 2008_SC-Key C-PL-6 & Key buildt of Numbers of EPU and Product Line for year 2008 \\
\hline 44 & 2008_SC-Key C-PL-7 & Key buildt of Numbers of EPU and Product Line for year 2008 \\
\hline 45 & 2008 SC-Key C-PL-8 & Key buildt of Numbers of EPU and Product Line for year 2008 \\
\hline 46 & 2008_SC-Key C-PL-9 & Key buildt of Numbers of EPU and Product Line for year 2008 \\
\hline 47 & 2008_SC-Key Grand Total & Key buildt of Numbers of EPU and Product Line for year 2008 \\
\hline 48 & 2008_SC-Key Total NM & Key buildt of Numbers of EPU and Product Line for year 2008 \\
\hline 49 & 2008_SC-Key Total Service & Key buildt of Numbers of EPU and Product Line for year 2008 \\
\hline
\end{tabular}


Annex 35: Structure of Case Classification Part 2 of 5

\begin{tabular}{|c|c|c|}
\hline \multicolumn{3}{|c|}{ Structure of Case Classification of Entrepreneurial Units } \\
\hline$\#$ & Attribute & Explanation of Value of Attribute \\
\hline 50 & 2008_Scoring CY Ex-Rate C-PL-1 & Key buildt of Numbers of EPU and Product Line for year 2008 \\
\hline 51 & 2008 Scoring CY Ex-Rate C-PL-2 & Key buildt of Numbers of EPU and Product Line for year 2008 \\
\hline 52 & 2008_Scoring CY Ex-Rate C-PL-3 & Key buildt of Numbers of EPU and Product Line for year 2008 \\
\hline 53 & 2008_Scoring CY Ex-Rate C-PL-4 & Key buildt of Numbers of EPU and Product Line for year 2008 \\
\hline 54 & 2008_Scoring CY Ex-Rate C-PL-5 & Key buildt of Numbers of EPU and Product Line for year 2008 \\
\hline 55 & 2008_Scoring CY Ex-Rate C-PL-6 & Key buildt of Numbers of EPU and Product Line for year 2008 \\
\hline 56 & 2008_Scoring CY Ex-Rate C-PL-7 & Key buildt of Numbers of EPU and Product Line for year 2008 \\
\hline 57 & 2008_Scoring CY Ex-Rate C-PL-8 & Key buildt of Numbers of EPU and Product Line for year 2008 \\
\hline 58 & 2008_Scoring CY Ex-Rate C-PL-9 & Key buildt of Numbers of EPU and Product Line for year 2008 \\
\hline 59 & 2008_Scoring CY Ex-Rate Grand Total & Key buildt of Numbers of EPU and Product Line for year 2008 \\
\hline 60 & 2008_Scoring CY Ex-Rate Total NM & Key buildt of Numbers of EPU and Product Line for year 2008 \\
\hline 61 & 2008_Scoring CY Ex-Rate Total Service & Key buildt of Numbers of EPU and Product Line for year 2008 \\
\hline 62 & 2009_SC-Key C-PL-1 & Key buildt of Numbers of EPU and Product Line for year 2009 \\
\hline 63 & 2009_SC-Key C-PL-2 & Key buildt of Numbers of EPU and Product Line for year 2009 \\
\hline 64 & 2009_SC-Key C-PL-3 & Key buildt of Numbers of EPU and Product Line for year 2009 \\
\hline 65 & 2009_SC-Key C-PL-4 & Key buildt of Numbers of EPU and Product Line for year 2009 \\
\hline 66 & 2009_SC-Key C-PL-5 & Key buildt of Numbers of EPU and Product Line for year 2009 \\
\hline 67 & 2009_SC-Key C-PL-6 & Key buildt of Numbers of EPU and Product Line for year 2009 \\
\hline 68 & 2009_SC-Key C-PL-7 & Key buildt of Numbers of EPU and Product Line for year 2009 \\
\hline 69 & 2009 SC-Key C-PL-8 & Key buildt of Numbers of EPU and Product Line for year 2009 \\
\hline 70 & 2009_SC-Key C-PL-9 & Key buildt of Numbers of EPU and Product Line for year 2009 \\
\hline 71 & 2009_SC-Key Grand Total & Key buildt of Numbers of EPU and Product Line for year 2009 \\
\hline 72 & 2009 SC-Key Total NM & Key buildt of Numbers of EPU and Product Line for year 2009 \\
\hline 73 & 2009_SC-Key Total Service & Key buildt of Numbers of EPU and Product Line for year 2009 \\
\hline 74 & 2009_Scoring 2008 Ex-Rate C-PL-1 & A - B - C Value based on 2008 exchange rate \\
\hline 75 & 2009 Scoring 2008 Ex-Rate C-PL-2 & A - B - C Value based on 2008 exchange rate \\
\hline 76 & 2009_Scoring 2008 Ex-Rate C-PL-3 & A - B - C Value based on 2008 exchange rate \\
\hline 77 & 2009 Scoring 2008 Ex-Rate C-PL-4 & A - B - C Value based on 2008 exchange rate \\
\hline 78 & 2009 Scoring 2008 Ex-Rate C-PL-5 & A - B - C Value based on 2008 exchange rate \\
\hline 79 & 2009_Scoring 2008 Ex-Rate C-PL-6 & A - B - C Value based on 2008 exchange rate \\
\hline 80 & 2009_Scoring 2008 Ex-Rate C-PL-7 & A - B - C Value based on 2008 exchange rate \\
\hline 81 & 2009 Scoring 2008 Ex-Rate C-PL- 8 & A - B - C Value based on 2008 exchange rate \\
\hline 82 & 2009_Scoring 2008 Ex-Rate C-PL-9 & A - B - C Value based on 2008 exchange rate \\
\hline 83 & 2009_Scoring 2008 Ex-Rate Grand Total & A - B - C Value based on 2008 exchange rate \\
\hline 84 & 2009_Scoring 2008 Ex-Rate Total NM & A - B - C Value based on 2008 exchange rate \\
\hline 85 & 2009_Scoring 2008 Ex-Rate Total Service & A - B - C Value based on 2008 exchange rate \\
\hline 86 & 2009_Scoring CY Ex-Rate C-PL-1 & A - B - C Value based on CY exchange rate \\
\hline 87 & 2009_Scoring CY Ex-Rate C-PL-2 & A - B - C Value based on CY exchange rate \\
\hline 88 & 2009 Scoring CY Ex-Rate C-PL-3 & A - B - C Value based on CY exchange rate \\
\hline 89 & 2009_Scoring CY Ex-Rate C-PL-4 & A - B - C Value based on CY exchange rate \\
\hline 90 & 2009_Scoring CY Ex-Rate C-PL-5 & A - B - C Value based on CY exchange rate \\
\hline 91 & 2009_Scoring CY Ex-Rate C-PL-6 & A - B - C Value based on CY exchange rate \\
\hline 92 & 2009_Scoring CY Ex-Rate C-PL-7 & A - B - C Value based on CY exchange rate \\
\hline 93 & 2009_Scoring CY Ex-Rate C-PL-8 & A - B - C Value based on CY exchange rate \\
\hline 94 & 2009_Scoring CY Ex-Rate C-PL-9 & A - B - C Value based on CY exchange rate \\
\hline 95 & 2009_Scoring CY Ex-Rate Grand Total & A - B - C Value based on CY exchange rate \\
\hline 96 & 2009 Scoring CY Ex-Rate Total NM & A - B - C Value based on CY exchange rate \\
\hline 97 & 2009_Scoring CY Ex-Rate Total Service & A - B - C Value based on CY exchange rate \\
\hline
\end{tabular}


Annex 36: Structure of Case Classification of Entrepreneurial Units Part 3 of 5

\begin{tabular}{|c|c|c|}
\hline \multicolumn{3}{|c|}{ Structure of Case Classification of Entrepreneurial Units } \\
\hline$\#$ & Attribute & Explanation of Value of Attribute \\
\hline 98 & 2010_SC-Key C-PL-1 & Key buildt of Numbers of EPU and Product Line for year 2010 \\
\hline 99 & 2010_SC-Key C-PL-2 & Key buildt of Numbers of EPU and Product Line for year 2010 \\
\hline 100 & 2010_SC-Key C-PL-3 & Key buildt of Numbers of EPU and Product Line for year 2010 \\
\hline 101 & 2010_SC-Key C-PL-4 & Key buildt of Numbers of EPU and Product Line for year 2010 \\
\hline 102 & 2010_SC-Key C-PL-5 & Key buildt of Numbers of EPU and Product Line for year 2010 \\
\hline 103 & 2010_SC-Key C-PL-6 & Key buildt of Numbers of EPU and Product Line for year 2010 \\
\hline 104 & 2010_SC-Key C-PL-7 & Key buildt of Numbers of EPU and Product Line for year 2010 \\
\hline 105 & 2010_SC-Key C-PL-8 & Key buildt of Numbers of EPU and Product Line for year 2010 \\
\hline 106 & 2010_SC-Key C-PL-9 & Key buildt of Numbers of EPU and Product Line for year 2010 \\
\hline 107 & 2010_SC-Key Grand Total & Key buildt of Numbers of EPU and Product Line for year 2010 \\
\hline 108 & 2010_SC-Key Total NM & Key buildt of Numbers of EPU and Product Line for year 2010 \\
\hline 109 & 2010_SC-Key Total Service & Key buildt of Numbers of EPU and Product Line for year 2010 \\
\hline 110 & 2010_Scoring 2008 Ex-Rate C-PL-1 & A - B - C Value based on 2008 exchange rate \\
\hline 111 & 2010_Scoring 2008 Ex-Rate C-PL-2 & A - B - C Value based on 2008 exchange rate \\
\hline 112 & 2010_Scoring 2008 Ex-Rate C-PL-3 & A - B - C Value based on 2008 exchange rate \\
\hline 113 & 2010 Scoring 2008 Ex-Rate C-PL-4 & A - B - C Value based on 2008 exchange rate \\
\hline 114 & 2010_Scoring 2008 Ex-Rate C-PL-5 & A - B - C Value based on 2008 exchange rate \\
\hline 115 & 2010_Scoring 2008 Ex-Rate C-PL-6 & A - B - C Value based on 2008 exchange rate \\
\hline 116 & 2010 Scoring 2008 Ex-Rate C-PL-7 & A - B - C Value based on 2008 exchange rate \\
\hline 117 & 2010 Scoring 2008 Ex-Rate C-PL-8 & A - B - C Value based on 2008 exchange rate \\
\hline 118 & 2010_Scoring 2008 Ex-Rate C-PL-9 & A - B - C Value based on 2008 exchange rate \\
\hline 119 & 2010_Scoring 2008 Ex-Rate Total & A - B - C Value based on 2008 exchange rate \\
\hline 120 & 2010 Scoring 2008 Ex-Rate Total NM & A - B - C Value based on 2008 exchange rate \\
\hline 121 & 2010_Scoring 2008 Ex-Rate Total Service & A - B - C Value based on 2008 exchange rate \\
\hline 122 & 2010_Scoring CY Ex-Rate C-PL-1 & A - B - C Value based on CY exchange rate \\
\hline 123 & 2010_Scoring CY Ex-Rate C-PL-2 & A - B - C Value based on CY exchange rate \\
\hline 124 & 2010_Scoring CY Ex-Rate C-PL-3 & A - B - C Value based on CY exchange rate \\
\hline 125 & 2010_Scoring CY Ex-Rate C-PL-4 & A - B - C Value based on CY exchange rate \\
\hline 126 & 2010 Scoring CY Ex-Rate C-PL-5 & A - B - C Value based on CY exchange rate \\
\hline 127 & 2010_Scoring CY Ex-Rate C-PL-6 & A - B - C Value based on CY exchange rate \\
\hline 128 & 2010_Scoring CY Ex-Rate C-PL-7 & A - B - C Value based on CY exchange rate \\
\hline 129 & 2010 Scoring CY Ex-Rate C-PL-8 & A - B - C Value based on CY exchange rate \\
\hline 130 & 2010_Scoring CY Ex-Rate C-PL-9 & A - B - C Value based on CY exchange rate \\
\hline 131 & 2010_Scoring CY Ex-Rate Total & A - B - C Value based on CY exchange rate \\
\hline 132 & 2010_Scoring CY Ex-Rate Total NM & A - B - C Value based on CY exchange rate \\
\hline 133 & 2010_Scoring CY Ex-Rate Total Service & A - B - C Value based on CY exchange rate \\
\hline 134 & 2011 SC-Key C-PL-1 & Key buildt of Numbers of EPU and Product Line for year 2011 \\
\hline 135 & 2011_SC-Key C-PL-2 & Key buildt of Numbers of EPU and Product Line for year 2011 \\
\hline 136 & 2011_SC-Key C-PL-3 & Key buildt of Numbers of EPU and Product Line for year 2011 \\
\hline 137 & 2011 SC-Key C-PL-4 & Key buildt of Numbers of EPU and Product Line for year 2011 \\
\hline 138 & 2011_SC-Key C-PL-5 & Key buildt of Numbers of EPU and Product Line for year 2011 \\
\hline 139 & 2011_SC-Key C-PL-6 & Key buildt of Numbers of EPU and Product Line for year 2011 \\
\hline 140 & 2011_SC-Key C-PL-7 & Key buildt of Numbers of EPU and Product Line for year 2011 \\
\hline 141 & 2011_SC-Key C-PL-8 & Key buildt of Numbers of EPU and Product Line for year 2011 \\
\hline 142 & 2011_SC-Key C-PL-9 & Key buildt of Numbers of EPU and Product Line for year 2011 \\
\hline 143 & 2011_SC-Key Grand Total & Key buildt of Numbers of EPU and Product Line for year 2011 \\
\hline 144 & 2011_SC-Key Total NM & Key buildt of Numbers of EPU and Product Line for year 2011 \\
\hline 145 & 2011_SC-Key Total Service & Key buildt of Numbers of EPU and Product Line for year 2011 \\
\hline
\end{tabular}


Annex 37: Structure of Case Classification of Entrepreneurial Units Part 4 of 5

\begin{tabular}{|c|c|c|}
\hline \multicolumn{3}{|c|}{ Structure of Case Classification of Entrepreneurial Units } \\
\hline$\#$ & Attribute & Explanation of Value of Attribute \\
\hline 146 & 2011_Scoring 2008 Ex-Rate C-PL-1 & A - B - C Value based on 2008 exchange rate \\
\hline 147 & 2011_Scoring 2008 Ex-Rate C-PL-2 & A - B - C Value based on 2008 exchange rate \\
\hline 148 & 2011_Scoring 2008 Ex-Rate C-PL-3 & A - B - C Value based on 2008 exchange rate \\
\hline 149 & 2011_Scoring 2008 Ex-Rate C-PL-4 & A - B - C Value based on 2008 exchange rate \\
\hline 150 & 2011_Scoring 2008 Ex-Rate C-PL-5 & A - B - C Value based on 2008 exchange rate \\
\hline 151 & 2011_Scoring 2008 Ex-Rate C-PL-6 & A - B - C Value based on 2008 exchange rate \\
\hline 152 & 2011_Scoring 2008 Ex-Rate C-PL-7 & A - B - C Value based on 2008 exchange rate \\
\hline 153 & 2011_Scoring 2008 Ex-Rate C-PL-8 & A - B - C Value based on 2008 exchange rate \\
\hline 154 & 2011_Scoring 2008 Ex-Rate C-PL-9 & A - B - C Value based on 2008 exchange rate \\
\hline 155 & 2011_Scoring 2008 Ex-Rate Grand Total & A - B - C Value based on 2008 exchange rate \\
\hline 156 & 2011_Scoring 2008 Ex-Rate Total NM & A - B - C Value based on 2008 exchange rate \\
\hline 157 & 2011_Scoring 2008 Ex-Rate Total Service & A - B - C Value based on 2008 exchange rate \\
\hline 158 & 2011_Scoring CY Ex-Rate C-PL-1 & A - B - C Value based on CY exchange rate \\
\hline 159 & 2011 Scoring CY Ex-Rate C-PL-2 & A - B - C Value based on CY exchange rate \\
\hline 160 & 2011 Scoring CY Ex-Rate C-PL-3 & A - B - C Value based on CY exchange rate \\
\hline 161 & 2011 Scoring CY Ex-Rate C-PL-4 & A - B - C Value based on CY exchange rate \\
\hline 162 & 2011 Scoring CY Ex-Rate C-PL-5 & A - B - C Value based on CY exchange rate \\
\hline 163 & 2011 Scoring CY Ex-Rate C-PL-6 & A - B - C Value based on CY exchange rate \\
\hline 164 & 2011_Scoring CY Ex-Rate C-PL-7 & A - B - C Value based on CY exchange rate \\
\hline 165 & 2011_Scoring CY Ex-Rate C-PL-8 & A - B - C Value based on CY exchange rate \\
\hline 166 & 2011 Scoring CY Ex-Rate C-PL-9 & A - B - C Value based on CY exchange rate \\
\hline 167 & 2011 Scoring CY Ex-Rate Grand Total & A - B - C Value based on CY exchange rate \\
\hline 168 & 2011 Scoring CY Ex-Rate Total NM & A - B - C Value based on CY exchange rate \\
\hline 169 & 2011 Scoring CY Ex-Rate Total Service & A - B - C Value based on CY exchange rate \\
\hline 170 & 2012_SC-Key C-PL-1 & Key buildt of Numbers of EPU and Product Line for year 2012 \\
\hline 171 & 2012_SC-Key C-PL-2 & Key buildt of Numbers of EPU and Product Line for year 2012 \\
\hline 172 & 2012_SC-Key C-PL-3 & Key buildt of Numbers of EPU and Product Line for year 2012 \\
\hline 173 & 2012 SC-Key C-PL-4 & Key buildt of Numbers of EPU and Product Line for year 2012 \\
\hline 174 & 2012_SC-Key C-PL-5 & Key buildt of Numbers of EPU and Product Line for year 2012 \\
\hline 175 & 2012_SC-Key C-PL-6 & Key buildt of Numbers of EPU and Product Line for year 2012 \\
\hline 176 & 2012 SC-Key C-PL-7 & Key buildt of Numbers of EPU and Product Line for year 2012 \\
\hline 177 & 2012 SC-Key C-PL-8 & Key buildt of Numbers of EPU and Product Line for year 2012 \\
\hline 178 & 2012_SC-Key C-PL-9 & Key buildt of Numbers of EPU and Product Line for year 2012 \\
\hline 179 & 2012_SC-Key Grand Total & Key buildt of Numbers of EPU and Product Line for year 2012 \\
\hline 180 & 2012_SC-Key Total NM & Key buildt of Numbers of EPU and Product Line for year 2012 \\
\hline 181 & 2012_SC-Key Total Service & Key buildt of Numbers of EPU and Product Line for year 2012 \\
\hline 182 & 2012_Scoring 2008 Ex-Rate C-PL-1 & A - B - C Value based on 2008 exchange rate \\
\hline 183 & 2012_Scoring 2008 Ex-Rate C-PL-2 & A - B - C Value based on 2008 exchange rate \\
\hline 184 & 2012 Scoring 2008 Ex-Rate C-PL-3 & A - B - C Value based on 2008 exchange rate \\
\hline 185 & 2012_Scoring 2008 Ex-Rate C-PL-4 & A - B - C Value based on 2008 exchange rate \\
\hline 186 & 2012_Scoring 2008 Ex-Rate C-PL-5 & A - B - C Value based on 2008 exchange rate \\
\hline 187 & 2012 Scoring 2008 Ex-Rate C-PL-6 & A - B - C Value based on 2008 exchange rate \\
\hline 188 & 2012_Scoring 2008 Ex-Rate C-PL-7 & A - B - C Value based on 2008 exchange rate \\
\hline 189 & 2012_Scoring 2008 Ex-Rate C-PL-8 & A - B - C Value based on 2008 exchange rate \\
\hline 190 & 2012 Scoring 2008 Ex-Rate C-PL-9 & A - B - C Value based on 2008 exchange rate \\
\hline 191 & 2012 Scoring 2008 Ex-Rate Grand Total & A - B - C Value based on 2008 exchange rate \\
\hline 192 & 2012_Scoring 2008 Ex-Rate Total NM & A - B - C Value based on 2008 exchange rate \\
\hline 193 & 2012 Scoring 2008 Ex-Rate Total Service & A - B - C Value based on 2008 exchange rate \\
\hline 194 & 2012_Scoring CY Ex-Rate C-PL-1 & A - B - C Value based on CY exchange rate \\
\hline 195 & 2012_Scoring CY Ex-Rate C-PL-2 & A - B - C Value based on CY exchange rate \\
\hline
\end{tabular}


Annex 38: Structure of Case Classifications Part 5 of 5

\begin{tabular}{|c|c|c|}
\hline \multicolumn{3}{|c|}{ Structure of Case Classification of Entrepreneurial Units } \\
\hline$\#$ & Attribute & Explanation of Value of Attribute \\
\hline 196 & 2012_Scoring CY Ex-Rate C-PL-3 & A - B - C Value based on CY exchange rate \\
\hline 197 & 2012_Scoring CY Ex-Rate C-PL-4 & A - B - C Value based on CY exchange rate \\
\hline 198 & 2012_Scoring CY Ex-Rate C-PL-5 & A - B - C Value based on CY exchange rate \\
\hline 199 & 2012 Scoring CY Ex-Rate C-PL-6 & A - B - C Value based on CY exchange rate \\
\hline 200 & 2012_Scoring CY Ex-Rate C-PL-7 & A - B - C Value based on CY exchange rate \\
\hline 201 & 2012 Scoring CY Ex-Rate C-PL-8 & A - B - C Value based on CY exchange rate \\
\hline 202 & 2012_Scoring CY Ex-Rate C-PL-9 & A - B - C Value based on CY exchange rate \\
\hline 203 & 2012_Scoring CY Ex-Rate Grand Total & A - B - C Value based on CY exchange rate \\
\hline 204 & 2012_Scoring CY Ex-Rate Total NM & A - B - C Value based on CY exchange rate \\
\hline 205 & 2012 Scoring CY Ex-Rate Total Service & A - B - C Value based on CY exchange rate \\
\hline 206 & BAB-Key_Name & Name of Cost distribution Sheet \\
\hline 207 & BAB-Key_Number & Number of Cost distribution Sheet \\
\hline 208 & BRIC & EPU belongs to a BRIC - country \\
\hline 209 & CP_A_Large & Poduction of Core Product A_Large (Yes/No) \\
\hline 210 & CP_A_Medium & Production of Core Product A_Medium (Yes/No) \\
\hline 211 & CP_A_Other & Production of Core Product A_Other (Yes/No) \\
\hline 212 & CP_A_Service & Production of Core Product A Service (Yes/No) \\
\hline 213 & CP_A_Small & Production of Core Product A_Small (Yes/No) \\
\hline 214 & CP_B_Large & Production of Core Product B_Large (Yes/No) \\
\hline 215 & CP_B_Medium & Production of Core Product B Medium (Yes/No) \\
\hline 216 & CP_B_Other & Production of Core Product B_Other (Yes/No) \\
\hline 217 & CP_B_Service & Production of Core Product B_Service (Yes/No) \\
\hline 218 & CP_B_Small & Production of Core Product B_Small (Yes/No) \\
\hline 219 & Cluster & EPU belongs to a group of defined countries \\
\hline 220 & Country & Name of the country EPU is located \\
\hline 221 & Currency & Currency of the country EPU is acting in \\
\hline 222 & EPU Name long & Long Name of EPU \\
\hline 223 & EPU Name short & Short Name of EPU \\
\hline 224 & Function & Values: Holding, Production Sales \&Service \\
\hline 225 & Quality of Reports & A-B-C "mark" for quality of reports \\
\hline 226 & Reference Unit_Name & Reference Unit is respective Reporting Unit of FC \\
\hline 227 & Reference Unit_Number & Reference Unit is respective Reporting Unit of FC \\
\hline 228 & Region_1 & Aggregated Name of the Region EPU is operating in \\
\hline 229 & Region 2 & More detailled Name of the Region EPU is operating in \\
\hline 230 & Scope C-PL1 & \multirow{10}{*}{ Product Line belongs to the scope of the production site (Yes/No) } \\
\hline 231 & Scope C-PL2 & \\
\hline 232 & Scope C-PL3 & \\
\hline 233 & Scope C-PL4 & \\
\hline 234 & Scope C-PL5 & \\
\hline 235 & Scope C-PL6 & \\
\hline 236 & Scope C-PL7 & \\
\hline 237 & Scope C-PL8 & \\
\hline 238 & Scope C-PL9 & \\
\hline 239 & Scope Service & \\
\hline
\end{tabular}


Annex 39: Developing 2010 Value from Test

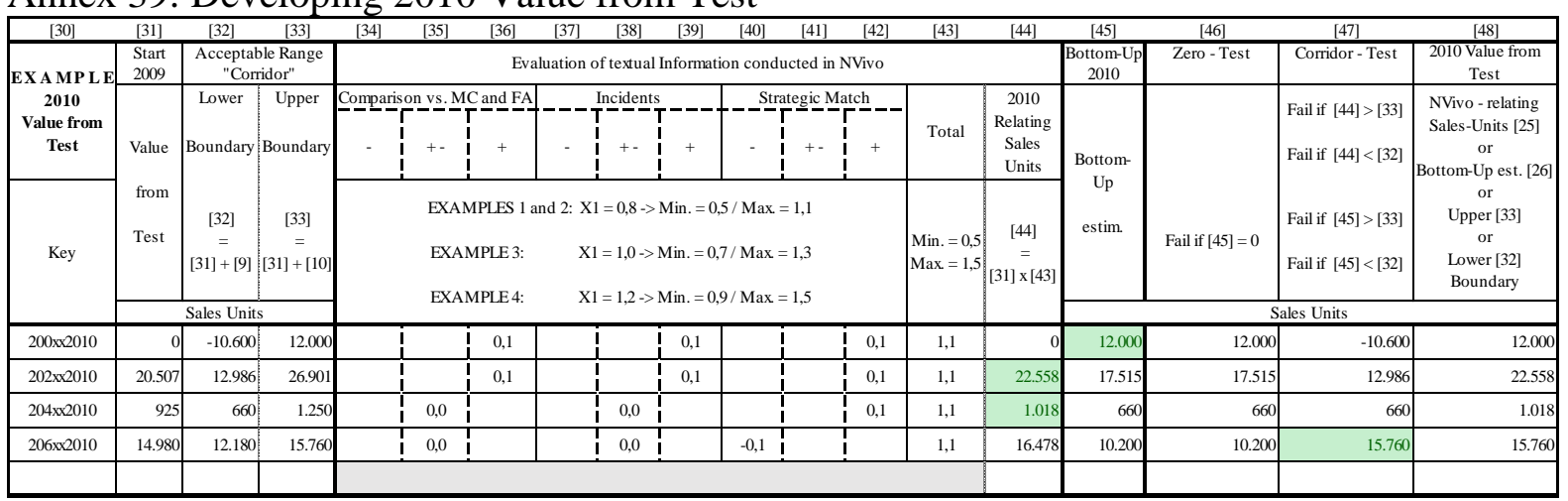

\begin{tabular}{|c|c|c|c|c|c|c|c|c|c|}
\hline \multicolumn{4}{|c|}{\begin{tabular}{|lll}
{$[1]$} & {$[2]$} \\
\end{tabular}} & [5] & {$[6]$} & {$[7]$} & {$[8]$} & {$[9]$} & {$[10]$} \\
\hline \multirow{2}{*}{\multicolumn{4}{|c|}{$\begin{array}{l}\text { EX A M P L E } \\
\text { Changes 2009-2012 }\end{array}$}} & \multicolumn{6}{|c|}{ Delta vs. PY } \\
\hline & & & & \multicolumn{6}{|c|}{ CHANGES $\quad 2009-2012$} \\
\hline \multirow[t]{2}{*}{ EPU } & \multirow[t]{2}{*}{$\begin{array}{l}\text { Example } \\
\text { Number }\end{array}$} & \multirow[t]{2}{*}{ Level } & \multirow[t]{2}{*}{ Key } & $\begin{array}{c}{[5]} \\
= \\
{[26]-} \\
{[12]}\end{array}$ & $\begin{array}{c}{[6]} \\
= \\
{[45]-} \\
{[26]}\end{array}$ & $\begin{array}{c}{[7]} \\
= \\
{[64]-} \\
{[45]}\end{array}$ & $\begin{array}{c}{[8]} \\
= \\
{[83]-} \\
{[64]}\end{array}$ & Min. & Max. \\
\hline & & & & \multicolumn{6}{|c|}{ Sales Units } \\
\hline 200 & Example 1 & Single Entity & $200 \times x 2008$ & -10.600 & 12.000 & 2.020 & 400 & -10.600 & 12.000 \\
\hline 202 & Example 2 & Single Entity & $202 \times x 2008$ & -7.521 & 6.393 & -4.149 & 1.199 & -7.521 & 6.393 \\
\hline 204 & Example 3 & Single Entity & $204 \times 20008$ & 325 & -265 & 275 & -85 & -265 & 325 \\
\hline 206 & Example 4 & Single Entity & $206 \times 2008$ & -2.800 & -1.200 & 780 & -530 & -2.800 & 780 \\
\hline & Total & Group & & & & & & & \\
\hline
\end{tabular}


Annex 40: Developing 2011 Value from Test

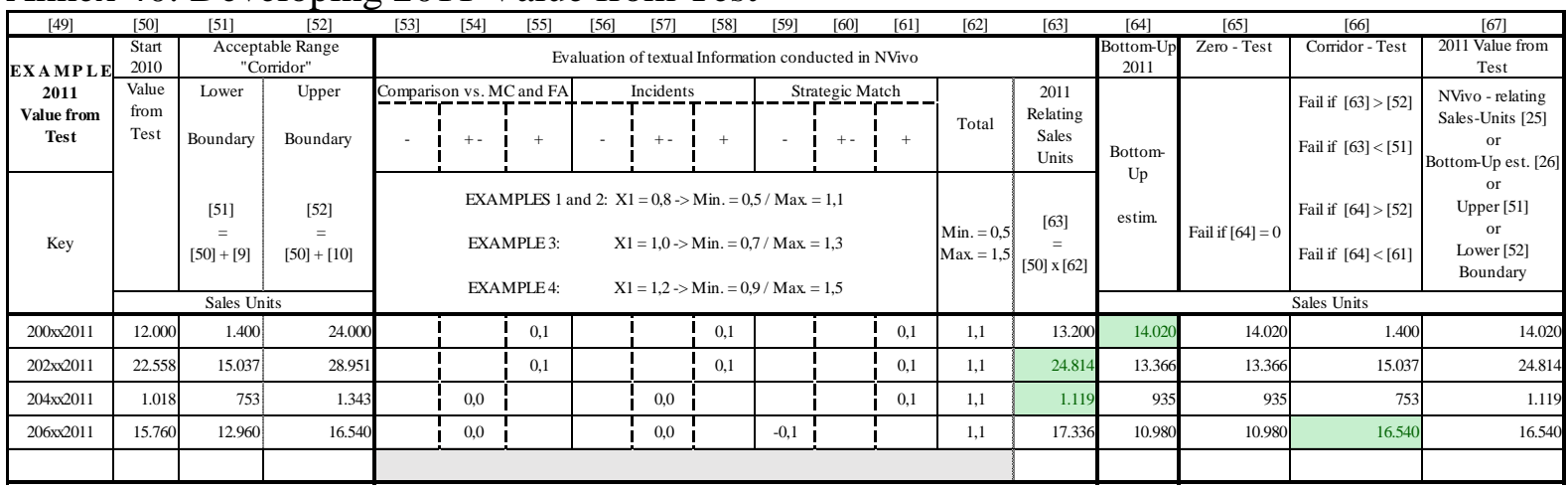

\begin{tabular}{|c|c|c|c|c|c|c|c|c|c|}
\hline 1] & {$[2]$} & [3] & [4] & [5] & {$[6]$} & {$[7]$} & [8] & [9] & {$[10]$} \\
\hline & & & & & & Delta v & s. PY & & \\
\hline & & & & 2009 & 2010 & \begin{tabular}{l|l}
2011 & \\
\end{tabular} & 2012 & Min & Max \\
\hline & $\begin{array}{r}\text { E } \\
\text { Chan }\end{array}$ & $\begin{array}{l}\text { A M P L E } \\
\text { ees } 2009 \text { - } 201\end{array}$ & & & $\mathrm{CH}$ & ANGES & $009-20$ & & \\
\hline EPU & $\begin{array}{l}\text { Example } \\
\text { Number }\end{array}$ & Level & Key & $\begin{array}{c}{[5]} \\
= \\
{[26]-} \\
{[12]}\end{array}$ & $\begin{array}{c}{[6]} \\
= \\
{[45]-} \\
{[26]}\end{array}$ & $\begin{array}{c}{[7]} \\
= \\
{[64]-} \\
{[45]}\end{array}$ & $\begin{array}{c}\stackrel{[8]}{=} \\
{[83]-} \\
{[64]}\end{array}$ & Min. & Max. \\
\hline & & & & & & Sales I & Units & & \\
\hline 200 & Example 1 & Single Entity & $200 \times 2008$ & -10.600 & 12.000 & 2.020 & 400 & $\mid-10.600$ & 12.000 \\
\hline 202 & Example 2 & Single Entity & $202 \times 2 \times 2008$ & -7.521 & 6.393 & -4.149 & 1.199 & -7.521 & 6.393 \\
\hline 204 & Example 3 & Single Entity & $204 \times 2008$ & 325 & -265 & 275 & -85 & -265 & 325 \\
\hline 206 & Example 4 & Single Entity & $206 \times 2008$ & -2.800 & -1.200 & 780 & -530 & -2.800 & 780 \\
\hline 1 & Total & Group & & & & & & & \\
\hline
\end{tabular}


Annex 41: Developing 2012 Value from Test

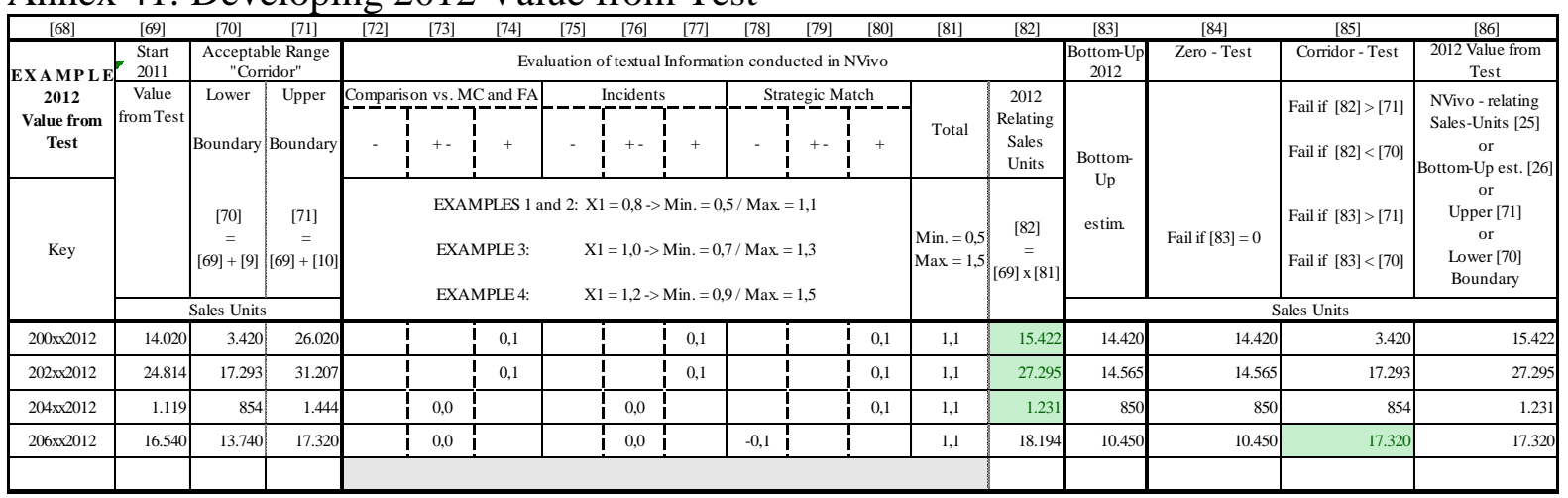

\begin{tabular}{|c|c|c|c|c|c|c|c|c|c|}
\hline$[1]$ & {$[2]$} & [3] & {$[4]$} & [5] & [6] & {$[7]$} & {$[8]$} & {$[9]$} & {$[10]$} \\
\hline \multirow{3}{*}{\multicolumn{4}{|c|}{$\begin{array}{l}\text { EXA M P L E } \\
\text { Changes 2009-2012 }\end{array}$}} & \multicolumn{6}{|c|}{ Delta vs. PY } \\
\hline & & & & 2009 & 2010 & 2011 & 2012 & Min & Max \\
\hline & & & & \multicolumn{6}{|c|}{ CHANGES $\quad 2009-2012$} \\
\hline \multirow[t]{2}{*}{ EPU } & \multirow[t]{2}{*}{$\begin{array}{l}\text { Example } \\
\text { Number }\end{array}$} & \multirow[t]{2}{*}{ Level } & \multirow[t]{2}{*}{ Key } & $\begin{array}{c}{[5]} \\
= \\
{[26]-} \\
{[12]}\end{array}$ & $\begin{array}{c}{[6]} \\
= \\
{[45]-} \\
{[26]}\end{array}$ & $\begin{array}{c}{[7]} \\
= \\
{[64]-} \\
{[45]}\end{array}$ & $\begin{array}{c}{[8]} \\
= \\
{[83]-} \\
{[64]}\end{array}$ & Min. & Max. \\
\hline & & & & \multicolumn{6}{|c|}{ Sales Units } \\
\hline 200 & Example 1 & Single Entity & $200 \times 2008$ & -10.600 & 12.000 & 2.020 & 400 & -10.600 & 12.000 \\
\hline 202 & Example 2 & Single Entity & $202 \times 2008$ & -7.521 & 6.393 & -4.149 & 1.199 & -7.521 & 6.393 \\
\hline 204 & Example 3 & Single Entity & $204 \times x 2008$ & 325 & -265 & 275 & -85 & -265 & 325 \\
\hline 206 & Example 4 & Single Entity & $206 \times 2008$ & -2.800 & -1.200 & 780 & -530 & -2.800 & 780 \\
\hline & Total & Group & & & & & & & \\
\hline
\end{tabular}


Annex 42: Schematic representation of Variance Analysis of basic Scenarios by Product Line

\begin{tabular}{|c|c|c|c|c|c|c|c|c|c|c|c|c|c|c|c|}
\hline \multicolumn{16}{|c|}{ Schematic representation of Variance Analysis of basic Scenarios by Product Line } \\
\hline & \multicolumn{15}{|c|}{ Columns } \\
\hline & [1] & [2] & {$[3]$} & [4] & {$[5]$} & [6] & [7] & {$[8]$} & [9] & {$[10]$} & {$[11]$} & {$[12]$} & [13] & [14] & {$[15]$} \\
\hline [1] & & & \multicolumn{4}{|c|}{2013} & \multicolumn{6}{|c|}{ Variance } & \multicolumn{3}{|c|}{ Variance - thereof translation effect } \\
\hline [2] & & & EST & ACT & EST & $\mathrm{ACl}$ & Volume & Structure & Total & Volume & Structure & Total & Volume & Structure & Total \\
\hline [3] & & & TLC & TLC & TGC & TGC & TLC & TLC & TLC & TGC & TGC & TGC & TGC & TGC & TGC \\
\hline [4] & \begin{tabular}{|l} 
Scenario 1 \\
\end{tabular} & Ex-Rate & & & 1,10 & 1 , & & & & & & & 0 & 0 & \\
\hline [5] & 1 & Sales & 100 & 121 & 110 & & & & 20 & & & 10 & & & -12 \\
\hline [6] & Section & $\mathrm{GM}$ & 35 & 4 & -39 & & 7 & -3 & 4 & 4 & -3 & -1 & -1 & 0 & \\
\hline [7] & 4.6.3.2 & GM- $\%$ & $35,2 \%$ & $33,0 \%$ & $35,2 \%$ & 33, & $35,2 \%$ & $-13,2 \%$ & $22,0 \%$ & $35,2 \%$ & $-26,4 \%$ & $8,8 \%$ & & 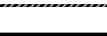 & \\
\hline \multirow{4}{*}{\begin{tabular}{|l|}
{$[8]$} \\
{$[9]$} \\
{$[10$} \\
{$[11$}
\end{tabular}} & \multirow{4}{*}{ Scenario 2} & Ex-Rate & & & 1,10 & 1, & & & & & & & 0 & 0 & \\
\hline & & Sales & 100 & 100 & 110 & 1 & & & 0 & & & 0 & 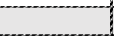 & 7 & \\
\hline & & $\mathrm{GM}$ & 35 & 3 & 39 & & 0 & 0 & 0 & 0 & 0 & 0 & 0 & 0 & \\
\hline & & GM- $\%$ & $35,2 \%$ & $35,2 \%$ & $35,2 \%$ & 35,2 & $0,0 \%$ & $0,0 \%$ & $0,0 \%$ & $0,0 \%$ & $0,0 \%$ & $0,0 \%$ & & s & \\
\hline [12] & \multirow{4}{*}{ Scenario 3} & $\overline{\text { Ex-Rate }}$ & & & $\overline{1,10}$ & $\overline{1,}$ & & & & & & & 0 & $\overline{0}$ & \\
\hline [13] & & Sales & 100 & 100 & 110 & & & & 0 & & & -10 & & & -10 \\
\hline$[14]$ & & $\mathrm{GM}$ & 35 & 3 & 39 & & 0 & 0 & 0 & -4 & 0 & -4 & -4 & 0 & \\
\hline$[15]$ & & GM- $\%$ & $35,2 \%$ & $35,2 \%$ & $35,2 \%$ & 35,2 & $0,0 \%$ & $0,0 \%$ & $0,0 \%$ & $35,2 \%$ & $0,0 \%$ & $35,2 \%$ & 4 & & \\
\hline [16 & \multirow{4}{*}{ Scenario 4} & Ex-Rate & & & 1,10 & 1, & & & & & & & 0 & 0 & \\
\hline$[17]$ & & Sales & 100 & 10 & 110 & & & & 0 & & & 10 & & & \\
\hline$[18$ & & $\mathrm{GM}$ & 35 & 3 & 39 & & 0 & 0 & 0 & 4 & 0 & & 4 & 0 & \\
\hline$[19]$ & & GM- $\%$ & $35,2 \%$ & $35,2 \%$ & $35,2 \%$ & 35,2 & $0,0 \%$ & $0,0 \%$ & $0,0 \%$ & $35,2 \%$ & $0,0 \%$ & $35,2 \%$ & & & \\
\hline$[20$ & \multirow{4}{*}{ Scenario 5} & Ex-Rate & & & 1,10 & 1, & & & & & & & 0 & 0 & \\
\hline$\left[\begin{array}{l}21 \\
{[21]}\end{array}\right.$ & & Sales & 100 & 12 & 110 & 1 & & & 20 & & & 22 & & & \\
\hline$[22]$ & & GM & 35 & 43 & 39 & & 7 & 0 & & 8 & 0 & $=$ & 0 & 0 & \\
\hline [23] & & GM- $\%$ & $35,2 \%$ & $35,2 \%$ & $35,2 \%$ & 35,2 & $35,2 \%$ & $0,0 \%$ & $35,2 \%$ & $35,2 \%$ & $0,0 \%$ & $35,2 \%$ & & & \\
\hline [24] & \multirow{4}{*}{ Scenario 6} & Ex-Rate & & & 1,10 & 1, & & & & & & & 0 & $\overline{0}$ & \\
\hline$[25]$ & & Sales & 100 & 121 & 110 & 1 & & & 20 & & & 10 & & & -12 \\
\hline$|26|$ & & $\frac{\mathrm{GM}}{\mathrm{G}}$ & 35 & 42 & 39 & & 7 & 0 & & 4 & 0 & 4 & -1 & 0 & \\
\hline [27] & & GM- $\%$ & $35,2 \%$ & $35,2 \%$ & $35,2 \%$ & 35,2 & $35,2 \%$ & $0,0 \%$ & $35,2 \%$ & $35,2 \%$ & $0,0 \%$ & $35,2 \%$ & & & \\
\hline |28] & \multirow{4}{*}{ Scenario 7} & Ex-Rate & & & 1,10 & 1, & & & & & & & 0 & 0 & \\
\hline [29] & & Sales & 100 & 126 & 110 & 1 & & & 20 & & & 34 & 9 & & 12 \\
\hline$[30]$ & & $\mathrm{GM}$ & 35 & 42 & 39 & & 7 & 0 & & 12 & 0 & 12 & 1 & 0 & \\
\hline$[31]$ & & GM- $\%$ & $35,2 \%$ & $35,2 \%$ & $35,2 \%$ & 35,2 & $35,2 \%$ & $0,0 \%$ & $35,2 \%$ & $35,2 \%$ & $0,0 \%$ & $35,2 \%$ & 7 & & \\
\hline 32 & \multirow{4}{*}{ Scenario 8} & Ex-Rate & & & 1,10 & 1, & & & & & & & 0 & $\overline{0}$ & \\
\hline$[33]$ & & Sales & 100 & 121 & 110 & 1 & & & 20 & & & 22 & & & \\
\hline [34] & & $\mathrm{GM}$ & 35 & 4 & 39 & & & -3 & & 8 & -3 & & 0 & 0 & \\
\hline [35] & & GM- $\%$ & $35,2 \%$ & $33,0 \%$ & $35,2 \%$ & 33,6 & $35,2 \%$ & $-13,2 \%$ & $22,0 \%$ & $35,2 \%$ & $-13,2 \%$ & $22,0 \%$ & & & \\
\hline [36] & \multirow{4}{*}{ Scenario 9} & Ex-Rate & & & 1,10 & 1, & & & & & & & 0 & 0 & \\
\hline$[37]$ & & Sales & 100 & 12 & 110 & & & & 20 & & & 10 & & & -12 \\
\hline [38] & & $\mathrm{GM}$ & 35 & 4 & 39 & & 7 & -3 & -2 & 4 & -3 & 1 & -1 & 0 & \\
\hline [39] & & GM- $\%$ & $35,2 \%$ & $33,0 \%$ & $35,2 \%$ & 33,6 & $35,2 \%$ & $-13,2 \%$ & $22,0 \%$ & $35,2 \%$ & $-26,4 \%$ & $8,8 \%$ & & & \\
\hline |40] & \multirow{4}{*}{ Scenario 10} & Ex-Rate & & & 1,10 & 1, & & & & & & & $\overline{0}$ & $\overline{0}$ & \\
\hline$[41]$ & & Sales & 100 & 12 & 110 & 1 & & & 20 & & & 34 & & & 12 \\
\hline$[42]$ & & $\mathrm{GM}$ & 35 & 4 & 39 & & & -3 & & 12 & -3 & 9 & 1 & 0 & \\
\hline$[43]$ & & GM- $\%$ & $35,2 \%$ & $33,0 \%$ & $35,2 \%$ & 33, & $35,2 \%$ & $-13,2 \%$ & $22,0 \%$ & $35,2 \%$ & $-9,3 \%$ & $25,9 \%$ & & & \\
\hline
\end{tabular}


